DEVELOPMENT OF ALASKAN GAS HYDRATE RESOURCES

Final Report

By

V. A. Kamath

G. D. Shama

S. L Patll

June 1991

Work Periomed Under Contrect No. FG21-86FE61114

For

U.S. Department of Energy

Worgantown Energy Technology Center

Morgantown, West Virginla

By

Unversity of Alacka

Fairbanks, Alaska 


\section{DISCLAIMER}

This report was prepared as an account of work sponsored by an agency of the United States Government. Neither the United States Government nor any agency thereof, nor any of their employees, makes any warranty, express or implied, or assumes any lezal liability or responsibility disclosed, or represents that ins, or usefuiness of any information, apparatus, product, or process any specific commercial product, wrould not infringe privately owned rights. Reference herein to otherwise does not necessarily constitut, or service by trade name, trademark, manufacturer, or by the United States Government or any agency thereof pressed herein do not necessarily state or reflect hereof. The views and opinions of authors exagency thereof.

This report has been reproduced directly from the best available copy.

Available to DOE and DOE contractors from the Office of Scientific and Technical Information, P.O. Box 62, Oak Ridge, TN 37831; prices available
from (615)576-8401, FTS 626-8401.

Available to the public from the National Technical Information Service, U.S. Department of Commerce, 5285 Port Royal Rd., Springfield, VA 22161. 


\title{
Development of Alaskan Gas Hydrate Resources
}

\author{
Final Report
}

\author{
V.A. Kamath \\ G.D. Sharma \\ S.L. Patil
}

Work Performed Under Grant No.: DE-FG21-86FE61114

For

U.S. Department of Energy

Office of Fossil Energy

Morgantown Energy Technology Center

P.O. Box 880

Morgantown, West Virginia 26507-0880

By

University of Alaska

Petroleum Development Laboratory

Fairbanks, Alaska 99775-1260

June 1991 


\section{ABSTRACT}

It is estimated that $\mathbf{5 0 0}$ to $\mathbf{7 0 0}$ trillion standard cubic feet (TCF) of natural gas is trapped as solid gas hydrate deposits in the northern Alaska and represents a significant, long-term future source for natural gas. The commercial production from this resource will require a detailed characterization of gas hydrate reservoirs and development of related technology for in-situ decomposition of hydrates.

The research undertaken in this project pertains to study of various techniques for production of natural gas from hydrates such as, depressurization, injection of hot water, steam, brine, methanol and ethylene glycol solutions through experimental investigation of decomposition characteristics of hydrate cores. An experimental study has been conducted to measure the effective gas permeability changes as hydrates form in the sandpack and the results have been used to determine the reduction in the effective gas permeability of the sandpack as a function of hydrate saturation.

A user friendly, interactive, menu-driven, numerical finite difference simulator has been developed to model the dissociation of natural gas hydrates in porous media with variable thermal properties. This simulator has been coupled with the wellbore hydraulics model and used to study hydrate dissociation under wide range of drilling conditions. The results have been used to generate nomogram to estimate drilling fluid parameters for safer drilling through hydrate zones.

A numerical, finite element simulator has been developed to model the dissociation of hydrates during hot water injection process. The finite element model is capable of conducting transient analysis of both conductive and convective heat transfer and two phase flow during hydrate dissociation process.

In addition, an experimental study of hydrate formation in presence of Alaskan North Slope crudes and it's effect on crude oil properties has been undertaken to understand the inter-relationships between gas hydrate, heavy oil and/or tar sand resources. 


\section{ACKNOWLEDGEMENTS}

This report was prepared for the U.S. Department of Energy under the Cooperative Agreement No. DE-FG-01-86FE61114. The financial support of the U.S. Department of Energy, Morgantown Energy Technology Center is gratefully acknowledged. The matching support was provided by the Petroleum Development Laboratory, University of Alaska Fairbanks

This report is a result of the work performed by following graduate students and their M.S. thesis:

"Measurement of Gas Permeability in Hydrate Saturated Unconsolidated Cores", by M. Nadeem, 1988.

"Experimental Study of Brine Injection and and Depressurization Methods For Dissociation of Gas Hydrates", by P.N. Mutalik, 1989.

"Numerical Solution of 2-D (r-z) Cylindrical Coordinate Dissociation of Natural Gas Hydrates with Variable Thermal Properties", by R.D. Roadifer, 1988.

"The Development of a Finite Element Model For the Dissociation of Natural Gas Hydrates in Porous Media By Hot Water Injection", by D.M. Scott, 1989.

"Experimental Study of Dissociation of Gas Hydrates With and Without Inhibitors", by J.S.H. Sira, 1991.

We would like to thank Dr. Sanjay Godbole and Dr. Deben Das for their contributions to the project. In addition, we would like to thank Ms. Judy Ward for typing the report. 


\section{TABLE OF CONTENTS}

PAGE

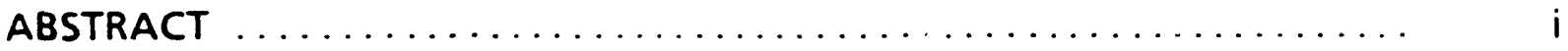

ACKNOWLEDGEMENTS $\ldots \ldots \ldots \ldots \ldots \ldots \ldots \ldots \ldots \ldots \ldots \ldots \ldots \ldots \ldots \ldots \ldots$

LIST OF TABLES $\ldots \ldots \ldots \ldots \ldots \ldots \ldots \ldots \ldots \ldots \ldots \ldots \ldots \ldots \ldots \ldots \ldots \ldots \ldots \ldots$

LIST OF FIGURES $\ldots \ldots \ldots \ldots \ldots \ldots \ldots \ldots \ldots \ldots \ldots \ldots \ldots \ldots \ldots \ldots \ldots \ldots \ldots \ldots$

EXECUTIVE SUMMARY $\ldots \ldots \ldots \ldots \ldots \ldots \ldots \ldots \ldots \ldots \ldots \ldots \ldots \ldots \ldots \ldots \ldots \ldots$

CHAPTER ONE: REVIEW OF GAS HYDRATES $\ldots \ldots \ldots \ldots \ldots \ldots \ldots \ldots \ldots$

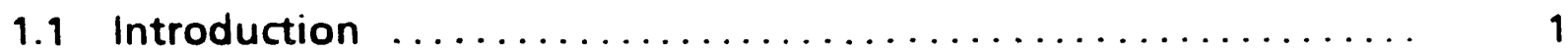

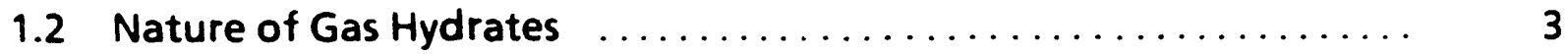

1.2.1 Structure of Gas Hydrates $\ldots \ldots \ldots \ldots \ldots \ldots \ldots \ldots \ldots \ldots$

1.2.2 Naturally Occurring Hydrates ................. 9

1.3 Occurrence of Gas Hydrates $\ldots \ldots \ldots \ldots \ldots \ldots \ldots \ldots \ldots \ldots \ldots \ldots \ldots \ldots \ldots$

1.3.1 Onshore Hydrates $\ldots \ldots \ldots \ldots \ldots \ldots \ldots \ldots \ldots \ldots \ldots \ldots \ldots \ldots$

1.3.2 Offshore Hydrates $\ldots \ldots \ldots \ldots \ldots \ldots \ldots \ldots \ldots \ldots \ldots \ldots \ldots \ldots$

1.4 Detection and Evaluation of In-Situ Natural Gas Hydrates . . . . . . 17

1.4.1 Hydrate Stability Zone Determination $\ldots \ldots \ldots \ldots \ldots \ldots$.

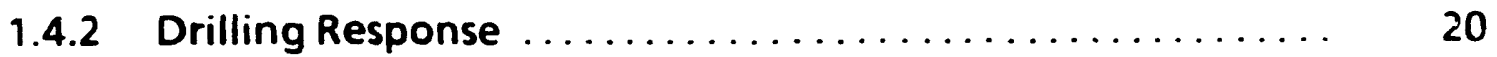

1.4.3 Seismic Profiling $\ldots \ldots \ldots \ldots \ldots \ldots \ldots \ldots \ldots \ldots \ldots \ldots \ldots \ldots \ldots \ldots \ldots$

1.4.4 Wire Line Log Evaluation .................. 21

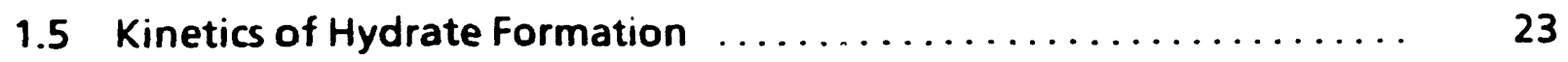

1.5.1 Hydrate Formation From Water ............... 23

1.5.2 Hydrate Formation From Ice ................ 27

1.6 Hydrate Formation and Decomposition Studies ............ 32

1.7 Thermodynamics of Gas Hydrates $\ldots \ldots \ldots \ldots \ldots \ldots \ldots \ldots \ldots \ldots \ldots$

1.8 Principles of Production of Natural Gas From Hydrate Reservoirs ... 49

1.8.1 Thermal Stimulation Techniques ................ 50 
1.8.2 Depressurization Techniques $\ldots \ldots \ldots \ldots \ldots \ldots \ldots \ldots \ldots, 52$

1.8.3 Injection of Inhibitors $\ldots \ldots \ldots \ldots \ldots \ldots \ldots \ldots \ldots \ldots \ldots \ldots \ldots \ldots \ldots$

1.8.4 Field Example of Gas Production From Hydrate/Free Gas

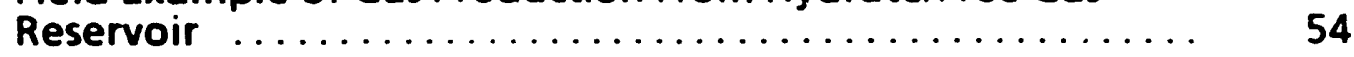

1.9 Drilling in the Presence of Hydrates $\ldots \ldots \ldots \ldots \ldots \ldots \ldots \ldots .65$

1.10 Prevention of Hydrate Formation in Natural Gas Processing

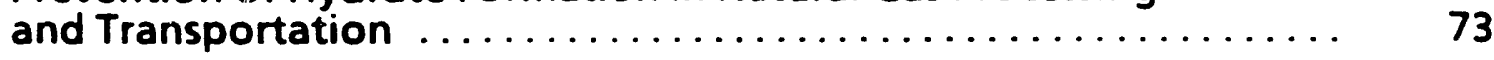

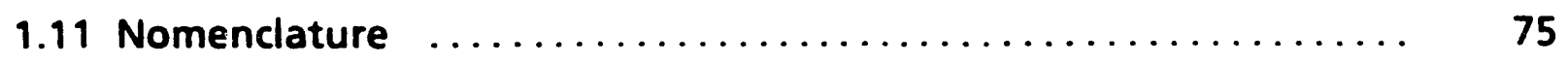

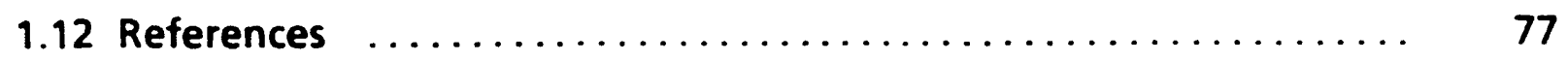

CHAPTER TWO: MEASUREMENT OF EFFECTIVE GAS PERMEABILITY

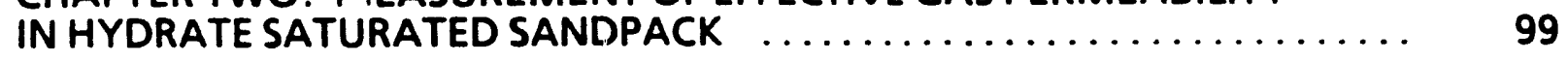

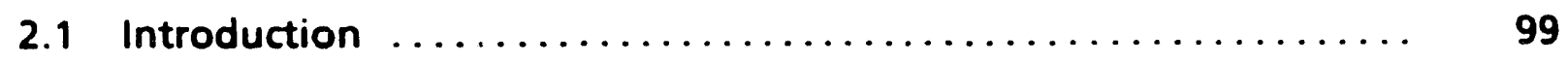

2.2 Experimental Set Up For Permeability Measurement $\ldots \ldots \ldots \ldots \ldots \quad 101$

2.3 Experimental Methods For Permeability Measurement ......... 105

2.4 Experimental Results and Discussion $\ldots \ldots \ldots \ldots \ldots \ldots \ldots \ldots . . \ldots 7$

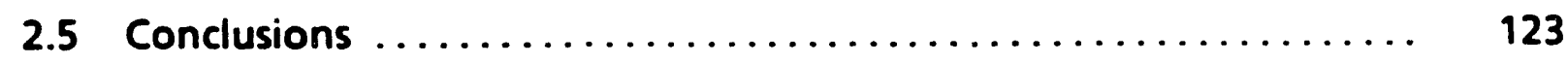

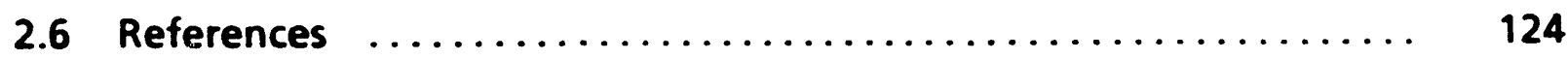

CHAPTER THREE: EXPERIMENTAL STUDY OF HYDRATE DISSOCIATION

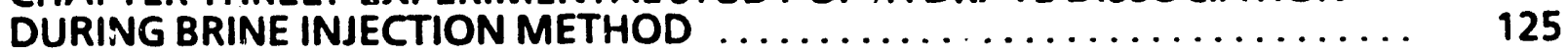

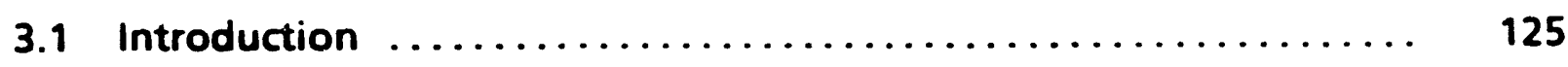

3.2 Experimental Set Up For Hydrate Dissociation Studies ........... 126

3.3 Experimental Methods ............................ 128

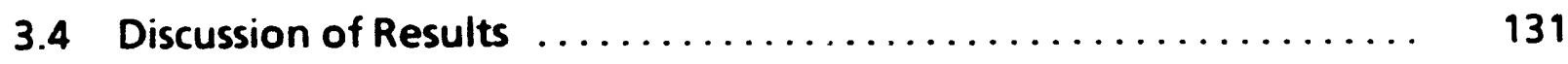

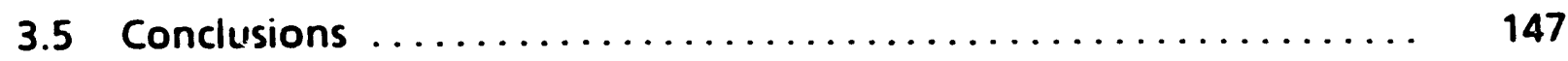

3.6 Nomenclature $\ldots \ldots \ldots \ldots \ldots \ldots \ldots \ldots \ldots \ldots \ldots \ldots . . \ldots \ldots$

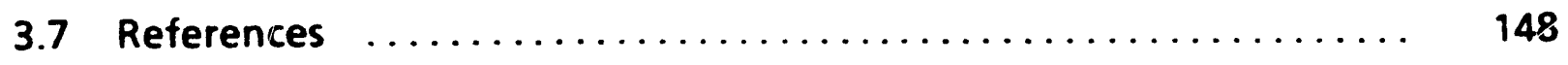




\section{TABLE OF CONTENTS (CONT'D)}

PAGE

CHAPTER FOUR: EXPERIMENTAL STUDY OF HYDRATE DISSOCIATION DURING HOT WATER INJECTION METHOD 150

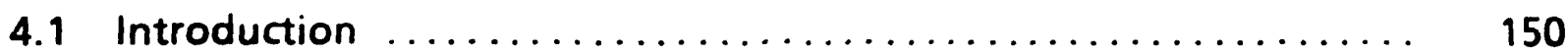

4.2 Experimental Methods ............................. 151

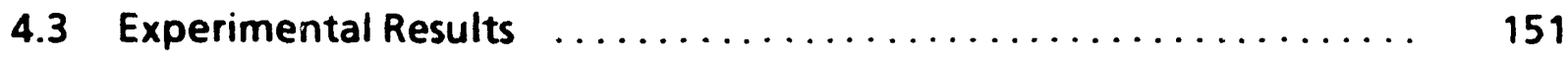

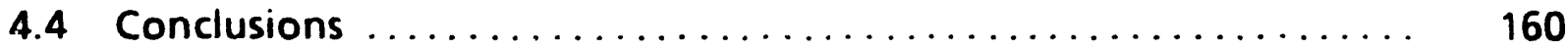

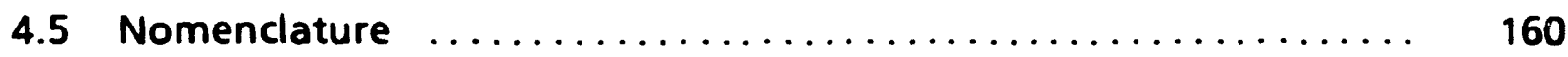

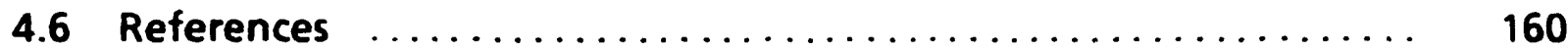

CHAPTER FIVE: EXPERIMENTAL STUDY OF HYDRATE DISSOCIATION

DURING DEPRESSURIZATION METHOD $\ldots \ldots \ldots \ldots \ldots \ldots \ldots \ldots \ldots \ldots \ldots, 162$

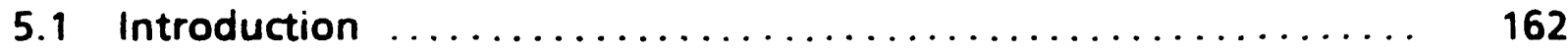

5.2 Experimental Methods ........................ 162

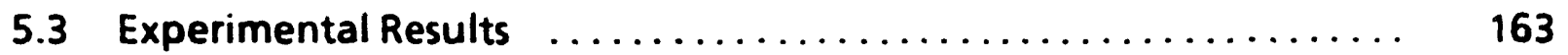

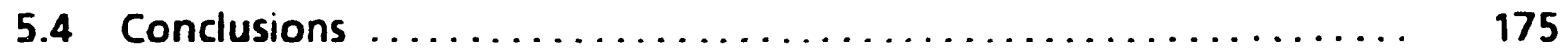

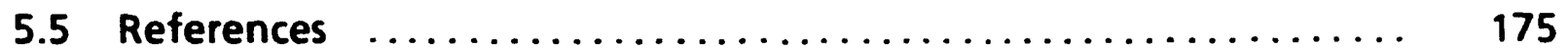

CHAPTER SIX: EXPERIMENTAL STUDY OF HYDRATE DISSOCIATION DURING METHANOL AND GLYCOL INJECTION .................. 177

6.1 Introduction $\ldots \ldots \ldots \ldots \ldots \ldots \ldots \ldots \ldots \ldots \ldots \ldots \ldots \ldots \ldots \ldots \ldots$

6.2 Methanol and Glycols as Hydrate Inhibitors ............. 177

6.3 Experimental Methods ......................... 181

6.4 Methanol Injection Experimental Results $\ldots \ldots \ldots \ldots \ldots \ldots \ldots \ldots \quad 184$

6.5 Glycol Injection Experimental Results .................. 195

6.6 Conclusions ............................... 204

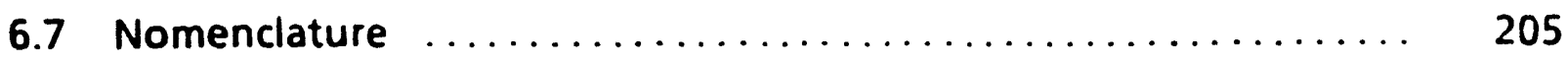

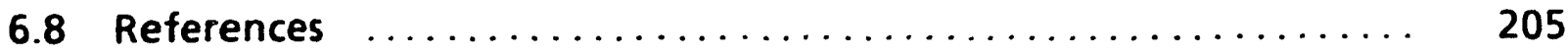


CHAPTER SEVEN: EXPERIMENTAL STUDY OF FORMATION OF HYDRATES IN PRESENCE OF ALASKAN NORTH SLOPE CRUDES $\ldots \ldots \ldots \ldots \ldots \ldots \ldots .207$

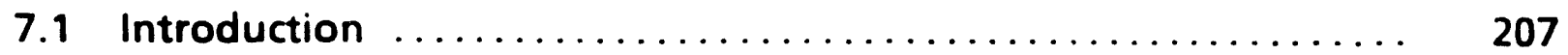

7.2 Experimental Set-Up ............................ 208

7.3 Procedure For Measuring Four Phase $\left(V L_{1} L_{2} H\right)$ Conditions for Crude Oil-Gas-Water Systems $\ldots \ldots \ldots \ldots \ldots \ldots \ldots \ldots \ldots \ldots \ldots \ldots \ldots \ldots$

7.4 Effect of Hydrate Formation on Crude Oil Properties .......... 211

7.5 Conclusions $\ldots \ldots \ldots \ldots \ldots \ldots \ldots \ldots \ldots \ldots \ldots \ldots \ldots \ldots \ldots \ldots \ldots \ldots$

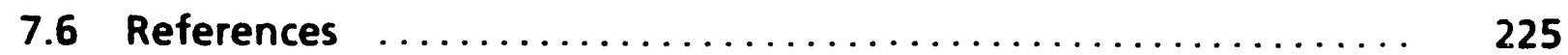

CHAPTER EIGHT: DEVELOPMENT OF NUMERICAL, FINITE-DIFFERENCE MODEL FOR DISSOCIATION OF GAS HYDRATES IN POROUS MEDIA . . . . 226

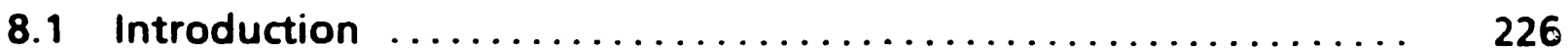

8.2 Review of Literature on Solution To Stefan Problems . . . . . . . . 228

8.2.1 Analytical Solutions $\ldots \ldots \ldots \ldots \ldots \ldots \ldots \ldots \ldots \ldots \ldots \ldots \ldots \ldots$

8.2.1.1 Exact Solutions ..................... 231

8.2.1.2 Heat Balance Integral Methods ........... 232

8.2.1.3 Embedding Method ................... 234

8.2.1.4 Isotherm Migration Method ............. 235

8.2.1.5 Use of Green's Function Derived Integrals ....... . 236

8.2.1.6 Source and Sink Methods ............. 238

8.2.1.7 Other Approximate Analytical Solutions ........ 239

8.2.2 Numerical Solution Techniques ................. 241

8.2.2.1 Finite Difference Schemes on a Fixed Grid ....... 242

8.2.2.2 Finite Difference Schemes on a Variable Grid ..... . 244

8.2.2.3 Equivalent Enthalpy and Heat Capacity Methods .. 246

8.2.2.4 Finite Elements on a Fixed Grid ............ 249

8.2.2.5 Finite Elements on a Variable Grid .......... 252 
PAGE

8.2.3 Applications to Hydration Dissociation $\ldots \ldots \ldots \ldots \ldots \ldots . \ldots 253$

8.3 Mathematical Model Description $\ldots \ldots \ldots \ldots \ldots \ldots \ldots \ldots \ldots \ldots$

8.3.1 Geometry of Problem .................... 255

8.3.2 Assumptions ......................... 257

8.3.3 Model Equations ....................... 257

8.3.4 Initial Conditions ...................... 259

8.3.5 Boundary Conditions .................... 260

8.3.6 Moving Boundary Conditions ................. 261

8.3.7 Dimensionless Form of the Mathematical Model ........ 266

8.3.8 General Solution Method .................... 273

8.4 Numerical Aspects of the Solution Method ............... 277

8.4.1 Solution of the Boundary Value Problems ........... 277

8.4.2 Solution of the Initial Value Problems $\ldots \ldots \ldots \ldots \ldots \ldots .286$

8.4.3 Starting Procedure $\ldots \ldots \ldots \ldots \ldots \ldots \ldots \ldots \ldots \ldots \ldots . \ldots \ldots$

8.5 Hydrate Dissociation Model Applications and Results ......... 291

8.5.1 General Uses and Applications of the Model ......... 291

8.5.2 Validation of Hydrate Dissociation Model ............ 291

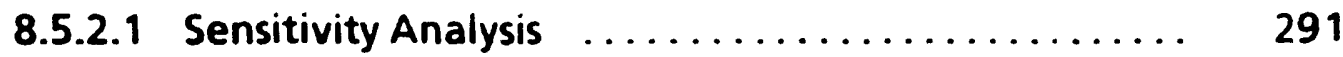

8.5.2.2 Comparison of Model Results With Published

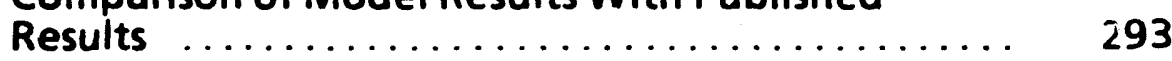

8.5.3 Application of Model to Hydrate Reservoirs and Parametric
Sensitivity Analysis $\ldots \ldots \ldots \ldots \ldots \ldots \ldots \ldots \ldots \ldots \ldots \ldots \ldots \ldots \ldots \ldots$

8.5.3.1 Geothermal Conditions .............. 301

8.5.3.2 Porosity ....................... 307

8.5.3.3 Wellbore Radius ................. 311

8.5.3.4 Wellbore Pressure and Temperature ........ 313 


\section{TABLE OF CONTENTS (CONT'D)}

PAGE

8.5.4 Application of Model to Drilling ............... 313

8.5.4.1 Wellbore Heat Transfer Model ............. 313

8.5.4.1.1 Determination of Convective Heat Transfer Coefficients .............. 315

8.5.4.1.2 Determination of Energy Source Terms .................... 316

8.5.4.1.3 Gas Influx Calculations .......... 317

8.5.4.1.4 Solution Method and Validation of Model

8.5.4.1.5 Drilling Parameters and Mud Degasser

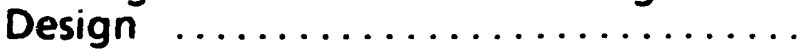

8.5.4.1.6 Selection of Drilling Parameters - Example Uses of Nomogiam

8.6 Additional Applications, Numerical Problems, Peculiarities and Limitations of Model

8.7 Conclusions and Recommendations $\ldots \ldots \ldots \ldots \ldots \ldots \ldots \ldots \ldots . \ldots \ldots$

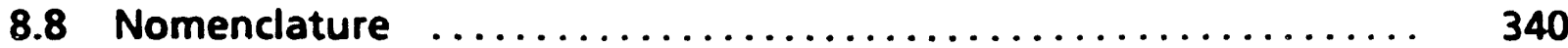

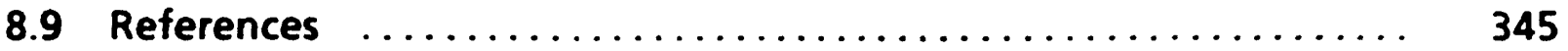

CHAPTER NINE: DEVELOPMENT OF A FINITE ELEMENT MODEL TO STIMULATE DISSOCIATION OF GAS HYDRATES IN POROUS MEDIA BY HOT FLUID INJECTION

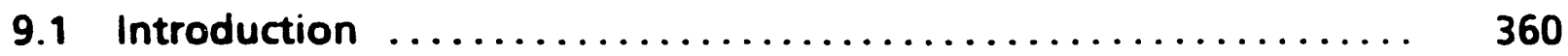

9.2 Development of Model $\ldots \ldots \ldots \ldots \ldots \ldots \ldots \ldots \ldots \ldots \ldots \ldots \ldots$

9.2.1 Reservoir Geometry $\ldots \ldots \ldots \ldots \ldots \ldots \ldots \ldots \ldots \ldots \ldots \ldots$

9.2.2 Recovery Process $\ldots \ldots \ldots \ldots \ldots \ldots \ldots \ldots \ldots \ldots \ldots \ldots \ldots$

9.2.3 Mathematical Formulation .................. 366

9.2.3.1 Governing Differential Equations ......... 366

9.2.3.2 Finite Element Formulation $\ldots \ldots \ldots \ldots \ldots \ldots \ldots$

9.2.3.3 Newton-Raphson Iterative Solution Scheme ...... 378 


\section{TABLE OF CONTENTS (CONT'D)}

PAGE

9.2.3.4 Phase Change Treatment ............. 382

9.2.3.5 Fluid Property Correlations .............. 389

9.2.3.6 Computer Implementation ............. 396

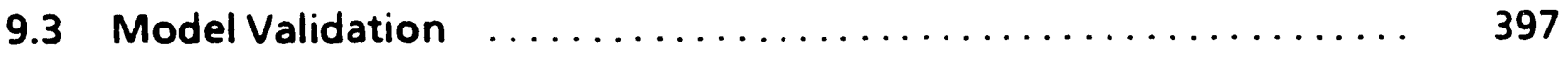

9.3.1 Single Phase Fluid Flow Through Porous Media ......... 397

9.3.2 Radial Conduction From Line Source ................. 399

9.3.3 Radial Conduction With Moving Phase Change Boundary . . 404

9.3.4 Convective Heat Transfer in an Aquifer ............. 407

9.3.5 Convective and Conductive Heat Transfer in an Aquifer ... 414

9.3.6 Two Phase Immiscible Flow In Porous Media ........... 417

9.3.6.1 Buckeley Leverett Solution ............. 417

9.3.6.2 Pistonlike Displacement .............. 430

9.4 Application of Model to Hydrate Reservoirs .............. 433

9.4.1 Two-Phase (GasMater) Convective Heat Transfer ........ 433

9.4.2 Hydrate Thawing Problem .................. 438

9.4.2.1 Case \# 1, Run With Constant Source Terms ....... 440

9.4.2.2 Case \#2, Thawing Run With Hydrate Region
Initialized With Gas and Water ....... 442

9.4.2.3 Case \#3, Run With Complete Hydrate
Thawing Model .................. 445

9.5 Model Performance With Other Convergence Schemes ......... 450

9.5.1 Assymetric Weighting Function .............. 451

9.5.2 Upstream Weighting of Mobility ............... 454

9.5.3 Lumped Schemes ..................... 455

9.6 Conclusions and Recommendations ................. 457 


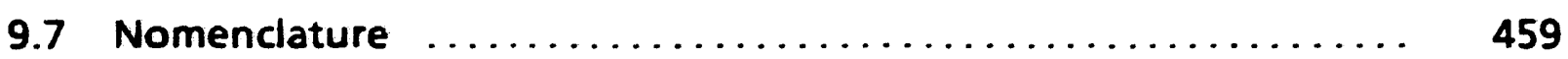

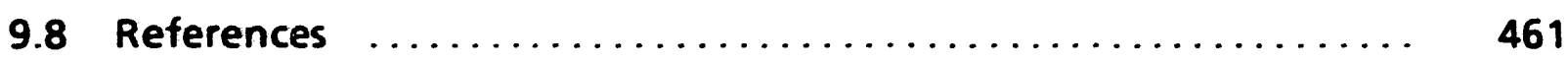

Appendix 1: Damping Factors $\ldots \ldots \ldots \ldots \ldots \ldots \ldots \ldots \ldots \ldots \ldots, 467$

Appendix 2: Integrals $\ldots \ldots \ldots \ldots \ldots \ldots \ldots \ldots \ldots \ldots \ldots \ldots \ldots \ldots \ldots \ldots \ldots, 468$

Appendix 3: Flow Chart for Main Program $\ldots \ldots \ldots \ldots \ldots \ldots \ldots, 472$

Addendum to Final Report 


\section{LIST OF TABLES}

TABLE

1.1

1.2

1.3 Preliminary Estimates of Natural Gas In

Hydrate Deposits

TITLE

PAGE

Properties of Hydrate Lattice $\ldots \ldots \ldots \ldots \ldots \ldots \ldots \ldots \ldots$

Hydrate Numbers For Different Gases

8

13

1.4 Resource Estimates of Hydrate Deposits In

Western Hemisphere

Geothermal Properties For Prudhoe Bay and

Kuparuk - West Sak Fields

1.6

Rate Expression Parameters For Methane and Ethane

19

1.7

Hydrate Forming Conditions For Pure Gases

1.8

Study of Binary Systems of Hydrates (With Water)

35

1.9

Ternary Systems of Hydrates (With Water)

Four Component Systems of Hydrates (With Water)

38

1.11

Properties of Messoyakha Gas/Hydrate Field

59

1.12 Test Results From Inhibitor Injection in the

Messoyakha Field

60

2.1

Physical Properties of Hydrate Cores (Method I)

109

2.2

Experimental Results for Run \#1

110

2.3

Experimental Results for Run \#2

111

2.4

Experimental Results for Run \#3

112

2.5

Experimental Results for Run \#4

113

2.6

Experimental Results for Run \#5

114

2.7 Experimental Results for Flow Runs During Method II Hydrate Formation

3.1 Properties of Methane Hydrate Cores Used in the Study of Hydrate Dissociation by Brine Injection Method

3.2 Summary of Hydrate Dissociation Runs (Brine Injection Method) 


\section{LIST OF TABLES (CONT'D)}

TABLE

TITLE

PAGE

4.1 Properties of Methane Hydrate Cores Used in the Study of Hydrate Dissociation by Hot Water Injection Method

4.2 Summary of Hydrate Dissociation Runs (Hot Water Injection Method)

5.1 Properties of Methane Hydrate Cores Used in the Study of Hydrate Dissociation by Depressurization Method

5.2 Summary of Hydrate Dissociation Runs (Depressurization Method)

6.1 Properties of Methane Hydrate Cores Used in the Study of Hydrate Dissociation by Methanol Injection

6.2 Experimental Conditions For Hydrate Dissociation by Methanol Injection

6.3 Properties of Methane Hydrate Cores Used in the Study of Hydrate Dissociation by Ethylene Glycol Injection

Experimental Conditions For Hydrate Dissociation by

6.5 Constants " $a$ " and " $b$ " in Hydrate Dissociation

Correlation (Equation 6.9).

$7.1 \quad V L_{1} L_{2} H$ Data for West Sak Crude-Methane-Water

Mixture

7.2

Live West Sak Crude Composition

213

West Sak Crude PVT Properties

Saturation Pressures of West Sak Crude

Hydrocarbon Analysis of West Sak Separator Gas

7.7 $V L_{1} L_{2} H$ Data For Prudhoe Bay Crude-Methane-Water

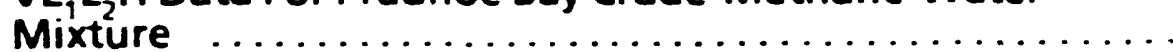




\section{LIST OF TABLES (CONT'D)}

TABLE

PAGE

8.3

Base Case Process Parameters

304

9.1

Parameters Used For Avdonin Validation Case

416

9.2

Parameters For Two-Phase Convective Heat Transfer

Case

434 


\section{LIST OF FIGURES}

FIGURE

TITLE

PAGE

$1.1 \quad$ Structure I Hydrate Representation $\ldots \ldots \ldots \ldots \ldots \ldots \ldots \ldots$

1.2 Structure II Hydrate Representation $\ldots \ldots \ldots \ldots \ldots \ldots \ldots$

1.3 Potentia! Regions of Hydrate Deposits ................ 12

$1.4 \quad$ Kihara Potential Function $\ldots \ldots \ldots \ldots \ldots \ldots \ldots \ldots \ldots \ldots \ldots$

1.5 Map Showing Location of Messoyakha Gas Hydrate Field . . . . 55

1.6 Cross Section of Messoyakha Gas Hydrate Field . . . . . . . . . 56

$1.7 \quad$ Gas Hydrate Stability Envelope at Messoyakha . . . . . . . . 57

1.8 Well Logs from Well Number 136 at Messoyakha ......... 61

1.19 Pressure Without Hydrates and With Hydrates as a Function of Time; Produced Gas both With and Without Hydrates .....

1.10a,b Messoyakha Pressure and Temperature With Hydrate Production Away From Hydrate Face Hypothesized at

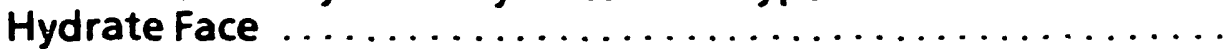

1.11 Nomogram to Determine Hydrate Stability in Arctic Onshore Regions .......................... 69

1.12 Zone of Hydrate Stability in the Arctic Subsea Region ....... 70

1.13 Zone of Hydrate Stability in the Subtropic Subsea Region ..... 71

1.14 Nomogram For Estimation of Parameters While Drilling

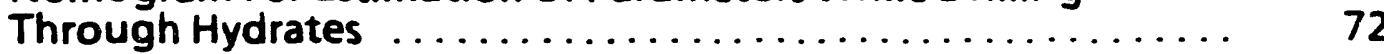

$2.1 \quad$ Hydrate Core Holder . . . . . . . . . . . . . . . . . 102

2.2 Experimental Set-Up For Hydrate Core Permeability Measurement .............................. 104

2.3 Conversion to Hydrates Versus Time For Runs 1 Through $5 \ldots \ldots$

2.4 Gas Permeability as a Function of Hydrate Saturation ...... 116

2.5 Effective Gas Permeability Reduction Factor as a Function of Hydrate Saturation $\ldots \ldots \ldots \ldots \ldots \ldots \ldots \ldots \ldots \ldots \ldots \ldots$

2.6 Conversion to hydrates Versus Time For Method II . . . . . 120 


\section{LIST OF FIGURES (CONT'D)}

FIGURE

TITLE

PAGE

2.7 Gas Permeability as a Function of Hydrate Saturation

(Method II)

3.1 Experimental Setup For Hydrate Dissociation Studies

3.2 Equilibrium Pressure-Temperature Diagram For Methane

Hydrate in Presence of Salt $(\mathrm{NaCl})$ Solutions

3.3 Rate of Gas Production From Hydrate Dissociation Versus

Time For a Typical Run (Brine Injection Method)

3.4 Temperature Difference at the Brine-Hydrate Interface Versus

Time For Various Dissociation Runs .......................

3.5 Variation in the Salinity of Brine During Dissociation Runs ...

3.6 Cumulative Gas Produced From Hydrate Dissociation Versus Time For Various Dissociation Runs (Initial Salinity $=5 \%$ ) ...

3.7 Effect of Salinity on the Rate of Hydrate Dissociation

(Brine Injection Rate $=11.67 \mathrm{cc} / \mathrm{sec}$ )

3.8 Effect of Salinity on the Rate of Hydrate Dissociation (Brine Injection Rate $=20.83 \mathrm{cc} / \mathrm{sec}$ )

3.9 Rate of Hydrate Dissociation as a Function of True

Temperature Driving Force and Brine Injection Rate

3.10 Effect of Brine Injection Rate on the Rate of Hydrate Dissociation

4.1 Rate of Hydrate Dissociation Versus Time For a Typical

Hydrate Dissociation Run (Hot Water Injection)

4.2 Effect of Hot Water Injection Rate on Cumulative Gas Production

4.3 Effect of Hot Water Injection Rate on Cumulative Gas

Production

4.4 Effect of Pressure on Cumulative Gas Production 158

4.5 Methane Hydrate Dissociation Correlation (Hot Water Injection Method)

5.1 Pressure Versus Time For Depressurization Runs at Various Gas Production Rates 


\section{LIST OF FIGURES (CONT'D)}

FIGURE

TITLE

PAGE

5.2 Pressure Versus Time For Extended Depressurization Run

(Gas Production Rate $=0.83 \mathrm{scc} / \mathrm{sec}$ )

167

5.3 A Typical Depressurization Run Illustrating Constant Gas

Production Rate Period and Flow Decline Period ............ 169

5.4 Pressure Versus Cumulative Gas Produced (0.83 $\mathrm{scc} / \mathrm{sec}) \ldots \ldots \quad 170$

5.5 Pressure Versus Cumulative Gas Produced (16.67 scc/sec) . . . 171

5.6 Pressure Versus Cumulative Gas Produced $(83.33 \mathrm{scc} / \mathrm{sec}) \quad \ldots \ldots \quad 172$

5.7 Effect of Gas Production Rate on the Average Hydrate

Dissociation and \% Hydrates Dissociated During Constan

Flow Period

5.8 Effect of Initial Temperature of Hydrates on the \% Total

Gas-In-Place Produced From Hydrate Dissociation During

Depressurization Runs (16.67 scc/sec)

174

6.1 Effect of Methanol Inhibition on Methane Hydrate

Forming Conditions

6.2 Effect of Glycol Inhibition on Methane Hydrate Forming

Conditions.

180

6.3 Typical Hydrate Dissociation Run ................. 187

6.4 Dilution of Methanol By Hydrate Dissociation $\ldots \ldots \ldots \ldots \ldots \quad 188$

6.5 Decrease in Temperature Driving Force .............. 189

6.6 Effect of Methanol Injection Rate on Cumulative Gas

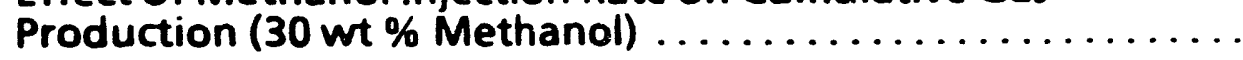

6.7 Effect of Methanol Injection Rate on Hydrate Dissociation

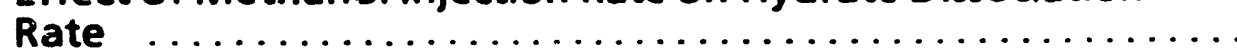

6.8 Effect of Methanol Concentration on Cumulative Gas

Production (Injection Rate $=26.67 \mathrm{cc} / \mathrm{sec}$ ) $\ldots \ldots \ldots \ldots \ldots \ldots$

6.9 Hydrate Dissociation Correlation (Methanol Injection) ...... 194

6.10 Effect of Methanol Inhibition on the Degree of Enhancement in Hydrate Dissociation Rate .................... 196

6.11 Dilution of Glycol by Hydrate Dissociation ............. 199 


\section{LIST OF FIGURES (CONT'D)}

FIGURE

TITLE

PAGE

6.12 Effect of Glycol Injection Rate on Cumulative Gas Production (30 wt \% Glycol)

6.13 Effect of Glycol Concentration on Cumulative Gas Production (Injection Rate $=26.67 \mathrm{cc} / \mathrm{sec}$ ) 201

6.14 Hydrate Dissociation Correlation (Glycol Injection) 202

7.1 Experimental Set-Up For Hydrate-Oil-Gas Phase Equilibrium Study 209

7.2 Effect of Hydrate Formation On the Bubble Point Pressure Curve For West Sak Crude

7.3 Effect of Hydrate Formation on Solution GOR of West Sak Crude

7.4 Effect of Hydrate Formation on Density of West Sak Crude

7.5 Effect of Hydrate Formation on the Bubble Point Pressure Curve For Prudhoe Bay Crude

7.6 Effect of Hydrate Formation on Density of Prudhoe Bay Crude 223

8.1 Geometry of Hydrate Dissociation Around a Wellbore 256

8.2 Explanation of Symbols For Moving Boundary Derivation .... 262

8.3 Explanation of Symbols For Moving Boundary Derivation .... 262

8.4 Discretization of Dimensional Space Coordinates ......... 279

8.5 Discretization of Dimensional Space Coordinates ......... 279

$8.6 \quad$ Irregular Grid Points $\ldots \ldots \ldots \ldots \ldots \ldots \ldots \ldots \ldots \ldots \ldots \ldots \ldots$

8.7 Comparison of Models for $\phi=-0.01 \ldots \ldots \ldots \ldots \ldots$

8.8 Comparison of Models for $\phi=-0.1 \ldots \ldots \ldots \ldots \ldots \ldots \ldots$

8.9 Comparison of Models for $\phi=-0.35 \ldots \ldots \ldots \ldots \ldots \ldots$

8.10 Typical Temperature Profiles Within the Reservoir ........ 306

8.11 Position of Hydrate Dissociation Front as a Function of Time . . 306

8.12 Methane Hydrate Stability Zone Below Permafrost ....... 308 


\section{LIST OF FIGURES (CONT'D)}

FIGURE

TITLE

PAGE

8.13 Effect of Porosity on Rate of Hydrate Front Advance ....... 309

8.14 Effect of Porosity on Rate of Hydrate Dissociation ......... 309

8.15 Effect of Wellbore Radius on the Rate of Hydrate

Dissociation

8.16 Effect of Wellbore Pressure and Temperature on Rate of Hydrate Front Advance

8.17 Effect of Wellbore Pressure and Temperature on Gas

Influx Rate

8.18 Effect of Mud Density and Circulation Rate on Bottomhole

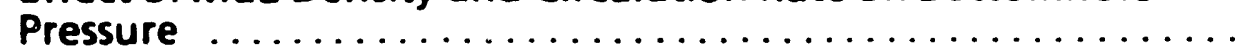

8.19 Effect of Mud Density and Viscosity on Bottomhole

Pressure

8.20 Effects of Casing and Mud Inlet Temperature on the Bottomhole Temperature

8.21 Effect of Mud Density and Circulation Rate on Bottomhole

Temperature

8.22 Nomogram For Estimation of Parameters For Drilling

Through Hydrates

8.23 Use of Nomogram--Example \#1: Sizing Surface Mud

Degasser

8.24 Use of Nomogram--Example \#2: Minimum Wellbore

Pressure Determination

8.25 Use of Nomogram--Example \#3: Determining Maximum

Wellbore Temperature

333

$9.1 \quad$ Model Hydrate Reservoir Geometry ................ 364

9.2 Calculation of Gas Source Terms ................. 393

9.3 Radial Pressure Profile at Time $=0.1$ hours ........... 400

9.4 Radial Pressure Profile at Time $=0.2$ hours $\ldots \ldots \ldots \ldots \ldots .400$

9.5 Radial Pressure Profile at Time $=0.5$ hours $\ldots \ldots \ldots \ldots \ldots .401$

9.6 Radial Pressure Profile at Time $=1$ hours $\ldots \ldots \ldots \ldots \ldots .401$ 


\section{LIST OF FIGURES (CONT'D)}

FIGURE

TITLE

PAGE

9.7 Radial Temperature Profile at Time $=0.1$ hours . . . . . . 402

9.8 Radial Temperature Profile at Time $=0.5$ hours $\ldots \ldots \ldots \ldots 2$

9.9 Radial Temperature Profile at Time $=1$ hours $\ldots \ldots \ldots \ldots .403$

9.10a Warm Temperature Boundary (O'Neill, 1983) .......... 405

9.10b Cold Temperature Boundary (O'Neill, 1983) ............ 405

9.11 Phase Front Versus Time $\ldots \ldots \ldots \ldots \ldots \ldots \ldots \ldots \ldots \ldots \ldots$

9.12 Lunardini Problem, Thawing Around a Circular Pipe ....... 406

9.13 Comparison of Lunardini Solution With Finite Element
Solution For Thawing Around Circular Pipe $\ldots \ldots \ldots \ldots \ldots$

9.14 Lauwerier's Model For Heat Transfer In an Aquifer ......... 408

Comparison of Formulation A with Formulation B for
Convection at $t_{D}=20 \ldots \ldots \ldots \ldots \ldots \ldots \ldots \ldots \ldots \ldots \ldots \ldots$

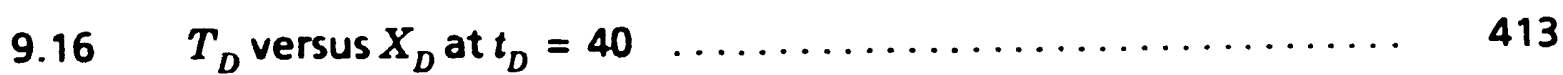

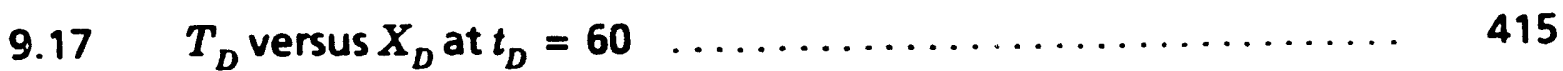

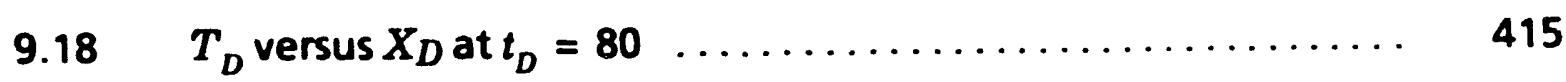

9.19 Radial Temperature Profile at $t=2$ years $\ldots \ldots \ldots \ldots \ldots .417$

9.20 Upstream Weighting Scheme $\ldots \ldots \ldots \ldots \ldots \ldots \ldots \ldots \ldots \ldots \ldots$

$9.21 \quad \begin{aligned} & \text { Saturation Profile For Viscosity Ratio }=1, w=0, \\ & \text { Consistent Formulation } \ldots \ldots \ldots \ldots \ldots \ldots \ldots \ldots \ldots \ldots \ldots\end{aligned}$

Saturation Profile For Viscosity Ratio $=1, w=0.2, \ldots \ldots \ldots \ldots \ldots \ldots \ldots \ldots$
Consistent Formulation $\ldots \ldots \ldots \ldots \ldots \ldots$

Saturation Profile For Viscosity Ratio $=1, w=0.4, \ldots \ldots \ldots \ldots \ldots \ldots \ldots \ldots$
Consistent Formulation $\ldots \ldots \ldots \ldots \ldots \ldots$

Saturation Profile For Viscosity Ratio $=1, w=0.6, \ldots \ldots \ldots \ldots \ldots \ldots \ldots \ldots$
Consistent Formulation $\ldots \ldots \ldots \ldots \ldots \ldots$

Saturation Profile For Viscosity Ratio $=1, w=0.8, \ldots \ldots \ldots \ldots \ldots \ldots \ldots \ldots \ldots \ldots \ldots$
Consistent Formulation $\ldots \ldots \ldots \ldots \ldots$

Saturation Profile For Viscosity Ratio $=1, w=1.0$,
Consistent Formulation $\ldots \ldots \ldots \ldots \ldots \ldots \ldots \ldots \ldots \ldots \ldots$ 


\section{LIST OF FIGURES (CONT'D)}

FIGURE

TITLE

PAGE

9.27 Saturation Profile For Viscosity Ratio $=1, w=0$, Lumped Formulation .......................... 426

9.28 Saturation Profile For Viscosity Ratio $=1, w=0.2$,

Lumped Formulation $\ldots \ldots \ldots \ldots \ldots \ldots \ldots \ldots \ldots \ldots \ldots$

9.29 Saturation Profile For Viscosity Ratio $=1, w=0.4$,

Lumped Formulation ........................ 427

9.30 Saturation Profile For Viscosity Ratio $=1, w=0.6$,

Lumped Formulation $\ldots \ldots \ldots \ldots \ldots \ldots \ldots \ldots \ldots \ldots \ldots \ldots \ldots \ldots$

9.31 Saturation Profile For Viscosity Ratio $=1, w=0.8$,

Lumped Formulation $\ldots \ldots \ldots \ldots \ldots \ldots \ldots \ldots \ldots \ldots \ldots \ldots . . .428$

9.32 Saturation Profile For Viscosity Ratio $=1, w=1.0$,

Lumped Formulation ..................... 428

9.33 Saturation Profile For Viscosity Ratio $=1, w=1.2$,

Lumped Formulation $. . . \ldots \ldots \ldots \ldots \ldots \ldots \ldots \ldots \ldots . . \ldots .429$

9.34 Saturation Profile For Viscosity Ratio $=1, w=1.4$, Lumped Formulation $\ldots . \ldots \ldots \ldots \ldots \ldots \ldots \ldots \ldots . . \ldots . \ldots 429$

9.35 Fractional Flow Curve For Viscosity Ratio $=1 \ldots \ldots \ldots \ldots .431$

9.36 Fractional Flow Curve For Viscosity Ratio $=100 \ldots \ldots \ldots \ldots .431$

9.37 Saturation Profile For Piston-Like Displacement Viscosity

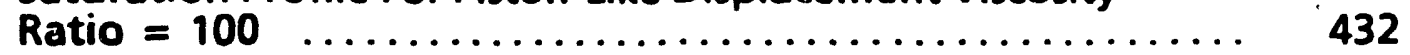

9.38 Radial Temperature Profile For Hot Water Injection Into Gas Water System ........................... 435

9.39 Radial Temperature and Saturation Profiles For Hot Water Injection Into Gas Water System .................. 435

9.40 Comparison of A Formulation With C Formulation ........ 439

9.41 Mesh For Case \#1 Simulation Run ................. 441

9.42 Pressure Profile For Case \#1 .................. 443

9.43 Saturation Profile For Case \# $1 \ldots \ldots \ldots \ldots \ldots \ldots \ldots \ldots . \ldots . \ldots 43$

9.44 Mesh For Case \#2 Simulation Run .................. 444

9.45 Temperature Profile For Case \#2, Before Thawing ........ 446 


\section{LIST OF FIGURES (CONT'D)}

FIGURE

TITLE

PAGE

9.46 Pressure Profile For Case \#2, Before Thawing $\ldots \ldots \ldots \ldots .446$

9.47 Saturation Profile For Case \#2, Before Thawing $\ldots \ldots \ldots \ldots .447$

9.48 Temperature Profile For Case \#2 After Thawing $\ldots \ldots \ldots \ldots .447$

$\mathbf{9 . 4 9}$ Pressure Profile For Case \#2, After Thawing $\ldots \ldots \ldots \ldots \ldots .448$

9.50 Saturation Profile For Case \#2, After Thawing ........... 449

9.51 Thawing lsotherms for Case \#2 $\ldots \ldots \ldots \ldots \ldots \ldots \ldots \ldots .449$

9.52 Asymmetric Weighting Functions $\ldots \ldots \ldots \ldots \ldots \ldots \ldots, 452$

9.53 Damping Factors For Triangular Elements ............. 469 


\section{EXECUTIVE SUMMARY}

This report summarizes four years of research efforts on the project, "Development of Alaskan Gas Hydrate Resources", which was funded jointly by the U.S. Department of Energy (Morgantown Energy Technology Center) and the University of Alaska Fairbanks (Petroleum Development Laboratory).

It is estimated that 500 to 700 trillion standard cubic feet (TCF) of natural gas is trapped in the form of solid natural gas hydrate deposits in the northern Alaska. This unconventional resource is huge in comparison to the conventional natural gas estimated reserves of 85 TCF in contiguous United States and represents a significant long-term future source for natural gas. The commercial production from this resource will require a detailed characterization of gas hydrate reservoirs and development of related technology for in-situ decomposition of hydrates.

The first chapter provides a brief overview of gas hydrates and provides a historical perspective and evolution of gas hydrate research since their first discovery in 1811. It describes nature, crystalline structures, thermophysical properties of hydrates, types of naturally occurring gas hydrate deposits, occurrence of hydrates in offshore and onshore environment and estimated reserves of natural gas in hydrated form in various locations. In the offshore Alaska, the seismic surveys indicate the presence of gas hydrates in the sediments of the Beaufort Sea, the Bering Sea, the North Pacific Ocean, and the Gulf of Alaska. The most extensive mapped occurrence of gas hydrates in offshore Alaska is found in the Beaufort Sea where the areal extent of the inferred hydrate occurrence exceeds 6,500 square miles at 300 to 900 feet below the seafloor and water depths of 1,200 to 7,400 feet. In the onshore regions of Alaska, the analysis of well logs, core data, drill cuttings, drilling reports and seismic surveys for $\mathbf{4 4 5}$ wells on the Alaskan North Slope, suggest that Prudhoe Bay-Kuparuk River area alone contains up to 44 TCF of natural gas 
trapped as hydrates (Collett, 1990). In addition, large accumulations of free gas occur downdip below hydrate zones. Rest of this chapter describes the techniques for detection and evaluation of in-situ hydrates, kinetics of hydrate formation, thermodynamics of hydrates, principles of production of natural gas from hydrate reservoirs, field example of gas production f.um hydrates, problems associated with drilling through hydrates and prevention of hydrate formation in natural gas processing and transportation.

The second chapter describes the experimental work conducted to measure the effective gas permeability of hydrate saturated sandpack. As hydrates form or decompose in a porous medium, the pore structure geometry and the physical properties such as effective porosity and permeability are altered. This experimental study was focused on gathering such information. The experimental results indicate that the formation of hydrates cause a drastic reduction in the effective permeability of the core (by a factor of 45 to 110). The permeability reduction is not only controlled by the hydrate saturation but also by the distribution of hydrates in the sandpack during formation process. A correlation between the permeability reduction factor and hydrate saturation was obtained.

Since hydrates are relatively impermeable and immobile within reservoirs, the production of gas from hydrates will require a technique for in-situ decomposition of hydrates to gas and water. Three principle techniques are: 1) reduction of reservoir pressure below the hydrate equilibrium decomposition pressure as in depressurization; 2) heating of the reservoir above the hydrate decomposition temperature by thermal stimulation such as injection of hot fluids (hot water, steam or hot brine) or microwave heating; 3 ) injection of hydrate inhibiting chemicals such as methanol and glycols to destabilize hydrates by shifting hydrate equilibrium conditions. 
The chapteri three through six provide the details of the experimental work conducted to study the decomposition characteristics of hydrates in the laboratory made cores containing methane hydrates during various decomposition techniques. Dissociation of natural gas from hydrates was accomplished by several techniques which include: depressurization, injection of hot water, steam, brine, methanol and glycol solutions. The rate of gas released from hydrate core was measured under different experimental conditions and related energy requirements. Experimental results for all the techniques were compared and used to correlate the rate of hydrate decomposition as a function of various experimental parameters. Experimental results show that all techniques were capable of yielding very high rate of hydrate decomposition is a heat transfer limited process. This suggests that the rate of decomposition and the hydrate decomposition of hydrates in the reservoir would be governed by the good surface contact between hydrates and injection fluid and thus can be further enhanced by injection of hot fluids in natural and artificial fractures. Depressurization scheme produced gas from hydrates at lower rates than those using heat transfer through injection. Thus, this technique is more suitable to reservoirs thai contain hydrates overlying free gas zones where gas production from free gas zone would be benefited from hydrate drive (or contribution to gas production due to hydrate dissociation). The experimental results show that hydrate dissociation resulted in the decrease in rate of decline of pressure and contributed significantly (15 to $70 \%$ ) to the cumulative gas production. Furthermore, the degree of contribution from hydrates to the total gas production increased with the decrease in gas withdrawal rate (thus allowing more time for dissociation), with the increase in initial temperature of hydrates and with the increase in hydrated gas to free gas in place. The brine injection experiments show that salinity of brine has a strong influence on the rate of hydrate dissociation (increase in salinity from 5 to $10 \%$ increased the rate of hydrate decomposition by a 
factor of four) and use of brine would be excellent way in enhancing the production of natural gas from hydrate reservoirs. The results of the methanol and glycol injection experiments also show that the rate of hydrate decomposition can be further enhanced by use of hydrate inhibitors. While field tests would be ultimate indicator of the recovery potential of gas hydrates, the experimental studies reported here show encouraging results that hydrates can be decomposed readily at very high rates to provide significant gas production.

It is reported that gas hydrates occur in conjunction with heavy oils and tar sands in the southwest up-dip continuation of West Sak and Ugnu formations in the Kuparuk River Unit, North Slope of Alaska (Collett, 1985). One theory suggests that, during an up-dip migration of light crude oils from the deeper Sadlerochit formations of the Prudhoe Bay Unit in the east towards the shallower formations in the Kuparuk River Unit on the west, the crude oil passed through bubble point releasing lighter hydrocarbon gases causing the oil to become heavier. Due to favorable conditions for hydrate formation, the released gases might have reformed into solid hydrate deposits. An experimental study was thus focused on formation of hydrates in presence of Alaskan North Slope crudes as described in chapter seven. The hydrate forming conditions for West Sak crude-methane-water mixture and Prudhoe Bay crude-methane-water mixture were measured. These experiments show that hydrate formation causes extraction or removal of lighter $\left(C_{1}-C_{4}\right)$ hydrocarbon components of the crude, lowers the bubble point of the crude, increases density of the crude and reduces solution gas-oil ratio. For West Sak crude, hydrate formation was possible below $56^{\circ} \mathrm{F}$. This temperature exists in shallower sections of the Ugnu and West Sak reservoirs. This supports the hypothesis that hydrate formation might have been the cause of alteration of crude oil properties in the shallower Wesi Sak and Ugnu formations. 
Chapter eight provides a review of literature on numerical modelling of phase change processes or Stefan problems and the details of the numerical finitedifference, two-dimensional $(r-z)$ simulator developed in this project to model the dissociation of gas hydrates in porous media with variable thermal properties. This model has been validated with the available literature solutions on permafrost thawing problems. This simulator has been coupled with a comprehensive wellbore hydraulics model and has been used for detailed examination of the effects of wide range of drilling and reservoir parameters on the hydrate dissociation rate for arctic terrestrial, arctic subsea and subtropic subsea locations. Parameters studied include formation porosity, wellbore radius, wellbore pressure, temperature and geothermal parameters such as geothermal gradient within and below permafrost and the depth to the permafrost base. The relative effects of many drilling parameters such as drilling mud circulation rate, mud density and mud viscosity on the wellbore pressure and effects of casing, mud inlet temperature, mud density and circulation rate on the wellbore temperature have been examined. The results have been used to generate a nomogram to estimate drilling fluid parameters for safer drilling through hydrate zones and for proper design of mud degasifier.

Lastly, chapter nine provides a detailed description of the numerical finite element (two-dimensional, r-z coordinate) simulator developed in this study to model dissociation of gas hydrates in reservoir during thermal stimulation by hot water injection. The finite element formulation is capable of conducting transient analysis of both conductive and convective heat transfer and two phase flow during hydrate dissociation process and is capable of handling three phases such as hot water injection, soak or shut in period and gas production. The finite element scheme has been successfully validated against analytical solutions for conductive and convective heat transfer, for radial thawing and for single and two-phase flow in porous media. This validation process has demonstrated the versatility of the 
finite-element scheme and its potential for application in other areas of simulation. Only limited success was achieved in applying this model to simulate hydrate dissociation problem. Further work will be needed to devise a better solution scheme to handle hydrate dissociation problem. 


\section{CHAPTER ONE \\ REVIEW OF GAS HYDRATES}

\subsection{Introduction}

Gas hydrates, also commonly called as inclusion compounds or clathrate hydrates are crystalline, ice-like solids in which, the gas molecules are encaged in the interstices of the hydrogen bonded water lattices. The first published study of hydrates goes back to 1810 , when the English chemist Sir Humprey Davy reported the formation of a yellow precipitate as a result of chlorine gas bubbling through water. These solid precipitates were called as "chlorine hydrates".

Since this discovery, the history of natural gas hydrates has evolved over four major periods. In the first period beginning their discovery in 1810 till 1930's, most of the studies were of purely academic nature which concerned with hydrates as a scientific curiosity. Most of these early studies focussed on identifying which compounds were capable of forming hydrates. A thorough review of this first 125 years of hydrate research is provided by Schroeder (1927). During this period various investigators reported forming hydrates of $\mathrm{Cl}_{2}, \mathrm{Br}_{2}, \mathrm{SO}_{2}, \mathrm{CS}_{2}, \mathrm{CO}_{2}, \mathrm{CH}_{3} \mathrm{Cl}_{2} \mathrm{H}_{2} \mathrm{~S}, \mathrm{CH}_{4}$, $\mathrm{C}_{2} \mathrm{H}_{6}, \mathrm{C}_{2} \mathrm{H}_{4}, \mathrm{C}_{2} \mathrm{H}_{2}, \mathrm{~N}_{2} \mathrm{O}, \mathrm{C}_{3} \mathrm{H}_{8}, \mathrm{Ar}, \mathrm{N}_{2}, \mathrm{O}_{2}, \mathrm{Kr}, \mathrm{Xe}$ and air. Mixed hydrates of $\left(\mathrm{CO}_{2}+\mathrm{PH}_{3}\right)$, $\left(\mathrm{H}_{2} \mathrm{~S}+\mathrm{PH}_{3}\right),\left(\mathrm{H}_{2} \mathrm{~S}+\right.$ halohydrocarbons) and mixtures of halohydrocarbons with $\mathrm{C}_{2} \mathrm{H}_{2}$, $\mathrm{CO}_{2}$ and $\mathrm{C}_{2} \mathrm{H}_{6}$ were also reported. It was also recognized that hydrates are nonstoichiometric compounds and differed from ic.. Use of Clausius-Clapeyron equation to determine composition of hydrates was also first proposed in this period (de Forcrand, 1902).

The study of gas hydrates did not have any direct industrial application until the beginning of the 1930's when Hammerschmidt (1934) first reported that the plugging of natural gas pipelines was caused by formation of natural gas hydrates during gas flow. This marked the beginning of the second period. With the rapid development of gas producing industries, subsequently, research efforts in this 
period were focussed on measurement of hydrate forming conditions for different gases and natural gas mixtures; development of simple $K$-value techniques for prediction of hydrate forming conditions for natural gas and determination of hydrate formation limits to Joule-Thompson expansions of natural gases during throttling of gas through a valve; generation of $K$-value charts for different gas hydrates; extensive $x$-ray diffraction studies to understand crystallographic nature and properties of gas hydrates; development of statistical thermodynamic model for prediction of hydrate equilibria; and development of methods for prevention and accumulation of hydrates in gas pipelines and in wells drilled for gas production. A brief review of some of these studies are provided later and detailed review of this work is given in Sloan (1990).

The third period began in 1950's when unusual drilling experiences in Arctic and offshore operations led to the speculation that hydrates could exist in nature and could represent potential gas resource. This resulted in a series of studies focussed on phase behavior relationships, pressure and temperature curves, hydrate stability in earth and speculations of naturally occurring gas hydrate deposits.

The fourth period began in mid 1960's when Soviet scientists announced the discovery and recovery of gas hydrate samples from sedimentary formations in Siberia. This announcement initiated the current stage of gas hydrate research. The research in this period is focussed on gas hydrates as a potential natural gas resource that needs to be developed. The studies have been focussed on defining hydrate stability fields in offshore and arctic permafrost regions, developing methods for hydrate detection and evaluation, characterization and assessment of hydrate resources, defining geology of hydrate occurring environments, understanding the origin of hydrates, recovery of actual hydrate core samples and determination of their thermo-physical properties, measurement of properties of synthetic hydrates, 
development of techniques for production of natural gas from hydrates, and experimental and theoretical modeling of hydrate decomposition in porous media.

The experimental studies conducted in this research project as well as studies conducted by other investigators and a field study reported in Messoyakha field provide a proof of potential that gas hydrate resources can be developed, considerable research efforts are still needed for the development of hydrate resources. This includes geological field research for detailed characterization of gas hydrate reservoirs, application of production models to predict recovery potential of gas hydrate reservoirs and field production studies to verify and define the recoverable reserves.

\subsection{Nature of Gas Hydrates}

Gas hydrates are clathrate, non-stoichiometric, crystalline, ice-like solid compounds in which each water molecule forms hydrogen bonds with four nearest neighbors to build a solid lattice which encages gas molecules like methane, ethane, propane and various others, in it's interstitial cavities. They are formed under favorable thermodynamic conditions such as high pressures and low temperatures, due to physical interaction between the gas and water molecules. The solid hydrate phase is characterized by a hydrate number, which is the equilibrium of number of molecules of water per molecules of gas. The gas molecules are not a part of the lattice framework of the water molecules, but occupy the interstices or cavities formed by the crystalline water lattice. The degree of occupancy of the interstitial cavities by the gas molecules depends upon the pressure, temperature and gas composition. It should be recognized that there is no chemical bonding between gas and water molecules, but the gas-water interactions are purely physical van der Waal type forces. 


\subsubsection{Structure of Gas Hydrates}

The first attempt to investigate the structure of hydrates was made by Nikitin (1936) who suggested that gas hydrates are nonstoichiometric inclusion compounds, called "clathrates," made up of a metastable "host" crystal lattice of water molecules within which the "guest" gas molecules are held by van der Waal forces. Claussen (1951), Pauling and Marshal (1952), and von Stackelberg and Muller (1954) employed $x$-ray diffraction techniques to study the structure of hydrates arid showed that gas hydrates crystallise in either of the two structures called structure I and structure II. The water molecules forming the crystal lattice interact among each other through hydrogen bonds whereas they interact with the "guest" gas molecules through weak van der waal forces. The crystalline structure formed by water lattice is composed of cavities of different sizes, and for producing a stable hydrate, only one-third of the cavity has to be occupied by gas molecules.

Structure I unit cell is made up of $\mathbf{4 6}$ water molecules, with 2 small and 6 large cavities of $5.1^{\circ} \mathrm{A}$ and $5.8^{\circ} \mathrm{A}$ average free diameter respectively whereas structure II consists of 136 water molecules, with 16 small and 8 large cavities of $5^{\circ} \mathrm{A}$ and $6.7^{\circ} \mathrm{A}$ average free diameter respectively. The small cavities of structure $I$ are regular pentagonal tetrahedra whereas the tetrakadecahedral large cavities consists of twelve pentagonal sides and two opposite hexagonal sides and are surrounded by twenty four water molecules. The cavity sizes are more equal in structure II, which is formed only when the "guest" gas molecules are too large to fit in cavities of structure $I$. Thus, e.g., propane, which has an average free diameter greater than $5.8^{\circ} \mathrm{A}$, does not form structure I hydrate and can only form structure II hydrate. The smaller cavities of structure II are pentagonal dodecahedra and are slightly deformed with a mean free diameter of $5^{\circ} \mathrm{A}$. On the other hand, the larger cavities of structure 
II are nearly spherical and are hexadecahedral. Table 1.1 gives the hydrate lattice properties of both the structures. Figures 1.1 and 1.2 give molecular arrangement of structures I and II.

Whether structure I or structure II hydrate is formed depends upon gas composition, molecular size and temperature of the system. In general, biogenic gases form structure 1, due to smaller molecules, whereas thermogenic gases usually form structure II, with molecules larger than ethane. A hydrate is formed when the lattice has been occupied by sufficient number of molecules to result in a stable structure. The hydrate number is defined as the ratio of number of water molecules to number of gas molecules in the hydrate phase. Different values of $n$ are possible due to the presence of unoccupied cavities at thermodynamic equilibrium. The minimum value of $n$ for structure $l$ is 5.75 when all the cavities are occupied and 7.66 when only the large cavities are occupied. The corresponding values for structure II are 5.67 and 17 respectively. Thus, isobutane, which can only fit into the larger cavities of structure II, should have hydrate number greater than or equal to 17. Table 1.2 gives the hydrate numbers for different gases.

As pointed above, the hydrate crystals can be stabilized even if the gas molecules partially occupy the available cavities in structure I or II. However, small molecules like methane cannot stabilize structure II alone. This is because the energy of stabilization results from van der Waal type forces, which are a function of the polarazeability of molecules, and hence small molecules interact weakly with the lattice. Also, as these forces are proportional to $\left(1 / r^{6}\right)$, where $r$ is the average separation between the guest and lattice walls, the empty water lattice cannot be sufficiently stabilized by small molecules in large cavities of structure I and II. However, Barrer and Ruzicka (1962) showed that in presence of other hydrate formers capable of stabilizing the structures, it is 
TABLE 1.1

PROPERTIES OF HYDRATE LATTICE

(After Kamath (1984))

\begin{tabular}{|l|c|c|c|c|}
\hline & \multicolumn{2}{|c|}{ Structure I } & \multicolumn{2}{c|}{ Structure II } \\
\cline { 2 - 5 } & $\begin{array}{c}\text { Small } \\
\text { Cavities }\end{array}$ & $\begin{array}{c}\text { Large } \\
\text { Cavities }\end{array}$ & $\begin{array}{c}\text { Small } \\
\text { Cavities }\end{array}$ & $\begin{array}{c}\text { Large } \\
\text { Cavities }\end{array}$ \\
\hline Cavities Per Unit Cell & 2 & 6 & 16 & 8 \\
\hline Cavity Radius, ${ }^{\circ} \mathrm{A}$ & 3.95 & 4.30 & 3.91 & 4.73 \\
\hline Coordination Number & 20 & 24 & 20 & 28 \\
\hline Cavities Per Molecule & $1 / 23$ & $3 / 23$ & $2 / 17$ & $1 / 17$ \\
\hline $\begin{array}{l}\text { Number of Water } \\
\text { Molecules Per Unit Cell }\end{array}$ & & 46 & & 136 \\
\hline Typical Examples & \multicolumn{2}{c|}{$\mathrm{CH}_{4}, \mathrm{C}_{2} \mathrm{H}_{6}, \mathrm{Ar}, \mathrm{Kr}$} & \multicolumn{2}{c|}{$\begin{array}{c}\mathrm{C}_{3} \mathrm{H}_{8,} \mathrm{C}_{3} \mathrm{H}_{6} \\
\text { i-butane, cyclo-propane }\end{array}$} \\
\hline
\end{tabular}




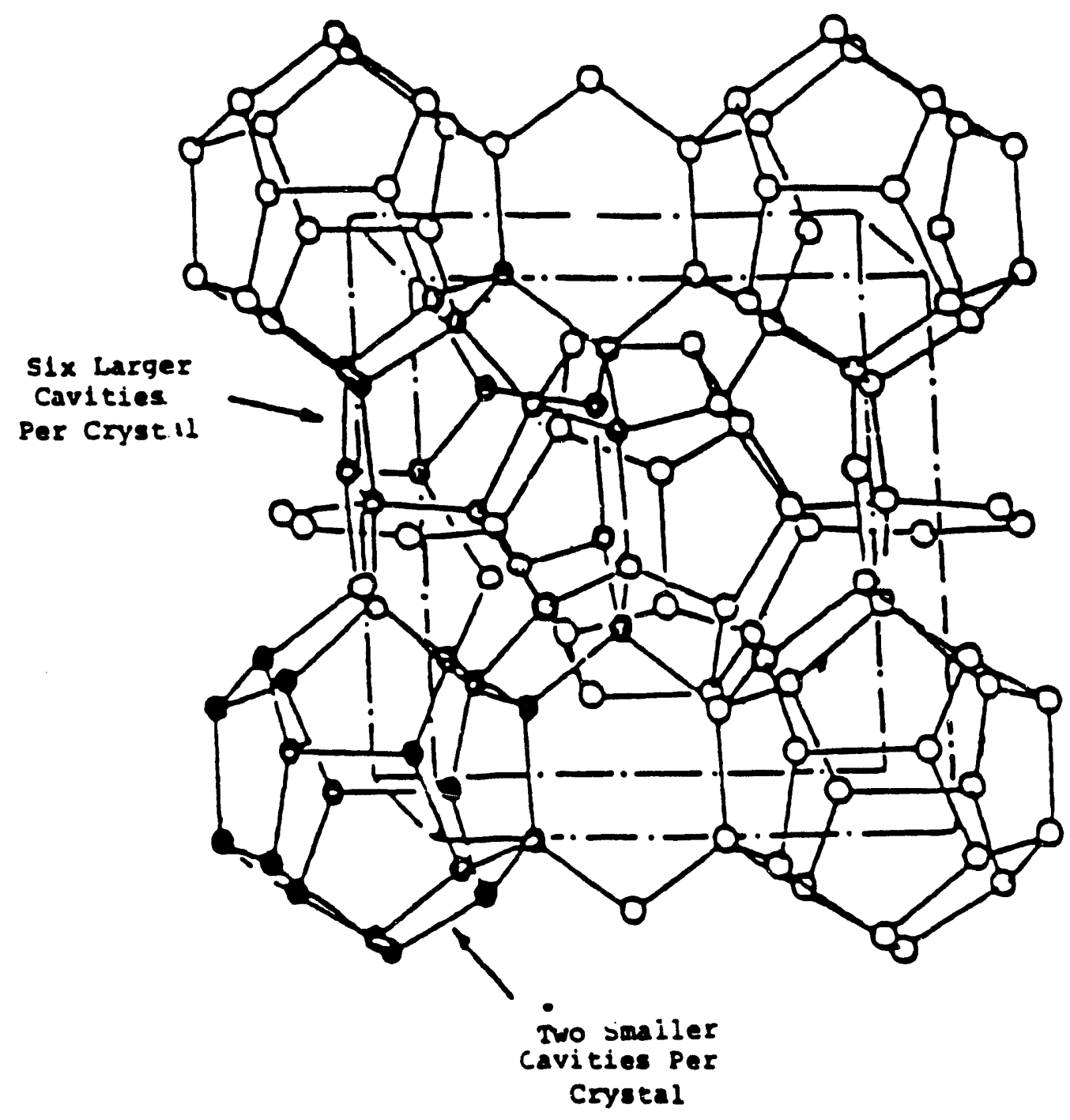

Figure 1.1: Structure I Hydrate Representation (After Kamath, 1982)

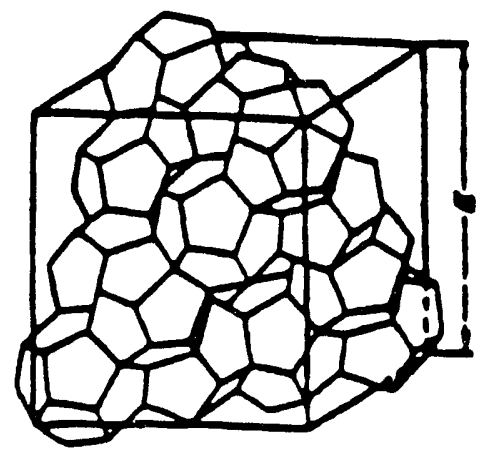

Figure 1.2: Structure II Hydrate Representation (After Makogon, 1981) 
TABLE 1.2

HYDRATE NUMBERS FOR DIFFERENT GASES

\begin{tabular}{|c|c|c|c|}
\hline Gas & $\begin{array}{l}\text { Hydrate No. } \\
\text { Experimental }\end{array}$ & $\begin{array}{l}\text { Hydrate No. } \\
\text { Theoretical }\end{array}$ & Reference \\
\hline \multirow[t]{5}{*}{ 1) Methane } & 6.0 & & de Forcrand (1902) \\
\hline & 6.0 & & Hammerschmidt (1934) \\
\hline & 7.0 & 5.75 & Roberts et al (1940) \\
\hline & $5.8-6.3$ & & Kobayashi et al (1976) \\
\hline & 6.15 & & Kamath (1984) \\
\hline \multirow[t]{6}{*}{ 2) Ethane } & 7.0 & & de Forcrand (1902) \\
\hline & 6.0 & & Hammerschmidt (1934) \\
\hline & 7.0 & & Roberts et al (1940) \\
\hline & 8.3 & 7.66 & Deaton and Frost (1946) \\
\hline & $7.9-8.5$ & & Kobayashi et al (1976) \\
\hline & 8.0 & & Kamath (1984) \\
\hline \multirow[t]{5}{*}{ 3) Propane } & 7.0 & & Hammerschmidt (1934) \\
\hline & 18.0 & & Deaton and Frost (1946) \\
\hline & 6.0 & 17 & Miller and Strong (1969) \\
\hline & $19.6-19.8$ & & Ceccotti (1966) \\
\hline & 18.0 & & Kamath (1984) \\
\hline \multirow[t]{3}{*}{ 4) i-butane } & 18 & & Schneider and Farar (1968) \\
\hline & 17.5 & 17 & Rouher and Barduhn (1969) \\
\hline & $15-17$ & & Godbole (1981) \\
\hline \multirow[t]{4}{*}{ 5) Carbon Dioxide } & 6.0 & & Villard (1888) \\
\hline & 6.0 & 7.66 & de Forcrand (1902) \\
\hline & 7.0 & & Deaton and Frost (1946) \\
\hline & 7.2 & & Kamath (1984) \\
\hline
\end{tabular}


possible for methane and even hydrogen molecules to occupy the smaller cavities of structure II.

In addition, Barrer and Edge (1967) and Ceccotti (1966) suggested that, apart from structures $I$ and $I I$, hydrates can also form other structures. Allen (1963) has substantiated this claim by showing that bromine hydrate can have a different structure with 172 water molecules and containing 20 cavities per hydrate crystal.

\subsubsection{Naturally Occurring Hydrates}

Naturally occurring gas hydrates exist in basically three different environments where thermodynamically favorable conditions for formation of gas hydrates existed for millions of years and still exist. The first type of environment is arctic regions of world where low temperatures persist far below the earth's surface. These are regions where a thick continuous permafrost cover overlies the hydrate deposits. The second type of environment is the deep oceanic sediments in tropical regions where high pressures exist to favor hydrate formation. The third type of environment is the shallow offshore sediments in arctic and sub-arctic regions. The review of these occurrences of hydrates is provided in the next section. In this section, the characteristics of naturally occurring hydrates are presented.

The naturally occurring hydrates contain approximately 170-180 SCF of natural gas per cubic feet of hydrates and have a composition of approximately $\mathbf{8 0 - 8 5} \mathrm{mol} \%$ water and $\mathbf{1 5 - 2 0} \mathrm{mol} \%$ natural gas. They are relatively immobile and impermeable within the porous media. In terms of energy content, they are more similar to heavy oil and tar sands than to other unconventional gas resources. While hydrates contain about 40-50 cf gas (40,000-50,000 BTU) per cubic feet of reservoir, coal bed methane contains 8-12, tight sands contain 5- 
10, devonian shales and geopressured aquifers contain 1-2 cf gas per $\mathrm{ft}^{3}$ reservoir. Conventional gas reservoir contains about 10-20 cf gas per cubic feet of reservoir.

Extensive geologic analysis research sponsored by U.S. Department of Energy, METC indicates that the naturally occurring hydrates exist in four forms (Malone, 1985). These four forms are: disseminated or dispersed, nodular, layered and massive hydrates.

The disseminated hydrate is a hydrate formation that contains dispersed crystals of hydrates throughout the formation. This type of hydrates have been recovered from the Orca and Mississippi Canyon area of the Gulf of Mexico in unconsolidated sediments. It is also believed that these type of hydrates also occur in the onshore areas in consolidated media (Malone, 1985). They probably formed in-situ with very little gas migration.

Nodular hydrate is similar to dispersed form of hydrate except that the size of the hydrate nodules is larger (1-2 inch diameter). Such hydrates have been observed in the Green Canyon area of the Gulf of Mexico. The recovered sample of hydrates of this type showed high quantities of ethane and propane along with methane which suggest thermogenic origin of gas at some depth which migrated into the hydrate stability zone.

Layered hydrates contain layers of hydrates separated by thin layers of sediments. Such core samples have been recovered from Blake Bahama, Offshore South Carolina to Florida. It is believed that these type of hydrates exists in both the offshore and onshore regions, in both consolidated and unconsolidated sediments. Migration of gas is probably involved to some extent during the hydrate formation. Hydrates on the Alaskan North Slope belong to this type of hydrate formation. 
The massive hydrate formation is probably mure common in the offshore environment. Massive hydrates are composed of large quantities of hydrates with varying quantities of sediment inclusions. The first massive hydrate core recovered from offshore Guatemala was 3.3 feet in length and contained 95\% hydrate and $5 \%$ sediment.

\subsection{Occurrence of Gas Hydrates}

In early 1950 's, drilling companies recorded unusual problems in regions in or adjacent to permafrow zones and in offshore areas. These unusual experiences included fizzing drill curtings, blowouts, casing collapse, sizable gas kicks, gas show on mud logs and well bore freeze-up. Many of these occurrences were attributed to the presence of gas hydrates in the geologic column.

In 1955, the existence of natural gas hydrates in the earth was first reported in the Soviet Union in the huge Messoyakha field (Makogon, 1965). Since then the presence of gas hydrate deposits has been established in both onshore and offshore regions of the world. The arctic onshore regions include: Alaskan North Slope, Wesiern Siberian Arctic, North West Territories in Canada and arctic islands. The offshore regions include: Beaufort Sea, Bering Sea, North Pacific Ocean, Gulf of Alaska, offshore California, mid-American trench regions, Gulf of Mexico, Blake Bahama outer ridge, New Jersey-Baltimore Canyon area and Labrador shelf. Figure 1.3 shows the potential regio. Is of hydrate existence in the offshore and onshore regions of the world.

There have been many attempts to estimate the quantity of natural gas trapped in the form of hydrates in the geosphere. Table 1.3 provides a summary of these resource estimates. These estimates range from very high values of Dobrynin et al (1981) who assumed that hydrates would occur wherever satisfactory thermodynamic conditions exist, to very low values of Mclver (1981) and Meyer 

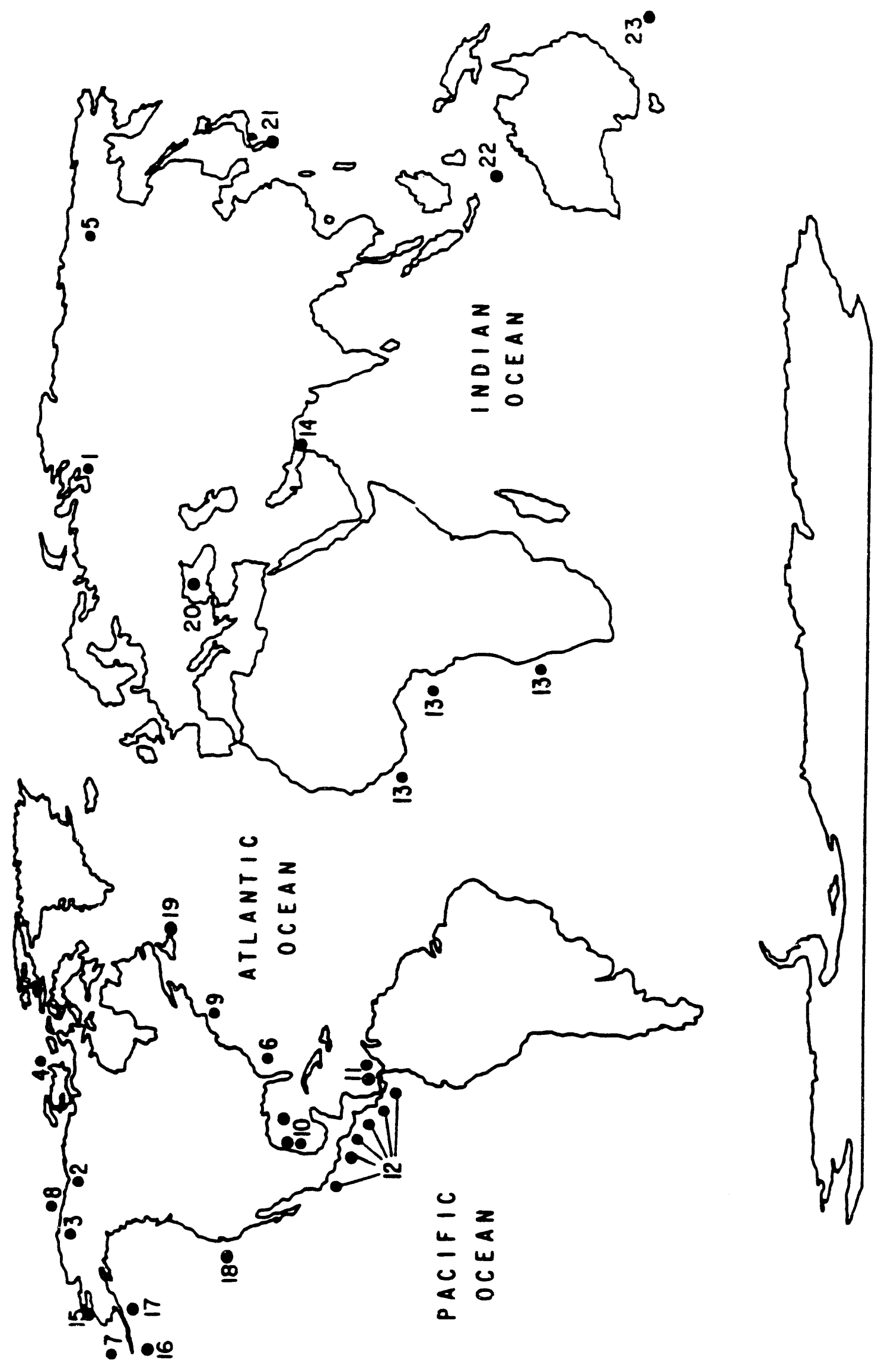

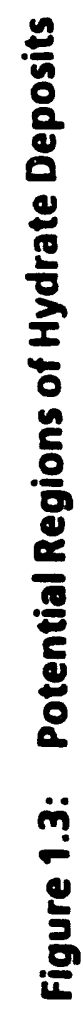


TABLE 1.3

PRELIMINARY ESTIMATES OF NATURAL GAS IN HYDRATE DEPOSITS

\begin{tabular}{|c|c|c|}
\hline $\begin{array}{c}\text { ONSHORE } \\
\left(\mathrm{m}^{3}\right)\end{array}$ & $\begin{array}{l}\text { OFFSHORE } \\
\left(\mathrm{m}^{3}\right)\end{array}$ & REFERENCE \\
\hline $\begin{array}{l}\text { Worldwide } \\
\begin{array}{l}5.7 \times 10^{13} \\
3.1 \times 10^{13} \\
2.8 \times 10^{16} \\
1.4 \times 10^{13} \\
1.0 \times 10^{14} \\
-\end{array}\end{array}$ & $\begin{array}{c}5-25 \times 10^{15} \\
3.1 \times 10^{15} \\
7.6 \times 10^{18} \\
- \\
1.0 \times 10^{16} \\
1.8 \times 10^{16}\end{array}$ & $\begin{array}{l}\text { Trofimuk et al. (1977) } \\
\text { Mclver (1981) } \\
\text { Dobrynin et al. (1981) } \\
\text { Meyer (1981) } \\
\text { Makogon (1988) } \\
\text { Kvenvolden (1988) }\end{array}$ \\
\hline $\begin{array}{l}\text { U.S. } \\
\qquad \begin{array}{l}7.1 \times 10^{14} \\
3.1 \times 10^{11}\end{array}\end{array}$ & $\begin{array}{c}7.6 \times 10^{13} \\
1.9 \times 10^{17} \\
-\end{array}$ & $\begin{array}{l}\text { Mclver (1981) } \\
\text { Dobrynin et al. (1981) } \\
\text { Meyer (1981) }\end{array}$ \\
\hline
\end{tabular}

TABLE 1.4

RESOURCE ESTIMATES OF HYDRTATE DEPOSITS IN WESTERN HEMISPHERE (After Malone, (1987)

\begin{tabular}{|l|c|}
\hline \multicolumn{1}{|c|}{$\begin{array}{c}\text { ONSHORE } \\
\left(\mathrm{m}^{3}\right)\end{array}$} & $\begin{array}{c}\text { OFFSHORE } \\
\left(\mathrm{m}^{3}\right)\end{array}$ \\
\hline Northern Alaska & $500-700$ \\
Offshore California & $5-10$ \\
Offshore Guatemala & $5-10$ \\
Gulf of Mexico & $200-2000$ \\
Blake Bahama Outer Ridge & $20-70$ \\
Baltimore Canyon Area & $20-40$ \\
Offshore Maritime Canada & $5-10$ \\
\hline
\end{tabular}


(1981) who considered more limiting factors such as availability of methane, limited porosity and percentages of organic matter, thermal history of various regions, etc. The U.S. Department of Energy provided more reliable estimates of natural gas hydrate resources (Malone, 1987) in the onshore and offshore regions of the Western hemisphere which are summarized in Table 1.4.

\subsubsection{Onshore Hydrates}

As mentioned before, the presence of naturally occurring gas hydrates has been established in the Arctic areas of Alaska, Canada and Western Siberia beneath the subsurface permafrost zones where low temperature persist far below the earth's surface. More than $23 \%$ of the earth's land mass is covered by permafrost and is mainly confined to Alaska (75\%), Canada (63\%), Siberia (47\%), polar regions of Scandinavia, Greenland and Antarctica.

The largest known onshore field is that reported by Makogon and Tribin (1971), where gas hydrates exist at a depth of $800 \mathrm{~m}$ in the upper section of the $84 \mathrm{~m}$-thick sandstone reservoir of the Messoyakha field. The hydrate zone in this field overlies a large free gas zone. Makogon (1981) estimated the gas in place of this field to be 200-500 billion standard $\mathrm{m}^{3}$. The field has been produced for past 19 years where hydrates have contributed about $36 \%$ of the total gas production. Techniques such as depressurization and injection of inhibitor chemicals have been used to produce gas from hydrates.

Bily and Dick (1974), first reported conclusive evidence that the Mackenzie Delta Belt of Canada contair.s enormous quantities of hydrates under permafrost base. Currently, detailed mapping of hydrate zones is underway to estimate the in-place gas associated with hydrate resources.

Katz (1971) first suggested that the thermodynamic conditions are favorable for existence of gas hydrates upto $1200 \mathrm{~m}$ depths in the North Slope 
of Alaska. On March 15, 1972 ARCO and EXXON provided the first confirmed evidence of presence of hydrates in Alaska when they recovered gas hydrate core samples in pressurized core barrel at several depths between 577 to 766 meters from the Northwest Eileen \#2 well in the Prudhoe Bay field. Recently, Collett (1990) completed the analyses of well logs, core data, drill cutting, drilling reports and seismic surveys for $\mathbf{4 4 5}$ wells on the Alaskan North Slope and reported that Prudhoe Bay - Kuparuk area alone contains up to 1.24 trillion $\mathrm{m}^{3}$ (44 TCF) of natural gas trapped as hydrates. In addition, large free gas accumulation occur down dip below hydrates. There appear to be between 4 to 6 laterally continuous hydrate saturated units within Kuparuk Unit. The gas hydrates are restricted to a series of sandstones and gravels interbedded with multiple thick siltstone units. Gas compositional data suggests that hydrates on the North Slope contain predominantly methane (92-95\%) with small quantities of $\mathrm{C}_{2}-\mathrm{C}_{4}$ hydrocarbons, $\mathrm{N}_{2}, \mathrm{CO}_{2}$ and $\mathrm{H}_{2} \mathrm{~S}$.

\subsubsection{Offshore Hydrates}

Oceanic hydrate deposits are considered to contain about 2 order of magnitude more gas than onshore hydrate deposits.

In offshore Alaska, gas hydrates have been inferred to be present in sediments of the Beaufort Sea, the Bering Sea, the North Pacific Ocean and the Gulf of Alaska based on seismic records. The most extensive mapped occurrence of gas hydrates in offshore Alaska is found in the Beaufort Sea. On the continental shelf and Slope of Alaska hydrates occur between 300 to 900 feet below seafloor where water depths range from 1,200 to more than 7,400 feet. The areal extent of inferred hydrate occurrence exceed 6,500 sq. miles.

In offshore California, seismic reflectors covering 2,000 square mile area at 540 to 930 feet subsurface depth below 2,400 to 3,600 ft water depths have 
indicated presence of hydrates in Klamath Plateau area. It is estimated to contain 5-10 TCF gas trapped as hydrates.

Six locations containing gas hydrates have been identified in the Gulf of Mexico (Malone, 1987). Hydrate cores have been recovered from all six of these locations. The bottom simulating reflectors covering about 3,000 sq. mile area occur at subsurface depths of 100-2,625 feet below 1,300-13,000 feet water depths. This area is estimated to contain about 200 to 2,000 TCF gas-inplace trapped as hydrates.

The presence of gas hydrates at the Blake Outer Ridge has been demonstrated by the recovery of hydrate-bearing sediments near the crest of the ridge. The gas hydrates occurred as fine crystals dispersed in the finegrained sediments, at a sub-bottom depth of 780 feet and a water depth of 15,090 feet. Decomposition experiments performed on a sample indicated that the gas was primarily methane, and the origin of the sample was biogenic. It is estimated that this region contains about 20-70 TCF of natural gas trapped as hydrates.

A geological analysis of the Baltimore Canyon area was initiated in 1985 (Malone, 1987). The Balkimore Canyon Trough is a major sedimentary basin that underlies the Atlantic Continental Margin of North America, offshore from New York, New Jersey, Delaware, Maryland, Virginia, and North Carolina. Estimates of the areal extent of the gas hydrates, mapped by seismic profiles and reflectors are of the order of 19,000 square miles. Reflectors have been observed down to sub-bottom depths of 950 feet. It is estimated that this region contains about 20-40 TCF of natural gas-in-place trapped as hydrates. 


\subsection{Detection and Evaluation of In-Situ Natural Gas Hydrates}

Natural gas hydrates have been studied in the past primarily to determine how to avoid their formation in natural gas transmission lines (Hammerschmidt, 1935). Also, the in-situ natural gas hydrates represent a potential drilling hazard and as such their detection of vital importance in regions where they occur. In addition, they may in the future provide a valuable resource for natural gas. Significant quantities of gas hydrates have been detected in many permafrost regions of the world, in West Siberia (Makogon, 1970), in the Mckenzie Delta of Canada, and on the North Slope of Alaska, as well as in the warmer offshore regions such as the Gulf of Mexico, Blake Bahama Outer Ridge and Mid-American Trench. The existence of hydrates in these areas has been confirmed from well log responses in the Mckenzie Delta (Bily and Dick, 1974), Prudhoe Bay and Kuparuk field (Osterkamp and Payne, 1981) as well as retrieved from Gulf of Mexico (Brooks et al, 1984). Also, extensive gas hydrates can exist in many areas beneath the sea floor (Makogon, 1970). The occurrence of hydrates in deep sea sediments in essentially tropical regions like the Gulf of Oman and off the northern coast of Columbia and Panama has also been indicated in drilling operations and seismic data. Bily and Dick (1974) provided one of the most conclusive studies on the occurrence and detection of in-situ natural gas hydrates wherein they incorporated well logs, including dual induction, sonic and mud logs as potential hydrate detection devices.

In spite of the fact that the present detection techniques serve to identify the location of hydrate fields, with the increased interest in naturally occurring hydrates, there is a greater need for improved detection and evaluation methods. The various techniques used to detect the hydrates in the earth are discussed in the following paragraphs. 


\subsubsection{Hydrate Stability Zone Determination}

The simplest and quickest way to check the zone of possible gas hydrate occurrence is to examine the zone of gas hydrate stability. For gas hydrates to be stable at a given depth, the earth temperature at that depth should be lower than the equilibrium temperature of hydrates corresponding to the pressure and gas composition conditions. However, the existence of gas hydrate stability conditions is not a necessary and sufficient condition for the existence of hydrates. For hydrates to occur, gas and water should coexist in the zone of hydrate stability.

The stability of gas hydrates in the earth and in the onshore regions depends upon several factors such as mean annual surface temperature, geothermal gradients above and below the base of permafrost, salinity, subsurface pressures, gas composition, permafrost depth, pore pressure conditions and soil particle effects. The geothermal gradients and subsurface temperatures in Arctic North Slope regions can be obtained from previous studies (Osterkamp and Payne, 1981) and (Lachenbruch et al, 1985; Lachenbruch et al, 1982; Blanchard and Tailleur, 1982; Ferrigna, 1965; Brewer, 1958; McCarthy, 1952). Also, several thermodynamic studies on the measurement of pressure-temperature relationships for different gas hydrates reported in literature are used for hydrate stability determination (Deaton and Frost, 1946; Kobayashi and Katz, 1955; Wu et al, 1976; Kamath, 1982). Table 1.5 gives the values of mean annual surface temperature $\left(T_{s}\right)$, permafrost base depth $\left(Z_{p}\right)$, geothermal gradient within permafrost $\left(G_{f r}\right)$, and geothermal gradient below the base of the fermafrost $\left(G_{t h}\right)$ in the Prudhoe Bay and Kuparuk - West Sak fields. Godbole et al (1986) have presented a nomogram for the determination of zone of methane hydrate stability (ZMHS) for specific conditions of mean annual surface temperature $\left(T_{s}\right)$, salinity, geothermal 
TABLE 1.5

\section{GEOTHERMAL PROPERTIES FOR PRUDHOE BAY AND KUPARUK - WEST SAK FIELDS}

\begin{tabular}{|c|c|c|}
\hline PARAMETER & PRUDHOE BAY & $\begin{array}{l}\text { WEST SAK AND } \\
\text { KUPARAK FIELD }\end{array}$ \\
\hline 1) Annual Surface Temperature, ${ }^{\circ} \mathrm{C}$ & -10.9 & -9.3 \\
\hline 2) Permafrost Depth, $m$ & 630 & 682 \\
\hline $\begin{array}{l}\text { 3) Geothermal Gradient Within } \\
\text { Permafrost, }{ }^{\circ} \mathrm{C} / 100 \mathrm{~m}\end{array}$ & 1.66 & 1.75 \\
\hline $\begin{array}{l}\text { 4) Geothermal Gradient Below } \\
\text { Permafrost, }{ }^{\circ} \mathrm{C} / 100 \mathrm{~m}\end{array}$ & 2.86 & 3.03 \\
\hline
\end{tabular}

TABLE 1.6

RATE EXPRESSION PARAMETERS FOR METHANE AND ETHANE

\begin{tabular}{|c|c|c|}
\hline & Methane & Ethane \\
\hline $\begin{array}{c}\dot{A} \\
(\mathrm{~cm} / \mathrm{cm} 2 / \mathrm{min} / \mathrm{bar})\end{array}$ & $6.55 \times 10-26$ & $2.4 \times 10-29$ \\
\hline $\begin{array}{c}\Delta E_{a} \\
(\mathrm{kj} / \mathrm{gmol})\end{array}$ & -106.204 & -133.015 \\
\hline$r$ & 2.986 & 2.804 \\
\hline$a$ & 0.0778 & 0.0778 \\
\hline$b$ & 2.411 & 2.411 \\
\hline & &
\end{tabular}


gradients $\left(G_{f r}\right.$ and $\left.G_{t h}\right)$. Osterkamp and Payne (1981) and Zoeller (1984) suggested that subsurface pressure for the shallow unit on the North Slope can be assumed to be in a hydrostatic equilibrium (0.435 psi/ft or $9.84 \mathrm{kPa} / \mathrm{m})$ and have a developed a nomogram assuming a hydrostatic variation in pressure. Sensitivity analysis indicates that the zone of hydrostatic stability increases by about 2.75 percent per percent increase in pressure gradient above hydrostatic value.

Evrenos (1971) has shown that the presence of salts in the formation fluids not only depresses the permafrost base temperature but also depresses the equilibrium by hydrate temperature and thus reduces the zone of hydrate stability. An increase in mean annual surface temperature and geothermal gradients lowers the zone of hydrate stability. Similarly, the reduction in ZHS is about $2.3 \%$ per $1,000 \mathrm{ppm}$ increase in salinity.

Gas composition strongly influences hydrate stability conditions. The stability of methane hydrate is increasingly affected by the addition of ethane, propane and isobutane. Addition of $\mathrm{CO}_{2}$ has an effect similar to ethane. A recent study by Kamath et al (1984) of 46 representative wells on the North Slope of Alaska has shown that the presence of small quantities of lighter hydrocarbons like propane, butane, etc. increases the stability of hydrates considerably and needs to be incorporated in the ruture calculations of hydrate stability.

\subsubsection{Drilling Response}

Severe mud gasification, drill stem tests, core sample studies, etc. can be used during drilling for the detection of hydrates. Cores have been retrieved in Prudhoe Bay (Northwest Eileen State Well \#2), Leg 84 of Blake Bahama Outer Ridge (Sloan, 1983) and in the Gulf of Mexico and the offshore region of 
Guatemala, core samples also provide useful information on the type of hydrate deposit (massive, laminated, modular, etc.).

\subsubsection{Seismic Profiling}

Shipley et al (1979) have presented data which show that many anomalous reflections from the continental slopes and rises have characteristics which can be explained by the formation of gas hydrates. Direct sampling of these horizons is needed to identify them conclusively and to substantiate the physical conditions of formation. It is found that acoustic wave velocities in hydrated sediments are much higher than in hydrate free sediments and can be utilized for detecting the presence of hydrates in suboceanic environment. Tucholke et al (1977) have studied gas hydrate horizons detected in seismic profiler data from the Western North Atlantic, wherein reflecting horizons have anomalously high amplitude. It has been found that these horizons cut across bedding planes in the sediment and are restricted to areas where seismic strata up landward. The bottom simulating reflectors in the seismic surveys are in general, very good indicators of presence of gas hydrates and have been used extensively for offshore locations.

\subsubsection{Wire Line Log Evaluation}

Logging of hydrate intervals with conventional logs provides significant information for hydrate identification. High acoustic velocities on sonic logs, high resistivity deflection or dual induction logs, high gas on mud logs, expanded well bore on caliper logs are some of the indications of presenre of hydrates. Direct log readings can often lead to misinterpretation of hydrate zones as either free gas zones or permafrost zones, particularly if decomposition has occurred during drilling. Log correlation and analysis 
provides additional proof of occurrence of hydrate zones. Goodman et al (1982) have presented five log analysis methods for specific application to insitu hydrates. In this study, a correlation technique based on temperature log has been presented.

Collett and Economides (1983) have reviewed the use of well logs in the detection of hydrates. Collett et al (1983) have presented a technique for confirming the distinction between ice and hydrate, as well as quantification of hydrate deposits, which involves the use of neutron porosity transtime cross plot along with Pickett cross plot. Similar to the neutron porosity correction factor. Collett et al (1984) have outlined a transtime porosity correction factor. They showed that the ratio of compressional velocity in boise core saturated with structure I hydrate to that in boise core saturated with ire at $-5^{\circ} \mathrm{C}$ is 1.18 , e.g., an apparent porosity of 0.28 in hydrate saturated zone would be corrected as $\mathbf{0 . 3 3 5}$. They also evaluated a series of matrix porosities and sonicvelocities for eighteen units in Kuparuk B-1 production well. For a mixture of hydrate-water coexistence, it is possible to calculate the average water saturation, and hence, the average hydrate saturation by use of Pickett cross plots. A similar study of hydrates in Canada was conducted by Judge (1984) and coworkers. In general, the best method for identification and quantification of gas hydrate deposits is to first determine the zone of hydrate stability, and then further determination of hydrates within stability zone by use of well logs.

Malone et al (1986) have evaluated the geologic factors that control the formation and detection of gas hydrates within offshore (Blake Outer Ridge), as well as onshore (North Slope of Alaska environments). In their study, they concluded that more detailed geology and reservoir data on the known hydrate occurrences, a detailed study of reservoir conditions and laboratory 
research a detailed analysis of individual targets with high potential for hydrate occurrence and greater drilling to recovery more samples, were necessary for geologic analysis of potential gas hydrate deposits.

\subsection{Kinetics of Hydrate Formation}

Although several studies have been done, to measure temperature and pressure conditions at which formation of gas hydrates begins, there have been very few studies reported in the literature on the study kinetics and mechanism of hydrate formation.

These studies of hydrate formation kinetics can be classified into two main categories:

a. Hydrate Formation from Water; and

b. Hydrate Formation from Ice Crystals.

\subsubsection{Hydrate Formation From Water}

The first attempt to study the steady state kinetics of gas hydrate formation from water was done by Knox et al (1961), who investigated the kinetics of propane hydrate formation in a bench scale water desalination unit. They combined liquefied propane (which forms structure II) with artificial water in a 10 gallon CSTR operating at 47 psig and $35^{\circ} \mathrm{F}$. Their study indicated that with increase in stirrer speed and thermal driving force, the rate of nucleation and hydrate growth increases, resulting in higher yield but produces smaller crystals. Hence, while separating the hydrate crystals from the brine solution, it is difficult to completely remove the entrapped water molecules within the solid hydrate mass.

In 1965, Pinder studied the kinetics of formation of tetrahdrofuran (THF) hydrate (structure II) at $-0.5^{\circ} \mathrm{C}$ in a stirred batch reactor from various THF-water 
mixtures and employed refractive index measurements to monitor concentration changes in the solution. In this case, since THF is water soluble, the question of a gas-liquid or liquid-liquid interface did not arise. It was found that the rate is directly proportional to concentration driving force and increases with stirrer speed. It was proposed that diffusion of reactant species between hydrogen-bonded, THF-water association complexes might be a plausible explanation of the mechanism of hydrate formation.

The majority of the studies on hydrate formation have employed dynamic conditions, where the gas-water contact surface is created by techniques like mixing, bubbling of gas through water, mechanical agitation, etc. and which results in the formation of an amorphous mass. In contrast to this, Makogon et al (1981) have studied the kinetics of nucleation and growth kinetics of hydrates of natural gas under isothermal quiescent conditions. It was found that the first step in the hydrate formation process is nucleation of hydrate crystals and it invariably occurred on an interface (e.g., gas-liquid, liquid-liquid, or solid-liquid). Thus the metal walls of the experimental setup can adsorb gas molecules either from the gas phase or in solution, providing good nucleation sites. Usually hydrate nuclei are formed on the gas-water interface. In presence of crystallization nuclei, initially the crystals grow at high rates till they cover the entire surface of gas-water contact (surface-film hydrate). Subsequently, the growth of hydrate crystals takes place within gas, water or ice phases by volume diffusion mechanism, and is limited by the rate at which the hydrate forming species (probably water) diffuses to the hydrate crystal growth surface.

The most important factors that affect the rate of hydrate formation are the composition of parent gas, the thermodynamic conditions, and the type of crystallization. The first step in hydrate formation is the formation of 
crystallization nuclei on the free water surface, and is followed by the diffusion of gas from the gas stream either to the hydrate formation surface or through the hydrate formed on the surface of gas-water contact. The size of hydrate film formed in time $\tau$ depends upon the rate of formation of nuclei $I$ and the radial growth rate of the surface film hydrate $V_{T}$

$$
F=I I V_{T}^{2} I \mathbf{c}
$$

The water diffusion rate $M_{W}$ through the hydrate film of uniform thickness $h$ and with surface $F$ is given by

$$
M_{W}=D_{W} \frac{P \Delta f \mathrm{P}_{w}}{h}
$$

where

$D_{w}=$ diffusivity of water through the hydrate film.

$P_{W}=$ water density in the hydrate phase.

$\Delta f=$ difference in volatility of water between water (ice) and hydrate phases.

The increase in hydrate film thickness with conversion of water or ice hydrate is given by

$$
h=\left(\frac{2 D_{W} \Delta f}{n}\right)^{0.5} \tau
$$

where
$n=$ hydrate number.
$\tau=$ hydrate growth time. 
For experimentally obtained diffusivities of $5 \times 10-6$ to $5 \times 10-8 \mathrm{~cm} 2 / \mathrm{sec}$ for methane and $1 \times 10^{-6} \mathrm{~cm}^{2} / \mathrm{sec}$ for natural gas, this model gave good agreement for volume diffusion growth of natural gas hydrate films on a water surface.

Maini and Bishnoi (1981) tried to simulate the fate of natural gas bubbles in case of a deep, offshore oil well blow-out by studying formation of hydrates in natural gas bubbles held stationary by downward water flow in a specially designed vertical tunnel. It was observed that hydrates form at the bubble interface at high pressures. However, the rate of conversion was not measured.

Vysiniquskas and Bishnoi (1983, 1985) have studied the kinetics of methane and ethane formation after the start of nucleation in a semibatch stirred tank reactor under isothermal and isobaric conditions. To enable the agitation of the reaction interface by vigorous stirring of water, water was contacted with the gas at temperatures above the freezing point. It was found that though the induction delay time for formation of nuclei depended initially on the history of water sample, it did not affect the overall hydrate formation kinetics, once the nucleation commenced. After an initial induction delay, data was collected only until $5 \%$ of the available water was converted, since beyond $5 \%$ conversion, the gas-liquid interfacial characteristics were greatly affected by the thickening of water-hydrate slurry. It was found that Arrechenius Law could not be used to describe hydrate growth rate at a function of temperature since it gave a negative value of apparent activation energy, whereas for the activation complex to be unstable, the activation energy should be positive. The growth rate was proportional to the gas-liquid interfacial area and which increased with stirrer speed due to vortex formation. 
To describe the gas consumption rate at STP, $(r)$ as a iunction of gas-liquid interfacial area $\left(a_{s}\right)$, pressure $(p)$, temperature $(T)$ and degree of subcooling $(\Delta T)$, they proposed a semi-empirical model and is given by

$$
r=A a_{s} \exp .\left(-\frac{\Delta E_{a}}{R T}\right) \exp .\left(-\frac{a}{\Delta T^{b}}\right) p^{Y}
$$

where

$$
\begin{aligned}
& A=\text { lumped pre-exponential factor. } \\
& \Delta E_{a}=\text { apparent energy of activation } \\
& R=\text { gas constant } \\
& a, b=\text { arbitrary constants } \\
& Y=\text { overall order w.r.t. pressure }
\end{aligned}
$$

Table 1.6 gives the best fit values obtained by Vysniquskas and Bishnoi (1983. 1985) of the rate expression parameters for methane and ethane.

\subsubsection{Hydrate Formation From Ice}

The first attempt to study hydrate formation from ice crystals was made by Barrer et al $(1958,1962,1967)$ when they measured the hydrate formation rate of rare gases $\mathrm{Ar}, \mathrm{Xe}, \mathrm{Kr}$ with ice crystals and ice and chloroform-mixed crystals at low temperatures. They formed fine crystallites by vacuum distilling water and water -chloroform mixtures into the reaction bulb, which was kept immersed in liquid nitrogen. However, the results could not be generalized since surface area was not measured. The hydrate growth was found to increase with temperatures at constant pressure, which might be due to that certain low temperature ice phases exhibit unoccupied hydrate structure. 
Fallabella (1975) used an analogous procedure to study the hydrate formation kinetics of natural gases (methane, ethane, ethene, acetylene and carbon dioxide) at low temperatures. Similar to krypton, an induction delay was observed for structure I methane hydrate, whereas, addition of $10 \%$ ethane to it, showed no induction delay indicating that ethane has a seeding effect on hydrate nucleation. It was observed that an increase in gas pressure results in a decrease in the induction delay and increase in growth rate. The fractional ice conversion rate was found to be second order w.r.t. unconverted ice and first order w.r.t. the pressure driving force.

$$
-\frac{d(1-x)}{d t}=k(1-x)^{2}\left(P-P_{\text {eq. }}\right)
$$

This expression on integration for the case of isothermal, isobaric conditions gives

$$
t=\left(-\frac{1}{k}\right) \frac{x}{(1-x)} \cdot \frac{1}{P-P_{e q}}
$$

where

$$
\begin{aligned}
& P=\text { gas pressure. } \\
& P_{\text {eq. }}=\text { hydrate equilibrium pressure } \\
& k=\text { rate constant } \\
& x=\text { fractional conversion of ice. }
\end{aligned}
$$

Fallabella suggested that hydrate growth was primarily due to high surface mobility of ice at low temperature, since the ice sublimation rate was too slow to account for the growth rate of hydrates. Also, the rate constant vs. 
temperature relationship indicated a maxima at $183^{\circ} \mathrm{K}$ and so the Arrhenius type equation was invalid.

In 1970, Miller and Smythe formed hydrates from carbon dioxide gas and finely divided ice (prepared by grinding ice and condensing water from air, both at liquid nitrogen temperature of $78^{\circ} \mathrm{K}$ ) under conditions similar to those existing at Martian ice caps ( $148^{\circ} \mathrm{K}, 6-5 \mathrm{mb} \mathrm{CO}_{2}$ partial pressure). Under isothermal conditions, the reaction was found to be first order w.r.t. pressure, as given by:

$$
t=\frac{1}{k} \cdot \ln \left(\frac{P_{0}-P_{\infty}}{P-P_{\infty}}\right)
$$

where

$$
\begin{aligned}
& k=\text { rate constant } \\
& P_{0}=\text { initial } \mathrm{CO}_{2} \text { pressure } \\
& P_{\infty}=\text { Final (equilibrium) } \mathrm{CO}_{2} \text { pressure } \\
& P \quad=\mathrm{CO}_{2} \text { pressure at any time } t
\end{aligned}
$$

Using Arrhenius type temperature dependence, the apparent activation energy for $\mathrm{CO}_{2}$ hydrate formation was found to be $5.9 \mathrm{kcal} / \mathrm{gmol}$ which is in reasonable agreement with that observed for the low temperature phase transformation from hexagonal to cubic ice.

Kamath (1984) studied the kinetics of methane hydrate formation from compacted ice crystals formed by condensing water from air at about $-20^{\circ} \mathrm{C}$ and compacting to about $50 \%$ porosity inside a vessel. The crystals were initially pressurized to methane pressures of about $7,000 \mathrm{kPa}$ and the temperature raised to just above the melting point of $274^{\circ} \mathrm{K}$. The drop in pressure with time was monitored to measure the rate of ice conversion and the experimental 
results obtained were correlated by two semi-empirical kinetic models. In the first surface area model, the rate of hydrate growth was assumed to be proportional to the surface area of ice and the methane concentration driving force.

$$
\frac{d x}{d l}=\frac{k S_{0} V_{R} M_{w}^{n}}{M_{0}}(1-x)^{3}\left(\frac{P_{o}}{Z o R T}-\frac{P_{e}}{Z e R T}-\frac{M_{o} x}{V_{R} M_{w}{ }^{n}}\right)
$$

where

$S_{0}=$ initial surface area of ice crystals

$x=$ fractional ice conversion

$t=$ time

$k=$ rate constant

$\boldsymbol{M}_{\boldsymbol{w}}=$ molecular weight of water

$T=$ temperature

$\boldsymbol{R}=$ gas constant

$M_{0}=$ initial mass of ice

$n \quad=$ hydrate number

$V_{R}=$ volume of pressure vessel

$P_{0} P_{e}=$ initial and equilibrium pressure

$Z_{0}, Z_{e}=$ initial and equilibrium compressibility factor

Numerical integration of the expression using the value of the temperature dependent lumped parameter $k S_{o}$ between $0.0125 \mathrm{hr}^{-1}$ and 0.038 $\mathrm{hr}^{-1}$ gave good agreement with the experimental conversion data.

In the volume model, it is assumed that the rate is considered proportional to the amount of unconverted ice rather than the surface area of ice. In this case, 


$$
\frac{d x}{d t}=k_{2} n(1-x)\left(\frac{P_{o}}{Z o R T}-\frac{P_{o}}{Z_{e} R T}-\frac{M_{o} x}{V_{R} M_{\omega} n}\right)
$$

The expression was integrated and an analytical solution was obtained. For $k_{2}=2.439 \mathrm{cc} / g \mathrm{~mol}$ water $/ \mathrm{hr}$, the model give a good agreement with the experimental results with average error of \pm 8.8 percent. For methane hydrate formation in unconsolidated sediments, the value of $k_{2}$ was found to be a function of the percentage of sand in the unconsolidated core.

The first attempt to quantify the surface area of the ice crystals used for hydrate formation was by Nair and Adamson (1970) who used the BET method to measure the surface area. The ice crystals were formed by condensing superheated steam at liquid nitrogen temperatures. The measurement of adsorption isotherms for nitrogen, argon and carbon dioxide gave surface areas are valid only at low temperatures and they can be significantly decreased by using different methods of forming ice crystals or by annealing at high temperatures.

Wright (1986) developed a new experimental technique to measure the rate of hydrate formation of non-condensable gases like methane from melting ice as a function of pressure and surface area. He found that the methane hydrate growth rate was gas diffusion limited and applied this technique to determine the effective diffusivity of methane within the structure I methane hydrate film. It was assumed that molar rate of methane hydrate growth per unit of active ice surface area $\left(r_{H}\right)$ is equal to the molar rate of diffusion of methane molecules from the gas phase, through the hydrate crystal film to nucleation sites on the ice surface and can be expressed as. the molar ice conversion rate per unit surface area by 


$$
r_{H}=-\frac{1}{n_{H} s} \frac{d n i}{d t}=\left(\frac{D}{R T}\right)\left(-\frac{d P}{d z}\right)
$$

where $D$ is the effective diffusivity based on a nonporous hydrate film and $d P / d z$ is the methane gas pressure gradient within the hydrate film.

\subsection{Hydrate Formation and Decomposition Studies}

In the early years, hydrates were primarily studied to determine operating conditions to prevent their formation in natural gas pipelines. Thus, efforts were concentrated on defining the vapor-water hydrate equilibrium conditions for binary mixtures of pure gas and water, and also for a few tertiary mixtures. In the 50's, Katz (1959), Scauzillo (1956) and later Koledezni (1970) found that the addition of a nonhydrate forming compound like $\mathrm{NaCl}$ or ethanol to the water phase, at a given pressure lowers the hydrate forming temperature. Similar "anti-freeze" effect was observed when the non-hydrate forming compound was added to the gas phase. This early work has been reviewed in detail by Katz et al (1959), Byk and Fomina (1968) and API Technical Data Book (1970).

Extensive literature is available regarding techniques of hydrate formation. In most instances, the experiments and apparasus were designed with the aim of determining:

a) Pressure-temperature equilibrium data as a function of gas composition.

b) The composition of the hydrate phase.

c) The rate of hydrate formation.

Also, it is seen that most of the hydrate data was obtained under such conditions of pressure and temperature that the hydrate formers are in the vapor phase. These have been very well reviewed by Katz et al (1959) and others (Byk and 
Fomina, 1968; Van der Waal and Platteau, 1959; API Technical Data Book, 1970). Kobayashi et al $(1949,1955)$ obtained three phase $V L_{1} H$ equilibrium data for pure methane at pressures up to 60,000 psi, whereas Wilcox et al (1941), Reamer et al (1952), and Teodorovich (1957) studied paraffinic and olefinic hydrates. Table 1.7 provides hydrate forming conditions for pure gases. Gaseous mixtures of methane and propane have been studied by Campbell and McLeod (1961) and also Carson and Katz (1966) who reported four phase $V_{1} L_{2} H$ equilibrium point data for methanepropane mixtures.

As far as the formation of hydrates from condensed liquid hydrocarbons is concerned, the only studies reported are those for pure liquids like propane by (Wilcox et al, 1941) and ethane, propylene, propane (by Reamer et al, 1952), refrigerants freon (Katz et al, 1959, 1975, 1973 ) and methyl chloride (Chinworth et al, 1967), an exception being study of propane-propylene liquid mixtures (Wilcox et al, 1952). The remaining studies of hydrate formation from liquid mixtures deal either with the determination of quadruple point $V L_{1} L_{2} H$ locus or the effect of nonhydrate formers on it, e.g.: $\mathrm{CH}_{4}, \mathrm{C}_{3} \mathrm{H}_{6}, \mathrm{CH}_{3} \mathrm{Cl}, \mathrm{CHCl}_{3}$ and binary mixtures of $\mathrm{C}_{2} \mathrm{H}_{5} \mathrm{Cl}$ with $\mathrm{CHCl}_{3}, \mathrm{CH}_{3} \mathrm{CHCl}_{2},\left(\mathrm{CH}_{2} \mathrm{Cl}_{2}, \mathrm{CCl}_{4}, \mathrm{CS}_{2}\right.$, and $\mathrm{C}_{6} \mathrm{H}_{6}$. Tables 1.8, 1.9, and 1.10 give a brief summary of studies on binary, ternary, and quarternary systems of hydrates. From these studies it is possible to say in general that,

a) For pure hydrate forming gases which have critical temperatures below $32^{\circ} \mathrm{F}$, hydrates can be formed under two or three phase conditions, only.

b) For pure hydrate formers having critical temperatures greater than $32^{\circ} \mathrm{F}$, there exists a four phase $V L_{1} L_{2} \mathrm{H}$ equilibrium temperature above which hydrates cannot be formed, i.e. the three-phase $L_{1} L_{2} H$ equilibrium hydrate curves are nearly vertical on a P-T diagram, e.g. propane.

c) Similarly, the three-phase $\mathrm{L}_{1} \mathrm{~L}_{2} \mathrm{H}$ equilibrium hydrates curves on a $\mathrm{P}-\mathrm{T}$ diagram for a binary liquid mixture of hydrate formers, are nearly vertical 
TABLE 1.7

HYDRATE FORMING CONDITIONS FOR PURE GASES

\begin{tabular}{|c|c|c|c|}
\hline Gas & $\mathrm{a}$ & $\mathrm{b}$ & Temp Range $\left.{ }^{\circ} \mathrm{C}\right)$ \\
\hline Methane & 16.717 & 1886.79 & -25 to 0 \\
\hline & 38.980 & 8533.80 & $>0$ \\
\hline Ethane & 17.511 & 3106.56 & -25 to 0 \\
\hline & 66.273 & 10626.25 & $>0$ \\
\hline Propane & 17.156 & 3269.65 & -25 to 0 \\
\hline & 67.130 & 16921.86 & $>0$ \\
\hline Isobutane & 18.950 & 3887.32 & -25 to 0 \\
\hline & 61.760 & 15571.63 & $>0$ \\
\hline Carbon Dioxide & 18.596 & 3161.61 & -25 to 0 \\
\hline & 66.580 & 10260.28 & 0 to 11 \\
\hline Nitrogen & 15.129 & 1506.28 & -25 to 0 \\
\hline & 37.808 & 7688.63 & 0 to 25 \\
\hline Hydrogen Sulphide & 16.560 & 3270.61 & -25 to 0 \\
\hline & 36.828 & 8266.10 & 0 to 25 \\
\hline
\end{tabular}

$$
\begin{aligned}
P & =\text { Dissociation Pressure in } \mathrm{kPa} \\
T & =\text { Temperature, }^{\circ} \mathrm{K} \\
& =P=\exp \left(a+\frac{b}{T}\right)
\end{aligned}
$$


TABLE 1.8

STUDY OF BINARY SYSTEMS OF HYDRATES (WITH WATER)

\begin{tabular}{|c|c|}
\hline SYSTEM & REFERENCES \\
\hline 1) Methane & $\begin{array}{l}\text { Villard (1888) } \\
\text { Deaton and Frost (1940) } \\
\text { Kobayashi and Katz (JPT, AIME - 1949) } \\
\text { Campbell and MCLeod (1961) } \\
\text { Marshall et al (1964) } \\
\text { Roberts et al (1941) } \\
\text { Kamath (1984) }\end{array}$ \\
\hline 2) Ethane & $\begin{array}{l}\text { Villard (1888) } \\
\text { Roberts et al (1941) } \\
\text { Deaton and Frost (1940-a) } \\
\text { Reamer et al (1952) }\end{array}$ \\
\hline 3) Acetylene & $\begin{array}{l}\text { Calletet (19) } \\
\text { Villard (1888-9) }\end{array}$ \\
\hline 4) Ethylene & $\begin{array}{l}\text { Van Cleef and Drepen (1962) } \\
\text { Villard (1888) } \\
\text { Deaton and Frost (1940) } \\
\text { Kobayashi and Katz (1949) } \\
\text { Diepen and Scheffer (1950) } \\
\text { Reamer et al (1952) } \\
\text { Snell et al (1961) }\end{array}$ \\
\hline 5) Propane & $\begin{array}{l}\text { Villard (1888) } \\
\text { Deaton and Frost (1940-a, 1941) } \\
\text { Reamer et al (1952) } \\
\text { Teodorowich (1957) } \\
\text { Wilcox et al (1941) } \\
\text { Holder and Godbole (1982) } \\
\text { Kamath (1984) }\end{array}$ \\
\hline 6) Cyclopropane & Hafemann (1969) \\
\hline 7) Propylene & $\begin{array}{l}\text { Reamer et al (1952) } \\
\text { Clarke et al (1964) } \\
\text { Byk et al (1955) }\end{array}$ \\
\hline 8) Isobutane & $\begin{array}{l}\text { Wu et al (1976) } \\
\text { Holder and Godbole (1982) }\end{array}$ \\
\hline 9) Normal Butane & $\begin{array}{l}\text { Schneider and Ferrar (1968) } \\
\text { Uchida and Hayano (1967) } \\
\text { McKetta and Katz (1968) } \\
\text { Ng and Robinson (1976) }\end{array}$ \\
\hline 10) Cis and Trans-2-Butane & Holder and Kamath (1984) \\
\hline 11) Dichloroethane & Garg (1979) \\
\hline
\end{tabular}


TABLE 1.8 (Continued)

\begin{tabular}{|l|l|}
\hline \multicolumn{1}{|c|}{ SYSTEM } & \multicolumn{1}{|c|}{ REFERENCES } \\
\hline 12) Carbon Dioxide & $\begin{array}{l}\text { Wiebe, R. (1961) } \\
\text { Unruh and Katz (1969) } \\
\text { Deaton and Frost (1940-a } \\
\text { Bozzo et al (1973) } \\
\text { Bogr }\end{array}$ \\
\hline 13)Chlorine & $\begin{array}{l}\text { Davy (1810) } \\
\text { Marsh (1952) }\end{array}$ \\
\hline 14) Sulphur Dioxide & Tamman and Kreige (1955) \\
\hline 15) Hydrogen & de Forcrand \& Villard (1888) \\
\hline 16) Nitrogen & Van Cleef and Diepen (1960,65) \\
\hline 17)Oxygen & Van Cleef and Diepen (1960,65) \\
\hline 18)Bromine & Dyadin and Aladko (1977) \\
\hline 19) Xenon & Garg (1977) \\
\hline 20)With Brine and Ethanol Solutions & Kobayashi et al (1957) \\
\hline
\end{tabular}


TABLE 1.9

TERNARY SYSTEMS OF HYDRATES (WITH WATER)

\begin{tabular}{|c|c|}
\hline SYSTEM & REFERENCES \\
\hline 1) Methane-Ethane & Holder and Grigoriou (1980) \\
\hline 2) Methane-Ethylene & Snell et al (1961) \\
\hline 3) Methane-Propane & Verma (1976) \\
\hline 4) Methane-Isobutane & Wu et al (1976) \\
\hline 5) Methane-Butane & $\begin{array}{l}\text { Mcketta and Katz (1968) } \\
\text { John and Holder (1982) } \\
\text { Ng and Robinson (1976) }\end{array}$ \\
\hline 6) Methane-Hydrogen Sulphide & Noaker and Katz (1956) \\
\hline 7) Methane-Carbon Dioxide & Unruh and Katz (1949) \\
\hline 8) Methane-Ci-2-Butene & Holder and Kamath (1984) \\
\hline 9) Methane-Trans-2-Butene & Holder and Kamath (1984) \\
\hline 10) Methane-Nitrogen & Jhaweri and Robinson (1965) \\
\hline 11) Methane-Ar-Kn & Holder et al (1980) \\
\hline 12) Methane-Hydrogen Sulphide & Noaker and Katz (1956) \\
\hline 13) Methane-Propylene & Otto and Robinson (1960) \\
\hline 14)Methane-Sulpher Hexafloride & Sortland and Robinson (1964) \\
\hline 15) Methane-Carbon Dioxide & Unruh and Katz (1949) \\
\hline 16) Methylene Chloride and Chloroform & Tester and Wiegardt (1969) \\
\hline 17)Propane-Propylene & . \\
\hline 18)Propane-Butane & $\begin{array}{l}\text { Kamath (1984) } \\
\text { Paranjpe et al (1987) }\end{array}$ \\
\hline 19)Propane-Isobutane & $\begin{array}{l}\text { Kamath et al 91982) } \\
\text { Patil (1987) }\end{array}$ \\
\hline 20)Propane-Trans-2-Butane & Kamath et al (1982) \\
\hline 21) Propane- $\mathrm{CO}_{2}$ & Robinson \& Mehta (1971) \\
\hline 22)Propane-Hydrogen Sulphide & Platteeuw and Van DerWaals (1959) \\
\hline 23)N-Butane-Isobutane & Rouher and Marsh (1952) \\
\hline
\end{tabular}


TABLE 1.10

FOUR COMPONENT SYSTEMS OF HYDRATES (WITH WATER)

\begin{tabular}{|l|l|}
\hline \multicolumn{1}{|c|}{ SYSTEM } & \multicolumn{1}{|c|}{ REFERENCE } \\
\hline 1) Methane-Ethane-Propane & Snell et al (1961) \\
\hline 2) Methane, $\mathrm{H}_{2} \mathrm{~S}$ and $\mathrm{CO}_{2}$ & Robinson and Hutton (1967) \\
\hline 3) Methane, Propane and I-Butane & Patil (1987) \\
\hline 4) Methane, Propane and $\mathrm{N}$-Butane & Paranjpe et al (1987) \\
\hline
\end{tabular}


if both of them stabilize similar hydrate structures by occupying similar cavities, e.g. propane-propylene mixture (Wilcox et al, 1961).

d) Due to "antifreeze" effect, non-hydrate forming liquids like benzene lower the quadruple point $V L_{1} L_{2} H$ temperature.

One of the most widely used techniques for determining the pressuretemperature data is to contact the gas and water in a high pressure glass window cell through which hydrate crystals can be seen. For pressures up to $70 \mathrm{MPa}$, the equilibrium point at which the hydrates form, can be determined by visual observation (Holder 1976, Kobayashi, 1955). Beyond these pressures, glass windows are not suitable. Similarly, in measurements below the ice point, the presence of ice makes the visual detection of ice like hydrate very difficult. In such cases, the technique commonly employed is to form large quantities of hydrates at low temperatures. (Marshail et al, 1964). The hydrate formation process is usually accompanied by a decrease in pressure, as the gas molecules enter the denser hydrate phase. An increase in temperature causes the hydrates to decompose, thereby increasing the corresponding pressure. The equilibrium point is considered as that point at which the pressure-temperature curve breaks indicating the end of hydrate dissociation.

A conmon technique of determining the composition of gas hydrates is to measure the amount of gas needed to convert a known weight of water into solid hydrate. A drawback of this method is that some water, occluded within the hydrate crystal matrix during crystal growth, is not available for hydrate formation. This problem can be partially overcome, e.g. by breaking the crystals in a ball mill. Ceccotti (1966) formed hydrates on a silver iodide coated tube, directly from gases saturated with water. However, this method also results in occlusion of water, condensed from the vapor phase or forced stabilization of a new hydrate crystal structure. Barrer et al (1962) determined the composition of hydrates of pure gases 
by monitoring the concentration change of a tracer or water soluble non-hydrate forming salt in water. In this method, it is necessary to account for the effect of dissolved solids on hydrate equilibrium for greater accuracy. For a gaseous mixture of hydrate formers, the only technique is to melt the hydrate crystals and analyze the gas evolved. However, there might be errors due to water occlusion in hydrate crystal matrix.

For large gas molecules that can only fit in large cavities, the fractional occupancy $(\theta)$ of the gas molecules in the hydrate can be directly obtained from the hydrate composition. This enables the calculations of chemical potential difference for hydrates from the van der Waal and Platteau model, without calculating the Langmuir coefficients.

For temperatures below the ice points, Holder and Gocibole (1982) measured $\mathrm{VIH}$ dissociation pressures for propane and iso-butane hydrates at temperatures as low as $-22 \circ \mathrm{C}$ using a gravimetric technique. The hydrate formation was detected by employing a sensitive electrobalance capable of measuring weights up to $10^{-4} \mathrm{gms}$.

Kaplan (1976), Evrenos (1971) and Stoll et al (1971), while studying thermal and acoustic properties of gas hydrate sediments, formed hydrates by passing the gas through a column of granular aggregates of water-saturated sand. Subsequently, Stoll and Bryan (1979) employed a pressure vessel with provision for stirring and compacting to form large cores of pure propane hydrates.

Kamath (1984) studied formation and measurement of hydrate dissociation in the core holder, by forming hydrate cores and dissociating these cores by hot water injection method.

One of the first attempts to view hydrate dissociation as a moving-boundary process was by Cherski and Pondarev (1972), who, however, failed to provide a complete solution. Kamath et al (1984) conducted interfacial heat transter studies during dissociation of propane hydrates and developed an experimental technique 
to measure the rate of heat transfer during dissociation of the solid hydrate phase simultaneously into gas and liquid phases. They showed that the heat transfer rate was a power function of $\Delta T$, the temperature difference between the (warm) bulk heating fluid and the (cold) hydrate surface undergoing phase change. The heat transfer correlation developed was found analogous to that for heat transfer during nudeate boiling of liquids. Later, Kamath and Holder (1987) studied the dissociation heat transfer characteristics of methane hydrates and found that the nucleate boiling analogy could be extended to methane hydrates as well. A unified heat transfer correlation for both methane and propane hydrates was developed and, at a fixed $\Delta T$, the heat flux density for propane hydrates was found to be 2 to 2.5 times higher than that for methane hydrates.

Selim and Sloan (1985) modeled the dissociation of a pure hydrate, by assuming that a heat flux is inc dent on a semi-infinite planer medium with constant physical properties. They considered the hydrate dissociation as a moving boundary ablation process, where it is assumed that the water formed due to dissociation is immediately blown away from the surface by the produced gas.

Ullerich et al (1987) obtained experimental data on rate of dissociation of methane hydrates. The dissociation experiments were conducted using a resistance heater of known heat flux, and the hydrate mass loss measurements were made with an electrobalance. The dissociation process was described by a mathematical model and the agreement between the model and the data was found to be within $10 \%$.

Recently, Selim and Sloan (1987) have modeled hydrate dissociation by thermal stimulation in porous media, wherein the dissociation of hydrate to gas and water is assumed to take place at a moving dissociation boundary. A similarity solution to the conservation equation was obtained and parametric studies were made, which indicated that the hydrate dissociation rate in sediments is strongly influenced by the thermal properties of the system and the porosity of porous medium. For 
thermal stimulation of hydrates, the average value of the energy efficiency ratio indicated that the heating value of the produced gas was nine times the heat input during dissociation.

\subsection{Thermodynamics of Gas Hydrates}

Several methods have been reported in literature for the prediction of hydrate phase equilibria. One of the earliest methods developed for prediction of dissociation pressures, was the K-value method of Katz (1944). In this method, analogous to vapor-liquid equilibria, the hydrate equilibria is characterized by a vapor-solid equilibrium constant $K_{u s i}$ given by,

$$
K_{v s, i}=\frac{y_{i}}{x_{i}}
$$

when $y_{i}$ and $x_{i}$ are the vapor phase and solid phase mole fractions, respectively, of the ith component on a dry basis. $K_{v s}$ is a function of temperature and pressure and can be calculated from experimental hydrate data by using the criteria

$$
\sum_{i} \frac{y_{i}}{K_{v s i}}=1
$$

However, this method lacks accuracy and is normally used for initial estimate of dissociation pressure.

van der Waal and Platteau (1959) first presented a basic statistical thermodynamic model for predicting hydrate equilibrium based on the crystal structure of hydrates. Their model was based on the following assumptions:

a. Each hydrate cavity can be occupied by either zero or one gas molecule only and this molecuie is iocaiized within the cavity. 
b. The cage is much larger in all dimensions than the largest dimension of the gas molecule, i.e., the gas molecule entrapped has the same rotational freedom as it would in the gas phase and does not distort the cavity. This assumption is not valid for larger molecules like propane and isobutane.

c. The mutual interaction between the solute (gas) molecules is negligible and the only interaction of the solute is with its nearest neighbor (water) molecules. In other words, the partition function for the motion of a gas molecule in its cage is independent of the number of types of gas molecules present. The distribution of the energy levels occupies by the molecules of a species are described by the work partition function.

d. The free energy contribution of the host (water) molecules is not affected by the mode of occupation of cavity by dissolved gases.

e. All the assumption of classical statistics are valid. The water-solute interaction is accurately described by a certain potential function, e.g., the Leonard Jones or the spherical core Kihara potential function.

Consider a hydrate crystal containing $N_{Q}$ molecules of $Q$ and occupying a volume $V$ at temperature $T$ and crystallized while in equilibrium with the solutes $A \ldots, J \ldots, M$ having absolute activities $\Lambda_{A}, \ldots \lambda_{M}$. Then the chemical potential of a solvent (water) molecule in the hydrate phase is given by

$$
\Delta \mu_{H}=\mu_{B}-\mu_{H}=-R T \sum_{j=1}^{2} v_{j} \ln \left(1-\sum_{i} \theta_{i j}\right)
$$

where $\mu_{H}$ and $\mu_{B}$ are the chemical potential of the occupied and the unoccupied lattice water, respectively, $R$ is the universal gas constant, $v_{j}$ is the ratio of the number of $j$ cavities to the number of water molecules in the hydrate phase. The 
variable $\theta_{i j}$ is the fraction of the $j$ cavities occupies by an $i$ type gas molecule, and is given by the Langmuir isotherm

$$
\theta_{i j}=\frac{c_{i j} f_{i}}{1+\sum C_{i j} f_{j}}
$$

where $f_{i}$ is the gas phase fugacity of the ith gas species and can be determined by the method of Prausnitz and Chuch (1968). $C_{i j}$ is the Langmuir constant whose value depends only on temperature and potential function parameters and is given by

$$
C_{i j}=\frac{4 \pi}{R T} \int_{\text {cell radius }} \exp \left|-\frac{w_{i j}(r)}{R T} r^{2} d r\right|
$$

where $r$ is the radial position of solute in the cavity, $w_{i j}(r)$ is the smoothed cell potential function.

Since chemical potential of water in equilibrium hydrate phase is equal to that in water rich liquid or ice phase $\left(\mu_{\omega}\right)$, we have

$$
\Delta \mu_{H}=\Delta \mu_{w}=\mu_{B}-\mu_{w}
$$

van der Waal modeled the gas-water interaction using the Leonard-Jones 12-6 potential function and found the dissociation pressure predictions were not quite accurate using literature values of $\sqcup$ 12-6 constants. Later, McKoy et al (1963) succeeded in predicting more accurately, the dissociation pressures of polyatomic gases by employing the Kihara potential function, which is given by

$$
\Gamma(u)_{H 2 O-g a s}=4 c\left(\frac{o}{r-2 a}\right)^{12}-\left(\frac{o}{r-2 a}\right)^{6} \text { for } r>29
$$




$$
=\infty \quad \text { for } r \leq 29
$$

where

$$
\begin{array}{ll}
\varepsilon & =\text { Kihara energy parameter } \\
r & =\text { Intermolecular separation between gas and water molecules. } \\
\boldsymbol{a} & =\text { radius of core of gas molecule. } \\
\sigma \quad & =\text { Kihara distance parameter. }
\end{array}
$$

Figure 1.4 shows the Kihara potential function $\sigma, \varepsilon / K$, and $a$. Tee et al (1968) have developed correlations for estimating the parameters of the Kihara potential function. However, use of these correlations leads to inaccurate prediction of hydrate forming conditions. Kobayashi and Katz (1955), Barduhn and Lee (1978) and Nagata and Kobayashi (1960), instead of employing second viral coefficient data, used a semi-empirical approach for predicting hydrate dissociation pressures of methane, $A r$ and $N_{2}$ by fitting the potential function parameters to experimental data. In 1972, Parrish and Prausnitz (1972) extended Kobayashi's work by fitting the potential function parameters and developed a generalized method of prediction of fifteen gases and their mixtures. Though their predictions of pure component data were very accurate, the predictions for mixture dissociation pressure were slightly in error.

In the above cases, it was assumed that the water molecules surrounding the gas molecules are evenly distributed over a sphere whose diameter is average of the actual cage dimensions. Fester et al (1966) calculated the sum of all gas-water interactions individually by employing the Monte Carlo approach, but with little improvement in the accuracy of the results. 


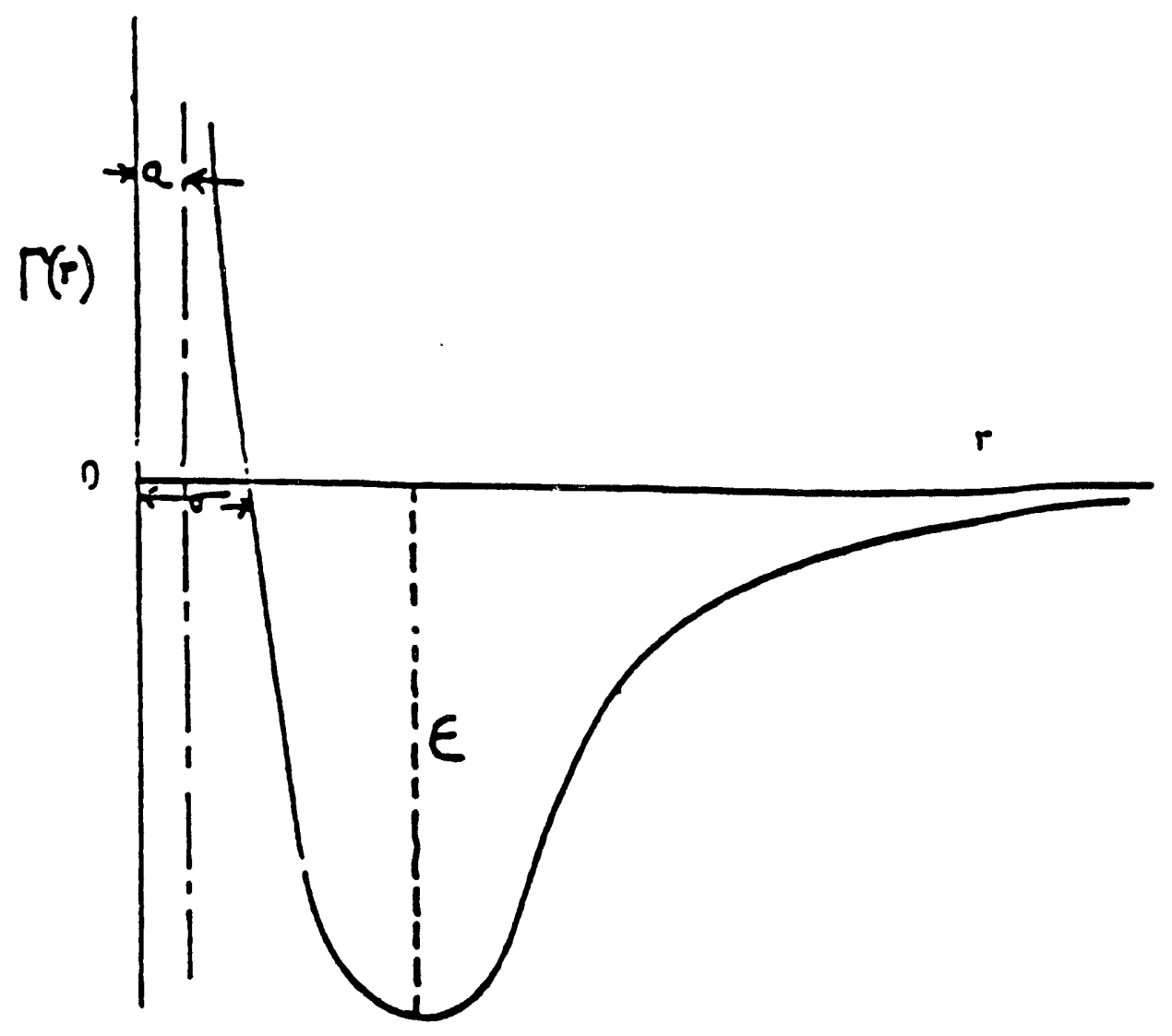

Figure 1.4: Kithara Potential Function

46

I 
Holder (1976) employed the Parrish and Prausnitz method for predicting the dissociation pressures of methane, ethane and propane mixtures and obtained optimum values of the different parameters involved in the hydrate model. $\mathrm{Ng}$ and Robinson (1977) added another adjustable parameter to obtain improved prediction of multi-component dissociation pressures, and also for prediction of conditions of hydrate formation from condensed systems.

Although the basic van der Waal model based on structure of hydrates, contributed significantly to the theory of hydrate compounds the original model has undergone many modifications in the last decade. In the van der Waal model it is assumed that only the neighboring interactions between gas and water molecules are important. John and Holder (1981, 1982) and John et al (1985) critically examined hydrate phase equilibrium theory of van der Waal and Platteau and found that the equilibrium calculations were significantly affected by the interactions of the guest molecules with those host molecules of the hydrate lattice, which are not in their immediate vicinity. They also defined second and third shells of water molecules for the four cavities of hydrate structures. For large asymmetric guest molecules whose internal motion is likely to be restricted, they used a modified semiempirical method for calculating Langmuir constants which gave improved predictions of hydrate equilibrium. However, this method suffers from the disadvantage that each gas species has to be treated according to its shape, i.e., linear, spherical, etc. A study was also made of restrictions to molecular rotations and of molecular locations within hydrate cavities caused by them.

John et al (1985) have suggested that the overall cell potential is represented by assuming three different shell contributions to the overall gas water interactions and is given by 


$$
w(r)=w_{1}(r)+w_{2}(r)+w_{3}(r)
$$

where $w_{1}, w_{2}, w_{3}$ represent first, second and third shell of water molecule, respectively.

To account for the asymmetric gas-water interactions for non-spherical gas molecules like $n$-butane and isobutane, Holder and John et al (1985) introduced a novel approach called the $\boldsymbol{Q}$ star correlation method for determination of true Langmuir constant. $Q^{*}$ represents an empirical correction factor for Langmuir constant due to restricted motion of gas molecules and the corresponding state correlation for $Q$ function is given by

$$
Q^{*}=\exp .\left|-A o\left\{w\left(\frac{\sigma}{R-a}\right)\left(\frac{\varepsilon}{K T}\right)\right\}^{n}\right|
$$

where $A o$ and $n$ are empirical parameters and depends on the particular cavity. The true Langmuir constant $C$ is then given by

$$
C=C^{*} Q^{*}
$$

This approach is recommended for hydrate phase equilibrium studies as it provides sufficiently accurate predictions.

Kamath (1982) used the $Q$ star correlation method developed by John and Holder (1982) and extended it to optimize Kihara parameters for $n$-Butane from their experimental data. 


\subsection{Principles of Production of Natural Gas From Hydrate Reservoirs}

The first step in the production of gas from hydrates is the dissociation of hydrates to gas and water. This transformation can be represented as:

$$
C_{n} H_{2 n+2} x H_{2} O(s) \rightarrow C_{n} H_{2 n+2}(g)+x H_{2} O(l)-\Delta H n
$$

$$
\left(\Delta H_{n}=+10-20 \mathrm{kcal}\right)
$$

where $C_{n} H_{2 n+2}$ represents either methane, ethane or propane and $x$ is called hydrate number and is a measure of the number of moles of water/mole of gas in the hydrate phase. Table 1.7 gives typical values for $x$.

The positive value of $\Delta H$ indicates that $10-20 \mathrm{kcal}$ of heat must be added to the hydrate reservoir per mole of methane dissociated, a part of which is used in heating up the reservoir to dissociation temperature and the remaining heat is available for achieving the above transformation. In addition, there are heat losses to overburden and underburden formations, and wellbore heat losses. !t has been found that heat obtained by burning gas produced from hydrates is nearly ten times that required to dissociate them. Thus, we can conclude that from a thermodynamic point of view, production of gas from hydrates is energy efficient.

The most important factors to be considered for assessing the feasibility of gas production from hydrates are the form in which they exist in the reservoir and the extent of their saturation in the reservoir rock pores (Holder et al, 1984). Hydrates can exist either in association with gas, water, ice, or as $100 \%$ hydrates. Other factors which should be considered are reservoir rock properties of hydrated and hydrate free zones, and heat losses, if any, to overburden and underburden formations. 
The quantity of gas that can be produced from a hydrate reservoir will also depend upon the energy efficiency, the rate of hydrate decomposition and how the dissociation of hydrates affects the porosity, permeability, formation structure, etc. of the reservoir. The hydrated gas may be present in the reservoir in consolidated or unconsolidated media. The reservoir rock properties may change drastically with dissociation of hydrates into gas and water (ice). Hence, in order to apply the conventional production techniques to a hydrate reservoir, it is necessary to compare the technical and economic aspects of the various production methods.

Various techniques have been put forward for the production of gas from gas hydrates. These include thermal recovery by injection of steam, hot water, hot brine or fire flooding, depressurization and injection of hydrate inhibitors like methanol or glycol (Halleck et al, 1982; McGuire, 1981; Holder et al, May 1982; Holder et al, Nov. 1982; Bayles et al, 1984; Kamath et al, 1985). These are discussed in the following paragraphs.

\subsubsection{Thermal Stimulation Techniques}

In this method, the dissociation of hydrates to gas and water is accomplished by providing thermal energy in the form of steam, hot water, hot brine or by fire flooding. From a thermodynamic point of view, thermal recovery technique has been found to be viable (Holder et al, 1982), but it may pose problems in the severe conditions where hydrates occur.

Gas production by thermal recovery is illustrated here by considering steam injection. Steam is injected into the hydrate reservoir at a specific rate and at a specific temperature in a cyclic manner. Each cycle is considered to be made up of steam injection stage, hydrate dissociation stage and gas production stage 
Bayles et al (1984) have developed a model to determine the limits of expected gas production for such single well cyclic steam process. Their results indicate that deeper reservoirs and reservoirs with higher hydrate filled porosity and higher zone thickness result in better gas production, and higher energy efficiency ratios.

McGuire (1981) has developed two models for the production of methane hydrate by hot water injection. The first frontal sweep model considers a production scheme which is similar to steam flooding of a heavy oil reservoir and predicts highly optimistic gas production rates. The fracture flow model simulates gas production from low permeability hydrate reservoirs and predicts the lower limit of hydrate gas production.

Kamath and Godbole (1985) have suggested the use of hot brine for gas production from hydrate reservoirs. The use of hot brine instead of steam results in lower heat losses, reduced reservoir heating and lower hydrate dissociation energy. For economic viability, they recommended that the hydrate reservoir should possess a porosity of, at least, 15\%, minimum hydrate zone thickness of $25 \mathrm{feet}$, high brine salinity, brine temperature between $250^{\circ} \mathrm{F}$ and $600^{\circ} \mathrm{F}$, and minimum brine injection rates of 5,000 BPD.

Kamath et al (1985) have studied the effect of hydrate dissociation during thermal recovery of heavy oils by steam drive. It was found that the presence of hydrates is beneficial for heavy oil recovery and results in improved reservoir heat efficiency, cumulative oil production and higher oil to steam ratio. Also, the generation of gas due to hydrate dissociation results in a higher reservoir pressure, reduced oil viscosity, reduced gravity override and provides gas drive mechanism. However, there is a decrease in steam zone efficiency due to significant loss of steam in dissociated zone. 


\subsubsection{Depressurization Techniques}

Another method for dissociating hydrates to gas and water is by reduction of pressure. In order that heat flows to the hydrates, a temperature gradient has to be generated between the hydrates and the surrounding media. This is accomplished by reduction of pressure which causes dissociation of hydrates to gas and hence a lowering of temperature of remaining hydrates. The generation of gas in turn, raises the pressure to the vapor pressure of hydrates at the new lower temperature, thus establishing a temperature gradient.

Holder et al (1982) have simulated gas production from a reservoir containing stratified layers of gas hydrates and free gas. The hydrate zone was assumed to be impermeable and hence acted as a gas cap. They showed that the contribution of gas from dissociation of hydrates to the total gas production, increases with production time, and can even reach up to $40 \%$ of total production.

McGuire (1981) has presented a depressurization production scheme wherein a fracture is deliberately generated to increase the permeability of the hydrate zone. As per the model, the rate of gas production is a strong function of permeability in the ice zone but is independent of permeability in the hydrate zone. McGuire (1981) has also suggested a salt-fret technique for melting the ice or hydrate surrounding the fracture and for maintaining the salt concentration in the area sufficient to prevent refreezing for the life of the well. This may enable the production of hydrate gas feasible even temperatures well below $0^{\circ} \mathrm{C}$ which might not be pessible by conventional fracturing techniques.

Recently, Burshears et al (1986) presented a 2 phase, 3-dimensional, variable composition numerical model for gas production from a conventional 
gas reservoir in contact with hydrates. They concluded that it is possible to dissociate hydrates without any external energy source. The production of gas from the gas reservoir causes pressure reduction which, in turn, results in dissociation of hydrates to gas and water by depressurization and consequently a further increase in gas production. Thus, an expected low rate of pressure decrease during production of conventional oil and gas might indicate the existence of hydrates. However, for depressurization the initial temperature of the reservoir should be near or above $32^{\circ} \mathrm{F}$. Otherwise, the hydrate would dissociate to gas and ice, which being impermeable prevents further dissociation of hydrates.

\subsubsection{Injection of Inhibitors}

A number of unconventional techniques for producing gas from hydrates have been suggested which include inhibitor injection, salt frac and in-situ combustion. The injection of solvents like methanol or glycols into a hydrate reservoir causes the hydrate to dissociate. An advantage of this technique is that the solvent can be recovered in a production well and recycled.

Another method suggested (McGuire et al, 1981) is the salt frac technique which improves the effectiveness of steam or solvent injection by using salt as a proppant. In the presence of salts, the hydrat:s stability curve shifts to the left, thus reducing the hydrate dissociation temperature in the thermal injection or reducing the quantity of solvent necessary for hydrate dissociation in the solvent injection technique.

In case of the in-situ combustion method, methane and oxygen are injected into the reservoir and ignited. As a result of controlled combustion of methane within the reservoir, the hydrates dissociate to produce gas. 
Some of the unconventional extraction techniques suggested are dissociation of hydrates by microwaves and electrical waves, water jet drilling, burial of radioactive wastes for providing thermal energy for dissociation, reservoir depressurization and sea floor mining.

In addition to the temperature and pressure conditions in the hydrate reservoir, geological parameters play an important role in determining the amount of hydrates formed. This, in turn, affects the producibility of gas from a reservoir. One of the most important factors which affects the heat necessary for hydrate dissociation and the flow rate of dissociated gas is reservoir porosity. The efficiency of thermal injection and the thermal properties of the hydrates are determined by the thermal properties of the hydrate reservoir like heat capacity and enthalpy of reservoir media, etc.

Holder et al (1980) have studied the effect of geological parameters on gas production from in-situ gas hydrates by steam injection recovery technique. Their study indicates that the geological and thermal conditions of the hydrate reservoir play an important role in maximizing thermal recovery of gas by hydrate dissociation.

\subsubsection{Field Example of Gas Production From Hydrate/Free Gas Reservoir}

While the Messoyakha gas hydrate field is the only available exemplar for gas production from hydrate, the hydrates have been produced from this field semi-continuously for over 19 years. The field is located in the north-east of western Siberia, close to the junction of the Messoyakha River and the Yenisei River, $250 \mathrm{~km}$ west of the town of Norilsk, as shown in Figure 1.5.

figure 1.6 provides a cross-section of the field, showing the hydrate deposit to be overlying the free gas zone. The depth-temperature plot of Figure 1.7 from Sheshukov et al. (1972) shows the hydrate layer to extend to 


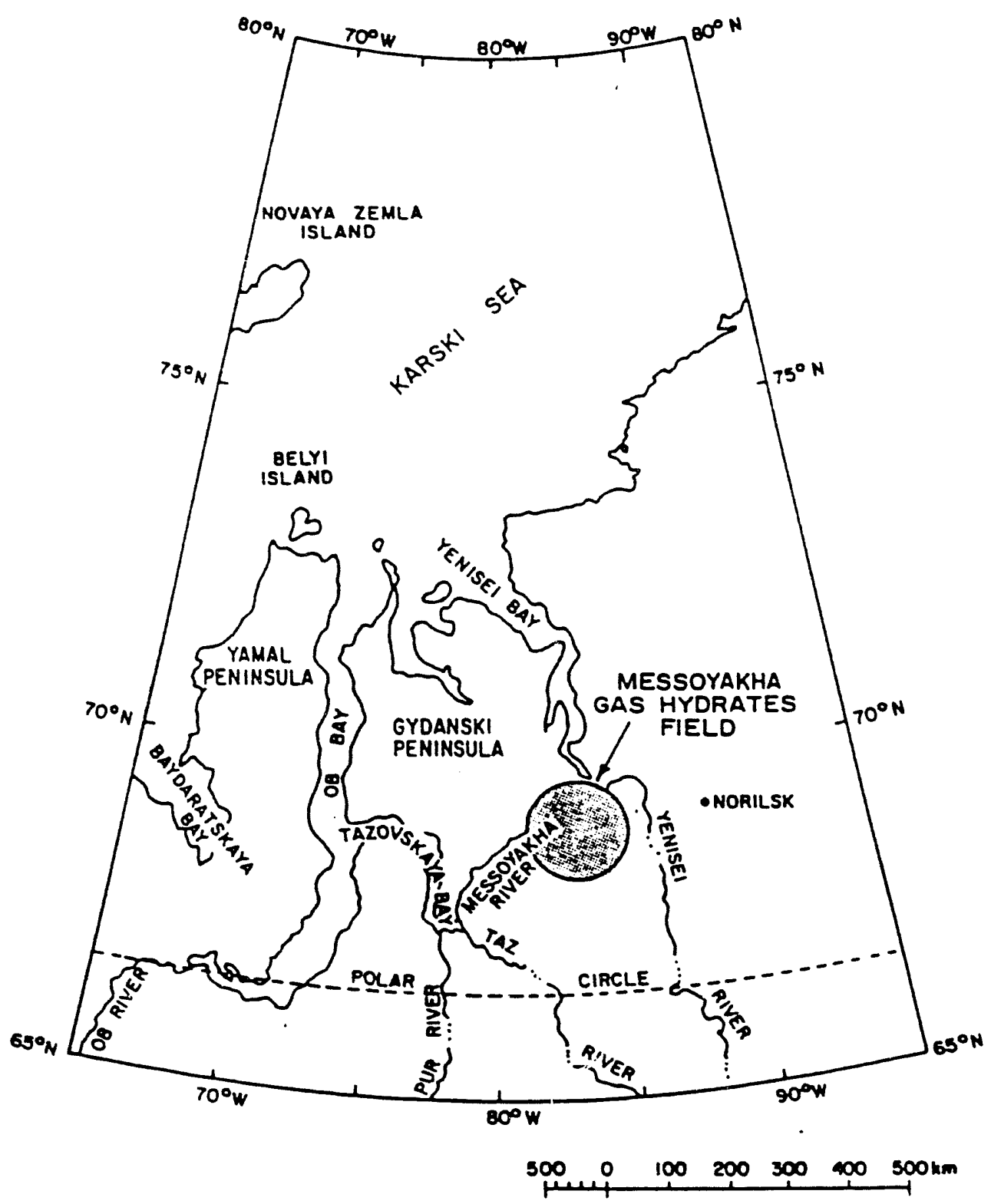

Figure 1.5: $\begin{aligned} & \text { Map Showing Location of Messoyakha } \\ & \text { Gas Hydrate Field }\end{aligned}$

(After Sloan, 1990) 


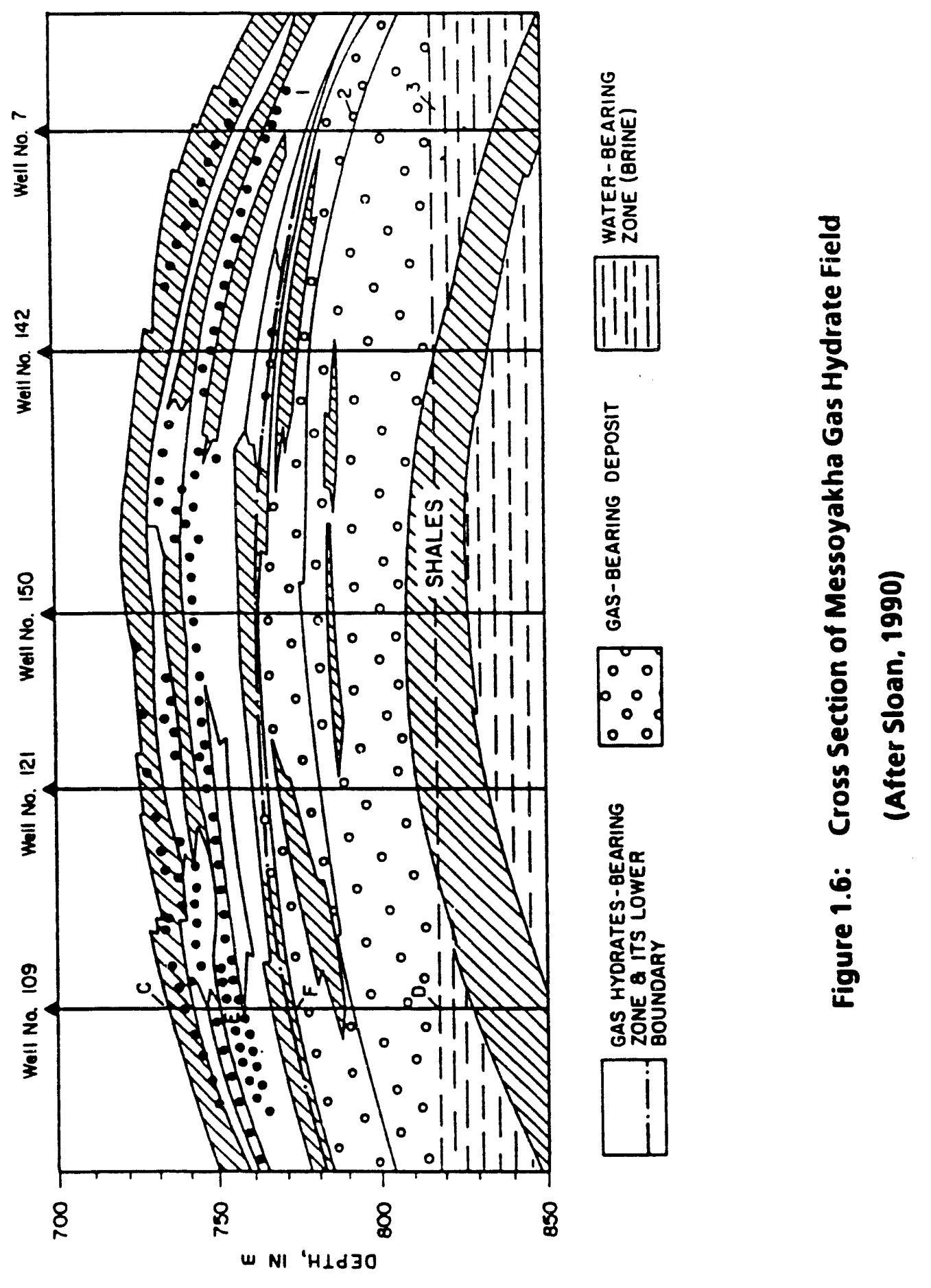


TEMPERATURE, $K$

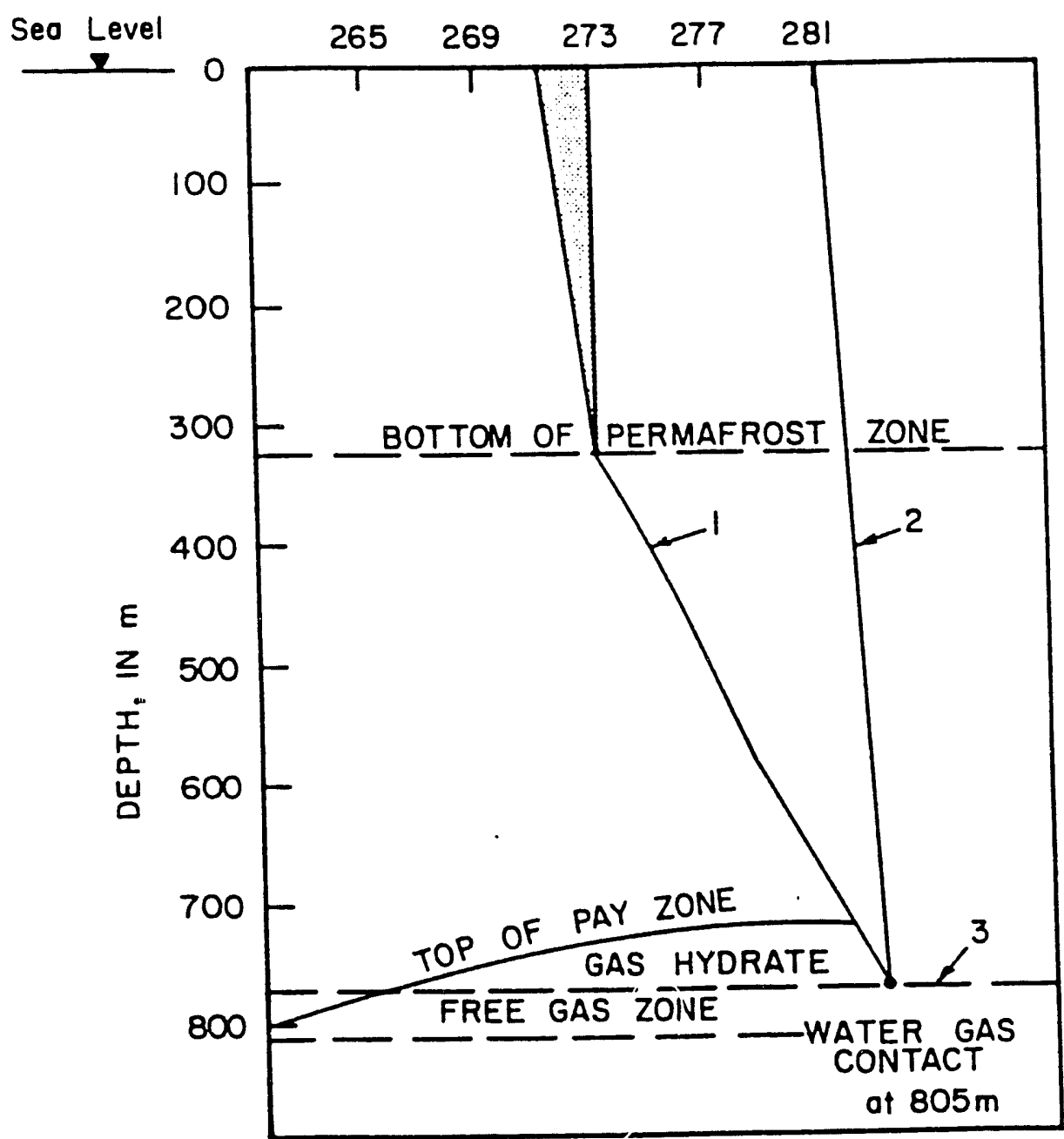

1 - CURVE OF STABILIZED FORMATION TEMPERATURES

2 - EQUILIBRIUM TEMPERATURES FOR GAS HYDRATE FORMATION

3 - LOWER BOUNDARY OF GAS HYDRATE ZONE

Figure 1.7: Gas Hydrate Stability Envelope at Messoyakha

(After Sloan, 1990) 
the intersection of the $281 \mathrm{~K}$ geotherm, later determined to be closer to $283 \mathrm{~K}$ by Makogon (1988). The gas in the hydrate zone is both in the free and in the hydrated state. Makogon (1988) provided the most recent information regarding the properties of the field, as tabulated in Table 1.11.

A suite of well logs from Well Number 136 of the Messoyakha field is presented in Figure 1.8 by Sapir et al. (1973). The Soviet work indicated the need to use a suite of well logs rather than a single log to indicate hydrates, similar to the later findings in the Western hemisphere.

The Messoyakha field has been produced through both inhibitor injection and depressurization, as well as combinations of the two. The inhibitor injection tests, presented in Table 1.12 from the combined results by Sumetz (1974) and Makogon (1974), frequently gave dramatic short-term increases in production rates, due to hydrate dissociation in the vicinity of each injected well bore. Methanol and mixtures of methanol and calcium chloride were injected under pressure, using a "cement aggregate". In order to promote long-term dissociation of hydrates, depressurization was used.

Makogon (1988) indicates that of all the complex studies obtained during the 19 years of the production life of the Messoyakha field, the most informative results came from an analysis of the reservoir pressure change as a function of the gas withdrawal rate. A diagram showing pressure and gas production as a function of time is shown in Figure 1.9, with the accompanying pressure-temperature relationship in Figures 1.10a,b. While Figure 1.10a may represent the measured pressure-temperature values (Makogon, 1988) far away from the hydrate, Poettmann (1988) suggested that the values in the neighborhood of the hydrate interface are better represented by Figure 1.10b, for reasons given below. The combination of these three figures represents a 
TABLE 1.11

PROPERTIES OF MESSOYAKHA GAS/HYDRATE FIELD (After Makogon, 1988)

\begin{tabular}{|l|l|}
\hline Area of the pay zone, & $12.5 \mathrm{~km} \times 19 \mathrm{~km}$ \\
\hline Thickness of the pay zone & $84 \mathrm{~m}$ \\
\hline Open porosity & $16-38 \%$ (average 25\%) \\
\hline Residual water saturation & $29-50 \%$ (average 40\%) \\
\hline Initial reservoir pressure & $7.8 \mathrm{MPa}$ \\
\hline Reservoir temperature range & $281-285 \mathrm{~K}$ \\
\hline Reservoir water salinity & $<1.5 \mathrm{Wt} \%$ \\
\hline Water-free gas composition & $98.6 \% \mathrm{CH}_{4}$ \\
\hline & $0.1 \% \mathrm{C}_{2} \mathrm{H}_{6}$ \\
\hline & $0.1 \% \mathrm{C}_{3} \mathrm{H}_{8}{ }^{+}$ \\
\hline & $0.5 \% \mathrm{CO}_{2}$ \\
\hline & $0.7 \% \mathrm{~N}_{2}$ \\
\hline &
\end{tabular}




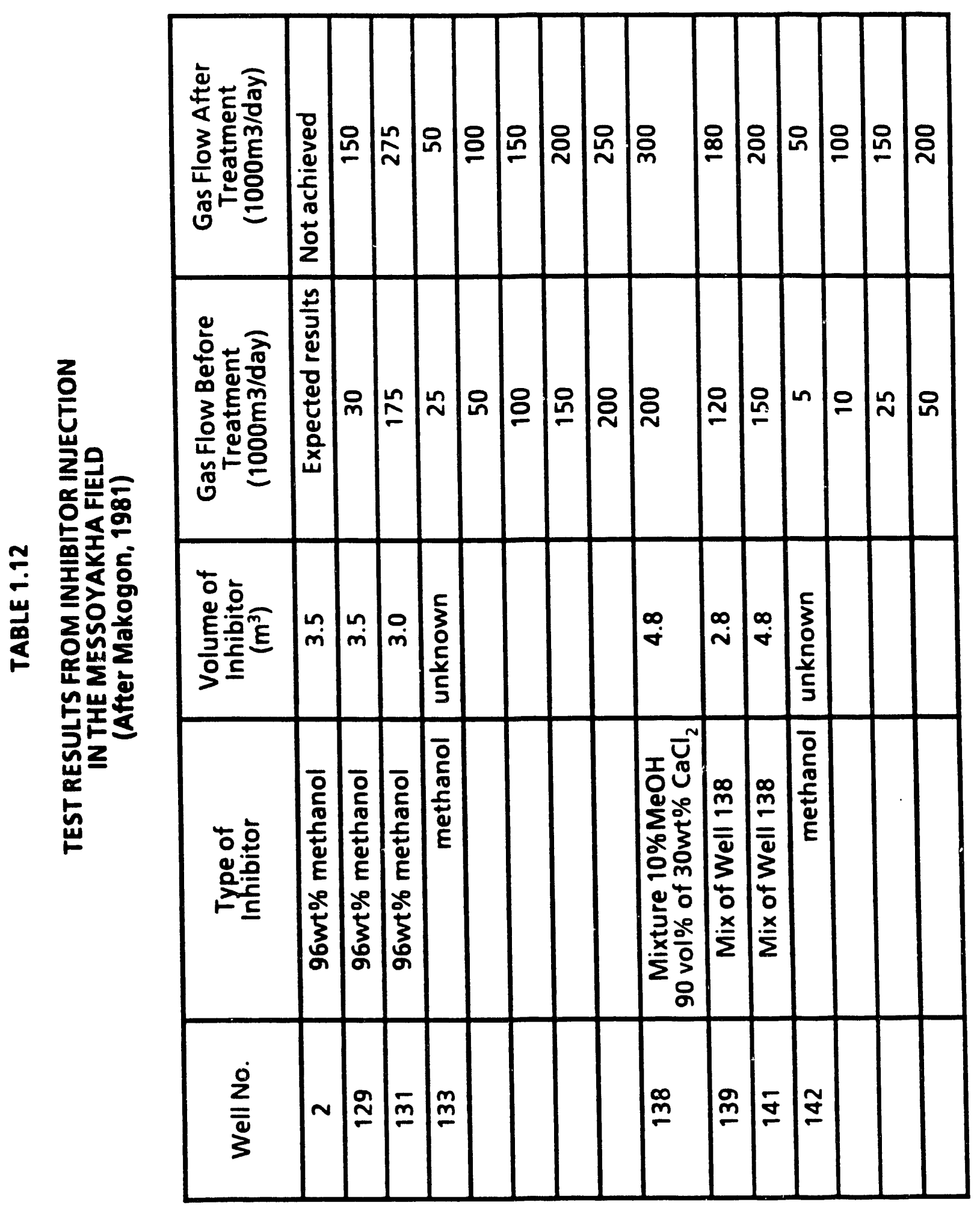




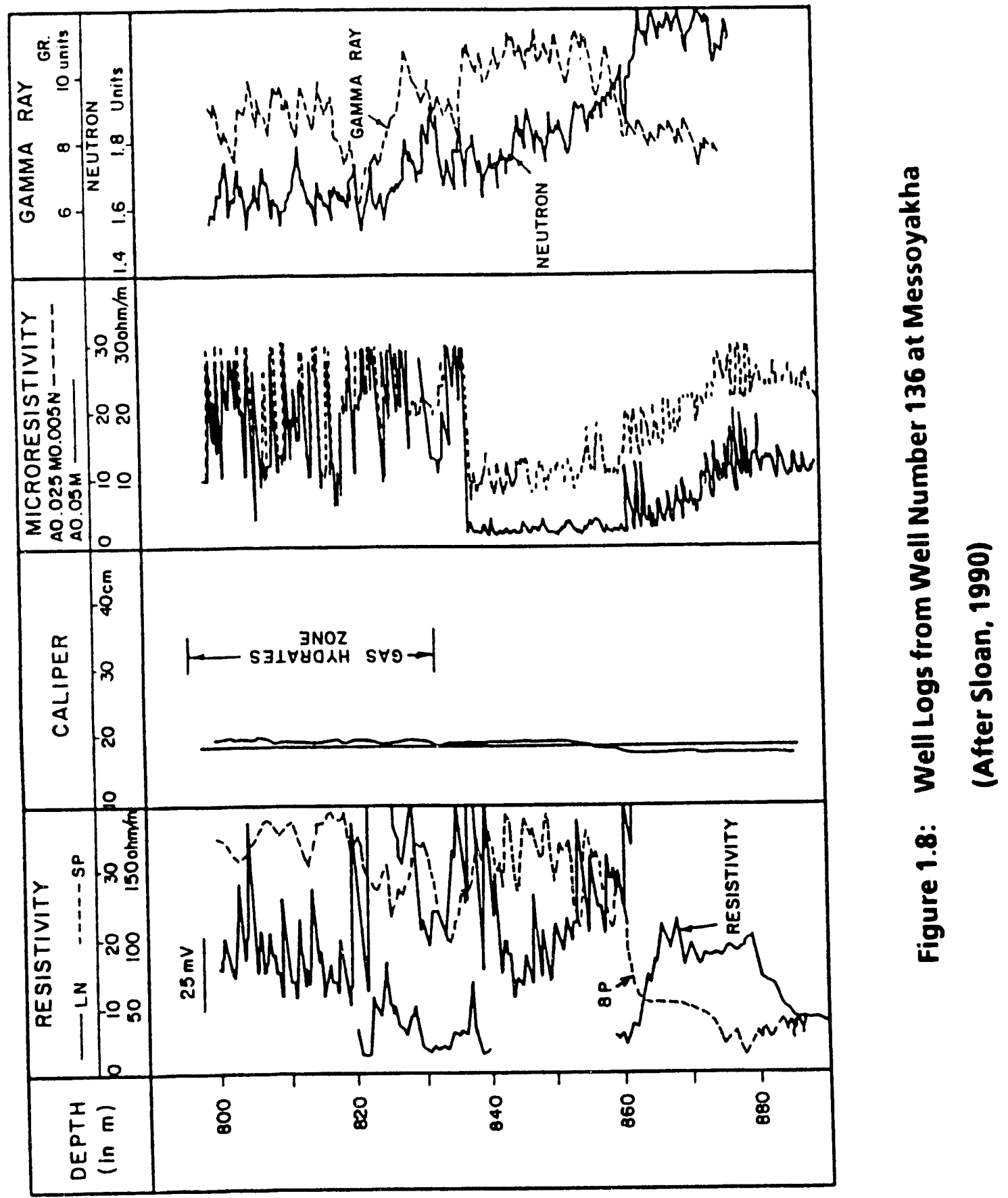




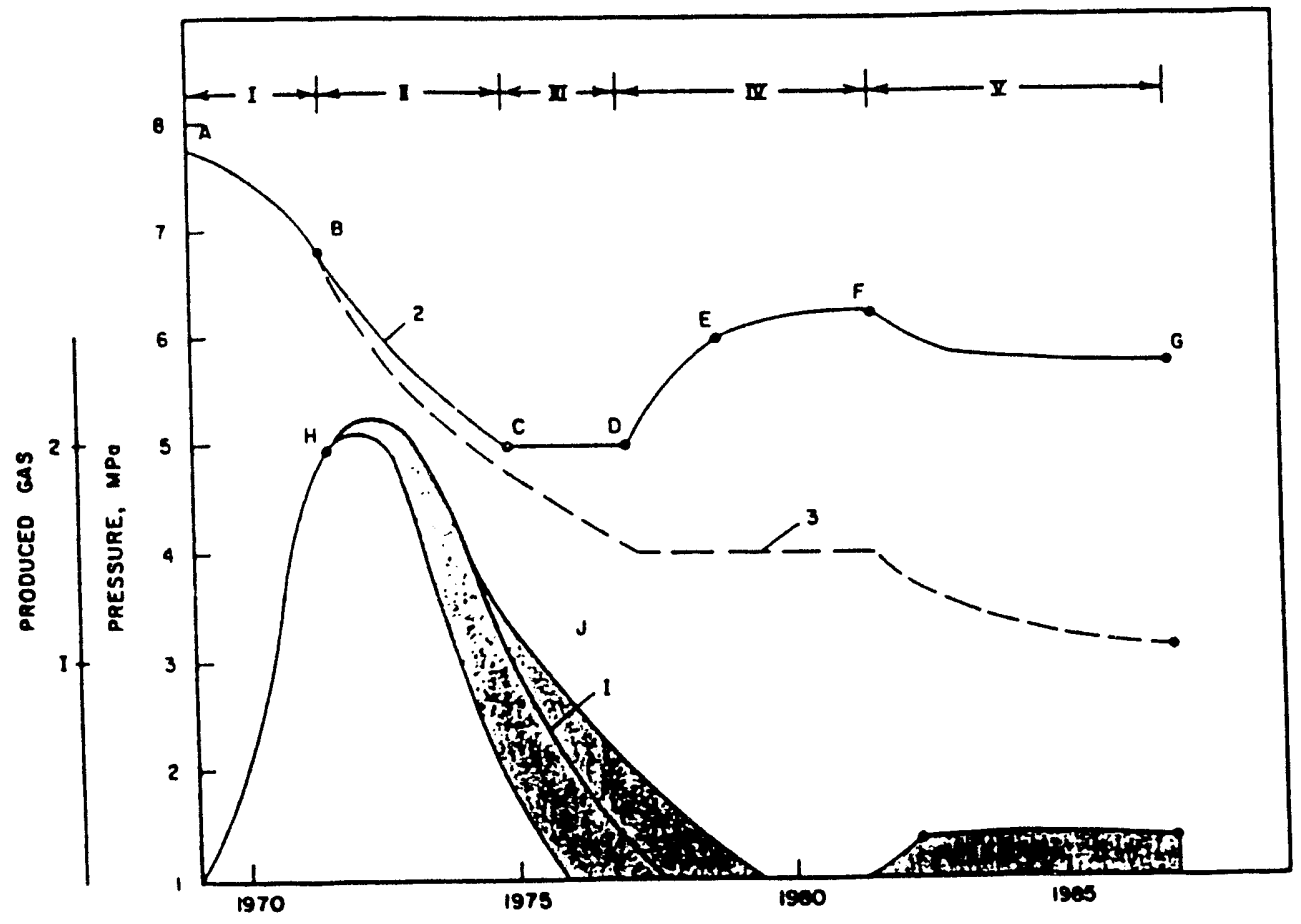

Figure 1.9: Pressure Without Hydrates and With Hydrates as a Function of Time; Produced Gas both With and Without Hydrates

(After Sloan, 1990)
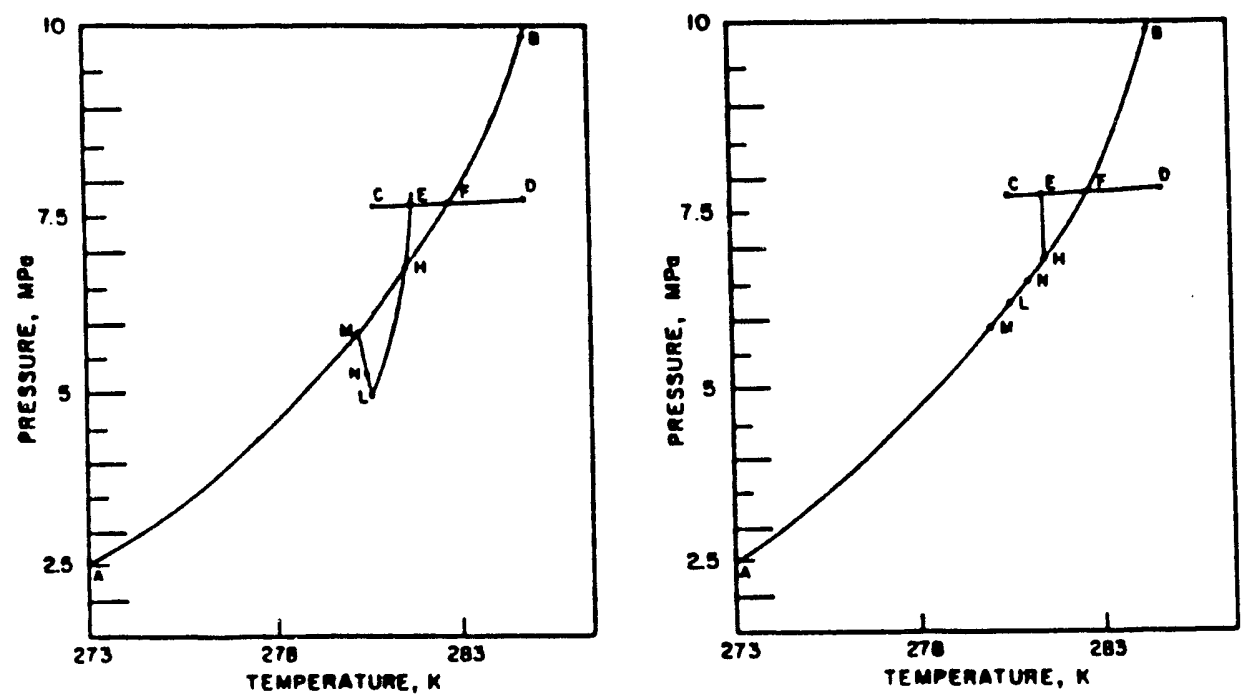

Figure 1.10: Messoyakha Pressure and Temperature With Hydrate Production Away From Hydrate Face Hypothesized at Hydrate Face

(After Sloan, 1990) 
classic study in slow depressurization, done via the production of the free gas reservoir over a period of years.

In Figures 1.10, the following initial points are used (with $C, D, E, F$ corresponding to letters on Well No. 109 in the reservoir diagram of Figure 1.6): $A B=$ hydrate equilibrium line; $C=$ temperature at the top of the pay zone; $D=$ temperature at a level of gas and water contact; $E$ = average gas. hydrate temperature; $F$ = temperature at boundary surface between gas and gas-hydrate reserves; $\mathbf{G}=$ minimum pressure at which gas hydrates are stable (at the intersection of the geothermal gradient and the phase boundary in Figure $1.7 ;) H$ = beginning dissociation pressure for gas hydrates.

As the production of the field was begun from 1969 to mid-1971, the pressure decreased from $E$ in Figure 1.10 to just above the hydrate dissociation point at $H$ in Figures 1.9 and $1.10 a, b$. During this period only fiee gas was produced because the pressure was above the hydrate equilibrium value.

When the pressure reached the hydrate equilibrium value at point $H$, the hydrates began to dissociate, adding the shaded portion to the gas production curve at the lower half of Figure 1.9. The top half of Figure 1.9 shows the reservoir pressure was maintained at a higher value (solid line 2) than the expected pressure (dashed line 3 ) due to the addition of gas to the reservoir by the hydrates. After Point $\mathrm{H}$ in Figure 1.10a, Makogon (1988) indicated that the pressure away from the hydrate decreased below the equilibrium value, with a slight decrease in temperature. The pressure at the hydrate interface in Figure 1.10b however, should not deviate from the equilibrium line, unless all of the hydrates were dissociated. Consequently the pressure and temperature at the hydrate interface decreased along the equilibrium cure as the reservoir was depressurized. Between the third and sixth year of the field development there was probably a pressure drop between the hydrate interface, from $H$ to $L$ 
in Figure 1.10b, and the measured pressure from $H$ to $L$ in Figure 1.10a, due to the flow of gas in porous media.

As the Messoyakha reservoir attained the pressure at point $L$, the average pressure stabilized for two years to point $M$, indicating that the volume of gas recovered was replenished by gas liberated from hydrate. The difference between curves $I$ and $J$ in Figure 1.9 indicates that the total gas produced (curve 1) was slightly less than the gas liberated (curve J) by the hydrates. During this period, from the seventh to the eighth year of the life of the reservoir, the pressure away from the hydrate face in Figure 1.10a rose slightly, compensated by a pressure decrease at the hydrate face in Figure 1.10b.

At point $M$, the reservoir was shut in, while other higher pressure gas reservoirs were produced (Makogon, 1988a). During the period, the average pressure of the reservoir began to rise from point $M$ to point $N$ in Figure 1.10b. The difference between curves $I$ and $J$ in Figure 1.9 indicates that gas continued to be liberated by the hydrates until the reservoir pressure was uniform at point $F$ of the top line in mid-1981. As the average gas pressure approached the equilibrium value the amount of gas produced decreased exponentially. Makogon indicated that the temperature of the reservoir tended to be restored to its original value, after a period of time. The equilibrium pressure itself rose slightly as the high reservoir heat capacity increased the temperature of the hydrate mass.

Since 1982 there has only been a modest production of the Messoyakha reservoir. The amount of gas withdrawn has been equivalent to the amount of gas liberated from the hydrate. The total amount of gas liberated from hydrates thus far has amounted to $36 \%$ of the total gas withdrawn irom the field. It is noted further that the position of the gas-water interface did not change over the seventeen year period of the production of the field. 
Makogon (1988) stated that the current production of gas from hydrates amounts to $0.2 \%$ of the total Soviet production of natural gas, and that the future production of gas from hydrate was forecast to be $1 \%$ of the total by 1997, increasing fivefold every five years thereafter.

\subsection{Drilling in the Presence of Hydrates}

The occurrence of hydrates in wells drilled in the polar region has been well documented. In the past, drilling through hydrate zones has resulted in problems of mud control due to severe mud gasification (Bily and Dick, 1974; Franklin, 1979), and the decomposition of hydrates during drilling has resulted in several gas kicks in the Mckenzie Delta and fires on seismic rigs (Judge, 1984). In addition, fizzed drill cuttings, wellbore freeze up, casing collapse and near blowout situations (Makagon, 1965; Franklin, 1979) have been reported. The low permeability of hydrate reservoirs prevents mud loss and results in the formation of a protective clay coating on well walls. Therefore, drilling through hydrate reservoirs results in decomposition of hydrate and also heats up near-hole hydrate containing rocks. The intergranular bonds weaken, the rock collapses, forming an intensive cavity and may lead to violent degassing, tool sticking and mud blowout (Makagon, 1983).

While drilling through a zone of naturally occurring hydrates, they are exposed to an increased temperature and the:eby dissociate into gas and water, providing gas influx in the wellbore. In addition, the introduction of gas for cleaning hole cuttings or for lubrication of the drill bit, reducss hydrostatic pressure of the mud column which further accelerates hydrate dissociation in the vicinity of the wellbore. Rapid dissociation of the hydrate zone can introduce a large gas influx from the dissociated hydrate zone into the wellbore causing a gas kick. 
In view of the expected increase in oil and gas exploration in the coming years, particularly in areas of potential hydrate occurrences, it has become increasingly important to use safe drilling practices. One of the standard drilling methods used in the past to overcome severe gasification problems has been to cool the drilling mud and increase the mud density. Though this approach eliminates heat input from the mud to the hydrate zone, it does not succeed in reducing the hydrate zone temperature primarily due to heat flow from deeper formations and also due to the heat exchange between down flowing drill pipe fluid and returning annulus fluid.

Another approach is to use cooler muds while increasing mud weights. In this case, the dissociation of hydrates during drilling can raise the shut-in pressures under closed in BOP stacks to levels sufficient to fracture formation below the casing shoe. Also, as a result of gas evolution, there is a reduction in mud density, which facilitates entry of free gas from other exposed holes into the drill hole. Goodman (1978) has analyzed the decomposition of hydrates during drilling considering thermal effects only as governed by the pressure-temperature equilibrium curves of hydrates. Factors affecting decomposition of hydrates include mud inlet temperature, flow rate, drilling schedule, geothermal gradient, well configuration, soil properties, etc.

In contrast to the foregoing methods which aim at inhibiting dissociation of insitu hydrates, Franklin (1980) suggested promotion of the dissociation while the drill pipe is in hole by using lower weight muds. The gasified mud on returning to wellhead is subjected to degassing, cooling and recirculated. Furthermore, the penetration rate is reduced to maintain the gas volume in proportion to the capacity of the available equipment. For replacement of drill bit or for logging purposes, hydrate dissociation can be interrupted by employing heavier muds. This approach has been effectively used for drilling through hydrates in the Canadian Arctic. 
Coring hydrates with conventional core equipment can be dangerous with a pressure core barrel. It is necessary to use cool drilling mud. Otherwise, special equipment would be needed at the surface to control the temperature of the hydrate filled core barrel during depressurization (Bily and Dick, 1974). For drilling to deeper depths, hydrate zones should be preferably cased off.

Goodman et al (1979) have simulated the drilling process of a Panarctic well in the arctic offshore which can be used for controlling hydrate dissociation during tripping and setting of the casing. To control the hydrate gas influx, increase the dissociation temperature should be increased by using higher mud weights. This causes a change in hydrate equilibrium conditions, so that further decomposition is prevented. Goodman (1978) has provided guidelines for the type of muds to be used in arctic conditions. Thompson (1985) presented a midel for determination of downhole mud temperatures to be used while drilling through non-hydrate zones.

Roadifer et al (1987) have presented an unsteady state, two dimensional ( $r-z)$ cylindrical coordinate finite difference simulator for modeling the dissociation of hydrates during drilling, for establishing guidelines for controlling the hydrate dissociation rate and the gas influx at wellbore, and for handling gas realized at the surface. The model determines dissociation rates, gas influx rates for given mud weight, mud temperature and specific reservoir conditions. Furthermore, it enables the determination of optimum mud weight and mud temperature for a given capacity of a degassing unit. Three methods have been suggested to control hydrate dissociation during drilling. These include: reducing mud temperature, increasing circulation rate and increasing mud weight. The specific method or combination to be used depends upon several factors like feasibility, economics and reservoir parameters.

Based on the wellbore heat transfer models of Keller et al (1973), Marshall and Bentsen (1982) and the wellbore hydraulics for newtonian fluids. Bingham plastics 
and power law fluids (Bourgoyne et al, 1986), Roadifer et al (1987) coupled the wellbore heat transfer and hydraulics with their hydrate dissociation model to model the hydrate dissociation under a wider range of drilling conditions. The model can be used to predict the effects of a wide range of drilling parameters on wellbore temperature, pressure, and subsequently the hydrate dissociation rate for arctic terrestrial, arctic subsea and subtropic subsea locations. They concluded that for preventing hydrate dissociation:

a. Turbulent flow conditions should be maintained in the annulus.

b. Run the casing after potential hydrate zones have been penetrated, if permafrost problems can be avoided.

c. There should be no casing run to the platform in subsea locations if it is feasible.

For promotion of hydrate dissociation:

a. Flow through the annulus should be laminar.

b. The casing should be run to the maximum depth above potential hydrate zones, where feasible.

A series of plots and nomographs have been presented for the determination of potential hydrate zones, selection of drilling parameters, or design of surface equipment for safe drilling through potential hydrate zones. Figure 1.11 (Godbole et al, 1987), Figure 1.12 and Figure 1.13 can be used to determine depths to which hydrates may be expected in arctic subsea and subtropic subsea locations. Figure 1.14 gives a nomogram for estimating parameters for drilling through hydrates. These can be used for predicting temperature and pressure necessary to keep hydrate dissociation within safe limits of drilling equipment, or vice versa, for design of surface degassing equipment for maximum temperatures and minimum pressures expected to occur over the hydrate zone. 

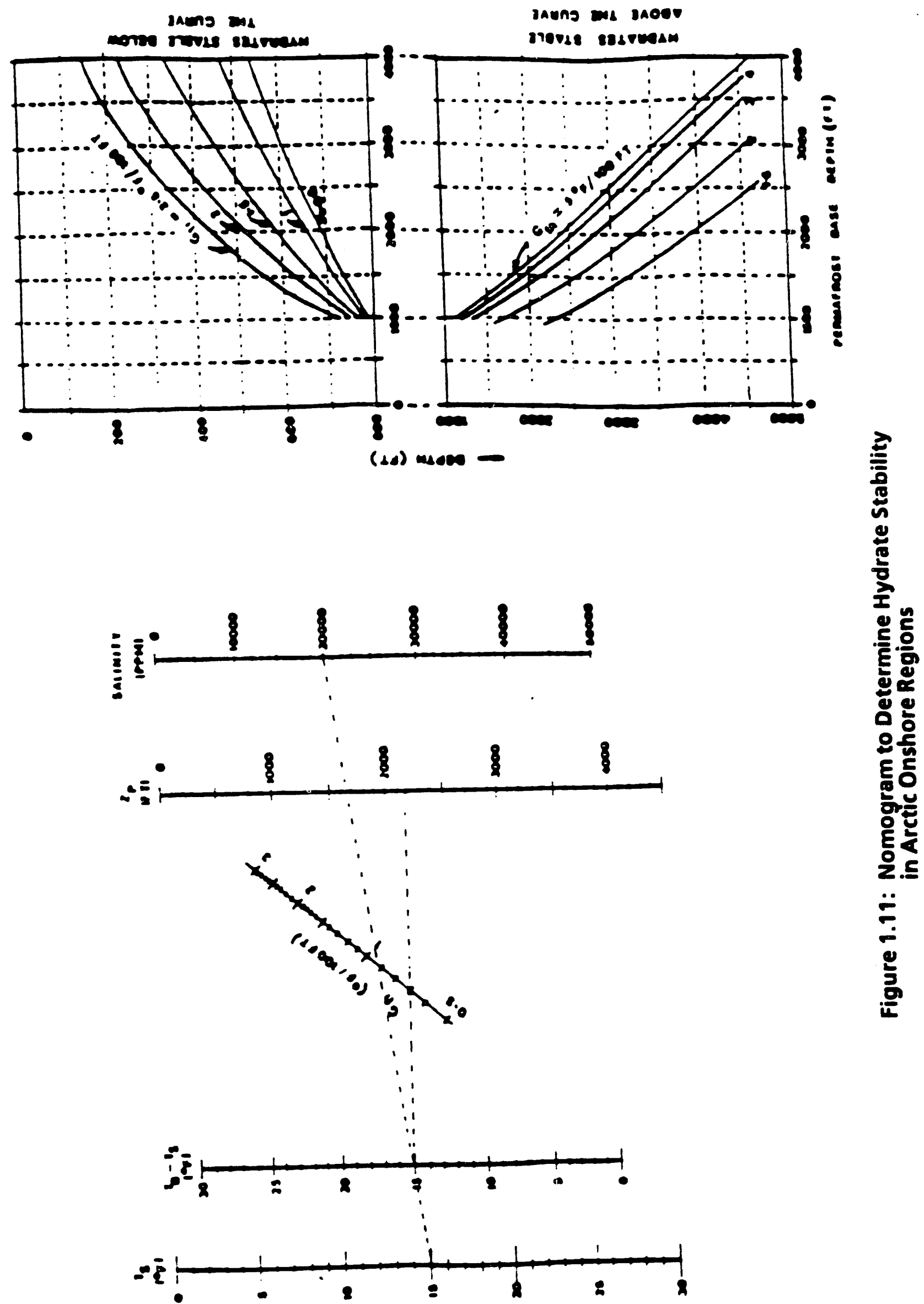


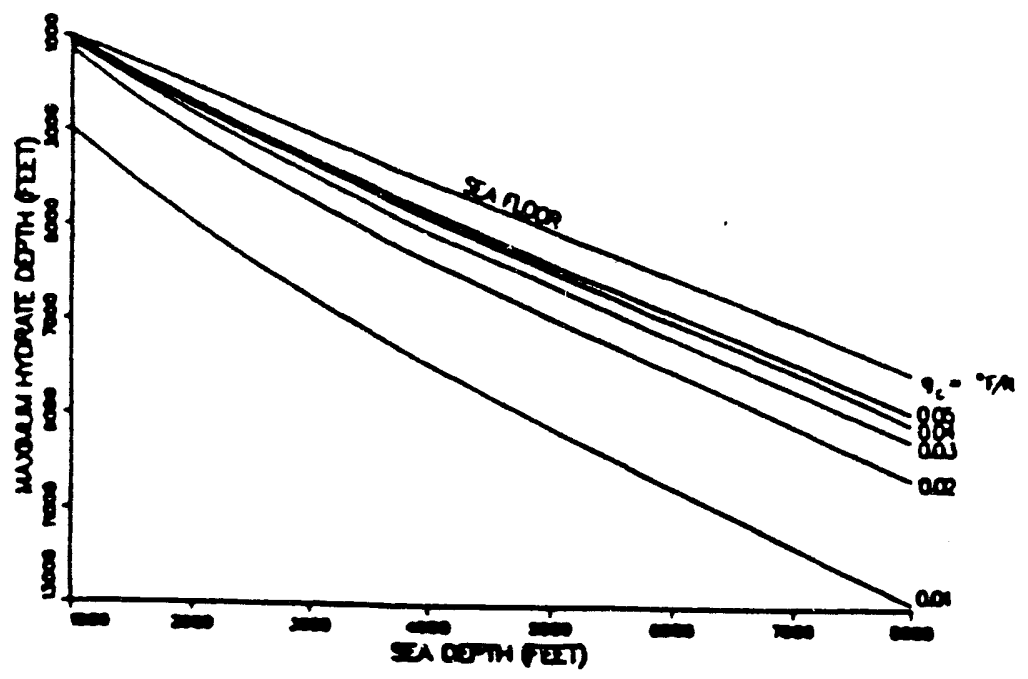

Figure 1.12: Zone of Hydrate Stability in the Arctic Subsea Region 


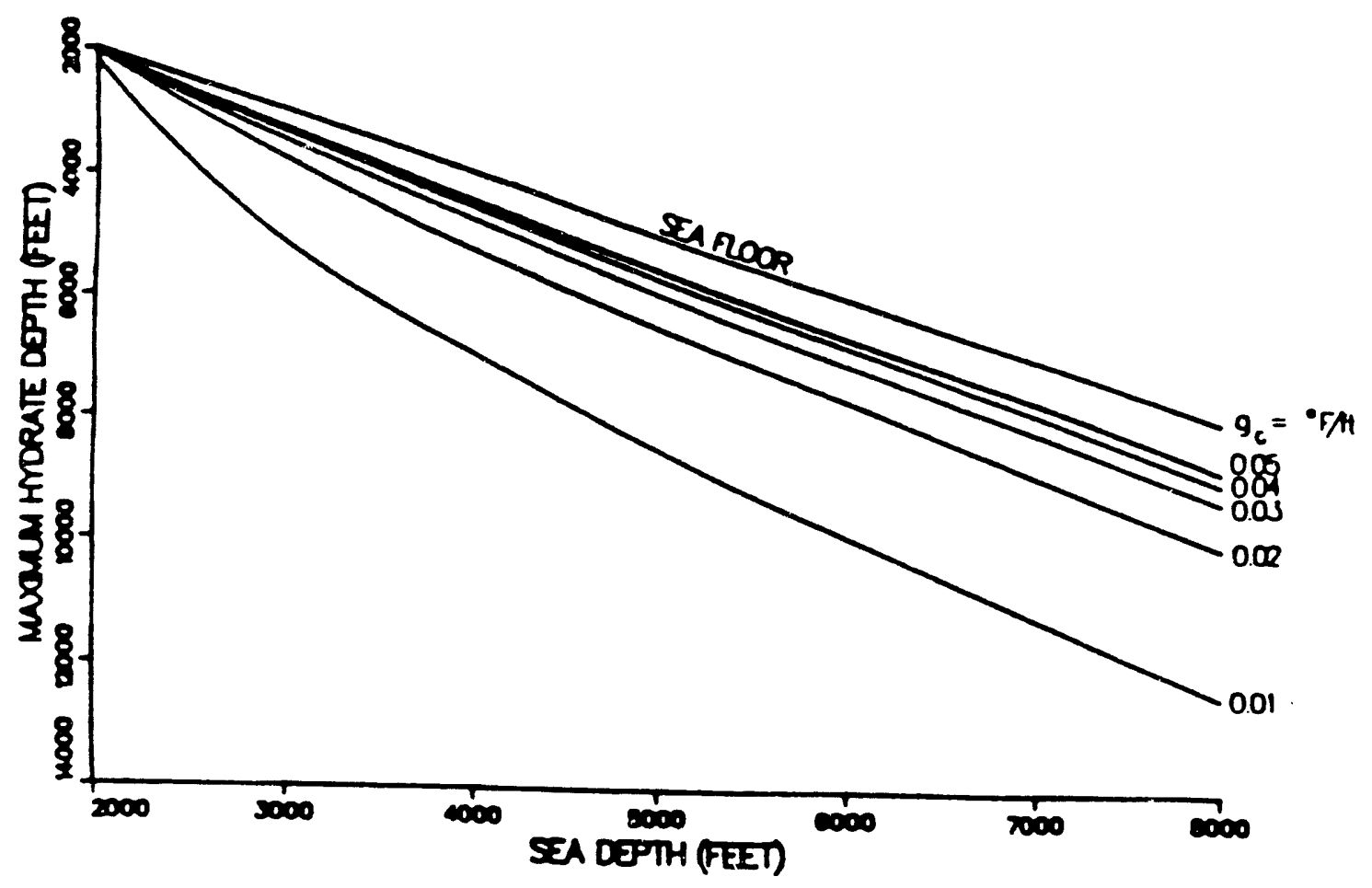

Figure 1.13: Zone of Hydrate Stability in the Subtropic Subsea Region 


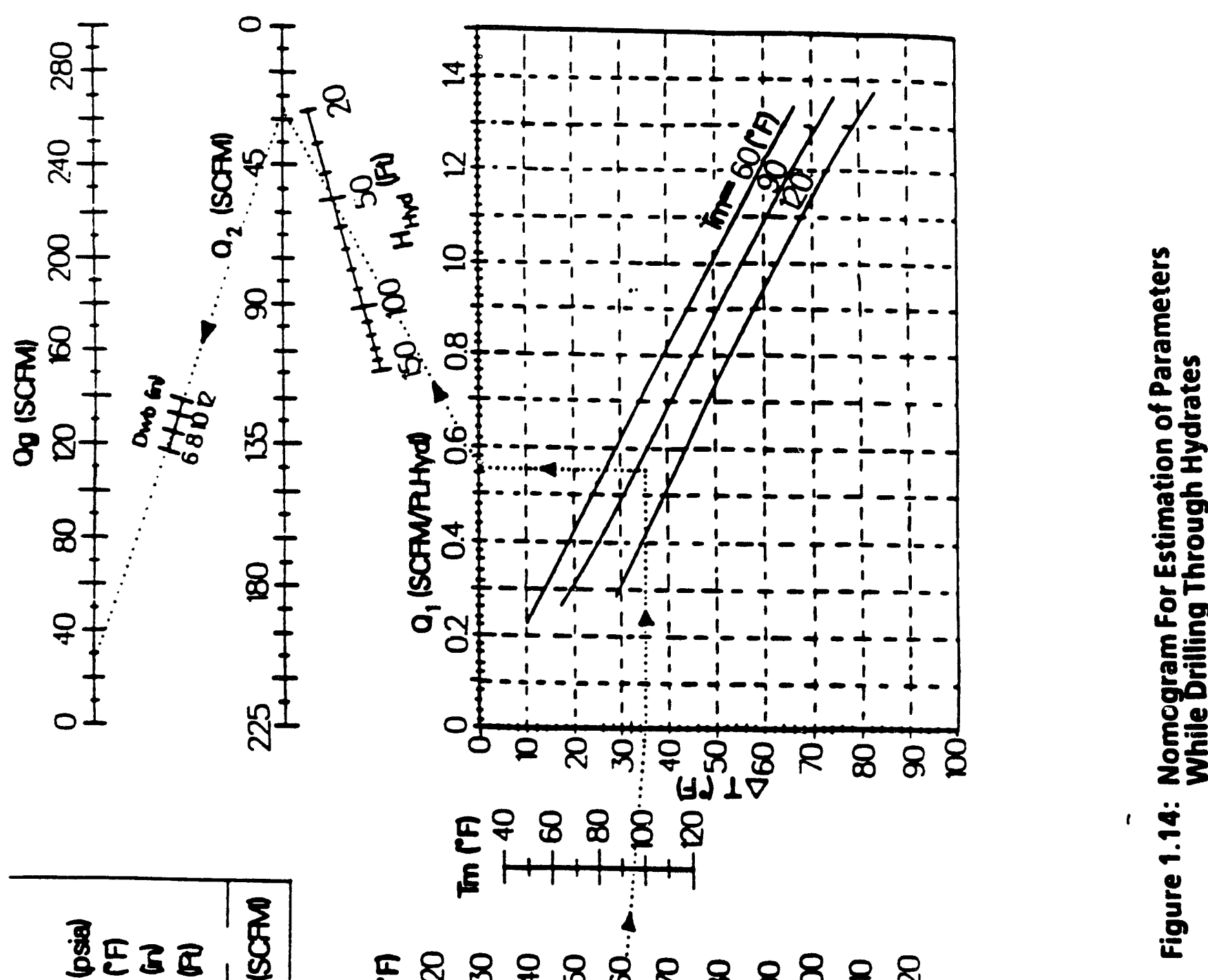

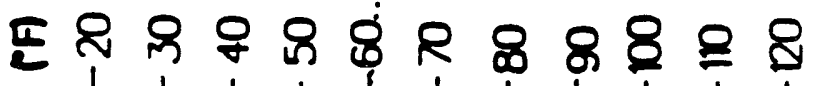
$-2$

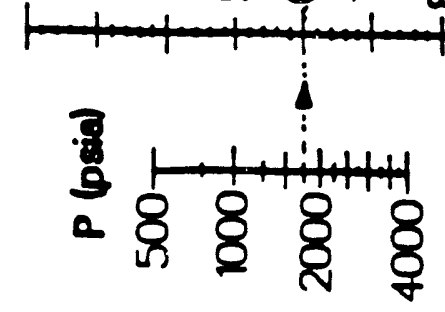




\subsection{Prevention of Hydrate Formation}

Though gas hydrates were discovered way back in 1810, the study of gas hydrates did not have any indirect industrial bearing until in 1936. Hammerschmidt (1934) discovered that the plugging of natural gas pipelines was primarily due to the formation of gas hydrates. It was then that the research of hydrates received an impetus and efforts were made to develop techniques to prevent formation of hydrates in natural gas pipelines.

One of the first attempts to study hydrate inhibition technique was in the late 50 's, when Scauzillo (1956) investigated the effectiveness of both liquid hydrocarbons and glycols in inhibiting the formation of gas hydrates. He conducted hydrate inhibition tests on three mixtures of natural gas and a saturated hydrocarbon oil in presence of excess brine, and also, on two mixtures of the residue gas and an absorber oil in presence of excess distilled water. He concluded that the hydrate formation temperature of gas was lowered if liquid hydrocarbons are also present in natural gas, and that hydrate formation can be inhibited by glycol solutions. It was also found that the combined effect of liquid hydrocarbons and the aqeous glycol solutions approach additive properties with decrease in gas/oil ratio.

In the late 1970's, Mobil reported the installation of a new methanol injection system to prevent production loss due to hydrate formation in the long flow lines between wells and production platforms in the Gulf of Mexico (Bleakley, 1970). A detailed analysis of the various techniques indicated that the most economically viable technique for prevention of hydrate formation was that of methanol injection directly at the well site. The system was so designed as to inject the optimum amount of methanol at each well head. The injection system was required to be operated only during the colder months of the year since no hydrate formation was found to occur below the Gulf water temperatures of $68^{\circ} \mathrm{F}$. Also, no attempt was 
made to recover the injected methanol, as it was found to be economically unattractive.

Recently, Menten et al (1981) have proposed a theoretical method to predict the effect of inhibitors on the conditions of formation of natural gas hydrates. The method can be used to predict the effect of inhibitors (like $\mathrm{KC}, \mathrm{CaCl}_{2}, \mathrm{CH}_{3} \mathrm{OH}$ and $\mathrm{C}_{2} \mathrm{H}_{5} \mathrm{OH}$ ) using existing hydrate parameters and literature data and can be readily extended to other inhibitors and gas mixtures.

To prevent hydrate formation in measuring and regulating equipment, certain precautions have to be taken. It is possible to avoid down time and a lot of operational problems by proper design and handling procedures in gas production e.g. avoiding unnecessary pressure and temperature drops, insulation of piping to keep gas temperature above hydrate zone, providing isolation and blowdown valves with points for methanol injection etc.

It is possible to predict change in conditions of hydrate formation and hydrate prevention from generalized graphs showing effect of pressure and inhibitor solution concentration on the hydrate formation conditions for different gases (Makagon, 1981). For gases of different compositions at different pressures, it is found that the hydrate formation temperature is lowered by different amounts by injecting an inhibitor solution of a specified concentration.

Koledezni and Arshinov (1970) have discussed the method of hydrate inhibitor injection in the bottom hole well bore vicinity at Messoyakha field. They suggested that $30 \%$ calcium chloride solution be used as inhibitor in summer and a mixture of methanol and calcium chloride in winter, the quantity of inhibitor being calculated taking into consideration the capacity of the casing. A cyclic procedure of inhibitor injection, followed by oil production is followed, where the frequency of inhibitor injection can be determined by field experimentation. They also suggested that if 
hydrates existed in well bore hole, it was necessary to inject inhibitor continuously to avoid formation of hydrates.

\subsection{Nomenclature}

a Kihara Special Core Radius

$b \quad$ Structure dependent parameter for specific heat

$C_{i j} \quad$ Langmuir constant for an $i$ th molecule in a $j$ th cavity

$L_{1} \quad$ Water rich liquid phase

$L_{2} \quad$ Hydrocarbon rich liquid phase

$M \quad$ Hydrocarbon gas $M$

$N \quad$ Integer Constant

$n \quad$ Hydrate number

$P \quad$ Dissociation pressure, $\mathrm{kPa}$ or $\mathrm{psi}$

$R \quad$ Gas Constant, Joule/mole.K

$R_{j} \quad$ Radius of cavity $j$

$r$ radial distance from center of cavity

$T$ temperature, $\circ C$ or $0 \mathrm{~K}$

V Vapour phase

$f \quad$ gas phase - fugacity

$W_{i j} \quad$ smoothed cell potential function

$V_{j} \quad$ ratio of number of $j$ cavities to the number of water molecules in hydrate phase

1 rate of formation of nuclei

$D_{w} \quad$ diffusivity of water through hydrate film

$V_{T} \quad$ radial growth rate of surface film hydrate

$M_{\omega} \quad$ water diffusion rate

$D_{w} \quad$ Diffusivity of water through hydrate film 
STP Standard Temperature and Pressure

as interfacial area

\section{Greek Letters}

$\Delta \quad$ indicates difference in property

$\varepsilon \quad$ gas-water Kihara energy parameter, joule/molecule

$\mu$ chemical potential of water, joule/mole

o Kihara distance parameter, pm

$\theta \quad$ Fractional occupancy of the cavity

$\omega$ Eccentric factor of gas molecule

$\tau \quad$ Hydrate growth time

Y overall order of reaction w.r.t. pressure

X absolute activities

$\zeta \quad$ density in hydrate phase

\section{Subscripts}

1 In pure water

2 in aqueous solution

g gas phase

h Hydrate Phase

$i \quad$ Gas Species, $i$

$j \quad$ Cavity type $j$

liq liquid phase

solid solid (ice) phase

$w \quad$ water or ice phase

$B$ unoccupied water phase 


\subsection{References}

1. Allen, K.W. and Jeffrey, G.A.: "On the Structure of Bromine Hydrate," J. Chem. Phys., 38, 2304. (1963).

2. Aoyagi, K., Song, K.Y., Sloan, E.D., Pharmawardhana, P.B. and Kobayashi, R.: "Improved Measurements and Correlation of the Water Content of Methane Gas in Equilibrium with Hydrates," Proc. 58th Ann. GPA Convention, Mar. 1921, 1979, Denver, CO.

3. Aoyagi, K., Song, K.Y., Kobayashi, R. Sloan, E.D. and Pharmawardhana, P.B.: Research Report RR-65, GPA, Dec. 1980.

4. Baner, R.M. and Ruzicka, D.I.: "Non-Stoichiometric Clathrate Compounds of Water, Part 6, Kinetics of Formation of Clathrate Phases," Trans. Faraday Soc. 58:2202-2271 (1964).

5. Barduhn, A.J. and Lee, W.C.: "Thermodynamic Properties of F-22 (CHCIF2) Hydrate for Use in Desalting," Desalination, Vol. 25, pp. 151-162 (1978).

6. Barduhn, A.J., Towlson, N.S., and Hu, Y.C.: "The Properties of Some New Gas Hydrates adn Their Use in Demineralizing Sea Water," AIChE Journal, May 1962, Vol. 8 (No. 2), pp. 176-183.

7. Barduhn, A.J.,: "Distillation by Crystallisation Processee," Chem. Eng. Prog. 63(1), 98 (1967).

8. Barrer, R.M. and Ruzicka, D.J.: "Non-Stoichiometric Clathrate Compounds of Water, Part 6 - Kinetics of Formation of Clathrate Phases," Transactions of the Faraday Society Vol. 58, pp. 2262-2271 (1982).

9. Barrer, R.M. and Edge, and A.V.J.: “Gas Hydrates Containing Argon, Krypton and Xenon: Kinetics and Energetics of Formation and Equilibria," Proceedings of the Royal Society of London, Vol. 300A, pp. 1-24 (1967).

10. Barrer, R.M. and Ruzicka, D.J.: "Non-Stoichiometric Clathrate Compounds of Water," Trans. Faraday Society, Vol. 58, No. 6, p. 2262 (1962). 
11. Bayles, G.A., Sawer, W.K., Anada, H.R., Reddy, S. and Malone, R.D.: "A Steam Cycling Model for Gas Production from a Hydrate Reservoir," paper presented at the Winter National American Institute of Chemical Engineers Meeting, Atlanta, GA (Mar. 11-14, 1984).

12. Bily, C. and Dick, J.W.L.: "Naturally Occurring Gas Hydrates in the McKenzie Delta, N.W.T.," Bulletin of Canadian Petroleum Geology, V. 22, No. 3, pp. 340352 (1974).

13. Blanchard, D.C. and Tailleur, I.L.: "Temperature and Interval GeothermalGradient Determinations from Wells in National Petroleum Reserve in Alaska," U.S. Geological Survey Open File Report, No. 82-391, p. 79 (1982).

14. Bleakley, W.B.,: "Mobil's Methanol-Injection System Prevents Gulf-Hydrate Formation," The Oil and Gas Journal, December 7, 1970, pp. 65-67.

15. Bourgoyne, A.T., Jr., Chenevent, M.E., Millheim, K.K., and Young, F.S., Jr.: Applied Drilling Engineering, SPE Textbook Series, Vol. 2 (1986).

16. Bozzo, A.T., Misiano - Sheng Chen, Kass, J.R., Barduhn, A.J.: "The Properties of the Hydrates of Chlorine and Carbon Dioxide (1973)," Paper 206 presented at the Symposium of European Federation of Chemical Engineers on Fresh Water from the Sea, Sept. 9-16, 1973, Heidelberg, Germany.

17. Brewer, M.C.: "Some Results of Geothermal Investigations of Permafrost in Northern Alaska," Trans. of the American Geophysical Union, V. 39, No. 1, pp. 19-26 (1958).

18. Brooks, J.M., Kennieutt, M.C., Fay, R.R., McDonald, T.J. and Sassen, R.: "Thermogenic Gas Hydrates in the Gulf of Mexico," Science, V. 225, pp. 409411.

19. Brown, J.F., Jr.,: "Inclusion Compounds," Sci. Amer. 207, 82 (1962).

20. Byk, S.Sh. and Fomina, V.I.: "Gas Hydrates," Russian Chemical Reviews, Vol. 37 (6), pp. 469-491 (1968). 
21. Byk, S.Sh., Fomina, V.I. and Skurgat, E.N., 992 Prom. No. 8,30 (1955).

22. Campbell, J.M. and MCLeod, H.O.: Trans, AIME, 222, 590 (1961).

23. Carson, D.B. and Katz, D.L.,: "Natural Gas Hydrates," Trans. AIME, Vol 160 (1962), p. 150.

24. Cecootti, D.J.: "Crystallization of Gas Hydrates from Vapor Phase," Industrial and Engineering Chemistry Fundamentals, Vol. 5 (1), p. 106 (1966).

25. Cherski, N.V. and Makogen, Y.F.,: "Solid Gas World Reserves are Enormous," Oil Gas Invest., 10 (8), 82 (1970).

26. Cherski, N.V. and Pondarev, E.A.,: "Thermal Dissociation of Gas Hydrate Deposits," Dokl, Akad. Nauk SSSR. 203,550 (1972).

27. Chinworth, H.E. and Katz, D.L.: Refrig. Eng., 541, 349 (1947).

28. Churchill, S.W. and Evans, L.B., : "Coefficients for Calculation of Freezing in a Semi-Infinite Region," Trans ASME, J. Heat Transfer, 93,236 (1971).

29. Clark, E.C., Ford, R.M. and Glew, D.N., Canad. J. Chem., 62,2027 (1964).

30. Claussen, W.F.: "Suggested Structures of Water in Inert Gas Hydrates," Journal of Chemical Physics, Vol. 19, pp. 662-665 (1951).

31. Coliett, T.S., Godbole, S.P. and Ehlig-Economides, C.: "Quantification of Gas Hydrates on North Slope of Alaska," Proceedings of the 35th Annual Meeting of Canadian Institute of Mining. Calgary, Canada (June 10-12, 1984).

32. Collett, T.S.: "Detection and Evaluation of Natural Gas Hydrates from Well Logs, Prudhoe Bay, Alaska," M.S. Thesis, University of Alaska - Fairbanks (1983).

33. Collett, T.S. and Ehlig-Economides, C.: "Detection and Evaluation of the In-Situ Natural Gas Hydrates in the North Slope Region, Alaska," a paper presented at the 1983 California Regional Meeting held in Ventura, CA, SPE \# 11673 (March 23-25, 1983).

34. Cook, J.G. and Leaist, D.G.: "An Exploratory Study of the Thermal Conductivity of Methane Hycrate." to be published. 
35. Cooper, A.K., Scholl, D.W., Marlow, M., Childs, J., Redden, G., Kvenvolden, K. and Stevenbon, A.: "Hydrocarbon Potential of Aleutian Basin, Berring Sea," Amer. Assoc. Petro. Geol. Bull., Vol. 63 (11) Nov. 1979, p. 1079-2087.

36. Davidson, D.W., El-Defrawg, M.K., Fuglem, M.O., and Judge, A.A.: "Natural Gas Hydrates in Northern Canada," Proceedings of the Third International Conference on Permafrost, Edmonton, Canada, Vol. 1 (1976).

37. Deaton, W.M. and Frost, E.M.: "Gas Hydrates and Their Relation to the Operation of Natural Gas Pipelines," U.S. Bureau of Mines, Monograph 8:108 (1946).

38. Deaton, W.M. and Frost, E.M., Gas, 16. No. 6,28 (1960).

39. Deaton, W.M. and Frost, E.M., Amer. Gas Assoc., Dallas (Texas) (1960-9).

40. Deaton, W.M. and Frost, E.M., Amer. Gas Assoc, Dallas (Texas) (1961).

41. Deaton, W.M. and Frost, E.M.: U.S. Department of the Interior, Bureau of Mines, Monograph 8, 1966.

42. de Boer, R.B.,: "Hydrate Formation in Cormorant South Subsea Oil Well," Shell Internationale Research Moatschappii, E.V., Publication 668, Oct. 1983.

43. de Forcrand: "Composition of Hydrates of Gases," Compt. Rend., Vol 134 (1902), pp.835, (J.Chem. Soc.) Vol. 82, pp. 666.

44. Diepen, G.A.M. and Scheffer, F.E.C., Rec. Trans. Chim., 69,593 (1950).

45. Dillon, W.P.,: "Unconventional Gas Hydrate Seals May Trap Gas Off Southeast U.S.," Oil Gas Journal, Jan. 7. 1980, p. 126.

46. Dobrynin, V.M., Korokajer, U.P., Plyuschev, D.V.,: "Gas Hydrates," IIASA Conf., 4th, Montreal, Canada (1979).

47. Dyadin, Y.A. and Aladko, L.S.: "Compositions of Clathrate Hydrates of Bromine," Inst. of Inorg. Chem., Academy of Science of the USSR, Siberian Branch. Translated from Journal Strukturnoi Khimit 18(1), pp. $51-57$ (1977). 
48. Evrenos, A.L., Heathman, J. and Ralstin, J.: "Impermeation of Porous Media by Forming Gas Hydrates In-Situ," Journal of Petroleum Technology, Vol. 23, p. 1059 (1971).

49. Ewing, J.I. and Hollister, C.D.,: "Regional Aspects of Deep Sea Drilling in the Western North Atlantic," in C.D. Hollister, et al; eds. Initial Reports of the Deep rea Drilling Project II, U.S. GPO, Washington, p. 951, 1972.

50. Fallabella, B.J.: "A Study of Natural Gas Hydrates," (unpublished Ph.D. Dissertation, University of Massachusetts - 1975).

51. Faraday, M.: "On Fluid Chlorine," Philosphical Royal Society London Transactions, Vol. 22A, pp. 160-189 (1823).

52. Ferriana, O.J., Jr.: "Permafrost Map of Alaska," U.S. Geological Survey, Misc. Geology Map 1-445 (1965).

53. Franklin, L.J.: "Hydrates in the Arctic Islands," Articles, Proceedings of Workshop on Clathrates (Gas Hydrates) in the National Petroleum Reserve in Alaska, Menlo Park, CA, edited by Bowsher, A.L. (July 16-17, 1979).

54. Franklin, L.J.: “In-Situ Hydrates: A Potential as Resource," Petroleum Enqineers International, pp. 112-122 (Nov. 1980).

55. Garg, S.K., Davidson, D.W., Gough, S.R., Reepmester, J.A.: "The Confirmation and Reorientation of Enclathrated 1,2 - dichloroethane," Can. J. Chem. 57,635 (1979).

56. Garg, S.K., Majid, Y.A., Ripmeester, J.A. and Davidson, D.W.: "Reonentation and Diffusion of Water Molecules in Xeron Hydrate and Other Structure Clothrate Hydrates," Mol. Phys. (1977), Vol. 33, No. 3.729-736.

57. Godbole, S.P. and Kamath, V.A.: "Simulation of Thermal Recovery of Heavy Oil in the Presence of Hydrates," Proceedings of the Unconventional Gas Recovery Contractors Review Meeting (DOE) held in July 28-29, 1987, Morgantown, WV (1987). 
58. Godbole, S.P.: “Dissociation pressures of propane and i-butane Hydrates below the Ice Point," M.S. Thesis, University of Pittsburgh, Chemical \& Petroleum Engineering Department. (1981).

59. Godbole, S.P., Kamath, V.A., and Ehlig-Economides, C.E.: "In-situ Natural Gas Hydrates in Alaska," to be published SPE Formation Evaluation (1987).

60. Godbole, S.P., Kamath, V.A. and Mutalik, P.N.: "Hydrate Formation as a Barrier to Environmental Problems in Deep Ocean Oil Well Blowout," to be submitted to Chemical Engineering Communications.

61. Godbole, S.P., Kamath, V.A., and Ehlig-Economides, C.E.: "Natural Gas Hydrates in the Alaskan Arctic," to be published SPE Reservoir Engineering (1387).

62. Goodman, M.A.: "World Oil's Handbook of Arctic Well Completions," World Oil, pp. 13-15 (1978).

63. Goodman, M.A. and Franklin, L.J.: "Thermal Model of New Concept for Hydrate Control During Drilling." Paper presented at the Canadian Permafrost Conference (1981).

64. Goodman, M.A. and Guissani, A.P.: "Detection and Evaluation Methods for InSitu Gas Hydrates," SPE/DOE \# 10831 (1982).

65. Gough, S.R.: "The Clathrate Hydrate of 2-Methylpropanol: Dielectric Evidence," Can. J. Chem., 562025 (1978).

66. Gough, S.R., Garg, S.K., Ripmeester, J.A. and Davidson, D.W.: "Dielectric Relaxation and NMR Studies of Two Clathrate Hydrates of Dimethyl Ether," J. of Phy. Chem. 81 (23), (1977).

67. Grantz, A., Boucher, A., Whitney, O.J.,: "Possible Solid Gas Hydrates and Natural Gas Deposits Beneath the Continental Slopes of the Beaufort Sea," U.S. Geol. Surv.Circ. 733:17 (1978). 
68. Hafemann, D.R. and Miller, S.L.: “The Clathrate Hydrates of Cydopropane," Phys. Chem., 73(5) (1969), pp. 1392-1397.

69. Hafemann, D.R. and Miller, S.L.: "The Deuterohydrate of Cydopropane," Phys. Chem. 73(5) (1969), pp. 1398-1601.

70. Halleck, P.M., Byrer, C.W., McGuire, P.L., Judge, A.S., Corlett, P.C., Barrclough, 8.: Group Discussion, Proc. Methane Hydrate Workshop, Morqantown, WV, pp. 663-72 (Mar. 29-30).

71. Hammerschmidt, E.G.: "Formation of Gas Hydrates in Natural Gas Transmission Lines," industrial and Engineering Chemistry Vol 26, p. 851 (1934).

72. Hawkins, R.E. and Davidson, D.W.: "Dielectric Relaxation in the Clathrate Hydrates of Some Cylic Ethers," Journal of Phys. Chem. 70(6) (1966) p. 1889.

73 Holder, G.D., Kamath, V.A. and Godbole, S.P.: "The Potential of Natural Gas Hydrates as an Energy Resource," Annual Review of Energy, pp. 427-45 (1984).

74. Holder, G.D., Angert, P.F., John, V.T., and Yen, S.: "A Thermodynamic Evaluation of Thermal Recovery of Gas from Hydrates in the Earth," J. Pet. Tech. (34), p. 1122 (May, 1982).

75. Holder, G.D., Angert, P.F., John, V.T., Yen, S.: "A Thermodynamic Evaluation of Thermal Recovery of Gas Hydrates in the Earth," J.Petr. Technol., 34:1127-32 (1982).

76. Holder, G.D., Angert, P.F., Godbole, S.P.: "Simulation of Gas Production from a Reservoir Containing Both Gas Hydrates and Free Natural Gas," Proc. Soc. Petr. Eng. Meet. New Orleans, LA, SPE 11105 (Sept. 26-29).

77. Holder, G.D., John, V.T. and Yen, S.: "Geological Implications of Gas Production from In-Situ Gas Hydrates," SPE/DOE 8929, Paper presented at the 1980 SPE/DOE Symposium on Unconventional Gas Recovery held in Pittsburgh, PA (May 18-21, 1980). 
78. Holder, G.D., Katz, D.L., and Hand, J.H.: "Hydrate Formation in Subsurface Environments," American Association of Petroleum Geologists Bulletin, Vol. 60 (6), pp. $981-994$ (1976).

79. Holder, G.D. and Godbole, S.P.: "Dissociation Pressures of Isobutane and Proparie Hydrates Below the Ice Point," AlChE Journal, Vol. 28, p. 830 (1982).

80. Holder, G.D., Malone, R.D. and Lawson, W.F.: "Effects of Gas Composition and Geothermal properties on the Thickness and Depth of Natural Gas Hydrate Zones," Journal of Petroleum Technology, September 1987, pp. 1167.

81. Holder, G.D. and Godbole, S.P.,: "A Gravimetric Technique for Determining Dissociation Pressures of Gas Hydrates Below the Ice Point," AlChE Journal, V. 28(6). pp. $930-34$ (Nov. 1982).

82. Holder, G.D., Corbin, D. and Papodopoulos, K.D.,: "Thermodynamic and Molecular Properties of Gas Hydrates from Mixtures Containing Methane, Argon and Krypton," Ind. Eng. Chem. Fundam., 1980, 19, 2828.

83. Holder, G.D., Stephenson, J.L., Joyce, J.I., John, V.T., Kamath, V.A. and Malekar, S., Ind. Eng. Chem. Proc. Des. Dev., Vol. 22 (1983), p. 170.

84. Holder, G.D.,: "Multiphase Equilibria in Methane-Ethane-Propane-Water Hydrate Forming Systems," Ph. D. Dissertation, School of Chemical Engineering, U. of Michigan (1976).

85. Holder, G.D. and Hand, J.M.,: "Multiphase Equilibria in Hydrates from Methane, Ethane, Propane and Water Mixtures," AlChE J, Vol. 28 (1982), pp. 440-447.

86. Holder, G.D. and Manganiello, R.J.: "Hydrate Dissociation Pressure Minima in Multicomponent Systems," Chem. Engg. Sci., 37 (1), pp. 9-16 (1982).

87. Holder, G.D. and Kamath, V.A..: "Experimental Determination of Dissociation Pressures For Hydrates of Cis and Trans Isomers of 2-Butene Below the Ice Temperature," J.Chem. Thermodynamics, 1982, 14, pp. 119-1128. 
88. Holder, G.D. and Kamath, V.A.: "Hydrates of methane + Cis-2-Butene and Methane \& Trans-2-Butene," J. Chem. Thermodynamics, 1984, 16, pp. 399-600.

89. Holder, G.D. and Grigoriou, G.C.: "Hydrate Dissociation Pressure sof (Methane +Ethane + Water): Existence of a Locus of Minimum Pressures," 1 . Chem. Thermodynamics, 1980, pp. 1093-1104.

90. Hollister, D.C. Ewang, J.I. et al, Initial Reports of the Deep Sea Drilling Project U.S. GPO, Washington, D.C., P. 951 (1972).

91. Jhaveri, J. and Robinson, D.B.: "Hydrates in the Methane-Nitrogen System," Can. J. Chem. Engg. 63 (2) p. 75 (1965).

92. John, V.T.: "Improved Predictions of Gas Hydrate Phase Equilibrium," Ph.D. Dissertation, Columbia University, School of Engineering and Applied Science (1981).

93. John, V.T. and Holder, G.D.: "Contribution of Second and Subsequent Water Shells to the Potential Energy of Guest-Host Interactions in Clathrate Hydrates," Journal of Physical Chemistry, Vol. 86, pp. 455-459 (1982).

94. John, V.T., Papadopoulos, K.D., and Holder, G.D.: "A Generalized Model for Predicting Equilibrium Conditions for Gas Hydrates, "AlChE J., Vol. 31, No. 2, p. 252 (1985).

95. John, V.T. and Holder, G.D.: "The Hydrates of Methane + N-Butane Below the Ice Point," J. Chem. Engg. Data, Vol. 27 (1982, p. 18.

96. Judge, A.S.: "Natural Gas Hydrates in the Mckenzie Delta-Beaufort Sea Areas of North Canada, AlChE Meeting (Mar. 1984).

97. Kamath, V.A.: "Study of Heat Transfer Characteristics During Dissociation of Gas Hydrates in Porous Media," (unpublished Ph.D. Dissertation, School of Engineering, University of Pittsburgh - 1983). 
98. Kamath, V.A., Godbole, S.P., Ostermann, R.D. and Collett, T.S.: "Evaluation of the Stability of Gas Hydrates in Northern Alaska," Cold Regions Science and Technology Vol. 14, p. 107 (1987).

99. Kamath, V.A.: "Dissociation Pressures of Hydates of Propane, Cis-2-Butene, Trans-2-Butene, Propane/n-Butane, and Propane/Trans-2-Butane Mixtures Below the Ice Point," M.S. Thesis, University of Pittsburgh, School of Chemical Engineering (1982).

100. Kamath, V.A. and Godbole, S.P.: "Evaluation of Hot Brine Stimulation Technique for Gas Production from Natural Gas Hydrates." Proceedings of the SPE Regional Meeting, CA, SPE 13596 (Mar. 1985).

101. Kamath, V.A., Godbole, S.P. and Baena, C.J.: "Effect of Dissociation of Hydrates During Thermal Recovery of Heavy Oils on the North Slope, Alaska," Paper presented at the 60th Annual Technical Conference and Exhibition of SPE, Las Vegas, NV, SPE 14224 (Sept. 1985).

102. Kamath, V.A., Godbole, S.P. and Meherdad, N.: "Permeability Measurements in Hydrate Saturated Cores," under preparation (1987).

103. Kamath, V.A., Holder, G.D. and Argert, P.F.: "Three Phase Interfacial Heat Transfer During the Dissociation of Propane Hydrates," Chem. Engq. Science, Vol. 39 (10), pp. 1635-1442 (1984).

104. Kamath, V.A. and Holder, G.D.: "Dissociation Heat Transfer Characteristics of Methane Hydrates," AlChE J., 33 (2), 347 (1987).

105. Kamath, V.A., Holder, G.D. and Ng. H.Y.: "The Hydrates of Propane/N-Butane, Propane/Trans-2-Butane, Propane/lsoButane, Hs-2-Butane and Trans-2-Butane, Below the Ice Point," Paper presented at the Annual AlChE Meeting, Los Angeles, CA (Nov. 1982). 
106. Kaplan, L.R., ed.: "Natural Gases in Marine Sediments," Review of Gas Hydrates with Implications for Ocean Sediments by J.H. Hand, D.L. Katz, and V.K. Verma, New York, Plenum Press, Chap. 3 (1974).

107. Kasper, J.S.,: "Clathrate Structure of Silicon NasSi46 and NaxSi136 (NC11)," Science, Dec. 1965, p. 1713.

108. Katz, D.L. et al: Handbook of Natural Gas Engineering, McGraw-Hill Book Company, New York (1959).

109. Katz, D.L.: "Depths to Which Frozen Gas Fields (Gas Hydrates) May Be Expected," Journal of Petroleum Technology, V. 23, pp. 419-423 (1971).

110. Katz, D.L.: "Predictions of Conditions for Hydrate Formation in Natural Gas," American Institute of Mining and Metallurgical Engineering Transactions Technical Publication No. 1748 (1944).

111. Katz, D.L.: Dornell, D., Kobayashi, R., Poettmann, F., Weinaug, C.F., Vary, J.A. and Elenbazs, J.R.: Handbook of Natural Gas Engineering, McGraw-Hill Book Company, N.Y. (1959), (Chris).

112. Keller, H.H., Couch, E.J., and Berry, P.M.: "Temperature Distribution in Circulating Mud Columns," Society of Petroleum Engineers Journal, pp. 23-30 (Feb. 1973).

113. Knox, W.G., Hess, M., Jones, G.E. and Smith, H.B.: "The Hydrate Process," Chemical Engineering Progress, Vol. 57, No. 2, pp. 66-71 (February 1961).

114. Kobayashi, R. and Katz, D.L.: "Metastable Equilibrium in the Dew Point Determination of Natural Gases in this Hydrate Region," Petroleum Transactions of AlME, pp. 262-263, Technical Notes \#294 (1955).

115. Kobayashi, R., and Katz, D.L.: "Methane Hydrates at High Pressure," Trans AlME, 186, 66 (1949). 
116. Kobayashi, R. and Katz, D.L.: "Metastable Equilibrium in the Dew Point Determination of Natural Gases in the Hydrate Region," Trans. AlME, 206, (1955).

117. Kobayashi, R. and Katz, D.L.: Trans AIME, 206, 51 (Aug. 1955).

118. Kobayashi, R. and Katz, D.L., Trans. AIME, p. 86,66 (1969).

119. Kobayashi, R. and Katz, D.L., J. Petrol. Technol., No. 3,66 (1969).

120. Kobayashi, R., Withrow, H.J., Williams, G.B. and Katz, D.L.: "Gas Hydrates Formation with Brine and Ethanol Solutions," Proc. of 13th Annual Convention, Natural Gasoline Assoc. of America, 27 (1957).

121. Koledezni, P.A. and Arshinov, S.A.: "The Technology of Hydrate Inhibitors Injection at Messoyakha Field," Russian Journal of Gas Business, No. 11, 1970, Moscow.

122. Krason, J. and Kiesnike, M.: "Gas Hydrates in the Russian Literature," Vol. 5. U.S. DOE, Fossil Energy Report, METC, Oct. 1985, pp. 111-112.

123. Kvenholden, K.A. and McMenamin, M.A.: "Hydrates of Natural Gas: A Review of Their Geological Occurrence," U.S. Geological Survey Circular 825, p. 11 (1980).

124. Kvenholden, K.A. and MCDonald, T.J.: "Gas Hydrates of the Middle American Trench," DSDP/IPODLeg 84: in R. Von Huene, J. Aubouin et al, Initial Reports DSDP186, U.S. Gov't. Printing Office, Washington, D.C.

125. Lachenbruch, A.H.: “Temperature and Depth of Permafrost on the North Slope of Alaska," paper presented at the 60th Annual Meeting AAPG Pacific Section Convention (May 22-24, 1985).

126. Lachenbruch, A.H., Sass, J.H., Marshall, V. and Moses, T.H.: "Permafrost Heat Flow and Geothermal Regime at Prudhoe Bay, Alaska," J. Geophys. Res. 87(B 11), pp. 197-200(1971). 
127. Laughlin, A.R.: "Water Content in Natural Gas," presented at the Gas Conditioning Conference, Norman, Oklahoma, 1969.

128. Laulhere, B.M. and Briscoe, C.F., Gas, 15(9), 21 (1939).

129. Lawson, W.F.: "Acoustic Velocity and Electrical Property Measurements in the DSDP Methane-Hydrate Core," U.S. DOE, presented at AlChE Winter National Meeting, March 12, 1986, Atlanta, Georgia.

130. Leas, W.J.: "Relative Permeability to Gas," Petroleum Transactions AlME, Vol. 189 (1950) p. 65.

131. Maini, B.B. and Bishnoi, P.R.: "Experimental Investigation of Hydrate Formation Behavior of a Natural Gas Bubble in a Simulated Deep Sea Environment," Chemical Engineering Science, Vol. 36, pp. 183-198 (1981).

132. Makogon, Y.F.: "Detection of a Pool of Natural Gas in a Solid (Hydrate Gas) State," Doklady Akad Naut SSSR, I'. 196, pp. 197-200 (1971).

133. Makogon, Y.F., Cieslewez, W.J.: trans, Hydrates of Natural Gas, Tulsa, Oklahoma: Pennwell Publishing Co. (1981).

134. Makogon, Y.F.: "Influence of Transition of Gas-Water Systems in the Earth's Crust on the Technology of Well Drilling and Operation," proceedings of the Eleventh World Petroleum Congress, Vol. 3, Production, pp. 141.

135. Makogon, Y.F.: "Hydrate Formation in Gas Bearing Strata Under Permafrost," Gozou. Promst., Vol. 5 (1965).

136. Makogon, Y.F.: "Hydrates of Natural Gas," translated from Russian by W.J. Cestwicz, Geoexplorer Association, Inc. (1978). Denver, Colorado.

137. Malone, R.D., Mroz, T.H. and Dominic, K.L.: "Geologic Analysis of Gas Hydrate Deposits," SPE \# 15224(1985).

138. Marshall, D.W. and Bentsen, R.G.: "A Computer Model to Determine the Temperature Distributions in a Wellbore," Journal of Canadian Petroleum Technology, pp. 63-75 (Jan.-Feb. 1982). 
139. Marshall, D.R., Saito, S.H. and Robayashi, R., AlChE J., 10,22 (1964).

140. Mathews, M.: "Logging Characteristics of Methane Hydrates," The Log Analyst, pp. 26-63 (May-June, 1986).

141. McCarthy, G.R.: "Geothermal Investigations on the Arctic Slope of Alaska," Trans. of the American Geophysical Union, V. 33, No. 4, pp. 589-593 (1854).

142. McCarthy, E.L., Boyd, W.L. and Reid, L.S.: Trans AIME, 189,261 (1950).

143. McKetta, J.J. and Katz, D.L., I.E.C. 40, 853 (1968).

144. McKetta, J.J., Wehe, A.H.: Pet. Refiner, 37,153, (Aug. 1958).

145. McKoy, '. and Sinanogly, O.: "Theory of Dissociation Pressures of Some Gas Hydrates," Journal of Chemical Physics, Vol. 38, pp. 2946-2956 (1963).

146. McGuire, P.L.: "Methane Gas Production by Thermal Stimu'ation," paper presented at the Fourth Canadian Perma'rost Conference, Alberta (Mar. 2-6, 1981).

147. McGuire, P.L.: "Methane Hydrate Gas Production: An Assessment of Conventional Production Technology as Applied to Hydrate Gas Recovery," Los Alamos Sci. Lab. Rep. LA-91-MS, Los Alamos, NM.

148. Menten, P.D., Parrish, W.R., and Sloan, E.D.: "Effect of inhibitors on Hydrate Formation," Ind. Chem. Process Des. Dev., Vol. 20 (1981), pp. 399-401.

149. METC Topical Report: "Gas Hydrate Project," Morgantown Energy Technology Center, Topica! Report (Feb. 1984).

150. Miller, B. and Strong, E.K.: "Hydrate Storage of Natural Gas," American Gas Association, Vol. 28, No. 2 (1969), pp. 63-67.

151. Miller, S.L. and Smythe, W.S.: "Carbon Dioxide Clathrate in Martian Ice Cap," Science, Vol. 170, pp. 531-532 (October 30, 1970).

152. Nair, N.K. and Adamson, A.W.: "Physical Adsorption of Vapors on Ice III, Argon, Nitrogen and Carbon Monoxide," The Journal of Physical Chemistry, Vol. 74, No. 10, pp. 2229-2230 (May 14, 1970). 
153. Nagata, L. and Kobayashi, R.: "Prediction of Dissociation Pressures of Mixed Gas Hydrates from Data for Hydrates of Pure Gases with Water." Industrial and Engineering Chemistry Fundamentals, Vol 5, p. 466 (1966).

154. Nagata, L. and Kobayashi, R.: "Calculation of Dissociation Pressures of Gas Hydrates Using the Kihora Model," I \& EC Fundamentals 5 (3) (1966).

155. Ng., H.J. and Robinson, D.B.: "The Role of N-Butane in Hydrate Formation," AlChE J, Vol. 22, No. 4 (1976), p. 636.

156. Ng., N.Y.: "Hydrates of Isobutane and Propane, Isobutane Mixtures and the Determination of Isobutane Composition." M.S. thesis, University of Pittsburgh, (1983), School of Chemical Engineering.

157. Noafer, L.J. and Katz, D.L.: "Gas Hydrates of Hydrogen Sulphide - Methane Mixtures," Trans AIME, 201,237 (1956).

158. Osterkamp, T.E. and Payne, M.W.: "Estimates for Permafrost Thickness from Well Logs in Northern Alaska," Cold Regions Science and Technology. Vol. 5. pp. 13-27 (1981).

159. Otto, F.D. and Robinson, D.B.: "A study of Hydrates in the Methane-PropyleneWater System," AlChE J. 6(6), (1960.

160. Paranjpe, S.G., Patil, S.L. and Kamath, V.A.: "Hydrate Formation in Crude Oils and Phasee Behavior of Hydrates in Mixtures of Methane, Propane, Isobutane and n-Butane," to be presented at the third Chemical Conference of the North American Continent to be held in Toronto, Ontario, from June 5-11, 1988.

161. Paranjpe, S.G., Patil, S.L., Kamath, V.A. and Godbole, S.P.: "Hydrate Equilibria for Binary and Tertiary Mixtures of Methane, Propane, Isobutane, and $n$ Butane: Effect of Salinity," SPE 16871, presented at the 62nd Annual Technica! Conference and Exhibition of SPE held in Dallas, TX, Sept. 27-30, 1987.

162. Parent, J.D.: "The Storage of Natural Gas as Hydrate," Inst. Gas Tech. Rep., Bull. $\# 1,16$ (1968). 
163. Parrish, W.R., and Prausnitz, J.M.: "Dissociation Pressures of Gas Hydrates Formed by Gas Mixtures," Industrial and Engineering Chemistry - Process Design and Development, Vol. 11, pp. 26-34 (1972).

164. Patil, S.L.: "Measurements of Multiohase Gas Hydrate Phase Equilibria: Effect of Inhibitors and Heavier Hydrocarbon Components," M.S. Thesis, University of Alaska, Fairbanks, Petroleum Engineering Department (1987).

165. Pauling, L. and Marsh, R.E.: "The Structure of Chlorine Hydrate," National Academy of Science Proceedings, Vol. 28, pp. 112-117 (1952).

166. Pearson, C., Murphy, J., Halleck, P., Hermes, R. and Mathews, M.: "Sonic \& Resistivity Measurements on Berea Sandstone Containing Tetrahydrofuran Hydrates: A Possible Analog to Narural Gas Hydrate Deposits," Earth \& Space Sciences Division, Las Almos National Laboratory, (1983).

167. Pharmarwardona, M.W.C.: "Thermal Conductivity of the Ice Polymorphs and the Ice Hydrates," The Journal of Physical Chemistry, Vol. 87, No. 21, 1983.

168. Pinder, K.L: "A Kinetic Study of the Formation of the Tetrohydrofuran Gas Hydrate," Canadian Jounral of Chemical Engineering, pp. 271-274 (October 1965).

169. Prausnitz, J.M., Chuch, P.L.: "Computer Calculations for High Pressure VaporLiquid Equilibria," Prentice Hall, Inc., Enqlewood Cliffs, New Jersey (1968).

170. Reamer, H.H., Selleck, F.T., Sage, B.H.: Trans. AIME, 195, 197 (1952).

171. Records, L.R. and Seely, D.H.: Trans, AIME, 192,61 (1951).

172. Roadifer, R.D., Godbole, S.P. and Kamath, V.A.: "Thermal Model for Establishing Guidelines for Drilling in the Arctic in the Presence of Hydrates," SPE Paper 16361, presented at the SPE California Regional meeting held in Ventura, CA, April 8-10, 1987. 
173. Roadifer, R.D., Godt ole, S.P. and Kamath, V.A.: "Estimation of Parameters for Drilling in Arctic and Offshore Environmental in the Presence of Hydrates," SPE Paper 16671, presented at the 62nd Annual Technical Conference and Exhibition of the SPE held in Dallas, TX (Sept. 27-30, 1987).

174. Roberts, O.L. , Brownscombe, E.R. and Hower, E.S.: "Constitution Diagrams and Composition of Methane and Ethane Hydrates," Oil and Gas Journal, Vol. 39 (1960), pp. 30-37.

175. Roberts, O.L., Brosonscome, E.R. and Howe, L.S., Petrol. Engr. 12, No. 6,56 (1961).

176. Robinson, D.B. and Mehta, B.R.: "Hydrates in the Propane - $\mathrm{CO}_{2}$-Water System," Journal of Canadian Petroleum Technology, Jan-Mar 1971, p. 33.

177. Robinson, D.B. and Huton, J.B.: "Hydrate Formation in Systems Containing Methane $\mathrm{H}_{2} \mathrm{~S}$ and $\mathrm{CO}_{2}$," Journal of Canadian Petroleum Technology, Jan-Mar 1967, p. 6.

178. Ross, R.G.: "Clathrate and Other Solid Phases in the Tetrohydrofuran - Water System: Thermal Conductivity and Heat Capacity Under Pressure," Can. J. Chem., 60, 1982, p. 881.

179. Ross, R.G.: “Unusual PT Dependence of Thermal Conductivity for a Clathrate Hydrate," Nature, Vol. 290, 26 Mar. 1981, p. 322.

180. Rouher, O.S. and Barduhn, A.J.: "Hydrates of Iso and Normal Butane and Their Mixtures," Desalination, Vol. 6, (1969), pp. 53-57.

181. Sada, E.: "Surface Tension of Some Molten Salt Hydrates by the Pendant Drop Technique," J. Chem. Engq. Data, 1986, 79, pp. 117-119.

182. Scauzillo, F.R.: "Inhibiting Hydrate Formations by Hydiucarbon Gases," Chemical Engineering Progress, Vol. 52 (No. 8), August, 1956, pp. 324-328.

183. Schneider, G.R. and Farrer, J., Tech.: "Office of Saline Water Research Deveiopment," Progíam Repuôt. \#2323 (1368). 
184. Schroeder, W.: "Gas Hydrates: A Review," Samml. Chem. and Chemical Technolgoy Vortrage, Vol. 29, p. 1 (1927).

185. Selim, M.S. and Sloan, E.D.: "Modelling of the Dissociation of an In-situ Hydrate," SPE 13597 Paper presented at the SPE California Regional Meeting, Bakersfield, CA, March 27-29, 1985.

186. Selim, M.S. and Sloan, E.D.: "Hydrate Dissociation in Sediment," SPE 16859, Paper presented at the 62nd Annual Technical Conference and Exhibition of the SPE held in Dallas, TX, September 27-30, 1987.

187. Selleck, F.T., Carmichael, L.T. and Sage, B.H., Ind. Eng Chem. 66,2219 (1952).

188. Sharma, G.D., patil, S.L., Kamath, V.1. and Godbole, S.P.: "The Potential of Natural Gas in the Alaskan Arctic," to be presented at the SPE 1988 California Regional Meeting, March 23-25, 1988, Long Beach, California.

189. Shipley, T.H., Houston, M.H., Buffler, R.T., Shaup, F.J., McMillen, K.J., Ladd, J.W., and Worzel, J.L: "Seismic Evidence for Widespread Possible Gas Hydrate Horizons on Continental Slopes and Rises," The American Association of Petroleum Geology Bulletin, V. 63, No. 12, pp. 2,204-2,213 (Dec. 1979).

190. Sloan, E.D.: "Measurement of In-Situ Hydrate Thermodynamic Properties," GRI Final Report (1983).

191. Sloan, E.D., Khoury, R.M. and Kobayashi, R.: "Water Content of Methane Gas in Equilibrium with Hydrate," Ind. Eng. Chem., 15, 318 (1976).

192. Sloan, E.D.: Progress Report on Project 775-A-82, NGL-Hydrate Two Phase Systems, Prepared for GPA Meeting, March 1982.

193. Snell, L.E., Otto, F.D. and Robinson, D.B.: “Hydrates in Systems Containing methane, Ethylene, Propylene \& Water," AlChE J, 7(3) (1961).

194. Song, K.Y. and Kobayashi, R.: "Measurement and Interpretation of the Water Content of a Methane-Propane Mixture in the Gaseous State in Equilibrium with Hydrate:" 1 and EC. Fundam.: 1982, 21 : pp. 391 -395. 
195. Song, K.Y. and Kobayashi, R.: "Measurements \& Interpretation of the Water Content of a Methane-Propane (5.31 Mol\%) Mixture in the Gaseous State in Equilibrium with Hydrate," Paper prepared for submission to I.E.C. Fundamentals, 1981.

196. Sortland, L.D. and robinson, D.B.: "The Hydrates of Methane and Mixaflouride," Can. J. of Chem. Engg. (1964).

197. Stackelberg, Von, M. and muller, H.R.: "Test Gas Hydrates," Zeit Electro Chemistry, Vol. 28, pp. 25-49 (1954).

198. Stoll, R.D., Ewing, J., Bryan, G.M.: “Anomoalous Wave Velocities in Sediments Containing Gas Hydrates," 1. Geophys., Res., Vol. 76, p. 2090 (1971).

199. Stoll, R.D. and Bryan, G.M.: "Physical Properties of Sediments Containing Gas Hydrates," Lamant-Doherty Geological Observatory, Vol. 23, p. 1059 (1971).

200. Stoll, R.D.: "Effect of Gas Hydrates in Sediments, Natural Gases in Marine Sediments," Ed. from Kaplan, I.R., Plenum Press (1976).

201. Tee, L.S., Gototh, S. and Stewart, W.R.: "Molecular Parameters for normal Fluids," Industrial and Engineering Chemistry Fundamentals, Vol. 5, pp. 363368 (1986).

202. Tester, J.W., Vjvins, R.L., and Herrich, C.C.: "Use of Monte Carlo in Calculating Thermodynamic Properties of Water Clathrates," AlChE Journal, 18 (6), 1220 (1972).

203. Tester, J.W. and Wiegandt, H.F: “The Fluid Hydrates of methlene Chloride and Chloroform: Their Phase Equilibria and Behavior as Influenced by Mexane," AlChE J, Vol. 15 (2), 1969, pp. 239-244.

204. Thompson, M.: "The Prediction and Interpretation of Downhole Mud Temperature While Drilling," Paper presented at the 60th Annual Technical Conference and Exhibition of the SPE held in Las Vegas, NV. SPE Paper \# 14180 (Sept. 1985). 
205. Topham, D.R.: "The Formation of Gas Hydrates on Bubbles of Hydrocarbon Gases Rising in Seawater," Chemical Engineering Science, Vol. 39, No. 5, pp. 821.828 (p. 986).

206. Tophane, D.R.: "The Modelling of Hydrocarbon Bubble Plumes to Include Gas Hydrate Formation," Chemical Engineering Science, Vol. 39, No. 11, pp. 16131622 (1984).

207. Tucholke, B.E., Bryan, G.M. and Ewing, J.I.: "Gas Hydrate Horizons Detected in Seismic Profiler Data from the Western North Atlantic," American Association of Petroleum Geologists Bulletin, 61(5), pp. 698-707 (1977).

208. Uchida, T. and Hayano, 1.: "Hydrate Formation in Isobutane or a Butane Isomer-water Systems at a Given Temperature," Desalination, Vol. 3 (1967), p. 373.

209. Ullerich, J.N., Selim, M.S., Sloan, E.D.: "Theory and Measurement of Hydrate Dissociation," AlChE Journal, Vol. 33, No. 5, p. 747 (May 1987).

210. Unruh, C.H. and Katz, D.: "Gas Hydrates of $\mathrm{CO}_{2}$-Methane Mixtures," Trans. AIME, 186, 83 (1949).

211. Van Cleff A. and Diepen, G.A.M.: "Gas Hydrates of Nitrogen and Oxygen-1," Recueill, 79 (1960) pp. 582-586.

212. Van Cleff.A. and Diepen, G.A.M.: "Gas Hydrates of Nitrogen and Oxygen I," Recueil, 86 (1965) pp. 1085-1093.

213. Van Cleff A. and Diepen, G.A.M.: Ethylene Hydrates at High Pressures, Recueil, 81 (1965) pp. 1085-1093.

214. Van der Waals, J.H. and Plateuw, J.C.: "Clathrate Solutions," Advances in Chemical Physics, Vol. 2 (1959), pp. 1-57.

215. Verma, V.K.: "Gas Hydrates from Liquid Hydrocarbon Water System," Ph.D. Thesis, University of Michigan, p. 145 (1974). 
216. Verma, V.K., Hand, J.H. and Katz, D.K.: "Gas Hydrates from Liquid Hydrocarbons (Methane-Propane-Water System); Munich, Germany." Am. Inst. Chem. Enqineers -Gesell, Verfahrstechni, V. Cheminingenieurwesen, p. 10 (1974).

217. Verma, V.K. and Holder, C.D.: "Denuding Hydrocarbon Liquid of natural Gas Constituents by Hydrate Formation," Journal of Petroleum Technology, No. 27. pp. 223-226 (1975).

218. Villard, M., Compt. Rend., 106, 1602 (1888-9).

219. Vysniquskas, A. and Bishoi, P.R.: "A Kinetic Study of Methane Hydrate Formation," Chemical Engineering Science, Vol. 38, No. 7, pp. 1061-1072 (1983).

220. Vysniquskas, A. and Bishoi, P.R.: "Kinetics of Ethane Hydrate Formation," Chemical Engineering Science, Vol. 40, No. 2, pp. 299-303 (1985).

221. Wagner, J., Erbar, R.C. and Majeed, A.I.: "Aqua + Sim and Phase Equilibria and Hydrate Inhibitor Using the PFGC Equation of State،" GPA Report (1984), pp. 129-136.

222. Weaver, J.S. and Steward, J.M.: "In-situ Hydrates Under the Beaufort Sea Shelf," Dome Petroleum Ltd. (1982).

223. Weibe, R., Chem. Rev. 29675 (1961).

224. Whalley, E.: "Speed of Longitudinal Sound in Clathrate Hydrates," Journal of Geophysical Research, Vol. 85, NO. B5, Pages 2539-2542, May 10, 1980.

225. Whitten, B.L., Kiefte, M., and Clouter, M.J.: "Determination of Acoustic Velocities in Xerox and Methane Hydrates by Brillouin Spectroscopy." Geophysical Research Letters, Vol. 9, No. 6, pp. 645-648, June 1982.

226. Wilcox, W.J., Carson, D.B. and Katz, D.L.: "Natural Gas Hydrates," ind. Eng. Chem., 33, $662(1941)$. 
227. Wright, D.A.: "A Kinetic Study of Methane Hydrate Formation from Ice," M.S. Thesis, School of Engineering, University of Pittsburgh (1985).

228. Wu, B.J., Robinson, D.B. and Ng, H.J.: "Three and Four Phase Hydrate Forming Conditionsin the Methane - Isobutane Water System," Journal of Chemical Thermodynamics, 8(5):461 (1976). 


\section{CHAPTER TWO}

\section{MEASUREMENT OF EFFECTIVE GAS PERMEABILITY \\ IN A HYDRATE SATURATED SANDPACK}

\subsection{Introduction}

As hydrates form or dissociate in a porous medium, the pore structure geometry and the physical properties such as effective porosity and permeability are altered. For example, a porous media fully saturated with gas hydrate may be essentially impermeable, but the porous media partially saturated with gas hydrates need not be completely impermeable. Thus, the effective permeability of porous media will be altered continuously as hydrates form or dissociate in situ. The knowledge of effective permeability of hydrate saturated porous media is needed for the simulators predicting performance of gas production from in situ gas hydrates. Specifically of interest is the relationship between the hydrate saturation and the permeability alteration.

Literature contains little information or data on the change in the effective permeability of porous media that occurs due to formation or dissociation of gas hydrates in situ. However, two qualitative experimental studies (Evrenos et al., 1971; Baker, 1978) are worth mentioning since they provide a proof that hydrate formation leads to permeability reduction observed through either increase in pressure drop for same flow rate as hydrates form or decrease in gas flow rate for same pressure drop as hydrates form.

Evrenos et al (1971) investigated the impermeation of porous media by forming gas hydrates in situ. The purpose of their study was two fold: (1) to confirm the possibility of gas hydrate formation in porous media, and (2) to determine if hydrate formation will render the porous media impermeable. The industrial application of this work was to study the possibilities of utilizing hydrates to stop leaks in cap rocks or to seal off homocline structures so they could be turned into 
storage reservoirs. Two schemes were applied to form hydrates in the core consisting of medium-to-fine St. Peterson sandstone. In Scheme I of the experiment, the core was saturated with water and gas was allowed to pass through the sand pack at constant pressure. By reducing the temperature, gas throughput was decreased indicating hydrate formation in the pressure vessel had occurred. In Scheme II of the experiments, sand pack was initially saturated with water and the system temperature was cooled and kept constant at the desired level. At this point, gas and water were passed through the core simultaneously and the pressure was increased until either of the two ceased to flow. The results obtained from Schemes 1 and II showed that second scheme resulted in a better rate of hydrate conversion, which led authors to conclude that higher water saturation in porous media gives better rate of hydrate formation. However, it was cited that the process of porous media impermeation by forming hydrates may not be economically feasible to seal off gas reservoirs leakage to the surrounding porous medium.

Baker (1975) carried out experiments to observe formation and decomposition of hydrates in unconsolidated sand pack using a gas mixture of $90 \%$ methane and $10 \%$ ethane. Procedures used to form hydrates in his study were different than the one that was originally recommended by Evrenos et al (1971). In the study by Evrenos et al (1971), water and gas were flowed through the core alternately and when a restriction to flow of either gas or water occurred, hydrate core was considered impermeable. In the study by Baker (1975), gas was supplied to the system through a constant pressure regulated valve and when hydrates were formed as the system pressure declined due to hydrate formation, the process was terminated. In this method, pressure vessel temperature was maintained between $5^{\circ} \mathrm{C}$ and $10^{\circ} \mathrm{C}$ with pressures between 508 and 624 psi. In order to ensure the formation of hydrates, gas was produced from the core. The comparison of the gas released to the amount that could have been sustained in the pressure vessel in the 
absence of hydrates indicated the formation of hydrates in the pressure vessel. The dissociation of hydrates was accomplished using two different schemes. One was to raise the temperature while keeping the pressure in the core holder constant by means of a back pressure regulator; the second method was to reduce the pressure at the outlet while core holder temperature was held constant.

Aguirre-Puente and Gruson (1983) developed an experimental technique for measuring the permeabilities of frozen soils. A specially designed vessel was built with provisions to keep the water-saturated soil at super cooled temperature along the length of the core, and outlet end of the core was fitted with plates impermeable to ice but permeable to water. Darcy's law was used to determine the permeability of the frozen soils. Small variations in temperature was the major difficulty encountered during their study. Techniques used in this study were reviewed due to the close similarities between the characteristics of frozen soils and hydrate-containing porous medium.

The objectives of our study were two-fold. First, it was necessary to develop a suitable experimental technique for measurement of effective gas permeability of a hydrate-saturated sandpack during hydrate formation process. Second, it was necessary to determine the effect of hydrate saturation on effective gas permeability of sandpack.

\subsection{Experimental Set-Up For Permeability Measurement}

In order to simulate in situ hydrate environment, a specially designed hydrate core holder manufactured by Setra, Inc. was used. The details of this core holder are shown in Figure 2.1. The core holder had an internal diameter of $10.16 \mathrm{~cm}(4 \mathrm{in})$ and a length of $30.48 \mathrm{~cm}$ (12 in). It had two removable flanges at the top and the bottom. The core holder was equipped with cooling jacket though which coolant methanol was continuously circulated to maintain the core holder at a desired 


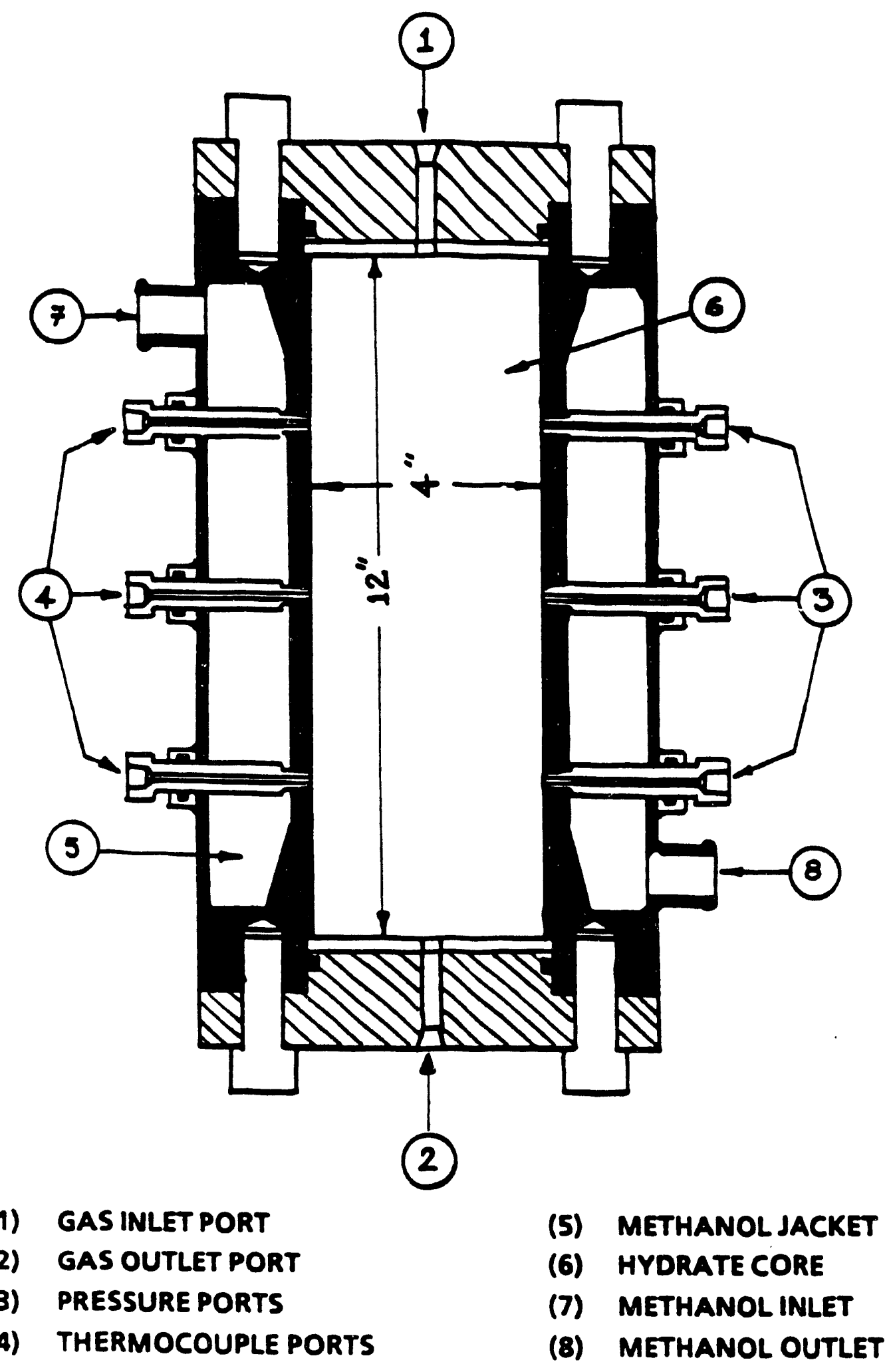

Figure 2.1: Hydrate Core Holder 
temperature. On one side of the core holder were three pressure ports at 3-, 6- and 9-inch distances from the bottom. On the opposite side, there were three temperature ports. The top flange of the core holder had a gas inlet port and the bottom flange of the core holder had a gas outlet port.

Figure 2.2 shows a schematic diagram of the entire assembly of the hydrate core permeability set-up. A bench top refrigerated bath circulator (Model RTE-4), manufactured by Neslab, Inc., was used for cooling methanol, controlling the temperature of methanol within $\pm 0.05^{\circ} \mathrm{C}$ and circulating it through the jacket of the hydrate core holder at a desired temperature. Three pressure transducers (Model \#PK-301-2KGV) were hooked up to the pressure ports of the core holder and connected to digital pressure monitor (Mode! \#PRC-3500-P3), all manufactured by Omega Engineering, Inc. and had a range of 0-2000 psia pressure. Three platinum resistance thermometers were inserted at the three temperature ports of the core holder and were connected to a digital temperature indicator $\left( \pm 0.1^{\circ} \mathrm{C}\right.$ divisions) manufactured by Omega Engineering, Inc.

The inlet gas port was initially equipped with three concentric gas spargers, designed to overcome any problems of plugging of the core during hydrate formation. The gas inlet line had a gas flow meter $10-1000 \mathrm{cc} / \mathrm{min}$, Model \#3270, Cole Parmer) and a gas flow controller (0-100\% range, Model \#BA-3275-00, Cole Parmer, $0.1 \%$ flow accuracy) to measure and control the inlet flow rate of gas into the core holder. The inlet gas line was passed through a series of coils inserted in the methanol bath circulator for precooling of inlet gas prior to reaching core holder.

The outlet gas port was connected to the outlet line through a gas flow meter to measure the outlet gas flow during permeability measurements. In addition, the outlet line was also hooked to a wet test flow meter to measure to volume of gas leaving the core holder. In addition to pressure transducers, a differential pressure transducer (0-50 psig differential pressure range, $0.1 \%$ accuracy) was hooked up 

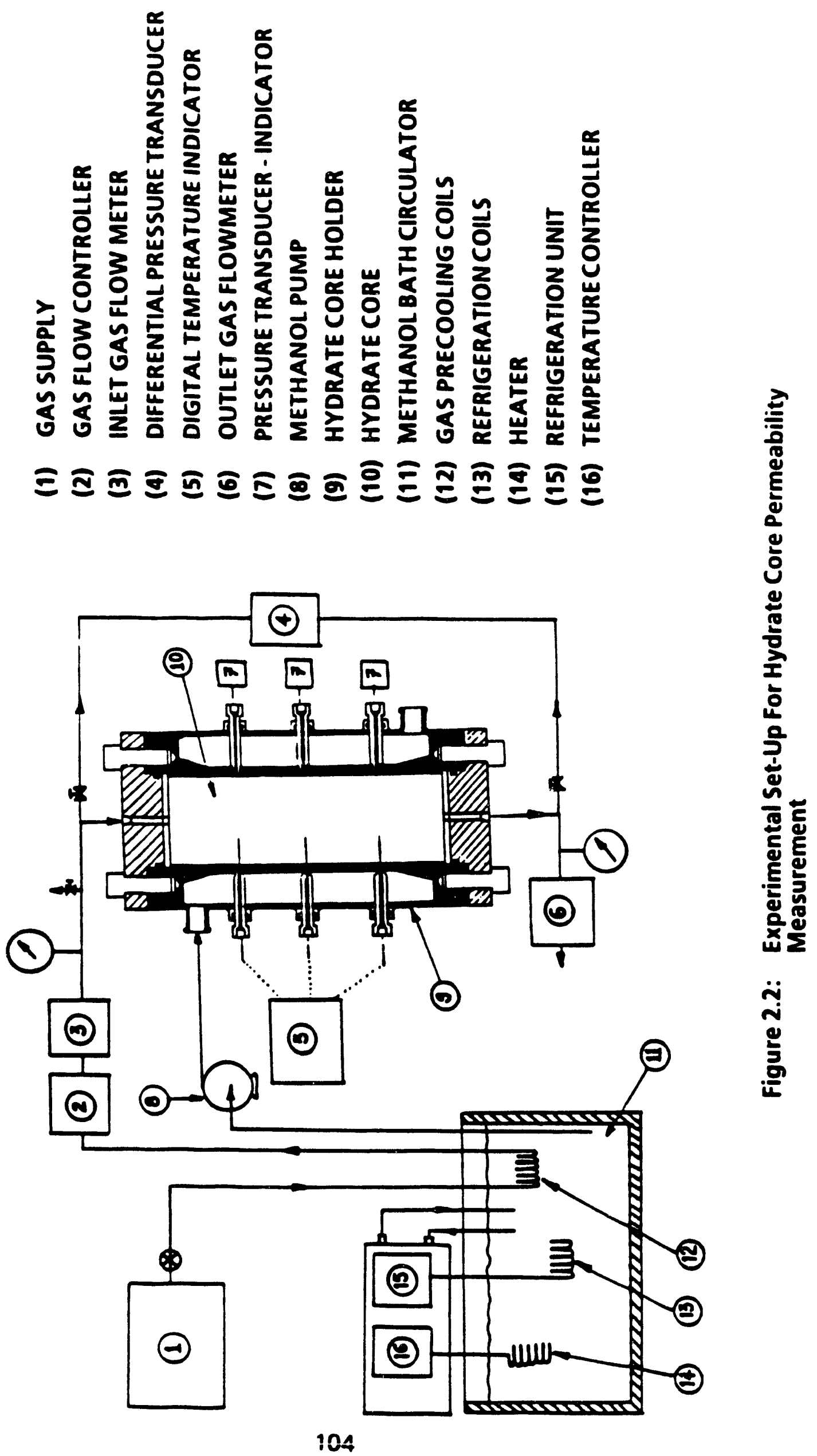

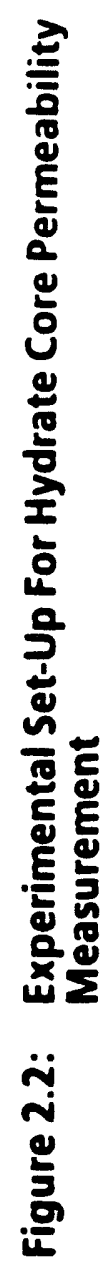


between gas inlet and outlet lines so that very low pressure drops could be measured accurately. The gas inlet and outlet lines were also connected to Heise pressure gauges (Model M 0-2000 psig, 2.5 psi divisions). The thermocouples, pressure transducers, methanol bath, wet test meter, gas flow meter and gas flow controller were calibrated prior to the start of the experiments.

\subsection{Experimental Methods For Permeability Measurement}

We investigated several methods and variations of hydrate formation. While all the methods were successful in hydrate formation, only two methods were considered to be most successful from the point of view of permeability measurements. These two methods are described here.

\section{Method I (Frost Method):}

In this method, we used finely divided ice crystals (frost, approximately 400 micron size) and fine sand particles (20 mesh Ottawa sand) for preparing a sand pack. Initially, the core holder temperature was reduced to $-15^{\circ} \mathrm{C}$ so that no melting of frost would take place during charging. It was very essential to maintain the quality of frost to be high (i.e. no wet frost). Known amounts of sand and frost were charged to the core holder and mixed thoroughly to obtain uniform distribution. The mixture was then compacted and packed to form a core with the help of a disk built specifically for this purpose. After preparation of the core, the porosity of the core was determined. The core holder temperature was then raised to $0.5^{\circ} \mathrm{C}$. After evacuation, core holder pressure was raised to 600 psia by injecting methane. The initial permeability when no hydrates are present was determined by continuously flowing methane gas from the top at a rate of $400-500 \mathrm{cc} / \mathrm{min}$ for $10-15$ minutes. During this flow run, the inlet and outlet gas flow rates and pressure drops 
were measured at every minute. From these readings, initial core permeability was determined from Darcy's law. Precautions were taken to ensure that the gas flow rates were less than that for which Darcy's law is valid. After determining initial gas permeability of the core, the system pressure was raised to about 700 psia. Hydrates were then allowed to form in a batch process as recognized from pressure decline within the core with time. When the core holder pressure dropped to 600 psia, the hydrate saturation in the core was determined to material balance. At this point, once again flow run was conducted to determine pressure drops due to flow and permeability of gas at the hydrate saturation. During these small flow periods, the hydrates actually did form in the core but the hydrate saturation did not increase more than 1 to $2 \%$. After the flow run, once again the system pressure was raised to 700 psia to form more hydrates in a batch process. This procedure was continued for 2-3 days until the conversion of frost to hydrates did not change much with time. This was inferred from a constant pressure in the core holder, indicating hydrate formation rates dropped considerably. After completion of the run, the hydrates were dissociated and the gas was metered to recheck the actual conversion of frost to hydrates achieved. These results were in full agreement with material balance approach.

\section{Method II (Water Method):}

In this method, sand pack was initially prepared by charging the known amount of 20 mesh Ottawa sand, and then packed using a vibrator assembly. The porosity was determined. The core was then saturated with water (typically 40-70\% water saturation level). The reason for not saturating the core completely with water was that at higher saturation levels, the water would displace out of the core and hydrates would form outside the core. This 
was certainly undesirable for permeability measurements. The core holder temperature was lowered to about 2 to $3^{\circ} \mathrm{C}$ and held constant throughout the run. The semipermeable end plates were installed at top and bottom ends of the core holder so that, during hydrate formation and permeability measurements, the water from the core holder will remain inside the core but will allow gas to flow through. The core holder was then completely evacuated and methane was continuously injected from the gas cylinder at a predetermined injection pressure (typically 1000 psia) and flow rate of $35-40$ comin. The inlet gas flow rate, core holder temperatures, differential pressure drops, pressure profiles within the core holder, and outlet gas flow rate were monitored and recorded continuously. During this continuous flow of gas, hydrates formed inside the sandpack. The hydrate saturation or conversion was determined by material balance approach. Gas permeability at various times were determined from these data. These experiments lasted from two to three days.

\subsection{Experimental Results and Discussion}

In order to calculate gas permeability, Darcy's law was used and considered applicable. The following equation was used:

$$
K_{G}=\frac{29.4 \bar{P} \bar{Q} \mu_{G} L}{A\left(P_{1}^{2}-P_{2}^{2}\right.}
$$

where $K_{G}$ is gas permeability in millidarcy, $\dot{P}$ is average pressure in the core holder $\left(\left(P_{1}+P_{2}\right) / 2\right)$ in psia, $Q$ is average gas flow rate $\left(\left(Q_{1}+Q_{2}\right) / 2\right)$ in cc/sec, $L$ is total core length, $\mu_{G}$ is gas viscosity at $\dot{P}$ and $T$ in CP; $A$ is cross sectional area of the core holder in $\mathrm{cm}^{2}, \bar{P}_{1}$, and $\vec{P}_{2}$ are iniet and outiet pressurues and $Q_{1}$ and $Q_{2}$ are inilet and outlet 
gas flow rates respectively. Note that the gas flow into core holder causes hydrate formation if the run is conducted at a pressure higher than the equilibrium hydrate dissociation pressure, and causes hydrate dissociation if the run is conducted at a pressure lower than equilibrium hydrate dissociation pressure. This creates a problem of continuous change of porous media due to hydrates which cannot be avoided and thus violates the Darcy's law. However, in our flow experiments, the time of gas flow was kept very low so that overall hydrate saturation change during a flow run is not more than $2 \%$. Thus, it is safe to assume that Darcy's law is not violated. In addition, we also chose to conduct flow runs very close to hydrate equilibrium pressure so that the rate of hydrate formation during flow runs would be very low.

Table 2.1 provides the physical properties of the hydrate cores studied by Method I. Listed in this table are the porosity, frost to sand volume ratio, final conversion of frost to hydrates, total hydrate formation period and the initial and final gas permeability. Experimental results for each of the five runs (Method $I$ ) in which flow runs were conducted are listed in Tables 2.2 to 2.6. Figure 2.3 provides the hydrate conversion versus time for all the five runs. This behavior of hydrate formation in a batch process is typical. Figure $\mathbf{2 . 4}$ provides a plot of permeability of gas as a function of hydrate saturation indicating drastic reduction in gas permeability due to hydrate formation. For example, in Run 1, gas permeability decreased from an initial value of $318 \mathrm{md}$ to $4.1 \mathrm{md}$ at $73 \%$ hydrate saturation, which is a factor of 75 in reduction of gas permeability.

In order to develop a correlation of gas permeability and hydrate saturation, permeability ratio (a ratio of instantaneous gas permeability to initial gas permeability) was plotted versus hydrate saturation (see Figure 2.5). Note that there is considerable scatter in this correlation since all the runs were included in this plot. The best fitted correlation is represented by the following equation ( $\pm 14 \%$ error) 


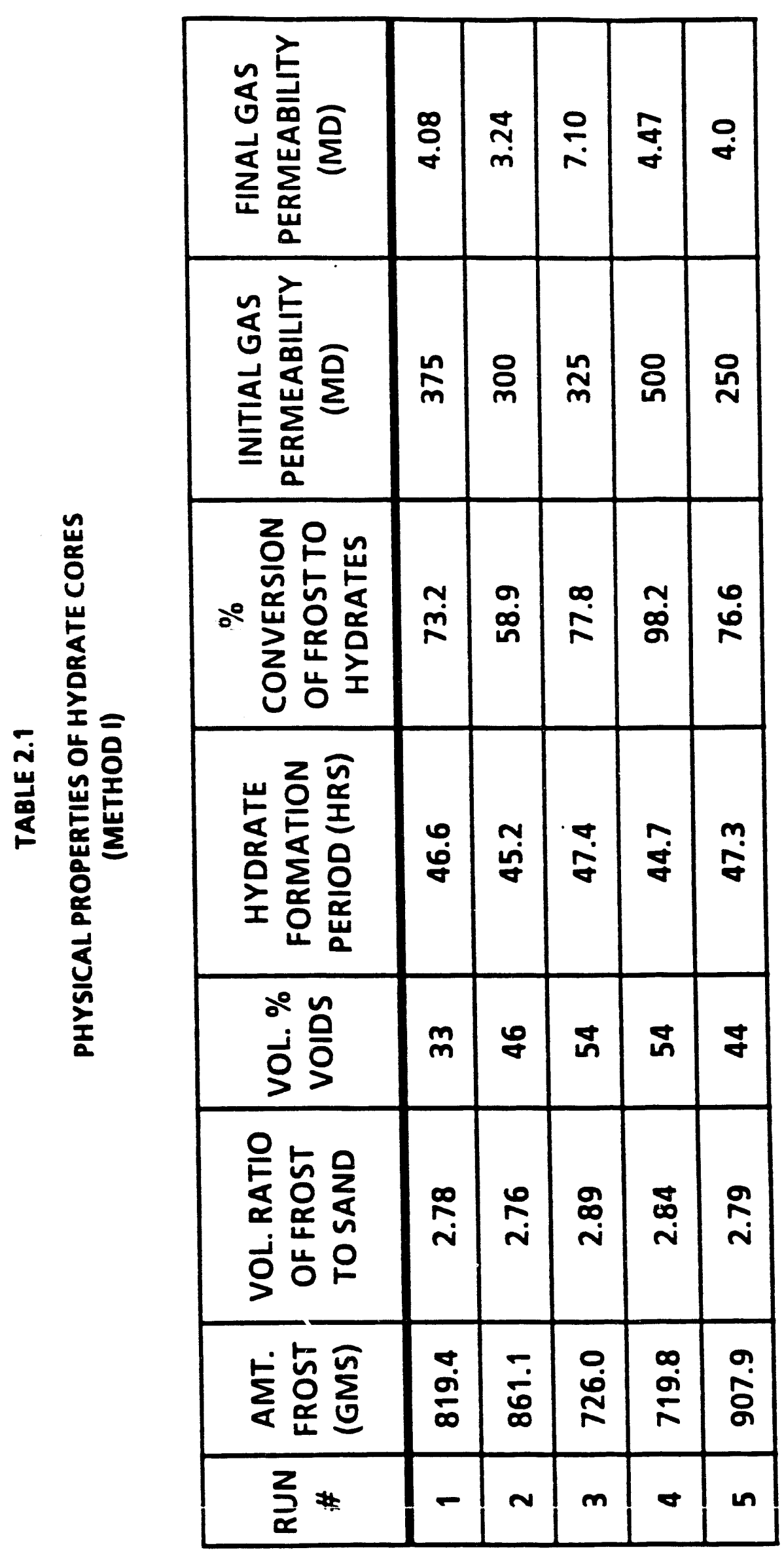




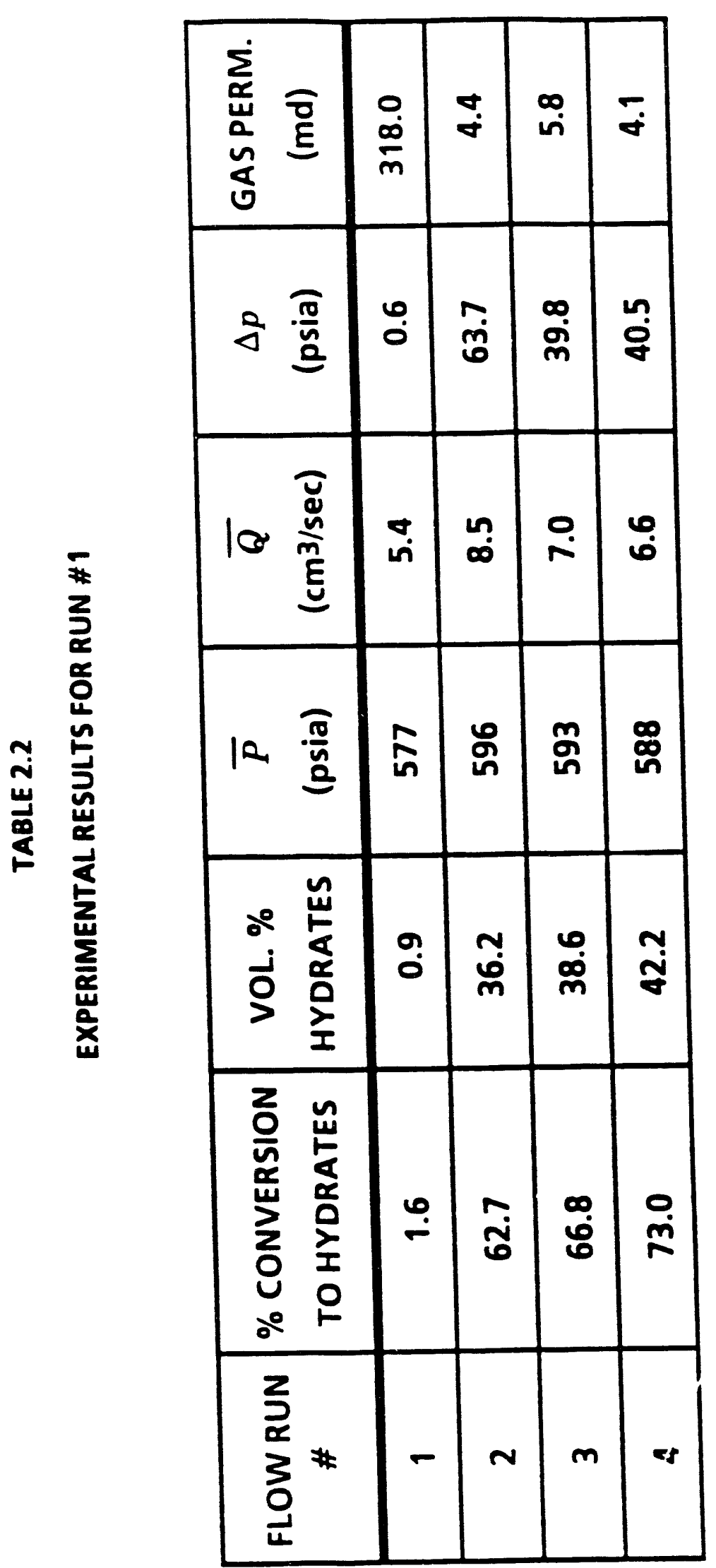




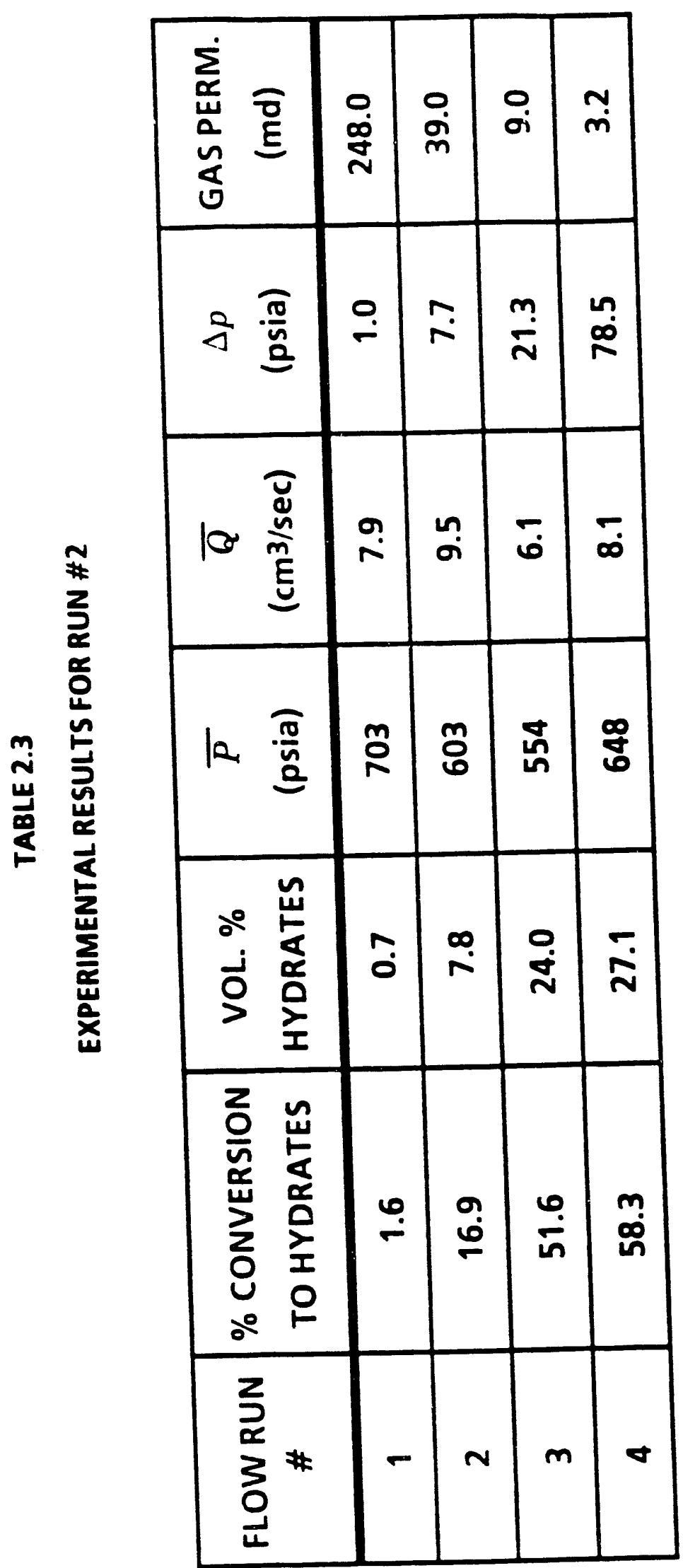




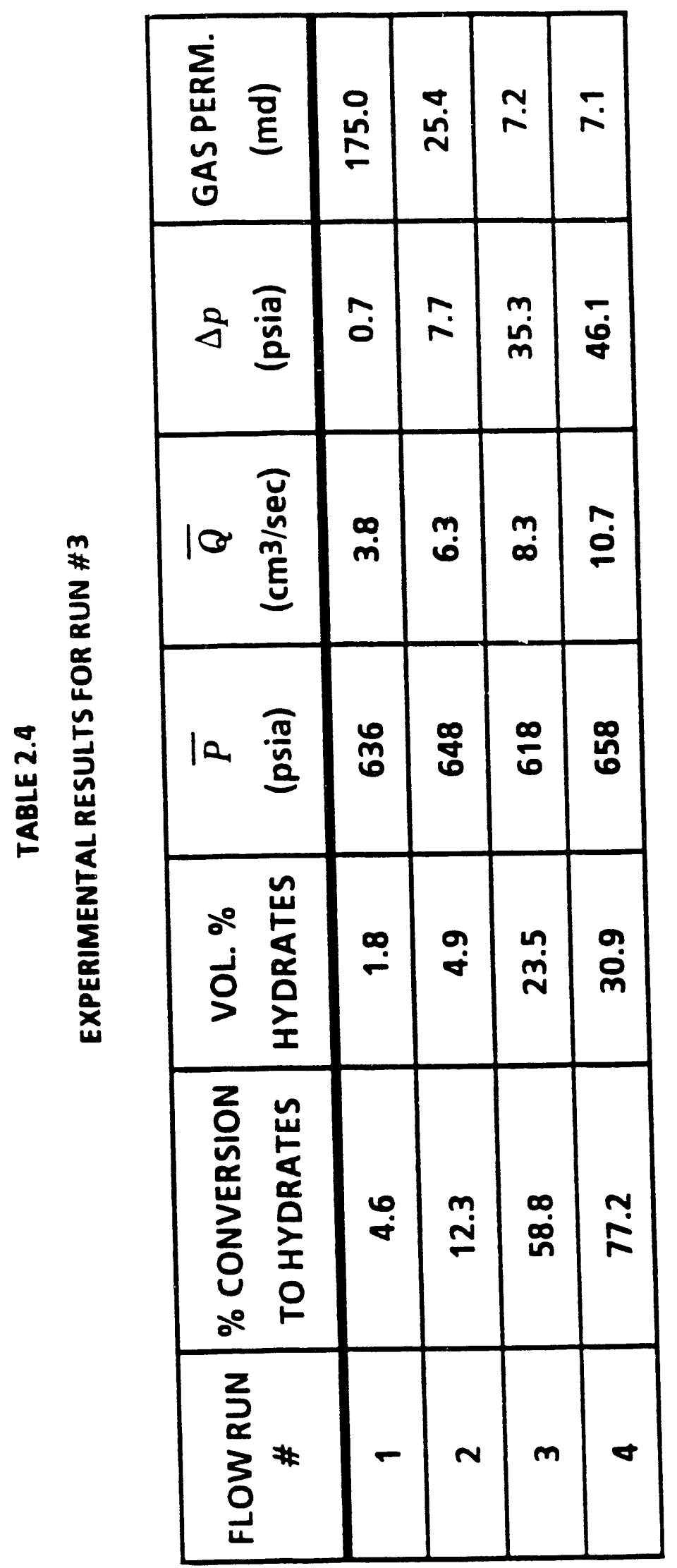




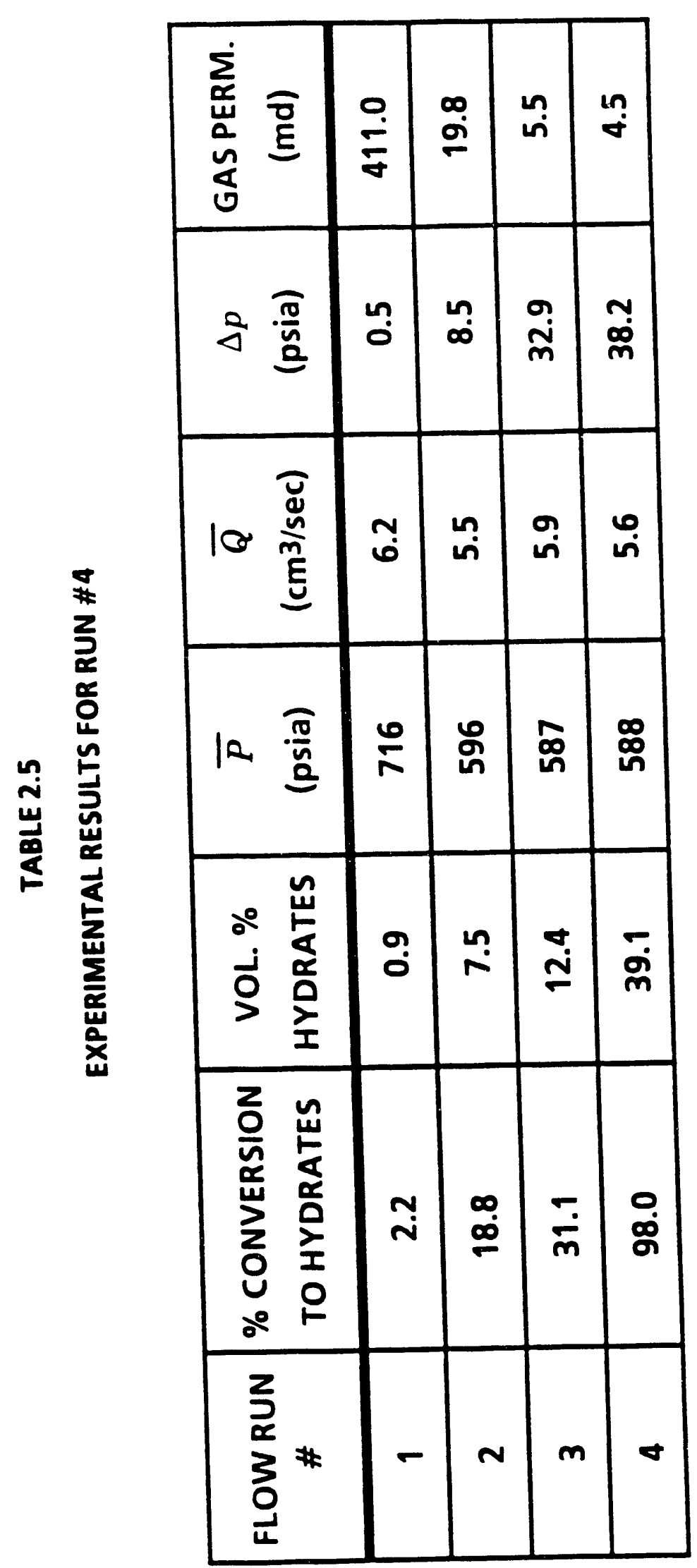




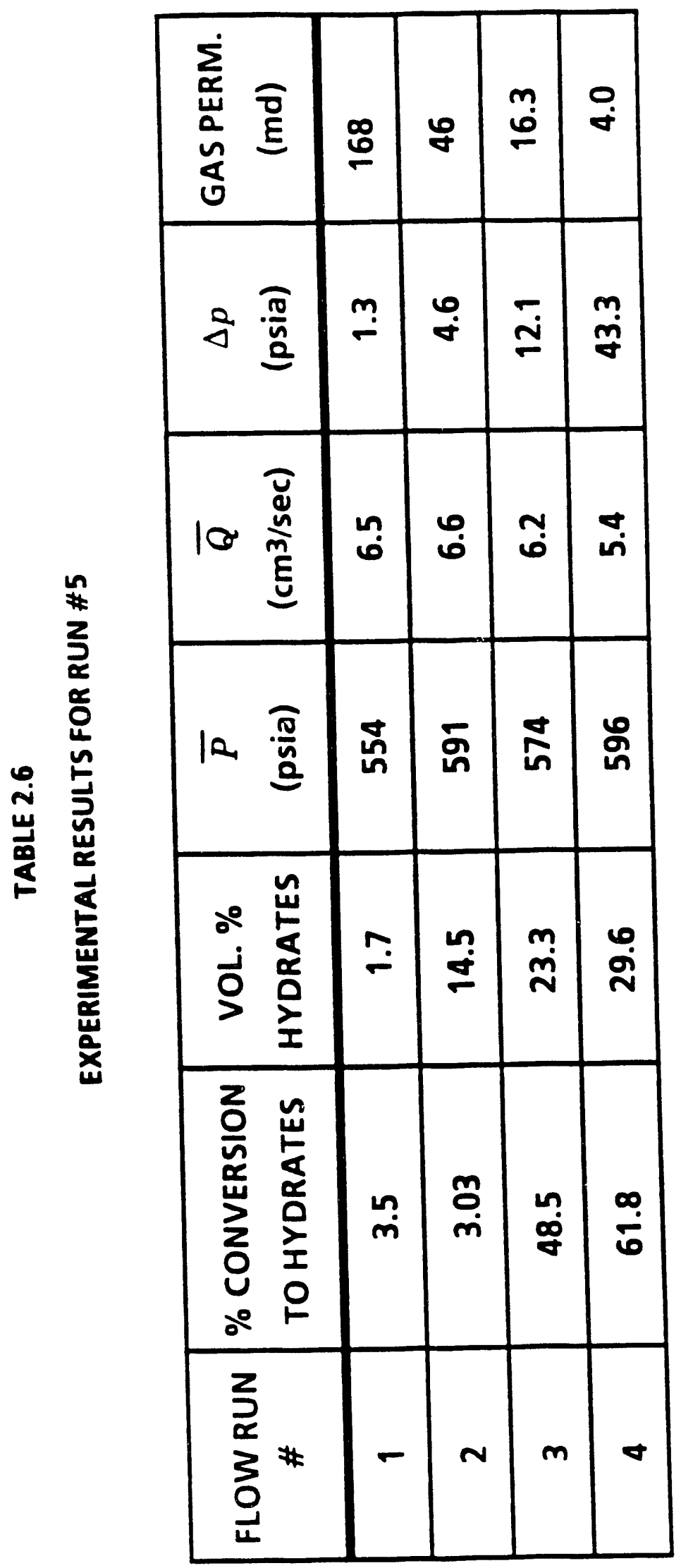



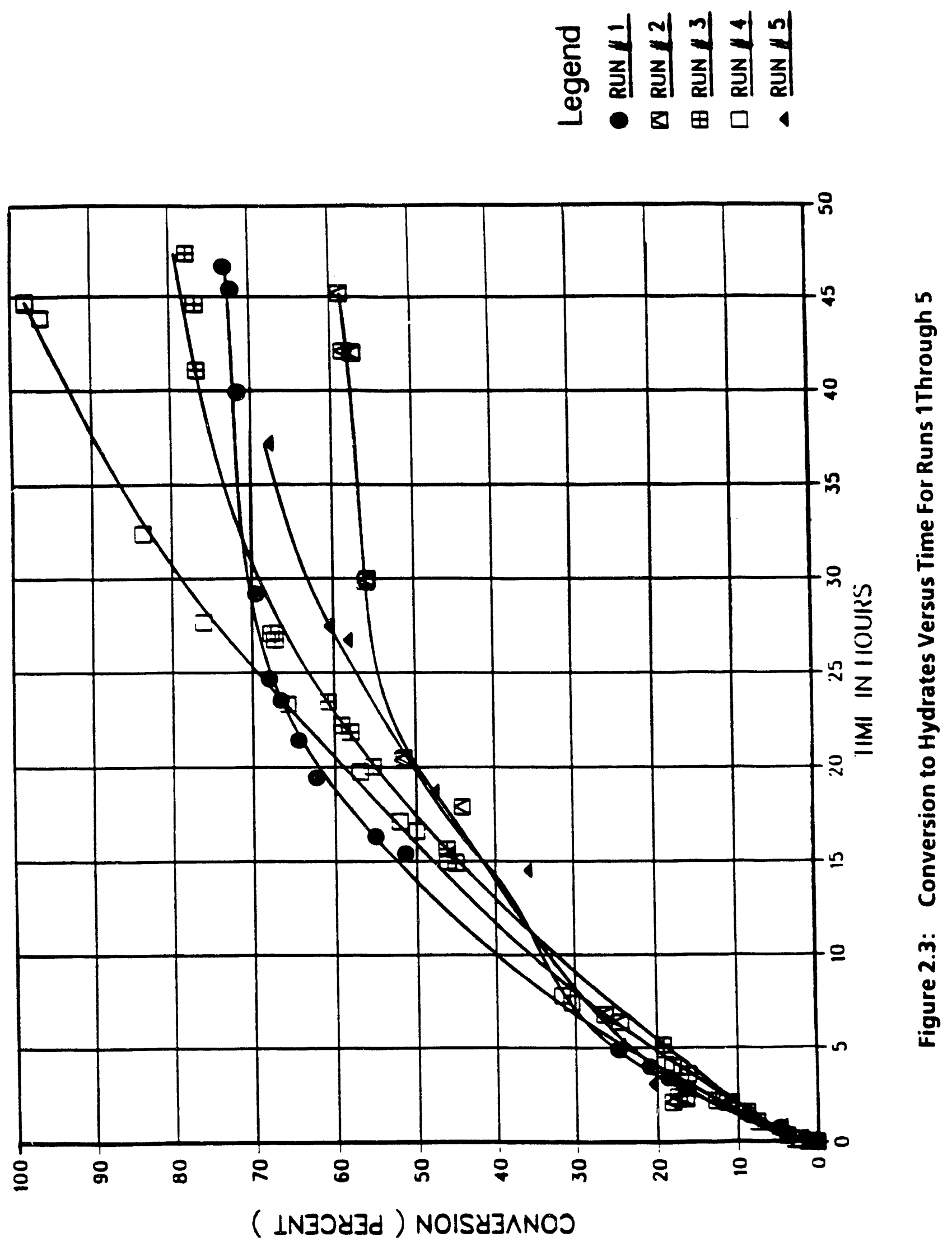


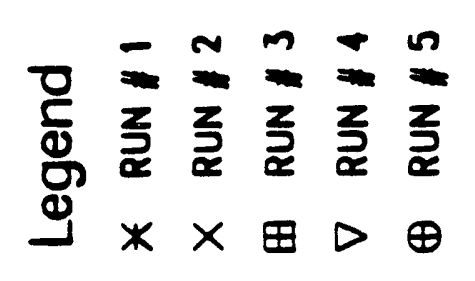

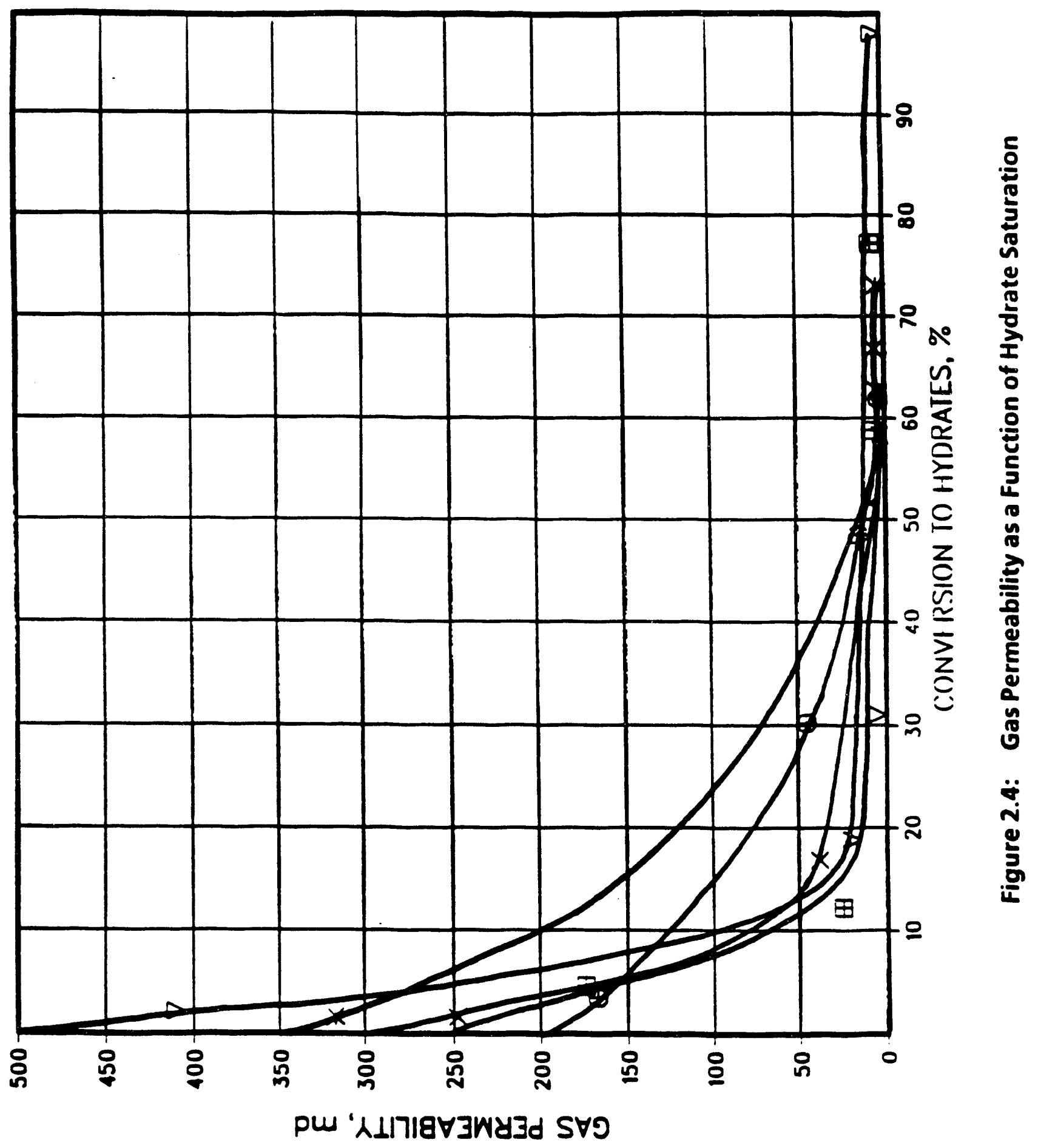




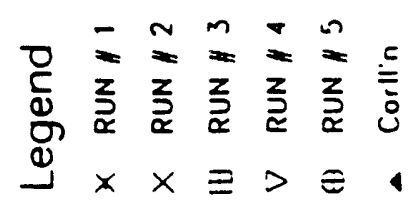

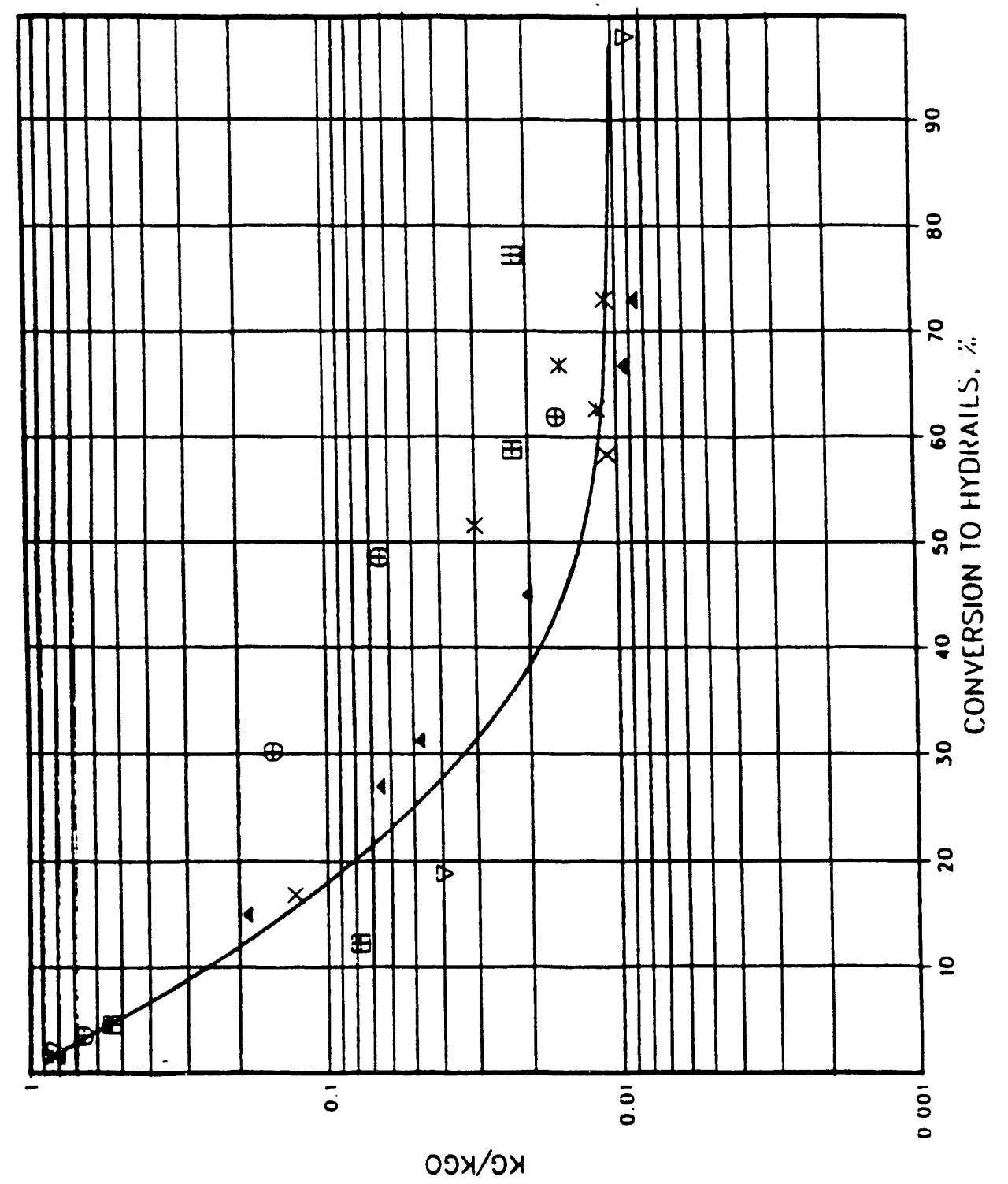

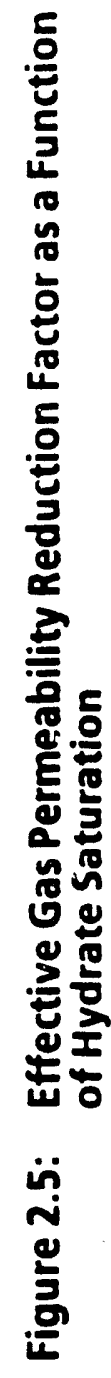




$$
K_{\text {geff }}=K_{\text {go }} \exp \left[-9.12 S_{H}+0.00076 S_{H}^{2}\right]
$$

where $K_{\text {geff }}$ is instantaneous effective gas permeability of the core, $S_{H}$ is the hydrate saturation, and $K_{g o}$ is the initial gas permeability when no hydrates were formed.

The scatter in the results are attributed to the following:

1. Nonuniformity of hydrate saturations in the core.

2. Variations in degree of packing and physical properties of the different cores used.

3. Variations of gas inlet and outlet flows with time, and difference between inlet and outlet flows.

4. Melting of frost to water. Note that the temperature in the jacket of the core holder was maintained at $0.5-1^{\circ} \mathrm{C}$. This might have caused some frost melt resulting in changes in pressure drops as well as gas permeability.

The experimental results for water run (Method II) are given in Table 2.7. The hydrate conversion versus time for this run is shown in figure 2.6 and gas permeability as a function of hydrate saturation is shown in figure 2.7. It was surprising to observe less drastic reduction in gas permeability of the core in this run (reduction factor of three) than in the frost run case.

The experimental results clearly indicate that the effective gas permeability of unconsolidated cores, partially saturated with hydrates, is reduced due to the increase in hydrate saturation which changes the pore structure. In such a process, the effective permeability will not only be the function of hydrate saturation, but also how the hydrates are distributed within the core. To illustrate this, consider three scenarios. In the first case, the hydrate saturation is assumed to be uniform across the length of the core. The effective permeability of the core in this case can be represented by two parallel beds along the length of the core, one bed being 


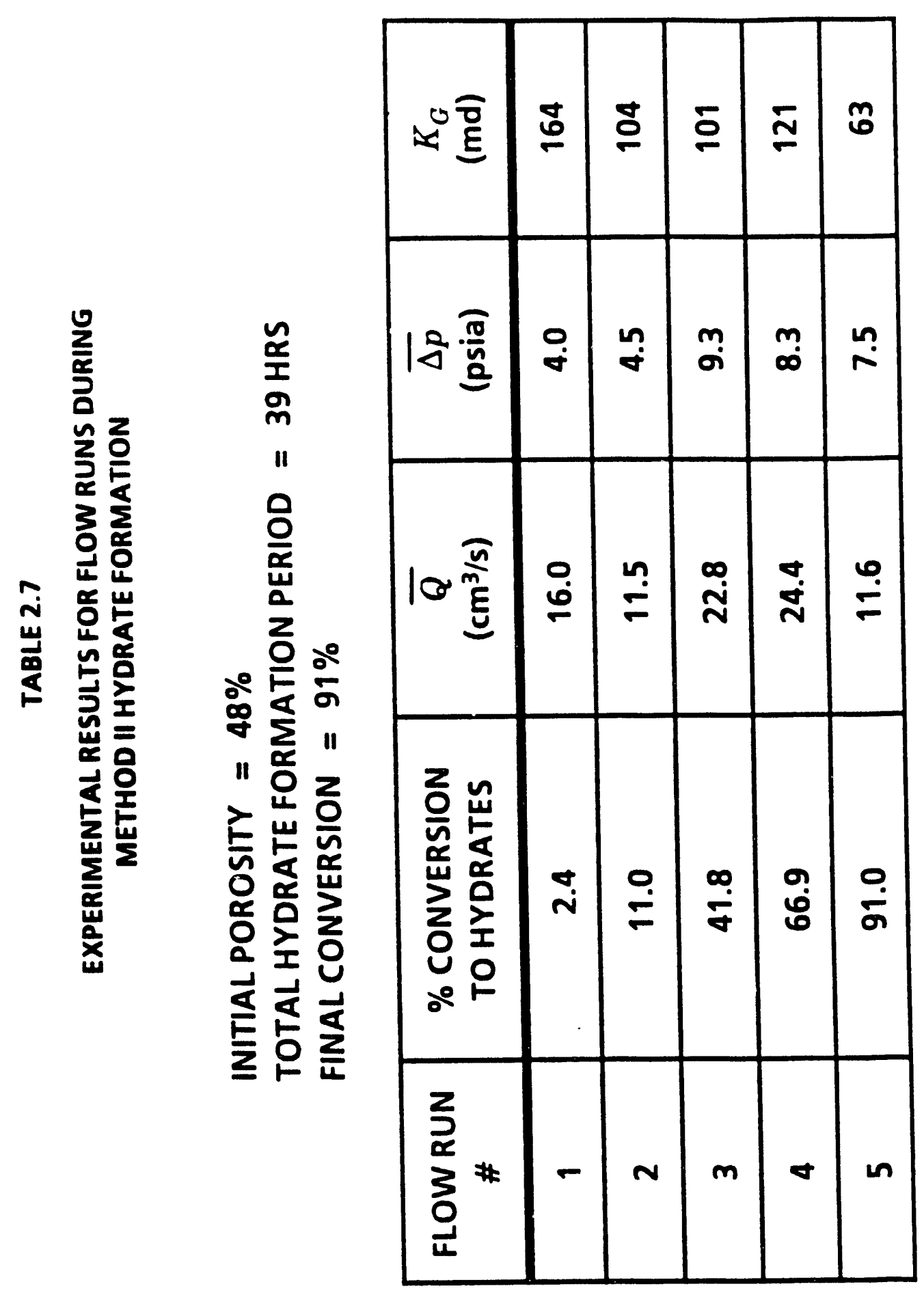




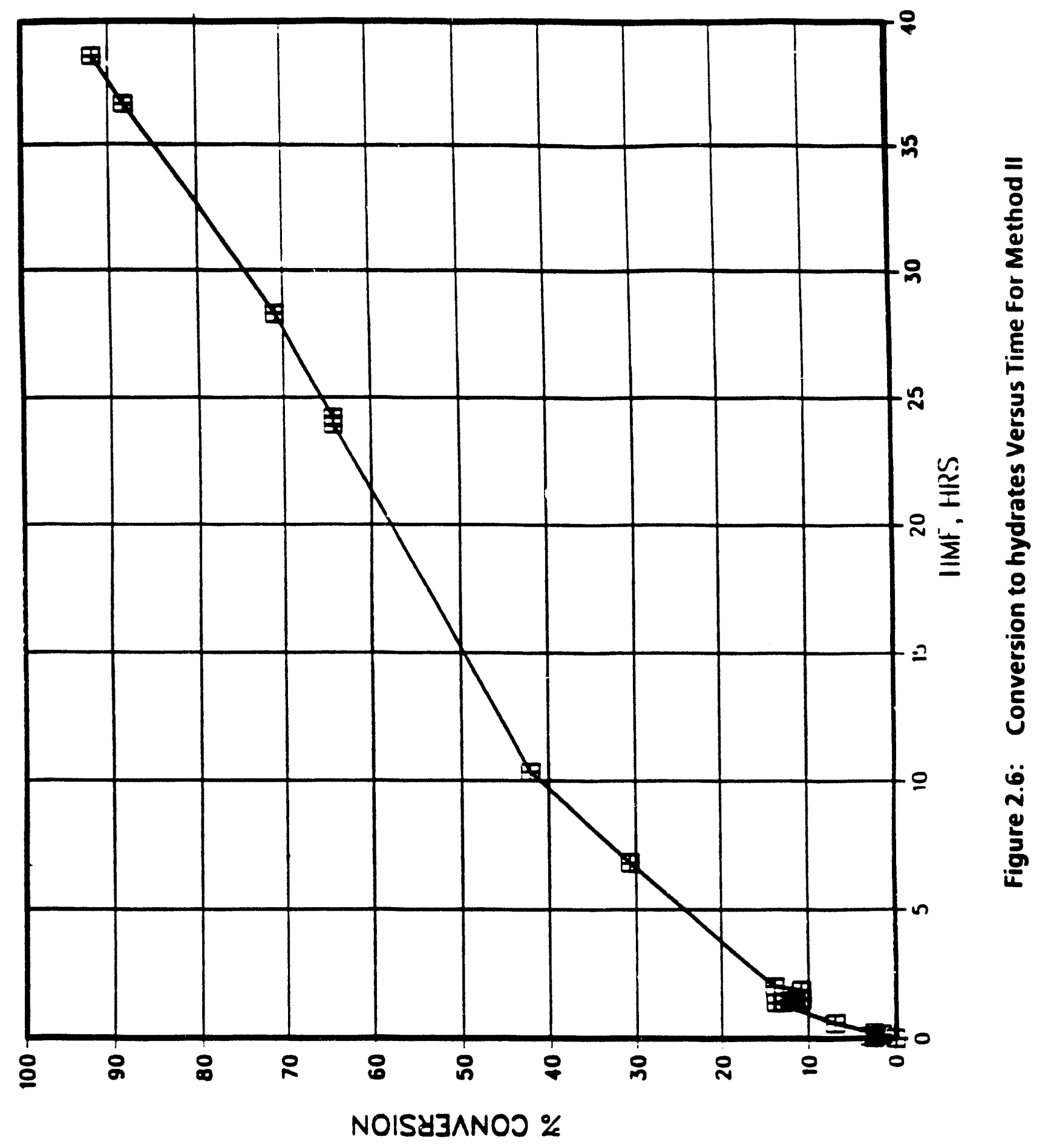




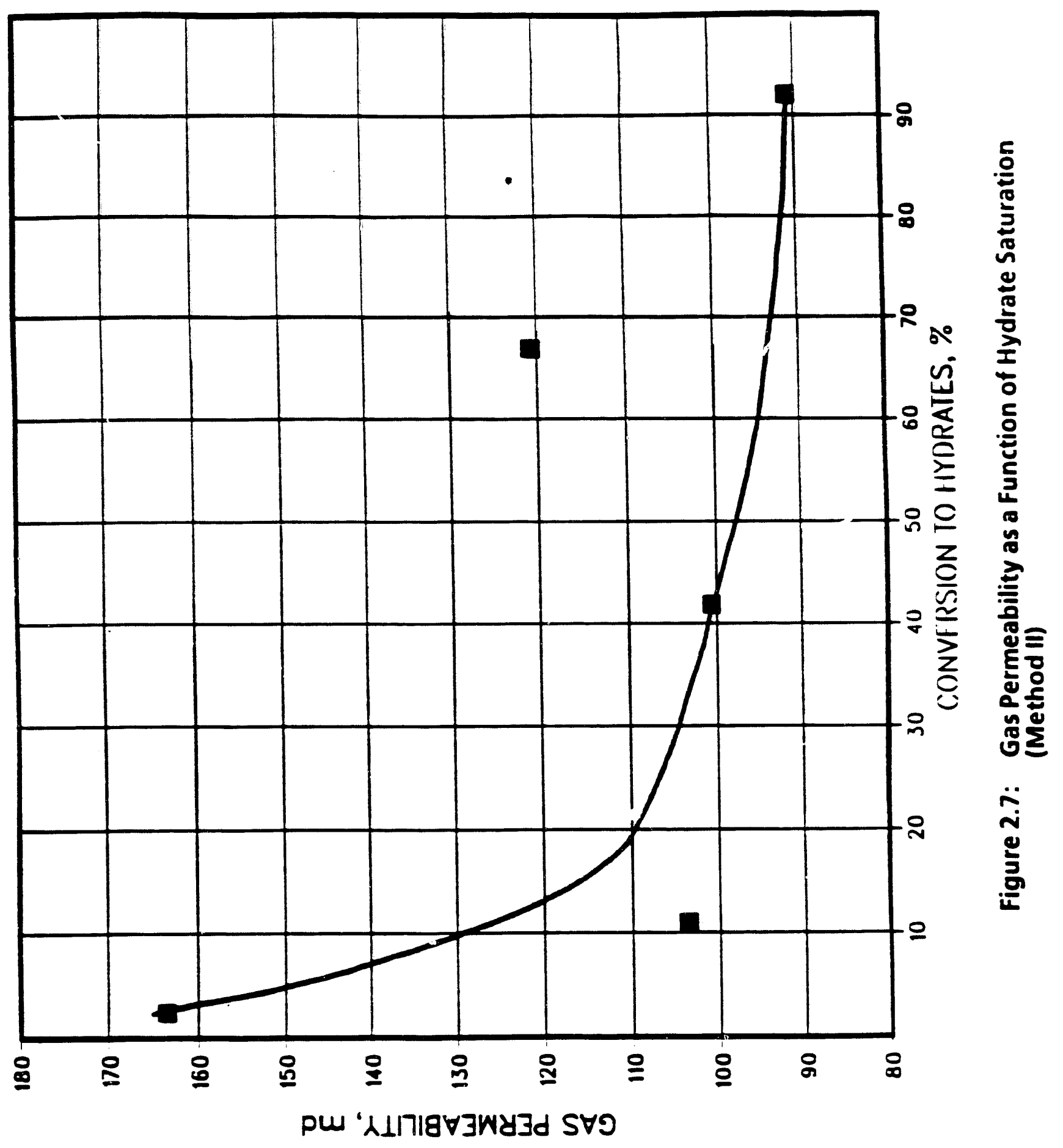


fully saturated by hydrates and the other bed being the original nonhydrate saturated portion. The overall hydrate saturation in the core will depend upon the cross- sectional area of the fully hydrate saturated bed. In other words, the crosssectional area of the fully hydrate saturated bed is $S_{H} A$, where $S_{H}$ is the actual overall hydrate saturation in the core. The cross-sectional area of nonhydrate sa Irated bed is $\left(1-S_{H}\right) A$. The effective gas permeability of the core considering this parallel combination (uniform hydrate saturated core) can be obtained by taking arithmetic area weighted averages of the permeability of fully hydrate saturated and nonhydrate saturated beds. In mathematical terms, this can be written as:

$$
K_{\text {geff }}=K_{g o}\left(1-S_{H}\right)+K_{g H} S_{H}
$$

where, $K_{g H}$ is the permeability of the bed fully saturated with hydrates. This results in a linear relationship between permeability and hydrate saturation.

In the second case, the effective permeability is represented by a series combination of two beds, the first bed being fully saturated with hydrate of effective length $\left(S_{H} L\right)$. The second bed being nonhydrate saturated with an effective length of $\left(1-S_{H}\right) L$. In such a situation, the effective permeability of the core can be obtained by length weighted harmonic means. The mathematical expression for this case is shown below:

$$
\frac{1}{K_{\text {eff }}}=\frac{S_{H}}{K_{\text {EH }}}+\frac{\left(1-S_{H}\right)}{K_{80}}
$$

Finally, it is assumed that hydrate saturation occurs randomly within the core. This is a more realistic picture. To determine the effective permeability in such a case, the core is divided into $N$ different infinitesima!!y sma!! ce!!s. Out of these $N$ 
cells, only $S_{H} N$ cells are considered to be fully saturated with hydrates and $\left(1-S_{H}\right) N$ cells are considered to be at zero hydrate saturation. The effective permeability of a porous medium in this situation is obtained by taking geometric averages of the permeabilities of these $N$ cells. In mathematical terms, this is represented by:

$$
\log \left(\frac{K_{g e f f}}{K_{g v}}\right)=S_{H} \log \left(\frac{K_{g H}}{K_{g v}}\right)
$$

Examination of these three relationships with the actual experimental results shown in Figure $\mathbf{2 . 5}$ indicates that hydrates are initially distributed inside the core in a random distribution process. However, once certain hydrate saturation is reached, the effective gas permeability of the sandpack is controlled by series type distribution.

\subsection{Conclusions}

1. Experimental techniques were developed and used to measure the effective gas permeability of hydrate saturated sandpacks.

2. Experimental results indicated that the effective gas permeability of the sandpack is considerably reduced (by a factor of 45 to 110).

3. A correlation between permeability reduction factor and hydrate saturation was developed, based on the experimental results.

4. The permeability reduction is not only controlled by the hydrate saturation, but also by the distribution of hydrates in the core during formation process. Initially, at low hydrate saturations, random distribution process governs the effective permeability saturation relationship. Once certain hydrate saturation is reached, however, the effective permeability is represented and controlled by series type distribution. 


\subsection{References}

1. Aguirre-Peunte, J., and Gruson, J.: "Measurement of Permeabilities of Frozen Soils," Proceedings of the International Conference on Permafrost, Fairbanks, AK, (July 17-22, 1983), pp. 5-9.

2. Baker, P.E.: "Experiments on Hydrocarbon Gas Hydrates in Unconsolidated Sand," in Natural Gases in Marine Sediments, Ed Kaplan, I.R. Plenum Press, New York, (1974), pp 227-233.

3. Evrenos, A.I., Heathman, J., and Ralstin, J.: "Impermeation of Porous Media by Forming Hydrates In-Situ," J.Pet. Tech., (Sept. 1971), pp 1059-1065.

4. Nadem, M.: "Measurement of Gas Permeability in Hydrate Saturated Unconsolidated Cores," M.S. Thesis, University of Alaska Fairbanks, (Dec. 1988).

5. Nadem, M., Patil, S.L., Mutalik, P.N., Kamath, V.A., and Godbole, S.P.: "Measurement of Gas Permeability in Hydiate Saturated Unconsolidated Cores." a paper presented at the Third Chemical Congress of the North American Continent and Annual ACS Meeting, held in Toronto, Canada, (June 6-10, 1988). 


\section{CHAPTER THREE}

\section{EXPERIMENTAL STUDY OF HYDRATE DISSOCIATION DURING BRINE INJECTION METHOD}

\subsection{Introduction}

In the first chapter, various techniques for production of natural gas from hydrate or hydrate/free gas reservoirs were described. The previous experimental as well as modelling studies on the dissociation of hydrates were also reviewed.

In this chapter, the experimental data on the rate of hydrate dissociation during brine injection method are presented. The objectives of this work were to determine dissociation characteristics of methane hydrates during brine injection technique and to investigate the effect of salinity, brine injection rate and brine temperature on the rate of dissociation of methane hydrates.

In order to study the dissociation characteristics of methane hydrates during brine injection method, brine of known initial salinity and temperature was injected at a constant rate into the core holder containing laboratory made methane hydrate cores. During each dissociation experiment, the temperature of brine and the pressure in the core holder were controlled so that a relatively constant rate of dissociation of hydrates was achieved. Hydrate dissociation rates were determined by measuring methane gas production and monitoring the moving brine-hydrate interface positions with time. A series of such experiments was conducted to study the effect of salinity, brine injection rate and brine temperature on the rate of methane hydrate dissociation. From the experiment results, a correlation was developed for the rate of hydrate dissociation as a function of salinity, brine temperature, brine injection rate, pressure, and hydrate-brine interfacial area. 


\subsection{Experimental Set up For Hydrate Dissociation Studies}

Figure 3.1 shows a schematic diagram of the apparatus used for the formation and dissociation of hydrates under controlled pressure and temperatures. The principal parts of the apparatus consisted of a hydrate core holder, an injection fluid vessel, a methanol bath, a fluid injection pump, a Jerguson gauge, a back pressure regulator and wet test gas flowmeter.

The hydrate core holder was a specially designed stainless steel cell, four inches in diameter and twelve inches in length, with removable flanges at the top and bottom ends and equipped with a cooling jacket for circulation of coolant. A Neslab bench top methanol bath, circulator, equipped with a refrigerant unit and a methanol pump, was used to circulate the coolant at a desired temperature, using a temperature controller. The top flange had one inlet port for fluid injection, one port for the temperature controller probe, and one outlet port for gas and injected fluid. The core holder had three Omega pressure transducer ports for measuring pressure drops across the core during hydrate formation and dissociation. Three temperature ports for thermocouples were also provided along the length of the core holder, to obtain the temperature profiles in the hydrate zone and dissociated zone during the dissociation run. The hydrate core holder, along with all the major piping, were completely insulated with glass wool to reduce heat transfer to the system from the surroundings.

An injection fluid vessel with a capacity of two liters was used for the storage of fluid to be injected and also for separation of gas and water (resulting from the dissociation of hydrates in core holder). The injection fluid vessel was equipped with one injection fluid outlet port at the top, one gas/water inlet port at the top, made up of two concentric tubings. Gas and water entering this vessel flowed through an inner tubing, whereas the separated gas flowed through an annulus to a wet test gas flow meter. The iniection fluid vessel was connected to Jerguson cell which 


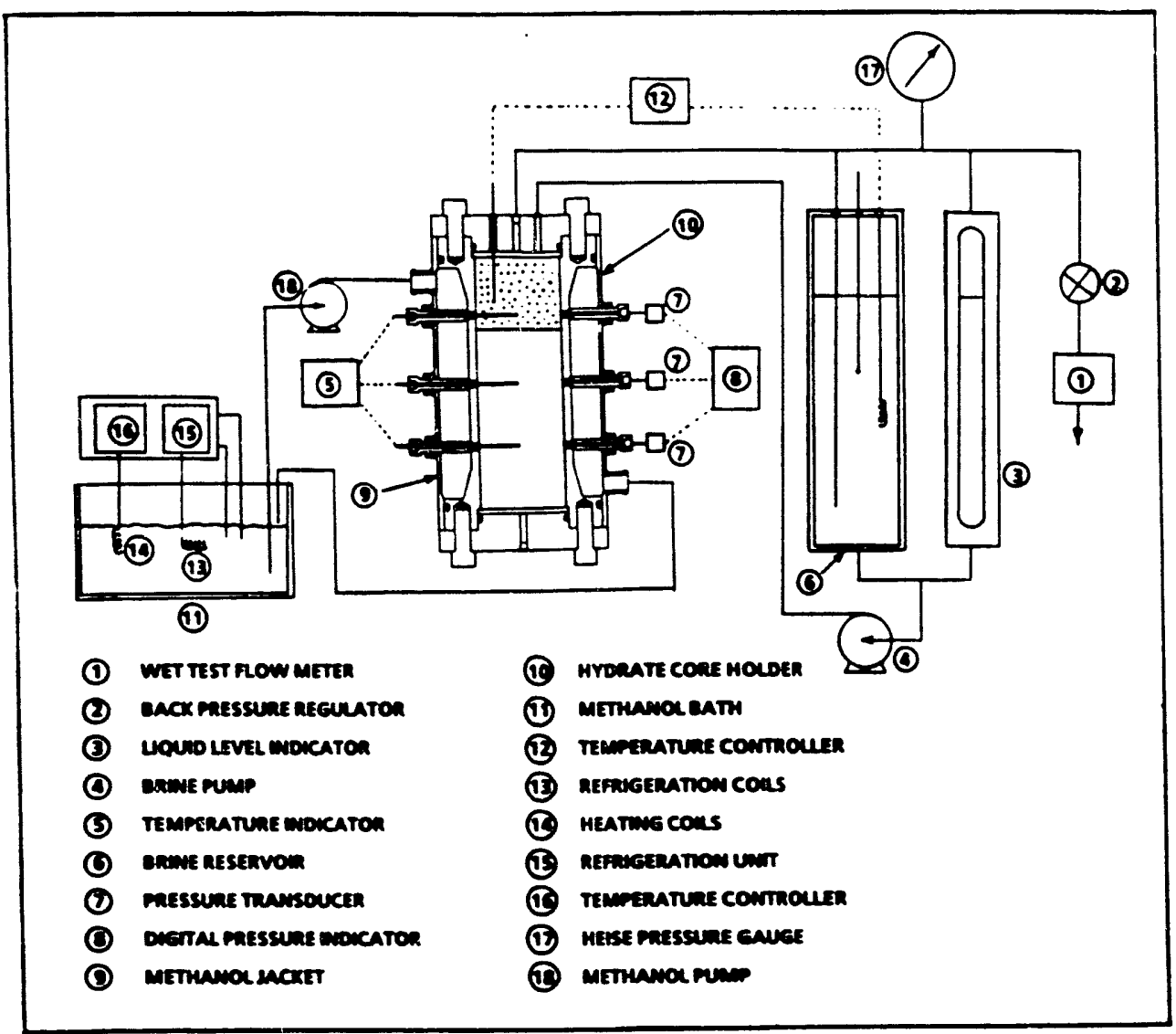

Figure 3.1: Experimental Setup For Hydrate Dissociation Studies 
acted as a liquid-level indicator with one liquid outlet port at the bottom and one gas inlet port at the top. Injection fluid vessel was also equipped with a $1000 \mathrm{~W}$ heater located at the top, which supplied heat to the bulk fluid phase and thus the temperature of the fluid was kept higher than the interfacial temperature of hyarates in the core holder. The injection fluid vessel was also connected to a Heise pressure gauge having a range of 0-2000 psig pressure. A diaphragm-type back pressure regulator, located at the gas outlet line, was used to maintain the system pressure at a constant value (within \pm 0.1 percent of the full range) during the hydrate dissociation run. The injection fluid outlet port of the injection fluid vessel was connected to a liquid circulating pump, which was a metering pump with an adjustable flow rate of $0-1600 \mathrm{cc} / \mathrm{min}$. The bulk fluid temperature was controlled by means of Extrol-150 temperature controller (manufactured by Neslab Co.). The temperature controller sensor was installed in the bulk fluid phase of the hydrate core holder. The wet test flow meter was used to volumetrically measure the amount of gas liberated from the hydrates during a dissociation run.

All platinum resistance thermometers, pressure gauges, wet test flow meter and liquid circulating pump were calibrated before beginning the experiments.

\subsection{Experimental Methods}

In order to prepare synthetic methane hydrate cores to be used for dissociation experiments, a known quantity of frost (finely divided ice crystals, approximately $\mathbf{4 0 0}$ micron size) was charged to core holder which was maintained at $258 \mathrm{~K}$ to prevent any melting of frost. The added frost was compacted in a stepwise manner to a desired void fraction, usually between 0.4 and 0.5 . The height of the core was measured and the core holder was closed. The core temperature was then raised to $0.5^{\circ} \mathrm{C}$ and the core was evacuated. The core holder was then pressurized to about 8.3 $\mathrm{MPa}$ by injecting methane at $274 \mathrm{~K}$ and was left in that condition for about two to 
five days. During this time, the nucleation and formation of hydrates took place, evident from the drop in core holder pressure. Hydrate formation was stopped when the rate of drop in pressure was reduced to below $2 \mathrm{kPa}$ per hour. Throughout the hydrate formation period, the pressure and temperature in the core holder were recorded as a function of time. From this data, the amount of hydrates formed was determined. The amount of methane in hydrate phase was determined from P-T conditions before and after hydrate formation.

Once the hydrates formed in the core of the hydrate core holder, the free gas space above the hydrate core was flooded with cold injection fluid (about $275 \mathrm{~K}$ ) from the injection fluid vessel by a circulating pump. The injection fluid vessel and all other pertinent lines were then evacuated. The injection fluid vessel was filled with additional hot injection fluid of desired salt concentration and heated to predetermined temperature ( 300 to $330 \mathrm{~K}$ ) depending upon the desired bulk temperature of brine $\left(T_{B}\right)$ during a dissociation run. The initial level of fluid in the fluid injection vessel was measured by the liquid level indicator. The hydrate core holder was then connected to the fluid injection vessel, liquid level indicator, and back pressure regulator. By opening the top valve on the hydrate core holder, the pressures in the injection fluid vessel reservoir and the downstream were equalized to core holder pressure. The initial core holder pressures and temperatures were recorded. The back pressure regulator was then set to desired pressure at which the dissociation run was to be connected. The dissociation run was then started by injecting fluid (brine) from the injection fluid vessel into the core holder at a constant preset injection rate. At one- minute intervals, the volume of gas flowing out, the bulk fluid temperature inside the core holder, the temperature of hydrates, the pressure and height of fluid in the injection fluid vessel were measured.

Injection fluid contacted the hydrates at the top surface of the core. During the entire dissociation run, the pressure in the core holder, temperature of the bulk 
fluid phase, and fluid injection rate were controlled to a constant value. Hydrates dissociated only at the flat hydrate-brine interface which moved vertically downward. Since hydrates dissociated at thermodynamically equilibrium conditions during a run, the interfacial temperature of hydrates was assumed to be that which corresponded to system pressure and salinity.

During dissociation run, the space above hydrate zone was completely filled with injection fluid and the gas bubbles that departed from the hydrate-water interface. The separation of these gas bubbles from the liquid took place in the injection fluid vessel. The brine was recirculated and gas was produced through the back pressure regulator and wet test gas flow meter. By monitoring the liquid level in the injection fluid vessel, the position of dissociating hydrate front was tracked. Hydrate dissociation run was stopped when the gas production rate started declining continuously. The initial and final concentration of $\mathrm{NaCl}$ in the brine solution were measured by Beckman thermal conductivity bridge.

The experimental dissociation data for all the brine injection runs were analyzed by our computer program specifically developed for this purpose.

The computer program used the following data from the experimental runs.

a. Hydrate Formation Period Data

- Core length

- Core porosity

- Hydrate formation period

- Initial amount of frost used to form core

- Initial pressure and temperature of the core prior to hydrate formation

- Pressure and temperature of the hydrate core as a function of time during hydrate formation period

b. Hydrate Dissociation Period Data 
- Brine injection rate

- Initial salinity of brine

- Initial temperature of brine

- Initial pressure and temperature of the core prior to hydrate dissociation

- Temperature of bulk brine phase and hydrates, pressure in the core holder, cumulative gas produced and hydrate-brine moving front position as a function of time for every minute interval during hydrate dissociation period.

Based on the hydrate formation data, the program computes the rate of hydrate formation and amount of hydrates formed (vol\%) during the hydrate formation period.

Based on the dissociation data, the program computes the rate of hydrate dissociation, the salinity of brine, and the true and apparent temperature driving force as a function of time.

For further refined analysis, the results of each computer run were further evaluated to identify the steady state dissociation period during which the brine (bulk) phase temperature, the gas production rate, and the core holder pressure remain relatively constant within $\pm 10 \%$. The average value of dissociation rate is obtained for the steady state period.

\subsection{Discussion of Results}

A total of 22 experimental dissociation experiments were conducted to determine a) the effect of brine injection rate $(330$ to $1640 \mathrm{cc} / \mathrm{sec}), \mathrm{b})$ effect of salinity $(0$ to $15 \%)$, c) brine injection temperature $\left(10.9\right.$ to $22.3^{\circ} \mathrm{C}$ ) on the rate of dissociation of hydrates. 
Table 3.1 provides the properties of the methane hydrate cores used for hydrate dissociation by brine injection. Figure 3.2 shows the equilibrium pressuretemperature diagram for methane hydrates in presence of salt solutions. The experimental data in this figure were taken from Deaton and Frost (1946) and de Roo et al. (1983).

The driving force for the dissociation of hydrates is the difference between the temperature of bulk brine phase, $\left(T_{B}\right)$ and the temperature of dissociating hydrates at the interface, $\left(T_{1}\right)$. For $0 \%$ salinity, the temperature of dissociating hydrates, $\left(T_{1}{ }^{\circ}\right)$ is obtained from the equilibrium P-T relationship for methane hydrates and is given by:

$$
T_{I}^{0}=\frac{8533.8}{38.98-\ln (P)}-273.15 \text { for } T_{I}^{0} \geq 0
$$

or

$$
=\frac{1886.8}{14.717-\ln (P)}-273.15 \text { for } T^{\prime \prime \prime}<0
$$

where $P$ is the core holder pressure in $\mathrm{kPa}$ and $T_{1}^{\circ}$ is in ${ }^{\circ} \mathrm{C}$. The temperature driving force, $\left(\Delta T^{\circ}\right)$ without considering the effect of salinity is then obtained from:

$$
\Delta T^{0}=T_{B}-T_{l}^{0}
$$

Brine, however, acts as a hydrate inhibitor and reduces the equilibrium hydrate dissociation temperature depending upon it's salinity. The true temperature driving force, $(\Delta T)$ is obtained by:

$$
\Delta T=\Delta T^{0}+\Delta T_{x}
$$


TABLE 3.1

PROPERTIES OF METHANE HYDRATE CORES USED IN THE STUDY OF HYDRATE DISSOCIATION BY BRINE INJECTION METHOD

\begin{tabular}{|c|c|c|c|c|c|c|}
\hline$\underset{\#}{\operatorname{RUN}}$ & $\begin{array}{l}\text { CORE } \\
\text { LENGTH } \\
(\mathrm{cm})\end{array}$ & $\begin{array}{c}\text { AMOUNT OF } \\
\mathrm{H}_{2} \mathrm{O} \text { IN THE } \\
\text { CORE } \\
(\mathrm{g})\end{array}$ & $\begin{array}{c}\text { INITIAL } \\
\text { CORE } \\
\text { POROSITY } \\
(\%)\end{array}$ & $\begin{array}{l}\text { HYDRATE } \\
\text { FORMATION } \\
\text { PERIOD } \\
\text { (Hours) }\end{array}$ & $\begin{array}{c}\% \\
\text { CONVERSION } \\
\text { OF H } \mathrm{H}_{2} \text { OTO } \\
\text { HYDRATES }\end{array}$ & $\begin{array}{l}\text { VOL. \% } \\
\text { HYDRATES } \\
\text { IN THE CORE }\end{array}$ \\
\hline $1 \mathrm{~A}$ & 15.2 & 632 & 44.1 & 48 & 64.0 & 42 \\
\hline $1 \mathrm{~B}$ & 15.2 & 632 & 44.1 & 48 & 64.0 & 42 \\
\hline 2 & 17.4 & 613 & 52.6 & 57 & 66.8 & 37 \\
\hline 3 & 16.9 & 600 & 52.3 & 77 & 64.8 & 37 \\
\hline $4 A$ & 17.1 & 616 & 51.6 & 77 & 78.6 & 45 \\
\hline $4 B$ & 17.1 & 616 & 51.6 & 77 & 78.6 & 45 \\
\hline 5 & 16.5 & 605 & 50.7 & 54 & 82.9 & 48 \\
\hline 6 & 17.0 & 619 & 51.0 & 75 & 75.6 & 44 \\
\hline 7 & 17.1 & 615 & 51.6 & 48 & 31.0 & 18 \\
\hline 8 & 16.9 & 623 & 50.4 & 80 & 38.3 & 23 \\
\hline 9A & 17.5 & 623 & 52.1 & 61 & 42.0 & 24 \\
\hline $9 B$ & 17.5 & 623 & 52.1 & 61 & 42.0 & 24 \\
\hline 10 & 19.1 & 579 & 59.2 & 56 & 20.8 & 11 \\
\hline 11 & 19.2 & 550 & 61.5 & 63 & 42.4 & 20 \\
\hline 12 & 19.2 & 619 & 56.6 & 39 & 32.8 & 17 \\
\hline 13 & 19.4 & 608 & 57.9 & 67 & 50.1 & 25 \\
\hline 14 & 19.4 & 639 & 55.7 & 43 & 28.8 & 15 \\
\hline 15 & 19.4 & 608 & 57.9 & 48 & 50.0 & 25 \\
\hline 16 & 19.1 & 584 & 58.9 & 62 & 37.3 & 18 \\
\hline 17 & 19.4 & 613 & 57.5 & 42 & 42.7 & 22 \\
\hline 18 & 19.0 & 632 & 55.3 & 43 & 42.7 & 23 \\
\hline 19 & 19.5 & 607 & 58.1 & 47 & 42.2 & 21 \\
\hline 20 & 19.2 & 580 & 59.4 & 48 & 64.0 & 31 \\
\hline 21 & 18.4 & 839 & 38.8 & 102 & 101.3 & 73 \\
\hline 22 & 17.7 & 877 & 33.5 & 69 & 71.7 & 56 \\
\hline
\end{tabular}




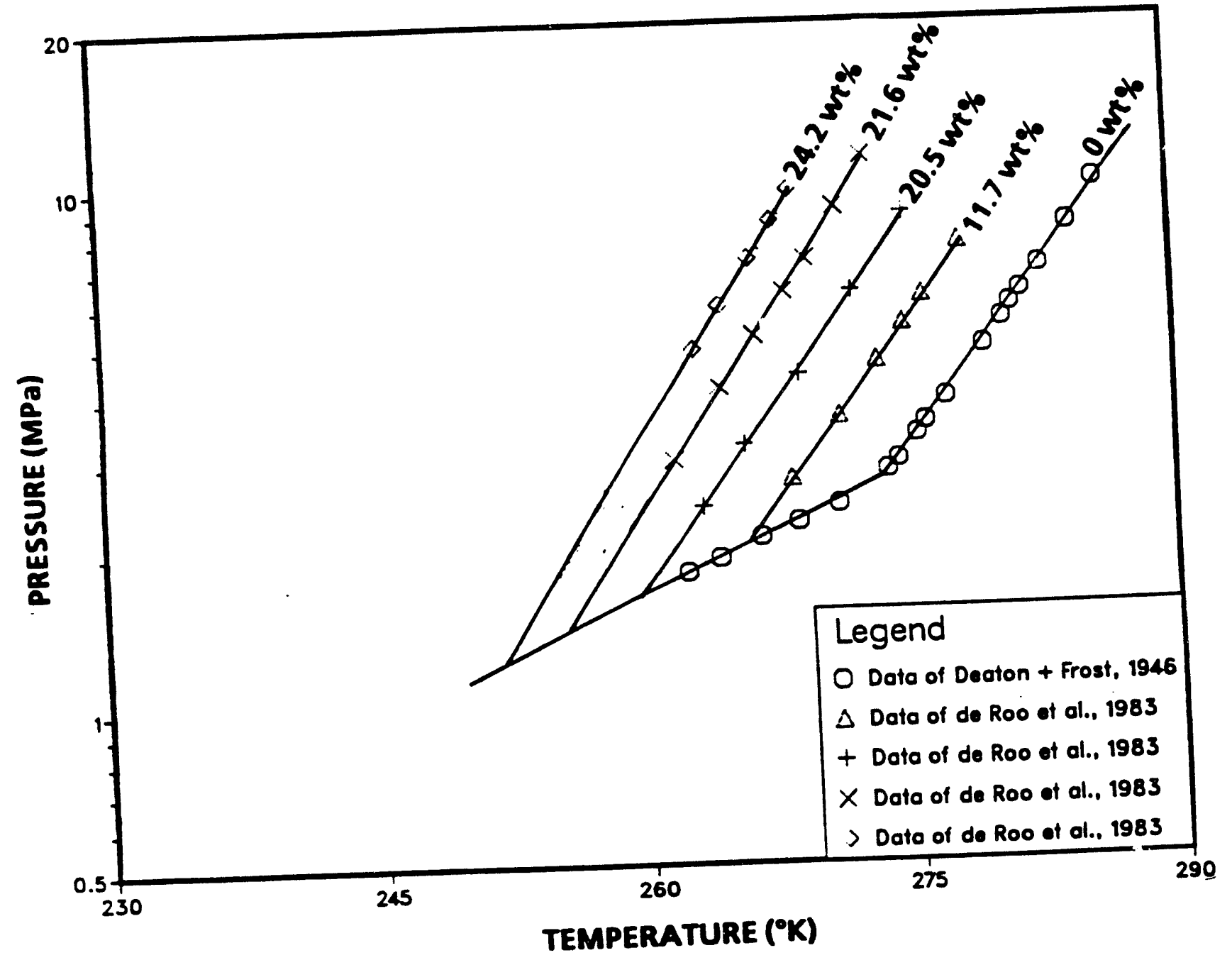

Figure 3.2: Equilibrium Pressure-Temperature Diagram For Methane Hydrate in Presence of Salt ( $\mathrm{NaCl}$ ) Solutions 
where,

$$
\Delta T_{x}=0.81+0.42 x+0.0202 x^{2}
$$

where $\Delta T_{x}$ is reduction in hydrate dissociation temperature due to salinity effect in ${ }^{\circ} \mathrm{C}$ and $x$ is wt\% $\mathrm{NaCl}$, in brine solution.

The raw data collected during a dissociation run was used to calculate the volume of hydrates remaining in the core holder, the salinity of brine, the volume of free gas phase, the true hydrate dissociation rate, and the location of hydrate-brine interface as a function of time. Note that the measured gas production rate was corrected to account for change in volume due to hydrate dissociation in order to ohtain true hydrate dissociation rate.

Figure 3.3 shows a plot of rate of methane production due to hydrate dissociation versus time for a typical hydrate dissociation run (Run \#6). Such behavior was observed for all the runs. There are three distinct dissociation periods in this plot. The first period is the initial period during which hydrate dissociation starts and the rate of dissociation increases until the thermal equilibrium is attained. The second period is the steady dissociation period during which the temperature driving force is constant and the dissociation rate fluctuates around a steady value. The third period is the decline period during which hydrate dissociation rate decreases continuously despite the fact that the temperature driving force is constant. The fluctuations in hydrate dissociation rate during steady dissociation period are attributed to three factors. First, the back pressure regulator causes fluctuations in gas production. Second, the time lag associated with control brine phase temperature may induce such fluctuations. Third, nonuniformity of hydrate distribution throughout the core may cause such fluctuations. Figure 3.4 shows that the temperature díriving fö́ce during steady dissociation period was he!d constant by controlling the brine temperature.. Figure 3.5 shows the decrease in salinity of 


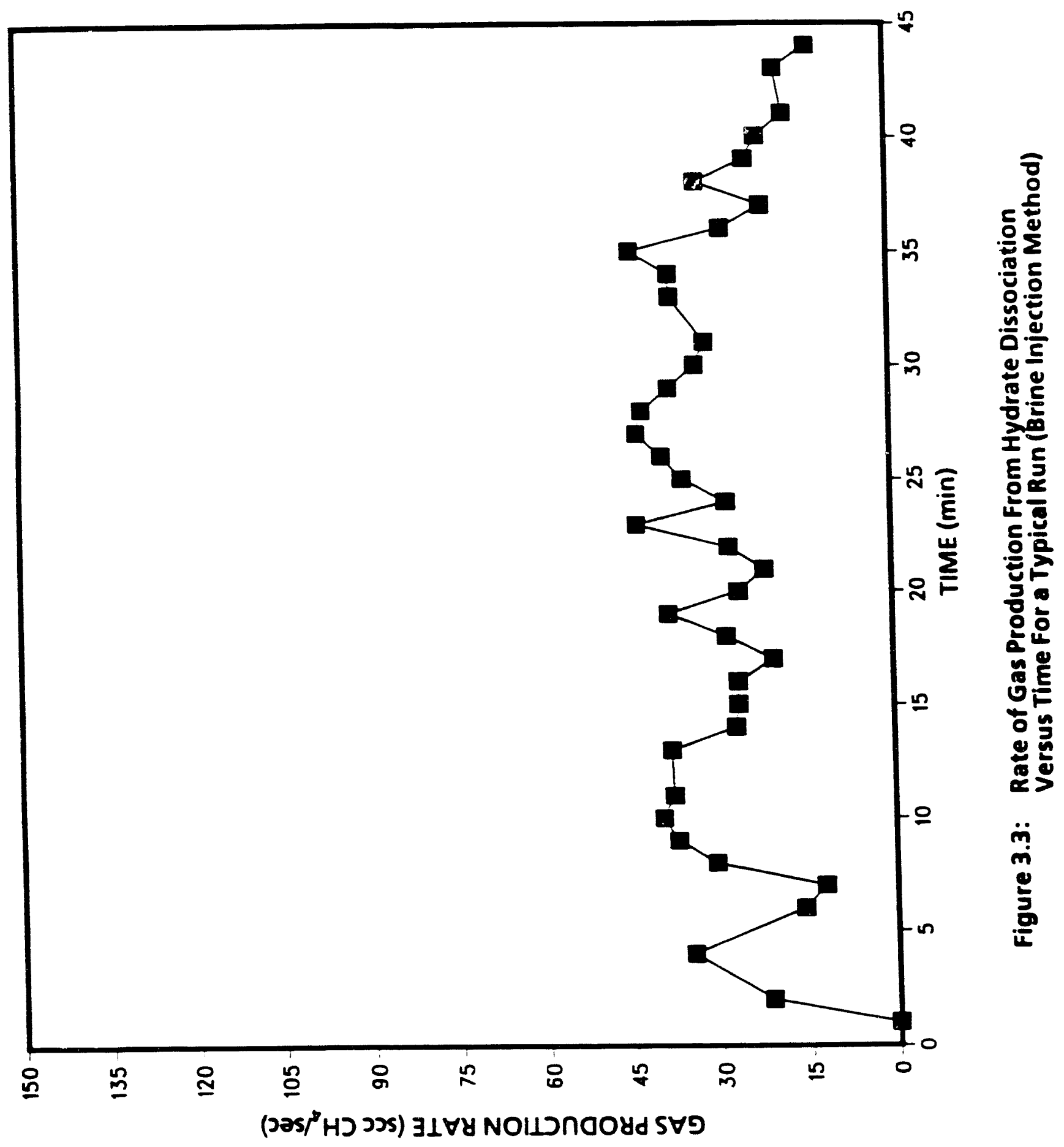




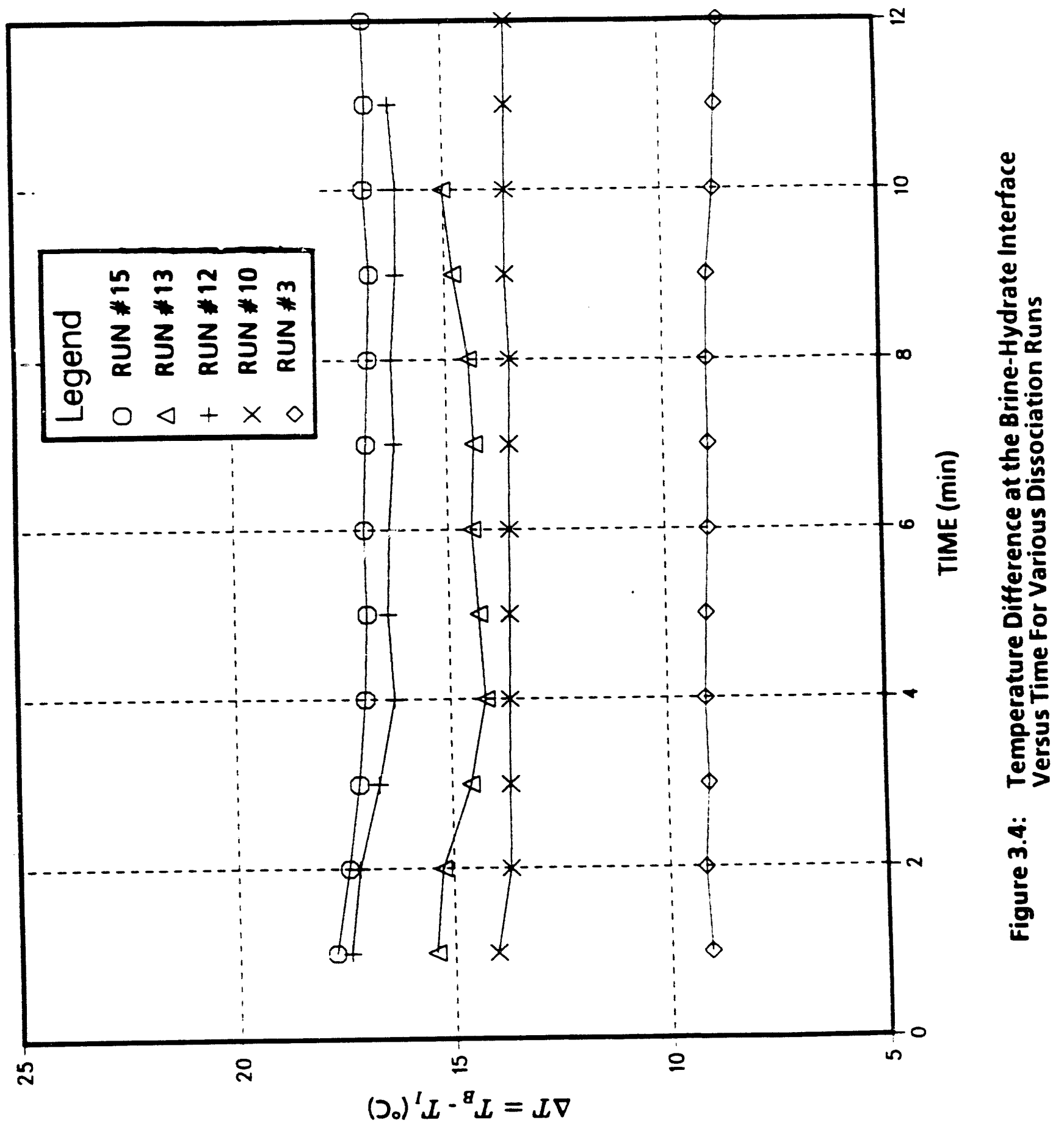




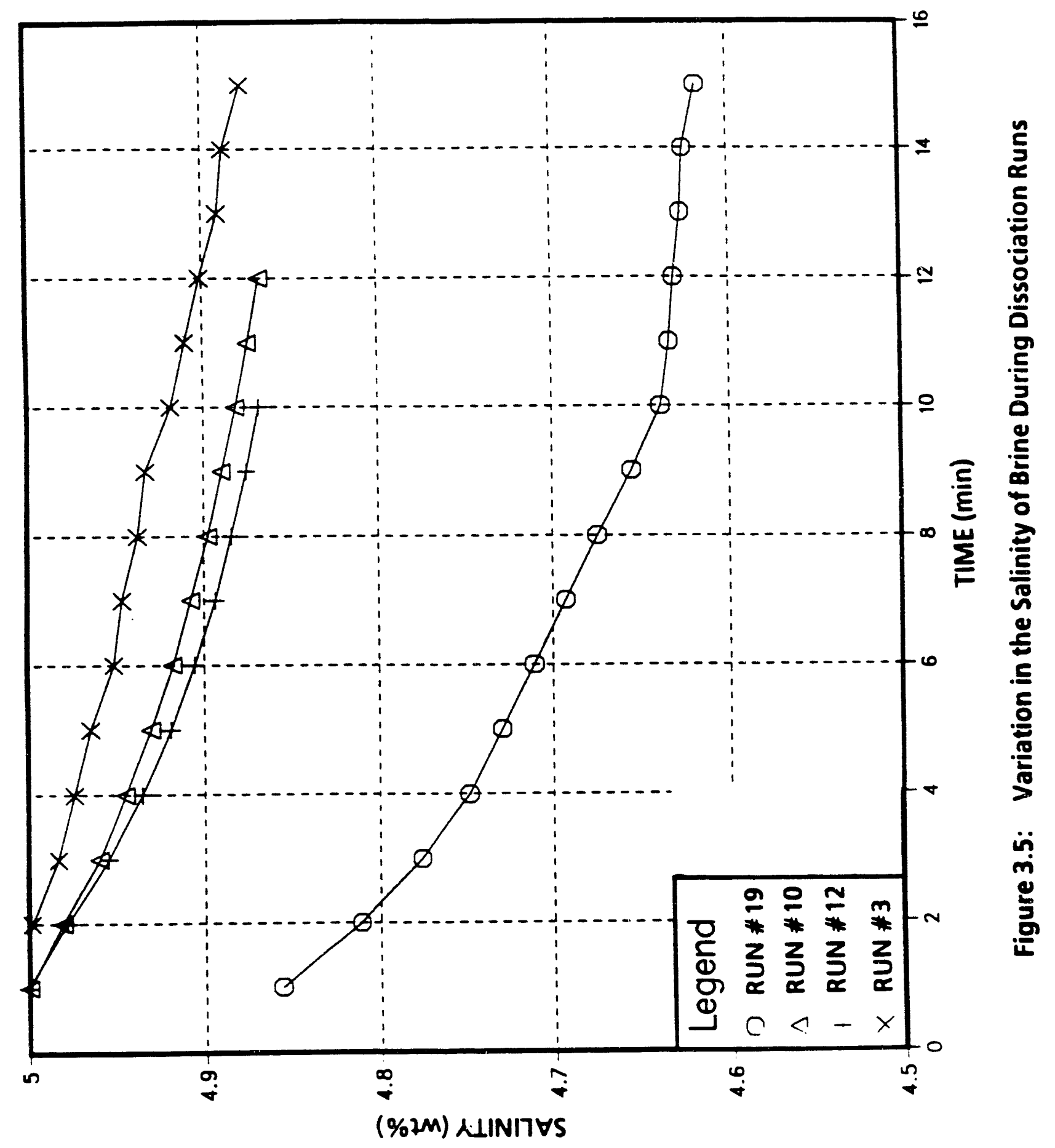


brine phase due to water generated from hydrate dissociation. Since it was not possible to measure instantaneous values of salinity during dissociation run, these values were computed based on the amount of hydrates dissociated.

Several dissociation experiments were conducted to study the effect of salinity, brine injection rate, and the brine temperature on the rate of hydrate dissociation. Table 3.2 provides a summary of results of all the hydrate dissociation experiments. The values of brine temperature $\left(T_{B}\right)$, pressure $(P)$, true temperature driving force $(\Delta T)$, temperature driving force without salinity effect $\left(\Delta T^{\circ}\right)$, gas production rate $\left(Q_{g}\right)$, hydrate dissociation rate $\left(Q_{g} / \Phi_{n} A\right)$, and the hydrate dissociation front velocity $\left(U_{f}\right)$ listed in Table 3.2 are the average values computed for the steady dissociation period. $\Phi_{H}$ represents the volume (or area) fraction of hydrates in the core and $A$ represents the cross-sectional area of the core.

The rate of gas production from hydrate dissociation during brine injection method is function of temperature of brine phase, pressure, salinity, brine injection rate, and the area occupied by hydrates at the brine- hydrate interface. The effect of pressure, temperature of brine phase, and salinity are accounted by defining temperature driving force $(\Delta T)$. The effect of brine-hydrate interfacial area is accounted by defining hydrate dissociation rate as $Q_{g} / \Phi_{H} A$ (gmol methane produced per $\mathrm{cm}^{2}$ hydrates at interface per sec.). In other words, the rate of gas production from hydrate dissociation is directly proportional to the saturation of hydrates inside the core.

Figure 3.6 shows that for given salinity (in this case $5 \%$ ), the cumulative gas produced increases as the temperature driving force $(\Delta T)$ increases.

To illustrate the strong effect of salinity on hydrate dissociation rate, the hydrate dissociation rate is plotted versus $\Delta T^{\circ}$ on $\log -\log$ scale (see figures 3.7 and 3.8). A unified correlation for hydrate dissociation rate is developed by plotting the data for all dissociation runs versus the true temperature driving force, $\Delta T$ (see 


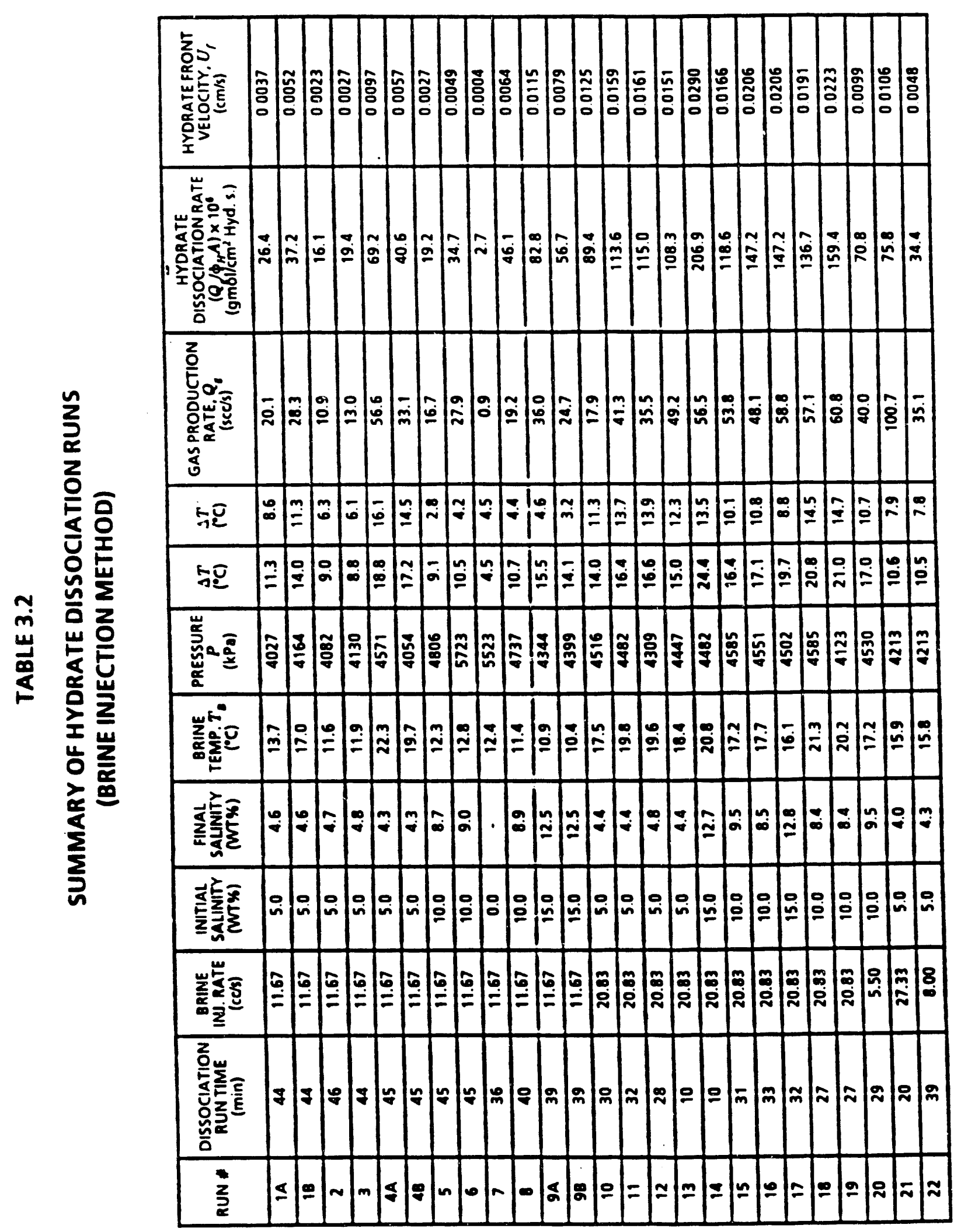




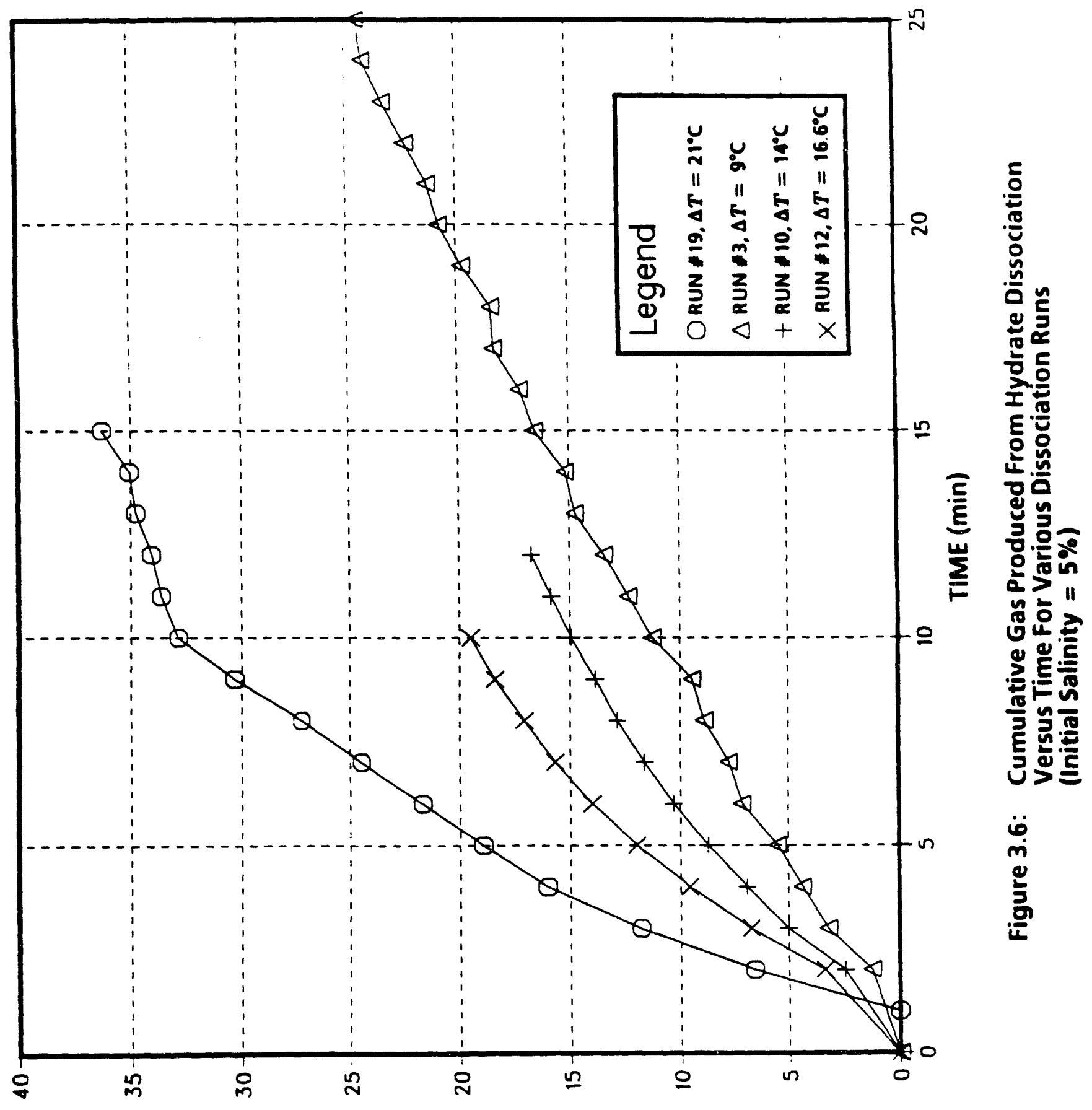

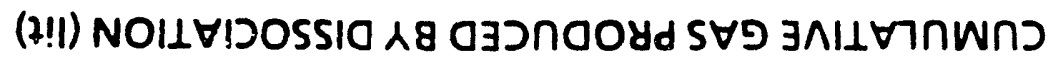




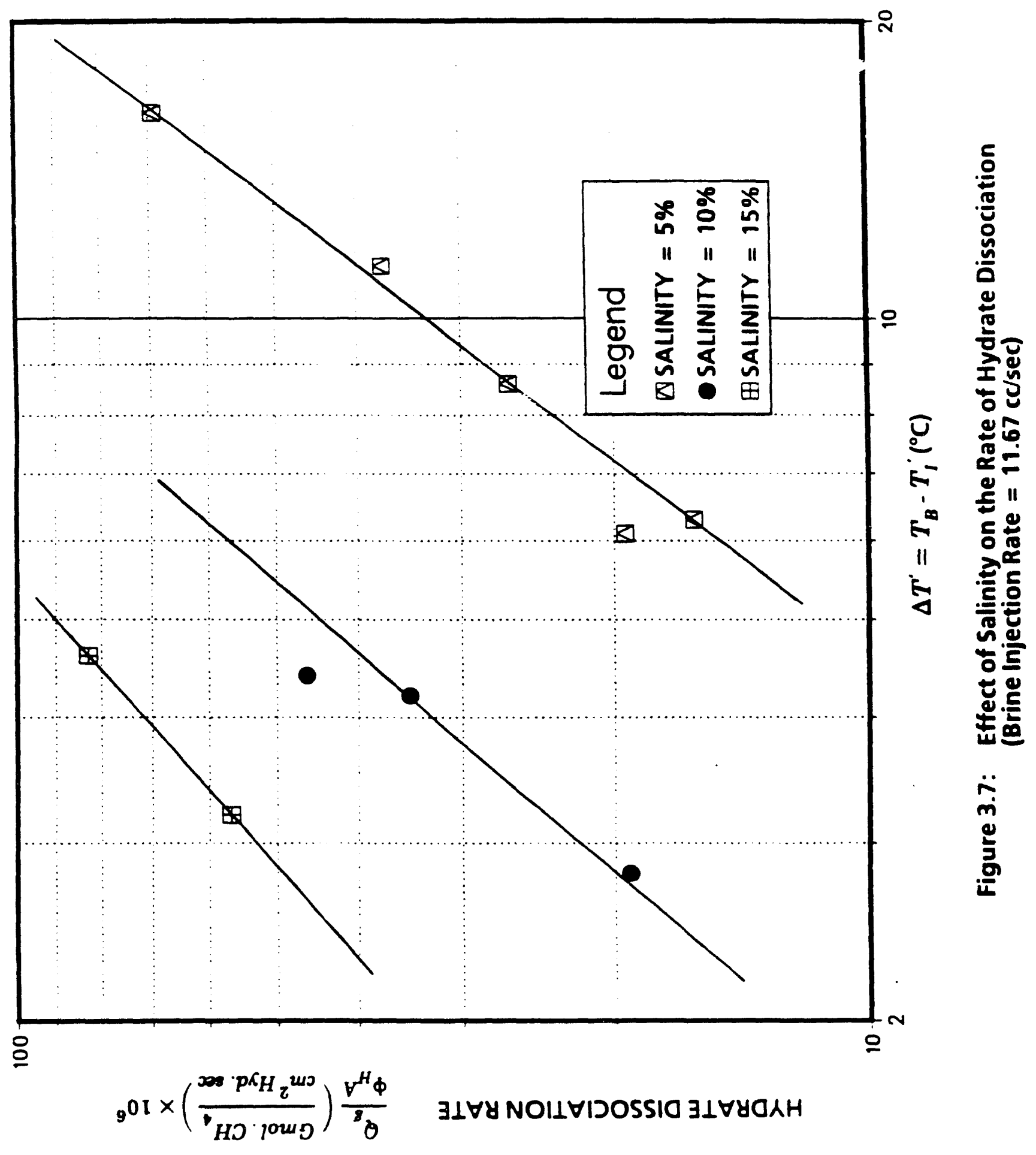




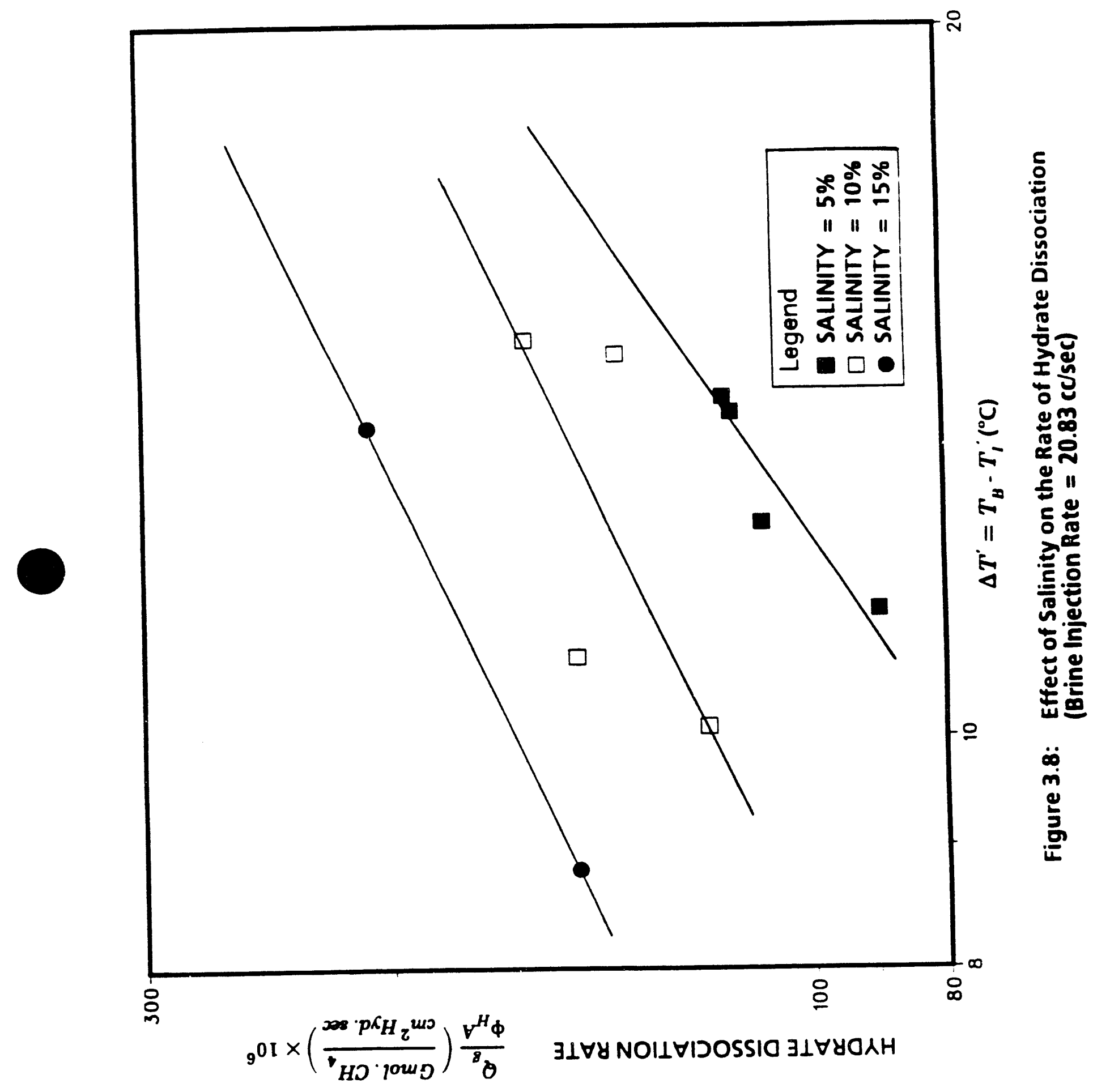


Figure 3.9). This correlation is similar to one developed by Kamath and Holder (1987) for methane hydrate dissociation under hot water injection method. The solid lines in Figure 3.9 represent fitted correlation. For brine injection rate of $11.67 \mathrm{cc} / \mathrm{sec}$, the following correlation is developed.

$$
Q_{g}=1.3553 \times 10^{-7} \Phi_{H} A\left(T_{B}-T_{l}^{0}+\Delta T_{x}\right)^{2.16}
$$

Where $Q_{g}$ is methane production rate in (gmol/sec $\mathrm{cm}^{2}$ hydrates).

The average absolute percentage error of this correlation is 20 percent. When this correlation was applied to experimental results on methane hydrate dissociation rate under hot water injection method (Kamath and Holder, 1987), the average absolute error between experimental values and predicted values was $13 \%$. For a higher brine injection rate $(20.83 \mathrm{cc} / \mathrm{sec})$, however, a separate correlation was developed as given below:

$$
Q_{g}=3.233 \times 10^{-6} \Phi_{H} A\left(T_{B}-T_{l}^{0}+\Delta T_{x}\right)^{1.28}
$$

The average absolute percentage error between the experimental values and correlated values was $\mathbf{5 . 8}$ percent. Note that at higher brine injection rate, the slope of log-log plot of $\left(Q_{g} / \Phi_{H} A\right)$ versus $(\Delta T)$ is much lower than that for lower brine injection rate. This agrees well with experimental results obtained by Kamath et al. (1984). This is due to the fact that at higher $\Delta T$ values, the forced convection effect is less dominant compared to the natural convection due to temperature difference. Figure 3.10 shows the effect of brine injection rate on the hydrate dissociation rate at constant $\Delta T$ values. The lower curve (solid squares) represent $\Delta T$ value of $10.5^{\circ} \mathrm{C}$ and the upper curve represents $\Delta T$ value of $17^{\circ} \mathrm{C}$. In general, the increase in brine 


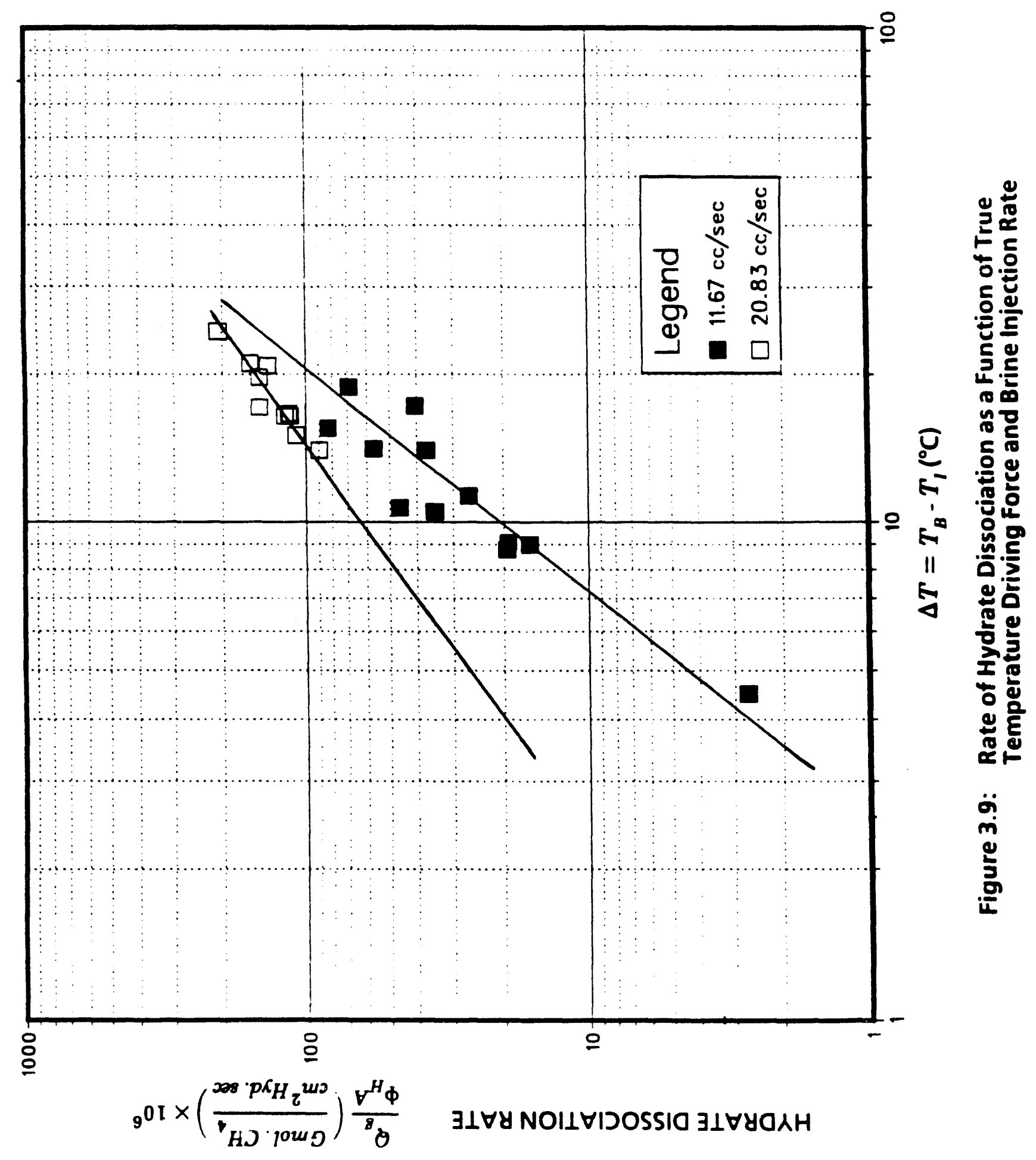




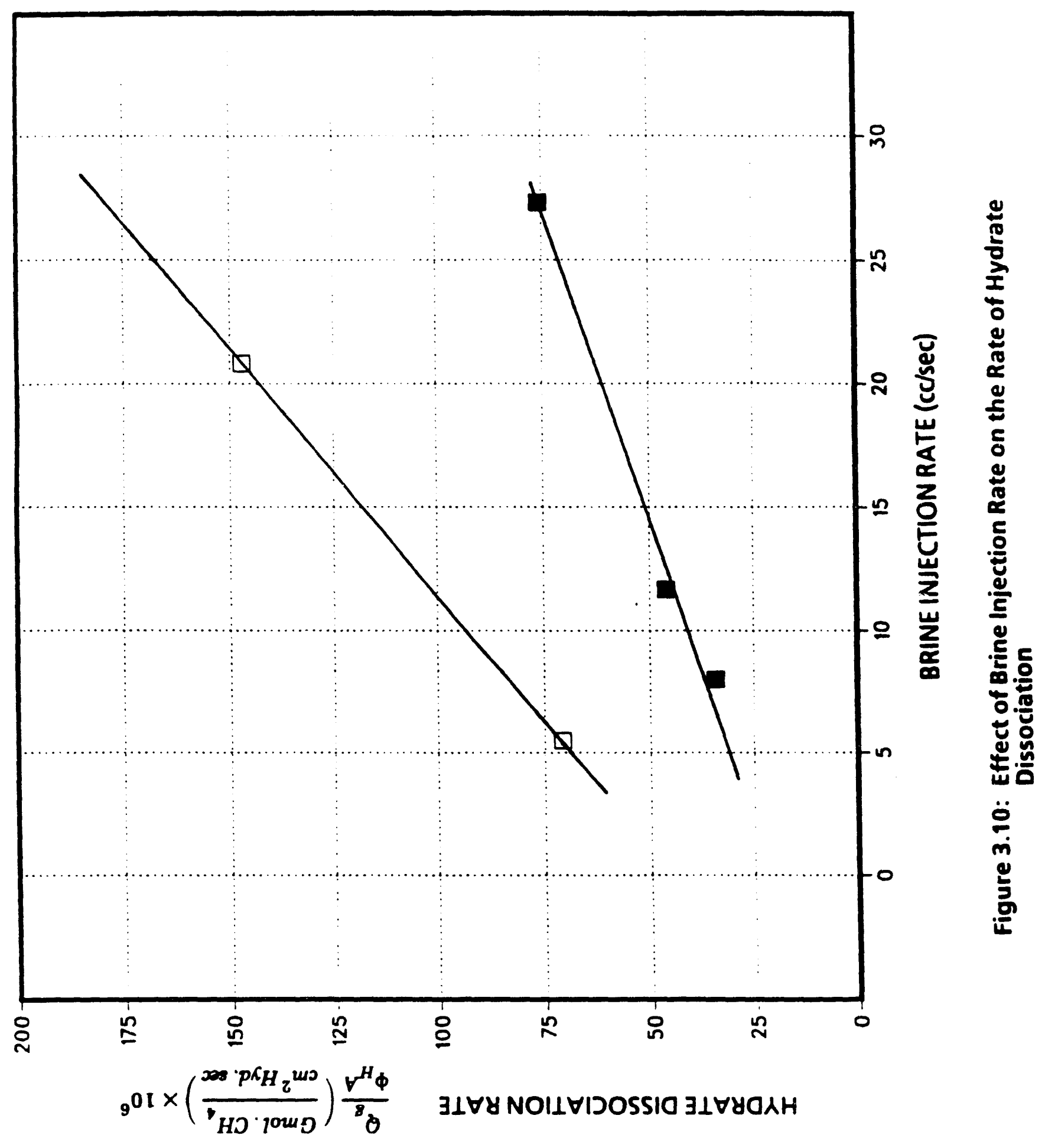


injection rate causes an increase in dissociation rate due to forced convection effect, but the effect is not as strong as the effect of salinity or temperature driving force.

\subsection{Conclusions}

From the experimental study of methane hydrate dissociation by brine injection method, the following conclusions are drawn:

1. The rate of gas production from hydrate dissociation is a function of brine temperature, salinity, pressure, brine injection rate and hydrate-brine interfacial area.

2. The effect of forced convection (or brine injection rate) on the dissociation rate becomes less important at higher brine temperatures and salinities. Forced convection effects become significant at lower temperature driving force for hydrate dissociation.

3. Since salinity of brine has a strong influence on the rate of hydrate dissociation (increase in salinity from 5 to $10 \%$ increases the rate of hydrate dissociation by a factor of about four), use of brine would be an excellent way of enhancing the production of natural gas from hydrate reservoirs.

4. Based on the experimental results, a consistent correlation for the rate of methane hydrate dissociation was obtained. This correlation, when extrapolated to $0 \%$ salinity, agrees with the experimental data on methane hydrate dissociation under hot water injection method.

\subsection{Nomenclature}

A Cross-sectional area of the core, $\left(\mathrm{cm}^{2}\right)$

$P \quad$ Core pressure, $(\mathrm{kPa})$

$Q_{g} \quad$ Gas production rate due to hydrate dissociation, (gmol/s) 
$T_{B} \quad$ Brine bulk phase temperature, $\left({ }^{\circ} \mathrm{C}\right)$

$T_{1} \quad$ Hydrate interfacial temperature, $\left({ }^{\circ} \mathrm{C}\right)$

$T_{l}{ }^{0} \quad$ Hydrate interfacial temperature without salinity effect, $\left({ }^{\circ} \mathrm{C}\right)$

$U$, Hydrate dissociation front velocity, $(\mathrm{cm} / \mathrm{s})$

$x \quad$ Brine salinity, $(w t \% \mathrm{NaCl})$

$\Phi_{H} \quad$ Volume (or area) fraction of hydrates at the interface

$\Delta T \quad$ True temperature driving force, $\left({ }^{\circ} \mathrm{C}\right)$

$\Delta T^{\mathrm{v}} \quad$ Temperature driving force without salinity effect, $\left({ }^{\circ} \mathrm{C}\right)$

$\Delta T_{x} \quad$ Reduction in hydrate interfacial temperature by brine, $\left({ }^{\circ} \mathrm{C}\right)$

\subsection{References}

1. Deaton, W.M and Frost, E.M., Jr.: U.S. Bureau of Mines Monograph 8, (1946).

2. deRoo, J.L., Peters, C.J., Lichtenthaler, R.N., and Diepen, G.A.M.: Am. Inst. Chem. Enq. Journal, Vol 29, (1983), p. 551.

3. Kamath, V.A. and Holder, G.D. "Dissociation Heat Transfer Characteristics of Methane Hydrates," Am. Inst. Chem. Eng. Journal, Vol. 33, No. 2, p. 347, (1987).

4. Kamath, V.A., Holder, G.D., and Angert, P.F.: "Three Phase Interfacial Heat Transfer During the Dissociation of Propane Hydrates," Chem. Eng. Sci., Vol. 39, No. 10, (1984), pp 1435-1442.

5. Kamath, V.A., and Godbole, S.P.: "Evaluation of Hot Brine Stimulation Technique For Gas Production From Natural Gas Hydrates," J. Pet. Tech., (Nov. 1987), pp 1379-88.

6. Kamath, V.A., Mutalik, P.N., Sira, J.H., and Patil, S.L.: "Experimental Study of Brine Injection and Depressurization Methods for Dissociation of Gas Hydrates," SPE 19810, Proceedings of the 64th Annual Technical Conference and Exhibition of SPE, held in San Antonio, TX, (Oct. 8-11, 1989). 
7. Mutalik, P.N.: "Experimental Study of Brine Injectior, and Depressurization Methods for Dissociation of Gas Hydrates," M.S. Thesis, University of Alaska Fairbanks, Alaska (Jan. 1989). 


\section{CHAPTEK FOUR}

\section{EXPERIMENTAL STUDY OF HYDRATE DISSOCIATION DURING HOT WATER INJECTION METHOD}

\subsection{Introduction}

The first experimental study of heat and mass transfer phenomena associated with dissociation of gas hydrates was reported by Kamath ei al. (1984). They reported experimental data on dissociation characteristics of propane hydrates during hot water injection method. They considered the heat transfer to dissociating hydrates as analogous to the nucleate boiling phenomena and presented a correlation for rate of heat transfer and rate of dissociation of propane hydrates. Kamath and Holder (1987) later extended this work to study dissociation of methane hydrates by hot water injection. They obtained the following correlation for the rate of methana hydrate dissociation:

$$
\left(\frac{Q_{g}}{\Phi_{H} A}\right)=1.4508 \times 10^{-7}\left(T_{B}-T_{l}\right)^{216}
$$

where $Q_{g}$ is methane production rate in ( $\left.\mathrm{gmol} \mathrm{CH}_{4} / \mathrm{sec}\right), \Phi_{H}$ is the volume fraction hydrates at the hydrate-water interface, $A$ is the cross-sectional area of the hydrate core $\left(\mathrm{cm}^{2}\right), T_{B}$ is bulk temperature of water phase contacting hydrates $(K)$ and $T_{l}$ is the equilibrium methane hydrate dissociation temperature $(K)$ corresponding to system pressure given by

$$
T_{I}=\left|\frac{8533.8}{38.98-\ln (P)}\right|
$$

where $P$ is pressure in $\mathrm{kPa}$.

In this work, the dissociation characteristics of methane hydrates during hot water injection method were studied for two reasons. First, the goal was to quantify 
the effect of pressure on the rate of dissociation of methane hydrates. Second, to verify and compare the experimental results of this work with previous results on methane hydrate dissociation during brine and hot water injection methods.

\subsection{Experimental Methods}

The experimental set-up and techniques used for hydrate formation and dissociation experiments here were the same as those described for the brine injection method in Chapter 3, except that hot distilled water was used as an injection fluid rather than brine solution.

\subsection{Experimental Results}

A total of eight dissociation experiments were conducted. Table 4.1 gives the properties of methane hydrate cores used for dissociation experiments. In runs one through five, the water injection rate was held constant at $27.17\left(\mathrm{~cm}^{3} / \mathrm{sec}\right)$ and the pressure was varied from 2452 to $6466(\mathrm{kPa})$. In runs six through eight, the water injection rate was varied from 6.83 to $20.5\left(\mathrm{~cm}^{3} / \mathrm{sec}\right)$. Table 4.2 provides the summary of results of all the methane hydrate dissociation experiments during hot water injection.

Figure 4.1 gives a typical profile of the rate of hydrate dissociation as a function of time over the entire dissociation run (Run \#2). This behavior was observed for all the runs. As can be observed from this plot, there are three distinct periods as in the brine injection method. Initially, the rate of hydrate dissociation is very high because of premature melting of hydrates caused by the introduction of cold water on top of hydrates prior to dissociation run. This is followed by steady state dissociation during which the hydrate dissociation rate is constant, and finally the hydrate dissociation rate decreases as most of the hydrates are dissociated. The fluctuations in hydrate dissociation rate during steady state period can be attributed to the 


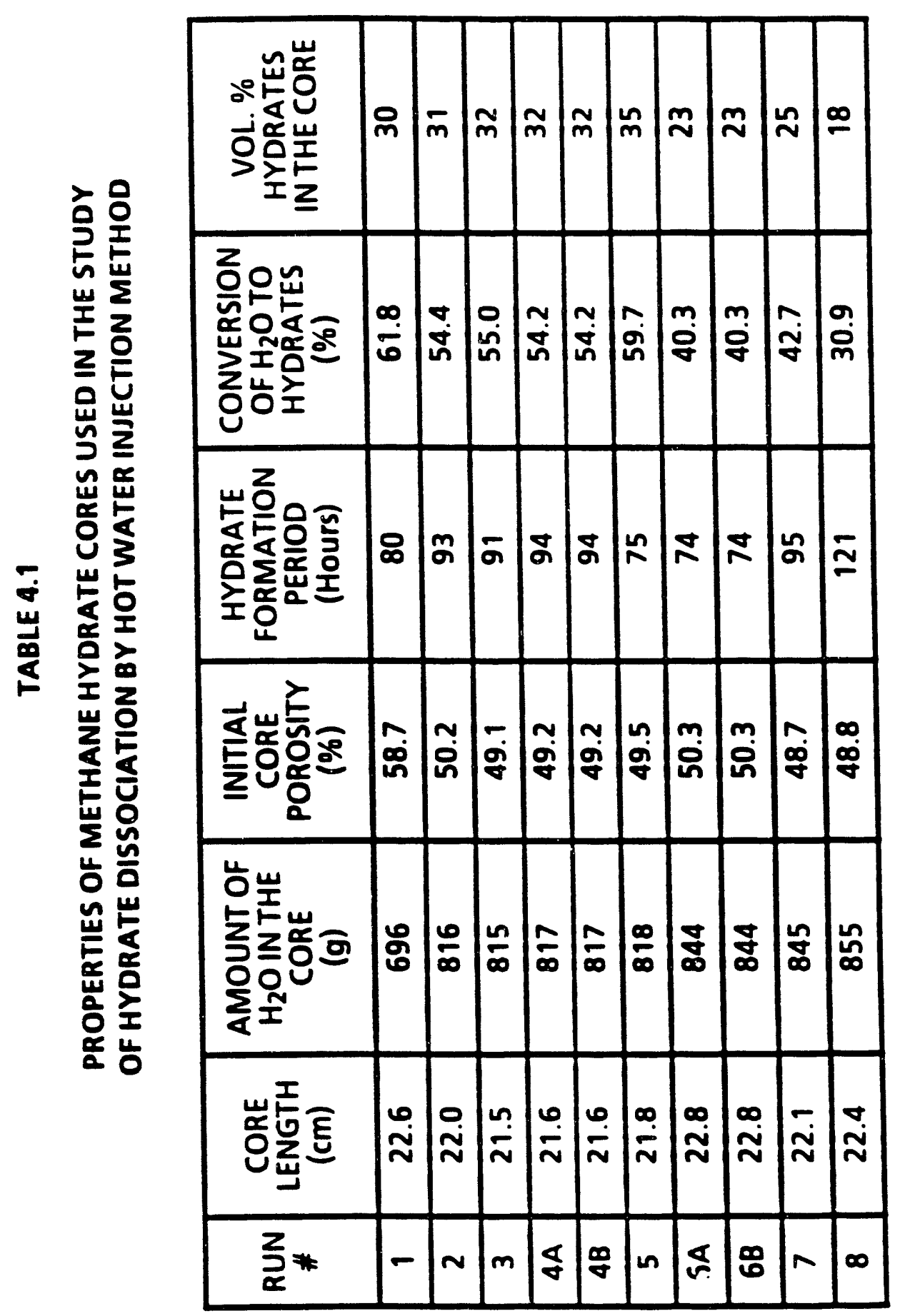




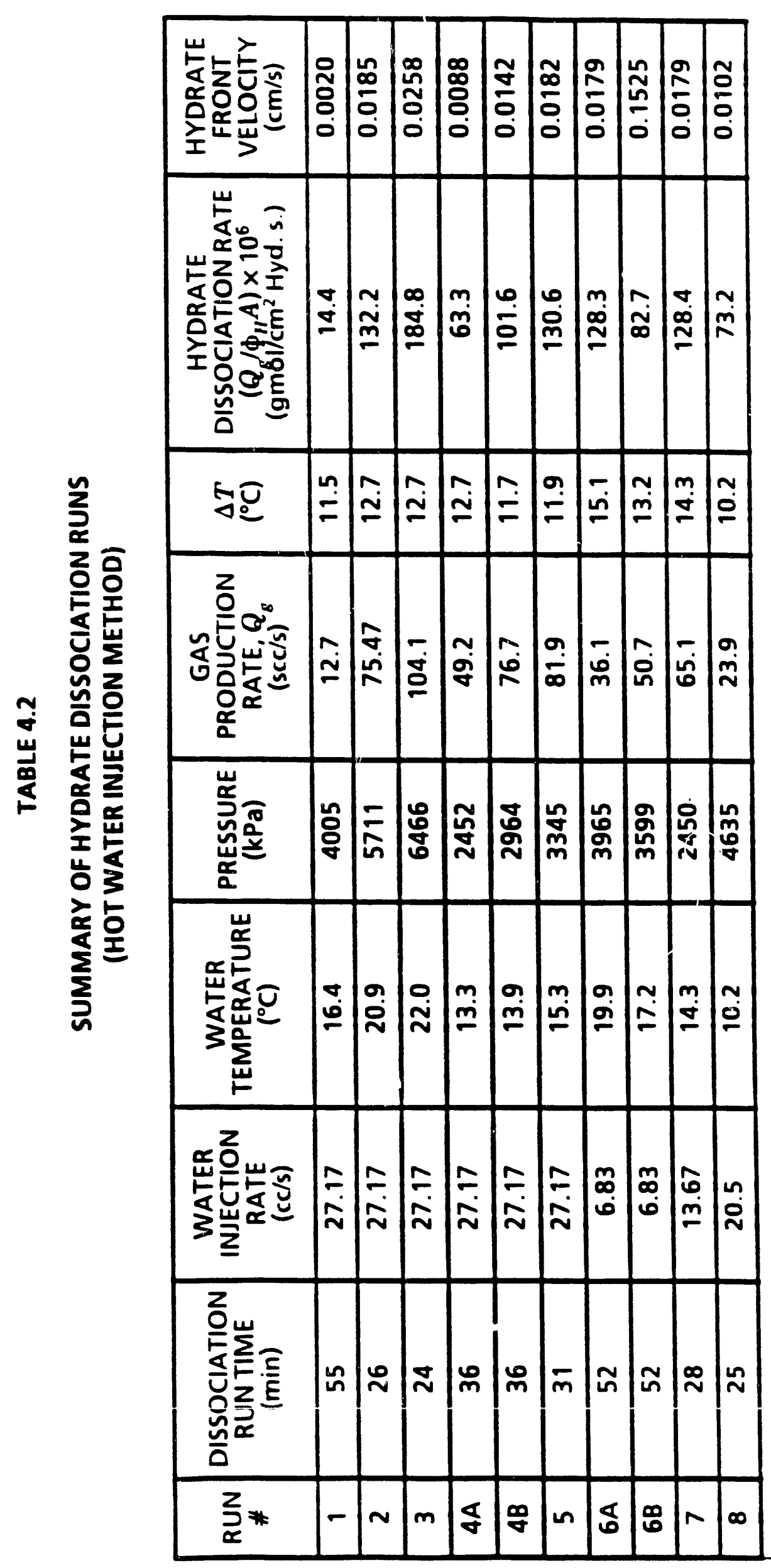




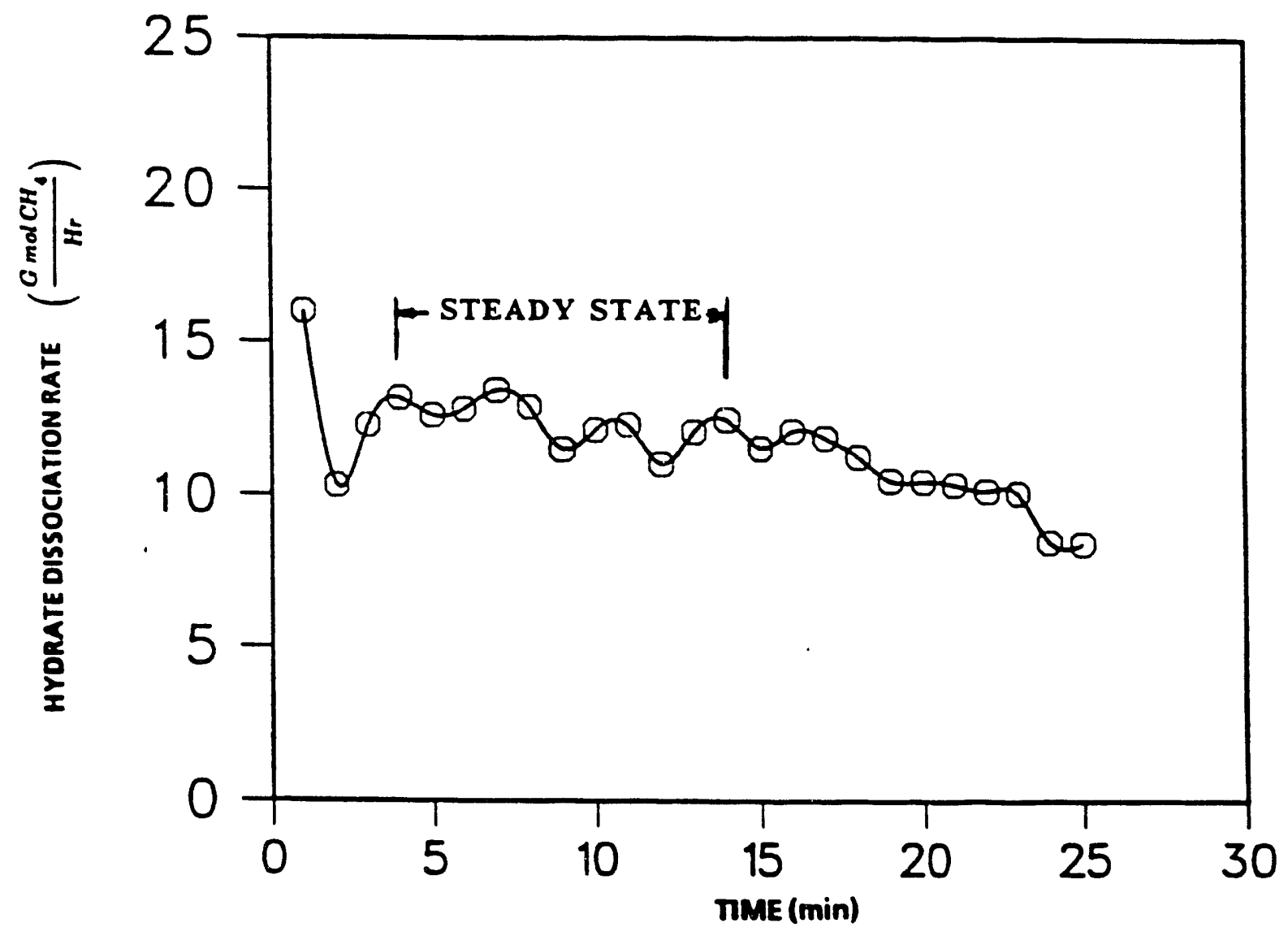

Figure 4.1: Rate of Hydrate Dissociation Versus Time For a Typical Hydrate Dissociation Run (Hot Water Injection) 


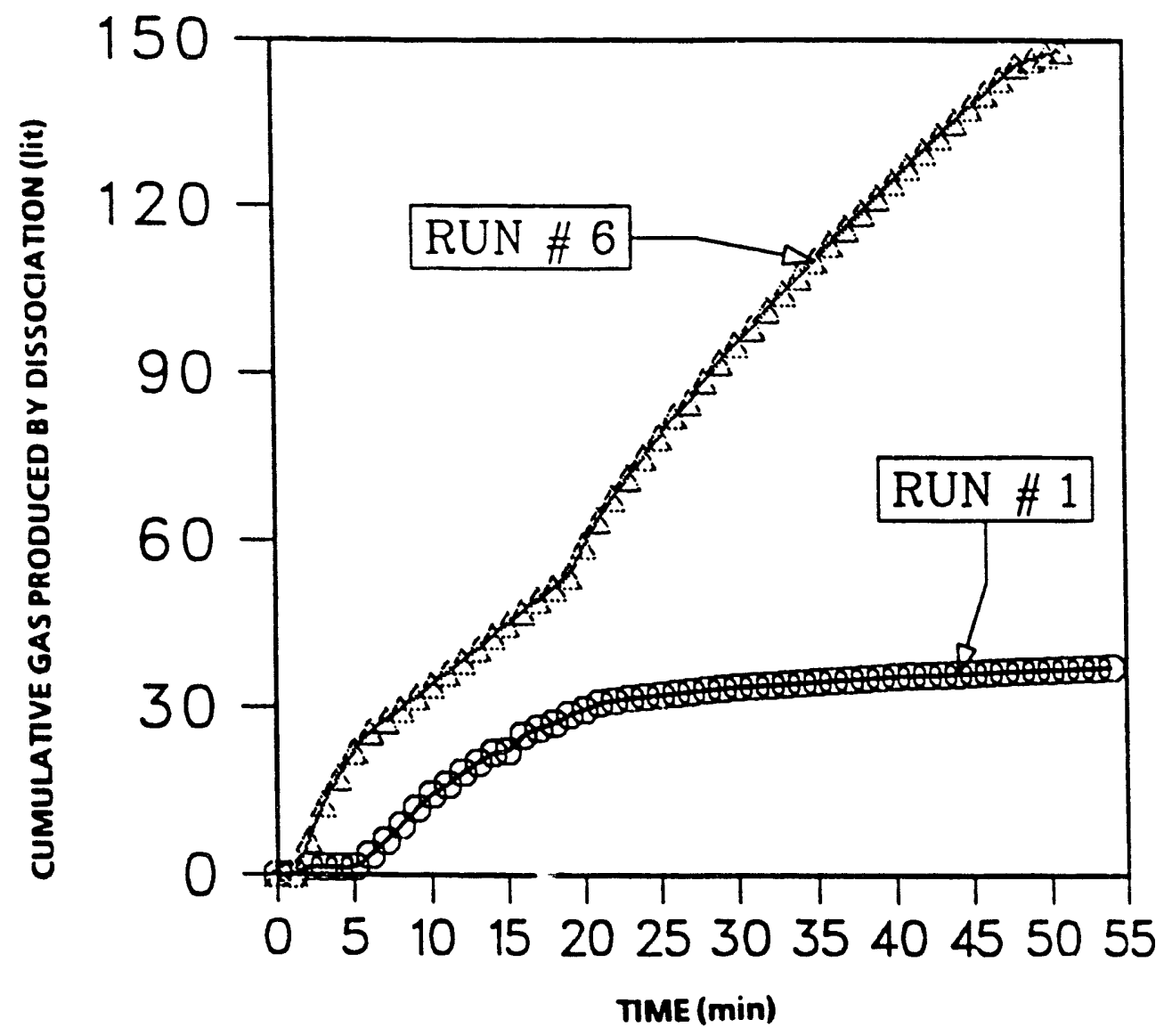

Figure 4.2: Effect of Hot Water Injection Rate on Cumulative Gas Production 
fluctuations in gas production rate due to the back pressure regulator, time lag between the temperature sensor and corrective action of the heater in the control of water temperature and nonuniformity of hydrate distribution in the core. The values in Table 4.2 are the average values calculated from the entire steady state period of the dissociation run.

Figures 4.2 and 4.3 show the cumulative gas produced as a function of time. It can be seen from this plots that the low injection rate and high temperature driving force results in a higher dissociation rate, i.e., the effect of forced convection on hydrate dissociation is not as significant as the effect of temperature driving force, especially at very high temperature driving force values. This is in agreement with the results obtained by Kamath (1984). However, it was not possible to separate the true effect of injection rate since, in the dissociation experiments, temperature driving forces varied from run to run along with injection rate.

Figure 4.4 shows the effect of pressure on the cumulative gas produced at constant temperature driving force and same injection rate. Results show that higher pressure increases the rate of dissociation. This is in agreement with the results obtained by Kamath (1984).

The correlation developed by Kamath was extended to incorporate the effect of pressure. Figure 4.5 shows this correlation for rate of methane hydrate dissociation by hot water injection which is given by the following equation

$$
\frac{Q_{g}}{\Phi_{H} A}=6.1613 \times 10^{-11}(\Delta T)^{2.16} P^{1.0116}
$$

where $\Delta T$ is the temperature driving force in ${ }^{\circ} \mathrm{C}, Q_{g}$ is in gmol methane produced per sec and $P$ is pressure in $\mathrm{KPa}$. The average absolute percentage error in this correlation is $9.9 \%$. 


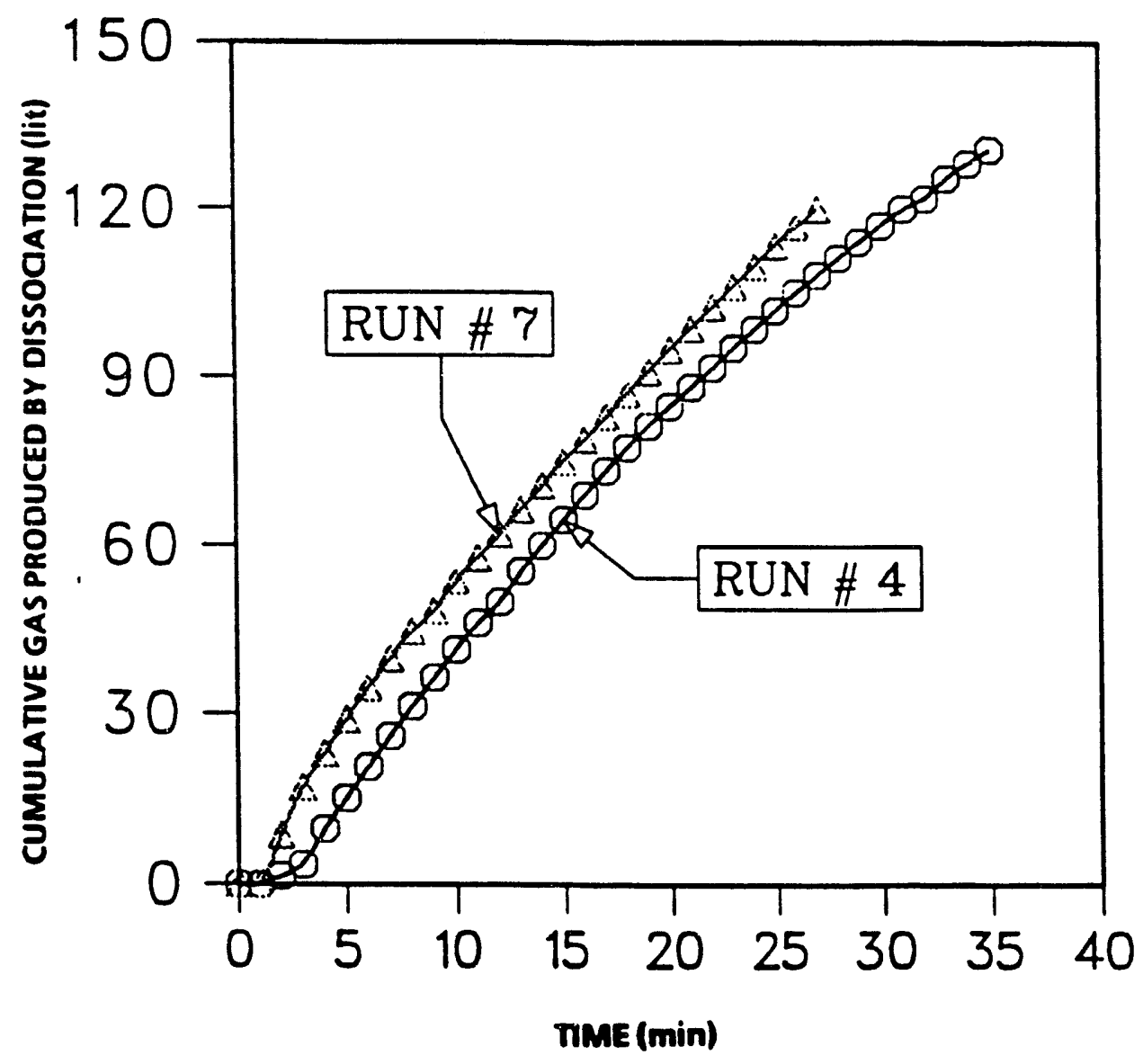

Figure 4.3: Effect of Hot Water Injection Rate on Cumulative Gas Production 


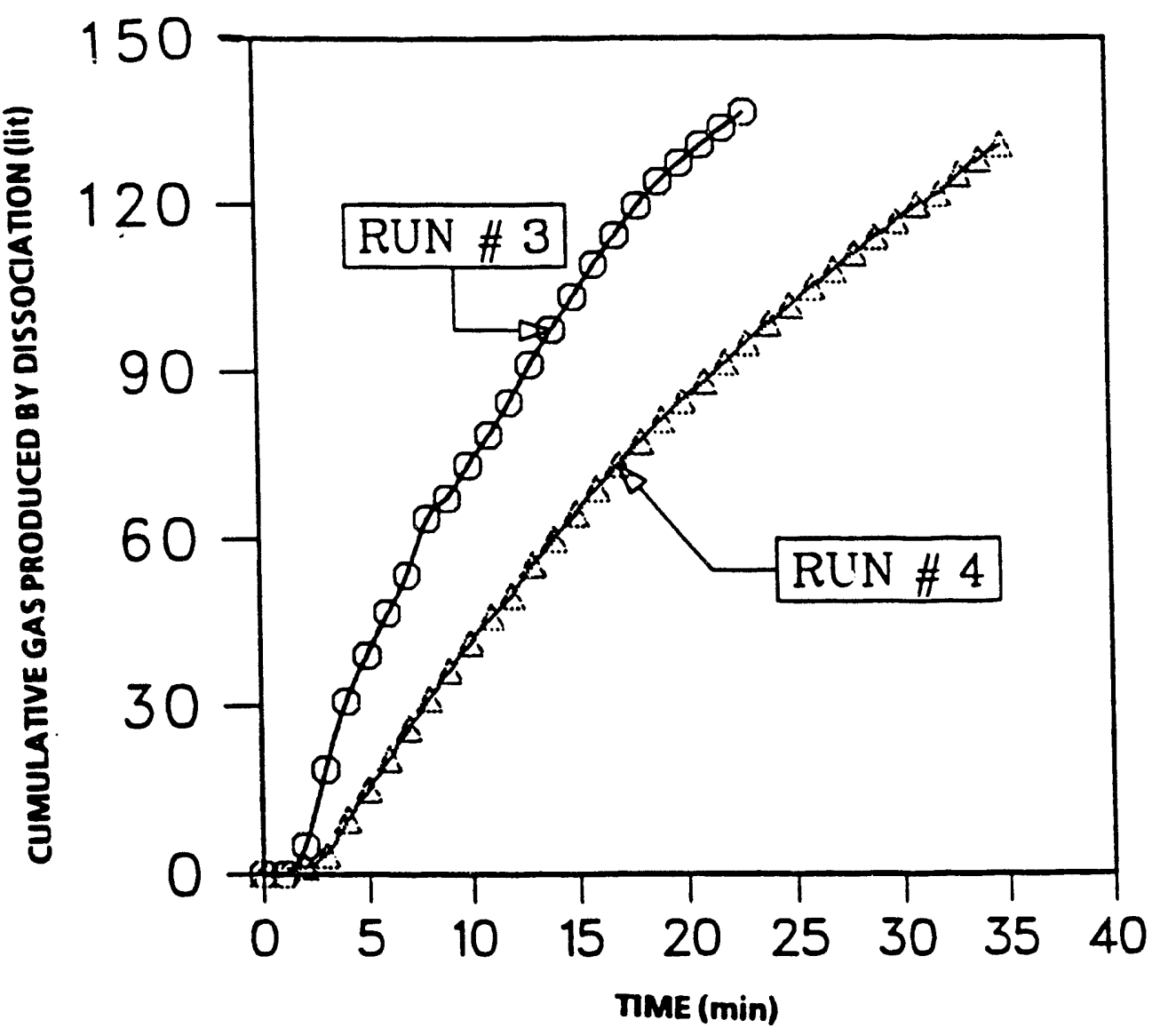

Figure 4.4: Effect of Pressure on Cumulative Gas Production 


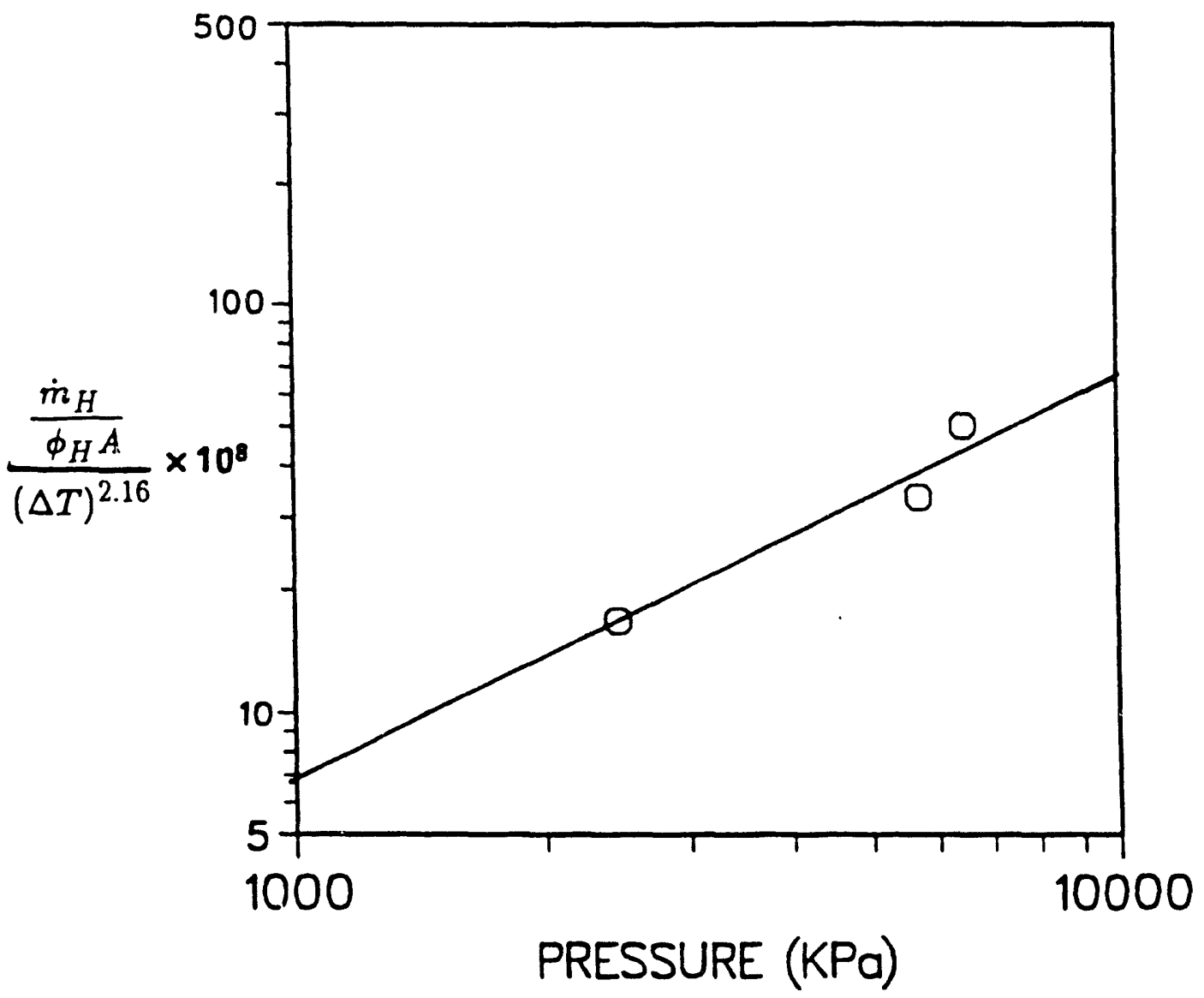

Figure 4.5: Methane Hydrate Dissociation Correlation (Hot Water Injection Method) 


\subsection{Conclusions}

1. Effect of pressure on the rate of methane hydrate dissociation was quantified. Results show that, for same temperature driving force $(\Delta T)$ and the same hot water injection rate, the rate of dissociation of methane hydrates increases with increase in pressure.

2. The previous correlation for methane hydrate dissociation rate during hot water injection method was intended to incorporate effect of pressure.

3. Under similar conditions (i.e. same injection fluid temperature, same pressure and same injection rates) the water injection results in significantly lower rates of dissociation than brine injection.

\subsection{Nomenclature}

A Cross-sectional area of the core, $\left(\mathrm{cm}^{2}\right)$

$P \quad$ Core pressure, $(\mathrm{kPa})$

$Q_{g} \quad$ Gas production rate due to hydrate dissociation, (scc/s)

$T_{B} \quad$ Water bulk phase temperature, $\left({ }^{\circ} \mathrm{C}\right)$

$T_{1} \quad$ Hydrate interfacial temperature, $\left({ }^{\circ} \mathrm{C}\right)$

$\Phi_{H} \quad$ Volume (or area) fraction of hydrates at the interface

$\Delta T \quad$ True temperature driving force, $\left({ }^{\circ} \mathrm{C}\right)$

\subsection{References}

1. Kamath, V.A. and Holder, G.D.: "Dissociation Heat Transfer Characteristics of Methane Hydrates," Am. Inst. Chem. Eng. Journal, Vol. 33, No. 2 (1987), p. 347.

2. Kamath, V.A., Holder, G.D., and Angert, P.F.: "Three Phase Interfacial Heat Iransfer During the Dissociation of Propane Hydrates," Chem. Eng. Sci., Vol. 39, No. 10 (1984), pp 1435-1442. 
3. Sira, J.H.: "Experimental Study of Dissociation of Gas Hydrates With and Without Inhibitors," M.S. Thesis, University of Alaska Fairbanks, AK, (July 1990). 


\section{CHAPTER FIVE}

\section{EXPERIMENTAL STUDY OF HYDRATE DISSOCIATION DURING DEPRESSURIZATION METHOD}

\subsection{Introduction}

In this chapter, the experimental data for the dissociation of hydrates in the core containing methane hydrates during depressurization method are presented. Objective of these experiments were to dissociate methane hydrates and determine dissociation characteristics by producing gas at a constant rate from the core holder and allowing the pressure in the core holder to decline freely with time.

\subsection{Experimental Methods}

The experimental set-up used for depressurization experiments was same as described earlier for brine injection experiments. Several modifications were made for conducting depressurization experiments. The injection fluid pump was not used. Also the back pressure regulator was removed from the system since system pressure was allowed to decline during dissociation experiment. Instead a gas flow meter and controller were connected to the system prior to ivet test flow meter for controlling gas production at constant value.

In order to study dissociation characteristics of methane hydrates under depressurization scheme, hydrates were dissociated by continuous withdrawal of methane from the core holder at a constant rate and pressure was allowed to decline freely. The approach used in these experiments was different from that reported by Dominic and Hilton (1987), where the pressures were controlled to a constant value during dissociation by means of a back pressure regulator and gas production rate was allowed to vary. The driving force for hydrate dissociation in depressurization is considered as the pressure driving force (the difference between hydrate dissociation pressure and actual core holder pressure). 
Hydrate formation technique used here was as same as described earlier in Chapter 3. Table 5.1 provides the properties of methane hydrate cores used for hydrate dissociation experiments by depressurization method. During each dissociation experiment, the pressure in the core holder, gas produced, the temperature of dissociating hydrates and the temperature of the gas phase were recorded continuously as a function of time. From these data, amount of hydrates dissociated, mols of methane in gas and hydrate phases, \% contribution of hydrate dissociation to the cumulative gas produced were computed. Series of dissociation experiments were conducted to study the effect of gas withdrawal rate and initial hydrate core temperature on ihe hydrate dissociation behavior. Gas production rates were varied from $0.83 \mathrm{scc}$. of methane/sec. to $83.33 \mathrm{scc}$. of methane/sec. Hydrate core initial temperatures were varied from $-3.6^{\circ} \mathrm{C}$ (to represent hydrate dissociation below ice point) to $4.5^{\circ} \mathrm{C}$ (to represent hydrate dissociation above ice point). The experimental results are summarized in Table 5.2 .

\subsection{Experimental Results}

Figures 5.1 and 5.2 show the pressure-time data at various gas withdrawal rates. The rate of pressure decline with time is arrested by hydrate dissociation. The extent of der,rease in the rate of decline in pressure with time is dependent on the rate of hydrate dissociation which in turn is dependent upon the rate of gas withdrawal, initial temperature of hydrates, \% of initial gas in place in hydrated form. For example, the slower the rate of gas withdrawal, the greater is the contribution from hydrate dissociation to the gas produced and lesser is the extent of pressure decline (see Figures 5.1 and 5.2).

In all the experiments, the initial pressure inside the core holder was kept above the equilibrium dissociation pressure. No hydrates were dissociated until the pressure declined below the equilibrium dissociation pressure. As the pressure 
TABLE 5.1

PROPERTIES OF METHANE HYDRATE CORES USED IN THE STUDY OF HYDRATE DISSOCIATION BY DEPRESSURIZATION METHOD

\begin{tabular}{|c|c|c|c|c|c|c|}
\hline $\begin{array}{c}\text { RUN } \\
\text { HENGTH } \\
(\mathrm{cm})\end{array}$ & $\begin{array}{c}\text { CORE } \\
\text { Ho INTHE } \\
\text { CORE } \\
(\mathrm{g})\end{array}$ & $\begin{array}{c}\text { INITIAL } \\
\text { CORE } \\
\text { POROSITY } \\
(\%)\end{array}$ & $\begin{array}{c}\text { HYORATE } \\
\text { FORMATION } \\
\text { PERIOD } \\
\text { (HOURS }\end{array}$ & $\begin{array}{c}\text { \% } \\
\text { CONVERSION } \\
\text { OF H2O TO } \\
\text { HYORATES }\end{array}$ & $\begin{array}{c}\text { VOL. \% } \\
\text { HYDRATES } \\
\text { IN THE CORE }\end{array}$ \\
\hline 1 & 17.5 & 603 & 53.7 & 111 & 42.6 & 23 \\
\hline 2 & 23.4 & 787 & 54.8 & 68 & 14.2 & 7 \\
\hline 3 & 19.8 & 700 & 52.5 & 76 & 19.9 & 11 \\
\hline 4 & 20.1 & 675 & 54.8 & 68 & 14.7 & 8 \\
\hline 5 & 19.0 & 674 & 52.3 & 60 & 28.0 & 15 \\
\hline 6 & 21.2 & 706 & 55.2 & 65 & 22.7 & 12 \\
\hline 7 & 19.9 & 715 & 51.7 & 48 & 27.9 & 16 \\
\hline 8 & 19.3 & 605 & 57.8 & 50 & 23.9 & 12 \\
\hline 9 & 17.6 & 845 & 35.6 & 93 & 88.4 & 66 \\
\hline
\end{tabular}




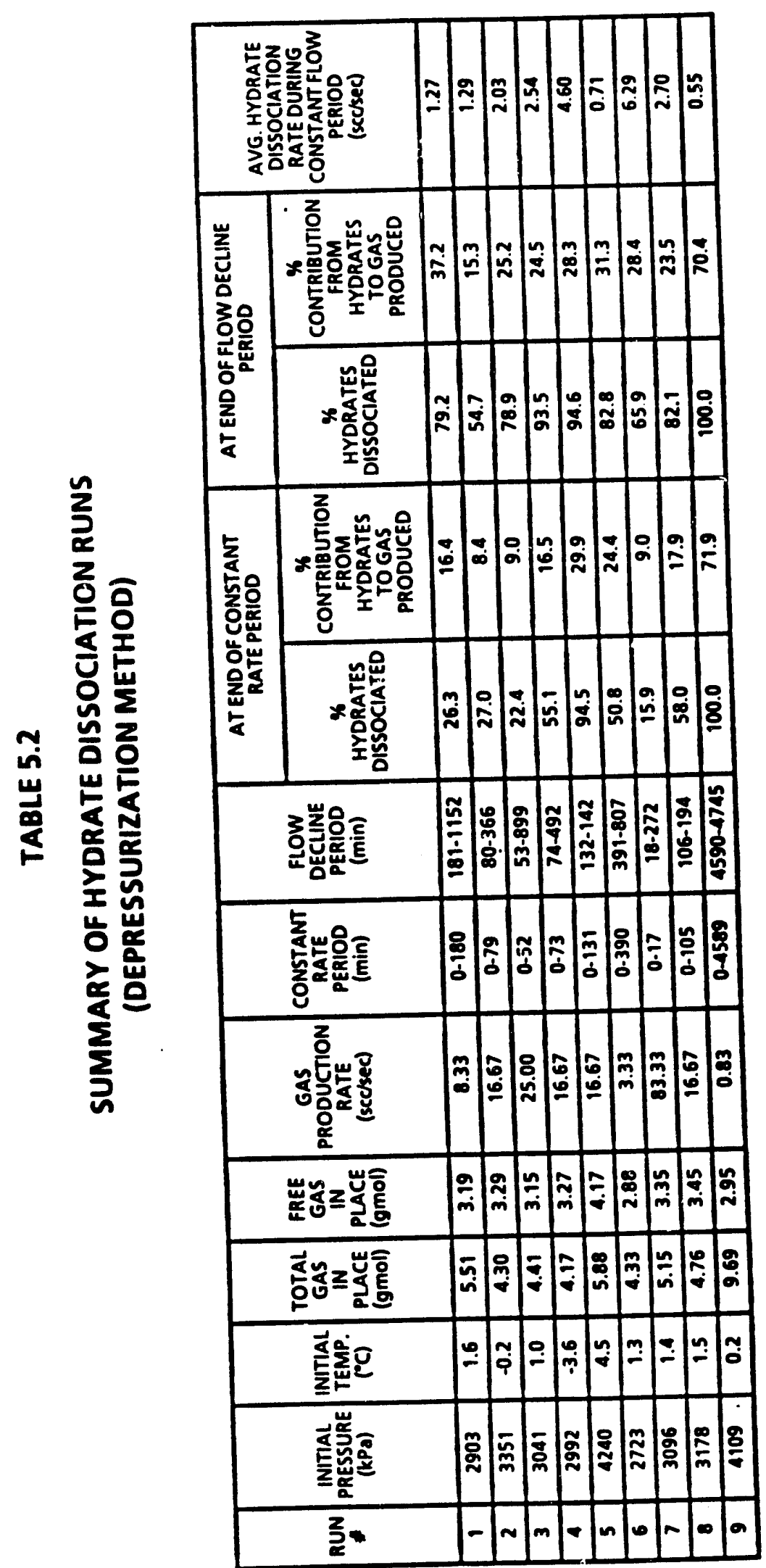




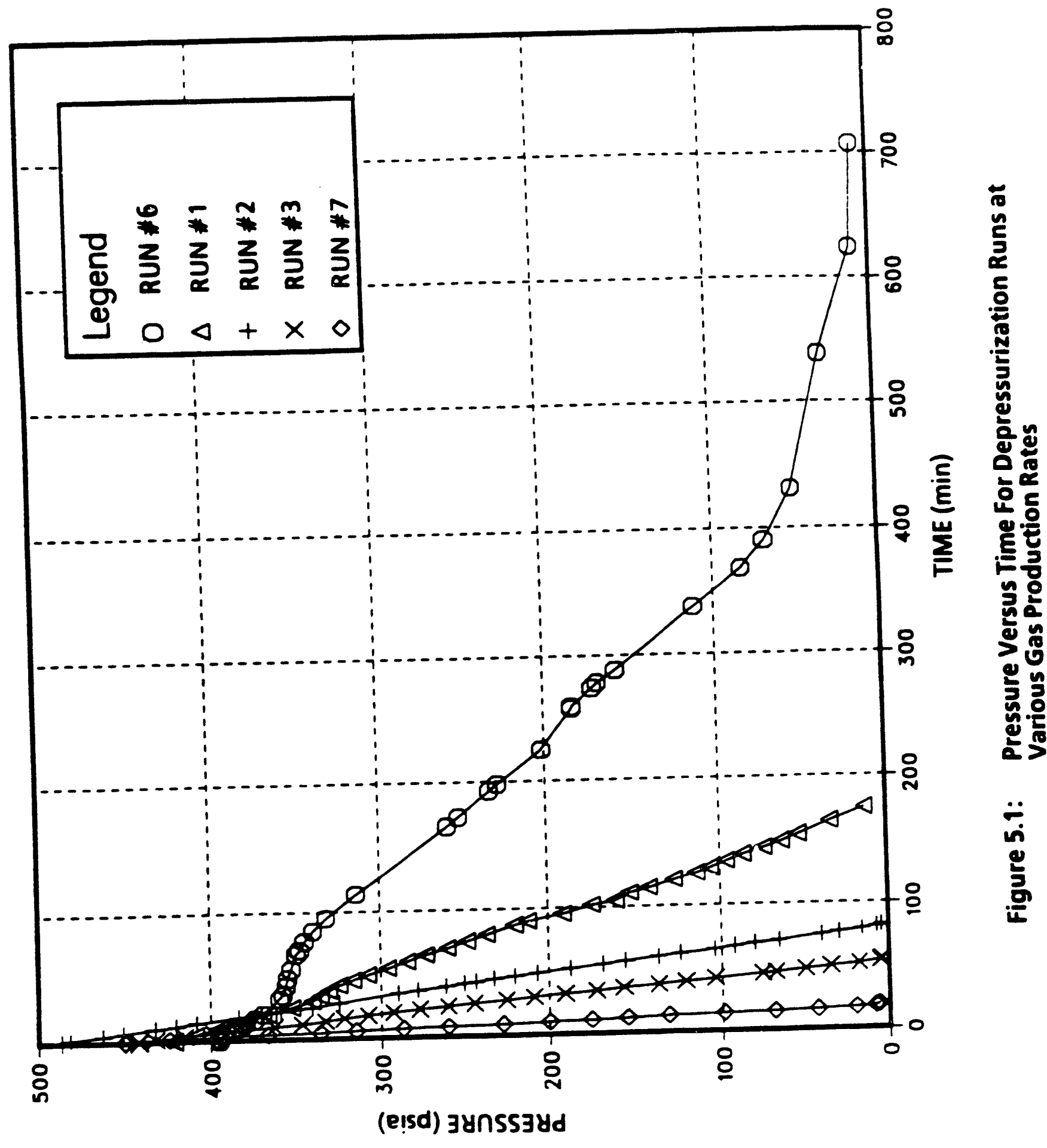




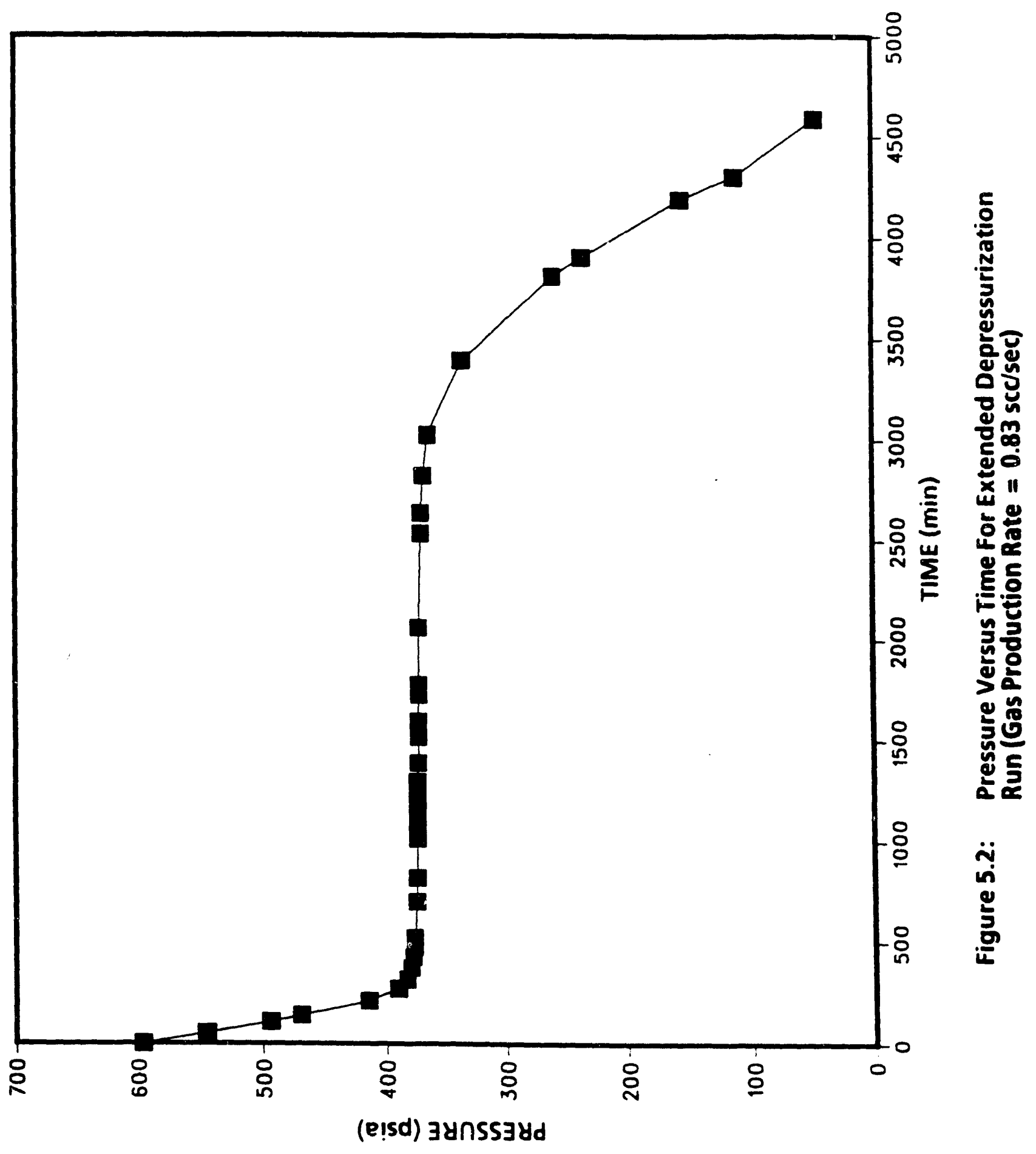


decreased below this equilibrium value, the hydrates began to dissociate. Figure 5.3 shows comparatively, the rate of total gas production and rate of gas production from hydrate dissociation versus time for a typical depressurization run. The entire depressurization run is characterized by two production periods. The first period is constant flow period during which it is possible to maintain constant rate of total gas production. The second period is the flow decline period during which the pressure in the core holder drops to atmospheric pressure and all the gas produced is from hydrate dissociation but the hydrate dissociation rate is so slow that the total gas production rate declines with time. It is also clear from figure 5.3 that the hydrate dissociation rate goes through maxima. Such behavior was observed in all the runs. This behavior may also be related to the fact that during a run the temperature of the core goes through a minima. Typically during depressurization runs, the core temperatures decreased by 2 to $3^{\circ} \mathrm{C}$ depending upon the rate of gas production.

The effect of gas withdrawal rate on the contribution of hydrate dissociation to the total gas produced is best illustrated by figures 5.4, 5.5 and 5.6 where pressure versus cumulative total gas produced and cumulative gas produced from gas phase is plotted. At lowest gas production rate $(50 \mathrm{cc} / \mathrm{min}$, Figure 5.4$)$, the hydrates dissociate at early times to arrest pressure decline and thus the contribution from hydrate dissociation to cumulative gas produced is highest (up to $72 \%$ during constant flow period). At higher gas production rate $(200 \mathrm{cc} / \mathrm{min}$, figure 5.5$)$ the hydrates dissociate at later times. As the gas production rate increases, the percentage contribution to total gas produced from hydrate dissociation decreases during constant flow period. Figure 5.7 shows the effect of gas withdrawal rate on the average rate of hydrate dissociation and the $\%$ hydrates dissociated during constant flow period. Even though, the rate of hydrate dissociation increases as the total gas withdrawal rate increases approximately linearly, the ratio of these two 


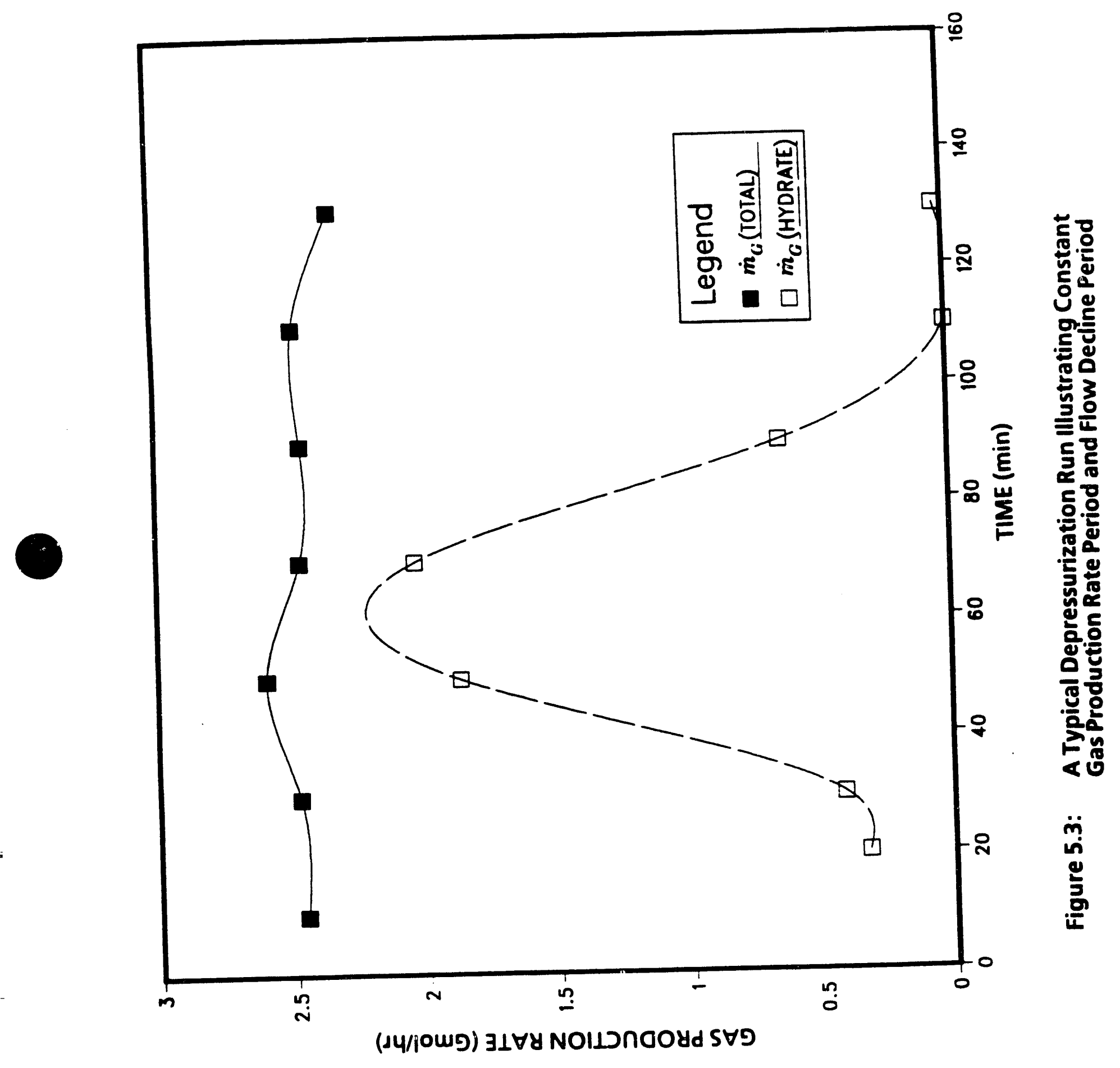




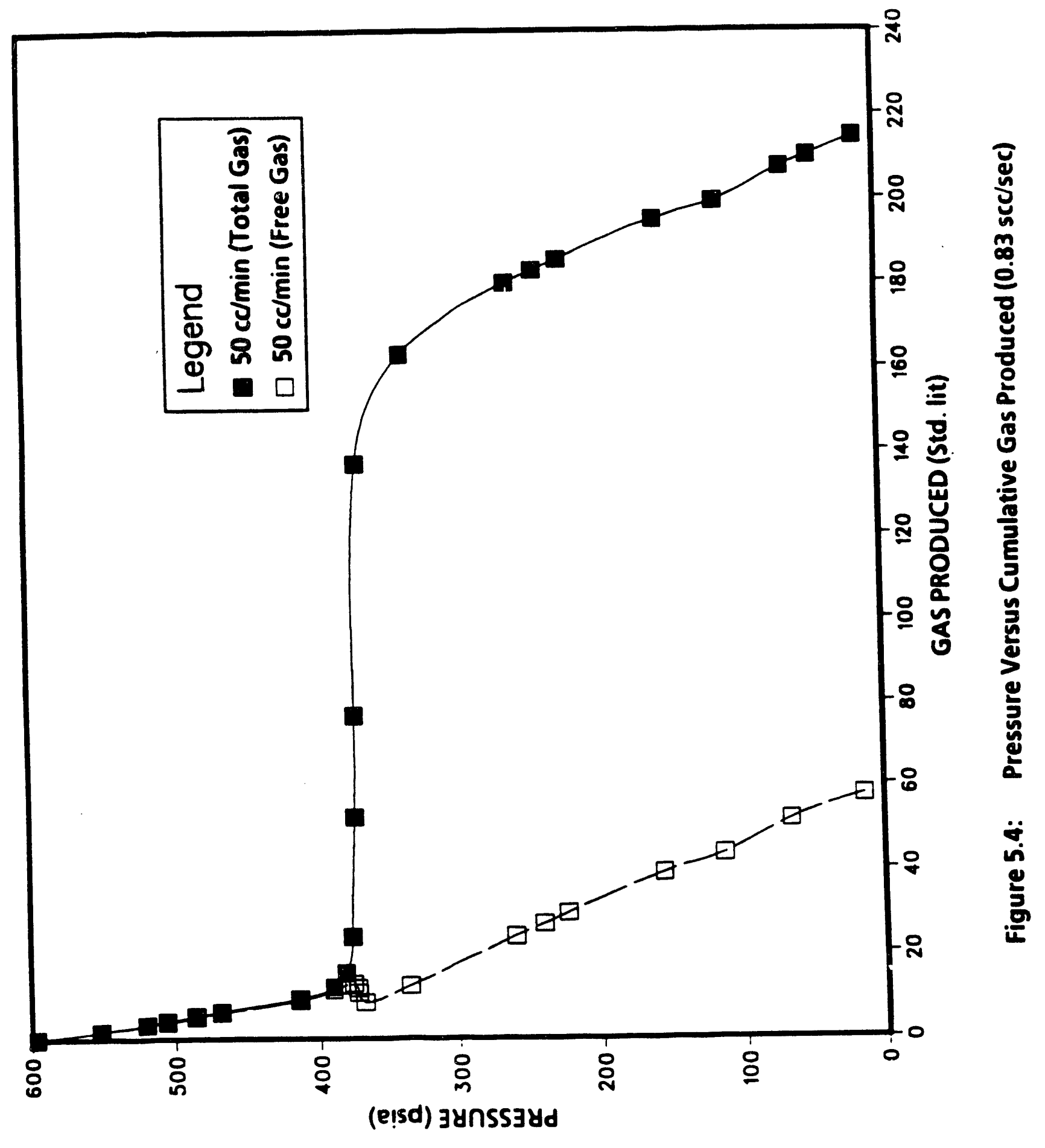




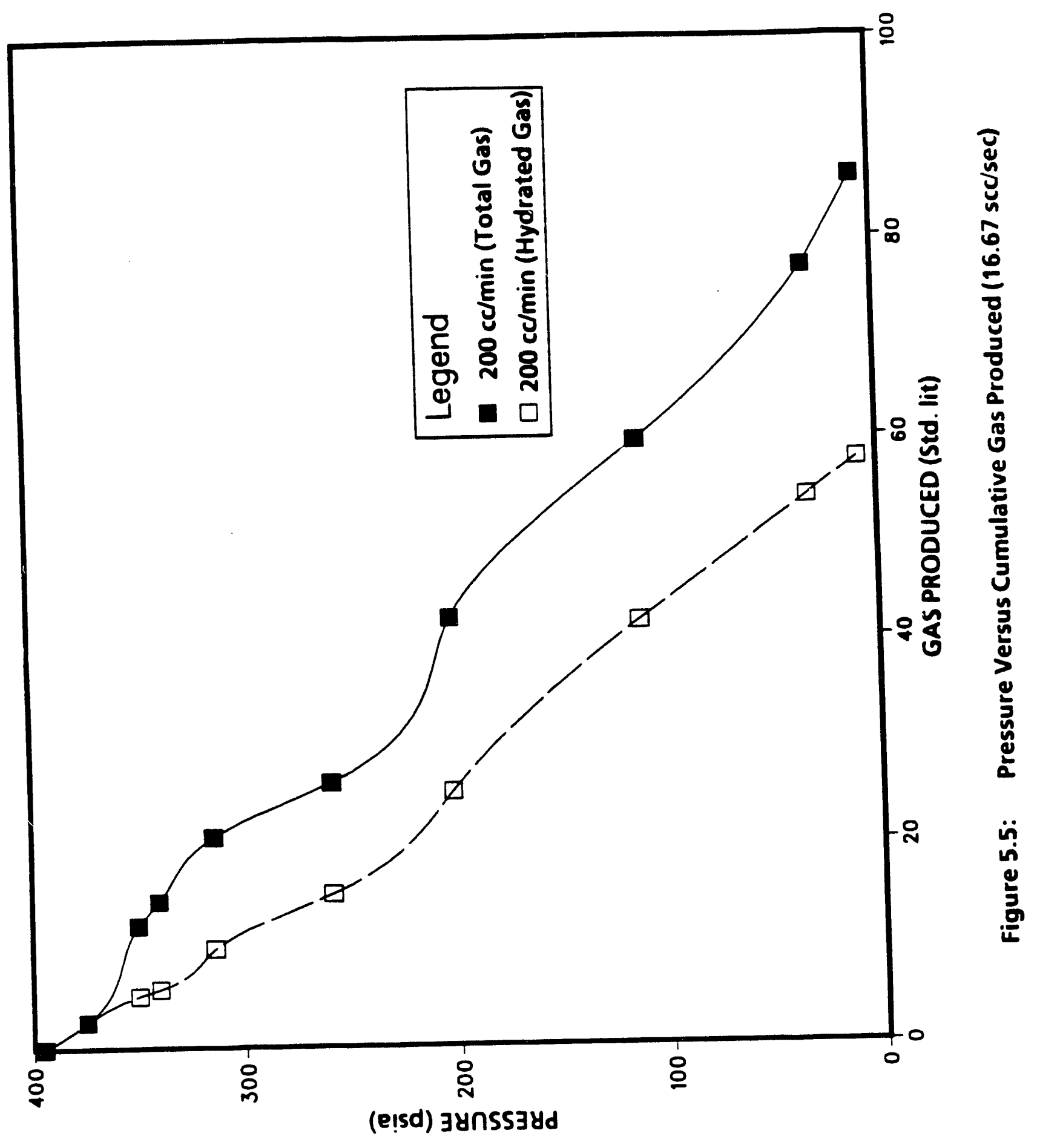




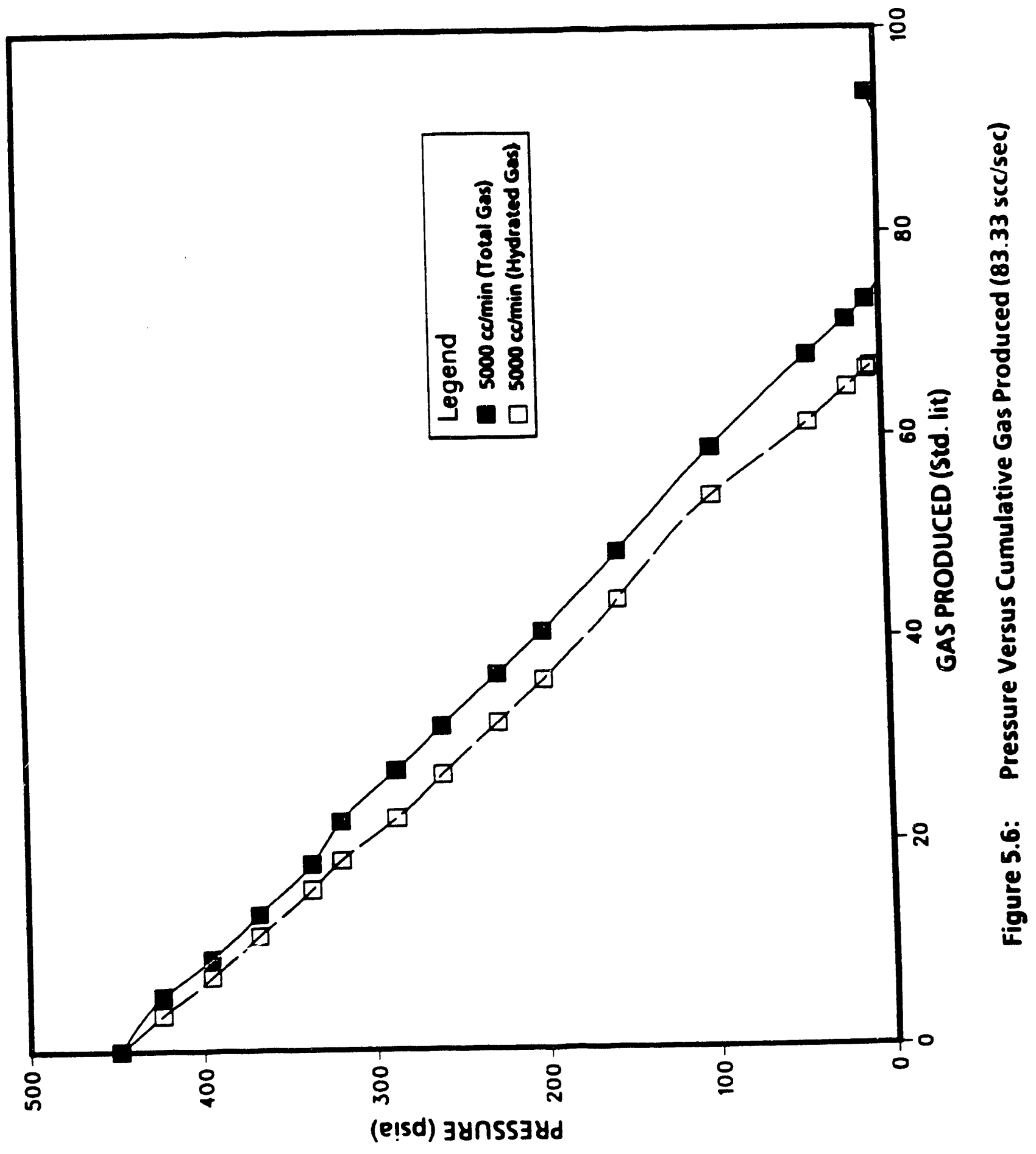




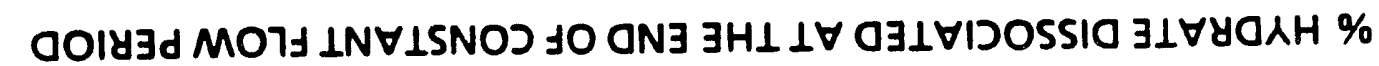
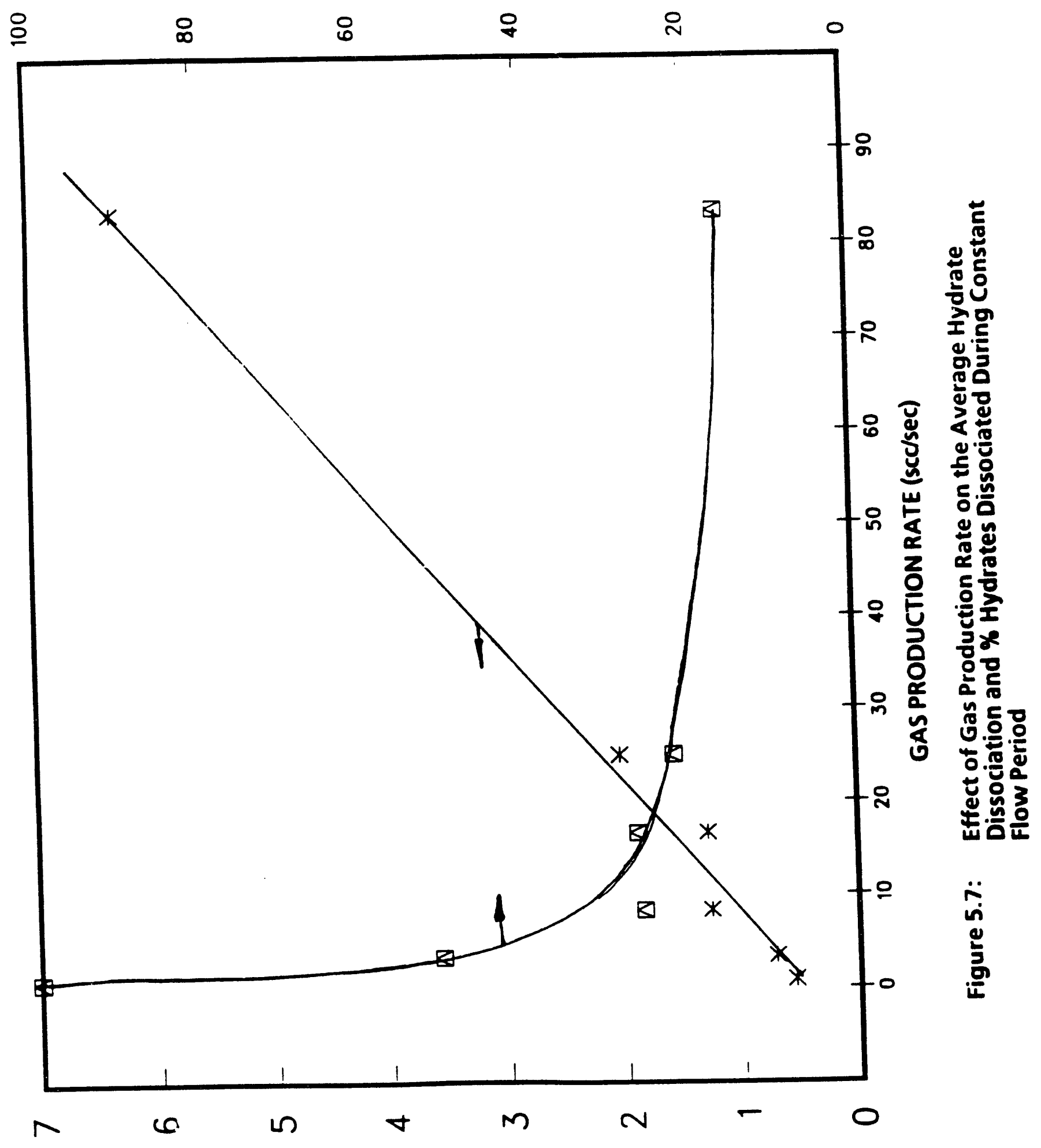

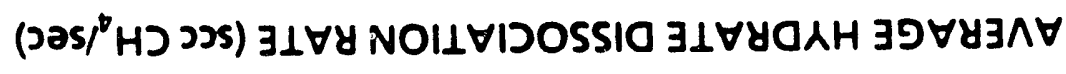




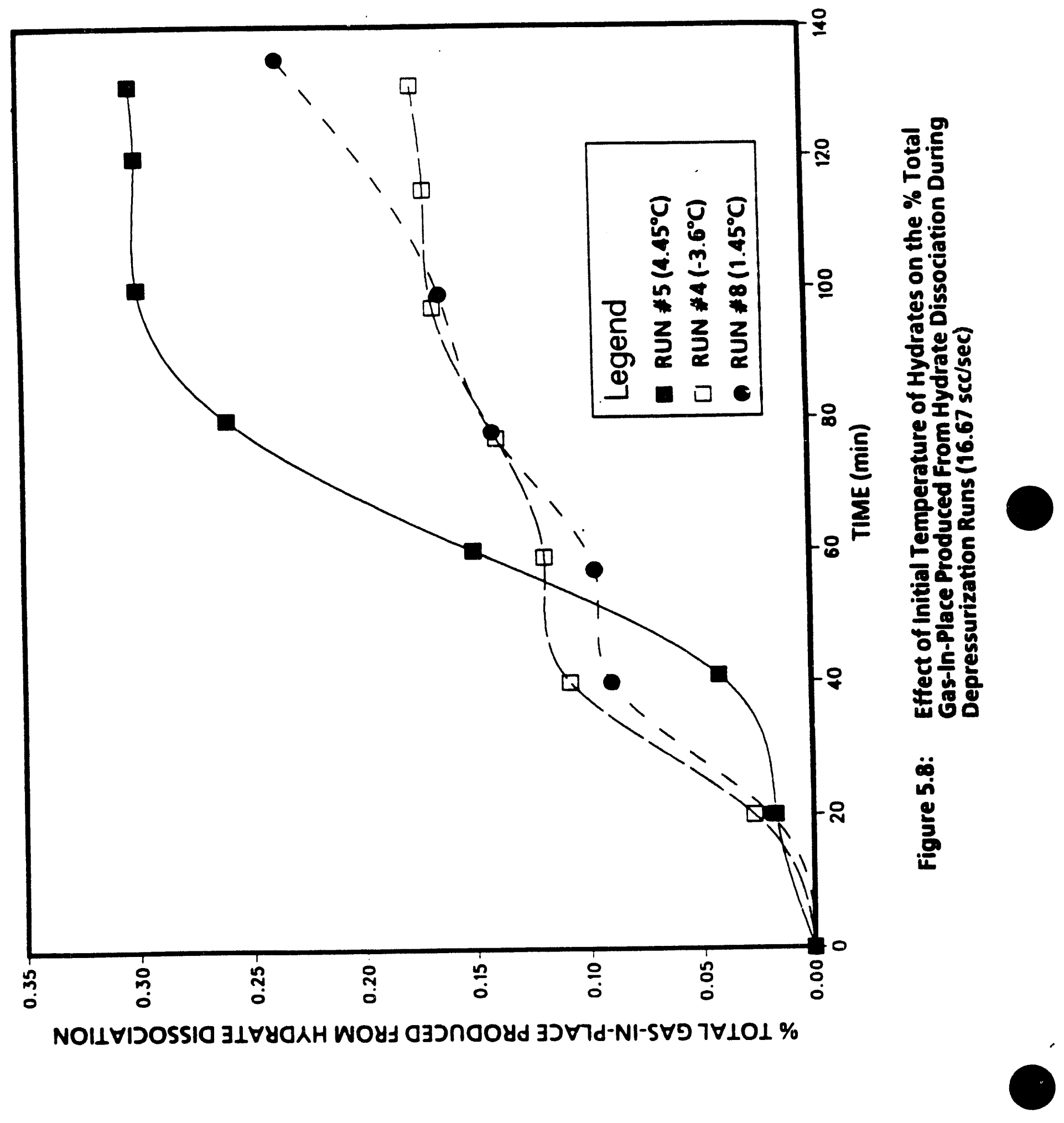


quantities decreases as tota! gas withdrawal rate increases indicating the smaller gas withdrawal rate is much more beneficial in terms of contribution of hydrates to total gas production. Also from this figure it is eviden that as the gas withdrawal rate increases the \% hydrates dissociated decreases drastically. Figure 5.8 shows the effect of initial temperature of hydrate core on the percentage of total gas-in-place produced from hydrate dissociation. Higher the initial temperature, higher is the contribution from hydrate dissociation.

\subsection{Conclusions}

The experimental results for methane hydrate dissociation under depressurization method show that:

1. The rate of decline in pressure is reduced by hydrate dissociation which contribute significantly to the total gas production (15 to $70 \%$ ).

2. The degree of contribution from hydrate dissociation to the total gas production increases with the decrease in gas withdrawal rate, the increase in the initial temperature of hydrates and the increase in the ratio of hydrated gas to free gas in place.

3. Depressurization method would be suitable to reservoirs containing free gas zone underlying the hydrate zone where gas production from free gas zone would be benefiteci from the hydrate drive (or contribution to gas production due to hydrate dissociation).

\subsection{References}

1. Dominic, K. and Hilton, D.: "Gas Production From Depressurization of Bench Scale Methane Hydrate Reservoirs," Tech. Note, Oifice of Fossil Energy, U.S. Dept. of Energy, M.E.T.C. DOE/METC-87/4073, March, (1987). 
2. Kamath, V.A., Mutalik, P.N., Sira, J.H. and Patil, S.L.: "Experimental Study of Brine Injection and Depressurization Methods For Dissociation of Gas Hydrates," SPE 19810, Proceedings of the 64th Annual Technical Conference and Exhibition of SPE, held in San Antonio, TX, Oct. 8-11, (1989). 


\section{CHAPTER SIX}

\section{EXPERIMENTAL STUDY OF HYDRATE DISSOCIATION DURING}

METHANOL AND GLYCOL INJECTION

\subsection{Introduction}

Formation of gas hydrates have been known to cause severe problems of blockages in natural gas pipelines, wellbores and natural gas processing units. Methanol and glycols are commonly used as hydrate inhibitors to control or prevent formation of gas hydrates, due to their ability to lower hydrate formation (or dissociation) temperatures considerably. For the same reason, they are very effective hydrate dissociation stimulants for enhancing gas production from hydrate reservoirs as demonstrated by a field study in the Messoyakha gas hydrate reservoir of the Soviet Union (Makogon, 1981). Effect of these hydrate inhibitors on the thermodynamic phase behavior of gas hydrates has been well established, however, no experimental data exist on effect of inhibitors on the rate of hydrate formation or dissuciation. Hence, the current methods of prevention of hydrate formation by inhibitors have relied upon the thermodynamic data rather than kinetic data.

In this study, the characteristics of hydrate dissociation process during methanol and ethylene glycol injection were investigated. After formation of methane hydrates in the synthetic cores, hydrates were dissociated by injection of inhibitor solution of known initial concentration, at a constant rate. The pressure was held constant during dissociation and gas production, inhibitor solution temperature and dissociating hydrate front position were monitored continuously.

\subsection{Methanol and Glycols As Hydrate Inhibitors}

In 1934, Hammerschmidt determined that solid gas hydrates form during transportation of natural gas and cause severe problems of blockages in pipelines. Since then, several methods of prevention of formation of gas hydrates were 
developed. The most commonly employed industrial methods include: removal of moisture content of natural gas by dew point lowering method, heating of a section containing hydrate plug to raise it's temperature above hydrate dissociation temperature above hydrate dissociation temperature, depressurization of a hydrate plug simultaneously from both ends at a slow rate to a pressure below hydrate dissociation pressure, and injection of chemicals which act as hydrate inhibitors into the gas flow stream. Makogon (1981) and Sloan (1990) provide comprehensive reviews of these processes.

The term "hydrate inhibitor" is used for those chemicals which have ability to lower hydrate formation temperature (or shift hydrate equilibria). These chemicals include: Methanol, glycols, ammonia, salts such as chlorides of sodium, potassium, calcium and magnesium. Several studies have been reported in literature which provide experimential data on effect of inhibitor concentration on the thermodynamic phase equilibria of gas hydrates. Makogon (1981) and Sloan (1990) provide good review of these studies and a discussion on effectiveness and screening of these inhibitors for hydrate prevention. In general, the degree of inhibition (i.e. lowering of hydrate formation temperature) is function of the type of inhibitor. inhibitor concentration, pressure and composition of hydrate forming gas. Figure 6.1 shows the effect of methanol inhibition on methane hydrate forming conditions obtained from experimental data reported in literature (Deaton and Frost, 1946; Ng et al., 1985; Robinson and $\mathrm{Ng}, 1985$ ). Figure 6.2 shows similar plot for effect of ethylene glycol inhibition on methane hydrate forming conditions obtained from the same sources. The effect of pressure on the degree of hydrate inhibition is small which is evident from the parallel nature of the curves in Figures 6.1 and 6.2. Using the data from Figures 6.1 and 6.2, correlation for degree of methane hydrate inhibition by methanol and ethylene glycol respectively is as follows: 


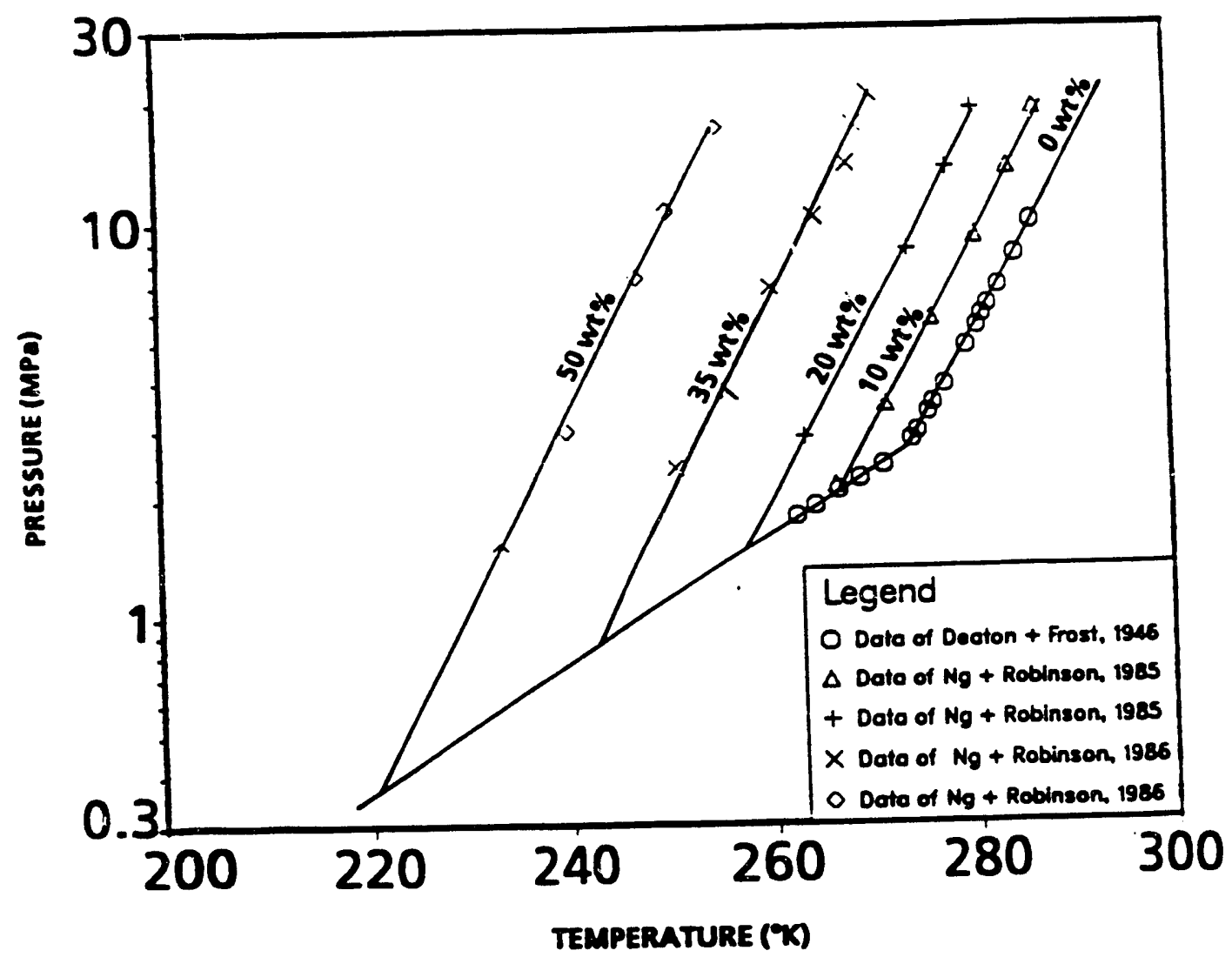

Figure 6.1: Effect of Methanol Inhibition on Methane Hydrate Forming Conditions 


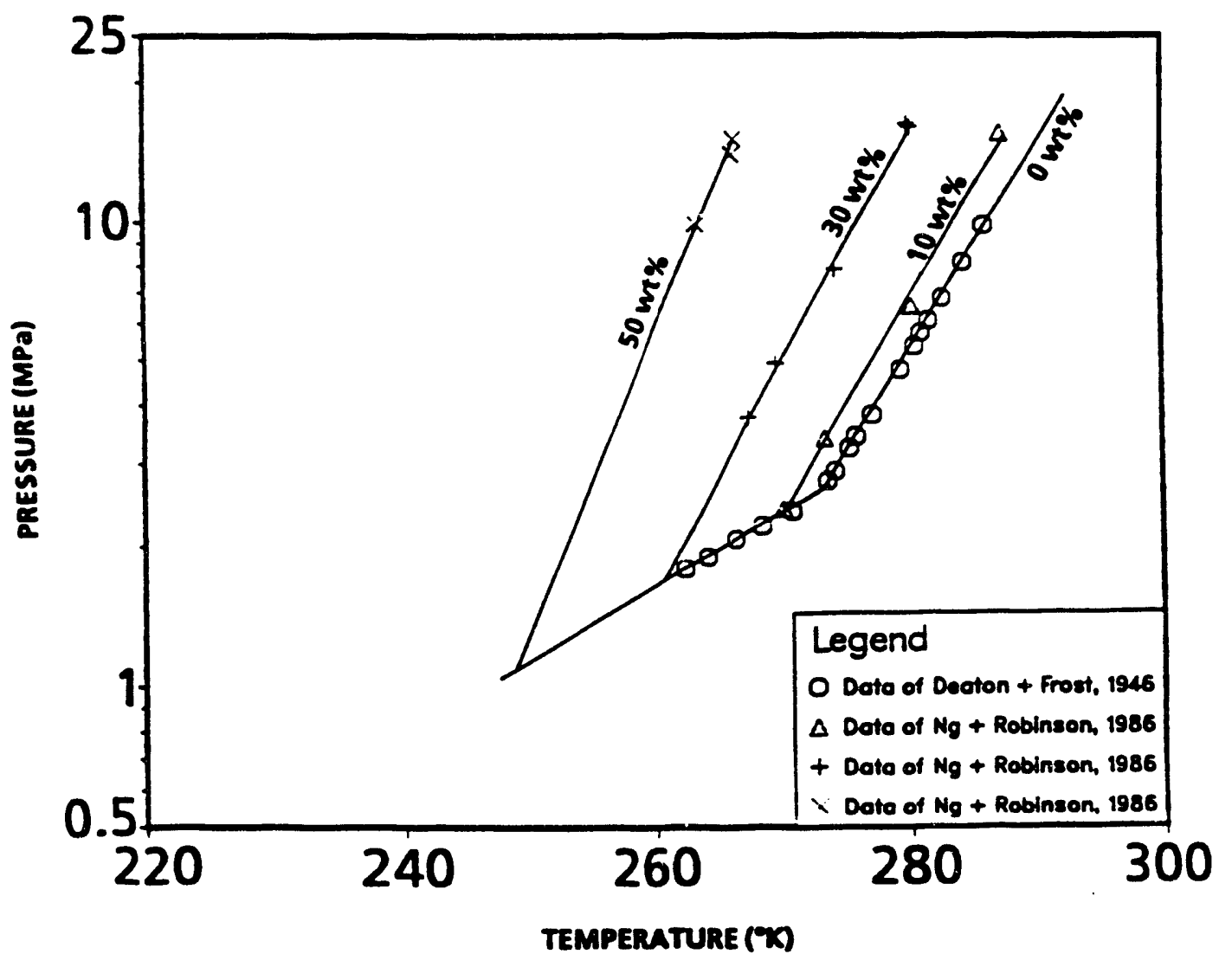

Figure 6.2: Effect of Glycol Inhibition on Methane Hydrate Forming Conditions 


$$
\Delta T_{x}=0.3938 x+0.00166 x^{2} \quad[M E T H A N O L]
$$

$$
=0.1721 x+0.004466 x^{2} \quad[E . G L Y C O L]
$$

where, $\Delta T_{x}$ is in $\left({ }^{\circ} \mathrm{C}\right)$ and $x$ is $w t \%$ inhibitor in. solution. Due to lack of availability of data on effect of these inhibitors on the rate of formation or dissociation of gas hydrates, the current industrial methods of prevention or control of hydrate formation have relied upon the thermodynamic data rather than the kinetic data.

The Messoyakha gas hydrate reservoir is the only field example for production of natural gas from hydrates where depressurization and methanol injection have been used to produce the field over past seventeen years (Makogon, 1988). In this reservoir, hydrate zone overlies the free gas zone. The reports show that injection of methanol in five wells increased the rate of gas production by a factor of four on the average (Makogon, 1981).

\subsection{Experimental Methods}

In this study, characteristics of methane hydrate dissociation process during injection of methanol and ethylene glycol were determined. The experimental setup used for formation and dissociation of hydrates is same as that described earlier.

In each experiment, the first step was to form methane hydrates in the laboratory made cores. The hydrate formation technique used in this study is same as that described earlier.

In order to study dissociation characteristics of methane hydrates by inhibitor (methanol or ethylene glycol) injection, following procedure was used. Initially, an aqueous solution of desired initial inhibitor concentration was prepared in the inhibitor reservoir. Methanol and glycol used were of technical grade ( $99 \%$ purity). 
Initial level of inhibitor solution in the inhibitor reservoir was measured from the liquid level indicator. The hydrate core holder was then connected to the inhibitor reservoir, liquid level indicator and back pressure regulator. By opening top valve on the hydrate core holder, the pressures in the inhibitor reservoir and the downstream were equalized to the core holder pressure. The initial core holder pressure and temperature were recorded. The back pressure regulator was then set to desired pressure at which run was to be conducted. The dissociation run was then started by injecting inhibitor solution from the inhibitor reservoir into the core holder at a constant preset injection rate. Inhibitor contacted the hydrates at the top surface of the core. During the entire dissociation run, pressure in the core holder and inhibitor injection rate were held to a constant value. The temperature of the inhibitor solution initially was at ambient conditions and declined as the run proceeded since the temperature of the inhibitor solution was not controlled by means of a heater-controller. The reason for not heating the methanol was due to it's low flash point. Hydrates dissociated only at the flat hydrate-inhibitor interface which moved vertically downwards as run proceeded. The inhibitor solution and gas mixture produced from the core holder was separated in the gas-inhibitor separator. The inhibitor solution was then recirculated back to the inhibitor reservoir and gas was produced through the back pressure regulator and wet test gas flow meter. During the entire dissociation run, the temperature of the bulk inhibitor solution in the core holder, the temperature of hydrates, the gas production, the pressure in the core holder and the level of inhibitor in the inhibitor reservoir were recorded at one minute intervals. By monitoring the inhibitor level in the inhibitor reservoir, the position of dissociating hydrate surface was tracked. The run was stopped when about 80 to $90 \%$ of the hydrates were dissociated. The initial and final concentration of inhibitor solution were measured by HP 5880 gas chromatograph. 
Series of dissociation experiments were conducted to study effect of inhibitor concentration and inhibitor injection rate.

As the hydrate dissociation proceeded in each run, the concentration of the inhibitor in the solution decreased continuously due to generation of water from hydrate dissociation. Moreover, the temperature of the inhibitor solution also decreased continuously since no temperature control was used. The driving force for the dissociation of hydrates is the difference between the temperature of inhibitor solution in contact with hydrates $\left(T_{i}\right)$ and the temperature of the dissociating hydrates at the interface $\left(T_{l}\right)$. For $0 \%$ concentration, temperature of dissociating hydrates $\left(T_{I}^{0}\right)$ was obtained from the equilibrium P-T relationship for methane hydrates and is given by

$$
\begin{aligned}
T_{I}^{o} & =\frac{8533.8}{38.98-\ln (P)}-273.15 \text { for } T_{I}^{o} \geq 0 \\
& =\frac{1886.8}{14.717-\ln (P)}-273.15 \text { for } T_{I}^{o}<0
\end{aligned}
$$

where $P$ is the core holder pressure in $\mathrm{kPa}$ and $T_{I}{ }^{\circ}$ is in ${ }^{\circ} \mathrm{C}$. The apparent temperature driving force, $\left(\Delta T^{0}\right)$ without taking in to account the effect of inhibition was then obtained from:

$$
\Delta T^{0}=T_{f}-T_{I}^{0}
$$

The "True" temperature driving force, $(\Delta T)$ was obtained by incorporating inhibition effect as follows:

$$
\Delta T=\Delta T^{0}+\Delta T_{x}
$$


where $\Delta T_{x}$ was obtained from equation (6.1) for methanol injection and equation (6.2) for ethylene glycol injection.

The raw data collected during a dissociation run was used to calculate the volume of hydrates remaining the core holder, the concentration of inhibitor solution, the volume of free gas phase, the true hydrate dissociation rate and the location of hydrate-inhibitor interface as a function of time. Note that, the measured gas production rate was corrected to account for change in volume due to hydrate dissociation in order to obtain true hydrate dissociation rate.

\subsection{Methanol Injection Experimental Results}

Table 6.1 provides the properties of methane hydrate cores used for methanol injection experiments.

Table 6.2 provides summary of experimental conditions during hydrate dissociation by methanol injection. In runs 1 to 4 , initial concentration of methanol solution injected was kept same at $30 \mathrm{wt} \%$ and methanol injection rate was varied from 7.33 (cc/sec) to 26.67 (cd/sec). In runs 4 to 7, the methanol injection rate was maintained same at $26.67(\mathrm{cc} / \mathrm{sec})$ and methanol concentration was varied from 10 to $30 \mathrm{wt} \%$. The pressure in the core holder during each run fluctuated within $\pm 35 \mathrm{kPa}$.

All dissociation runs (methanol and glycol injection) were unsteady state during which the hydrate dissociation rate decreased continuously with time as illustrated by a typical run in Figure 6.3. Reasons for the unsteady state behavior are as follows. The concentration of inhibitor in the solution decreased continuously with time as shown in Figure 6.4 due to dilution of inhibitor from water generated.by hydrate dissociation. In addition, the temperature of inhibitor or the temperature difference between inhibitor and hydrates decreased continuously with time as shown in Figure 6.5 since no temperature control was adopted. Thus, the true temperature driving force, $(\Delta T)$ decreased with time in all the runs. Figure 


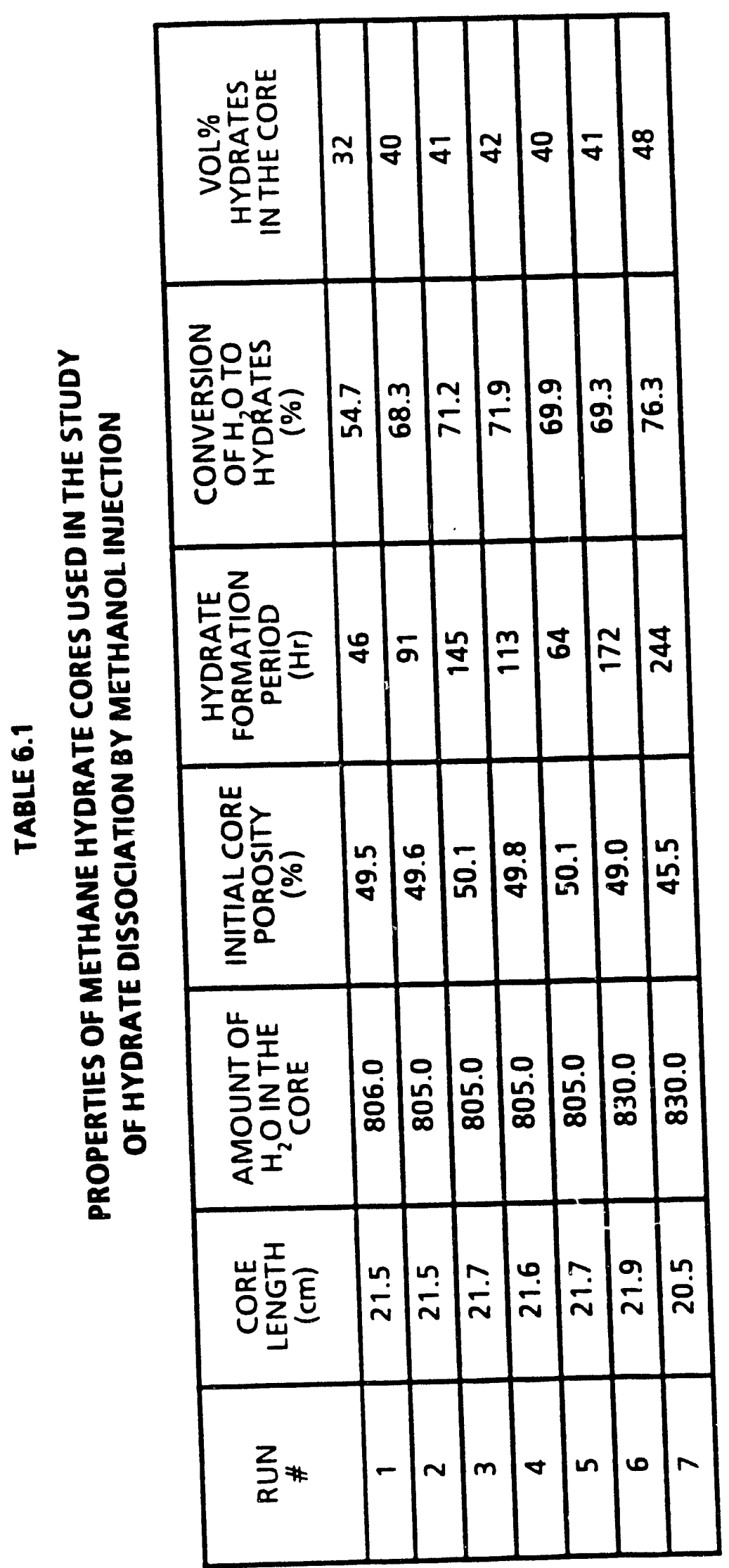




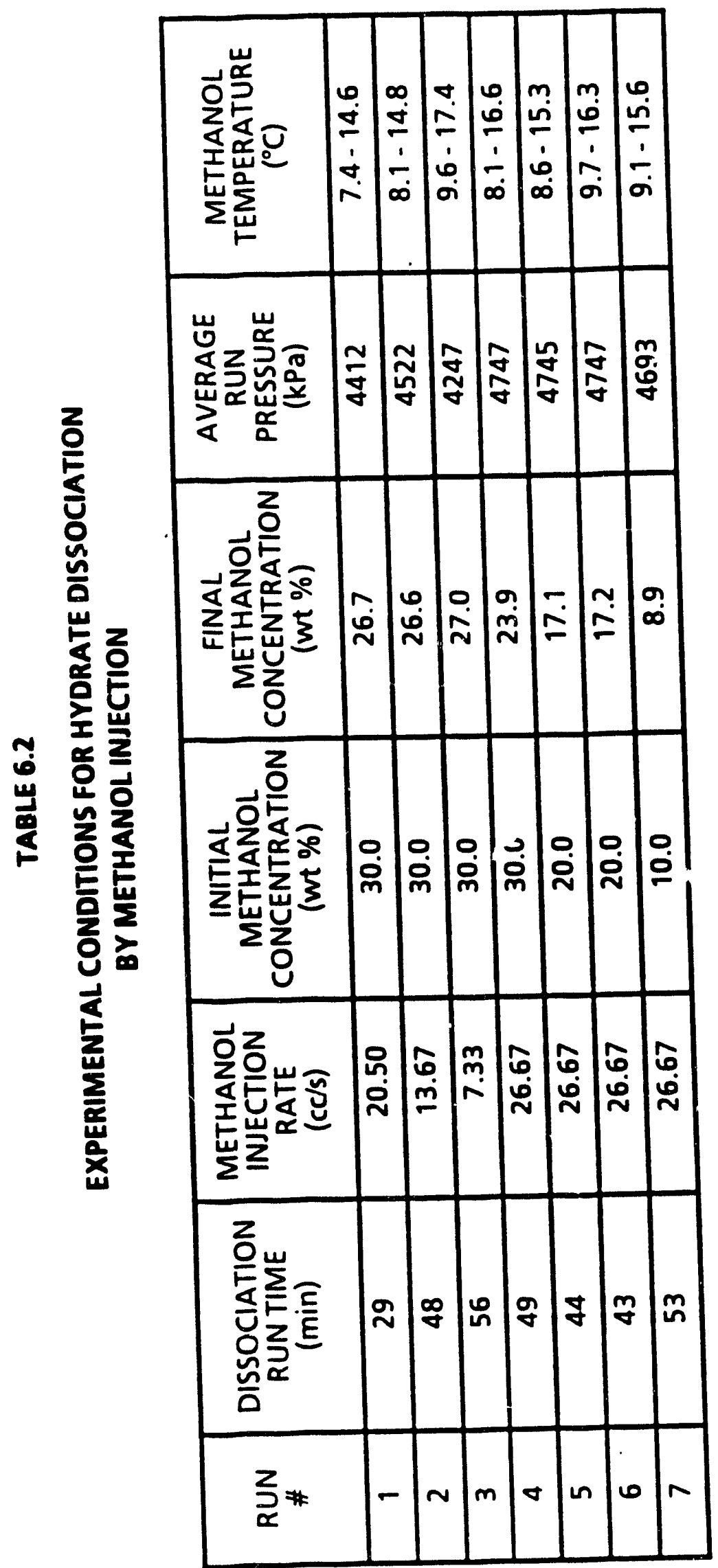




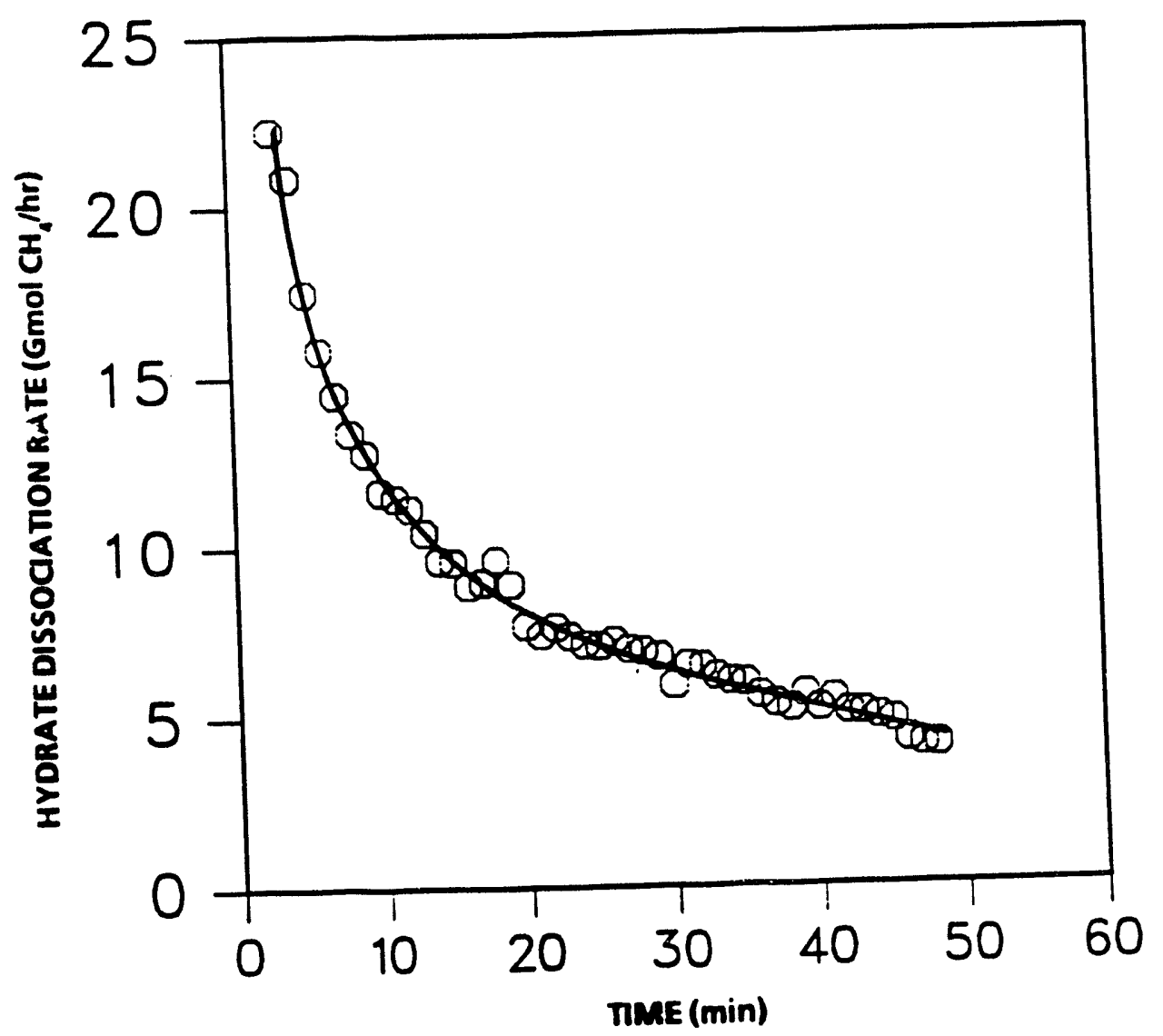

Figure 6.3: Typical Hydrate Dissociation Run (Methanol) 


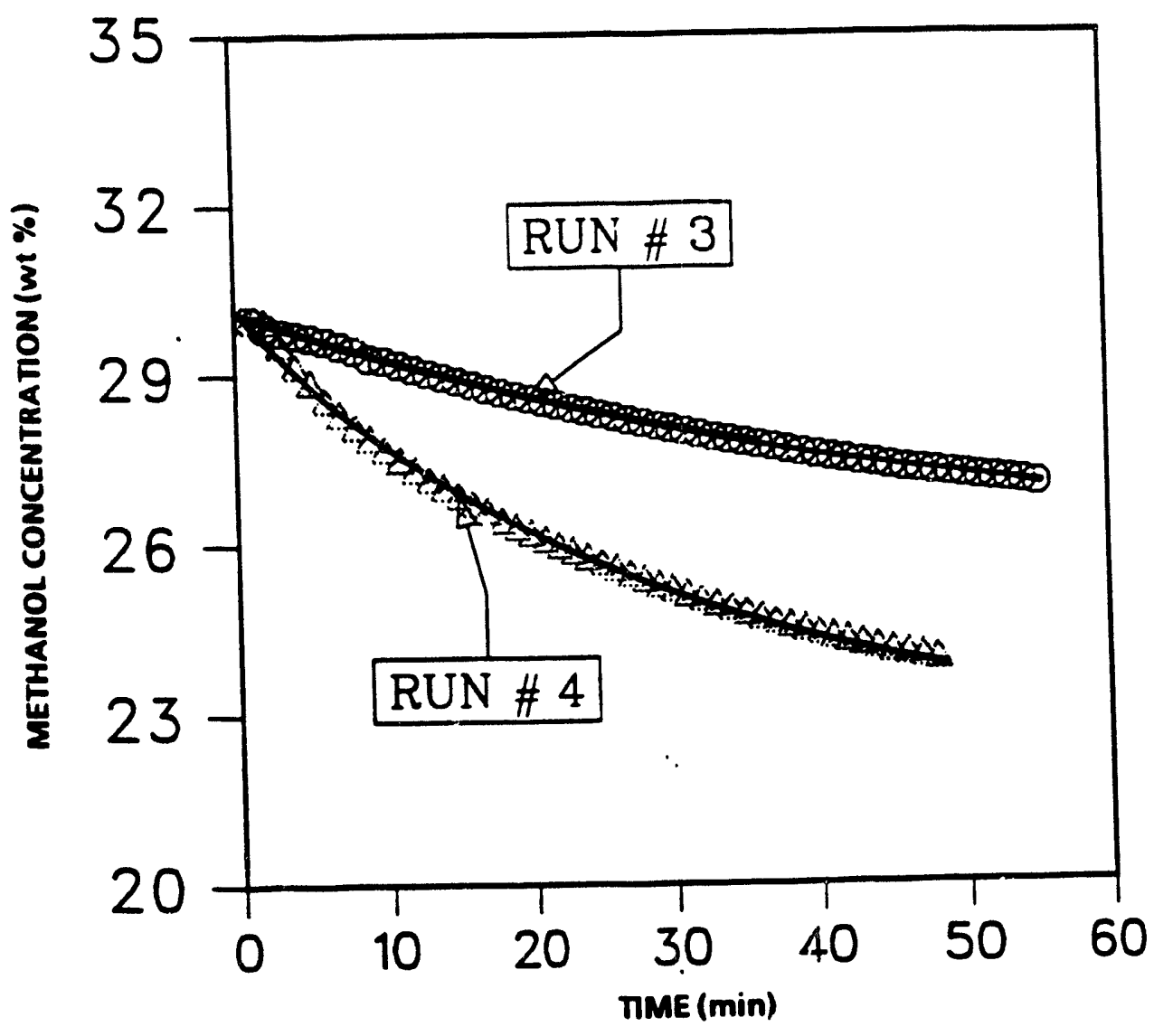

Figure 6.4: Dilution of Methanol By Hydrate Dissociation 


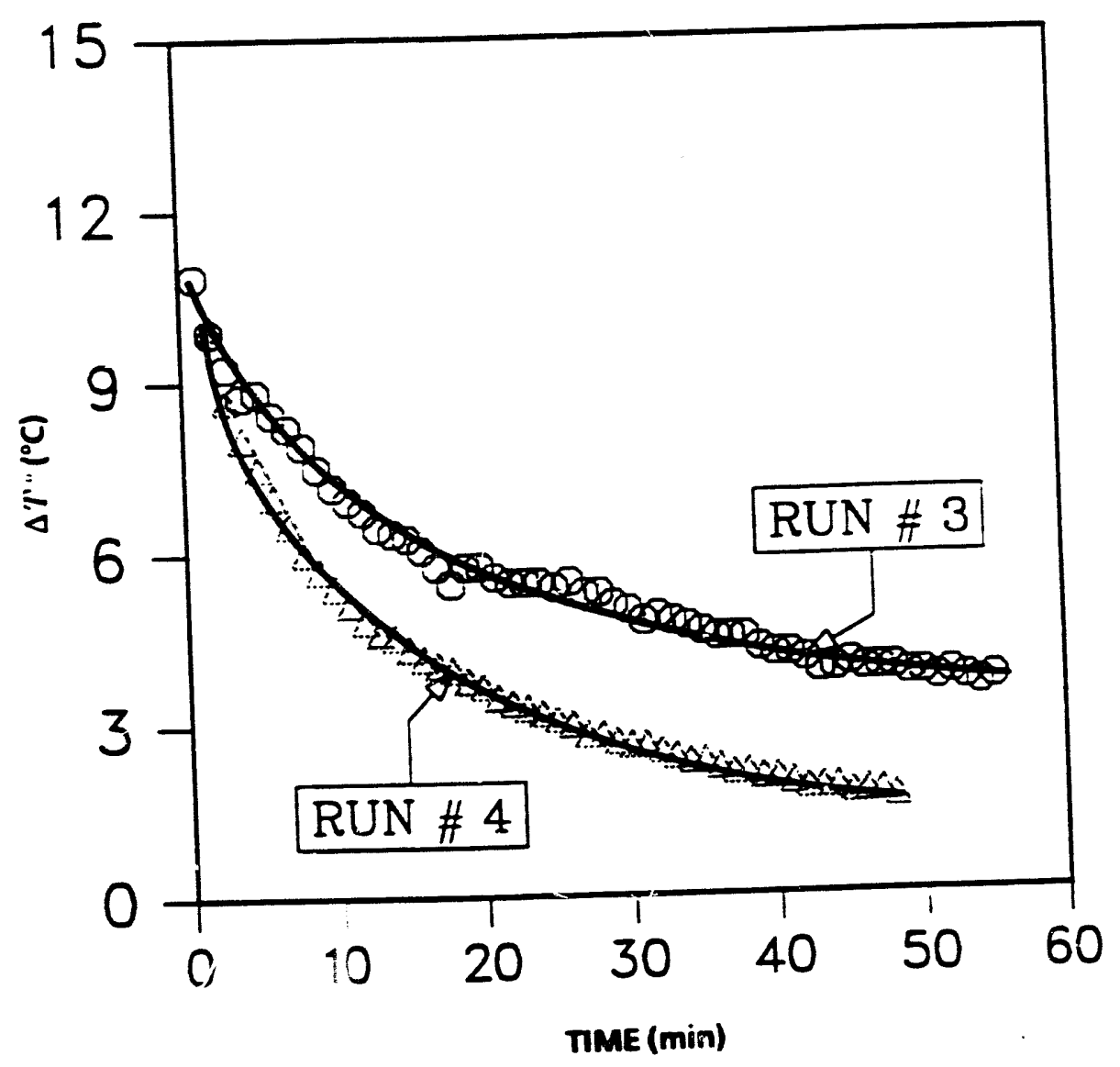

Figure 6.5: Decrease in Temperature Driving Force 
6.6 shows the effect of methanol injection rate on the cumulative gas produced from hydrate dissociation as a function of time for runs 1-4. In general, the increase in methanol injection rate increased the cumulative gas production since the forced convection effect played role in hydrate dissociation. The same effect is also shown in Figure 6.7 where hydrate dissociation rate is plotted as a function of apparent temperature driving force $\Delta T^{\circ}$. Figure 6.8 shows the effect of initial methanol concentration on the cumulative gas produced as function of time for fixed injection rate (runs 4-7). Increase in initial concentration results in higher true temperature driving force causing increased rate of hydrate dissociation.

In order to develop a correlation for rate of hydrate dissociation as a function of pressure, methanol solution temperature, methanol concentration, and hydratemethanol interfacial area, unsteady state data from runs 4-7 were considered. The effect of pressure, temperature of methanol solution and concentration of methanol on hydrate dissociation was accounted by defining the true temperature driving force given in equation (6.6). The effect of inhibitor-hydrate interfacial area is accounted by defining hydrate dissociation rate as $Q_{g} / \Phi_{H} A$ (gmol methane produced per $\mathrm{cm}^{2}$ hydrates at interface per sec.), where $\Phi_{H}$ is the volume (or area) fraction hydrates in the core. Figure 6.9 shows the correlation for rate of methane hydrate dissociation by methanol injection which is given by following equation:

$$
\frac{Q_{B}}{\phi_{H} A}=4.557 \times 10^{-7}(\Delta T)^{1.668}
$$

where $\Delta T$ is true temperature driving force $\left({ }^{\circ} \mathrm{C}\right)$ given by equation $(6.6)$. The average absolute percentage error in this correlation is $13.9 \%$.

To illustrate the effect of methanol inhibition on the degree of enhancement in the hydrate dissociation rate, which is defined as the ratio of dissociation rate at 


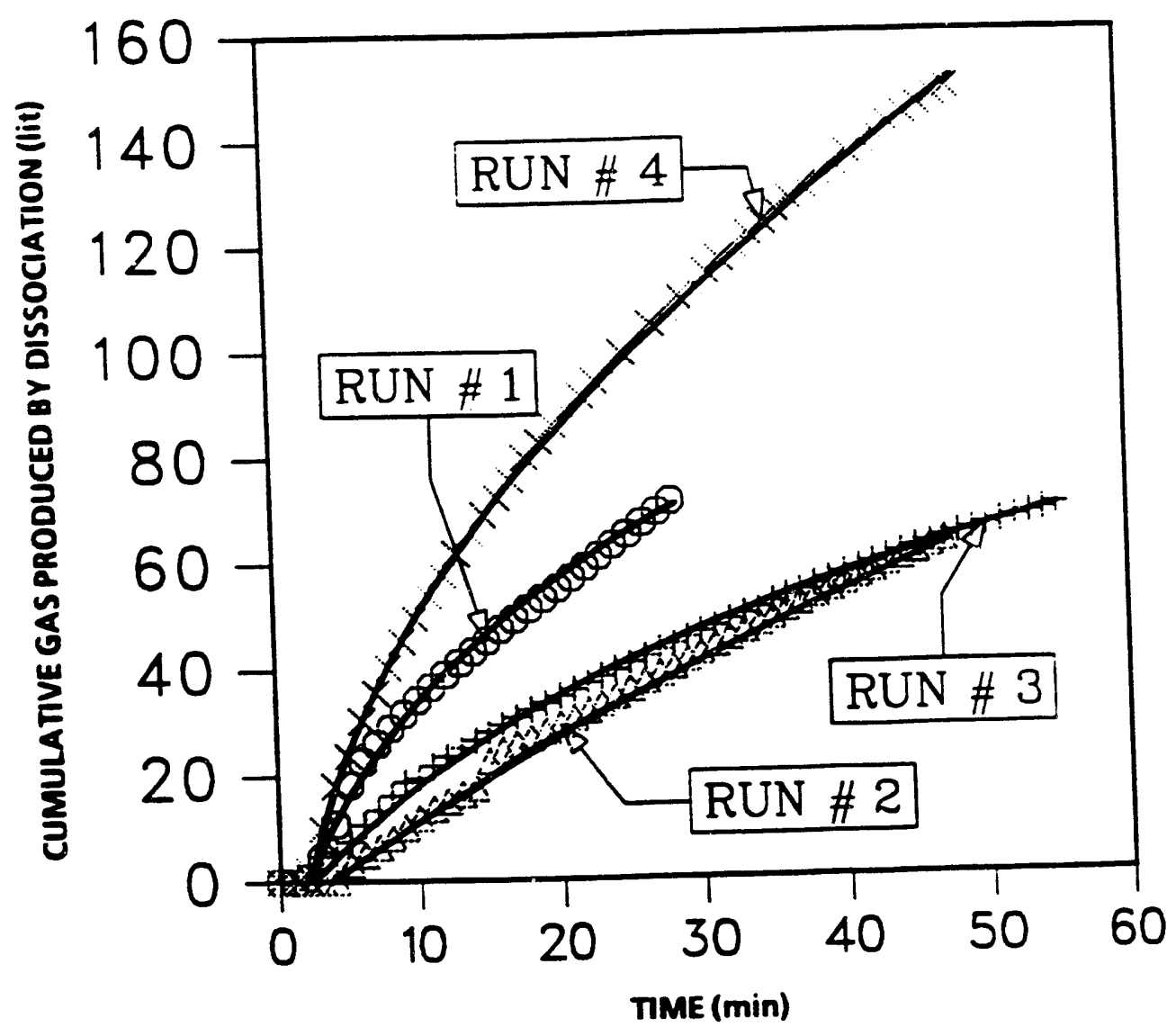

Figure 6.6: Effect of Methanol Injection Rate on Cumulative Gas Production (30 wt \% Methanol) 


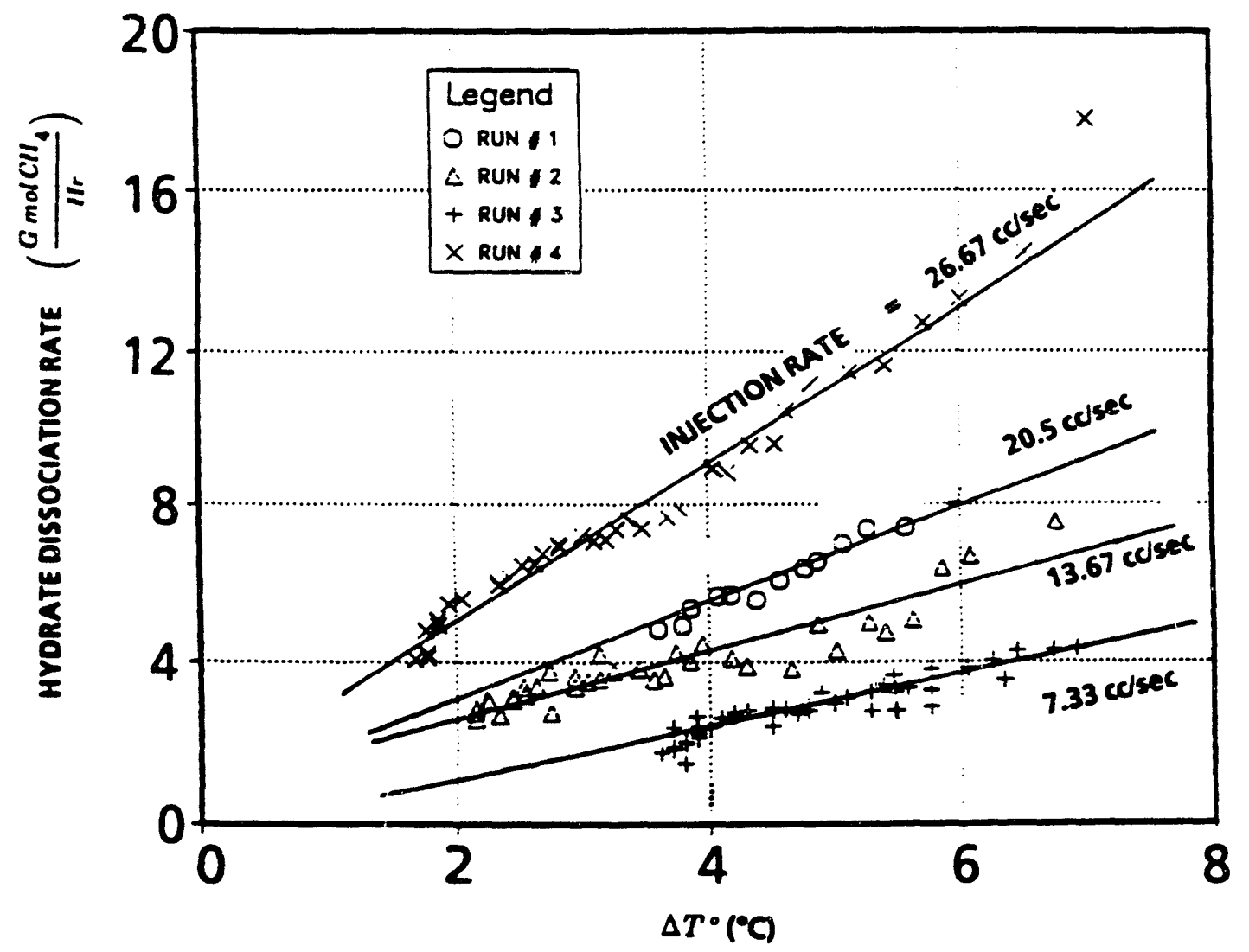

Figure 6.7: Effect of Methanol Injection Rate on Hydrate Dissociation Rate 


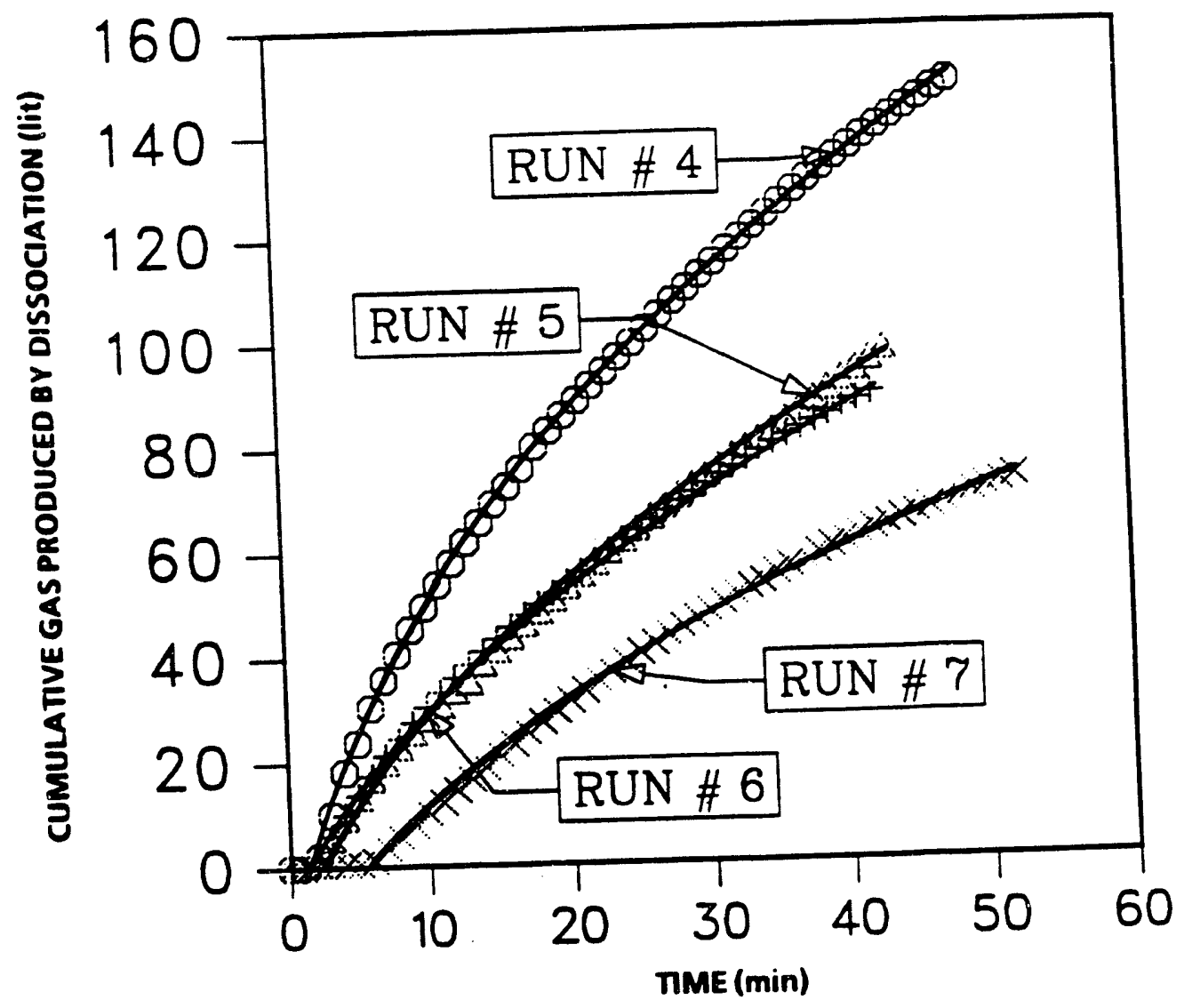

Figure 6.8: Effect of Methanol Concentration on Cumulative Gas Production ("njection Rate $=26.67 \mathrm{cdsec}$ ) 


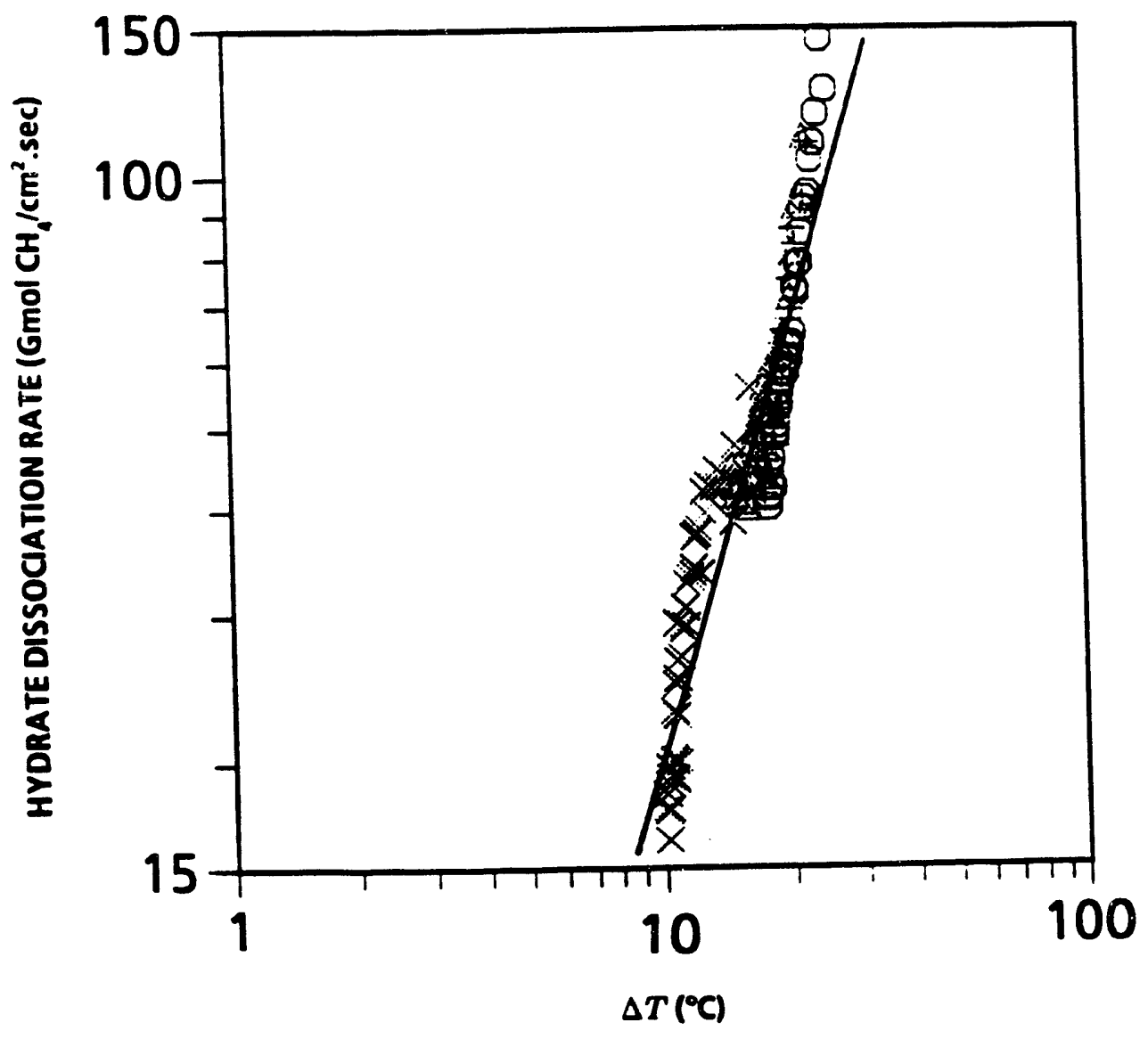

Figure 6.9: Hydrate Dissociation Correlation (Methanol Injection) 
$0 \%$ concentration, $\left(Q_{g}{ }^{0}\right)$ to dissociation rate at specified methanol concentration, $\left(Q_{g}\right)$ at given $\Delta T^{\circ}$ (apparent temperature driving force) was plotted versus methanol concentration (see Figure 6.10). At low $\Delta T^{o}$ values there is stronger effect of methanol inhibition than at high $\Delta T^{\circ}$ values.

\subsection{Glycol Injection Experimental Results}

Table 6.3 provides the properties of methane hydrate cores used in the dissociation experiments by ethylene glycol injection.

Table 6.4 provides a summary of experimental conditions during hydrate dissociation by ethylene glycol injection. In runs 1-3 and 7, ethylene glycol injection rate was maintained same as $26.67 \mathrm{cc} / \mathrm{sec}$ and initial glycol concentration was varied from 10 to $30 \mathrm{wt} \%$. In runs 3-7, initial glycol concentration was kept same at $30 \%$ and injection rate was varied from 6.67 to $26.67 \mathrm{cc} / \mathrm{sec}$. The experimental method, data analysis procedure was same as described earlier.

Figure 6.11 shows the effect of hydrate dissociation on the dilution of glycol solution. Figure 6.12 shows the effect of glycol injection rate (forced convection effect) on the cumulative gas produced. Figure 6.13 shows the effect of glycol concentration on the cumulative gas production. These effects are similar to those described for methanol injection runs. Figure 6.14 shows the correlation for rate of methane hydrate dissociation by glycol injection which is given by following equation:

$$
\frac{Q_{g}}{\Phi_{H} A}=8.606 \times 10^{-8}(\Delta T)^{2.578}
$$

The average absolute percentage error in this correlation is $17.3 \%$. In general, the rate of hydrate dissociation during water, brine, methanol or glycol injection methods can be expressed as: 


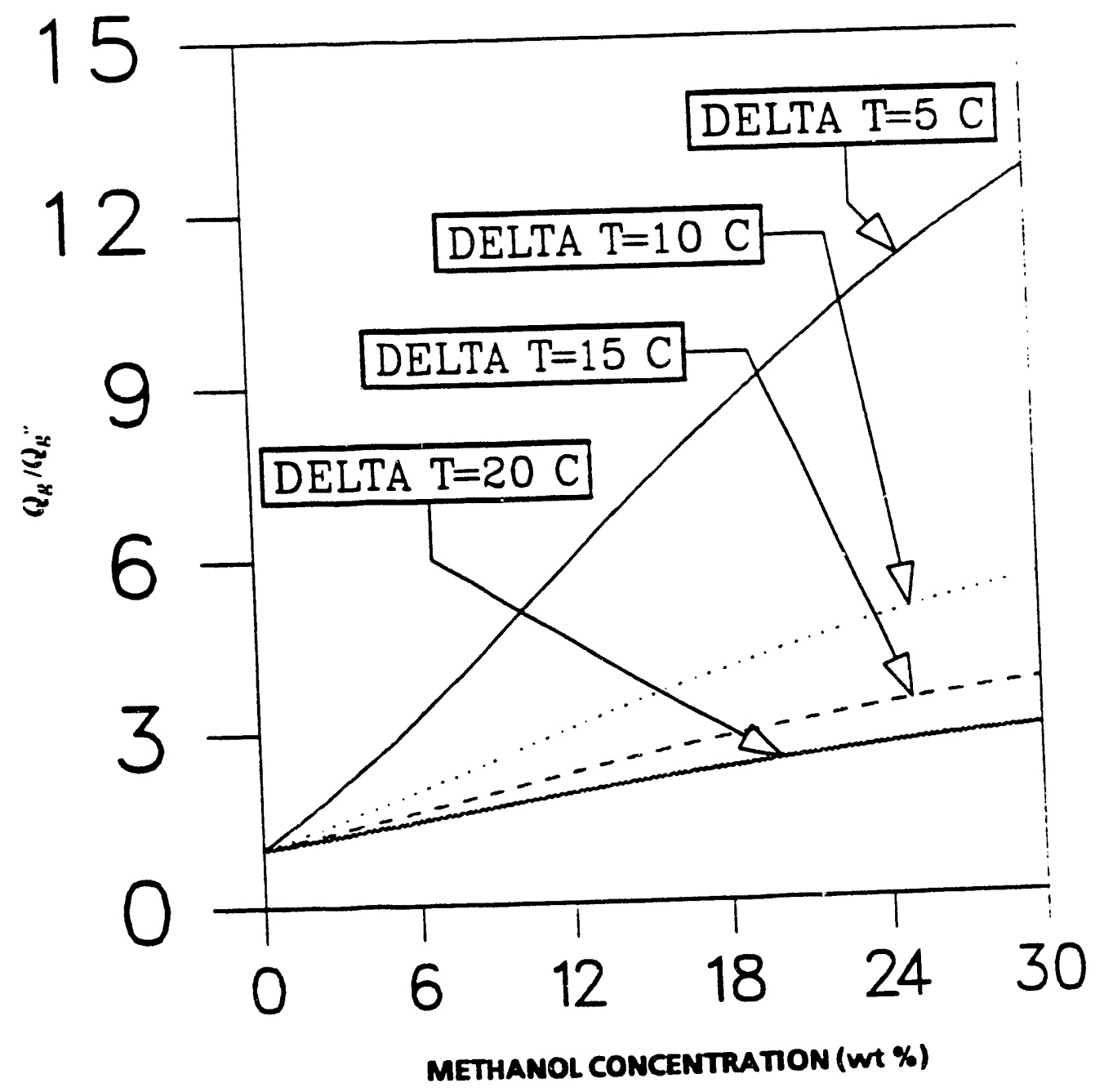

Figure 6.10: Effect of Methanol Inhibition on the Degree of Enhancement in Hydrate Dissociation Rate 


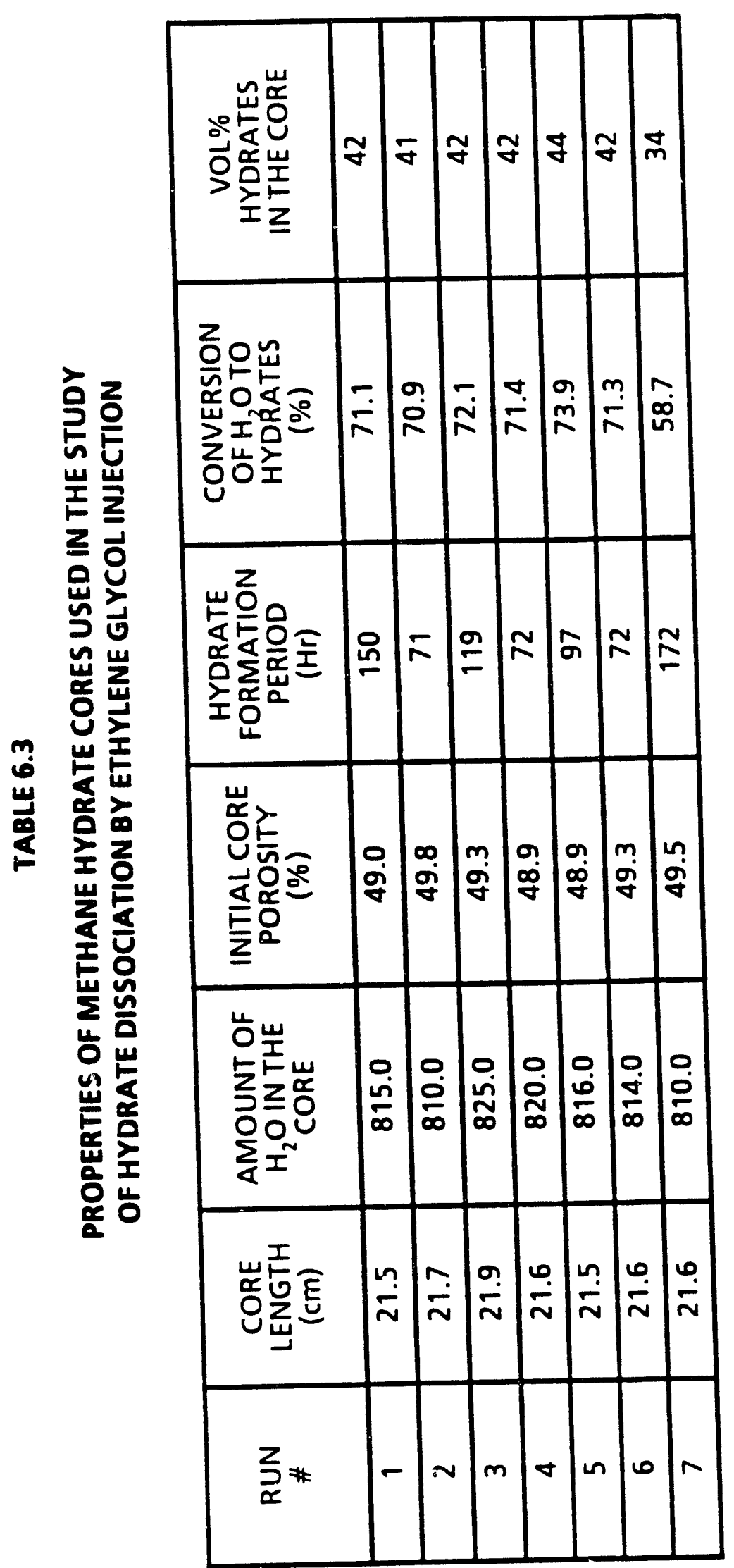




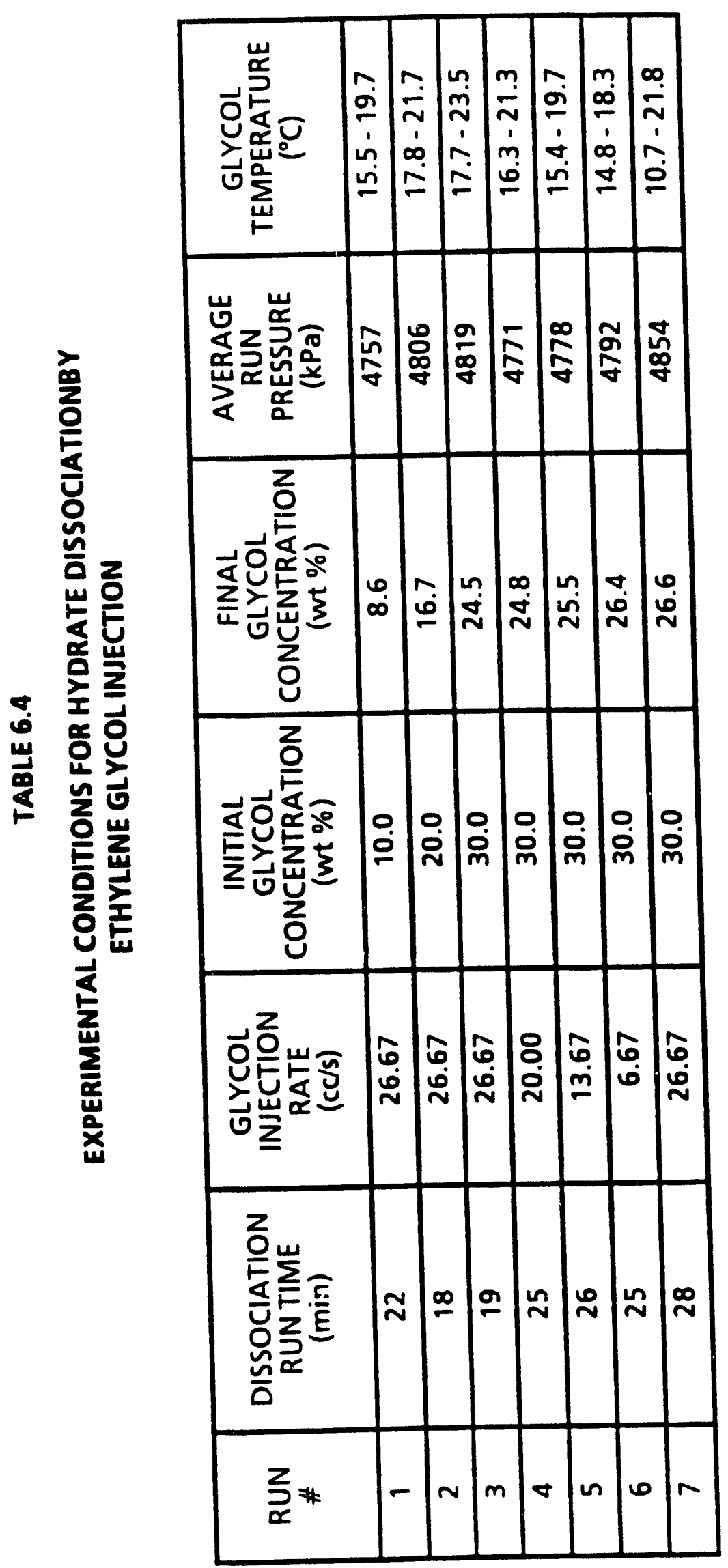




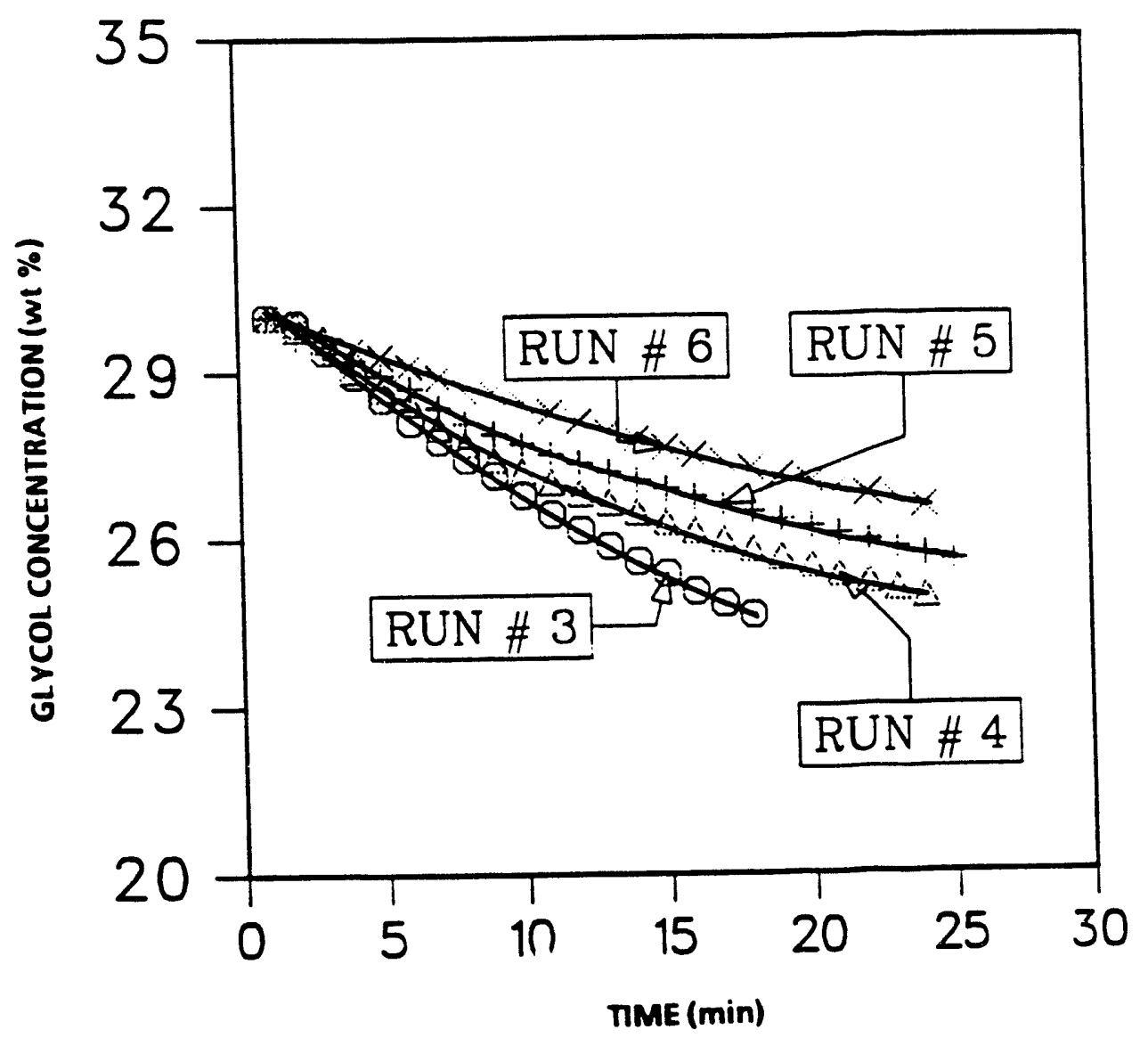

Figure 6.11: Dilution of Glycol by Hydrate Dissociation 


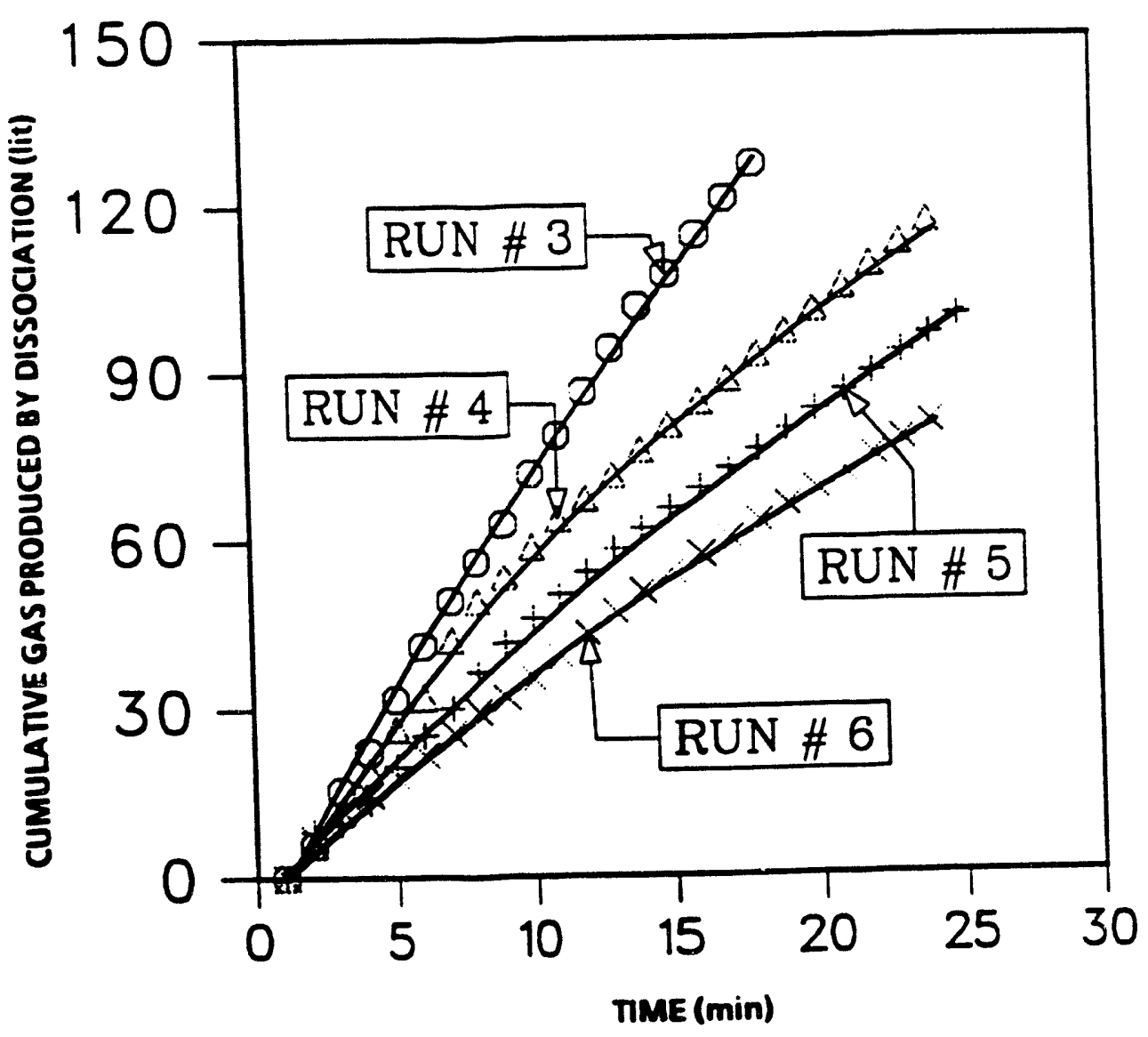

Figure 6.12: Effect of Glycol Injection Rate on Cumulative Gas Production (30 wt \% Glycol) 


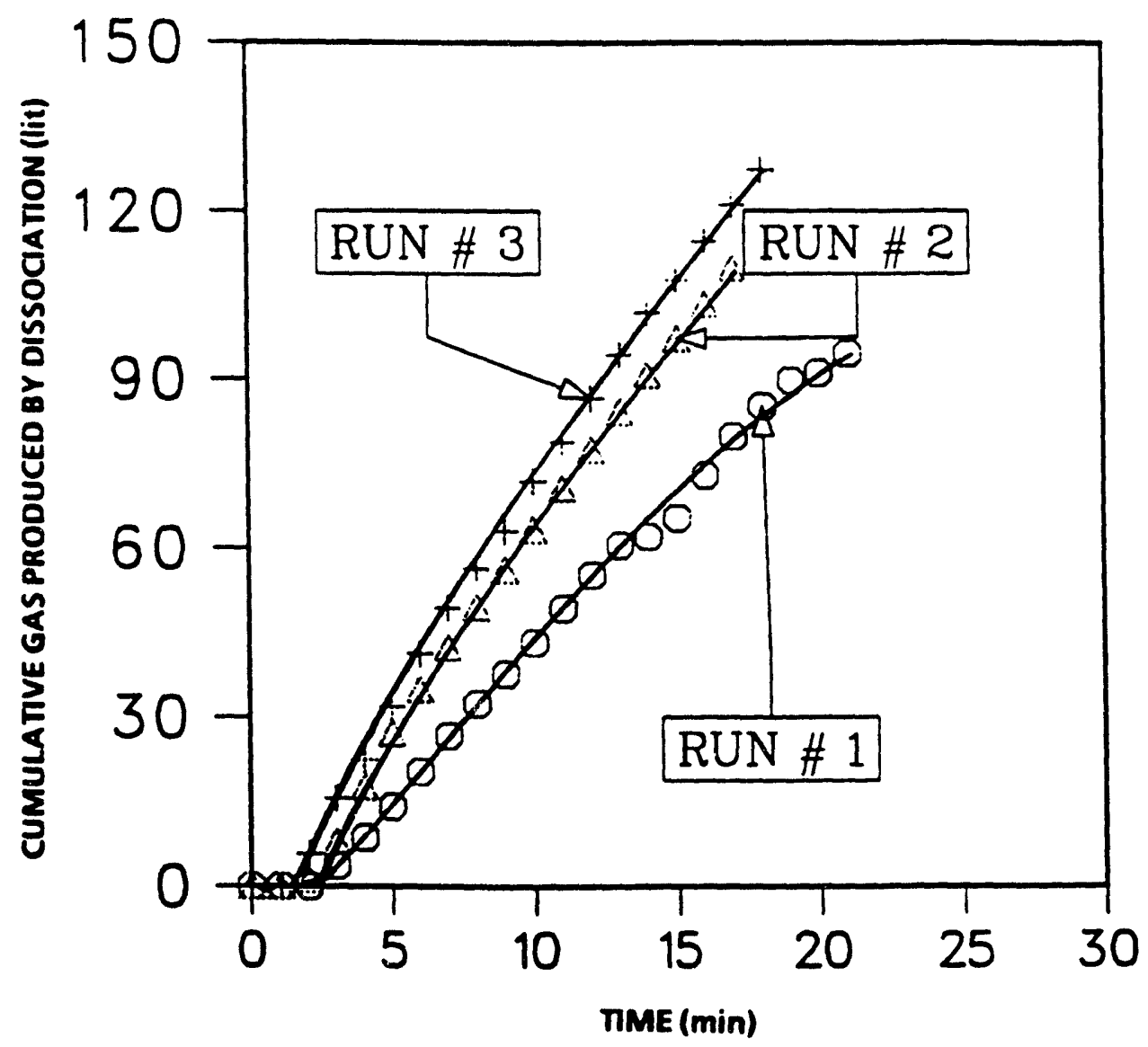

Figure 6.13: Effect of Glycol Concentration on Cumulative Gas Production (Injection Rate $=26.67 \mathrm{cc} / \mathrm{sec}$ ) 


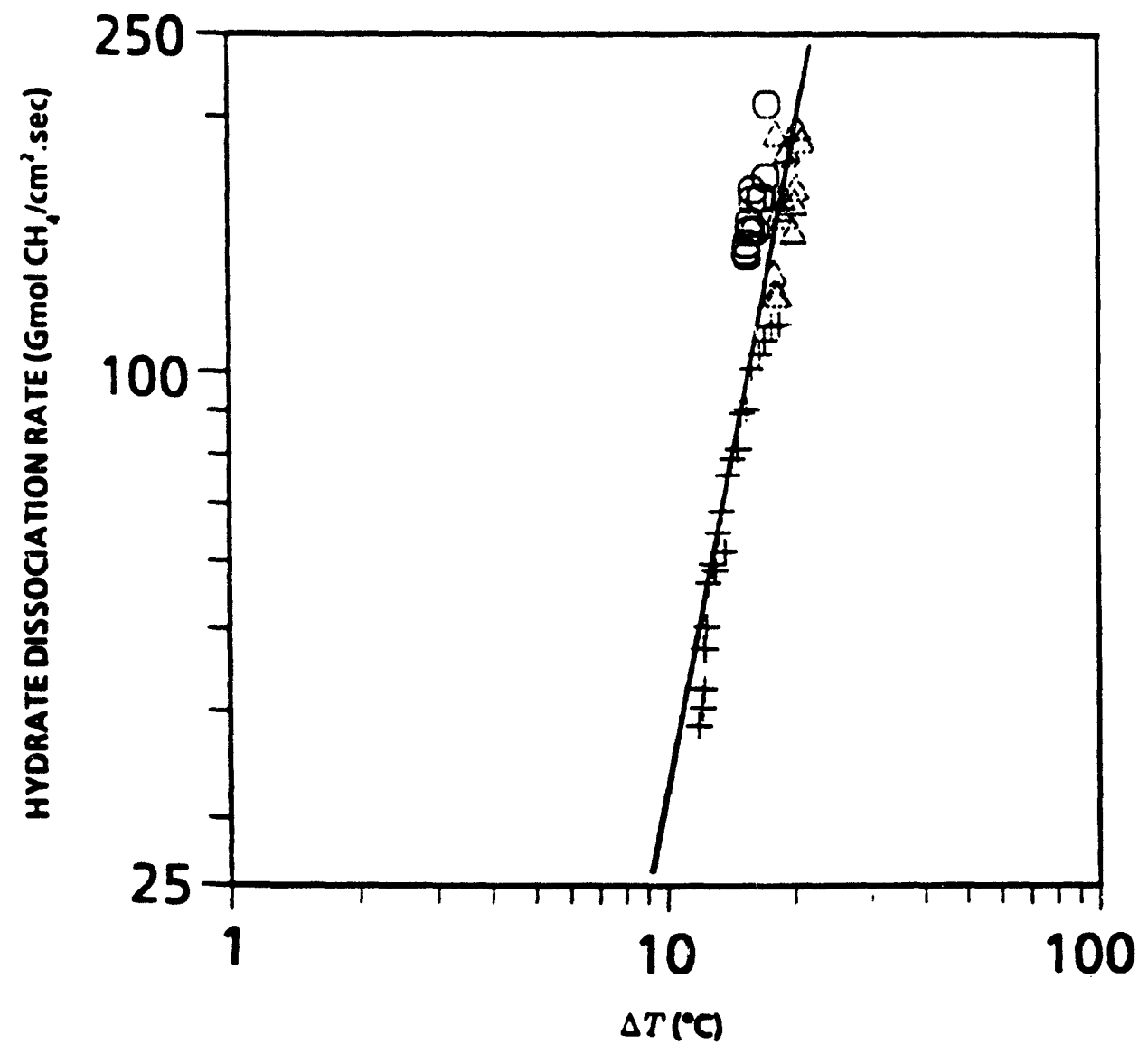

Figure 6.14: Hydrate Dissociation Correlation (Glycol Injection) 


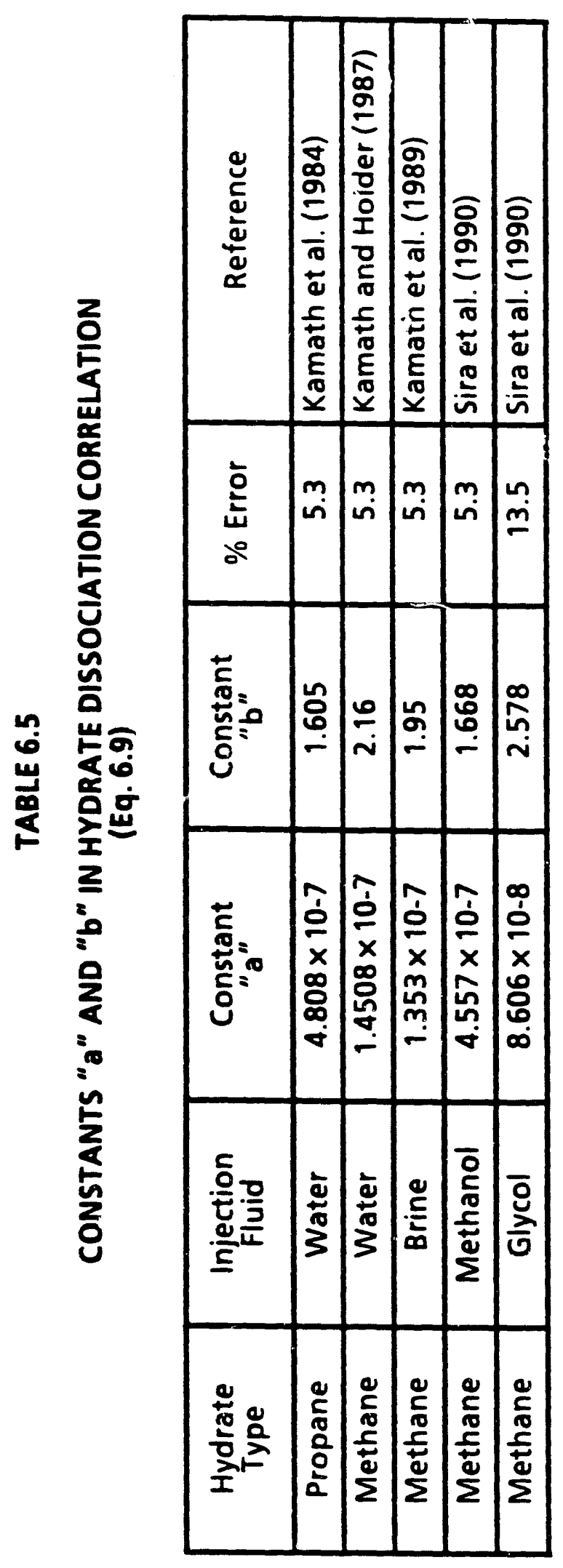




$$
\frac{Q_{g}}{\Phi_{H} A}=a \Delta T^{b}
$$

where $a$ and $b$ are constants and $\Delta T$ is true temperature driving force. The comparison of constants $a$ and $b$ for various hydrate dissociation methods is provided in Table 6.5. The experimental results show that effect of forced convection on hydrate dissociation rate is significant especially at very low temperature driving force $(\Delta T)$ values. Further work is needed to model this effect to incorporate correction factor in the correlation. In hydrate reservoirs where the darcy flow would be present, the experimental results can be extrapolated to very low flow rates to determine dissociation rates.

\subsection{Conclusions}

1. In this experimental study, the effect of inhibitors such as methanol and ethylene glycol on the rate of methane hydrate dissociation was investigated. Applications of this work include use of inhibitors for prevention of hydrate formation in natural gas processing and transportation and for production of natural gas from hydrate reservoirs.

2. Experimental results show that the rate of hydrate dissociation is function of concentration of inhibitor, rate of injection of inhibitor, pressure, temperature of inhibitor solution and hydrate-inhibitor interfacial area.

3. The inhibitors are excellent hydrate dissociation stimulants and the use of inhibitor results in significant enhancement in the rate of hydrate dissociation.

4. Based on experimental results, correlations of hydrate dissociation rates for methanol and glycol injection are developed and are consistent with the previous correlations for hydrate dissociation rate for brine and water injection. 


\subsection{Nomenclature}

A Cross sectional area of the core, $\left(\mathrm{cm}^{2}\right)$

$Q_{g} \quad$ Gas production rate due to hydrate dissociation in presence of inhibitors (Gmol/s)

$\mathbf{Q}_{\boldsymbol{g}}{ }^{\circ} \quad$ Gas production rate due to hydrate dissociation in absence of inhibitors (Gmol/s)

$T_{f} \quad$ Temperature of inhibitor fluid $\left({ }^{\circ} \mathrm{C}\right)$

$T_{1} \quad$ Equilibrium hydrate dissociation temperature in presence of inhibitors $\left({ }^{\circ} \mathrm{C}\right)$

$T_{I}^{0} \quad$ Equilibrium hydrate dissociation temperature in atsence of inhibitors $\left({ }^{\circ} \mathrm{C}\right)$

$x \quad$ Inhibitor concentration (wt \%)

$\Phi_{H} \quad$ Volume (or area) fraction hydrates at the interface

$\Delta T \quad$ True temperature driving force $\left({ }^{\circ} \mathrm{C}\right)$

$\Delta T^{\circ} \quad$ Apparent temperature driving force $\left({ }^{\circ} \mathrm{C}\right)$

$\Delta T_{x} \quad$ Inhibition effect on hydrate dissociation temperature $\left({ }^{\circ} \mathrm{C}\right)$

\subsection{References}

1. Deaton, W.M. and Frost, E.M.: "Gas Hydrates and Their Relation to the Operation of Natural Gas Pipelines", U.S. Bureau of Mines, Monograph No. 8 (1946).

2. Hammerschmidt, E.G.: "Formation of Gas Hydrates in Natural Gas Transmissirın Lines", Ind. Eng. Chem., Vol. 26 (1934), pp. 851-855.

3. Kamath, V.A. and Holder, G.D.: "Dissociation Heat Transfer Characteristics of Methane Hydrates", Am. Inst. Chem. Eng. Journal, Vol. 33, No. 2 (1987), p. 347. 
4. Kamath, V.A., Holder, G.D., and Angert, P.F.: "Three Phase Interfacial Heat Transfer During the Dissociation of Propane Hydrates", Chem. Eng. Sci., Vol. 39, No. 10 (1984), pp. 1435-1442.

5. Kamath, V.A., Mutalik, P.N., Sira, J.H. and Patil, S.L.: "Experimental Study of Brine Injection and Depressurization Methods for Dissociation of Gas Hydrates", SPE Paper 19810, Presented at the 64th Annual Technical Conference and Exhibition of the SPE, San Antonio, TX (Oct. 8-11, 1989).

6. Makogon, Y.F.: "Hydrates of Natural Gas", translated by Cieslewicz, W.J., Pennwell Publishing Company, Tulsa, OK (1981), p. 174.

7. Makogon, Y.F.: "Natural Gas Hydrates - The State of Study in the USSR and Perspectives for Its Using", a paper presented at the Third Chemical Congress and the 19th ACS Meeting, Toronto, Canada (June 1988).

8. Ng, H.J., Chen, C.J., and Robinson, D.B.: "Hydrate Formation and Equilibrium Phase Compositions in the Presence of Methanol: Selected Systems Containing Hydrogen Sulfide, Carbon Dioxide, Ethane or Methane", Gas Proc. Assoc. Report, RR-87, Project 825-84 (1985).

9. Robinson, D.B. and Ng, H.J.: "Hydrate Formation and Inhibition in Gas or Gas Condensate Streams", Paper No. 85-36-10, Proceedings of the 36th Annual Technical Meeting of the Petroleum Society of CIM, Edmonton, Canada (June 2-5, 1985).

10. Sloan, E.D. Jr.: "Clathrate Hydrates of Natural Gases", Marcel Dekkar Inc. (1990), pp. 477-536. 


\section{CHAPTER SEVEN}

\section{EXPERIMENTAL STUDY OF FORMATION OF HYDRATES IN PRESENCE OF ALASKAN NORTH SLOPE CRUDES}

\subsection{Introduction}

It is reported that gas hydrates occur in conjunction with heavy oils and tar sands in the southwest up-dip continuation of West Sak and Ugnu formations in the Kuparuk River Unit, North Slope of Alaska (Collet, 1985). Other studies by Molenaar (1983) have indicated that the source of hydrocarbon accumulations in the Prudhoe Bay Unit and Kuparuk River Unit have same origin. While crudes from Prudhoe Bay

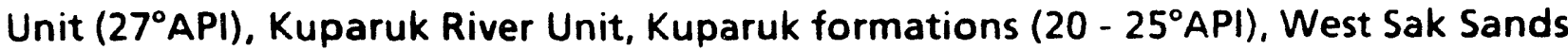
in Kuparuk River Unit (14-22 API) and Ugnu Sands in Kuparuk River Unit (8 - $\left.12^{\circ} \mathrm{API}\right)$ differ significantly in oil gravities, the sulfur contents of these crudes are identical (1.8 - $1.85 \% \mathrm{wt})$. One theory suggests that the light crude oils from deeper Sadlerochit formations of the Prudhoe Bay Unit in the east, migrated up-dip towards shallower formations in the Kuparuk River unit in the west. During this up-dip migration process, crude oils passed through bubble point releasing lighter gases causing oils to become heavier. Due to favorable conditions for hydrate formation, the released gases might have reformed into solid hydrates. Absence of gases in the shallower West Sak and Ugnu formations along with well log analysis supports this postulation of presence of gas hydrates along with heavy oils in the southwest extensions of these formations of the Kuparuk River Unit.

Since heavy oil accumulations in the West Sak sands are now considered as near term target for recovery, it has become important to establish the hydrate phase equilibrium conditions for light gases, crude oils typically found in this region. In addition, the effect of hydrate formation on the physical properties of crude oils and their compositional changes will be helpful in developing a better understanding of 
hydrate - oil occurrences and developing guidelines for the enhanced oil recovery from West Sak and Ugnu reservoirs.

This experimental work was focused towards the hydrate formation from mixtures of Alaskan North Slope crudes, methane and water. The oil samples from Prudhoe Bay - Sadlerochit formation and Milne Point Unit - West Sak formations were used. The four phase $\left(V L_{1} L_{2} H\right)$ equilibrium pressure-temperature conditions were measured. Here $V$ refers to the vapor phase, $L$, refers to aqueous phase, $L_{2}$ refers to liquid hydrocarbon phase and $H$ refers to solid hydrate phase. The effect of hydrate formation on crude oil properties such as bubble point pressure, solution gas-oil ratio and oil density were determined.

\subsection{Experimental Set-Up}

The equipment used in this study was essentially similar to that used by previous investigators (Kamath et al., 1982). The schematic diagram of the experimental set up is shown in Figure 7.1. The hydrate cell was a windowed Jerguson gauge (model 19-TL-10) with a capacity of $50 \mathrm{cc}$. and designed for pressures up to 3000 psia $(\approx 21 \mathrm{MPa})$. The hydrate cell was suspended in a constant temperature bath by means of a lever connected to an in-line gear motor to agitate its contents. The constant temperature bath (20 gallon capacity) was made up of glass, equipped with two windows and was completely insulated with styrofoam. The bath was equipped with a refrigeration unit (Cryocool CC-100), immersion heater and temperature controller (Exatrol-150 Neslab model, $\pm 0.05 \mathrm{~K}$ accuracy), thermocouples and temperature readout device. Accuracy of temperature measurements were $\pm 0.18^{\circ} \mathrm{R}( \pm 0.1 \mathrm{~K})$ and pressure measurement were \pm 0.5 psia $( \pm 3.45 \mathrm{KPa})$. HP 5790A model gas chromatograph with natural gas analyzer assembly was used for gas analysis accurate up to $\pm 2 \%$. Research grade methane 

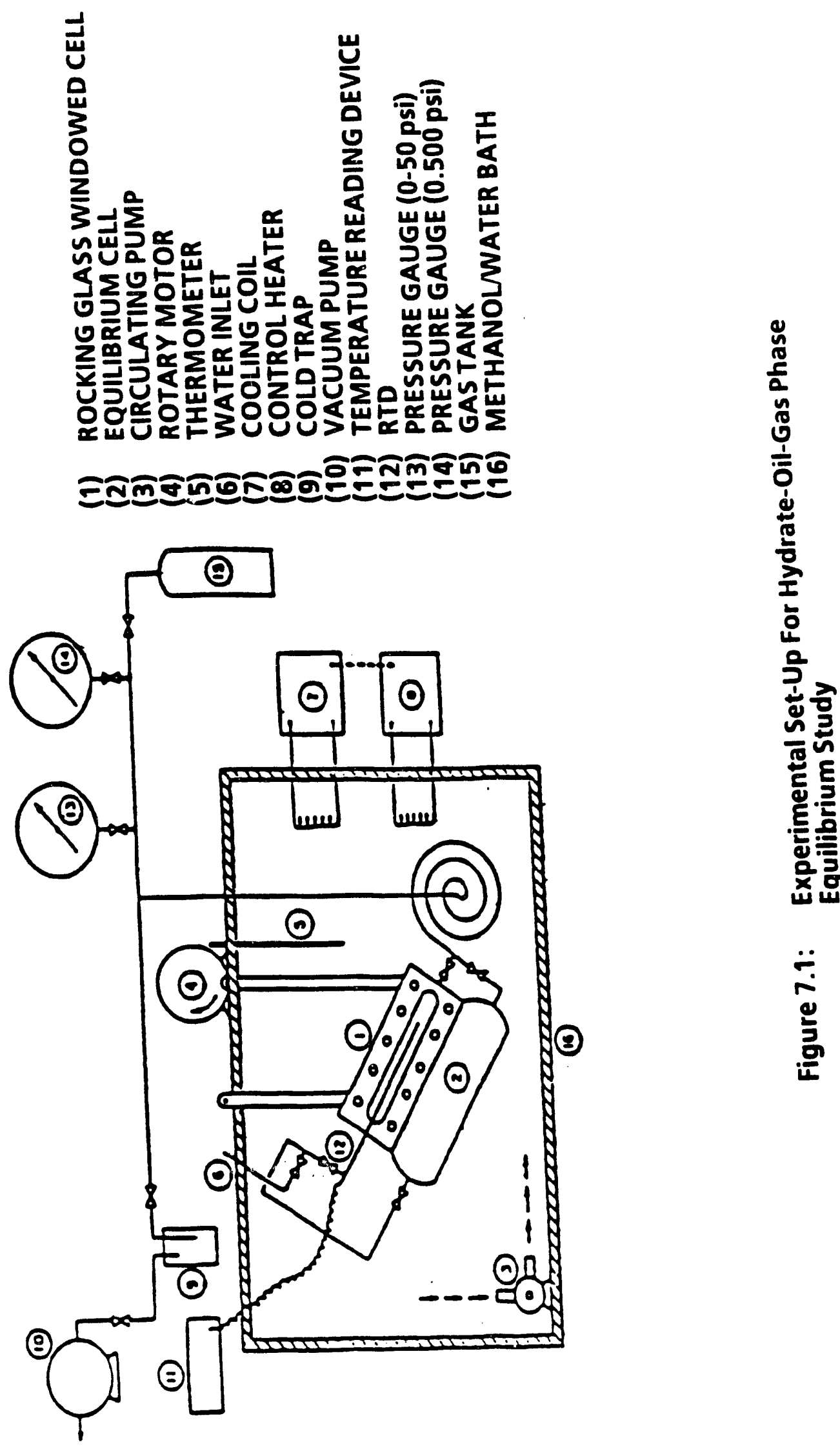
was used. Prior to the start of the experiments, all platinum resistance thermometers, gas chromatograph and pressure gauges were calibrated.

\subsection{Procedure for Measuring Four Phase $\left(V_{1} L_{2} H\right)$ Conditions for}

\section{Crude Oil-Gas-Water Systems}

In order to form hydrates from crude oil-gas-water mixtures and to measure the $\left(V L_{1} L_{2} H\right)$ four phase locus following procedure was adopted:

1. Initially the hydrate cell was cleaned thoroughly with distilled water and the cell and tubing were evacuated.

2. About $20 \mathrm{cc}$. of doubly distilled water was charged to the hydrate cell and cell was re-evacuated to remove traces of dissolved air from the water phase.

3. About 5 - $10 \mathrm{cc}$. of crude oil was then injected into the visual cell.

4. The visual cell was then pressurized to a predetermined pressure with methane. At this point only three phases coexisted in the visual cell (namely, gas, water rich liquid and crude oil rich phase).

5. The system was cooled to 0 to $1^{\circ} \mathrm{C}$ temperature and the cell contents were agitated vigorously by rock motor and hydrate formation was allowed to occur as observed visually.

6. The cell temperature was then increased slowly in small increments to dissociate hydrates partially. When only few crystals of hydrates remained in the cell, the cell temperature was held constant and the system was allowed to equilibriate for 8 to 10 hours. Precautions were taken so that at equilibrium all four phases (hydrate, vapor, water rich liquid and hydrocarbon rich liquid) coexisted. The equilibrium pressure and temperature conditions were recorded. 
7. More methane was injected in the cell at this point to raise the pressure as well as from more hydrates. Step 6 was repeated to obtain four phase equilibrium conditions at a higher temperature. This procedure was repeated to obtain the entire four phase locus.

\subsection{Effect of Hydrate Formation on Crude Oil Properties}

\section{West Sak Crude:}

The four phase $\left(V L_{1} L_{2} H\right)$ equilibrium conditions for West Sak Crude-methane and water are given in Table 7.1. In order to determine the effect of hydrate formation on West Sak crude oil properties, it was necessary to determine West Sak crude oil properties at experimental pressure and temperature conditions.

The crude oil bubble point pressures, constant composition expansion data, differential expansion data, separator data, oil and gas viscosity data were used to tune the parameters in the equation of state. We used Peng Robinson Equation of State for this purpose. The data used for tuning purposes is given in Tables 7.2 to 7.6.

After tuning the Peng Robinson Equation of State (Peng and Robinson, 1976), the phase behavior simulator was then used to calculate, bubble point pressure, solution gas oil ratio, oil density for the experimental pressure and temperature conditions.

Figure 7.2 shows that the original bubble point pressure of West Sak crude (two phase, $\mathrm{VL}_{2}$ curve) is lowered due to the hydrate formation (four phase, $V L_{1} L_{2} \mathrm{H}$ curve). This effect is due to denudation of crude off it's lighter hydrocarbon components by hydrate phase.

Similarly, hydrate formation causes, lowering of solution GOR of the crude (Figure 7.3), and increase in oil density (Figure 7.4). 
TABLE 7.1

VL,L2H DATA FOR WEST SAK CRUDE-METHANE-WATER MIXTURE

\begin{tabular}{|c|c|}
\hline Temperature (K) & Pressure (KPa) \\
\hline 279.75 & 5363 \\
\hline 280.85 & 6026 \\
\hline 281.55 & 6385 \\
\hline 282.05 & 6791 \\
\hline 282.45 & 7033 \\
\hline 284.05 & 8301 \\
\hline
\end{tabular}


TABLE 7.2

LIVE WEST SAK CRUDE COMPOSITION

\begin{tabular}{|c|c|}
\hline Component & Mol\% \\
\hline $\mathrm{CO}_{2}$ & 0.016 \\
\hline $\mathrm{N}_{2}$ & 0.032 \\
\hline$c_{1}$ & 38.333 \\
\hline$c_{2}$ & 0.857 \\
\hline$c_{3}$ & 0.359 \\
\hline$C_{4}$ & 0.179 \\
\hline$C_{5}$ & 0.064 \\
\hline$C_{6}$ & 0.200 \\
\hline$C_{7}$ & 0.016 \\
\hline$C_{8}$ & 0.008 \\
\hline$C_{9}$ & 0.823 \\
\hline$C_{10}$ & 1.496 \\
\hline$c_{11}$ & 1.720 \\
\hline$C_{12}$ & 1.346 \\
\hline$C_{13}$ & 1.496 \\
\hline$C_{14}$ & 1.795 \\
\hline$C_{15}$ & 1.944 \\
\hline$C_{16}$ & 1.795 \\
\hline$C_{17}$ & 1.570 \\
\hline$C_{18}$ & 1.795 \\
\hline$C_{19}$ & 2.468 \\
\hline$C_{20}$ & 2.841 \\
\hline$C_{21+}$ & 39.037 \\
\hline
\end{tabular}

Avg. Mol Wt. $\mathrm{C}_{21+}=455 \mathrm{lb} / \mathrm{lb}-\mathrm{mol}$ 
TABLE 7.3

WEST SAK CRUDE PVT PROPERTIES

\begin{tabular}{|c|c|c|c|c|c|}
\hline $\begin{array}{c}\text { Pressure } \\
(\mathrm{psi})\end{array}$ & $\begin{array}{c}\text { GOR } \\
(\text { sct/stb) }\end{array}$ & $\begin{array}{c}B_{\mathbf{o}} \\
(\mathrm{rb} / \mathrm{stb})\end{array}$ & $\begin{array}{c}\text { Density } \\
(\mathrm{g} / \mathrm{cc})\end{array}$ & $\begin{array}{c}\text { Viscosity } \\
(\mathrm{cp})\end{array}$ & $\begin{array}{c}B_{g} \\
\left(\mathrm{ft}^{3} / \mathrm{scf}\right)\end{array}$ \\
\hline 1690 & 210 & 1.069 & 0.902 & 35.4 & 0.00825 \\
\hline 1500 & 188 & 1.063 & 0.905 & 40.0 & 0.00966 \\
\hline 1300 & 165 & 1.056 & 0.908 & 45.2 & 0.01162 \\
\hline 1100 & 141 & 1.049 & 0.911 & 51.2 & 0.01450 \\
\hline 900 & 117 & 1.042 & 0.914 & 58.5 & 0.01906 \\
\hline 700 & 93 & 1.036 & 0.917 & 68.4 & 0.02724 \\
\hline 500 & 68 & 1.029 & 0.920 & 82.5 & 0.04593 \\
\hline 300 & 42 & 1.022 & 0.923 & 102.1 & 0.04593 \\
\hline 100 & 15 & 1.014 & 0.927 & 127.6 & 0.13004 \\
\hline
\end{tabular}


TABLE 7.4

SATURATION PRESSURES OF WEST SAK CRUDE (psia)

\begin{tabular}{|c|c|c|}
\hline $\begin{array}{c}\text { Temp. } \\
\text { (deg F) }\end{array}$ & $\begin{array}{c}\text { Bubble Point } \\
\text { Pressure } \\
\text { (psia) }\end{array}$ & $\begin{array}{c}\text { Bubble Point } \\
\text { Pressure Predicted } \\
\text { (psia) }\end{array}$ \\
\hline 80 & 1705 & 1704.7 \\
\hline 100 & 2048 & 1800.0 \\
\hline 200 & 2355 & 2300.0 \\
\hline 250 & 2495 & 2470.0 \\
\hline
\end{tabular}


TABLE 7.5

HYDROCARBON ANALYSIS OF WEST SAK SEPARATOR GAS

\begin{tabular}{|c|c|}
\hline Component & Mol\% \\
\hline $\mathrm{H}_{2} \mathrm{~S}$ & 0.00 \\
\hline $\mathrm{CO}_{2}$ & 0.02 \\
\hline $\mathrm{N}_{2}$ & 0.16 \\
\hline $\mathrm{C}_{1}$ & 98.33 \\
\hline $\mathrm{C}_{2}$ & 0.24 \\
\hline $\mathrm{C}_{3}$ & 0.31 \\
\hline $\mathrm{i}-\mathrm{C}_{4}$ & 0.07 \\
\hline $\mathrm{n}-\mathrm{C}_{4}$ & 0.12 \\
\hline $\mathrm{i}-\mathrm{C}_{5}$ & 0.03 \\
\hline $\mathrm{n}-\mathrm{C}_{5}$ & 0.03 \\
\hline $\mathrm{C}_{6}$ & 0.02 \\
\hline $\mathrm{C}_{7}$ & 0.02 \\
\hline Total & 100.0 \\
\hline
\end{tabular}

Separator gas @ 300 psig \& $65^{\circ} \mathrm{F}$ 
TABLE 7.6

CONSTANT COMPOSITION EXPANSION DATA FOR WEST SAK CRUDE AT 80\%

\begin{tabular}{|c|c|}
\hline $\begin{array}{c}\text { Pressure } \\
\text { (psia) }\end{array}$ & $\begin{array}{c}\text { Relative } \\
\text { Liquid Volume }\end{array}$ \\
\hline 1704.7 & 1.0000 \\
\hline 1447.7 & 0.9742 \\
\hline 1372.7 & 0.9544 \\
\hline 1258.7 & 0.9339 \\
\hline 1021.7 & 0.8777 \\
\hline 907.7 & 0.8441 \\
\hline 705.7 & 0.7615 \\
\hline 594.2 & 0.6849 \\
\hline 460.2 & 0.6054 \\
\hline
\end{tabular}

Relative Liquid Volume $=$ Vol. of liquid at any pressure Vol. of liquid at bubble point pressure 

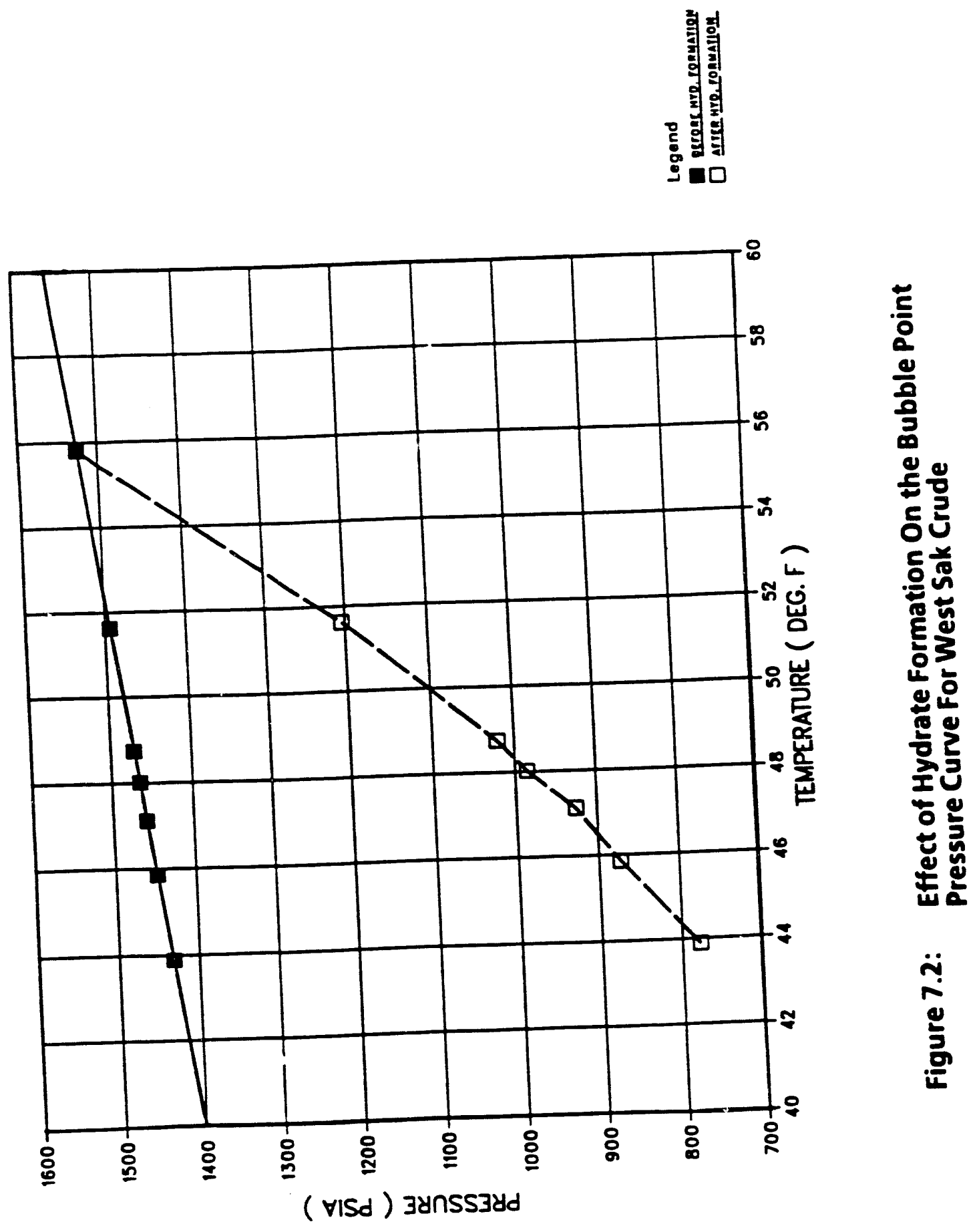

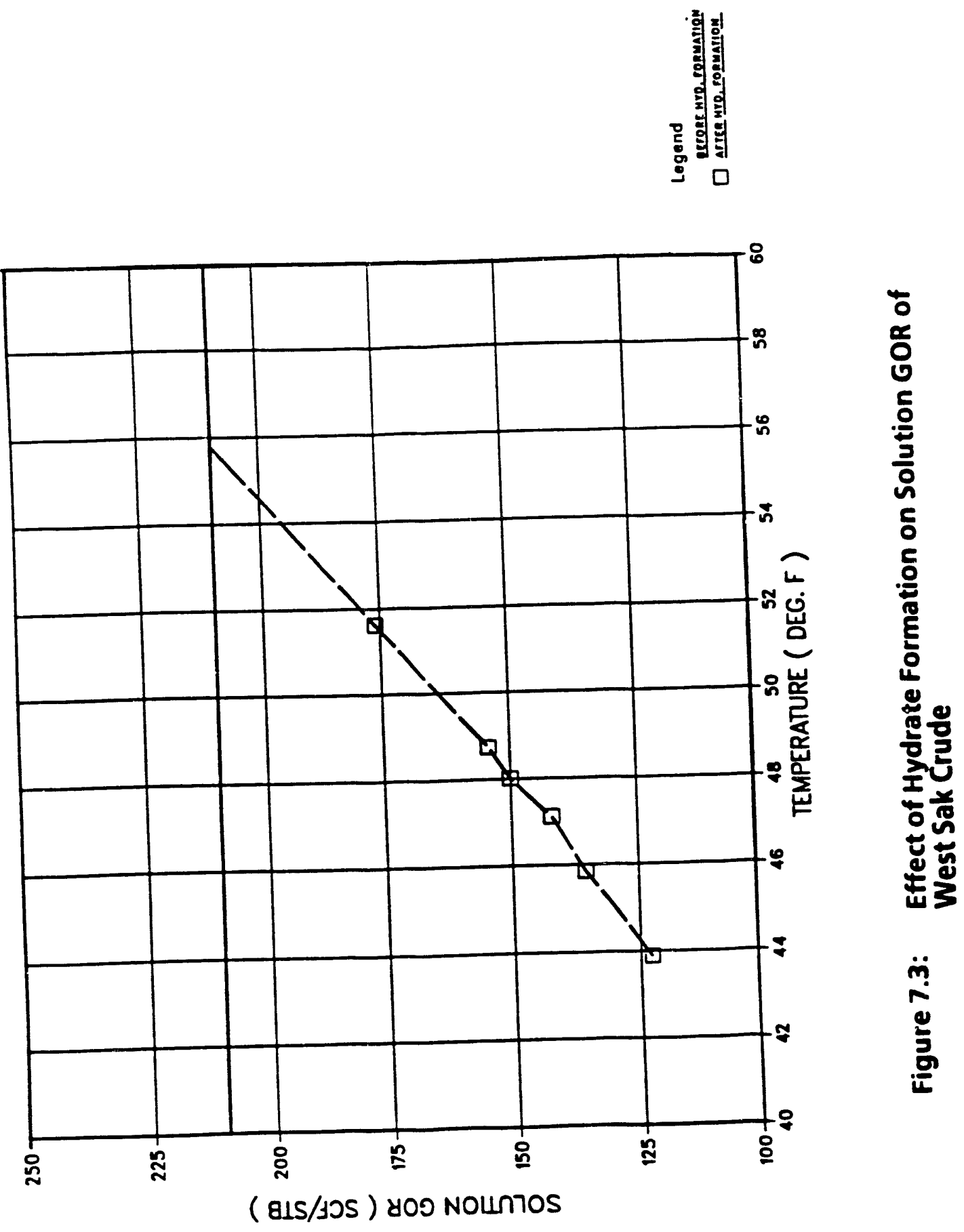

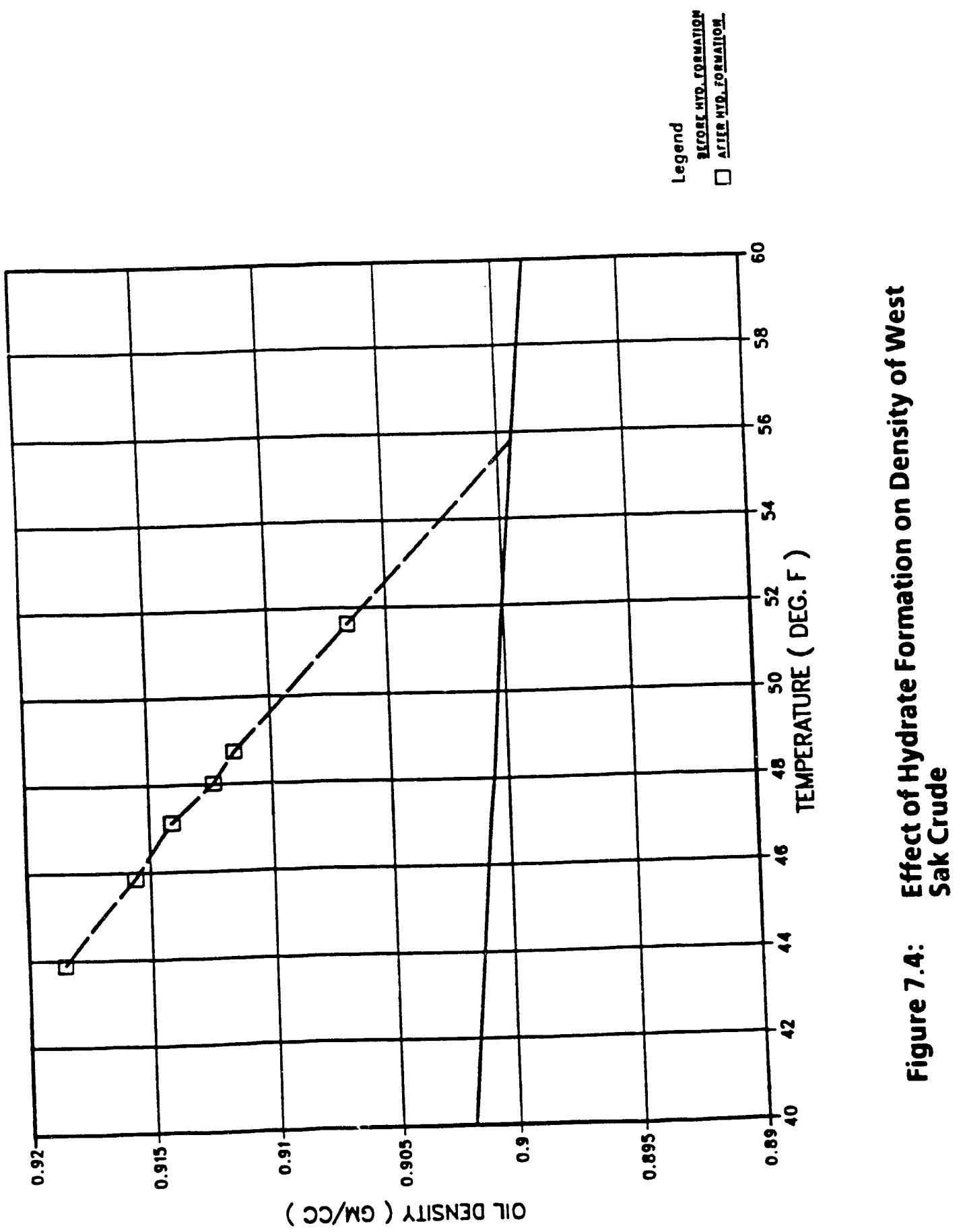
TABLE 7.7

VL, $L_{2}$ H DATA FOR PRUDHOE BAY CRUDE-METHANE-WATER MIXTURE

\begin{tabular}{|c|c|}
\hline Temperature (K) & Pressure (kPa) \\
\hline 276.35 & 4033 \\
\hline 277.45 & 5102 \\
\hline 279.35 & 6343 \\
\hline 282.95 & 7722 \\
\hline 284.25 & 8550 \\
\hline 285.35 & 9653 \\
\hline 286.55 & 11110 \\
\hline 287.05 & 11721 \\
\hline
\end{tabular}



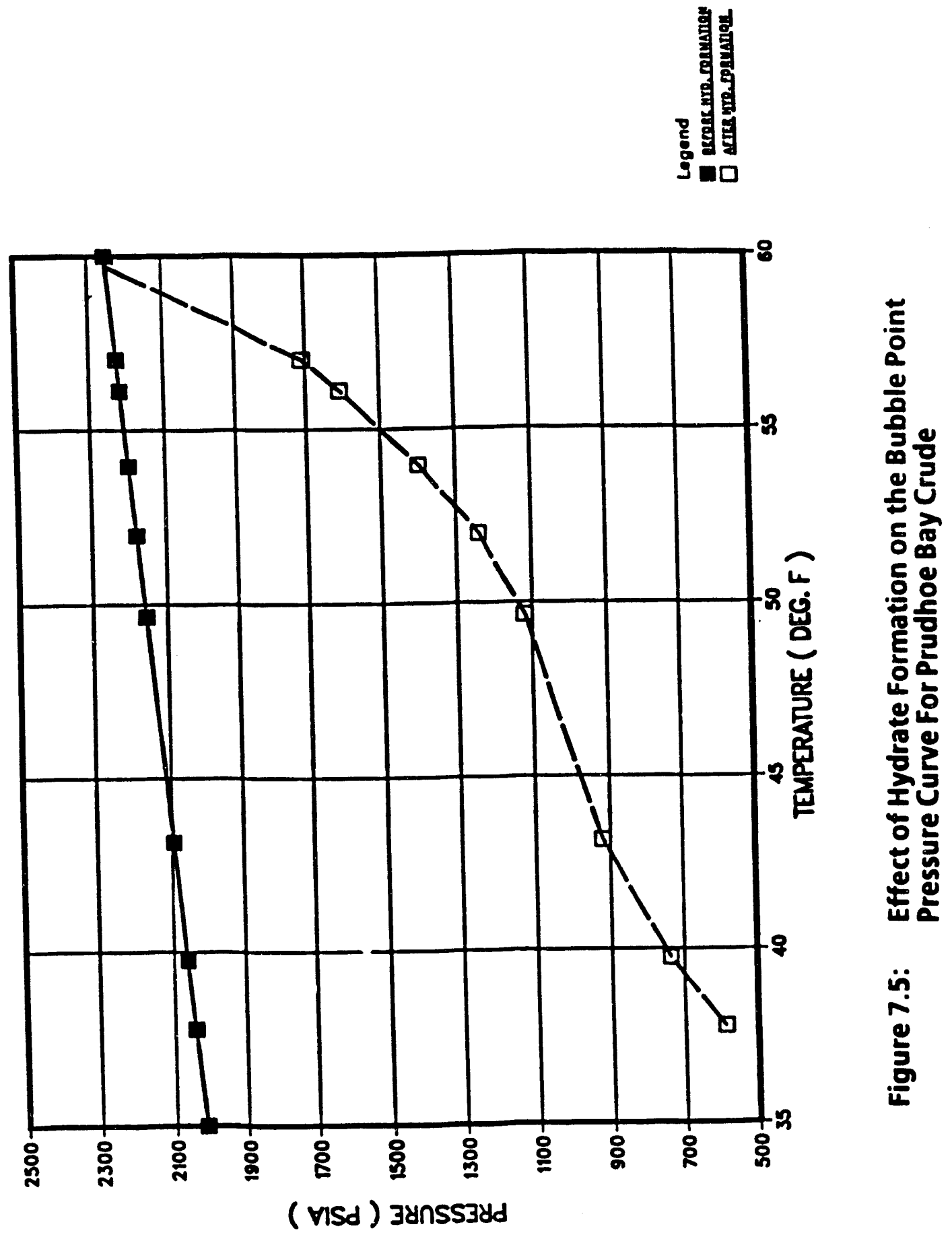
II

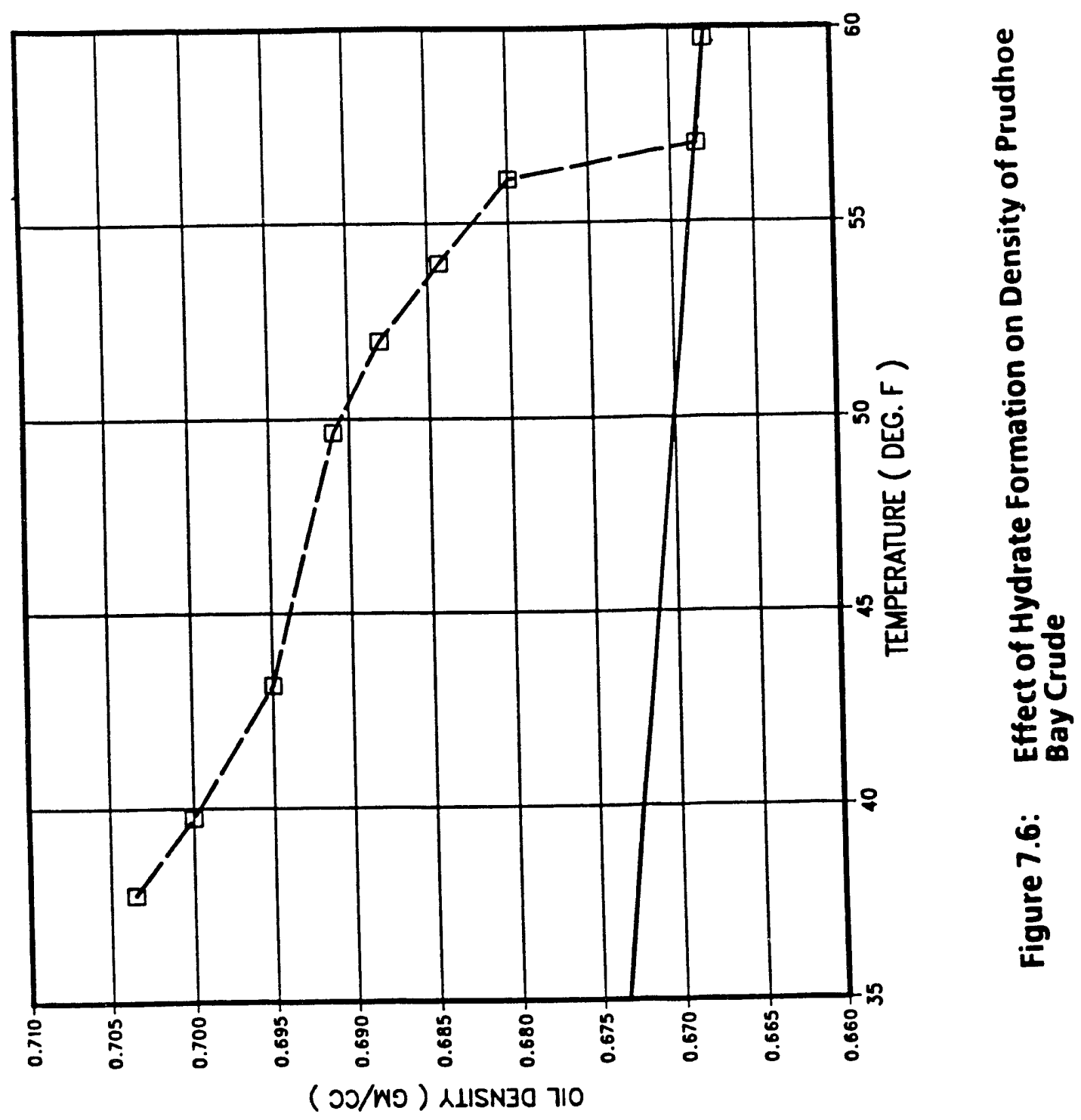


Note that in Figure 7.2, the four phase ( $V L_{1} \mathrm{~L}_{2} \mathrm{H}$ locus) intersects the two phase $\left(\mathrm{VL}_{2}\right.$ curve) at approximately $56^{\circ} \mathrm{F}$ indicating that the four phase locus terminates at this temperature. Since reservoir temperatures in Ugnu and West Sak are quite low $\left(45-100^{\circ} \mathrm{F}\right)$ the experimental results here supports the hypothesis that, the West Sak crude properties might have been altered due to hydrate formation especially in the shallower sections of the reservoir where lower temperatures exist.

\section{Prudhoe Bay Crude}

Experimental work was also conducted for Prudhoe Bay Crude - methane water mixtures. The four phase $\mathrm{VL}_{1} \mathrm{~L}_{2} \mathrm{H}$ equilibrium conditions are for this system are given in Table 7.7. The effect of hydrate formation on bubble point pressure lowering of Prudhoe Bay crude and on increase in crude density is depicted in Figures 7.5 and 7.6 respectively.

\subsection{Conclusions}

1. The hydrate forming conditions for West Sak crude-methane-water mixture and Prudhoe Bay crude-methane-water mixture were measured.

2. Hydrate formation causes extraction or removal of lighter $\left(C_{1}-C_{4}\right)$ hydrocarbon components from the crude.

3. Hydrate formation lowers the bubble point of the crude, increases or density of the crude, increases viscosity of crude and reduces solution gasoil ratio.

4. For West Sak crude, hydrate formation was possible below $56^{\circ} \mathrm{F}$. This temperature exists in shallower sections of Ugnu and West Sak reservoirs. This supports the hypothesis that hydrate formation might have been the cause of alteration of crude oil properties in the shallower West Sak and Ugnu formations. 


\subsection{References}

1. Collett, T.S.: "Detection and Evaluation of Natural Gas Hydrates From Well Logs, Prudhoe Bay, Alaska", M.S. Thesis, U. of Alaska Fairbanks, AK (1983).

2. Collett, T.S.: "Interrelationships Between In-Situ Gas Hydrates and Heavy Oil Occurrences on the North Slope of Alaska," SPE paper 13594, presented at the 1985 SPE California Regional Meeting, Bakersfield, CA, (March 27-29, 1985).

3. Godbole, S.P., Kamath, V.A., and Ehlig-Economides, C.E.: “Natural Gas Hydrates in the Alaskan Arctic", SPE Formation Evaluation, Vol. 3, No. 1 (1988), pp. 263-266.

4. Holder, G.D.: "Multiphase Equilibria in Methane-Ethane-Propane-Water Hydrate Forming Systems", Ph.D. Dissertation, School of Chemical Eng., U. of Michigan (1976).

5. Holder, G.D., Katz, D.L., and Hand, J.H.: "Hydrate Formation in Subsurface Environments", AAPG Bulletin (1976), Vol. 60, No. 6, pp. 981-994.

6. Kamath, V.A., Godbole, S.P., and Baena, C.J.: "Effect of Dissociation of Hydrates During Thermal Recovery of Heavy Oils on the North Slope, Alaska", SPE 14224, Presented at the 60th Annual Technical Conference and Exhibition of the SPE held in Las Vegas, NV (Sept. 22-25, 1985).

7. Kamath, V.A., Godbole, S.P., Collett, T.S., and Ostermann, R.D.: "Evaluation of Stability of Gas Hydrates in Northern Alaska". Cold Regions Science and Technology, Vol. 14 (1987), pp. 107-119.

8. Katz, D.L.: "Predictions of Conditions for Hydrate Formation in Natural Gases", Trans. AIME, Tech. Pub. \#1748 (1944).

9. Molenaar, C.M.: "Depositional Relations of Cretaceous and Lower Ternary Rocks, Northern Alaska", AAPG Bulletin (1983), Vol. 67, No. 7, pp. 1066-1080.

10. Ng, H.J. and Robinson, D.B.: "The Prediction of Hydrate Formation in Condensed Systems", AlChE J., Vol. 23, No. 4 (1977). 


\section{CHAPTER EIGHT}

\section{DEVELOPMENT OF NUMERICAL, FINITE DIFFERENCE MODEL FOR DISSOCIATION OF GAS HYDRATES IN POROUS MEDIA}

\subsection{Introduction}

The goal of this study was to develop a numerical two-dimensional $(r-z)$ cylindrical coordinate finite-difference simulator for the dissociation of natural gas hydrates in porous media.

The model could be used to simulate dissociation of hydrates during thermal stimulation technique or during drilling.

Irrespective of the location (offshore or onshore), drilling through hydrate formations can cause well control problems due to severe mud gasification if proper drilling procedures and precautions are not followed. Sizable gas kicks and potential blowout conditions have been reported in the literature. The potential for well control problems is expected to increase in the future as further exploratory drilling occurs in known or potential hydrate stability areas; i.e., as oil and gas exploration expands into the more expensive exploration of deep sea and arctic environments.

Currently, two different methods are used to drill through potential hydrate containing formations. One method involves attempting to prevent the hydrate dissociation with the use of cool drilling fluids with higher mud weights and high circulation rates. The second method attempts to promote hydrate dissociation while the drill pipe is in the hole and simply sizing the surface mud degasser accordingly. Nowhere, however, have the specifics of these methods been reported, thereby requiring the drilling engineers and operators to either over-compensate for the potential hydrates (safe but expensive), or to ignore the hydrates altogether (potentially disastrous which would be even more expensive). 
As a case study the model was applied to simulate hydrate dissociation during wide range of drilling conditions and results were used to provide specific guidelines for the drilling of potential or known hydrate bearing formations independent of the method being used. This problem falls under a class of problems known as heat conduction problems with phase change. There are many examples of such problems in engineering, including metal casting, deyradation of permafrost, freezing and thawing of food stuffs, and anti-icing on airfoil surfaces. All of these problems have a common feature that distinguishes them from ordinary heat conduction problems; that being the existence of a moving interface separating the liquid and solid phases. These problems are usually known as Stefan problems or moving boundary problems.

The solution to the problem at hand, namely the dissociation of natural gas hydrates, was to obtain the temperature distributions within both the dissociated hydrate and solid hydrate regions and the position of the moving boundary as functions of time and drilling conditions. The mathematics of the problem are complicated by the fact that the position of the moving boundary is not known a priori and depends on the variables which are to be solved. Furthermore, there exists a discontinuity in the derivatives (and/or the variables themselves) at the moving boundary. For example, due to the effect of latent heat, the temperature gradient across the interface is not continuous. As a result of these nonlinearities, analytical solutions to the Stefan problem are difficult, at best, and are available for relatively few simple configurations. Consequently, discrete methods must be used for problems of practical interest.

In this study, a finite-difference model for the dissociation of natural gas hydrates has been developed to determine the temperature distributions and position of the moving interface as functions of time. Validation of the model results has been accomplished by using a simplified version of the model to obtain 
results for the degradation of permafrost and these results were compared to data reported in the literature.

At each discrete time interval, the results from the hydrate dissociation model were used to determine the amount of gas that will influx into the wellbore under the wide range of drilling conditions that could be expected to exist in Arctic and subsea environments. Parametric sensitivity studies were performed to establish guidelines for drilling through hydrate bearing formations and correlated in a simple to use nomogram.

\subsection{Review of Literature on Solution to Stefan Problems}

Solution of heat equations with a moving boundary are required for many physical problems of practical importance. Problems of this type are usually referred to as moving boundary problems, or collectively as "Stefan problems" after the classical study (1890) on the melting and freezing of glaciers. Other examples include metal casting, degradation of permafrost, anti-icing on airfoil surfaces, and the dissociation of natural gas hydrates being investigated in this study. The single mest difficult aspect involved in obtaining solutions to these problems is that the location of the moving boundary is not known a priori and depends on the variables which are to be solved, resulting in the problems being highly non-linear mathematically. An additional obstacle to obtaining solutions to problems of this type is the existence of a discontinuity in the derivatives (and/or the variables themselves) at the moving boundary. The phenomenon of melting and freezing is a typical example in which case the interface between phases is a moving boundary. In this example, the temperature gradient across the interface is not continuous due to the effect of latent heat. Though this subject has been investigated since Stefan and Neumann in the nineteenth century, known exact solutions of this class of problems are very limited. 
There have been many methods, both analytical and numerical, proposed for solution of Stefan problems. Reports and proceedings of conferences or parts of conferences devoted to moving boundary problems (Ockendon and Hodgkins, eds., 1975; Wilson et al, eds., 1978; Furzeland, 1977 and 1979; Lewis and Morgan, eds., 1979; Fasano and Primicerio, 1983) serve as excellent reviews of the status of solution methods employed for such problems. More detailed survey articles (Bankoff, 1964; Boley, 1972; Fox, 1975; Shamsunder, 1978; Furzeland, 1977 and 1980; Crank, 1981) attempt to categorize the types of moving boundary problems and solution techniques.

Predominately, these surveys have noted that due to mathematical complexities almost all investigations of moving boundary problems are limited to a single space variable. The problem in its most general form may have singularities due to non-linearities in the equation itself and in the boundary conditions. Even if the coefficients in the equation and in the boundary conditions are constant, the problem is made nonlinear by the motion of the boundary. As a result, only a few exact solutions are available for some simplified cases (Stefan, 1890; Neumann, 1919; Evans et al, 1950; Budhia and Kreith, 1973; Tao, 1986).

Approximate solutions to moving boundary problems have been obtained with the development and application of approximate analytical techniques such as the heat balance integral (Goodman, 1958; Poots, 1962; Cho and Sunderland, 1969; Imber and Huang, 1973), embedding (Boley, 1961; Boley and Yagoda, 1969), isotherm migration (Crank and Gupta, 1975), Green's function derived integrals (Chuang and Szekely, 1971), variational (Yeh and Chung, 1975) and source and sink (Lightfoot, 1930; Budhia and Kreith, 1973; Keung, 1980) methods. Hsiao (1985) noted that a common drawback to these approximate techniques is that they are either limited to one-dimensional analysis, or result in very complicated mathematical formulations when applied to multidimensional problems. 
Numerical methods are often more practical in solving the phase change problem provided the position of the moving interface is properly resolved. Metriods which have been employed include finite-differences on a fixed grid (Ehrlick, 1958; Koh et al, 1969; Sparrow et al, 1977; Sengul, 1977; Kolesnikov et al, 1978; Dmitriev and Solov'eva, 1985; Roadifer et al, 1987), finite-differences on a time-variant mesh (Murray and Landis, 1959; Lotkin, 1960), finite-elements on a fixed grid (Lemmon, 1981; Hornung, 1983), finite-elements on a variable spaced grid (Bonnerot and Janet, 1977; O'Neill and Lynch, 1981; Morgan et al, 1983), body-fitted curvilinear coordinate transformations (Landau, 1950; Sparrow and Ohkubo, 1986), method of lines (Meyer, 1970 and 1971) and equivalent enthalpy or heat capacity methods (Eyres et al, 1946; Comini et al, 1974; Merriam et al, 1975; Morgan et al, 1978; Morgan, 1981; Frivik and Comini, 1982; Voller and Cross, 1983; Raw and Schneider, 1985; Hsiao, 1985; White, i986).

It should be noted that the categorization of the particular studies listed above may be somewhat arbitrary, as many of these works could be listed under one or more of the categories listed. Throughout this discussion, a moving boundary problem, or Stefan problem, will be taken to mean a time-dependent problem represented by a parabolic partial differential equation together with a prescribed initial condition and boundary conditions, two of which are given on a boundary or boundaries which move in a way that depends on the solution of the partial differential equation. A detailed development and discussion of each of the mathematical and numerical methods which have been used to obtain solutions to Stefan type problems is far beyond the scope of this study. A general discussion of some of the methods will, however, be presented, and examples of their use are discussed. For the methods that are not discussed in detail, some examples of their use will still be presented for reference. 


\subsubsection{Analytical Solutions}

\subsubsection{Exact Solutions}

Neumann's (1919) analytic solution for a specific linear melting (or solidification) problem remains the best analytical solution known to date. Subsequent solutions of two-phase, one-dimensional Stefan problems are patterned after the general form of Neumann's solution. Neumann solved for melting or solidification in a semi-infinite region for $x>0$. Considering a melting problem, for example, the solid is initially at a temperature at or below the freezing temperature, and at time zero the temperature at the surface $x=0$ is aised to a temperature higher than the melting temperature of the solid. The mathematical equations representing his solution appeär in Crank (1981) and Sengul (1977).

Stefan (1890) found a simple exact solution for the case of the interface moving with a constant speed. In 1958, Ruoff obtained an alternate solution to that of Neurna: in and Stefan with the use of a simple variable transformation.

Assuming a uniform heat source at $x=0$ and an insulated back face, Evans et al (1950) presented a solution for a Stefan-like problem of recrystallization of a semi-infinite metal slab initially at the recrystallization temperature. Additional assumptions incorporated into their solution included different diffusivities for each phase and a power series representation for the temperature distribution. The position of the moving boundary was derived using series expansions. They reported that the coefficients in the series were very difficult io obtain and that convergence of the solution was yet undetermined. 
In 1986, Tao presented a method for solving moving boundary problems in which he introduced two associated problems, one for each phase, satisfying the prescribed boundary and initial conditions in the given fixed domain without any moving boundary. He showed that together with moving heat sources of unspecified strengths, it is possible to reduce the original equations of the problem to two equations in the given fixed domain. Except for the strengths of the two moving sources, the two equations are obtainable by well known methods, arid the formulation leads to integral equations for determination of the unspecified source strengths. Tao applied his method to the problem solved by Neumann (1919) and obtained the classical solution to the problem. If the heat flux is proportional to the inverse of square root of time, Tao shows that a simple exact solution is obtained.

For problems concerning radial heat conduction with phase change, only one exact solution is known to exist. This solution, in cylindrical coordinates, is for the melting or solidification due to a continuous line source at $r=0$, i.e., constant heat flux at $r=0$. Patterson (1952) has shown that this is the only solution for radial heat conduction.

\subsubsection{Heat Balance Integral Methods}

In 1958, Goodman obtained approximate analytic solutions to a variety of heat conduction problems involving change of phase using an approximate mathematical technique utilizing the heat-balance integral. To obtain the heat balance integral, a thermal boundary layer is defined for which it is at an equilibrium temperature and no heat transfer exists beyond that location. The partial differential heat conduction equation is then integrated with respect to the space variable, resulting in what is 
referred to as the heat-balance integral. This equation is analogous to the momentum integral in the boundary-layer theory of hydrodynamics. By assuming a temperature profile for each phase, the system of integral equations is reduced to a set of ordinary differential equations in time which gives the velocity of the moving boundary. Having determined the position of the moving boundary, the temperature profiles are obtained by working back through the equations.

Analytical expressions for a variety of boundary conditions, including those for the melting of a semi-infinite solid with fixed boundary temperature and with fixed boundary heat flux, were derived by Goodman (1958). Only one-dimensional problems were considered, and by representing the temperature distribution by a quadratic, results for each case were able to be expressed in closed analytical form. For those cases possible, comparisons were made to the exact solutions to the problem and the accuracy of the method determined. In general, results from the heat-balance integral, though inexact, provide reasonable enough accuracy for a large number of engineering applications. Though complicating the problem, it was observed that the result obtained using a cubic temperature profile was more accurate than that which used a quadratic temperature profile.

Additional applications of the heat-balance integral to phase change problems include those by Altman (1961), Poots (1962), and Imber and Huang (1973). Poots (1962) has applied the heat-balance integral in two dimensions. While investigating inward solidification of several geometric regions, Poots (1962) determined that the heat-balance integral failed in the cases of a circular cylinder and sphere. In 1973, 
Imber and Huang introduced temperature dependent thermal properties into the heat-balance integral technique.

\subsubsection{Embedding Method}

In 1961, Boley presented a method known as embedding for the treatment of moving boundary problems. In this method, a domain whose dimensions vary with time in an unknown way is treated by considering it to be embedded or to form part of a larger domain of constant dimensions. All parts of the larger domain which do not coincide with the actual domain are fictitious and have no physical meaning. Though the boundary conditions on the embedding domain are also fictitious, they are constructed in such a way that the actual conditions on and within the embedded body are satisfied. The utility of Boley's method is that well known methods and solutions for domains of constant dimensions can often be utilized.

Boley applied his embedding technique to the one-dimensional melting of an infinite slab with the instantaneous removal of the melt, i.e., ablation. He obtained two integro-differential equations for the temperature distributions, however, these cannot be solved in simple analytic form. He did, however, find a series solution for the case of a constant heat input at small times, for which he obtained comparable results to those found by Landau (1950) for the same problem.

Boley and Yagoda (1969) used this embedding technique to study melting and solidification in a half-space at early times. Results of their study indicated that the shape of the interface separating the phases was independent of both the material properties and the heat input. Also determined was, that for short times, the rate of propagation of the front 
is proportional to $\tau_{D}{ }^{1 / 2}$ along the surface, and proportional to $\tau_{D}{ }^{3 / 2}$ normal to the surface.

Crank (1981) notes that in practice, any one phase can be considered to be embedded as described. For the two-phase problem, it becomes necessary to solve four integro-differential equations. A review of embedding techniques, including extensions to two dimensions, is provided by Boley in Ockendon and Hodgkins (1975).

\subsubsection{Isotherm Migration Method}

Chernousko (1970) and Dix and Cizek (1970) independently proposed a method for the solution of the heat equations which monitors the manner in which specified temperatures or isotherms move through a medium. This method represents an alternative to the classical methods which seek to express the time dependence of temperature at a fixed point in space. Mathematically, the classical methods seek solutions of the form $T(x, t)$, whereas isotherm migration methods seek solutions of the form $x(T, t)$. The utility of this method arises when the phase change boundary is an isotherm, where by this method becomes a way of fixing the boundary and evaluating the position of the isotherm on a fixed domain. Advantages also become apparent when dealing with temperature-dependent thermal properties.

Crank and Phahle (1973) examined the melting ice problem and found close agreement to the exact analytical solution. In 1975, Crank and Gupta extended the isotherm migration method to the $y$ variable only in the heat flow equation. The resulting equations, discretized on a $(T, x)$ grid, were then solved for values of $y$. Linear interpolation was used to obtain the temperature values at each of the $x$-grid locations required 
for the discretized equations. An alternative application of the isotherm migration method in two dimensions was developed by Crank and Crowley in 1978. The method they present makes use of the concept that in an isotropic medium, any point on an isotherm moves along flow lines normal to the isotherm at that point. An analogy in fluid flow would be a particle of the fluid on an isopotential line moving along a flow line normal to the isopotential at that point.

\subsubsection{Use of Green's Function Derived Integrals}

Green's functions have been used in a variety of cases, to convert the partial differential equations into integral or integro-differential type equations, which may then be solved by either analytical or numerical methods. Hansen and Hougaard (1974) used Green's functions to develop an integral equation type solution for an oxygen consumption problem.

In their study on the solidification and melting of a metal slab or rod immersed in its own melt, Chuang and Szekely (1971) found the solution for the temperature distribution in the solid phase using Green's functions. This solution was in integral form, and only obtainable due to the assumption of a constant ambient temperature arising from the continual stirring of the melt. Their problem was essentially a one-phase problem due to this assumption. The integral solution they obtained was transformed into the form of an algebraic equation which was then numerically integrated. The position of the moving boundary was determined by successive approximations.

Frivik and Comini (1982), in their study of freezing and thawing of soils in the presence of seepage fluid flow, used Green's functions to 
eliminate the second derivatives in the integrals derived for use with the Galerkin finite element discretization method. They compared their solution to their experimental results, and found that the calculations tended to underestimate the frozen zones.

Bobula and Twardowska (1985) studied a certain inverse Stefan problem for which they sought to find the temperature of a twocomponent mixture on the given boundary of contact between the liquid and its solid. Because of the two-component nature of the mixture, this temperature is not a constant. The problem was formulated such that, if the boundary of the solidifying liquid was known from experiments, then the temperature of solidification on the boundary was sought. This problem would be almost meaningless in the classical sense of the Stefan problem because liquid solidifies at the constant temperature, and information about it at any time would then designate that information for all other times. In this case, however, the temperature of solidification is not a constant, but depends on the proportional composition of the liquid. The authors indicate that they are not interested to know the composition because that information is contained in the measured curve solidification. Neumann's and Green's functions were used to convert the system of partial differential equations into a system of integral equations. They prove the existence and uniqueness of the solution to this problem using Green's identity and the Banach fixed point theorem, which provides a method of calculation of the approximate solution. 


\subsubsection{Source and Sink Methods}

There have been several analytical methods reported in the literature that are similar to Boley's (1961) embedding technique or to Tao's (1986) two-problem formulation in that the resulting formulation has an additional problem the determination of moving sources or sinks of unspecified strengths.

Lightfoot (1930) has shown that when the material constants of both phases can be considered to be equal, the moving boundary can be treated as a moving heat source with strength proportional to the jump in the derivative conditions across the interface. This led to an integral equation for the location of the interface. Kolodner (1956) removed the restriction of equal material constants by suggesting that the solution is comprised of two parts, a fundamental part due to moving sources and doublets of unknown strength, and an auxiliary part involving a function in the extended domain to match the required initial and boundary conditions.

In 1970, Rathjen and Jiji solved a two-dimensional problem of freezing in a right-angle corner by considering a moving heat source of strength $L_{\rho}(\partial s / \partial t)$, where $L$ is the latent heat of fusion, $p$ is the density, and $(\partial s / \partial t)$ is the velocity of the moving boundary. Budhia and Kreith (1973) extended their method to a wedge with any angle between $0^{\circ}$ and $360^{\circ}$.

In their study, Budhia and Kreith divided the problem into two subproblems, the first of which involved heat transfer without phase change. The second sub-problem involved the use of a moving source or sink for melting or freezing. Green's functions were used to obtain the temperature distributions in each sub-problem and then these were 
superimposed. They were ablt to superimpose solutions only because of the assumption of identical thermal properties for each phase. For the case when the thermal properties were not the same in each phase, they presented an empirical method to compensate for the resultant error in the solution.

\subsubsection{Other Approximate Analytical Solutions}

Pekeris and Slichter (1939) developed a solution for the freezing of water initially at the freezing temperature around an infinitely long cylinder. The temperature of the cylinder was considered a function of time, and was at all times lower than the freezing temperature of water. Sengul (1977) noted that their method of solution was the same as Stefan's (1890), and that their solution was attainable due to the temperature in the solid region closely approximating that of steadystate. Pekeris and Slichter found that the deviation from the steady-state temperature distribution was proportional to the ratio of the specific heat of ice to its latent heat fusion. They also noted that if the deviation from steady-state was ignored, the resulting error was small for a limited range of values of moisture content and small temperature amplitudes.

Also in 1939, Huber developed an approximate method for solving two- and multi-dimensional Stefan problems. His method involved dividing the total time interval for which the solution was sought into small time steps. For a given time step, the velocity of the moving boundary between the two phases was assumed constant and equal to the velocity determined using one of the boundary conditions and by the temperature gradients of the phases at the interface. The moving 
boundary was assumed to be fixed at each subinterval of time, while the temperature distributions were found using Green's functions.

Kumar and Gupta (1977) have studied the heat and mass transfer between a capillary porous medium and an external gas stream during drying. They present a solution to what they term a "Generalized Stefan Problem" with variable thermal properties and taking thermal diffusion into account. The variable thermal properties have been represented by a simple function of the dimensionless temperature and dimensionless mass transfer potential. An approximate solution to the problem was obtained using a boundary layer approach in local potential. The authors indicated that the effect of the deepening evaporation front on the unsteady heat and mass transfer in a porous body is characterized by a parameter they call the nondimensional heat of vaporization. This parameter is essentially the Stefan number multiplied by the ratio of moisture density to the porous medium density and by one minus the coefficient of internal evaporation, which they did not define. It was also shown that with an increase in the criterion Posnov number, there is a reduction in the nondimensional mass transfer potential and the rate of motion of the evaporation interface.

An asymptotic, large time solution of the convection Stefan problem with surface radiation was obtained by Tokuda (1986). The moving boundary problem was reformulated as a fixed boundary problem where Lagrange-Bürmann expansions were used to complete the variable transformation. 


\subsubsection{Numerical Solution Techniques}

\subsubsection{Finite Difference Schemes on a Fixed Grid}

The use of finite-difference to approximate the derivatives is the usual manner of solving the heat flow equation over a fixed domain in which the temperatures are evaluated at discrete points on a fixed grid. Because this is the method used in the present study, the details of this method are discussed later. Several aspects of this method will, however, be discussed. The major complication associated with a moving boundary is that at any time, that boundary will usually be located between two neighboring grids. This can be allowed for by using modified finitedifference formulae based on unequal space intervals in the vicinity of the boundary; e.g., Lagrangian type interpolation formulae can be used to derive modified finite-difference formulae for use near the boundary. Ehrlich (1958) and Koh et al (1969) used Taylor expansions in both time and space near the moving boundary.

The heat and mass transfer problem in a passive transpiration cooling system involving two moving boundaries has been formulated by Koh et al (1969). The numerical calculation scheme used to solve the problem was presented and computations performed for the case of porous tungsten infiltrated with copper exposed to an environment of high pressure and high heat flux. The effects of porosity and radius of curvature on the thermal response and infiltrant recession were shown. An implicit finite difference scheme was used to solve numerically the system of equations. The method is similar to that or Ehrlich (1958), however in this case two moving boundaries are present instead of one, and also the boundary conditions of this problem are much more 
complicated. Both porosity and permeability were considered to be a function of location. The effect of mass transfer was accounted for by a correlation. An assumption that resolidification or remelting would not occur was also included in the model. Equations were presented for a plate, cylinder and sphere. Details of the discretized equations were also presented, making their paper one of the most complete and detailed examinations of the numerical computation of moving boundary problems.

In 1977, Sengul presented two one-dimensional models, and a twodimensional model for the degradation of permafrost. Sengul used three-point Lagrangian formulae to develop the finite-difference equations near the moving boundary. This was possible due to a coordinate transformation in which the irregularly spaced radial coordinate was transformed into equally space dimensionless coordinates. As the modei developed in this study was patterned after that of Sengul, details are discussed later. It should be noted, however, that Sengul was unable to obtain results for his two-dimensional model because of what he termed time constraints in it's development. From his one-dimensional models, one which uses fixed time steps and solves for the position of the moving boundary and one which uses fixed locations for the interface position and solves for the time required for the boundary to achieve that location, Sengul developed an empirical correlation based on three dimensionless parameters.

Also in 1977, Sparrow et al. performed an analysis of multidimensional $(r-z)$ melting which takes account of natural convection induced by temperature differences in the liquid region. Sparrow et al also used a coordinate transformation which resulted in the 
dimensionless radius varying from 0 to 1 for all dimensionless vertical positions. They used an implicit finite-difference scheme in which the position of the moving boundary was allowed a small time lag behind the temperature calculations. In their model developmerit, the authors noted that for gradually or even moderately sloping interfaces, the slope terms may be neglected due to their relative magnitude. To account for the disparity in initial and inner boundary conditions, the authors assumed the presence of a thin melt region and used the Stefan (1890) solution to obtain the value of time corresponding to this initial melting. The authors note that their results differed decisively from those corresponding to a conventional pure conduction model of the melting problem. It should be noted, however, that this result is not for melting within porous media.

Kolesnikov et al (1978) have investigated the effect of characteristic heat and mass transfer parameters on the behavior of solutions. A differencing method was employed which places the phase front in a grid node, straightens the phase front, and employs "through-the-boundary" computational schemes with and without smoothing of the solutions. Details of this method were not presented, however, the authors state that "experience with various difference solution methods" shows that through-the-boundary solutions are the least labor consuming. It is assumed that equivalent enthalpy or equivalent heat capacity methods fall under this category. The authors indicate that these methods have somewhat lower accuracy in the vicinity of the moving front than those methods in which the front is explicitly identified. Results represented by the location of the moving boundary and the temperature distributions 
are presented for several different heat fluxes for a particular set of thermal-physical parameters.

Dmitriev and Solov'eva (1985) proposed a method for the numerical investigation of a multiple-free-boundary Stefan problem with a variable critical temperature. Example problems of this type arise in geothermics, i.e., the process of melting the Earth's mantel as a result of heating by radioactive sources of heat. The method involves setting up a ripplethrough difference scheme and an iteration method for solving the resultant non-linear system of differential equations. The authors emphasize the setting up of the initial approximation of the solution and the stability of the iterative process. In contrast to the classical Stefan problems, the problem studied is one where a new phase appears inside a region in the form of one or more layers, making it necessary to simultaneously seek at least one pair of unknown boundaries. The authors state that available computational algorithms employed to solve Stefan problems are only weakly stable in this case. For the problem studied, the authors indicate that the initial approximation of the temperature distribution and the velocities of the moving boundaries play a major if not decisive role in both the convergence of the iterative process and the rate of convergence. Initially, only the boundary whose position with time is changing most rapidly is involved in the iterative process. Once a stable solution is close, the iterative process is switched to the second stage in which both boundaries are iterated simultaneously.

\subsubsection{Finite Difference Schemes on a Variable Grid}

Lotkin (1960), in his study of one-dimensional melting in a solid slab with ablation used a finite difference method with both variable space 
and time increments, with smaller grids being used near the melting interface where the temperature changes were the greatest. He assumed a variable heat input rate at the inner boundary and an insulated outer boundary.

In 1977, Sparrow et al. performed an analysis of multi-dimensional $(r-z)$ melting which takes account of natural convection induced by temperature differences in the liquid region. Sparrow et al. also used a coordinate transformation which resulted in the dimensionless radius varying from 0 to 1 for all dimensionless vertical positions. Because this dimensionless radius included the interface position, its definition will change at every time step, thereby resulting a mesh which varies with time. The result of this time variant mesh is that the field variables must be re-evaluated subsequent to the determination of the interface position. This re-evaluation was carried by interpolation at all grid points except those in the newly created melt region. They used an implicit finice-difference scheme in which the position of the moving boundary was allowed a small time lag behind the temperature calculations. In their model development, the authors note that for gradually or even moderately sloping interfaces, the slope terms may be neglected due to their relative magnitude. To account for the disparity in initial and inner boundary corsitions, the authors assumed the presence of a thin melt region and used the Stefan (1890) solution to obtain the value of time corresponding to this initial melting. The authors note that their results differed decisively from those corresponding to a conventional pure conduction model of the melting problem. It should be noted, however, that the authors also indicate that for many phase change probiems, natural convection is relegated an ineffectual role due to the high 
resistance uffered to fluid motion by passages of small dimensions; e.g., such effects are operative in low permeability porous materials.

\subsubsection{Equivalent Enthalpy and Heat Capacity Methods}

One widely used approach for solving the Stefan problem is the equivalent enthalpy model, in which an enthalpy function is defined to be the sum of the sensible and latent heats. Whereas the classical formulation of the conduction Stefan problem consists of two heat conduction equations (one for the solid and one for the liquid phase) and a heat balance equation at the moving solid/liquid interface, the enthalpy formulation reduces these equations to a single equation which is applied throughout both phases with the appropriate boundary conditions. This approach does not track the solidification or melt front explicitly, but, rather, it works with the temperature and enthalpy on a control volume basis. Changes in control volume enthalpy are calculated from the temperature field, and the temperature is, in turn, calculated from the enthalpy via an equation of state. The nonlinearity in the discrete problem appears in the form of a highly nonlinear equation of state.

A variant of the enthalpy model is the equivalent heat capacity method. The equivalent heat capacity model superimposes the latent heat effect onto the specific heat of the system over a small temperature interval $2 \Delta T$ across the fusion temperature. This introduces a severe nonlinearity in the thermal property.

Merriam et al (1975) used the equivalent heat capacity method in their analysis of permafrost thaw around insulated and uninulated hot oil-producirig wells. The form of the heat capacity was assumed to be represented by a ramp function which accounted for the total change in 
the enthalpy through the melt region. The nonlinear partial differential equations for the temperature distributions where replaced by a series of simultaneous, nonlinear algebraic equations using a control volume approach. The equations were then solved using a method of simultaneous displacements with block-relaxation.

The authors indicated that available analytical solutions for melting in one and two dimensions are not applicable to the heat flow in the surrounding soil because of the complicity of heat exchange between the flowing hot oil and the ground, and the variation of thermophysical properties with temperature and depth. The thermophysical properties were all considered to be functions of position and, with the exception of the density, functions of temperature. The method of updating these variables in time was one in which they are allowed to lag in time by one iteration, i.e., the temperature distributions were solved assuming the previous iteration values of the specific heat and thermal conductivities, these thermophysical properties were then updated using the just solved temperature distributions, which are then recalculated to account for the variation in the properties, and so on.

Validation of their model was accomplished in several ways. First, a classical one-dimensional freeze/thaw problem was solved and the results were compared to the analytical solution. Second, a two-dimensional corner freezing problem was solved and the results again were compared to available analytical solutions. Finally, an example of the thaw problem around producing oil wells reported in the literature was solved and the results were compared. In all cases, agreement between solutions appears to have been excellent. 
In 1985, Voller and Cross presented a number of enthalpy based algorithms for the solution of Stefan problems. Cartesian, cylindrical and spherical coordinate systems were considered. The authors indicate that other investigations of enthalpy numerical schemes have shown that most direct applications lead to unphysical results; temperature oscillations occur and the phase change front moves discontinually. The reason given was that the reported direct applications did not properly account for the true amount of phase change material present in the control volume. Methods of treating this problem was presented. Example problems in several coordinate systems were solved and compared to the analytical solutions and found to be in excellent agreement.

An algorithm incorporating the equivalent heat capacity model for the finite-difference heat transfer analysis involving melting and solidification was presented by Hsiao in 1985. He accounted for the amount of phase change material within each control volume (i.e., the latent heat of fusion) using linear interpolation of the nodal temperatures. Solutions to both one- and two-dimensional models were presented. The author noted that while many studies have indicated some difficulty in the selection of the phase transition temperature interval, $2 \Delta T$, his solution scheme was insensitive to the magnitude of this term. An explicit finite-difference method with a fixed mesh was used to obtain the numerical solution.

Also in 1985, Raw and Schneider presented an implicit solution prosedure for the multi-dimensional finite-difference modeling of the Stefan problem which incorporates the enthalpy model. The advantage to their solution method is that the nodal enthaipies are expressed as 
algebraic functions of the surrounding nodal enthalpies (or more precisely, the surrounding nodal temperatures) and these functions are included directly into the implicit finite-difference equations, allowing the simultaneous solution of all unknowns. The authors show how this method of formulating the enthalpy model can result in significant savings in computer time.

\subsubsection{Finite Elements on a Fixed Grid}

Morgan (1981) presented an explicit finite element algorithm for the solution of the partial differential equations describing combined conductive and convective heat transfer in materials which may experience liquid-solid phase changes. While a quadratic finite element representation is required for the accurate modelling of the phase change process by the enthalpy method with implicit time-stepping of the solution, Morgan states that linear elements may be used to represent the temperature field when an explicit method is used.

In modelling the phase change, Morgan neglected any change in density from the solid to liquid phase, however, included density changes in the melt region due to both temperature and pressure effects. An equivalent heat capacity model was used to account for the latent heat of fusion To account for the no-slip boundary condition at the phase boundary, Morgan adopted the approach of reducing the nodal velocity to zero whenever the nodal temperature lies below the fusion temperature. This approach results in less accuracy, but is much simplier than having to explicitly track the front position. Morgan compared the results obtained from his model to experimental results reported in the literature, but due to incomplete data, this comparison was only 
qualitative in nature. He stated that a complete analysis of the accuracy of the method was not possible due to the scarcity of suitable experimental results.

Also in 1981, Lemmon presented a method based on a non-moving finite elements mesh technique to overcome some of the problems reported in the literature for other finite element models. The primary thrust of this model was to outline how the thermal properties (conductivity and heat capacity) could be evaluated so that typical conduction finite element models could be used to approximate multidimensional phase-change problems. One of the primary aims of the method was the determination of the amount of material which changed phases, and the location of the phase-change interface as a function of time. A method of accounting for the convective heat transfer at the moving interface was also included.

The method of weighted residuals was used to obtain the solution to the partial differential equations. A basic integration method was used to determine various property values. An effective volumetric specific heat was defined to account for the jump in the enthalpy at the moving interface. The author noted that the definition for the heat capacity used not only approximated the volumetric average of the heat capacity within the element, but also accounted for the latent heat of fusion.

The method of incorporating the effects of convective heat transfer was accomplished by requiring that the effective liquid conductivity in the fluid phase be proportional to the convective heat flux and the inverse of the temperature gradient. Lemmon noted that this requires that the effective conduction flux in the liquid region of the element be 
approximately the same as the imposed convective flux. The equivalent liquid conductivity was allowed to lag in time. Because of the nonlinearities in the problem, successive approximations had to be employed for the updating of these variables in time. While Lemmon stated that the process of choosing the effective conductivity based only on the temperature gradient from the previous iteration is divergent, he does not indicate if this is only for the case when convection is included in the melt region, or for other variation in his model. Several numerical examples were solved, and results agreed quite well with results obtained by other authors using different models.

Hornung (1983) studied the effects caused by the change of phase due to freezing and melting on the coupled heat and water transport in a homogeneous and isotropic porous medium. When the water content is discontinuous on the moving boundary, there is a nonzero mass transfer flux on the interface. Assumptions incorporated into this model included a temperature independent diffusivity which vanishes in the frozen zone; the thermal conductivity was assumed to depend on the water content, but not 0.1 the temperature in the two regions; and, specific heats were considered to be constant in both phases. A Dirichlet condition was imposed on the moving interface for the water content, and Neumann conditions for the heat flux. Hornung noted that up to the time of his paper, there were not theoretical results on the existence or uniqueness of the solution available for the initial boundary value problem being considered. A fully implicit time scheme with a Galerkin finite element approach with respect to the space variable were used to solve the problem. The iterative algorithm used was presented, and numerical 
results of the model were compared to exact analytical solutions obtained by elementary methods based on Boltzmann's transformations.

\subsubsection{Finite Elements on a Variable Grid}

As for finite elements, there have been several methods reported in the literature which employ a variable or adaptive grid mesh in the numerical representation of the Stefan problem. Using a fixed number of grids, a spatial transformation may be implemented where grid locations remain constant in the transformed coordinate system, however, due to the form of the transformation, the true physical location of the grids changes with time. Consider, for example, a case where the number of grids is kept constant at some value $M$ within the region $x=0$ and $x=x_{f}(t)$, i.e., between a fixed and moving boundary. For equal intervals $\delta x=x_{f}(t) / M$, it is apparent that the size of the intervals will be different for each time step. In this manner, the moving boundary is always on the $M$ th grid line. Morgan et al (1983) noted that this method has been criticized as the number of grids must be chosen a priori. This could lead to either too many or too few nodes being available, resulting in inefficient or inaccurate solutions.

An alternative method discussed by Morgan et al (1983) is the introduction of additional elements into those areas requiring enhanced resolution while removing elements from those regions which are over refined. In this manner, the solution will always contain the optimum number of elements consistent with the required degree of accuracy, thus improving its efficiency. O'Neill and Lynch (1981) presented a method which incorporates mesh evolution directly in the finite element 
equations. Points on the mesh associated with established ones move, with the effects being automatically accounted for.

\subsubsection{Applications to Hydrate Dissociation}

Just as there have been a variety of analytical and numerical methods used to solve moving boundary problems in general, so have there been a variety of methods used in the study of hydrate dissociation, In 1981 , Goodman and Franklin presented a paper on a thermal model capable of modelling the dissociation of natural gas hydrates during drilling. The reported that both radial and vertical heat conduction were accounted for in the transient energy transfer within the soil, however they did not report the method (analytical or numerical) being used to calculate the heat transfer.

Holder and Angert (1982) used finite-differences to simulate the gas production from a reservoir containing both gas hydrates and freenatural gas. While their simulator was as such a three-dimensional model, hydrate dissociation was limited to the one-dimensional vertical direction, and pressure variations were limited to the $x$ and $y$ horizontal directions. In discussing the assumptions incorporated in their model, the authors indicated that the coordinate system used for the temperature profile has as its origin the hydrate dissociation interface. This assumption indicates the use of a constantly deforming mesh in the vertical direction. The authors indicated that the temperature profiles are updated in time using a central difference operator for finite-differences. An energy balance was used at the hydrate interface to determine the hydrate dissociation rate.

Bayles et al's (1984) steam cycling model for gas production from a hydrate reservoir uses an approximate solution to an energy balance method in which heat is cyclically injected into the reservoir, allowed to dissociate 
hydrates, and produced back out of the reservoir. The temperatures in the dissociated hydrate zone are assumed the same everywhere within that zone, as are the temperatures within the solid hydrate zone. These temperatures are then assumed to instantaneously decay into the final temperature profile, which is one similar to the beginning profile, except for the dissociation temperature being lower, and the hydrate interface having moved. The complexity of coupling the movement of the hydrate interface with the temperature profiles has, therefore, been greatly reduced and requires no detailed estimation of the actual temperature gradients at the interface.

Selim and Sloan (1985) have used Goodman's (1958) heat balance integral, with a polynomial of the fourth degree for the temperature profile, to calculate the hydrate dissociation rates. The model considers semi-infinite one-dimensional hydrate reservoir with a constant heat flux applied to the surface. The model considered is similar to the ablation problem considered by Goodman (1958).

Also in 1985, Kamath et al used a modified version of Neumann's analytical solution along with analytic solutions to the steamflood problem to estimate the hydrate dissociation rate and the effects of that dissociation on the thermal recovery of heavy oils. In a separate paper, Kamath and Godbole (1985) evaluated a hot brine stimulation technique for gas production from natural gas hydrates. In this model, they used an empirical correlation developed by Sengul (1977) for one-dimensional radial melting of permafrost to approximate the hydrate dissociation. They noted that Sengul's correlation was applicable to hydrate dissociation in this case because certain dimensionless parameters for methane hydrates under the temperature conditions specified fall within the range of those same parameters for which Sengul's correlation was valid. 


\subsection{Mathematical Model Description}

The mathematical formulation for two-dimensional $(r-z)$ cylindrical coordinate dissociation of natural gas hydrates is presented in this chapter. The complete formulation necessarily requires a geometric description of the problem, assumptions incorporated into the model, the partial differential equations describing the thermal energy balance, boundary and initial conditions, and lastly, the solution method employed.

\subsubsection{Geometry of the Problem}

Figure 8.1 shows the physical situation around a wellbore penetrating a layer of gas hydrates when the temperature of the wellbore is greater than the dissociation temperature of the hydrates. In general, the model considers a continuous layer of natural gas hydrates bounded on top and bottom by impermeable cap rock (e.g., shale). More specifically, the system may be considered to consist of four separate regions: the overburden, $\Psi_{O}$; underburden, $\Psi_{U}$; solid hydrate zone, $\Psi_{S}$; and dissociated hydrate zone, $\Psi_{D}$. The solid hydrate and dissociated hydrate zones are separated by a moving boundary, $\Psi_{D S}$, which reduces to a curve in the $(r-z)$ plane.

As heat is supplied to the system from the wellbore, the solid hydrates dissociate into water and natural gas, and the moving interface, $\Psi_{D S}$ moves away from the wellbore. The determination of the location of this interface with respect to time represents a major portion of the complete solution to the problem at hand, the temperature distributions within each region representing the rest of the problem solution. 


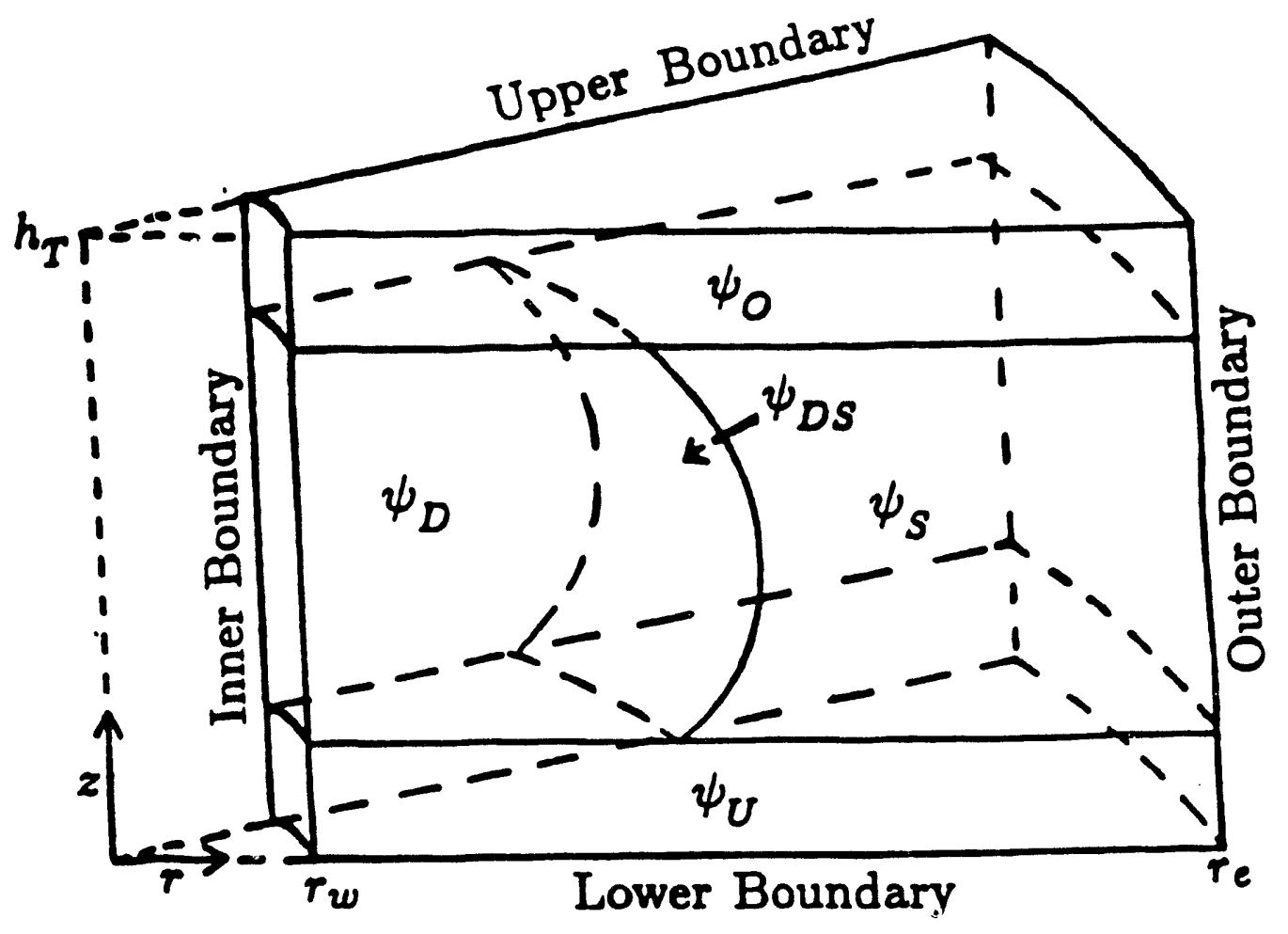

Figure 8.1: Geometry of Hydrate Dissociation Around a Wellbore 


\subsubsection{Assumptions}

In order to obtain a solution to this complex problem, certain assumptions were required to simplify the calculations, while at the same time maintain the accuracy of the solution to provide meaningful results and answers to the primary goals of this study.

1. Radial symmetry about the wellbore.

2. There are no heat sources or sinks.

3. Effects beyond the outer boundaries of the system are negligible.

4. The solid hydrate, dissociated hydrate, overburden, and underburden zones are individually homogeneous and isotropic.

5. The thermophysical properties of each zone, i.e. thermal conductivity, heat capacity, and density, are constant within each zone and different across the boundaries separating each zone.

6. The overburden and underburden zones are impermeable.

7. The gas produced from the dissociation of hydrates migrates rapidly to the wellbore.

8. Heat transfer in each region is by conducting only.

9. The solid hydrate zone is completely saturated with methane hydrates.

\subsubsection{Model Equations}

The partial differential equation describing unsteady-state heat condu tion in an isotropic medium may be expressed in vector notation as

$$
\nabla^{2} T-\frac{1}{a} \frac{\partial T}{\partial t}=0
$$


where $T=T(x, y, z, t)$ and $a$ is the thermal diffusivity of the medium and is given by $a=(k / \rho C p)$. Equation (8.1) assumes no heat source or sink within the medium.

Crinverting equation (8.1) into cylindrical coordinates and using the assumption of radial symmetry about the wellbore, results in a twodimensional equation in $r$ and $z$ coordinates:

$$
\frac{1}{r} \frac{\partial}{\partial r}\left(r \frac{\partial^{\prime} T}{\partial r}\right)+\frac{\partial^{2} T}{\partial z^{2}}=\frac{1}{a} \frac{\partial T}{\partial t}
$$

For the case at hand, namely, heat conduction with phase change (dissociation of hydrates), there are a variety of equations corresponding to equation (8.2). These various equations describe the unsteady-state heat conduction in the dissociated zone, solid hydrate zone, overburden, underburden, and across the boundaries between the dissociated zone and underburden, the dissociated zone and the overburden, the solid hydrate zone and underburden, and lastly, the solid hydrate zone and overburden. All of these equations are of the same form as equation (8.2) and so may be written as a single subscripted equation:

$$
\frac{1}{r} \frac{\partial}{\partial r}\left(r \frac{\partial T_{i}}{\partial r}\right)+\frac{\partial^{2} T_{i}}{d z^{2}}=\frac{1}{a_{j}} \frac{\partial T_{j}}{\partial t} ; i=D, S, O, U ; j=D, S, O, U
$$

where the subscripts $i, j=D, S, O, U$ represent the dissociated, solid hydrate, overburden, and underburden zones, respectively. The reason for the different subscripts $i$ and $j$ is that heat conduction at a point on one of the zonal boundaries occurs through two different materials which have different thermophysical properties. 


\subsubsection{Initial Conditions}

Initial conditions required for the model include the initial temperature and pressure distributions and the initial position of the hydrate front. Note that the pressure is required for both material balance calculations and to determine the hydrate dissociation temperatures.

The initial and subsequent pressure distributions are taken to be the same as the wellbore pressure:

$$
P(r, z, l)=P_{\omega b}(Z) ; r_{w} \leq r \leq r_{e}, 0 \leq z \leq h_{T}, l \geq 0
$$

where $Z$ is the depth to the point $(r, z)$, and $h_{T}$ is the total height of the reservoir including the underburden and overburden. The method of determining the wellbore pressure $P_{w b}(Z)$ is the same as presented in Bourgoyne et al (1986).

The geothermal temperature gradient is used to establish the initial temperature distribution:

$$
T(r, z, t)=T_{\text {in }}(Z), r_{w} \leq r \leq r_{e}, 0 \leq z \leq h_{r}, t=0
$$

where

$$
T_{\text {in }}(Z)=T_{b p r}+g_{G}(Z-b)
$$

Here, $T_{b p f}$ is the temperature at the base of the permafrost, $g_{G}$ is the geothermal temperature gradient beneath the permafrost, $b$ is the depth to the base of the permafrost, and $Z$ is the depth to the point of interest. 
The moving boundary is initially assumed to coincide with the wellbore:

$$
r_{f}(z, 0)=r_{w}
$$

\subsubsection{Boundary Conditions}

1. Inner Boundary

The temperature at the wellbore is assumed to be a constant with time and independent of vertical direction.

$$
T\left(r_{w}, z, t\right)=T_{w b}, r=r_{w}, 0 \leq z \leq h_{T}, \iota>0
$$

2. Outer Boundary

The temperature at the outer boundary is taken as the initial temperature distribution at that boundary.

$$
T\left(r_{e}, z, t\right)=T\left(r_{e}, z, 0\right), r=r_{e}, 0 \leq z \leq h_{r}, T>0
$$

3. Upper and Lower Boundaries

Heat transfer at these boundaries is by radial conduction only, the boundaries representing no flow boundaries to vertical heat flow.

$$
\begin{aligned}
& \frac{\partial T}{d z}=0, r_{\omega}<r<r_{e}, z=0, \imath>0 \\
& \frac{\partial T}{d z}=0, r_{\omega}<r<r_{e}, z=h_{T}, \iota>0
\end{aligned}
$$




\subsubsection{Moving Boundary Conditions}

There are two boundary conditions at the solid hydrate - dissociated hydrate incerface; the first one requires local thermodynamic equilibrium (i.e.. the temperature has to be continuous across the boundary), and the second condition requires that the energy be balanced at the surface (Patel, 1968).

The continuity of the temperature at the moving boundary may be expressed as

$$
T_{D}\left(r_{f}, z_{f}, l\right)=T_{S}\left(r_{f}, z_{f}, l\right)=T_{f}(z)
$$

The second interface condition results from heat conservation considerations and is usually called the Stefan condition. Because the Stefan conditions represent an integral part of the mathematical model and are not so prevalent in the literature, they will be derived in detail.

To derive this condition, let $P$ be a point on the moving boundary, $\Psi_{D S}(t)$, at some time $t$, and denote the outward normal at $P$ (relative to the liquid region, $\left.\Psi_{D S}\right)$ as $n_{p}-$ as shown in Figure 8.2.

After some time $\delta t$ has passed, denote the new position of the moving boundary as $\Psi_{D S}(t+\delta t), P^{\prime}$ as the point of intersection of $n_{p}-$ with $\Psi_{D S}(t+\delta t)$, and $\delta \boldsymbol{B}_{p}$ as the distance between $P$ and $P^{\prime}$.

If $P$ lies in the solid region $\left(\delta-n_{p}<0\right)$ at time $(t+\delta t)$, solidification occurs with the liberation of latent heat. If $P$ lies in the liquid region $\left(\delta^{-} n_{p}<0\right)$, melting takes place with the absorption of latent heat.

Letting $w$ be an infinitesimal area on $\left(\Psi_{D S}(t)\right)$ enclosing $P$, form a cylinder with area $w$ as the base and generators equal and parallel to the line $P P^{\prime}$ whose length $\delta \rightarrow n_{p}$ is an infinitesimal of lower order than the linear dimensions of $w$ (Figure 8.3). 


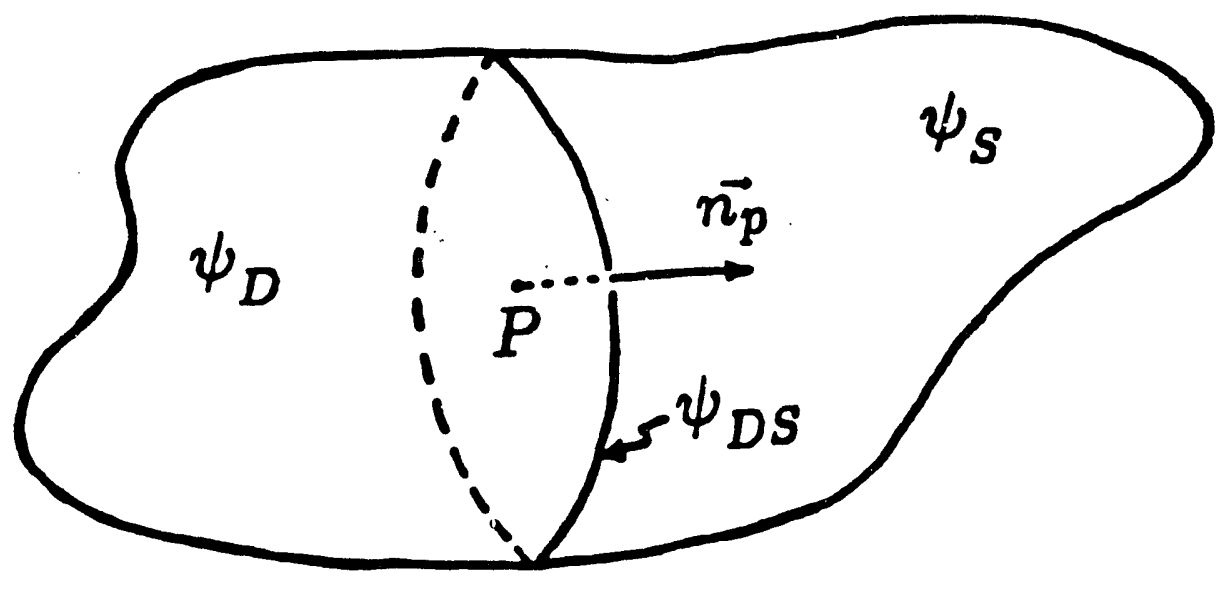

Figure 8.2: Explanation of Symbols For Moving Boundary Derivation (After Sengul, 1977)

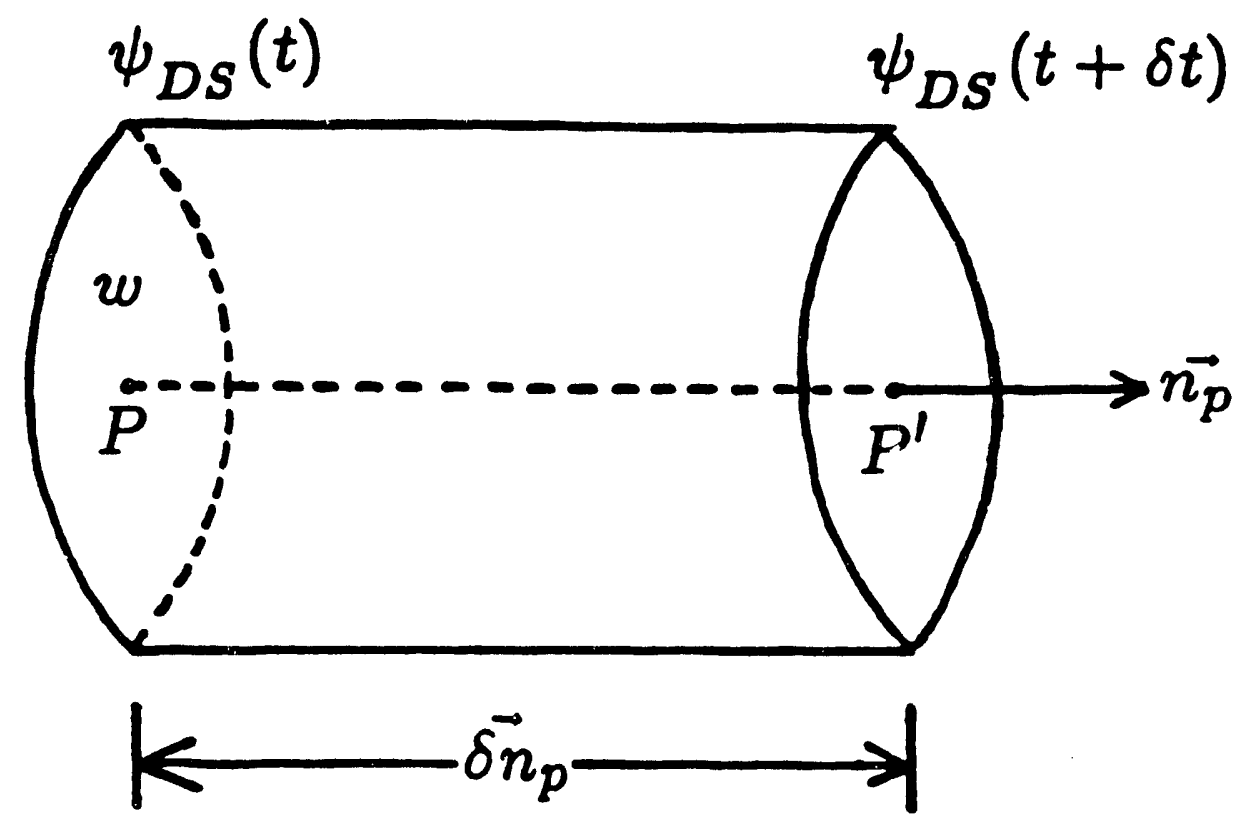

Figure 8.3: Explanation of Symbols For Moving Boundary Derivation (After Sengul, 1977) 
The rates of heat flow per unit time across the plane surfaces of the cylinder through $P$ and $P^{\prime}$ are $-w k_{D}\left(\partial T_{D} / \partial n_{p}\right)$ and $-w k_{S}\left(\partial T_{S} / \partial n_{p}\right)$, respectively. The flow of heat across the curved surface may be considered negligible compared to these because of the assumptions on the dimensions of $\delta \rightarrow n_{p}$ and $w$. The rate of heat flow into the cylinder is thus

$$
w\left(k_{S} \frac{\partial T_{S}}{\partial n_{p}}-k_{D} \frac{\partial T_{D}}{\partial n_{p}}\right)
$$

The rate at which the cylinder gains heat is considered in two parts. First, as a result of the phase change, the formation of the phase inside the cylinder involves an amount of heat equal to

$$
w \rho L_{f} \frac{\partial n_{p}}{\partial t}
$$

where, $L_{f}$ is the latent heat of hydrate dissociation, and $\rho$ is the density of the material in the cylinder at time $t$. Second, if $p$ and $C_{p}$ are the average densiiy and specific heat of the material inside the cylinder and $T$ the average temperature, then the additional rate of heat gain in the cylinder is

$$
\omega_{p} C_{p} \delta \rightarrow_{p} \frac{\partial T}{\partial t}
$$

Since, the sum of equations (8.14) and (8.15) must be equal to Eq. (8.13), we obtain

$$
k_{S} \frac{\partial T_{S}}{\partial n_{p}}-k_{D} \frac{\partial T_{D}}{\partial n_{p}}=\rho C_{p} \delta n_{p} \frac{\partial T}{\partial t}+\rho L_{f} \frac{\partial n_{p}}{\partial t}
$$


Taking the limit of equation (8.16) as $\delta_{s}^{-} n_{p} \rightarrow 0$, the first term on the right hand side tends to zero and we have

$$
{ }^{k} S \frac{\partial T_{S}}{\partial n_{p}}-k_{D} \frac{\partial T_{D}}{\partial n_{p}}=\rho L_{f} \frac{\partial n_{p}}{\partial t}
$$

Noting that at the interface, the following relations hold (Patel, 1968):

$$
\frac{\partial T_{i}}{\partial n_{p}}=\nabla T_{i}, i=D, S
$$

$$
\frac{\partial n_{p}}{\partial t}=-\frac{(\partial f / \partial t)}{\nabla f}
$$

where $f(x, y, z, t)=0$ defines the position of the interface, Eq. (8.17) can be expressed as

$$
{ }_{S} \nabla T_{S} \cdot \nabla f-k_{D} \nabla T_{D} \cdot \nabla f=-\rho L_{f}\left(\frac{\partial f}{\partial l}\right)
$$

If we express the temperature gradients in the $x$ and $y$ directions at the interface in terms of the gradient in the $z$-direction

$$
\frac{\partial T_{i}}{\partial x}=\frac{(\partial / \partial y)}{(\partial / \partial z)} \frac{\partial T_{i}}{\partial y} \text { and } \frac{\partial T_{i}}{\partial y}=\frac{(\partial f / \partial y)}{(\partial / \partial z)} \frac{\partial T_{i}}{\partial z}
$$

and substitute Eq. (8.21) into Eq. (8.20) we obtain

$$
\left.\left[1+\left(\frac{\partial f / \partial x}{\partial f / \partial z}\right)^{2}+\left(\frac{\partial / \partial y}{\partial / / z z}\right)^{2}\right] \mid k_{S} \frac{\partial T_{S}}{\partial z}-k_{D} \frac{\partial T_{D}}{\partial z}\right]=-\rho L_{f}\left(\frac{\partial f / \partial t}{\partial f / \partial z}\right)
$$


If we express the temperature gradients in the $y$ and $z$ directions oat the interface in terms of the gradient in the $x$-direction

$$
\frac{\partial T_{i}}{\partial y}=\frac{(\partial / \partial y)}{(\partial / / \partial z)} \frac{\partial T_{i}}{\partial x} \text { and } \frac{\partial T_{i}}{\partial z}=\frac{(\partial f / \partial z)}{(\partial f / \partial x)} \frac{\partial T_{i}}{\partial x}
$$

and substitute Eq. (8.23) into Eq. (8.20) we obtain

$$
\left[1+\left(\frac{\partial f / \partial y}{\partial f / \partial x}\right)^{2}+\left(\frac{\partial f / \partial z}{\partial / / \partial x}\right)^{2}\right]\left[k_{S} \frac{\partial T_{S}}{\partial x}-k_{D} \frac{\partial T_{D}}{\partial x}\right]=-\rho L_{f}\left(\frac{\partial f / \partial t}{\partial f / \partial x}\right)
$$

Suppose now that we wish to convert to cylindrical coordinates with assumed symmetry about the $z$-axis. The normal conversions are

$$
x=r \cos \theta, y=r \sin \theta, z=z
$$

but because of the symmetry, we let $\theta \rightarrow 0$ and the conversion become

$$
x=r, y=0, z=z
$$

Making use of Eq. (8.26), we convert Eqs. (8.22) and (8.24) into cylindrical coordinates with the assumed symmetry to obtain Eqs. (8.27) and (8.28), respectively.

$$
\begin{aligned}
& \left|1+\left(\frac{\partial f / \partial r}{\partial f / \partial z}\right)^{2}\right|\left[k_{S} \frac{\partial T_{S}}{\partial z}-k_{D} \frac{\partial T_{D}}{\partial z} \mid=-\rho L_{f}\left(\frac{\partial f / \partial t}{\partial f / \partial z}\right)\right. \\
& \left.\mid 1+\left(\frac{\partial f / \partial z}{\partial f / \partial r}\right)^{2}\right]\left|k_{S} \frac{\partial T_{S}}{\partial r}-k_{D} \frac{\partial T_{D}}{\partial r}\right|=-\rho L_{f}\left(\frac{\partial f / \partial t}{\partial f / \partial z}\right)
\end{aligned}
$$


If we now let

$$
f(r, z, t)=z-s(r, t)=0
$$

then

$$
\frac{\partial f}{\partial r}=-\frac{\partial s}{\partial r} \text { and } \frac{\partial f}{\partial z}=1
$$

Substituting Eq. (8.30) into Eq. (8.27) we obtain

$$
\left\lfloor 1+\left(\frac{\partial s}{\partial r}\right)^{2}\right]\left[k_{S} \frac{\partial T_{S}}{\partial z}-k_{D} \frac{\partial T_{D}}{\partial z}\right]=-\rho L_{f} \frac{\partial z_{f}}{\partial t}
$$

Similarly, letting

$$
f(r, z, t)=r-s(z, t)=0
$$

then

$$
\frac{\partial f}{\partial z}=-\frac{\partial s}{\partial z} \text { and } \frac{\partial f}{\partial r}=1
$$

Substituting Eq. (8.33) into Eq. (8.28) we obtain,

$$
\left\lfloor 1+\left(\frac{\partial s}{\partial z}\right)^{2}\right]\left[k_{S} \frac{\partial T_{S}}{\partial r}-k_{D} \frac{\partial T_{D}}{\partial r}\right]=-\rho L_{f} \frac{\partial r_{f}}{\partial t}
$$

Equations (8.31) and (8.34) represent the second moving boundary condition.

\subsubsection{Dimensionless Form of the Mathematical Model}

Conversion of the mathematical model represented by equations (8.3) through (8.12), (8.31) and (8.34) into dimensionless form has many advantages 
including simplification of the sensitivity analysis and making the model generally more applicable to melting and solidification problems other than hydrate dissociation.

The radial coordinator $r_{w} \leq r \leq r_{e}$ is transformed into a normalized coordinate, $u$, through the logarithmic transformation

$$
u=\frac{\ln \left(r / r_{w}\right)}{\ln \left(r_{e} / r_{w}\right)}
$$

and a normalized coordinate, $v$, is obtained by transforming the vertical coordinate $0 \leqq z \leqq h_{r}$ by

$$
v=\frac{z}{h_{T}}
$$

Two of the advantages realized from these transformations are:

1. When $u$ is discretized for finite difference purposes, closely spaced grid points result near the inner boundary where the solution changes rapidly, and

2. the rectangular domain $\left(r_{w} \leqq r \leqq r_{e}\right) \times\left(0 \leqq z \leqq h_{T}\right)$ is mapped to a square, $(0 \leqq u \leqq 1) \times(0 \leqq v \leqq 1)$.

Prior to defining a dimensionless time, the thermal diffusivities of each an zone are determined.

Hydrate Zone:

$$
\left(\rho C_{p}\right)_{S}=(1-\phi) \rho_{R} C_{p_{R}}+\phi \rho_{H} C_{p_{H}}
$$




$$
k_{S}=k_{R}\left|\frac{\phi^{2 / 3}\left(\delta_{H}-1\right)+1}{\left(\delta_{H}-1\right)\left(\phi^{2 / 3}-\phi\right)+1}\right|
$$

where $\delta_{H}=k_{H} / k_{R}$.

The thermal diffusivity for the solid hydrate zone can now be defined as

$$
a_{S}=\frac{{ }^{k} s}{\left(\rho C_{p}\right)_{s}}
$$

Dissociated Zone:

$$
\left(\rho C_{p}\right)_{D}=(1-\phi) \rho_{R} C_{p_{R}}+\phi\left(\rho_{w} C_{p_{W}} S_{W}+\rho_{g} C_{p_{g}} S_{g}\right.
$$

The gas density used here is calculated as

$$
\rho_{g}=\frac{Y_{g} P(Z)}{z_{g} T_{f}(z)}
$$

where $P(Z)$ is equal to the wellbore pressure at depth $Z$,

$$
P(Z)=P_{\omega b}(Z)
$$

and $T_{f}(Z)$ is the hydrate dissociation temperature (methane hydrates),

$$
T_{f}(Z)=\frac{15360.8}{37.05-\ln P(Z)}-459.6-a_{f x}
$$


Here, $a_{f x}$ is the freezing point depression due to salinity. The gas compressibility factor, $z_{g^{\prime}}$ is calculated using the Standing modification of the Brill and Beggs correlation for curve fitting the Standing-Katz $z$-factor charts (Standing, 1977).

The thermal conductivity of the dissociated zone is defined as

$$
k_{D}=k_{R}\left\{\frac{S_{W}\left|\phi^{23}\left(\delta_{W}-1\right)+1\right|}{\left|\left(\delta_{W}-1\right)\left(\phi^{23}-\phi\right)+1\right|}+\frac{S_{g}\left|\phi^{2 / 3}\left(\delta_{g}-1\right)+1\right|}{\left|\left(\delta_{g}-1\right)\left(\Phi^{23}-\phi\right)+1\right|}\right\}
$$

where

$$
\delta_{W}=\frac{k_{W}}{k_{R}} \text { and } \delta_{g}=\frac{k_{g}}{k_{R}}
$$

The dissociated zone thermal diffusivity is now defined:

$$
a_{D}=\frac{k_{D}}{\left(\rho C_{P}\right)_{D}}
$$

Underburden and Overburden:

The thermal diffusivities of the overburden and underburden are defined by

$$
\mathrm{a}_{i}=\frac{k_{R}}{\rho_{R} C_{p_{R}}}, i=0, U
$$

Dimensionless time (Fourier's number) can now be defined for each region:

$$
\tau_{i}=\frac{a_{i} t}{r_{w}^{2}}, i=D, S, O, U
$$


Dimensionless temperatures will be defined as

$$
\theta_{i}\left(u, v, \tau_{i}\right)=\frac{T(r, z, l)-T_{f}(z)}{T_{\omega b}-T_{f}^{(0)}}, i=D, S, O, U
$$

where $T_{f}(z)$ is given by Eqs. (8.42) and (8.43), and $T_{f}^{(0)}$ is the hydrate dissociation temperature at the hydrate - underburden boundary.

In addition to the dimensionless variables defined above, the following dimensionless constants result from the transformation of the equations to dimensionless form:

$$
\begin{gathered}
\beta=\frac{r_{e}}{r_{w}} \\
\lambda=\left[\left.\ln \left(\frac{r_{e}}{r_{w}}\right)\right|^{2}\right. \\
\mu=\left(\frac{r_{w}}{h_{T}}\right)^{2} \\
\sigma(u)=\frac{1}{\left(T_{\omega b}-T_{f}^{(0)}\right)} \frac{\partial^{2} T_{f}}{\partial v^{2}}
\end{gathered}
$$

and

$$
\omega(v)=\left(\frac{k_{S}}{k_{D}}-1\right) \frac{\partial T}{\partial v}
$$

where 


$$
\frac{\partial T}{\partial v}=\frac{15360.8}{P(37.05-\ln P)^{2}} \frac{\partial P}{\partial v}
$$

and

$$
\frac{\partial^{2} T}{\partial v^{2}}=\frac{15360.8}{P(37.05-\ln P)^{2}}\left\{\frac{\partial^{2} P}{\partial z^{2}}+\frac{1}{P}\left|\frac{2}{(37.05-\ln P)}-1\right|\left(\frac{\partial P}{\partial v}\right)^{2}\right\}
$$

Transforming the mathematical model with the dimensionless terms defined in this section results in the following form for the model. Equation (8.3) becomes

$$
\frac{\beta^{-2 \mu}}{\lambda} \frac{\partial^{2} \theta_{i}}{\partial u^{2}}+\mu \frac{\partial^{2} \theta_{i}}{\partial v^{2}}+\mu \sigma=\frac{\partial \theta_{i}}{\partial \tau_{j}}, i, j=D, S, O, U
$$

Initial Conditions:

$$
\begin{gathered}
P\left(u, v, \tau_{D}\right)=P_{\omega b}(v), 0 \leq u \leq 1,0 \leq v \leq 1, \tau_{D}=0 \\
\ldots \ldots \ldots \\
\theta_{i}(u, v, 0)=\frac{T_{i n}(v)-T_{f}(v)}{T_{\omega b}-T_{f}^{(0)}}, 0 \leq u \leq 1,0 \leq n \leq 1, \tau_{j}=0, i, j=D, S, O, U
\end{gathered}
$$

and

$$
u_{f}(u, 0)=0
$$

Inner Boundary: 


$$
\theta_{i}\left(0, v, \tau_{j}\right)=\frac{T_{\omega b}-T_{f}(v)}{T_{\omega b}-T_{f}^{(0)}}, u=0,0 \leq v \leq 1, \tau_{j}>0, i, j=D, O, U
$$

\section{Outer Boundary:}

$$
\theta_{i}\left(1, v, \tau_{j}\right)=\frac{T_{i n}(v)-T_{f}(v)}{T_{\omega b}-T_{f}^{(0)}}, u=1,0 \leq v \leq 1, \tau_{j} \geq 0, i, j=S, O, U
$$

Upper and Lower Boundaries:

$$
\frac{\partial^{2} \theta_{i}}{\partial v^{2}}+0=0,0 \leq u \leq 1, v=1, \tau_{0} \geq 0, i=0
$$

and

$$
\frac{\partial^{2} \theta_{i}}{\partial v^{2}}+0=0,0 \leq u \leq 1, v=0, \tau_{U} \geq 0, i=U
$$

Moving Boundary Conditions:

1. From temperature continuity considerations,

$$
\theta_{D}\left(u_{f}, v_{f}, \tau_{D}\right)=\theta_{s}\left(u_{f}, v_{f}, \tau_{s}\right)=\theta_{f}=0
$$

where $u_{f}$ and $v_{f}$ are the coordinates of any point on the moving boundary.

2. From energy balance considerations at the moving boundary, the Stefan conditions given by Eqs. (8.31) and (8.34) may be represented in dimensionless form as, respectively 


$$
\left|1+\frac{\beta^{-2 u}}{\mu \lambda}\left(\frac{\partial v_{f}}{\partial u}\right)^{2}\right|\left|\frac{k_{S}}{k_{D}} \frac{\partial \theta_{S}}{\partial v}-\frac{\partial \theta_{D}}{\partial v}+w\right|=-\frac{\rho_{H} L_{f} a_{D}}{\mu k_{D}\left(T_{\omega b}-T_{f}^{(0)}\right)}\left(\frac{\partial v_{f}}{\partial \iota_{D}}\right)
$$

and

$$
\left|1+\mu \lambda \beta^{2 u}\left(\frac{\partial u}{\partial v}\right)^{2}\right|\left|\frac{\beta^{-2 u}}{\lambda}\left(\frac{k_{S}}{k_{D}} \frac{\partial \theta_{S}}{\partial u}\right)-\frac{\partial \theta_{D}}{\partial u}\right|=-\frac{\rho_{H} L_{f} a_{D}}{k_{D}\left(T_{\omega b}-T_{f}^{(0)}\right)}\left(\frac{\partial u_{f}}{\partial \mathrm{u}_{D}}\right)
$$

\subsubsection{General Solution Method}

This section includes a general method which can be used to obtain solutions to the problem of two-dimensional cylindrical heat conduction with phase change. This solution algorithm is similar to that presented by Sengul (1977) with some minor differences. While the method can be used to obtain solutions for either melting or solidification problems, only melting problems will be considered here. Details on the numerical methods used and computational considerations will be covered in the next section.

The solution of this problem is taken to be the temperature distributions in the dissociated hydrate zone, $\theta_{D}\left(u, v, \tau_{D_{n}}\right)$, the solid hydrate zone, $\theta_{S}(u, v$, $\left.\tau_{S_{n}}\right)$, the overburden, $\theta_{O}\left(u, v, \tau_{D_{n}}\right)$, and the underburden, $\theta_{U}\left(u, v, \tau_{u_{n}}\right)$ and the position of the moving boundary, $u_{f}\left(v, \tau_{D_{n}}\right)$ and $v_{f}\left(u, \tau_{D_{n}}\right)$, where we seek the solution in the time interval $0 \leqq \tau_{D n} \leqq \tau_{D N}, n=0,1,2 \ldots, N$.

In general, we are required to solve five separate problems to obtain the solution at $\tau_{D_{n+1}}$ for the time interval $\Delta \tau_{D_{n}}$. The first four problems are boundary value problems, the solutions of which give the temperature distributions in the four different zones. 
The fifth problem consists of two sets of initial value problems, the solutions of which give two sets of vectors $u_{f p^{\prime}} p=1,2, \ldots, P$ and $v_{f q}^{-{ }_{f}}, q=1$, $2, \ldots, Q$ defining the position of the moving boundary, where $P$ is the number of points that the interface intersects grid lines parallel to the radial or $u$ coordinate axis and $Q$ the number of points that the interface intersects grid lines parallel to the vertical or $v$ coordinate axis.

The boundary value problems, given in dimensionless form by Eqs. (8.57) through (8.65) and written over each zone, are solved using an iterative, semiimplicit line successive over-relaxation technique.

To begin the solution, the two sets of initial value problems given in dimensionless form by Eqs. (8.66) and (8.67) are rearranged into the more useful forms:

$$
\frac{\partial v_{f}}{\partial \tau_{D}}=\frac{\mu k_{D}\left(T_{\omega b}-T_{f}^{(0)}\right)}{\rho_{H} L_{f} a_{D}}\left|1+\frac{\beta^{-2 u}}{\mu \Lambda}\left(\frac{\partial v_{f}}{\partial u}\right)^{2}\right|\left|\frac{k_{S}}{k_{D}} \frac{\partial \theta_{S}}{\partial v}-\frac{\partial \theta_{D}}{\partial v}+w\right|
$$

and

$$
\frac{\partial u}{\partial u_{L}}=\frac{k_{D}\left(T_{w b}-T_{f}^{(0)}\right)}{\rho_{H} L_{f} a_{D}}\left|1+\mu \lambda \beta^{2 u}\left(\frac{\partial u}{\partial v}\right)^{2}\right|\left|\frac{\beta^{-2 u}}{\Lambda}\left(\frac{k_{S}}{k_{D}} \frac{\partial \theta_{S}}{\partial u}-\frac{\partial \theta_{D}}{\partial u}\right)\right|
$$

To advance the solution from $\tau_{D n}$ to $\tau_{D n+1}$, the following procedure is used:

1. An initial guess for the new position of the moving boundary is made by solving the initial value problems using Euler's method:

$$
u_{f_{p_{n+1}}^{(0)}}^{(0)}=u_{f_{p_{n}}}+\left(\frac{\partial u}{\partial f_{p}}\right)_{n}^{(0)} \Delta \tau_{D_{n}}, p=1,2, \ldots, P
$$


and

$$
v_{f_{n+1}^{(0)}}^{(0)}=v_{f_{q_{n}}}+\left(\frac{\partial v_{q}}{\partial \tau_{D}}\right)_{n}^{(0)} \Delta \tau_{D_{n}}, q=1,2, \ldots, Q
$$

The values of $\left(\partial u_{f_{p}} / \partial \tau_{D}\right)$ and $\left(\partial u_{f_{q}} / \partial \tau_{D}\right)$ are found by evaluating equations (8.69) and (8.68), respectively, at $\tau_{D_{n^{\prime}}} u_{f_{p n}}$ and $v_{f_{q n}}$.

2. Assume the moving boundary to be stationary halfway between this initial guess and its position at $\tau_{D n}$ and solve the boundary yalue problems to find the temperature distributions in the dissociated zone, solid hydrate zone, overburden and underburden.

3. A first approximation for the rate of front advancement is then made using the temperature distributions found in (2) above by solving equations (8.68) and (8.69) at $\tau_{D_{n+1}}{ }^{(0)}, u_{f_{p n+1}}{ }^{(0)}$ and $v_{f_{y n+1}}{ }^{(0)}$ :

$$
\left(\frac{\partial u_{p}}{\partial \tau_{D}}\right)_{n+1}^{(1)}=f\left(u_{f_{p_{n+1}}^{(0)},}^{\tau_{D_{n+1}}}\right), p=1,2, \ldots P
$$

and

$$
\left(\frac{\partial v_{q}}{\partial \tau_{D}}\right)_{n+1}^{(1)}=f\left(v_{f_{q_{n+1}}}^{(0)}, \tau_{D_{n+1}}\right), q=1,2, \ldots Q
$$

4. Using the trapezoidal method, a first approximation for the new interface position is found by

$$
u_{p_{p_{n+1}}}^{(1)}=u_{f_{p_{n}}}+\left|\frac{\left(\frac{\partial u_{f_{p}}}{\partial \tau_{D}}\right)_{n}^{(0)}+\left(\frac{\partial u_{p}}{\partial \tau_{D}}\right)_{n+1}^{(1)}}{2}\right| \Delta \tau_{D_{n}}, p=1,2, \ldots, P
$$


and

$$
v_{f_{q_{n}}}^{(1)}=v_{f_{q_{n}}}+\left|\frac{\left(\frac{\partial v_{f_{q}}}{\partial \tau_{D}}\right)_{n}^{(0)}+\left(\frac{\partial v_{f_{q}}}{\partial \tau_{D}}\right)_{n+1}^{(1)}}{2}\right| \Delta v_{D_{n}}, q=1,2, \ldots, Q
$$

5. This first approximation to the position of the moving boundary is then used to get a better estimate of the temperature distributions by assuming the interface to be stationary between this first estimate and its position at $\tau_{D_{n}}$ and resolving the boundary value problems.

6. The initial value problems are then resolved for each $u_{f_{p n+1}}{ }^{(1)}$ and $v f_{4 n+1}{ }^{(1)}$ to obtain second approximations of the rates of front advancement:

$$
\left(\frac{\partial f_{p}}{\partial \tau_{D}}\right)_{n+1}^{(2)}=f\left(u_{p_{n+1}}^{(1)}, v_{D_{n+1}}\right), p=1,2, \ldots P
$$

and

$$
\left(\frac{\partial f_{q}}{\partial t_{D}}\right)_{n+1}^{(2)}=f\left(v_{q_{n+1}}^{(1)}, \tau_{D_{n+1}}\right), q=1,2, \ldots Q
$$

7. A second approximation to the position of the moving boundary is now given by

$$
u_{f_{p_{n+1}}^{(2)}}^{(2)}=u_{f_{p_{n}}}+\left|\frac{\left(\frac{\partial u_{p}}{\partial \tau_{D}}\right)_{n}^{(0)}+\left(\frac{\partial u_{p}}{\partial \tau_{D}}\right)_{n+1}^{(2)}}{2}\right| \Delta_{\iota_{D_{n}}, p=1,2, \ldots, P}
$$

and 


$$
v_{q_{n+1}^{(2)}}=u_{f_{q_{n}}}+\left|\frac{\left(\frac{\partial f_{q}}{\partial \tau_{D}}\right)_{n}^{(0)}+\left(\frac{\partial v_{f_{q}}}{\partial \tau_{D}}\right)_{n+1}^{(2)}}{2}\right| \Delta v_{D_{n}}, q=1,2, \ldots, Q
$$

This procedure of using each new approximation of the moving boundary position to improve the temperature profile approximation which is then used to improve the approximation of the interface position is repeated until the successive approxi nations for $u f_{p n+1}$ and $v_{f_{n+1}}$ are within specified error limits.

After the position of the moving boundary has been determined for $\tau_{D_{n+1}}$ , the entire procedure is repeated for $\tau_{D n+2}$.

\subsection{Numerical Aspects of the Solution Method}

Because of the complexity and non-linearity of the mathematical model presented in the previous chapter, numerical methods are required to obtain a solution to the problem. The particular numerical methods to be employed will be discussed in three sections as they apply to solution of the boundary value problems, solution of the initial value problems, and lastly, the starting procedure.

\subsubsection{Solution of the Boundary Value Problems}

A finite difference discretization scheme is used to approximate the partial differential equations representing the mathematical model. The first step required in this scheme is the discretization of the time and space variables.

\section{Time Interval}

The time interval, $0 \leq \tau_{D n} \leq \tau_{D N}$, for which the solution is sought, is divided into subinterval $\Delta \tau_{D_{n}}=\tau_{D n+1}-\tau_{D n}, n=0,1,2, \ldots, N-1$, where $\tau_{D n}=$ $\sum_{j=1}^{n} \Delta \tau_{D_{j}}$. All of the subintervals need not be the same size, and for efficiency 
should not be. In general, the time interval should be small for early time when the solution changes rapidly, and larger as time progress. The limiting factors on the size of the time increment are the stability and accuracy requirements.

\section{Space Coordinates}

Equidistant grid lines are used to discretize the region of interest, $0 \leq u$ $\leq 1) \times(0 \leq v \leq 1)$, along both the space ccordinates $u$ and $v$. Letting $M$ be the number of space intervais in both directions, the distance between grid lines will be $\Delta u=\Delta v=1 / M$. The coordinates $(u, v)$ of the grid points can now be defined as $u=m \Delta u$ and $v=l \Delta v$, where the variables $m$ and $l$ are finite difference spatial locators. The relationship between this spatial discretization and the original space variables $r$ and $z$ is shown in Figures (8.4) and (8.5). For the model developed in this study, forty grids are used in both coordinate directions with the hydrate zone occupying the center twenty grids vertically.

\section{Heat Flow Equations}

As mentioned earlier, a semi-implicit line successive over-relation (LSOR) iterative technique is used to solve the boundary value problems. To demonstrate the use of LSOR, let us write a fully implicit formulation of the thermal energy balance equation (8.57) at the $(n+1)$ time level for a grid point at least one grid away from any boundaries:

$$
\begin{gathered}
\frac{\beta^{-2 \mu}}{\lambda}\left[\frac{\theta_{m+1, l}^{n+1}-2 \theta_{m \downarrow}^{n+1}+\theta_{m-1 \perp}^{n+1}}{(\Delta u)^{2}}|+\mu| \frac{\theta_{m, l+1}^{n+1}-2 \theta_{m, l}^{n+1}+\theta_{m, l-1}^{n+1}}{(\Delta u)^{2}} \mid\right. \\
+\mu 0_{l}=\frac{\theta_{m l}^{n+1}-\theta_{m, l}^{n}}{\Delta r_{D_{n}}}
\end{gathered}
$$




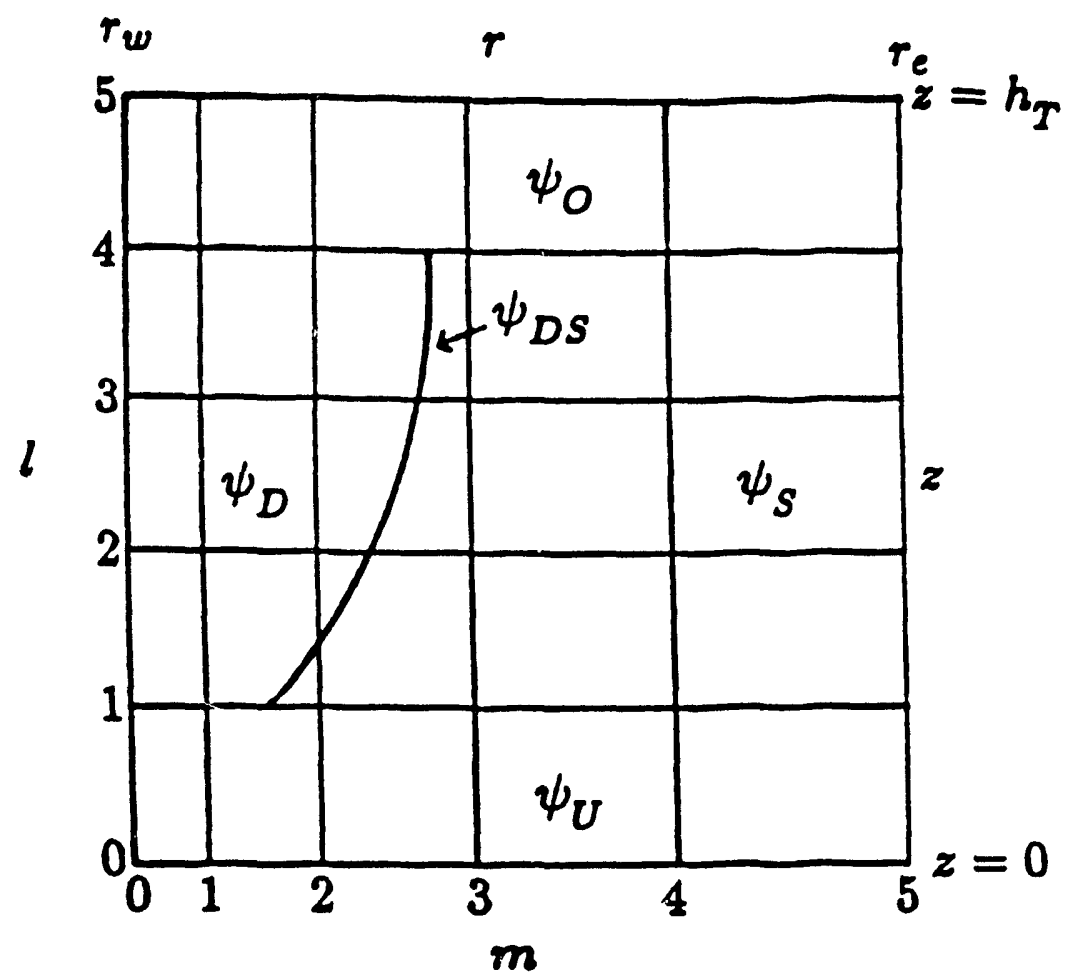

Figure 8.4: Discretization of Dimensional ipace Coordinates (After Sengul, 1977).

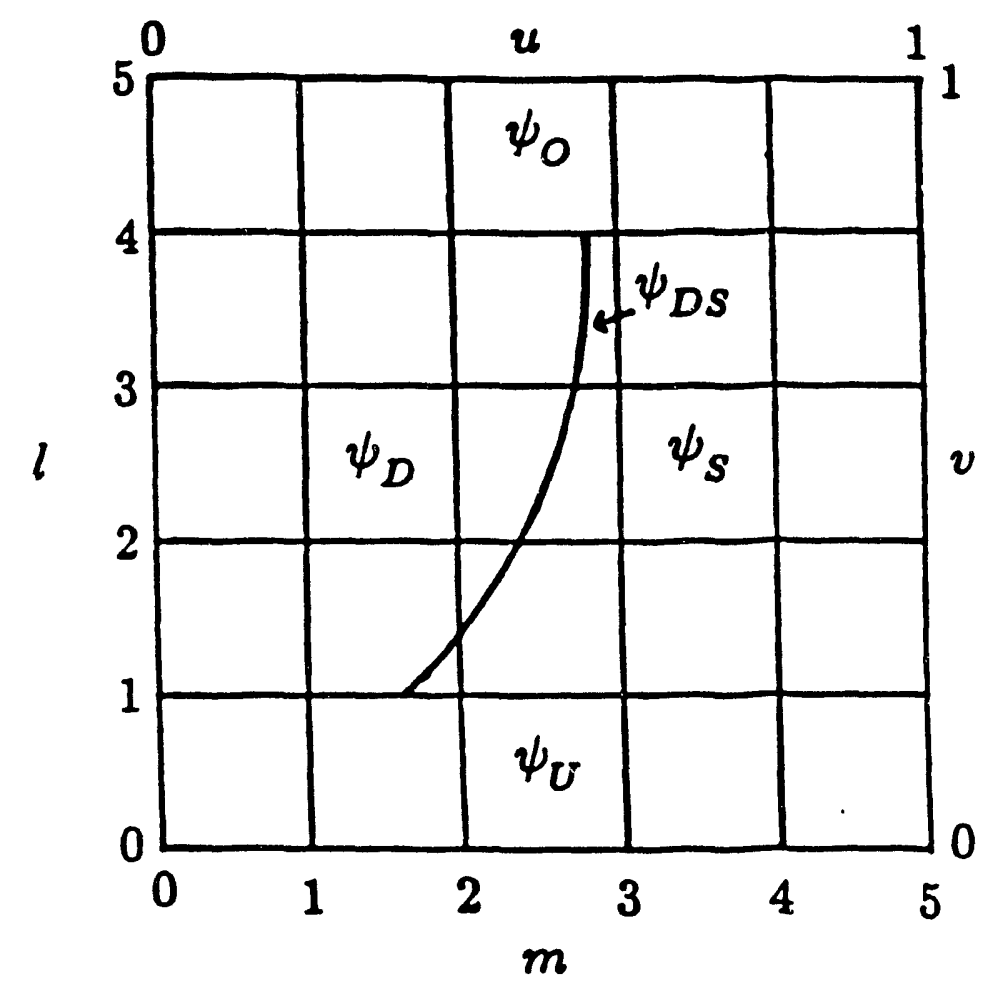

Figure 8.5: Discretization of Dimensional Space Coordinates (After Sengul, 1977). 
where $\theta_{m . l}{ }^{n+1}$ denotes the value of the temperature at the grid point whose coordinates are given by $u=m \Delta u$ and $v=l \Delta v$ at dimensionless time $\tau_{D}=\tau_{D n}$. Note that the subscripts $D, S, O, U$ of $\theta$ will be dropped for clarity and since they are implied in the location subscripts $m$ and $l$.

To use LSOR, the temperature values on a line are solved simultaneously, assuming that the values on the previous line, i.e., $(l-1)$ terms, are known since they have just been calculated, and the values at $(l+1)$ are approximated by the old iteration values. Implementing these changes, Eq. (8.80) becomes

$$
\begin{gathered}
\eta_{i} \frac{\beta^{-2 u}}{\lambda} \theta_{m+i, l}^{n+1}{ }^{k+1}-\left|2 \eta_{i}\left(\frac{\beta^{-2 u}}{\Lambda}+\mu\right)+1\right| \theta_{m, l}^{n+1}{ }^{k+1}+\eta_{i} \frac{\beta^{-2 u}}{\Lambda} \theta_{m-1, l}^{n+1} k+1 \\
=\mu \eta_{i} \theta_{m, L+1}^{n+1^{k}}-\mu \eta_{i} \theta_{m, l-1}^{n+1^{k+1}}-\theta_{m, l}^{n}-\mu \sigma_{l}, i=D, S, O, U
\end{gathered}
$$

where $k$ is the iteration number and $\eta_{i}=\Delta \tau_{i_{n}} /(\Delta u)^{2} ; i=D, S, O, U$. This technique resolves the two-dimensional problem into a succession of temporary one-dimensional problems.

Equation (8.81) is of tridiagonal form since all terms on the righthand side are known. When written for each point on a line, this equation produces a diagonally dominate tridiagonal matrix which is readily solvable by a variety of techniques, e.g., the Thomas algorithm. Equation (8.81) may be written in condensed form as

$$
a \theta_{m+1, l}^{n+1^{k+1}}-b \theta_{m, l}^{n+1}+c \theta_{m-1, l}^{n+1^{k+1}}=d
$$

After each line computation, the next approximation to the $\theta_{m, l^{n+1}}{ }^{k+1}$ values are obtained by over-relation as follows: 


$$
a \theta_{m, l}^{n+1^{k+1}}=\theta_{m, l}^{n+1^{k}}+w\left(\theta_{m, l}^{n+1^{k+1}}-\theta_{m, l}^{n+1^{k}}\right)
$$

where $w$ is a relaxation parameter and $1 \leq w \leq 2$.

A convergence criteria used in this model for the boundary value problems is

$$
\max \left(\frac{\theta_{m, l}^{n+1^{k+1}}-\theta_{m, l}^{n+1^{k}}}{\theta_{m, l}^{n+1^{k+1}}}\right) \leq \varepsilon_{T}, 0,<m \leq M, 0<l \leq M
$$

The iterative procedure is continued until the convergence criterion is satisfied. The number of iterations required is significantly affected by the value of $w$, and when this relaxation parameter is judiciously selected, rapid convergence is the result. The methods of determining the optimum relaxation factor will not be discussed, but is referenced in a variety of literature (Varga, 1962; Crichlow, 1977; Aziz and Settari, 1972).

In applying the above iterative procedure to the dissociated and solid hydrate zones for a particular iteration and grid line, the temperature distribution in the dissociated zone is solved first, followed by the temperature distribution in the solid hydrate zone, and then the temperatures along the entire grid line are relaxed according to Eq. (8.83).

The finite difference equations at the boundaries between the dissociated zone and overburden, dissociated zone and underburden, solid hydrate zone and overburden, and solid hydrate zone and underburden are of the same form as Eq. (8.81) with the only difference being in the evaluation of $\eta$ to represent the difference in physical properties of each zone. For example, 
the finite difference equation for the boundary between the solid hydrate zone and the underburden is

$$
\begin{gathered}
\eta_{S U} \frac{\beta^{-2 u}}{\lambda} \theta_{m+1, l}^{n+1}-\left|2 \eta_{S U}\left(\frac{\beta^{-2 u}}{\lambda}+\mu\right)+1\right| \theta_{m, l}^{n+1}+\eta^{k+1}+\eta_{S U} \frac{\beta^{-2 u}}{\Lambda} \theta_{m-1, l}^{n+1} k+1 \\
=\mu \eta_{S} \theta_{m, l+1}^{n+1}-\mu \eta_{U} \theta_{m,-1}^{n+1^{k+1}}-\theta_{m,}^{n}-\mu \sigma_{l}, i=D, S, O, U
\end{gathered}
$$

where

$$
\begin{gathered}
\eta_{U}=\left(\frac{a_{U}}{a_{D}}\right) \eta_{D} \\
\eta_{S U}=\left(\frac{a_{S U}}{a_{D}}\right) \eta_{D} \\
\eta_{D}=\frac{\Delta \tau_{D}}{(\Delta u)^{2}}
\end{gathered}
$$

and

$$
\tau_{D}=\frac{a_{D^{b}}}{r_{w}^{2}}
$$

This conversion is necessary to insure that the heat flux at the boundaries is the same on either side of the boundary. For brevity, the other equations occurring at the boundaries will not be presented here, but caution is urged that $n$ properly reflect the thermophysical properties of the zone for which the heat transfer occurring. 
Equations of the form of Eqs. (8.81) and (8.85) apply at the regular grids which are at least one full grid removed from the moving boundary (e.g., grid point $T$ in Figure 8.6).

At irregular grid points near the moving boundary, such as point $P$ in Figure 8.6, the finite difference formula for the dissociated zone will be, after dropping the iteration parameter $k$ for clarity:

$$
\begin{gathered}
\frac{\eta_{D}}{(1+a) a} \frac{\beta^{-2 u}}{\lambda} \theta_{m+a, l}^{n+1}-\left|\frac{2 \eta_{D}}{a} \frac{\beta^{-2 u}}{\lambda}+2 \mu \frac{\eta_{D}}{b}+1\right| \theta_{m, l}^{n+1}+\frac{\eta_{D}}{(1+a)} \frac{\beta^{-2 u}}{\lambda} \theta_{m-1, l}^{n+1} \\
=\frac{\mu \eta_{D}}{(1+b) b} \theta_{m, l+b}^{n+1}-\frac{\mu \eta_{D}}{(1+b)} \theta_{m, l-1}^{n+1}-\theta_{m, l}^{n}-\mu \sigma_{l}
\end{gathered}
$$

where

$$
\theta_{m+a, l}^{n+1}=\theta_{m+b, l}^{n+1}=\theta_{f}=0
$$

The Lagrangian three-point interpolation formulae was used to derive equation (8.90). Note that even though the actual hydrate dissociation temperature, $T_{f}$ is different at $(m+a, l)$ and $(m, l+b)$, the dimensionless temperatures at the front are everywhere equal to zero due to the definition of dimensionless temperature (Eq. 8.49) and the first moving boundary condition (Eq. 8.66).

Equation (8.90) is applicable to those points in the dissociated zone for which the grid point is irregular with respect to both space coordinates. The applicable finite difference equation for grid points irregular only with respect to the $u$ coordinate, such as point $R$ in Figure 8.6, is

$$
\frac{\eta_{D}}{(1+a) a} \frac{\beta^{-2 u}}{\lambda} \theta_{m+a, l}^{n+1}-\left|\frac{\left.2 \eta_{D}\right)}{a} \frac{\beta^{-2 u}}{\Lambda}+2 \mu \eta_{D}+1\right| \theta_{m\rfloor}^{n+1}+\frac{\eta_{D}}{(1+a)} \frac{\beta^{-2 u}}{\Lambda} \theta_{m-1, l}^{n+1}
$$




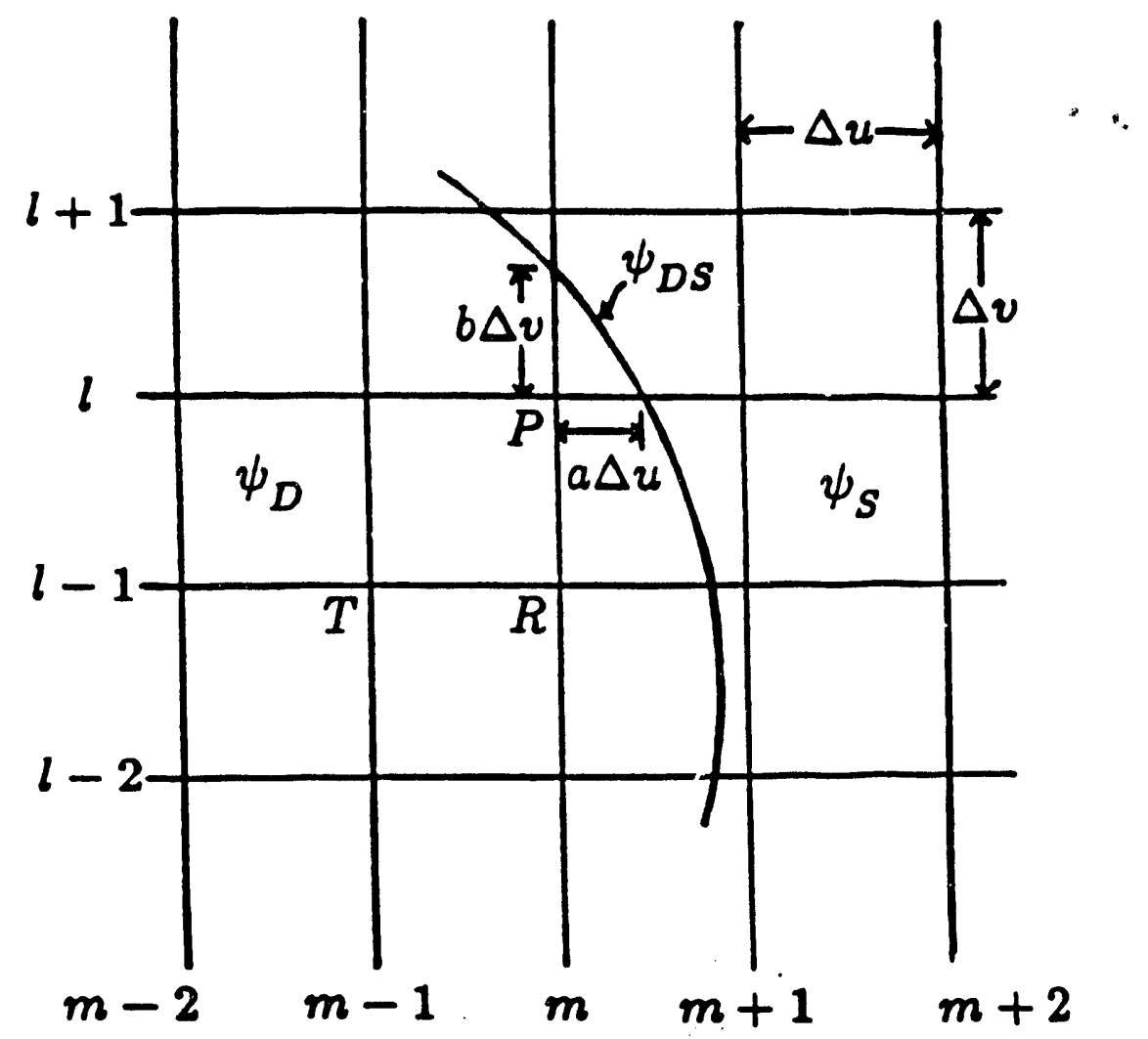

Figure 8.6: Irregular Grid Points (After Sengul, 1977) 


$$
=\mu \eta_{D} \theta_{m, l+b}^{n+1}-\mu \eta_{D} \theta_{m, l-1}^{n+1}-\theta_{m, l}^{n}-\mu v_{l}
$$

where $0_{m+a, l}^{n+1}=\theta_{f}=0$.

For those grid points irregular with respect to the $v$ coordinate only, the following finite difference equation results:

$$
\begin{gathered}
\eta_{D} \frac{\beta^{-2 u}}{\lambda} \theta_{m+1, l}^{n+1}-\left|2 \eta_{D} \frac{\beta^{-2 u}}{\lambda}+2 \mu \frac{\eta_{D}}{b}+1\right| \theta_{m, l}^{n+1}+\eta_{l} \frac{\beta^{-2 u}}{\lambda} \theta_{m-1, l}^{n+1} \\
=\frac{\mu \eta_{D}}{(1+b) b} \theta_{m, l+b}^{n+1}-\frac{\mu \eta_{D}}{(1+b)} \theta_{m, l-1}^{n+1}-\theta_{m, l}^{n}-\mu \sigma_{l}
\end{gathered}
$$

where $\theta_{m, l+b}^{n+1}=\theta_{f}=0$.

Inner Boundary Condition

$$
\theta_{0, \downarrow}^{n}=\frac{T_{\omega b}-T_{f}^{(v)}}{T_{\omega b}-T_{f}^{(0)}}, m=0, l=0,1, \ldots, M, n=1,2, \ldots, N
$$

\section{Outer Roundary Condition}

$$
\theta_{M \downarrow}^{n}=\theta_{M \downarrow}^{n}, m=M, l=0,1,2, \ldots, M, n=0,1,2, \ldots, N
$$

\section{Upper and Lower Boundary Conditions}

\section{Upper Boundary:}

$$
\frac{\theta_{m,+1}^{n+1}-2 \theta_{m, l}^{n+1}+\theta_{m, l-1}^{n+1}}{(\Delta v)^{2}}+0_{l}=0, m=1,2, \ldots, M-1, l=M, n=0,1, \ldots, N^{\prime}
$$


Lower Boundary:

$$
\frac{\theta_{m, l+1}^{n+1}-2 \theta_{m, l}^{n+1}+\theta_{m, l-1}^{n+1}}{(\Delta v)^{2}}+\sigma_{l}=0, m=1,2, \ldots, M-1, l=0, n=0,1, \ldots, N
$$

\section{Initial Conditions}

The initial condition is taken as the position of the moving boundary and the temperature distributions at time, $(t=0)$.

\subsubsection{Solution of the Initial Value Problems}

The next step to obtaining a complete solution is to determine the position of the moving boundary at time, $\tau_{D_{n+1}}$. This is accomplished by solving the nonlinear initial value problems using the trapezoidal method as outlined in the previous section on the general solution method. The numerical peculiarities associated with the initial value problems and the numerical methods used to resolve them will be discussed.

The equations representing the trapezoidal method are given by:

$$
u_{f_{p_{n}+1}}=u_{f_{p_{n}}}+\left(\frac{\left(\frac{\partial u_{p}}{\partial \tau_{D}}\right)_{n}+\left(\frac{\partial u_{p}}{\partial \tau_{D}}\right)_{n+1}}{2}\right) \Delta \tau_{D_{n}, p=1,2, \ldots, P}
$$

and

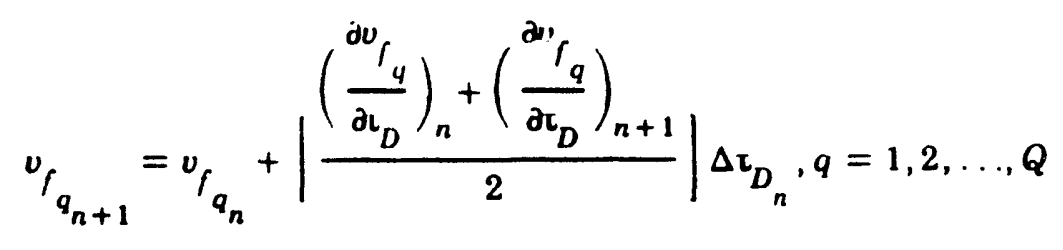


where the rates of front advancement, $\left(\partial v_{f_{q}} / \partial \tau_{D}\right)$ and $\left(\partial u f_{p} / \partial \tau_{D}\right)$, are given by Eqs. (8.68) and (8.69), respectively. Because the position of the hydrate dissociation front at the new time level, $u_{f p_{n+1}}$ and $v_{f q_{n+1}}$, appears implicitly on the righthand sides of Eqs. (8.68) and (8.69), these equations must be solved by iteration at each time step.

Successive values of $u_{f p_{n+1}}{ }^{k+1}$ and $v_{f q_{n+1}}{ }^{k+1}$ are calculated using the following equations after each solution of the boundary value problems until the results converge:

$$
u_{f_{p_{n+1}}^{k+1}}^{k+1}=u_{f_{p_{n}}}+\left(\frac{\left(\frac{\partial f_{p}}{\partial \tau_{D}}\right)_{n}^{(0)}+\left(\frac{\partial u_{p}}{\partial u_{D}}\right)_{n+1}^{k+1}}{2}\right) \Delta \tau_{D_{n}}, p=1,2, \ldots, P
$$

and

$$
u_{q_{n+1}^{k+1}}=v_{f_{q_{n}}}+\left(\frac{\left(\frac{\partial f_{q}}{\partial \tau_{D}}\right)_{n}^{(0)}+\left(\frac{\partial f_{f_{q}}}{\partial t_{D}}\right)_{n+1}^{k+1}}{2} \mid \Delta \tau_{D_{n}}, q=1,2, \ldots, Q\right.
$$

where

$$
\left(\frac{\partial u}{\partial \tau_{p}}\right)_{n+1}^{k+1}=f\left(u_{p_{p_{n+1}}^{k}}^{k}, \tau_{D_{n+1}}\right), p=1,2, \ldots, P
$$

and

$$
\left(\frac{\partial v_{q}}{\partial \tau_{D}}\right)_{n+1}^{k+1}=f\left(v_{q_{n+1}^{k}}^{k},{ }^{L} D_{n+1}\right), q=1,2, \ldots, Q
$$

From the above four equations, the iteration and time level dependence of the front positions and the rates of front advancement can be seen. From Eqs. 
(8.100) through (8.103), we see that the hydrate dissociation front must be tracked at three distinct times or iteration levels, e.g., for the $u$-coordinate position of the front, $u_{f p_{n},} u_{f p_{n+1}}{ }^{k}$, and $u_{f p_{n+1}}{ }^{k+1}$. Convergence is assumed when the successive approximations for $u_{f p_{n+1}}$ and $v_{f p_{n+1}}$ are within specified error limits:

$$
\begin{aligned}
& \max \left(u_{f_{p_{n+1}}}^{k+1}-u_{f_{p_{n+1}}}^{k}\right) \leq \varepsilon_{f}, p=1,2, \ldots, P \\
& \max \left(v_{q_{q_{n+1}}^{k+1}}^{k}-v_{q_{q_{n+1}}}^{k}\right) \leq \varepsilon_{f}, q=1,2, \ldots, Q
\end{aligned}
$$

In seeking a solution to the initial value problems, one of the major difficulties is in the evaluation of the rates of front advancement (Eqs. 8.68 and 8.69) because it requires an estimation of the temperature gradients $\left(\partial \theta_{D} / \partial u\right.$, $\left.\partial \theta_{S} / \partial u, \partial \theta_{D} / \partial u, \partial \theta_{S} / \partial v\right)$ at the moving boundary, and also, the slopes of the moving boundary ( $\partial u / \partial v$ and $\partial v / \partial u$ ) at each discrete grid line intersected by the moving interface.

Sengul (1977) indicated that the accuracy of estimating these derivatives may determine whether or not a stable and convergent solution is obtained. Because there are no analytical solutions for multi-dimensional Stefan type problems, analytical expressions for the stability requirements which must be determined by a trial and error process and which will change (perhaps significantly, perhaps not) with every change in the particular numerical method used to obtain a solution.

To evaluate the temperature gradients at the moving boundary, the temperatures at the grid points on either side of the interface and the 
temperature of the interface are fit to a polynomial using a least squares method (Gerald and Wheatley, 1984). Each of these polynomials fit to the temperature profiles is allowed to vary from degree one and degree nine. The optimum degree of the polynomial is selected by increasing the degree of the polynomial, beginning with degree one, so long as there is a significant decrease in the variance (Gerald and Wheatley, 1984).

Once these polynomials have been determined for the temperature profiles in each of the dissociated and solid hydrate zones for both the $u$ and $v$ directions, Richardson Extrapolation (Cheney and Kincaid, 1985) is used to determine the first derivative of the polynomials, i.e. the temperature gradients at the moving boundary.

The position of the dissociated hydrate - solid hydrate interiace is also fit to a polynomial using the method of least squares. At every discrete intersection between the hydrate front and a grid line, Richardson Extrapolation is once again used to obtain the first derivative of the polynomials, which in this case represent the slopes of the hydrate front with respect to the coordinate axis.

All variables in the equations for the moving boundary condition are now known, and so those equations ( 8.68 and 8.69 ) may be solved for the rates of hydrate front advancement required for the general solution of this problem.

\subsubsection{Starting Procedure}

The initial boundary conditions include specifications of the initial temperatures throughout the reservoir as being the same as the geothermal temperatures and the initial hydrate front as coinciding with the wellbore. The inner boundary condition, however, specifies an increased temperature (above the hydrate dissociation temperature) at the wellbore. Because there is no 
continuous agreement between the inner and initial boundary conditions at $\tau_{D}$ $=0$, some alternative to the solution procedure outlined must be used to find the position of the moving boundary and the temperature distributions for some small finite value of $\tau_{D}$.

Sengul (1977) states that for his one-dimensional models, he found insensitivity to the particular methods used to obtain these initial approximations, and that if the errors incurred in these initial approximations are small, they diminish rapidly with time.

For the model being developed in this study, the position of the moving boundary is arbitrarily set equal to a small value for a small initial time, $0<u_{f_{p}}$ $\ll<1, p=1,2, \ldots, P$, the temperature distributions determined, and the solution allowed to proceed from there. Sengul's (1977) correlation is used to obtain a value for the dimensionless time, $\tau_{D}$, corresponding to this initial position of the interface.

Remembering the relationship between the radial cylindrical coordinate and the dimensionless horizontal coordinate, $u_{\text {, several advantages are }}$ realized when this initial position of the hydrate front is specified to be several (2 to 3) grid points removed from the wellbore. Firstly, in real space, the initial position of the moving boundary is still very close to the wellbore. Second, instead of there being only two known temperatures, the wellbore temperature and the dissociation temperature, from which to calculate the temperature gradient in the dissociated zone at the moving boundary, there results the additional temperatures at the grid points between the moving boundary and the wellbore. This will allow a more accurate initial approximation of the temperature gradient at the moving boundary. Lastly, this starting procedure avoids the sometimes complex and involved one- 
dimensional analytical solutions that are available in the literature and that have been used by other authors.

\subsection{Hydrate Dissociation Model Applications and Results}

\subsubsection{General Uses and Applications of the Model}

The hydrate dissociation model, as developed, has several applications which include: parametric sensitivity analysis of reservoir and wellbore properties on hydrate dissociation and heat transfer rates; when used in conjunction with a wellbore hydraulics and heat transfer model, drilling fluid properties can be optimized to promote or prevent hydrate dissociation while drilling hydrate bearing formations; and given the drilling fluid properties used while drilling, design criteria for surface degassing equipment can be established.

In addition to these direct applications, this hydrate dissociation model provides insight into the numerical aspects associated with solving moving boundary problems. The numerical aspects involved in obtaining a solution to this type of moving boundary problem are identified and discussed.

Lastly, this hydrate dissociation simulator could be modified into a completely general model, allowing application to any sort of melting or solidification problem, either in porous media or a continuous slab.

\subsubsection{Validation of Hydrate Dissociation Model}

\subsubsection{Sensitivity Analysis}

Aziz and Settary (1979) recommend that a sensitivity analysis be performed on a simulator to define the necessary grid size and time step size required to obtain accurate and meaningful results. The term 
"sensitivity analysis" used here refers to the sensitivity of the primary variables to grid size and time step size. Such a study requires performing a series of simulation runs with increasing and decreasing grid size and a series of simulation runs with increasing or decreasing time step size. Abou-Kassem and Aziz (1982) comment that sensitivity studies of grid size and time step size are meaningful only if each is carried out while the other variable has minimum truncation error.

A sensitivity analysis on the hydrate dissociation model presented in this study indicates that the grid size and time step sizes used in the model result in the primary variables (temperatures distribution and position of the hydrate front) being accurate to within a fraction of a percent to the limiting case where numerical dispersion becomes significant. In performing the sensitivity analysis on the hydrate dissociation model, the time step size was varied between $\Delta t=0.1$ (hrs) and $\Delta t=6.0$ (hrs). The number of grids used within the model remained at all times $\mathbf{4 0}$ grids, and so to ascertain the effect of grid size on the model results, the radial extent and vertical extent of the reservoir were varied as follows: the radial extent of the reservoir was varied between $r_{e}=50 \mathrm{ft}$ and $r_{e}=1000$ $\mathrm{ft}$; the vertical extent of the reservoir was varied between $h_{T}=20 \mathrm{ft}$ and $h_{T}=300 \mathrm{ft}$. For all cases considered, the results compared to within 0.1 percent of each other.

These results indicate that the use of $\mathbf{4 0}$ grid blocks in each direction was more than sufficient to reduce spatial truncation errors for set of data under investigation. The results also indicate that the time steps used within the model were sufficiently small to reduce any time truncation errors. It should be noted that double-precision computations were used in the model as some oscillation was noted when using single- 
precision. All simulation runs were performed on a VAX 8800 computer running VAXNMS 4.2. Run times for the simulation runs varied only slightly from $0.7 \mathrm{cpu}$ seconds per time step to $0.9 \mathrm{cpu}$ seconds per time step. These times indicate that approximately $5 \times 10^{-4} \mathrm{cpu}$ seconds per time step per grid block were required for each run.

\subsubsection{Comparison of Model Results With Published Results}

Several methods exist for validating the results obtained from the numerical simulation of some process. The most dependabie and convincing is when results from a numerical simulator can be compared directly with experimental or field data. Lack of either of these sources of data, the next best method of validation is to compare results from the numerical simulator to analytical solutions of the mathematical problem being approximated. When no such solutions exist, or when the model formulation precludes such a comparison, the remaining method for validation is the comparison of model results to the results published in the literature for similar numerical models.

For the hydrate dissociation model developed in this study, there are no experimental or field data to which the model results can be compared. Due to the complexity and non-linearity of the mathematical problem being approximated, there exists no analytical solutions to which the model results can be compared. The model presented in this study, however, can be simplified in several ways so as to allow a comparison of the results obtained from it to the results for a model published in the literature.

Sengul (1977) published results for a one-dimensional Stefan problem in which he studied the thawing of permafrost around a 
producing oil well. He found the solution to the problem to be a function of three dimensionless parameters, plus a dimensionless radius and dimensionless time. These dimensionless parameters are:

$$
\begin{gathered}
\mathrm{Y}=\frac{\mathrm{a}_{D}}{\mathrm{a}_{S}} \\
\Phi=\frac{k_{S}\left(T_{i n}-T_{f}\right)}{k_{D}\left(T_{w b}-T_{f}\right)} \\
\sigma=\frac{L_{f}}{C_{p_{D}}\left(T_{w b}-T_{f}\right)} \\
r_{D}=\frac{r}{r_{w}}
\end{gathered}
$$

and

$$
\tau_{D}=\frac{a_{D} t}{r_{w}^{2}}
$$

Parameter $r_{D}$ is a dimensionless radius and parameter $\tau_{D}$ is a dimensionless time. The other dimensionless terms may be interpreted as follows: $\mathrm{Y}$ is a parameter of the differential heat equation describing heat conduction in the solid region; $\phi$ can be interpreted as the ratio of heat flow in the solid region resulting from the temperature difference $\left(T_{\text {in }}-T_{\vec{f}}\right)$ to the heat flow in the liquid region resulting from the imposed 
temperature difference $\left(T_{w b}-T_{j}\right)$; and the physical interpretation of $\delta$ is that it represents the ratio of the heat required to melt a unit volume of solid to the maximum available heat content of a unit volume of liquid.

Sengul generated solutions for the range of values of these dimensionless parameters typically found in Alaska's North Slope. He found that the relationship between the dimensionless radius of the thawed permafrost region and dimensionless radius of the thawed permafrost region and dimensionless time could be expressed by a simple power law equation containing two constants. The relationship between these two constants and the three dimensionless parameters were presented in two correlating curves and in tables.

In order to compare the results froin the hydrate dissociation model to those obtained by Sengul for the degradation of permafrost, several simplifying assumptions were incorporated into the hydrate model to approximate one-dimensional heat flow. These assumptions essentially include only the specification of the same constant pressure and initial temperature throughout all of the hydrate zone and the overburden and underburden zones, i.e., removing the geothermal gradient and pressure gradient. Following these simplifications, the reservoir, fluid and process parameters used in the hydrate dissociation model were specified so as to obtain values of the three dimensionless parameters $y, \phi$, and $\sigma$ within the range of those parameters studied by Sengul. The hydrate dissociation model was then run, and the relationship between the dimensionless radius and dimensionless time obtained was compared to the relationship obtained by using Sengul's two constant correlation. Results for several values of the dimensionless constant $\phi$ are shown in Figures 8.7 to 8.9 . 


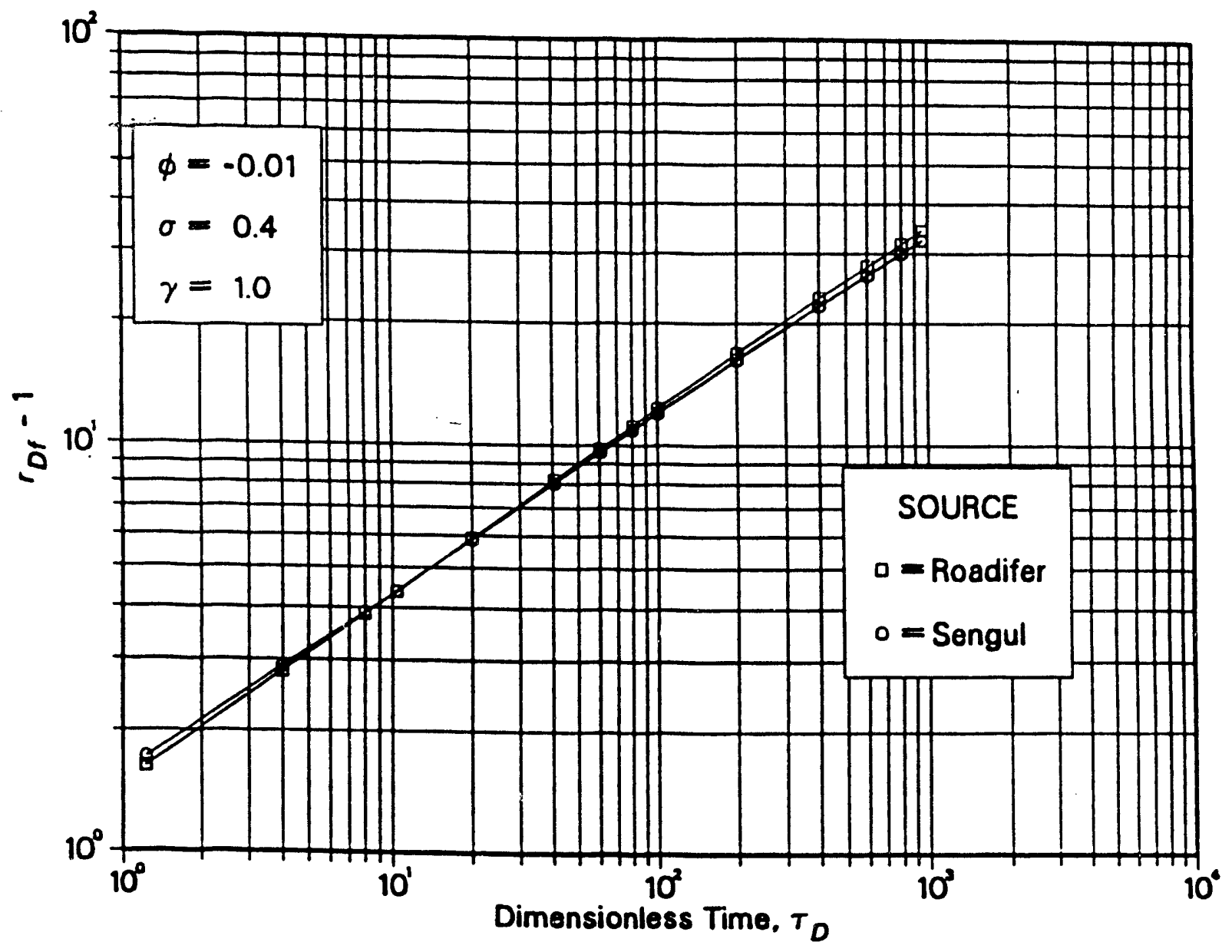

Figure 8.7: Comparison of Models for $\Phi=-\mathbf{0 . 0 1}$ 


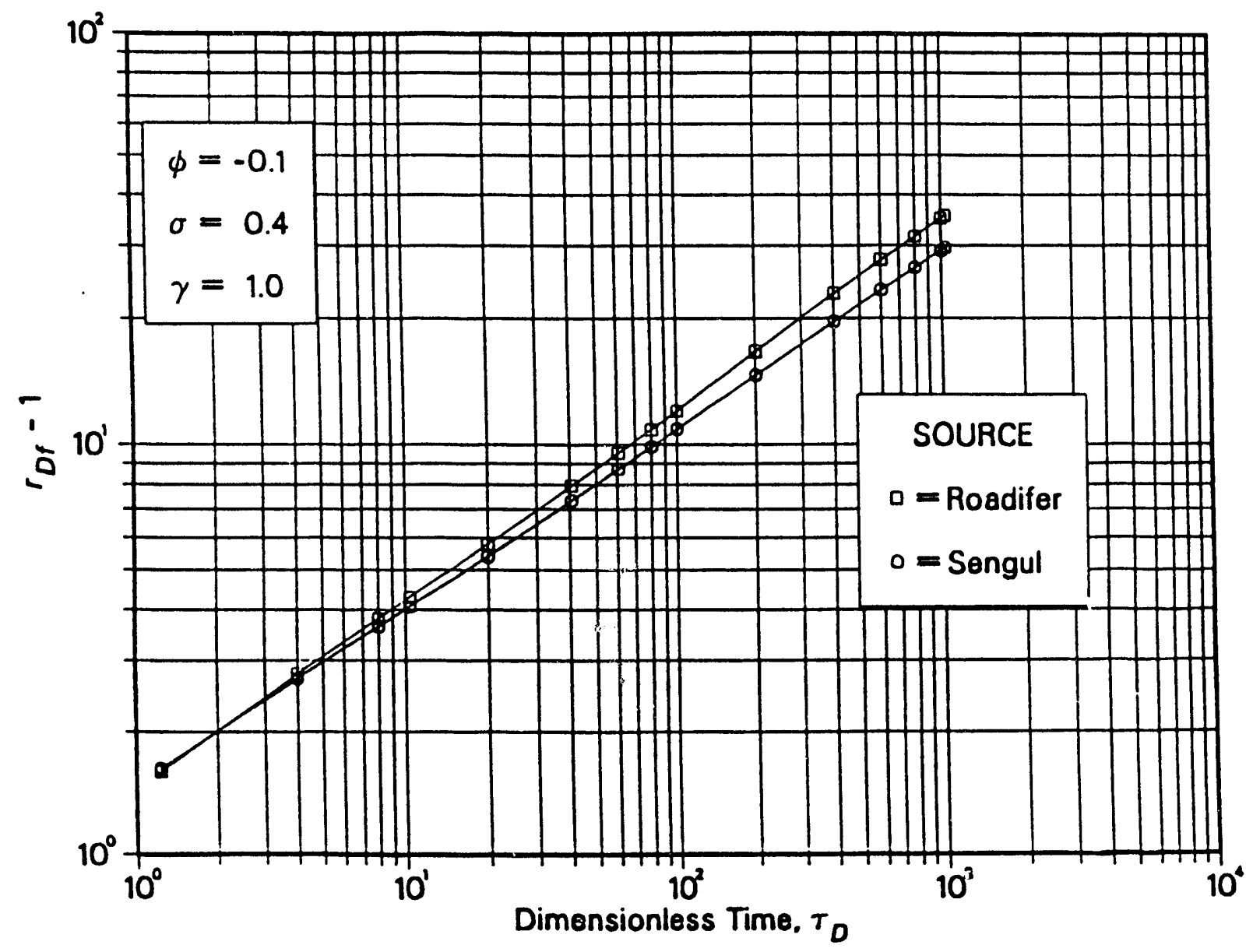

Figure 8.8: Comparison of Models for $\phi=-\mathbf{0 . 1}$ 


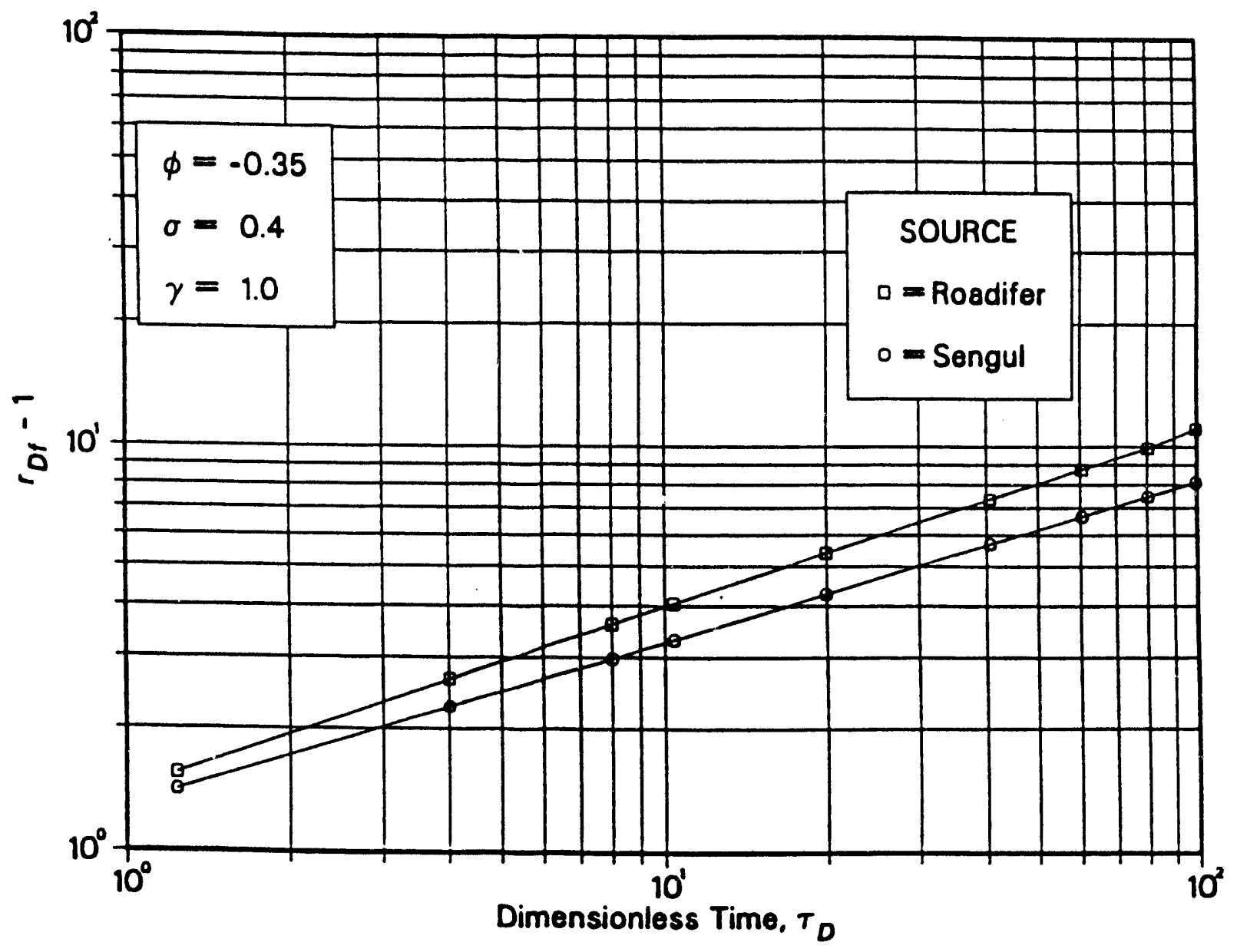

Figure 8.9: Comparison of Models for $\phi=\mathbf{- 0 . 3 5}$ 
Figures 8.7 to 8.9 indicate that the hydrate dissociation model closely approximates the one-dimensional model of Sengul for small values of dimensionless time for the range of values of $\phi$ considered. Results show a marked difíerence, however, for large values of dimensionless time for larger magnitude values of $\phi$. For the low value of $\Phi=-0.1$, the results compare favorably for both small and large dimensionless times.

The deviation from Sengul's results for large times is considered to be the result of including the overburden and underburden zones within the hydrate dissociation model. The effect of including these zones is to increase the amount of heat available within the reservoir for the dissociation of hydrates. Observing the definitions of the dimension ess parameters $\phi$ and $\sigma$, this would indicate that tile values for the hydrate dissociation model would in actuality be less for both dimensionless terms. As indicated by Sengul, a smaller magnitude for the parameter $\Phi$ results in the slope of the $\log -\log$ plot of $r_{D f}-1$ versus $\tau_{D}$ being larger. The intercept of the curve (value of $r_{D f}$ at $\tau_{D}=1$ ) increases for smaller magnitude values of parameter $\phi$ and decreases for smaller values of parameter $\sigma$. The effect of including the overburden and underburden zones in the hydrate dissociation model, therefore, has offsetting effects on the intercapt of the curves, and this is indicated in figures 8.7 to 8.9. Similar results were apparent for other value of the parameter $\sigma$.

The close comparison to the results obtained by Sengul does not in itself validate the hydrate dissociation model, but it does give confidence to the numerical methods used in the hydrate dissociation model, and indicates that those methods are sufficiently accurate for the problem considered. 


\subsubsection{Application of Model to Hydrate Reservoirs and}

Parametric Sensitivity Analysis

In applying the hydrate dissociation model to drilling through hydrate bearing formations, it may be used to perform a sensitivity analysis on various reservoir and wellbore parameters. The term "sensitivity analysis" used here means the determination of the sensitivity of the primary variables to variations in the parameters being studied. The primary variables of concern are the temperature distribution in the reservoir and the position of the hydrate dissociation front. Directly related to these primary variables is the rate of gas influx into the wellbore resulting from the hydrate dissociation, and in some cases, the sensitivity of this independent variable to parameter variations is discussed. Note that when the term "rate of hydrate dissociation" is used, it means the actual material amount of hydrates that have been dissociated for a given period of time. When the term "rate of hydrate front advance" is used, it means the location rate by the reservoir volumetrics, e.g., porosity and hydrate saturation.

There are numerous parameters, reservoir, hydrate, fluid (reservoir or drilling), and wellbore, that may affect the rate of heat transfer into and within the hydrate reservoir and it's confining formations, and therefore, the rate of hydrate dissociation is also affected. Some of the parameters that have been studied include reservoir porosity, hydrate zone thickness, geothermal gradient within the permafrost zone, geothermal gradient below the permafrost zone, depth of permafrost, depth of hydrate zone, mean annual surface temperature, wellbore diameter, wellbore pressure (including the drilling or drilling fluid parameters which affect that pressure), and wellbore temperature fincluding the drilling, drilling fluid, or well completion 
parameters which affect that temperature). It should be noted that interaction between parameters was ignored, i.e., only one parameter was varied at a time. If several of the parameters were varied simultaneously, it is possible that where individually such variation had an insignificant effect, the sum effect could be significant. It should also be noted that variations in certain parameters necessarily implies a variation in all additional parameters which are a function of that parameter; e.g., for a constant mean annual surface temperature, a variation in the geothermal gradient within the permafrost necessarily implies a variation in the vertical extent of the permafrost.

Input data used for this study are given in Tables 8.1 to 8.3. Various fluid and reservoir properties of these data sets are considered to be representative of those found on the North Slope, Alaska. No single data set, however, should be considered representative of any particular reservoir. Any deviations from the base case model parameters listed in Table 8.3 are shown directly on the figures presented.

\subsubsection{Geothermal Conditions}

The geothermal parameters considered within this study (mean annual surface temperature, geothermal gradients within and below the permafrost, and depth to the permafrost base) have been examined only in so far as their effects on the hydrate dissociation rate within the reservoir is concerned. For all cases considered, the sensitivity of the hydrate dissociation rate to these parameters was found to be negligible, i.e., results differed by less than one or two percent.

Analysis as to the validity of these results is quite straight forward when one considers the physical problem and the thermal properties associated with the problem. The effect of varying the geothermal 
TABLE 8.1

WELLBORE, DRILLING FLUID AND RESERVOIR PARAMETERS

$\mathbf{P}_{R}$

$C_{p_{R}}$

$k_{R}$

$\rho_{\boldsymbol{w}}$

$C_{p_{W}}$

$k_{w}$

$C_{p_{g}}$

$k_{g}$

$\rho_{H}$

$\boldsymbol{C}_{p_{H}}$

$\boldsymbol{k}_{\boldsymbol{H}}$

$\boldsymbol{\beta}_{\boldsymbol{H}}$

$S_{H}$

$S_{w}$

$S_{g}$

$\boldsymbol{k}_{\boldsymbol{m}}$

$C_{p_{m}}$

$\rho_{s t}$

$k_{\text {st }}$

$k_{O B}$

$a_{O B}$

$T_{c_{C 1}}$

$P_{c_{C 1}}$

$Y_{g}$
167.0

0.2

3.22

62.4

1.08

0.343

0.5

0.0178

57.1

0.54

0.2274

181.3

1.0

0.2

0.8

1.0

0.4

486.0

25.28

1.36

0.04

343.04

667.8

0.5539 $\left(/ b / f t^{3}\right)$

(Btu/lb $\left.{ }^{\circ} \mathrm{F}\right)$

(Btu/ft hr ${ }^{\circ} \mathrm{F}$ )

$\left(/ \mathrm{b} / \mathrm{ft}^{3}\right)$

$\left(\right.$ Btullb $\left.{ }^{\circ} \mathrm{F}\right)$

(Btu/lb hr ${ }^{\circ} \mathrm{F}$ )

$\left(B t u / l b{ }^{\circ} \mathrm{F}\right)$

(Btu/ft $h r^{\circ} \mathrm{F}$ )

$\left(/ b / f t^{3}\right)$

$\left(\right.$ Btu/lb $\left.{ }^{\circ} \mathrm{F}\right)$

(Btulft $h r^{\circ} \mathrm{F}$ )

(scf/ft ${ }^{3}$ Hydrate)
(Btulft $h r^{\circ} \mathrm{F}$ )

$\left(B t u / l b^{\circ} \mathrm{F}\right)$

$\left(\mid b / f t^{3}\right)$

(Btu/ft $h r^{\circ} \mathrm{F}$ )

(Btu/ft hr ${ }^{\circ} \mathrm{F}$ )

( $\left.f t^{2} / h r\right)$

(R)

(psia)

$($ Air $=1.0)$ 
TABLE 8.2

KEY PROCESS PARAMETERS

$\begin{array}{lll}\text { Wellbore Diameter, } d_{w b} & 6-12 & \text { (in) } \\ \text { Mud Density, } \rho_{m} & 10-18 & (/ \mathrm{b} / \mathrm{ga} /) \\ \text { Mud Viscosity, } \mu_{m} & 20-100 & (\mathrm{cp}) \\ \text { Mud Circulation Rate, } q_{m} & 100-500 & (\mathrm{gal} / \mathrm{min}) \\ \text { Mud Inlet Temperature, } T_{m i} & 50-120 & \left({ }^{\circ} \mathrm{F}\right) \\ \text { Bottomhole Mud Temperature, } T_{m} & 40-120 & \left({ }^{\circ} \mathrm{F}\right) \\ \text { Porosity, } \Phi & 0.10-0.45 & \\ \text { Hydrate Zone Thickness, } h_{H y d} & 20-150 & (\mathrm{ft}) \\ \text { Mean Annual Surface Temperature, } T_{m s} & 5-30 & \left({ }^{\circ} \mathrm{F}\right) \\ \text { Geothermal Gradient Within Permafrost, } g_{G 1} & 0.0075-0.0035 & \left({ }^{\circ} \mathrm{F} / \mathrm{ft}\right) \\ \text { Geothermal Gradient Below Permafrost, } g_{G 2} & 0.01-0.06 & \left({ }^{\circ} \mathrm{F} / \mathrm{ft}\right) \\ \text { Depth to Permafrost Base, } Z_{p / b} & 500-3000 & (\mathrm{ft}) \\ \text { Depth to Top of Hydrate Zone, } Z_{\text {thz }} & 500-4000 & (\mathrm{ft}) \\ \text { Sea Depth, } Z_{\text {sea }} & 1000-8000 & (\mathrm{ft})\end{array}$


TABLE 8.3

BASE CASE PROCESS PARAMETERS

\begin{tabular}{|c|c|c|c|c|}
\hline$\Phi$ & 0.20 & & 0.20 & \\
\hline$h_{H y d}$ & 50.0 & $(f t)$ & 15.24 & $(m)$ \\
\hline$d_{w b}$ & 8.375 & (in) & 21.27 & $(\mathrm{~cm})$ \\
\hline$d_{p i}$ & 5.921 & (in) & 15.04 & $(\mathrm{~cm})$ \\
\hline$d_{p o}$ & 6.625 & (in) & 16.83 & $(\mathrm{~cm})$ \\
\hline$r_{e}$ & 100.0 & $(f t)$ & 30.48 & $(m)$ \\
\hline$Z_{t h z}$ & 2000 & $(f t)$ & 609.6 & $(m)$ \\
\hline$Z_{p f b}$ & 1500 & (ft) & 457.2 & (m) \\
\hline$g_{G 1}$ & 0.0135 & $\left({ }^{\circ} \mathrm{F} / \mathrm{ft}\right)$ & 0.0246 & $\left({ }^{\circ} \mathrm{C} / \mathrm{m}\right)$ \\
\hline$g_{G 2}$ & 0.015 & $\left({ }^{\circ} \mathrm{F} / \mathrm{ft}\right)$ & 0.027 & $\left({ }^{\circ} \mathrm{C} / \mathrm{m}\right)$ \\
\hline$g_{p r}$ & 0.435 & (psi/ft) & 9.84 & $(\mathrm{kPa} / \mathrm{m})$ \\
\hline$T_{m s}$ & 10.0 & $\left({ }^{\circ} \mathrm{F}\right)$ & -12.22 & $\left({ }^{\circ} \mathrm{C}\right)$ \\
\hline$\rho_{m}$ & 10.0 & (lb/ga) & 1198 & $\left(\mathrm{~kg} / / \mathrm{m}^{3}\right)$ \\
\hline$\mu_{a}$ & 45.0 & (cp) & 0.045 & $(P a-s)$ \\
\hline$q_{m}$ & 200.0 & (gal/min) & 45.4 & $\left(m^{3} / h r\right)$ \\
\hline$Q_{p}$ & 20.0 & $(f t / h r)$ & 6.10 & $(\mathrm{~m} / \mathrm{hr})$ \\
\hline$T_{m}$ & 80.0 & $\left({ }^{\circ} \mathrm{F}\right)$ & 26.67 & $\left({ }^{\circ} \mathrm{C}\right)$ \\
\hline$w$ & 350 & (rpm) & $\star$ & * \\
\hline $\mathbf{\tau}$ & 1875.8 & $\left(f t-1 b_{f} / \min \right)$ & 0.0424 & $(k w)$ \\
\hline$T_{m i}$ & 80.0 & ( $\left.{ }^{\circ} \mathrm{F}\right)$ & 26.67 & $\left.{ }^{\circ} \mathrm{C}\right)$ \\
\hline$Z_{t}$ & 4000 & $(f t)$ & 1219.2 & (m) \\
\hline$Z_{c a s}$ & 2200 & $(f t)$ & 670.6 & (m) \\
\hline
\end{tabular}


properties is to vary the initial temperatures within the reservoir. The additional amount of heat either required to bring the solid hydrate zone temperatures up to the dissociation temperature, or saved by not having to raise the solid hydrate zone temperatures as much, is insignificant compared to the amount of thermal energy required for the actual hydrate dissociation or to the amount of energy required to heat the dissociated hydrate zone.

The resulting conclusion is that heat transfer occurs predominately within the dissociated hydrate zone where the temperature is above the initial reservoir temperature. Figure $\mathbf{8 . 1 0}$ shows typical temperature profiles in the reservoir for several different times, and tends to support the above conclusions.

Figure 8.11 shows the position of the hydrate front for the same values of time reported in Figure 8.10. The item of interest here is the shape of the hydrate dissociation interface, which is essentially straight except for slight curvature near the underburden and overburden boundaries, heights of $0(\mathrm{ft})$ and $50(\mathrm{ft})$, respectively. Interpretation of this phenomenon is that the thermal diffusivity (ratio of the ability to transfer heat by conduction to the heat storage capacity) of the overburden and underburden zones is greater than the thermal diffusivity of the dissociated hydrate zone, resulting in a greater amount of heat being transferred to the hydrate dissociation front from a unit volume of the dissociated zone, than for a unit volume of the confining strata.

It should be noted that the results shown in Figure 8.11 were obtained strictly for the values of the thermal properties for which the simulation run was based. For the case when the thermal diffusivity of 


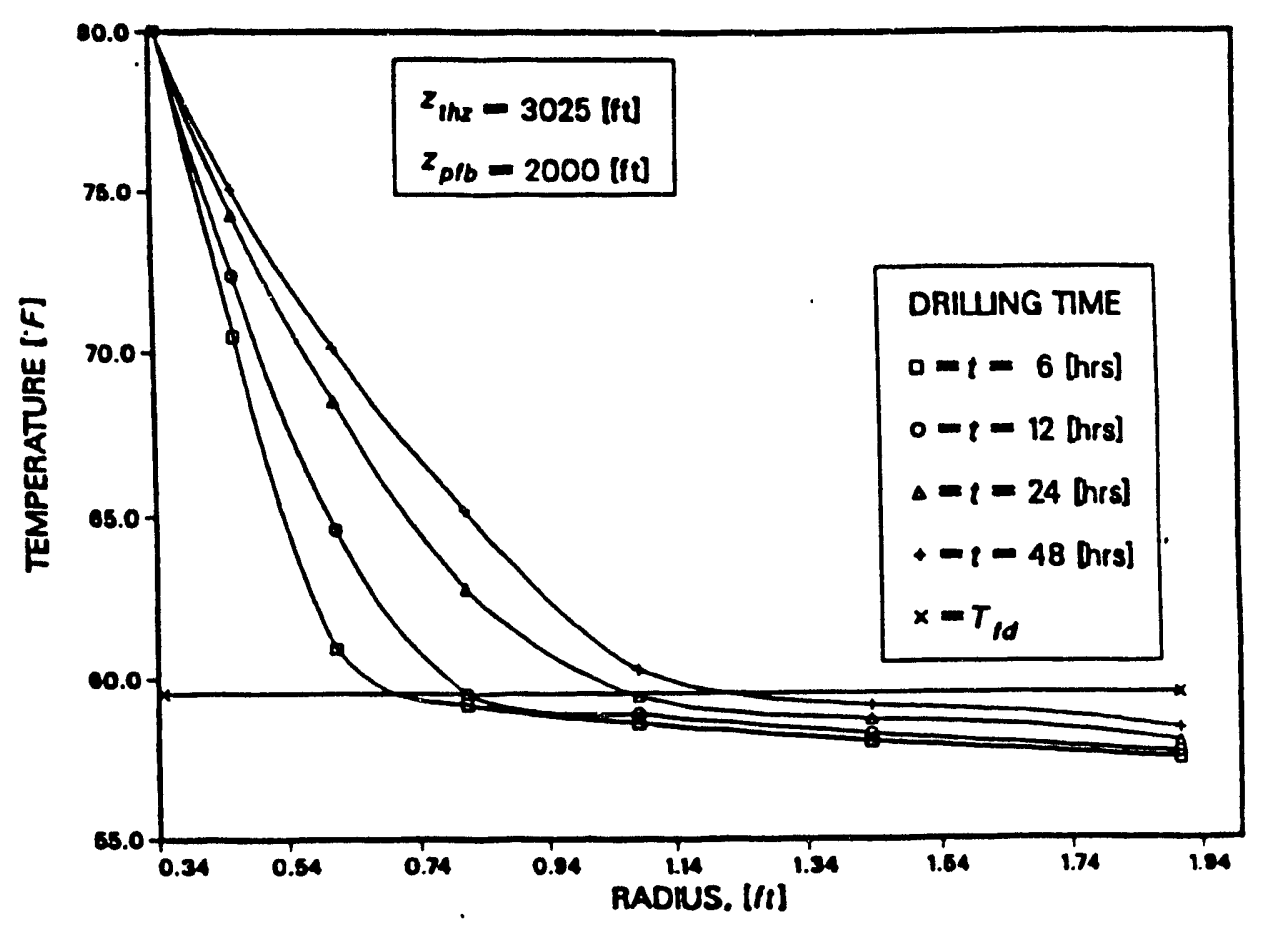

Figure 8.10: Typical Temperature Profiles Within the Reservoir

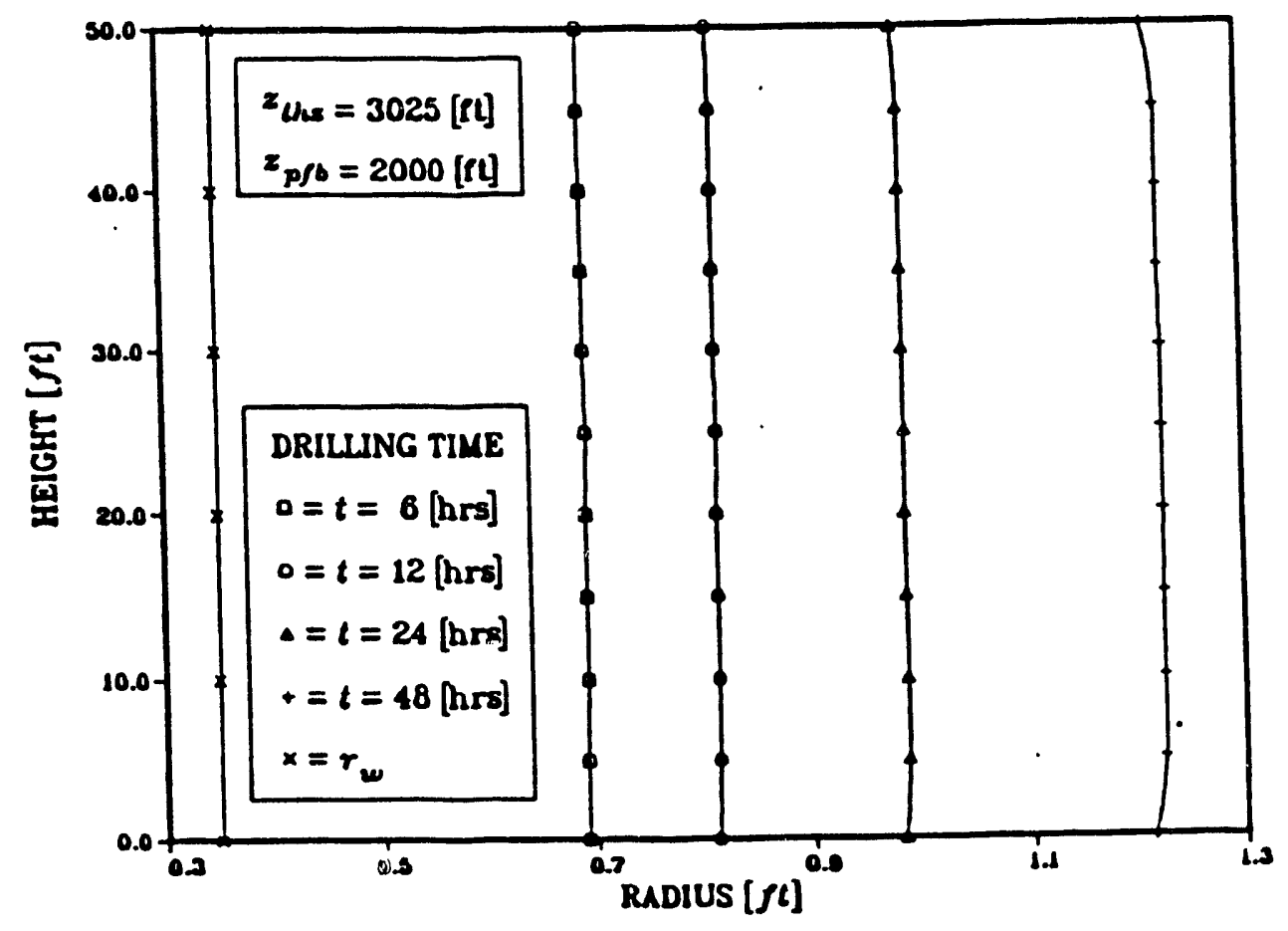

Figure 8.11: Position of Hydrate Dissociation Front as a Function of Time 
the overburden and underburden is greater than for the dissociated zone, one may expect the hydrate dissociation to be greater near the boundaries with these zones. Due to time limitations, a complete analysis of this possibility was not investigated.

An additional conclusion which can be drawn from Figure 8.11 is that for small values of time, or for relatively thick hydrate zones, the interface slope terms in Eqs. (8.31) and (8.34) may be neglected without causing significant errors. For every thin hydrate zones, however, this assumption could lead to significant errors as the effects of the confining strata on the hydrate dissociation become more significant and could lead to highly non-linear shapes for the interface.

As mentioned above, the geothermal parameters were found to have negligible effect on the hydrate dissociation rate only so far as their effects are seen within the reservoir. This does not mean that they are not important or that they do not need to be considered. On the contrary, it is these same parameters that indicate the locations of potential hydrate stability zones that are of concern. Figure 8.12 shows the methane hydrate stability zone for particular geothermal gradient and permafrost depth. In addition, Marshall and Bentsen (1982) found the geothermal gradient to have a very significant effect on the annulus or wellbore temperatures experienced while drilling. As will be discussed later in this chapter, the wellbore temperature is a primary variable on which the rate of hydrate dissociation depends.

\subsubsection{Porosity}

The effect of porosity on hydrate dissociation is shown in Figures 8.13 and 8.14. Figure 8.13 shows the effect of porosity on the rate of 


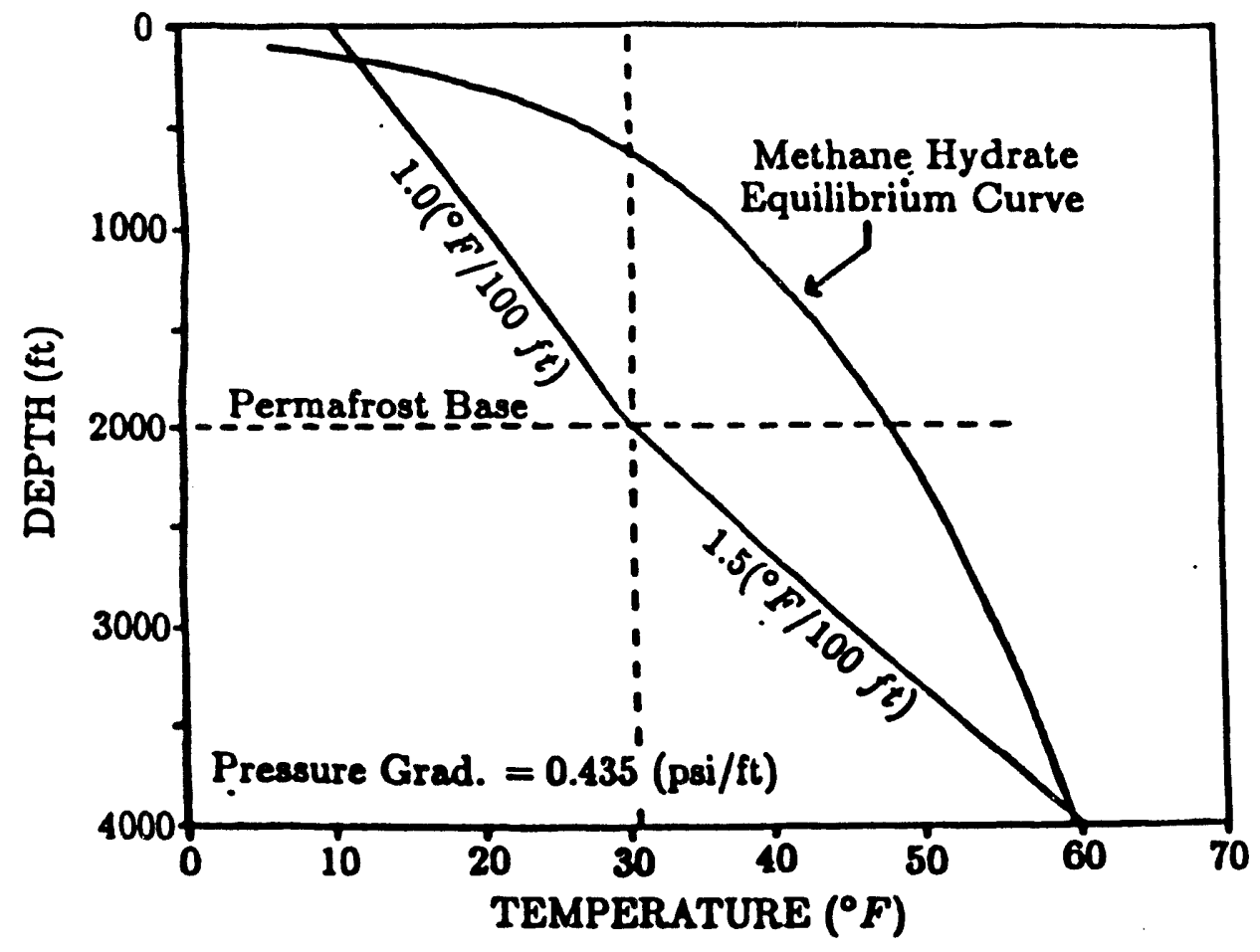

Figure 8.12: Methane Hydrate Stability Zone Below Permafrost 


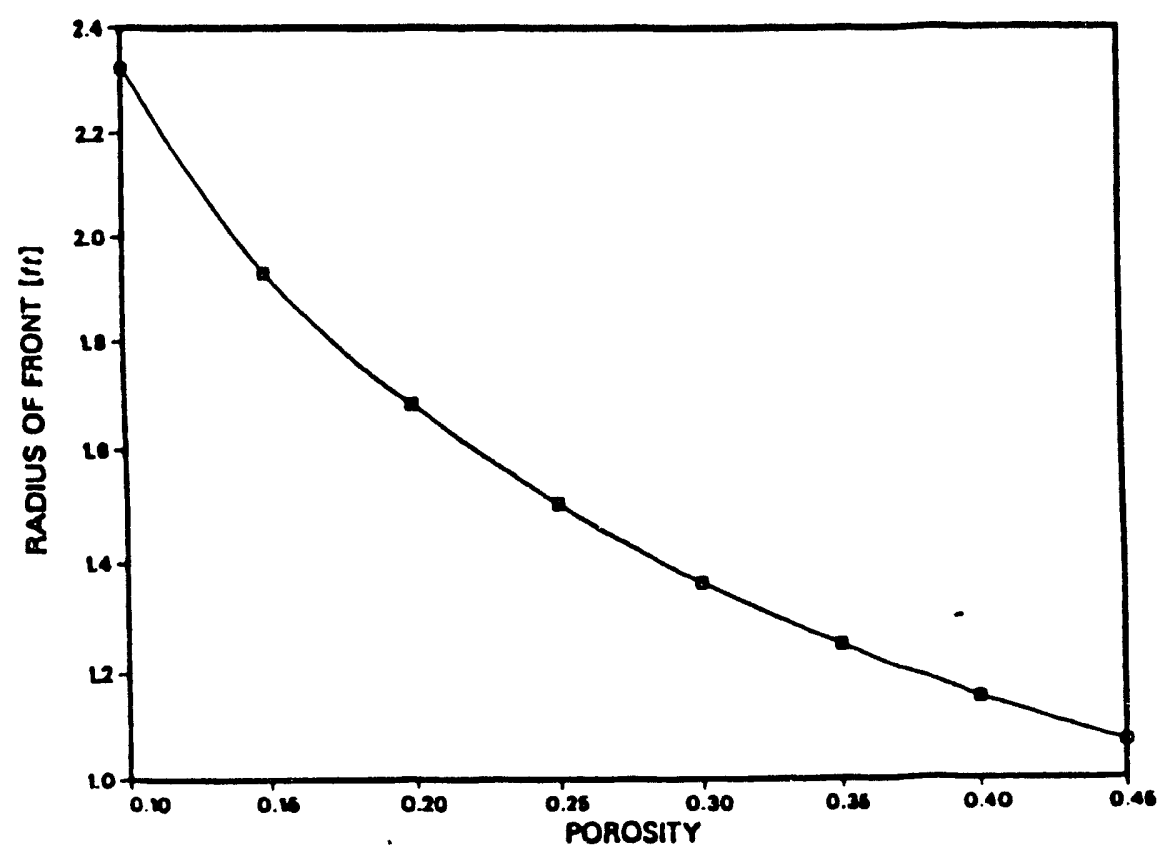

Figure 8.13: Effect of Porosity on Rate of Hydrate Front Advance

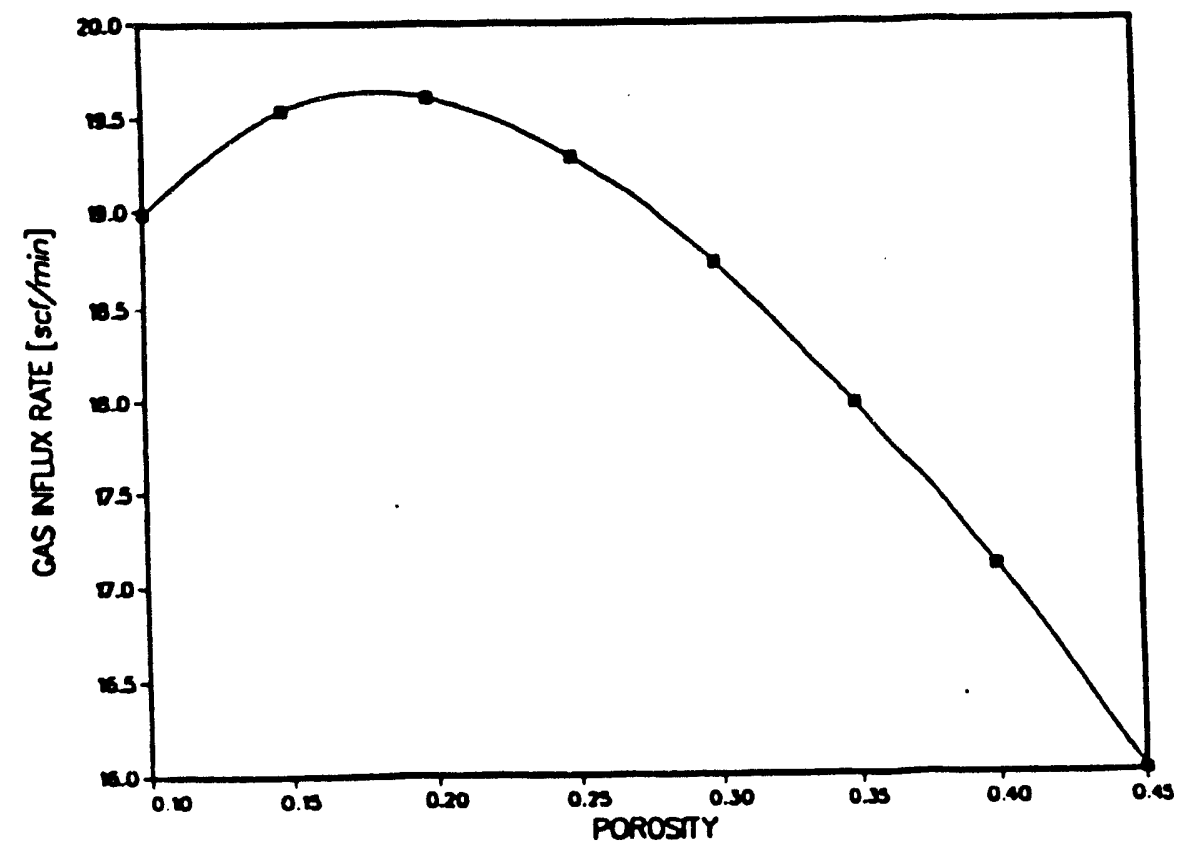

Figure 8.14: Effect of Porosity on Rate of Hydrate Dissociation 
front advance and Figure 8.14 shows the effect on the rate of hydrate dissociation (as indicated by the rate of gas influx into the wellbore). The important item to note here is that while the rate of front propagation increases (accelerates) with a decrease in the porosity, the actual rate of hydrate dissociation increases to a maximum at a porosity of approximately 15 percent, then decreases.

The reason for this complex behavior can be described in the following manner. First, a decrease in the porosity results in an increase in the thermal diffusivity of the dissociated hydrate zone, indicating that relative to the heat storage capacity of the dissociated zone, the ability to transfer heat energy by conduction through the dissociated zone increases. Due to the heat flux at the wellbore being proportional to the thermal conductivity of the dissociated zone, the amount of heat energy input into the reservoir also increases The volumetric latent heat of hydrate dissociation (based on reservoir pore volume) is directly proportional to the porosity, and therefore, decreases as the porosity is decreased. The tendency here, therefore, is to assume that the amount of energy transferred to the hydrate interface must increase and with a lower latent heat, the hydrate dissociation should increase as the porosity is decreased. This may not be the case under a variety of conditions, and in fact for the case considered in Figure 8.14 is only partially true. One reason for this is that it is not the relative magnitudes of the thermal conductivity and volumetric heat capacity that control the amount of heat delivered to the solid hydrate zone, but rather, the absolute magnitudes of these parameters. As porosity is decreased, a point is reached wherein the increase in the heat sink capacity of the dissociated zone offsets the reduction in the latent heat of hydrate dissociation and 
the increased heat transfer rate from the wellbore. A maximum in the hydrate dissociation rate is observed at this point as indicated in Figure 8.14. For porosities lower than this, the amount of sensible heat required to raise the temperature of the dissociated zone is greater than the combination of the increased amount of heat input to the system and the decreased amount of heat required to dissociate the hydrates.

Koh et al (1969) observed behavior similar to that observed for this model at the higher porosities, that is, a decrease in the melting or dissociation rate as porosity is increased. They did not consider the lower values of porosity for which the maximum in the hydrate dissociation rate was observed in this study. The absolute difference in the rates of hydrate dissociation for different porosities is significant and therefore must be accounted for in any model which considers hydrate dissociation in porous media.

\subsubsection{Wellbore Radius}

The effect of the wellbore radius on the rate of hydrate dissociation is shown in Figure 8.15. This figure shows an almost linear relationship, similar to that observed for steady-state heat conduction for small values of the radius. This result is to be expected at early times when the hydrate dissociation front is close to the wellbore. At later times, however, as the front moves away from the wellbore, the profile is expected to show little effect. The reason for this is that for steady-state heat transfer, the rate of heat transfer is inversely proportional to $\ln \left(r_{e} / r_{w}\right)$. Because the heat transfer occurs predominately in the dissociated zone, $r_{e}$ can be considered to be the front radius. When $r_{e}$ is small, the change in the term $\ln \left(r_{e} / r_{w}\right)$ is larger for a given increase in $r_{\omega}$ then when $r_{e}$ is large and 


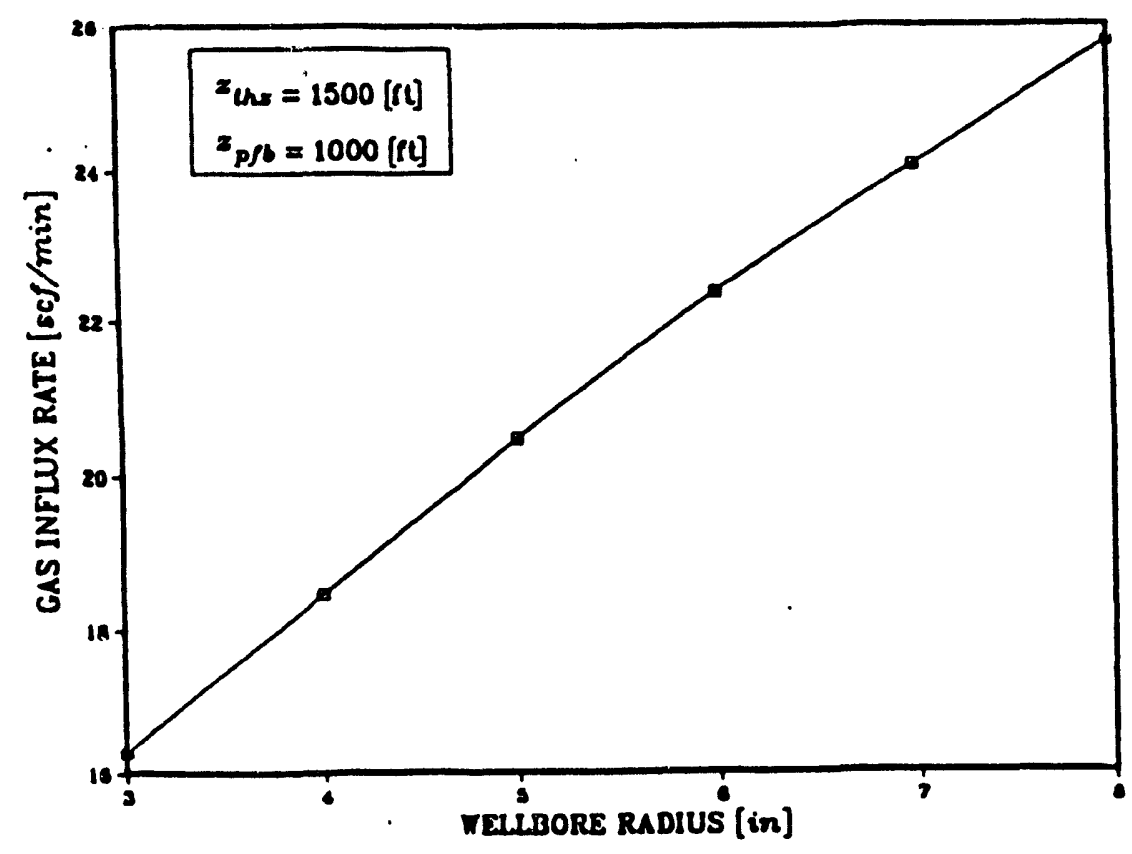

Figure 8.15: Effect of Wellbore Radius on the Rate of Hydrate Dissociation

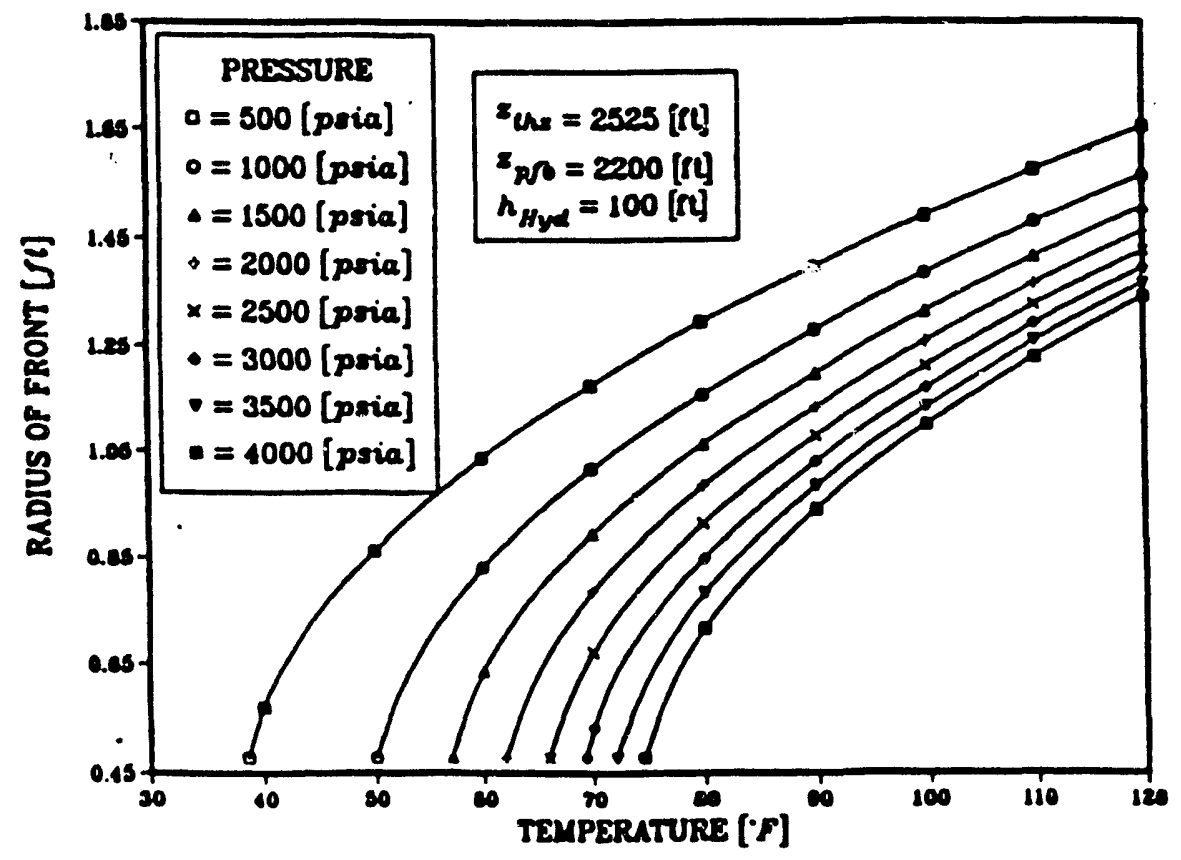

Figure 8.16: Effect of Wellbore Pressure and Temperature on Rate of Hydrate Front Advance 
the change in term $\ln \left(r_{e} / r_{w}\right)$ will be much less. This result was similarly observed by Sengul (1977), who observed that the wellbore radius had little effect on the thaw rate of permafrost for values of dimensionless time greater than 1.

\subsubsection{Wellbore Pressure and Temperature}

Figure 8.16 shows the effects of wellbore pressure and temperature on the hydrate dissociation rate. The effect of pressure is to increase the hydrate dissociation temperature with an increase in the pressure, thereby decreasing the hydriste dissociation rate The effect of temperature is obvious, increasing the dissociation rate with an increase in the temperature.

\subsubsection{Application of Model to Drilling}

\subsubsection{Wellbore Heat Transfer Model}

In order to determine the drilling parameters required to safely drill and complete hydrate bearing formations, accurate wellbore hydraulic and heat transfer models are required. Early wellbore heat transfer models assumed constant temperatures in the drilling fluid or used correlations determined experimentally to compute temperatures (Edwardson et al, 1962; Tragesser et al, 1967). Other models were based on a steady-state analysis of heat transfer in the wellbore (Ramey, 1962; Holmes and Swift, 1970). In 1969, Raymond developed a model to predict temperature distributions for both transient and pseudo-steady-state sonditions, but indicated that the pseudo-steady-state solution was accurate enough for all applications. Major drawbacks of all these early 
models include neglecting the wellbore makeup, fluid rheology, energy source terms, and being highly inaccurate for short term transient periods.

In 1973, Keller et al developed a fully transient heat transfer model that included the effects of casing strings and energy sources in the wellbore. Marshall and Bentsen (1982) extended that work. Limitations of these two models appear in the assumptions of specific fluid rheology and wellbore hydraulics.

Corre et al (1984) presented a comprehensive wellbore heat transfer model that avoids the drawbacks of the previous models by accounting for the complex fluid rheology of the drilling fluids, thus improving the fluid mechanics representation.

A comprehensive wellbore heat transfer and hydraulics model similar to the model of Marshall and Bentsen (1982) was developed in this work. Major improvements in the model were accomplished by removing the assumptions regarding fluid mechanics and drilling mud rheology. The model also considers rheology dependent convective heat transfer coefficients.

The Model equations and boundary conditions are essentially the same as those presented by Marshall and Bentsen (1982), and as such, they will not be presented in this study. The manner of determining the wellbore hydraulics also will not be presented here, but rather, referenced as being the same as presented in Bourgoyne et al (1986) for Newtonian fluids, Bingham plastics, and power law fluids. 


\subsection{Determination of Convective Heat}

\section{Transfer Coefficients}

For laminar flow of any type of fluid, i.e., Newtonian, Bingham plastic, or power law, the Newtonian value of 4.12 for the Nusselt number is used:

$$
N_{N u}=4.12
$$

where the Nusselt number is defined as the ratio of convection heat transfer to conduction in a fluid slab of thickness $L$ :

$$
N_{N u}=\frac{h_{c} L}{k}
$$

and $h_{c}$ is the convective heat transfer coefficient, $L$ is the thickness of the area of concern, and $k$ is the thermal conductivity.

For turbulent flow of Newtonian and Bingham Plastic fluids, the Seider-Tate equation is used with the term $\left(\mu / \mu_{\omega}\right)^{0.14}$ set equal to 1.0 (Incropera and Devyitt, 1981). For Bingham Plastics, the plastic viscosity is used to calculate the Reynold's and PrandtI numbers. The Nusselt number is thus calculated as

$$
N_{N u}=0.027 N_{R e}^{0.8} \operatorname{Pr}^{0.333}
$$

Following the recommendation of Marshall and Bentsen (1982), the correlation developed by Lakshminarayanan et al (1976) is used for power-law fluids in turbulent flow:

$$
S t=0.0107 N_{R e^{-0.33}} \operatorname{Pr}^{-0.67}
$$


where $S t$ is the Stanton number defined as

$$
S t=\frac{h_{c}}{\rho \mu C_{p}}=\frac{N_{N u}}{N_{R e} P r}
$$

In annular flow, the hydraulic diameter of the annulus is used in these correlations, and the equivalent fluid properties accounting for the drill cuttings is used.

\subsection{Determination of Energy Source Terms}

The source of heat generation within the wellbore system is a result of the rotational energy due to the work required to rotate the drill string, viscous energy due to frictional pressure losses within the drill pipe, dril! bit and annulus, and the work done by the bit.

The thermal energy generated due to rotation and work by the drill bit is calculated by assuming that all of the mechanical energy input by the rotating drive is converted to thermal energy. This energy is then divided $60 \%$ to the drill pipe and $40 \%$ to the drill bit. The rotational energy input is calculated from the equation (8.116):

$$
E_{\text {rot }}=C \omega \tau
$$

where $C$ is a units conversion constant ( 0.4844 for U.S. oilfield units), $w$ is the rotational velocity of the drill string (revimin), and $\tau$ is the torque ( $f t$ - Ibf/min) applied to the drill string. 
The total thermal energy generated due to frictional pressure losses in the system may be calculated as

$$
E_{f_{r}}=C \Delta P_{f_{r}} q_{m}
$$

where $C$ is a units conversion factor for U.S. oilfield units (1.4843), $\Delta P_{f r}$ is the total frictional pressure loss in the drill string, annulus and drill bit, and $q_{m}$ is the drilling fluid circulation rate. This energy is then divided among the drill string, drill bit and annulus by the ratios of their respective frictional pressure losses.

\subsection{Gas Influx Calculations}

Once the hydrate dissociation problem has been solved for some time period, $\Delta t$, a simple material balance is used to calculate the gas influx into the wellbore.

The volume of hydrate dissociated is given by

$$
V_{H y d}=n \Phi h_{H y d}\left\{\left[r_{f}(t+\Delta t)\right]^{2}-\left[r_{f}(t)\right]^{2}\right\}
$$

where $V_{H y d}$ is the volume of hydrate dissociated, $\Phi$ is the porosity, $h_{H y d}$ is the hydrate zone thickness, and $r_{f}$ is the radius of the hydrate dissociation front.

The moles of methane gas originally contained in this volume is

$$
n_{B_{H y d}}=\frac{\beta_{H y d}}{379.6} V_{H y d}
$$


where $n_{g_{H y d}}$ is the number of moles initially contained in the volume of hydrates just dissociated, $B_{H y d}$ is the hydrate gas content, and 379.6 is the standard cubic feet of gas per lb-mole.

The moles of methane gas in the dissociated volume would contain under wellbore condition is

$$
n_{g_{w b}}=\frac{P_{w b} V_{H} S_{g}}{z_{g} R T T_{\omega b}}
$$

where $S_{g}$ is the gas saturation in the dissociated zone, $T_{w b}$ is the wellbore temperature opposite the hydrate zone, and $P_{w b}$ is the circulating wellbore pressure against the formation, and includes the hydrostatic pressure exerted by the mud column, and the frictional pressure loss due to annular circulation.

The natural gas influx into the wellbore is then calculated as the difference in the original amount of gas contained in the hydrates just dissociated, and the amount of natural gas that would exists in that same volume at the wellbore conditions of pressure and temperature:

$$
q_{g}=\frac{379.6\left(n_{B_{H}}-n_{B_{\omega b}}\right)}{\Delta t}
$$

\subsection{Solution Method and Validation of Model}

The partial differential equations were written in a fully implicit finite-difference form, and the temperature distributions 
were solved using a direct solution method involving the LU decomposition of the resultant matrix. The sensitivity analysis was performed on the grid size in both the radial and vertical directions and also on the time step size to insure the accuracy and stability of the solutions. Grid sizes were limited to 200 feet in the vertical direction, and to 5 feet in the radial direction. A variable time step size was used in the model, with a small time step being used initially to avoid the possible numerical dispersion resulting from a large change in the primary variables at early time. Subsequently, a time step of 2 hours was found sufficient to maintain the accuracy of the solution.

Partial validation of the model was accomplished by comparing results with the results obtained by Marshall and Bentsen (1982) for the particular problem studied in their paper. Though all required parameters were not listed by Marshall and Bentsen, approximations for those parameters within the ranges quoted in the literature were made, and results obtained. Results compared within $5^{\circ} \mathrm{F}$ for all cases considered. This represented a deviation of less than 3 percent. Run times for the model are represented by times repeatedly less than 0.01 seconds per time step per grid.

\subsection{Drilling Parameters and Mud Degasser Design}

When the hydrate dissociation model is used in conjunction with a wellbore hydraulics and heat transfer model, drilling parameters can be selected or surface degassing equipment designed to allow the safe drilling of hydrate formations. 
The effects of wellbore temperature and pressure on hydrate dissociation were discussed above, however, the drilling engineer is more interested in the gas influx rate resulting from the dissociation, than the actual radial extent of the dissociation. Figure 8.17 shows the relative effects of wellbore pressure and temperature on the resulting gas influx rate.

The drilling and mud engineers have control over several parameters which directly affect the wellbore pressure and temperature, i.e. drilling fluid density, drilling fluid viscosity, drilling fluid circulation rate, drilling fluid inlet temperature, and lastly, whether or not to case the hole prior to penetrating the hydrate formation.

\section{Pressure Control Parameters}

The three parameters affecting the wellbore pressure at the hydrate depth and directly controlled by the drilling engineers include the mud density, circulation rate, and viscosity. An increase in any one of these parameters results in an increases in the pressure exerted in the wellbore. Increasing the mud weight has the direct effect of increasing the hydrostatic pressure and, though less obvious, the frictional pressure drop in the annulus. The circulation rate and mud viscosity affect only the frictional pressure drop.

Figure 8.18 shows the relative effects of mud density and circulation rate on the bottomhole pressure. This figure shows that a drastic increase in the circulation rate is required to achieve the same pressure as the one obtained by small increases in mud weight.

Figure 8.19 indicates an even more drastic increase in the mud viscosity is required to achieve the same pressure increase. 


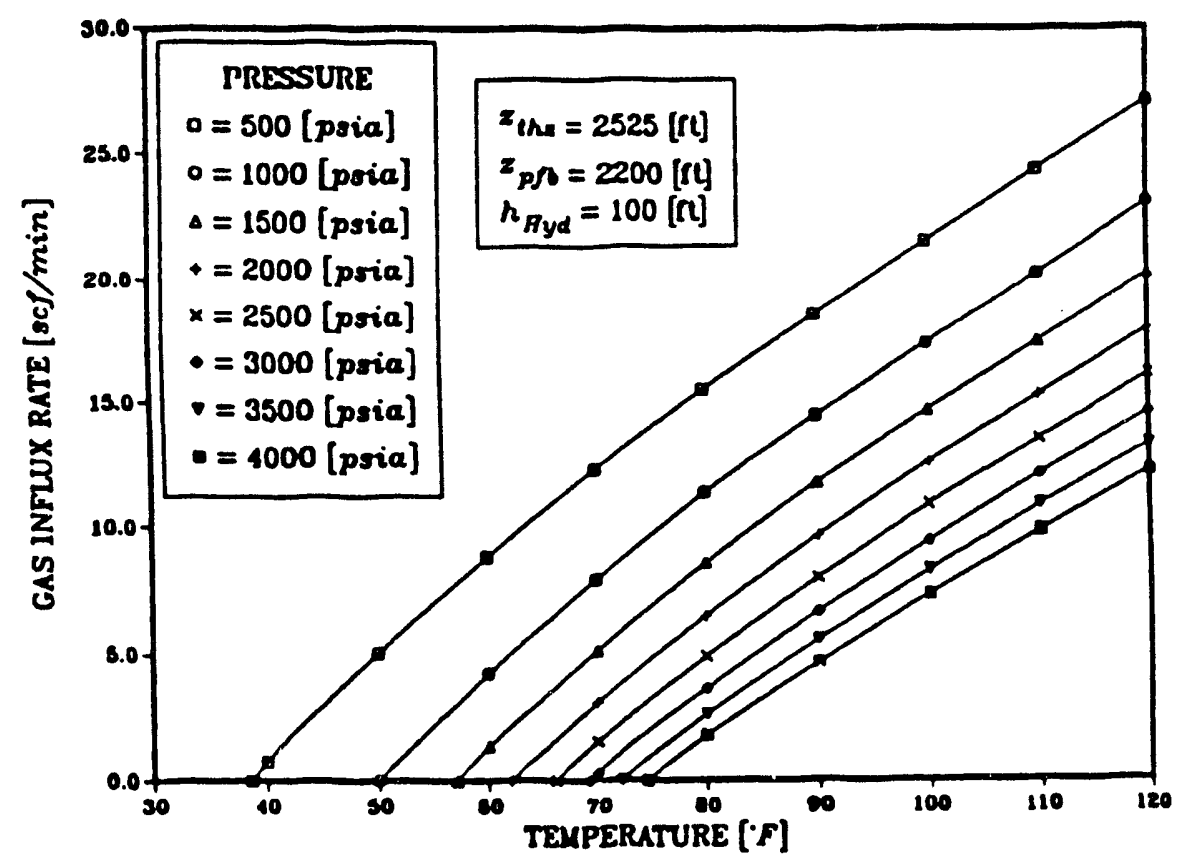

Figure 8.17: Effect of Wellbore Pressure and Temperature on Gas Influx Rate

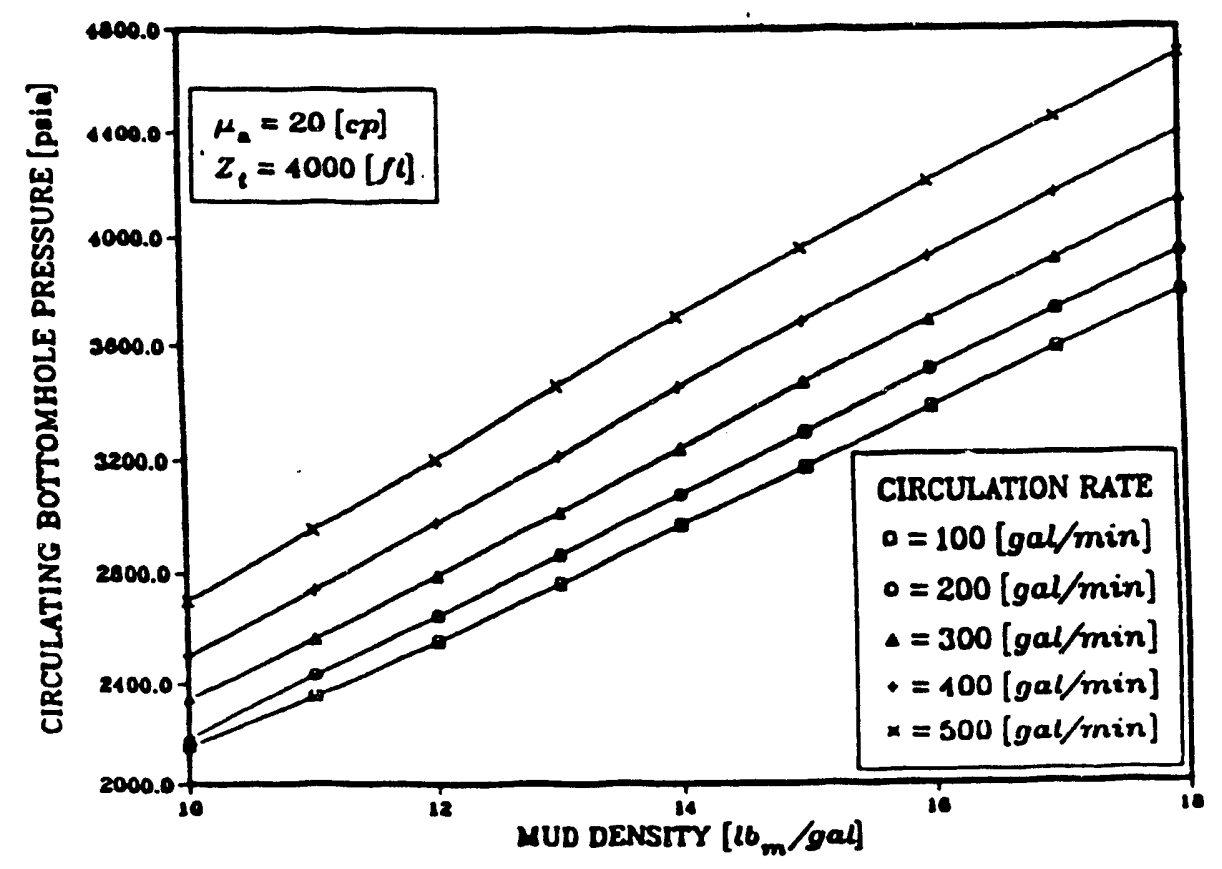

Figure 8.18: Effect of Mud Density and Circulation Rate on Bottomhole Pressure 


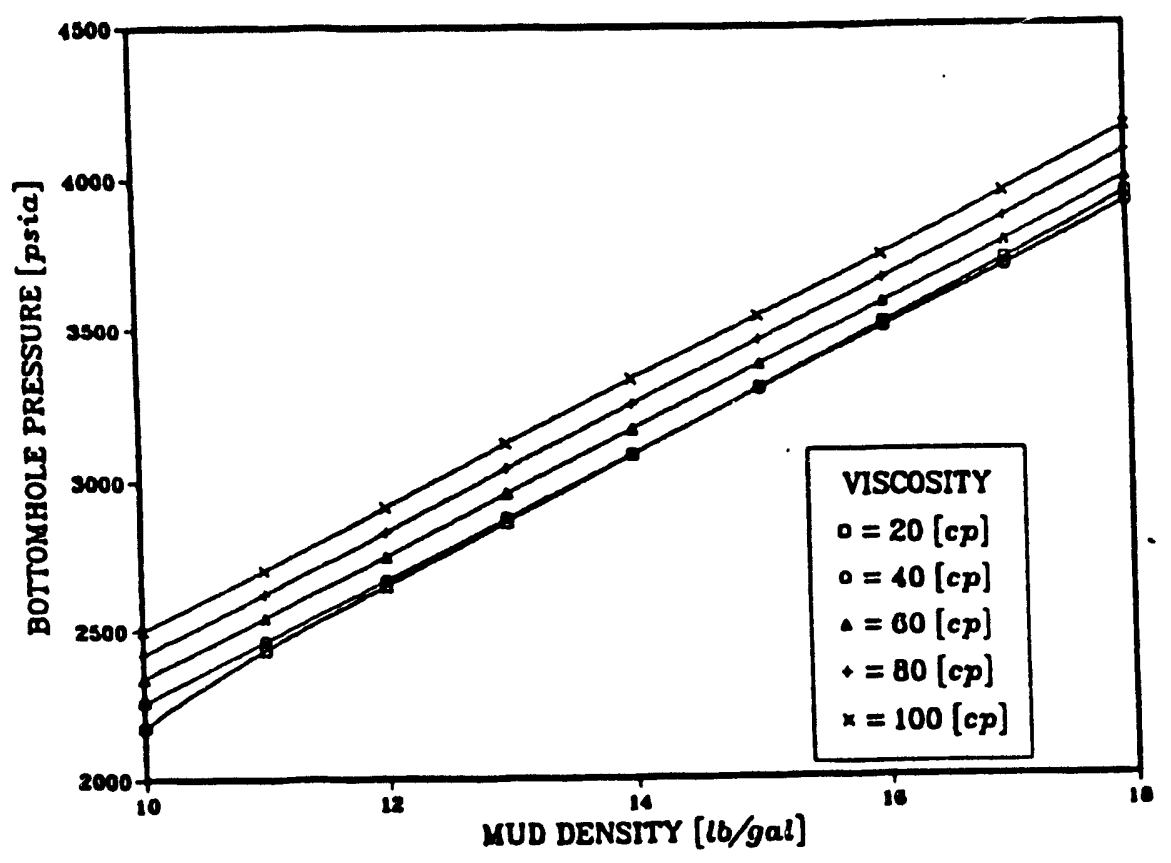

Figure 8.19: Effect of Mud Density and Viscosity on Bottomhole Pressure

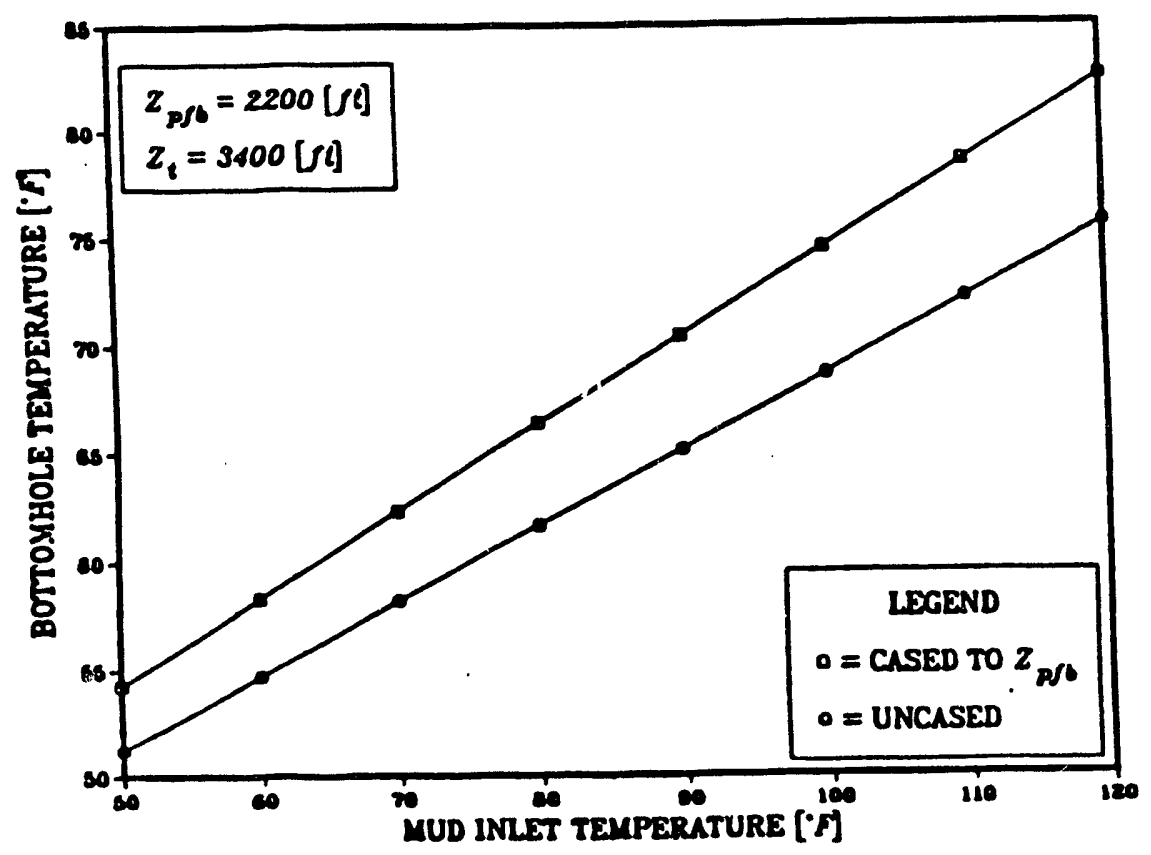

Figure 8.20: Effects of Casing and Mud Inlet Temperature on the Bottomhole Temperature 


\section{Temperature Control Parameters}

The wellbore annulus temperature profile is a function of many variables. The primary parameters of concern are the mud inlet temperature, density, circulation rate, and whether or not the hole has been cased. Figure 8.20 is a comparison of the bottomhole temperatures generated due to inlet mud temperature for an uncased well and a well cased to the permafrost base.

There are two effects worth noting in this plot. First, the change in the bottomhole temperature is much less than the change in the mud inlet temperature. Second, casing the permafrost zone results in significantly higher bottomhole temperature!..

The effects of mud density and circulation rate on bottomhole temperature is a much more complex problem as indicated by figure 8.21 .

Within the wellbore, heat transfer occurs due to vertical convection down the drill string and up the annulus, radial convection between fluid, pipe wall and formation, and lastly due to heat generation.

When the mud circulation rate is increased, vertical convection increases tending to increase the bottomhole temperature; because the boundary layer convection coefficient increases with circulation rate, radial convection increases tending to decrease the bottomhole temperature; lastly, the frictional pressure drop increases, resulting in higher heat generation and an increase in temperature. 


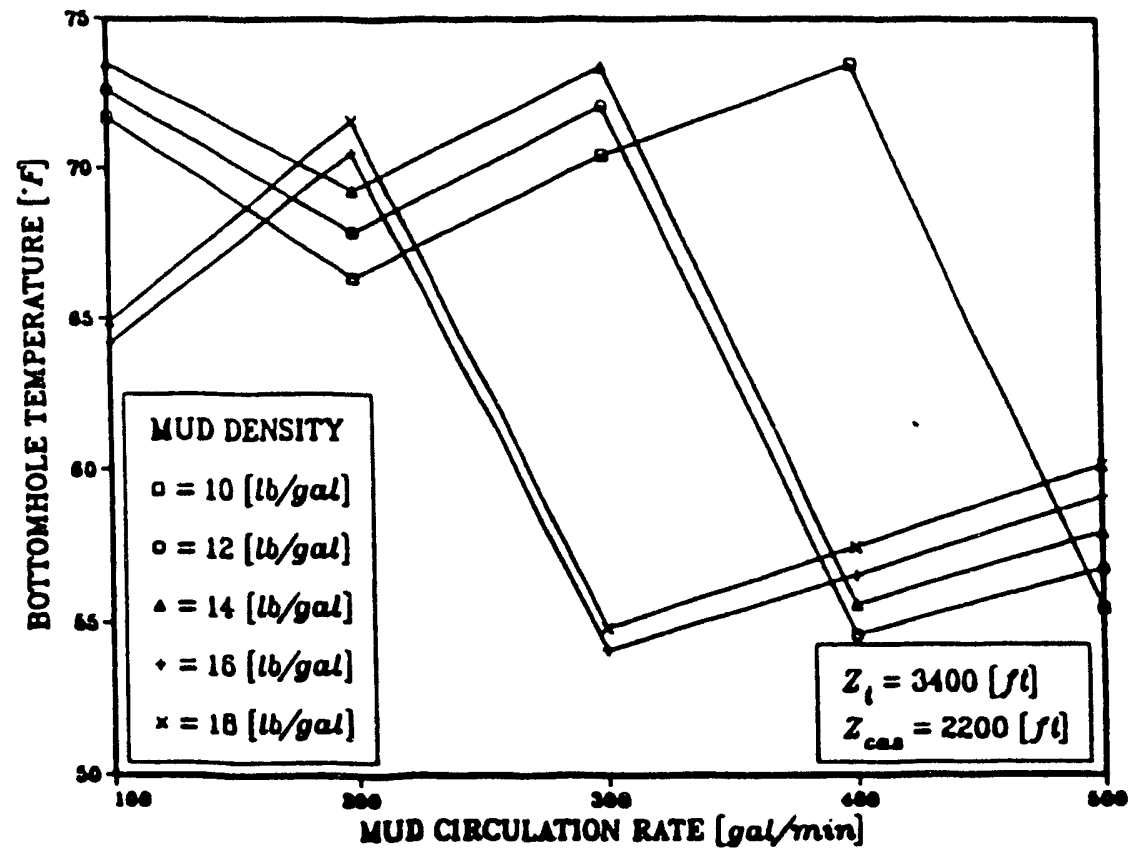

Figure 8.21: Effect of Mud Density and Circulation Rate on Bottomhole Temperature 
The most significant result seen in Figure 8.21 is that there is a drastic decrease in the bottomhole temperature when the flow in the annulus becomes turbulent. This is due to a drastic increase in the convection coefficient, resulting in the annular drilling fluid being increasingly cooled by the formation, and in turn, the annular fluid cooling the downward flowing fluid in the drill string. Similar results are expected as long as the formation temperatures are less than the drilling fluid temperatures. The magnitudes of the variations in the bottomhole temperatures will, of course, depend upon the differences between all of the temperatures considered, and should show less variation for small temperature differences. When the formation has just been penetrated, however, assuming no artificial cooling of the inlet drilling fluid, the heat transfer between the annulus fluid and the formation and the annulus fluid and the drill string fluid will be at a maximum.

The above discussion provides guidelines for selection of a flow regime for drilling fluid. If the goal is to prevent hydrate dissociation, the drilling fluid should be in the turbulent flow regime in the annulus. If the goal is to promote hydrate dissociation, a laminar flow regime is desired in the annulus.

If the drilling engineer can determine the wellbore pressure and annular mud temperature at the hydrate zone depth, the basic hydrate dissociation model can be used to determine the maximum gas influx into the wellbore resulting from the hydrate dissociation. This has become more practical with the implementation of measurement while drilling (MWD) instruments which can record 
and transmit information on the temperatures and pressures experienced in the wellbore while drilling is being performed.

\subsection{Selection of Drilling Parameters - \\ Examples Uses of Nomogram}

The relative effects of many drilling and mud parameters on the wellbore pressures and temperatures, and therefore hydrate dissociation rate and gas influx rate, have been shown and discussed. The precise combination of these parameters to be used to achieve the desired results cannot be stated as each new well is unique and controlled by many factors, e.g., economics, legal restrictions, equipment availability, etc. What can be stated, however is the temperature and pressure necessary to keep hydrate dissociation within the limits of the drilling equipment, or vice versa, design criteria for the surface degassing equipment can be established for the maximum temperatures and minimum pressures expected to occur over the hydrate zone. These results are presented in nomogram form in Figure 8.22.

The nomogram in Figure 8.22 represents a correlation between several drilling parameters including the wellhore pressure, wellbore temperature and wellbore diameter, the hydrate zone thickness, and the maximum gas influx rate resulting from hydrate dissociation. The nomogram has three primary uses: First, given the maximum mud temperature expected to occur over the hydrate zone and the minimum wellbore pressure, the maximum gas influx rate resulting from hydrate dissociation can be determined and the surface mud degasser therefore designed to 


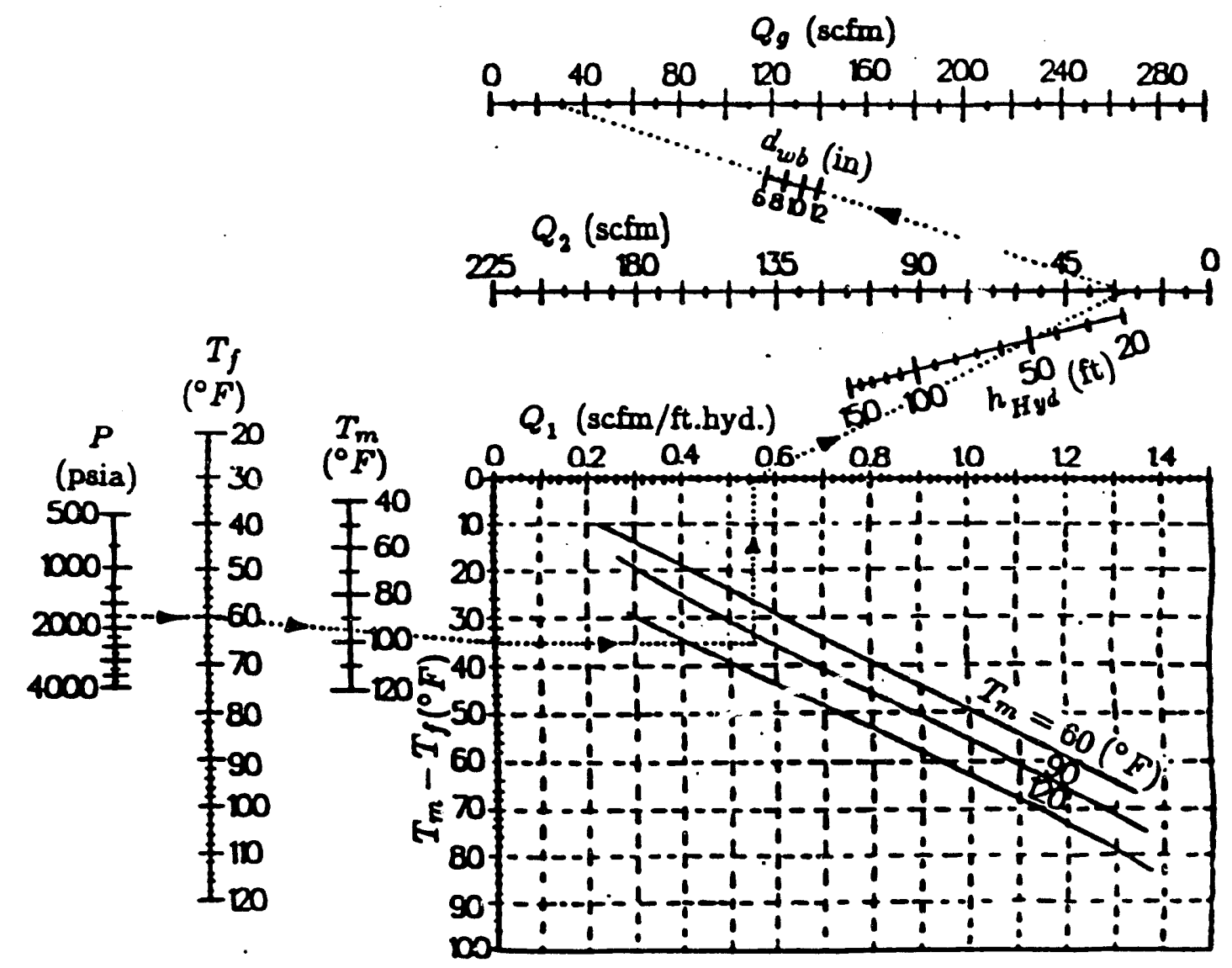

Figure 8.22: Nomogram For Estimation of Parameters For Drilling Through Hydrates 
handle this gas; second, given the size of the surface mud degasser and the minimum wellbore pressure expected to occur, the maximum wellbore mud temperature that can be allowed to maintain the gas influx rate below the size of the mud degasser determined; and lastly, given the size of the mud degasser and an estimate of the maximum mud temperature expected, the minimum wellbore pressure that can be allowed can be determined. Specific examples of these uses are shown here.

There are essentially three ways in which the nomogram (Figure 8.22) may be used in the design or determination of the optimum drilling parameters to be used when drilling through potential hydrate bearing formations. The first example concerns the sizing of the surface mud degasser to insure the degasser has the capacity to remove the maximum potential amount of gas resulting from hydrate dissociation. The second example concerns the determination of the minimum wellbore pressure required to keep the hydrate dissociation rate within the limits of the surface mud degasser capacity for a given wellbore temperature. The final example, shows how to use the nomogram for the determination of the maximum wellbore temperature which may be allowed for a given wellbore pressure in order to keep the hydrate dissociation, and therefore the gas influx into the wellbore, within the limits of the capacity of the surface mud degasser.

Example 1 - Sizing the Mud Degasser

$\begin{array}{lll}\text { Hydrate Zone Thickness, } h_{H y d} & = & 50.0(\mathrm{ft}) \\ \text { Wellbore Diameter, } D_{w b} & = & 8.375(\mathrm{in})\end{array}$




$$
\begin{array}{ll}
\text { Minimum Wellbore Pressure, } P_{w b}= & 1750 \text { (psia) } \\
\text { Maximum Wellbore Temperature, } T_{m}= & 95.0\left({ }^{\circ} \mathrm{F}\right)
\end{array}
$$

Given the above information, the problem then remains to determine the minimum gas capacity of the surface mud degasser required to handle the potential gas influx resulting from the hydrate dissociation. The solution to the problem may be described as follows: In Figure 8.23, connect a horizontal line from the pressure scale at 1750 psia to the hydrate dissociation temperature, $T_{H}$, scale $\left(T_{H}=60^{\circ} \mathrm{F}\right)$; next connect a line from the hydrate dissociation temperature through the mud temperature scale at $T_{m}$ $=95^{\circ} \mathrm{F}$ to the $\Delta T$ axis of the figure at $\Delta T=35^{\circ} \mathrm{F} ;$ draw a horizontal line from this point to the figure mud temperature, $T_{m}=95^{\circ} \mathrm{F}$; draw a vertical line to the figure axis, $Q_{1}=0.55 \mathrm{scfm} / \mathrm{ft}$. Hyd; draw a line connecting $Q_{1}$ to $Q_{2}$ passing through the hydrate zone thickness, $h_{H y d}=50 \mathrm{ft}$; read $Q_{2}=28 \mathrm{scfm}$; draw a line connecting $Q_{2}$ to $Q_{g}$ passing through the wellbore diameter, $D_{w b}=8.375$ (in.); read the maximum gas influx rate, i.e., minimum gas capacity of surface mud degasser required, as $Q_{g}=28 \mathrm{scfm}$.

\section{Example 2 - Wellbore Pressure Required to Limit Dissociation}

$\begin{array}{lll}\text { Hydrate Zone Thickness, } h_{H y d} & = & 100.0(\mathrm{ft}) \\ \text { Gas Capacity of Mud Degasser, } Q_{g}= & 80.0(\mathrm{scfm}) \\ \text { Wellbore Diameter, } D_{w b} & = & 11.0(\mathrm{in}) \\ \text { Maximum Wellbore Temperature, } T_{m}= & 100.0\left({ }^{\circ} \mathrm{F}\right)\end{array}$



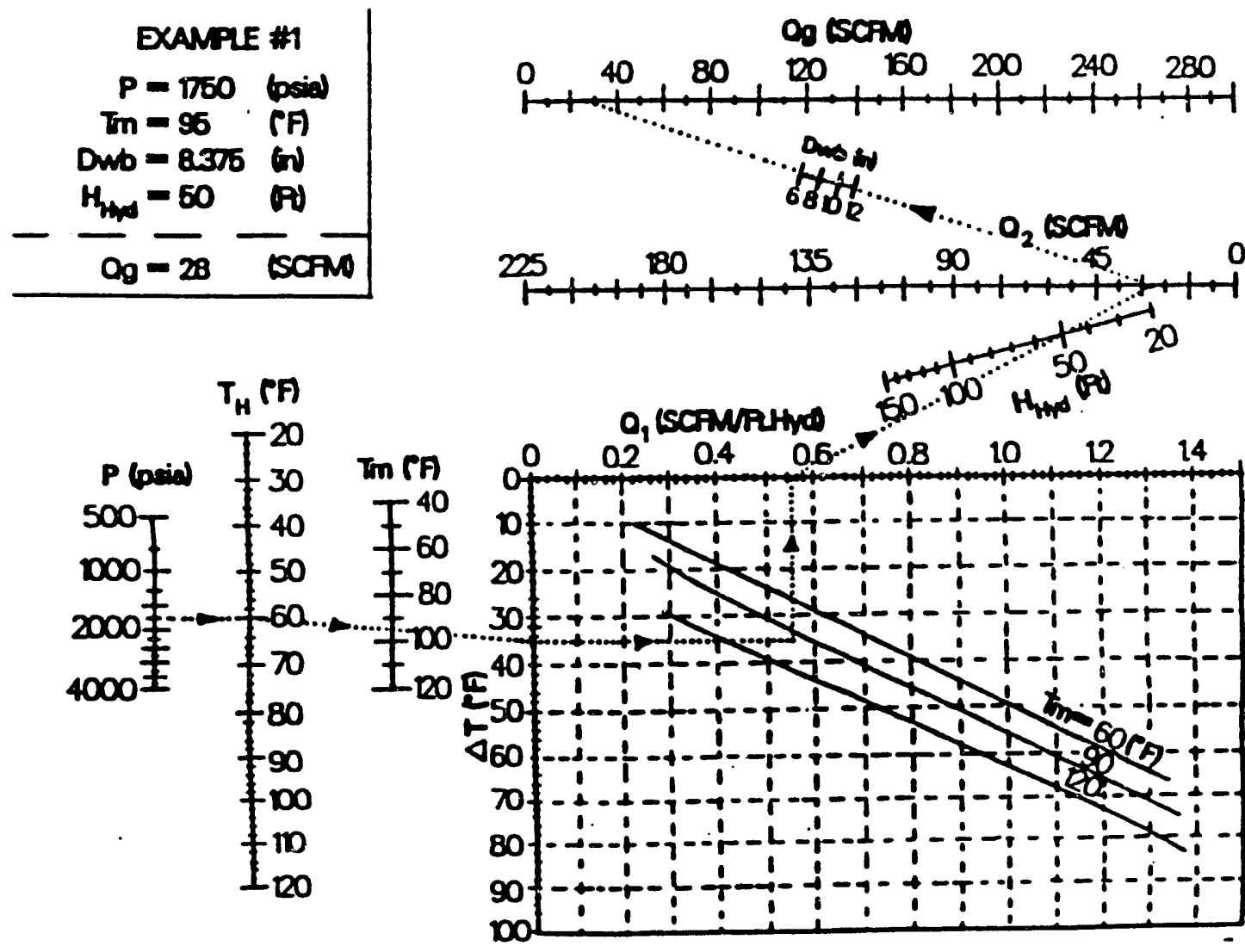

Figure 8.23: Use of nomogram - Example \# 1: Sizing surface mud degasser 
Given the above information, the problem then remains to determine the minimum wellbore pressure required to limit the hydrate dissociation and, therefore, the gas influx into the wellbore, to an amount that may be handled by the surface mud degasser. The solution to the problem is presented graphically in Figure 8.24, and is represented by the following numbers: $Q_{2}=75 \mathrm{scfm} ; Q_{1}=$ $0.74 \mathrm{scfm} / \mathrm{ft}$. Hyd.; $\Delta T_{H}=56^{\circ} \mathrm{F} ; P_{w b}=1420 \mathrm{psia}$.

Example 3 - Wellbore Temperature Required to Limit Dissociation
$\begin{array}{lll}\text { Hydrate Zone Thickness, } h_{H y d} & = & 75.0(\mathrm{ft}) \\ \text { Gas Capacity of Mud Degasser, } Q_{g} & = & 50.0(\mathrm{scfm}) \\ \text { Wellbore Diameter, } D_{w b} & = & 10.0(\mathrm{in}) \\ \text { Maximum Wellbore Pressure, } P_{w b} & = & 1000.0 \text { (psia) }\end{array}$

Given the above information, the problem then remains to determine the maximum wellbore temperature required to limit the hydrate dissociation and, therefore, the gas influx into the wellbore, to an amount that may be handled by the surface mud degasser. The solution to the problem is presented graphically in Figure 8.25. It should be noted that this problem has a trial and error solution and is represented by the following numbers: $Q_{2}=51.0 \mathrm{scfm} ; Q_{1}=$ $0.68 \mathrm{scfm} / \mathrm{ft}$. Hyd.; guess $T_{m}=90^{\circ} \mathrm{F} ; \Delta T=40^{\circ} \mathrm{F} ; T_{H}=50^{\circ} \mathrm{F} ;$ guess $T_{m}$ $=90^{\circ} \mathrm{F} ; \Delta T=40^{\circ} \mathrm{F}$. 

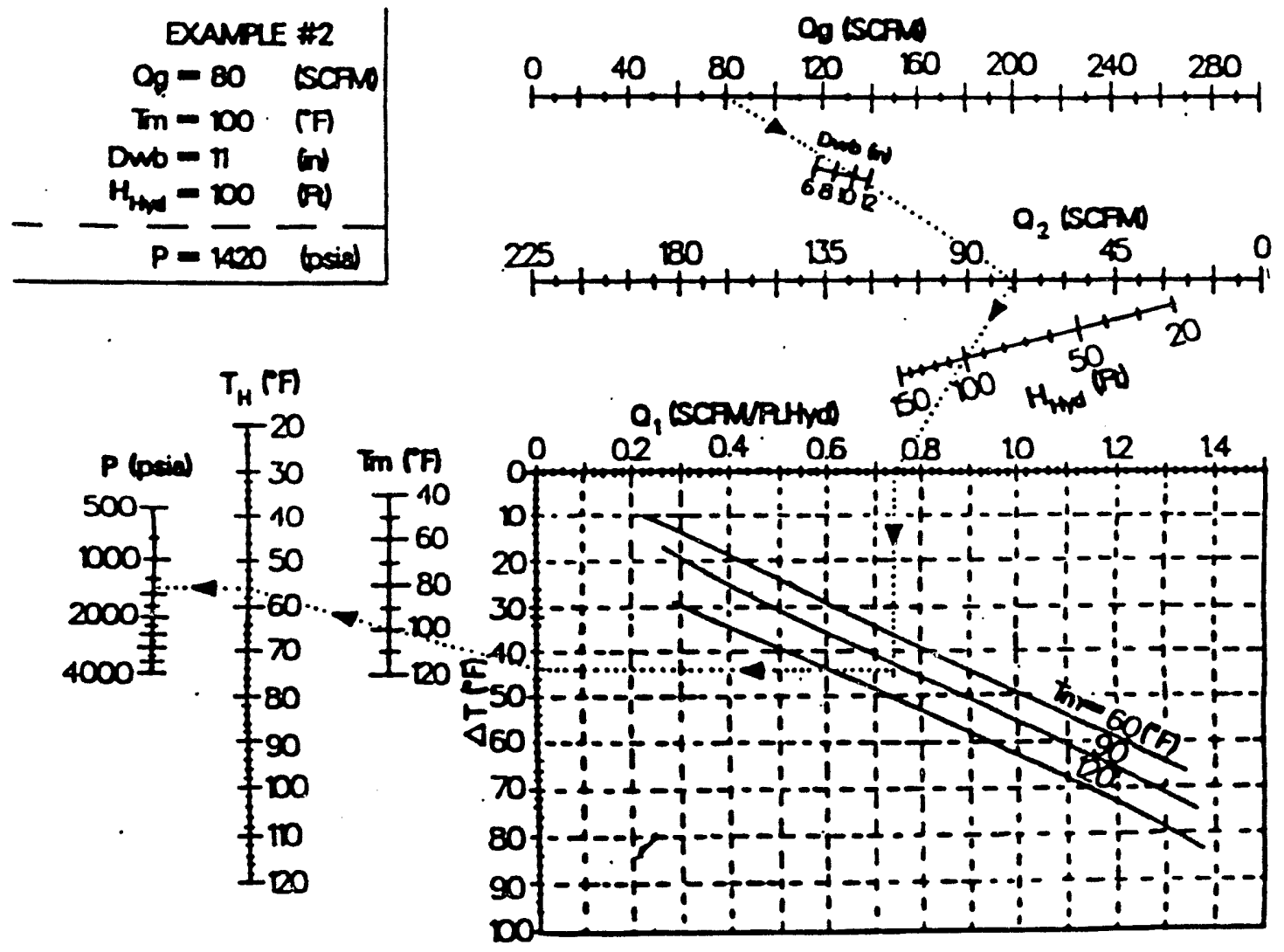

Figure 8.24: Use of Nomogram--Example \#2: Minimum Wellbore Pressure Determination 

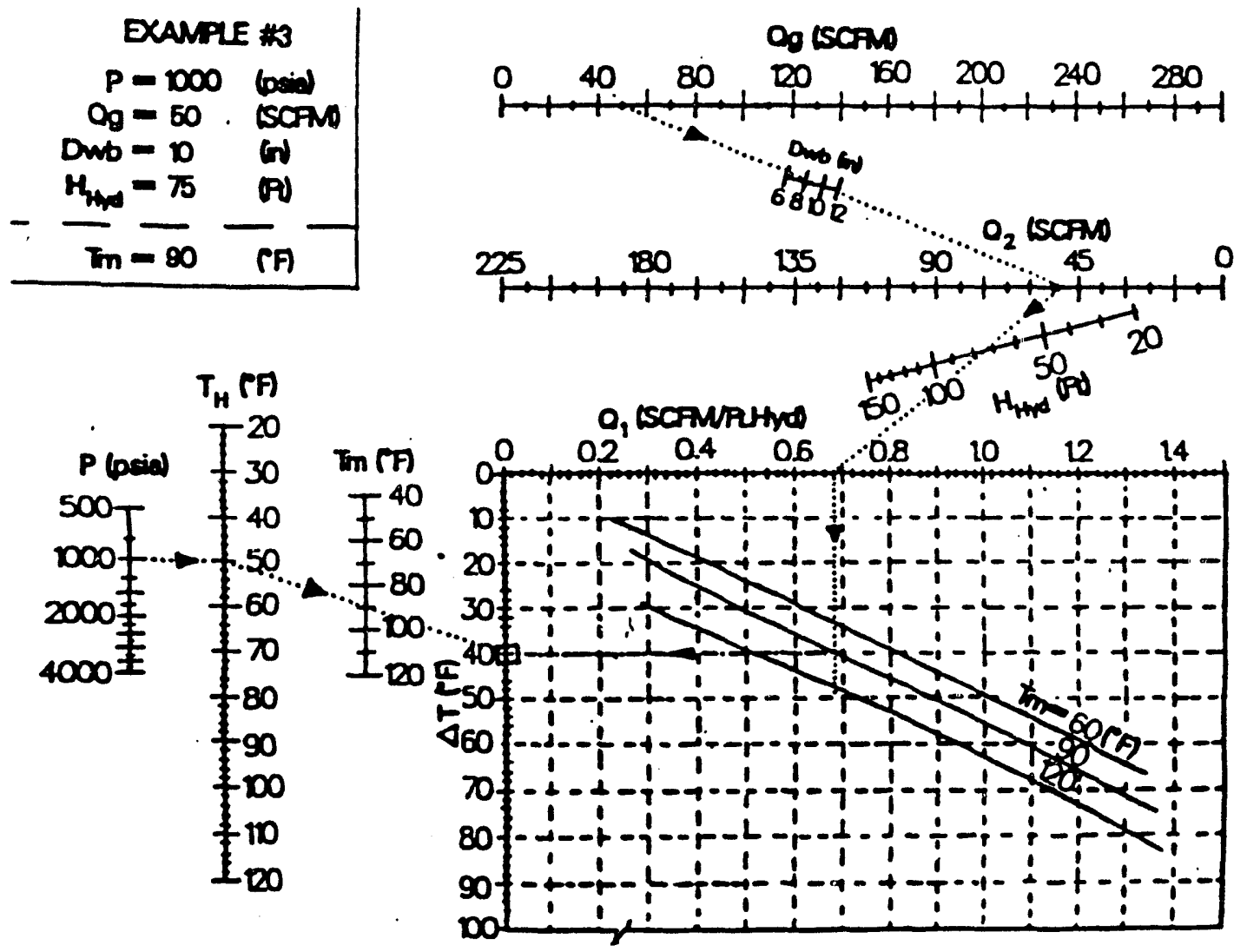

Figure 8.25: Use of Nomogram--Example \#3: Determining Maximum Wellbore Temperature 


\subsection{Addition Applications, Numerical Problems, Peculiarities, and Limitations of Model}

The basic hydrate dissociation model could also be used to model the melting or solidification of other materials, either within porous media or as a solid slab. The modifications required to allow these additional applications are slight and essentially require only a modification in the determination of the "dissociation" temperature and the thermophysical properties of the melt, solid, and porous medium. For example, permafrost thaw can be modeled simply by specifying the thaw temperature, specific heats of solid and liquid water, thermal conductivities of ice and water, densities of ice and water, and the latent heat of fusion at the formation conditions. For a continuous slab, the additional modification of setting the porosity equal to 1.0 is required.

In creating the basic hydrate dissociation model, many numerical problems were assessed and removed, or at the least, their effect minimized by alternative numerical methods. In addition, it was discovered that there are several program coding peculiarities required to accurately track the moving boundary.

The first problem occurs due to the discontinuity between the initial and inrier boundary conditions. The initial boundary condition specifies the initial temperatures everywhere as being the same as the geothermal temperature. The inner boundary condition, however, specifies an increased temperature at the wellbore. Because of this disagreement at the inner boundary, the initial position of the front cannot be specified as occurring at the inner boundary, the initial position of the front cannot be specified as occurring at the inner boundary. At large times, this poses little problem as Sengul (1977) has shown that slight errors in the position of the moving boundary at early times has little effect on the position at late times.

If the dissociation is to be modeled accurately at early times, however, this could pose problems. By specifying the grids to be closely spaced near the wellbore, 
accuracy can be regained by specifying the initial hydrate front to be several grid points into the formation, yet still very close to the inner boundary. This method of initializing the initial front position has the added advantage of allowing temperatures at several grid points to be used to calculate the temperature gradients in the dissociated zone at the moving boundary instead of using the straight line approximation obtained by using only the wellbore temperature and the hydrate dissociation temperature. The time corresponding to the location of the initial hydrate front is approximated with the use of the correlation developed by Sengul (1977) with minor modifications to account for the slight deviation between this model and his.

At early times, when the position of the hydrate front is changing most rapidly across the closely spaced grids, small time steps are required to obtain stable and convergent solutions. The time step required for early time are found by a trial and error process as exact stability and convergence requirements are virtually impossible to prove due to the extreme nonlinear nature of the model equations and boundary conditions. The stability requirement quandary arises because there are not analytical solutions to the two-dimensional moving boundary type problems. At later times, the time step may be increased and convergent solutions obtained, however, care is required to ascertain the reduction in solution accuracy obtained by doing so.

The accuracy of the solution is also dependent on the method of determining the temperature gradients both within the dissociated zone and the solid hydrate zone at the moving boundary, and the slope of the moving boundary in both the radial and vertical directions at grid line intersections. Several previous studies on moving boundary problems used cubic splines to obtain approximations to these gradients and slopes. Cubic splines have the limitations of requiring specific end conditions, i.e., linear extrapolation, parabolic or hyperbolic ends. Because it is the 
accuracy at the moving boundary (the end condition) which is of most concern, cubic splines appear not to be the best method available. In the current model, the temperature profiles and hydrate front positions are fit to polynomials using least squares, and their derivatives at the moving boundary determined by Richardson Extrapolation (Gerald and Wheatley, 1984). The degree of polynomial is allowed to vary from degree one to degree nine, the optimum determined when there is no significant decrease in the variance. This method removes most assumptions concerning the temperature gradients at the moving boundary, and, also, removes all but the extreme restrictions on the shape of the hydrate front itself.

There is an added problem with the above procedure. When increasing the degree of polynomial, the LU decomposed matrix may become singular. In this case, the matrix must be tested, and if found to be singular, the optimum degree polynomial must be selected as one less.

As discussed earlier in this chapter, the shape of the front may be concave towards the inner boundary or concave towards the outer boundary depending on various thermal parameters in the overburden, underburden, and dissociated zone. This poses programming problems in assigning variables to the minimum and maximum radial positions of the front and must be accounted for. In the current model this is accounted for by first determining the convexity of the front and using the same variable as the inflection point, whether convex inward or outward. The calculation procedure can then be performed in the positive radial and vertical directions throughout the program.

Because the moving boundary may be either convex inward or outward, there arise a possible 70 different boundary conditions that need to be tested in order to calculate the matrix coefficients for the temperature calculations. There are two methods of calculating these coefficients. The first method involves assigning properties as functions of the position of the moving boundary, and then simply 
applying the appropriate system boundary conditions in determining the matrix coefficients. The second method involves writing individual matrix coefficients for each boundary condition. There are positive and negative aspects to each method which will not be discussed, but rather it is simply stated that the second method was used in the current model.

Because the hydrate front may intersect vertical grid lines more than once, two separate variables are required to track the moving boundary in the vertical direction. The reason for this is simply that the position variables are indexed arrays, and if the moving boundary intersects a vertical grid line twice, the computer does not know which intersection to use. To avoid this problem, one variable is used for the moving boundary above the inflection point and one variable used below the inflection point.

In order to determine when the solution has converged, the position of the moving boundary must be tracked at three separate times; once at the old time level and twice at the new time level At the new time level, the front is tracked for two consecutive iterations before convergence is tested. Because some oscillatory behavior was noted in the calculation of the new time level front position, after a certain number of iterations, partial substitution is used for each successive iteration of the front position. A position halfway between successive iteration values is used for this updated front position.

In performing calculations for advancing the front, only those points lying on the front and intersecting grid lines are used. There are several programming peculiarities that occur when performing these calculations.

First, the advanced front (calculated from vertical intersecting points) may extend into the overburden, underburden, or even outside the system altogether. The arrays used to track the front cannot handle these cases as they result in trying to assign negative values to the front position, or trying to assign negative values as 
the array index. To avoid this problem, if the new front position is outside the hydrate zone boundaries; those points are not used to determine convergence, and in fact, all calculations that were to be performed at those points must be avoided altogether.

Second, the new time level or iteration level front position may intersect previously non-intersecting vertical grid lines. In these cases, these new intersecting points should be used in the convergence calculations, however, they need to be located first. Because of this, when a previously unintersected line is encountered, the vertical position of that intersecting point must be interpolated from the current calculated position of the hydrate front. To do this, the front is fit to a polynomial, using the method mentioned previously, and Richardson interpolation used to located to the position of the point.

\subsection{Conclusions and Recommendations}

A two-dimensional $(r-z)$ cylindrical coordinate mathematical and numerical model has been developed for the dissociation of natural gas hydrates. Finite differences on a fixed grid are used to obtain a solution to the model. This represents the first instance in which an unsteady-state $(r-z)$ finite difference model has been used to model the dissociation of natural gas hydrates.

Along with a comprehensive wellbore hydraulics and heat transfer model, the hydrate dissociation model has been used for a detailed examination of the effects of a wide range of drilling and reservoir parameters on the hydrate dissociation rate for Arctic terrestrial, Arctic subsea and subtropic subsea locations. Parameters studied include the geothermal parameters of geothermal gradient within and below the permafrost and the depth to the permafrost base, the formation porosity,

the wellbore radius, and the wellbore pressure and temperature. The relative effects of many drilling parameters on the wellbore pressure and temperature have 
also been examined and include the relative effects of the drilling mud circulation rate, density and viscosity on the wellbore pressure, and the relative effects of casing, mud inlet temperature, mud density and mud circulation rate on the wellbore temperature.

Results presented in a series of easy to use plots and nomograms, can be used to determine potential hydrate locations, select drilling parameters, or design surface equipment to ensure the safe drilling through potential hydrate zones. Parameters investigated which show significant effect on the rate of hydrate dissociation during drilling include the reservoir porosity, the wellbore diameter, the wellbore pressure exerted against the formation, and the drilling fluid or weitbore temperature opposite the hydrate bearing formation.

Validation of the hydrate dissociation model could only be ascertained as far as results for a simplified version of the program compare to the results for a onedimensional model for the degradation of permafrost presented in the literature (Sengul, 1977). While the comparison lends confidence to the numerical methods applied within the hydrate dissociation program, experimental or actual field data for the dissociation of natural gas hydrates are required to fully ascertain the accuracy of the model results. Parameters such as the annular mud temperature, which previously could not be determined to a significant degree of accuracy, can now be measured directly with the implementation of measurement while drilling (MWD) instrumentation.

Representing a numerical solution to a moving boundary problem, the hydrate dissociation model developed in this study can be used to provide insight into the numerical aspects associated with solving moving boundary problems by finitedifference methods. One such insight obtained in performing this study is that while the finite-difference method of solution for the temperature distributions, coupled with the method of front determination, give detailed information on the location 
of the moving boundary, the amount of effort required for the painstaking numerical formulation of the problem in more than one dimension is not worth the comparatively minor improvement in the delineation of the moving boundary for the case of hydrate dissociation. It is the opinion of this author that the much simpler methods of equivalent enthalpy or equivalent heat capacity for obtaining approximate solutions to Stefan problems, would be sufficiently accurate to model the hydrate dissociation problem considered here, while at the same time would require far less programming effort in multiple dimensions.

Lastly, the model developed could be modified into a completely general model, allowing application to any sort of melting or solidification problem, either in porous media or as a continuous slab, and in some instances, the programming effort required may be justifiable.

\subsection{Nomenclature}

Variable

a

$A_{\text {but }}$

$a_{f_{x}}$

b

$C_{p}$

$d$

D

$f$

$g_{G 1}$

\section{Definition}

distance between irregular grid points

total cross-sectional area of drill bit nozzles

freezing point depression of natural gas hydrates due to pore fluid salinities

distance between irregular grid points

specific heat

diameter

diameter

1. position of the moving boundary

2. function of

geothermal temperature gradient within permafrost 


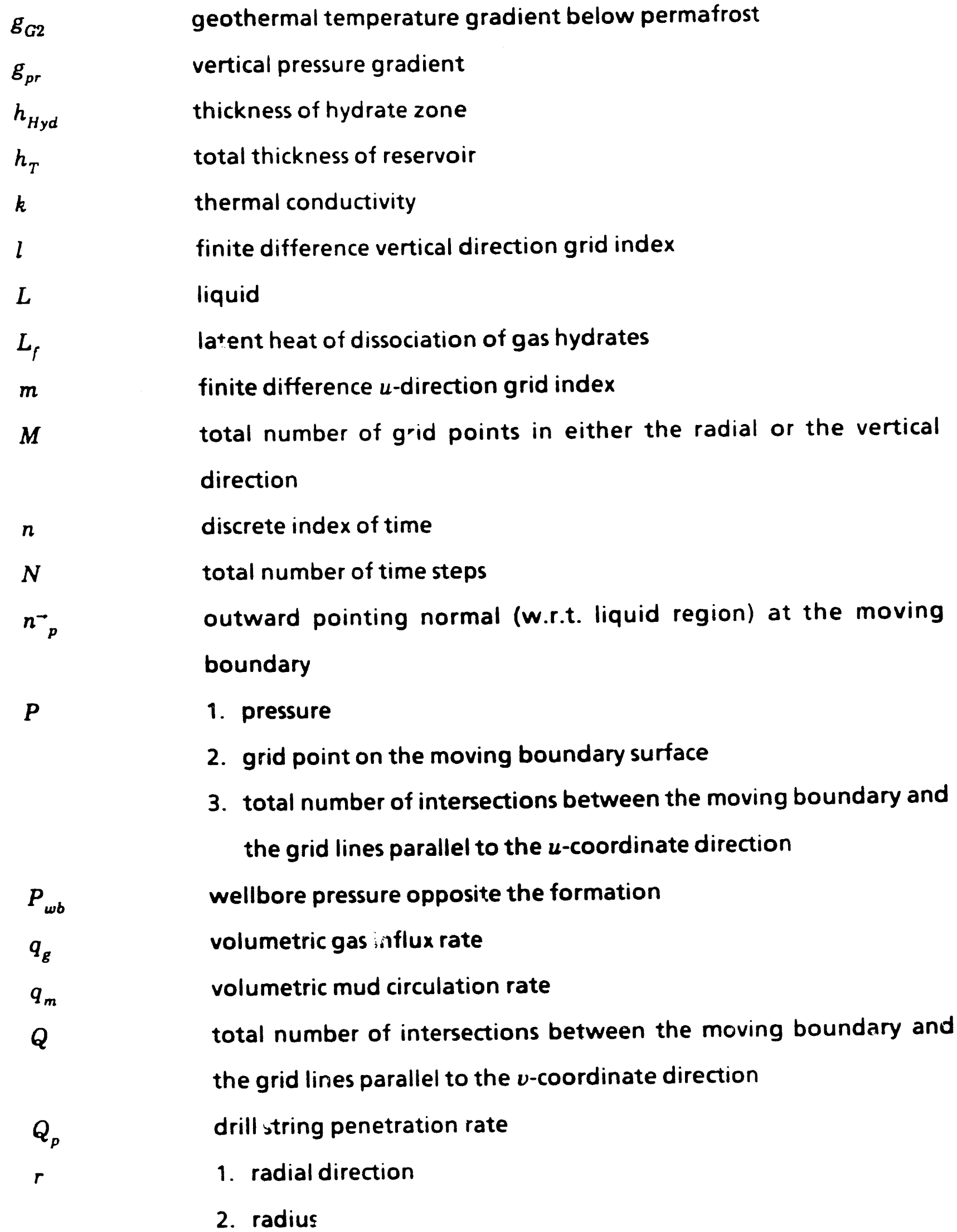




\begin{tabular}{|c|c|}
\hline$r_{D}$ & dimensionless radius \\
\hline$r_{e}$ & radial extent of the reservoir \\
\hline$r_{f}$ & radius of the hydrate front \\
\hline$r_{w}$ & wellbore radius \\
\hline$s$ & surface \\
\hline$S_{H}$ & hydrate saturation \\
\hline$S_{g}$ & gas saturation \\
\hline$S_{w}$ & water saturation \\
\hline$t$ & time \\
\hline$T$ & temperature \\
\hline$T_{p f b}$ & temperature at the permafrost base \\
\hline$T_{f}$ & hydrate dissociation temperature \\
\hline$T_{\omega b}$ & wellbore temperature \\
\hline$u$ & dimensionless radial direction \\
\hline$u_{r}$ & $\begin{array}{l}\text { dimensionless radius of the hydrate front in the } u \text {-coordinate } \\
\text { direction }\end{array}$ \\
\hline$u f_{p}$ & $\begin{array}{l}\text { dimensionless radius of the hydrate front in the } u \text {-coordinate } \\
\text { direction at the intersecting point } p\end{array}$ \\
\hline $\boldsymbol{v}$ & dimensionless vertical direction \\
\hline $\mathbf{V}$ & (2) \\
\hline$v_{f}$ & dimensionless vertical position of the hydrate boundary \\
\hline$u^{-} f_{p}$ & vector of all dimensionless radial positions of the hydrate front \\
\hline$v^{-} f_{q}$ & vector of all dimensionless vertical positions of the hydrate front \\
\hline$w$ & area \\
\hline$x$ & sartesion coordinate direction $x$ \\
\hline $\boldsymbol{y}$ & cartesion coordinate direction $y$ \\
\hline$z$ & vertical direction or position (positive upwards) \\
\hline
\end{tabular}


vertical direction or position (positive downward)

$z_{f}$

vertical position of moving boundary

$z_{g}$

gas compressibility factor

\section{Greek Symbols}

\begin{tabular}{|c|c|}
\hline$a$ & thermal diffusivity \\
\hline$\beta$ & dimensionless term defined by Eq. (8.50) \\
\hline$\beta_{H}$ & gas content of hydrates \\
\hline \multirow[t]{2}{*}{$Y$} & 1. specific gravity \\
\hline & 2. dimensionless term defined by Eq. (8.106) \\
\hline$\delta_{g}$ & ratio of gas to water thermal conductivities \\
\hline$\delta_{H}$ & ratio of hydrate rock thermal conductivities \\
\hline$\delta_{w}$ & ratio of water to rock thermal conductivities \\
\hline$\varepsilon_{f}$ & convergence criteria for initial value problems \\
\hline$\varepsilon_{T}$ & convergence criteria for boundary value problems \\
\hline$\eta$ & dimensionless parameter \\
\hline$\theta$ & dimensionless temperature defined by Eq. (8.49) \\
\hline $\mathbf{\Lambda}$ & dimensionless term defined by Eq. (8.51) \\
\hline$\mu$ & dimensionless term defined by Eq. ( 8.52$)$ \\
\hline $\boldsymbol{\mu}_{m}$ & apparent mud viscosity \\
\hline$\rho$ & density \\
\hline \multirow[t]{2}{*}{ 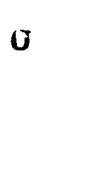 } & 1. dimensionless term defined by Eq. (8.53) \\
\hline & 2. dimensionless term defined by Eq. (8.108) \\
\hline \multirow[t]{2}{*}{$\tau$} & 1. dimensionless time (Fourier's number) \\
\hline & 2. torque supplied to drill string \\
\hline$\dot{\Phi}$ & i. pórosity \\
\hline & 2. dimensionless term defined by Eq. (8.107) \\
\hline
\end{tabular}


$\Psi$

$\omega$

$\boldsymbol{\nabla}$

$\nabla^{2}$

\section{Subscripts}

C1

D

DS

$f$

g

G1

G2

H

Hyd

i

in

j

$l$

m

$\boldsymbol{M}$

$m b h$

ms domain

1. dimensionless term defined by Eq. (8.54)

2. LSOR relaxation parameter

3. angular velocity of drill rig kelly bushing

difference operator

"del" operator, differential operator

Laplacian differential operator

methane

1. dissociated zone

2. dimensionless

at the moving boundary or front

at the moving boundary or front

gas

geothermal within permafrost

geothermal below permafrost

hydrate

hydrate

region indicator

initial

region indicator

finite difference vertical direction spatial index

finite difference radial direction spatial index

maximum $\mathrm{m}$ or I discrete spatial index

mud at bottomhole

mean at surface 


$\begin{array}{ll}n & \text { finite difference discrete index of time } \\ N & \text { maximum discrete index of time } \\ O & \text { overburden } \\ p & \text { at point } P \\ p f b & \text { at permafrost base } \\ p i & \text { inside drill pipe } \\ p o & \text { outside drill pipe } \\ p r & \text { pressure } \\ q & \text { at point } Q \\ R & \text { rock } \\ S & \text { solid hydrate zone } \\ s e a & \text { sea } \\ s t & \text { steel } \\ S U & \text { solid hydrate - underburden boundary } \\ \text { thz } & \text { top of hydrate zone } \\ U & \text { underburden zone } \\ W b & \text { water } \\ & \end{array}$

\section{Superscripts}
$n$
discrete index of time
$k$
iteration number
(0)
old time step value

\subsection{References}

1. Altman, M.: "Some Aspects of the Melting Solution for a Semi-Infinite Slab," Chem. Eng. Prog. Symp. Series, Vol. 57, No. 32, (1961), pp. 16-23. 
2. Aziz, K. and Settari, A.: Petroleum Reservoir Simulation, Applied Science Publishers Ltd, London, (1972).

3. Bankoff, S.G.: "Heat Conduction or Diffusion With Change of Phase," Adv. Chem. Eng., Vol. 5, (1964). pp. 75-150.

4. Bayles, G.A., Sawyer, W.K., Anada, H.R., Reddy, S. and Malone, R.D.: "A Steam Cycling Model for Gas Production From a Hydrate Reservoir," paper presented at the AlChE Winter National Meeting, Atlanta, Georgia, (March 11-14, 1984).

5. Bobula, E. and Twardowska, K.: "On a Certain Inverse Stefan Problem," Bulletin of the Polish Academy of Sciences - Technical Sciences, Vol. 33, No. 7-8, (1985), pp. 359-370.

6. Boley, B.A.: "A Method of Heat Conduction Analysis of Melting and Solidification Problems،“ J. Math. Phys., Vol. 40, (1961), pp. 300-313.

7. Boley, B.A.: "Survey of Recent Developments in the Fields of Heat Conduction in Solids and Thermodynamics," Nuclear Eng. Des., Vol. 18, (1972), pp. 377-399.

8. Boley, B.A. and Yagoda, H.P.: "The Starting Solution for Two-Dimensional Heat Conduction Problems with Change of Phase," Quart. Appl. Math., Vol. 27. No. 2, (1969), pp. 223-246.

9. Bonacina, C., Comini, G., Fasano, A. and Primicerio, M.: "Numerical Solutions of Phase Change Problems،" Int. J. Heat Mass Transfer, Vol. 21, (1978), pp. 215219.

10. Bonnerot, R. and Janet, P.: "Numerical Computation of the Free Boundary for the Two-dimensional Stefan Problems by Space-Time Finite Elements," Comput. Phys., Vol. 25, (1977), pp. 163-181.

11. Bourgoyne, A.T. Jr., Chenevert, M.E., Millheim, K.K. and Young, F.S. Jr.: Applied Drilling Engineering, SPE Textbook Series, Vol. 2, (1986).

12. Budhia, H. and Kreith, F.: "Heat Transfer with Melting or Freezing in a Wedge," Int. J. Heat Mass Transfer, Vol. 16, (1973), pp. 195-211. 
13. Carnahan, B., Luther, H.A. and Wilkes, J.W.: Applied Numerical Methods, John Wiley and Sons, New York, (1969).

14. Carslaw, H.S. and Jaeger, J.C.: Conduction of Heat in Solids, Oxford University Press, Oxford, 2nd Edition (1980).

15. Chapra, S.C. and Canale, R.P.: Numerical Methods for Engineers With Personal Computer Applications, McGraw-Hill Book Company, New York, (1985).

16. Cheney, W. and Kincaid, D.: Numerical Mathematics and Computing, Brooks Cole Publishing Company, Monterey, CA, 2nd Edition, (1985).

17. Chernousko, F.L.: Int. Chem. Engng., Vol. 10, No. 1, (1970), p. 42.

18. Cho, S.H. and Sunderland, J.E.: "Heat-Conduction Problems With Melting or Freezing," J. Heat Transfer, Trans. ASME (C), Vol. 91, (1969), pp. 421-426.

19. Chuang, Y.K. and Szekely, J.: "On the Use of Green's Functions for Solving Melting and Solidification Problems," Int. J. Heat Mass Transfer, Vol. 14, (1971), pp. $1285-1294$.

20. Comini, G., del Guidice, S., Lewis, R. and Zienkiewicz, O.: "Finite Element Solution of Non-Linear Heat Conduction Problems with Special Reference to Phase Change," Int J. Numer. Methods Eng., Vol. 8, (1974), pp. 613-624.

21. Corre, B., Eymard, R. and Guenot, A.: "Numerical Computation of Temperature Distribution in a Wellbore While Drilling," SPE Paper 13208, presented at the 59th Annual Technical Conference and Exhibition of the Society of Petroleum Engineers, Houston, TX, (Sept. 16-19, 1984).

22. Crank, J.: "How to Deal with Moving Boundaries in Thermal Problems," Numerical Methods in Heat Transfer, eds. Lewis, R.W., Morgan, K. and Zienkiewiez, O.C., John Wiley and Sons Ltd., (1981), pp. 177-200.

23. Crank, J. and Crowley, A.B.: Int. J. Heat Mass Transfer, Vol. 21, (1978), pp. 393398. 
24. Crank, J. and Gupta, R.: "Isotherm Migration Method in Two Dimensions," Int. J. Heat Mass Transfer, Vol. 18, (1975), pp. 1101-1117.

25. Crank, J. and Phahle, R.D.: Bull. Math. Applic., Vol. 9, (1973), pp. 12-14.

26. Crichlow, H.B.: Modern Reservoir Engineering - A Simulation Approach, Prentice-Hall, Inc., Englewood Cliffs, NJ, (1977).

27. Dix, R.C. and Cizek, J.: Heat Transfer 1970, Vol. 1, 4th Int. Heat Transfer Conf., Paris, Versailles, Elsevier, Amsterdam, (1970).

28. Dmitriev, V.I. and E.N. Solov'eva: "Numerical Solution Method for the Multiple-Free-Boundary Stefan Problem With a Variable Critical Temperature," Vestnik Moskovskogo Universiteta. Seriya 15: Vychislitel'naya Matematika i Kibernetika, No. 1, (1985), pp. 25-31.

29. Edwardson, M.J., Girnen, H.M., Parkison, H.R., Williamson, C.D., and Mathews, C.S.: "Calculation of Formation Temperature Disturbances Caused by Mud Circulation," Jour. Pet. Tech., (April 1962), pp. 410-426.

30 Ehrlick, L.W.: "A Numerical Method of Solving a Heat Flow Problem With Moving Boundary." JACM, Vol. 5, No. 2, (1958), pp. 161-176.

31. Ekrann, S. and Rommetveit, R.: "A Simulator for Gas Kicks in Oil-Based Drilling Muds," SPE Paper 14182, presented at the 60th Annual Technical Conference and Exhibition of the Society of Petroleum Engineers, held in Las Vegas, Nevada, (Sept. 22-25, 1985).

31. Evans, G.W., Isaacson, E. and MacDonald, J.K.L.: "Stefan-Like Problems," Quarterly of Applied Mathematics, Vol. 8, (1950), pp. 312-319.

32. Eyres, N.R., Hartree, D.R., Ingham, J., Jackson, R., Sarjant, R.J., and Wagstaff, J.B.: "The Calculation of Variable Heat Flow in Solids," Proc. Royal Soc. London, Series A, Vol. 240, (1946), pp. 1-57.

33. Fasano, A. and Primicerio, M. (eds.): Free Boundary Problems: Theory and Applications, Pitman Press, Boston, (1983). 
34. Fox, L.: "What are the Best Numerical Methods?" in Moving Boundary Problems in Heat Flow and Diffusion, edited by J.R. Ockendon and W.R. Hodgkins, Oxford University Press, Oxford, (1975), p. $210+$.

35. Franklin, L.J.: "Hydrates in the Arctic Islands," Article 5, Proceedings of Workshop on Clathrates (Gas Hydrates) in the National Petroleum Reserve in Alaska, July 16-17, Menlo Park, CA, Edited by A.L. Bowsher, (1979).

36. Franklin, L.J.: "In-Situ Hydrates - A Potential Gas Resource," Petroleum Engineers International, (Nov., 1980), pp. 112-122.

37. Franklin, L.J.: "Gas Hydrates Drilling Procedure," Canadian Patent 1161027. issued (Jan. 24, 1984).

38. Frivik, P.E. and Comini, G.: "Seepage and Heat Flow in Soil Freezing," Trans. ASME - Jour. Heat Transfer, Vol. 104, (May, 1982), pp. 323-328.

39. Furzeland, R.M.: "A Survey of the Formulation and Solution of Free and Moving Boundary (Stefan) Problems," Brunel University Math. Report TR/76, (1977).

40. Furzeland, R.M.: "Free and Moving Boundary Problems in Heat Flow and Diffusion," symposium held at the University of Durham in July, 1978, Bull. Inst. Math. Applics. 15, (7), (1979), pp. 172-175.

41. Furzeland, R.M.: "A Comparative Study of Numerical Methods for Moving Boundary Problems," J. Inst. Math. Applics. 26, (1980), pp. 411-429.

42. Gerald, C.F. and Wheatley, P.O.: Applied Numerical Analysis, Addison-Wesley Publishing Company, Reading, Massachusetts, 3rd Edition, (1984).

43. Goodman, M.A.: Handbook of Arctic Well Completions, World Oil, Houston, TX, (1978).

44. Goodman, T.R.: "The Heat-Balance Integral and Its Application to Problems Involving a Change of Phase," Trans. of ASME, (Feb., 1958), pp. 335-342. 
45. Goodman, M.A. and Franklin, L.J.: "Thermal Model of New Concept for Hydrate Control During Drilling," private communications, (1981).

46. Gunderson, J.R. and Lock, G.S.H.: "An Extension of Neumann's Solution for Ice Formation," paper presented at the First Western Canadian Heat Transfer Conference, Sasktoon, Sakatchewan, (Sept. 6, 1966).

47. Hansen, E. and Hougaard, P.: J. Inst. Math. Applic., Vol. 13, (1974), pp. 385-398.

48. Heggs, P.J. and O'Sullivan, P.A.: " $A$ Numerical Solution of the Effects of Fluid Convection and Axial Conduction and Solid Internal Conduction on the Heat Transfer in Porous Media," in Numerical Methods in Thermal Problems Proceedings of the Third International Conference held in Seattle, WA, August 2-5, 1983, eds. Lewis, R.W., Johnson, J.A., and Smith, W.R., Pineridge Press, Swansea, U.K., (1983), pp. 184-196.

49. Hippman, A. and Kelley, W.: "The Single Steel Drilling Caisson: A New Arctic Drilling System," SPE Paper 12060, presented at the 58th Annual Technical Conference and Exhibition held in San Francisco, CA, (October 5-8, 1983).

50. Holder, G.D. and Angert, P.F.: "Simulation of Gas Production From a Reservoir Containing Both Gas Hydrates and Free Natural Gas," SPE Paper 11105. presented at the 57th Annual Fall Technical Conference and Exhibition of the Society o Petroleum Engineers at AIME held in New Orleans, LA, (Sept. 26-29, 1982).

51. Holmes, C.S. and Swift, S.C.: "Calculation of Circulating Mud Temperatures," Jour. Pet. Tech. (June, 1970), pp. 670-674.

52. Hopkirk, R.J., Sharma, D. and Pralong, P.J.: "Coupled Convective and Conductive Heat Transfer in the Analysis of Hot Dry Rock Geothermal Sources," in Numerical Methods in Heat Transfer, eds. Lewis, R.W., Morgan, K. and Zienkiewicz, O.C., John Wiley \& Sons Ltd., (1981), pp. 261-306. 
53. Hornung, U.: "The Finite Element Method for Coupled Heat and Water Movement in a Partially Frozen Soil," in Numerical Methods in Thermal Problems - Proceedings of the Third International Conference held in Seattle, WA, August 2-5, 1983, eds. Lewis, R.W., Johnson, J.A., and Smith, W.R., Pineridge Press, Swansea, U.K., (1983), pp. 163-170.

54. Houi, D. and Bacon, G.: "Heat Transfer in Porous Media: The Good Concordance Between Numerical and Experimental Results May Be a Lure," in Numerical Methods in Thermal Problems - Proceedings of the Third International Conference held in Seattle, WA, August 2-5, 1983, eds. Lewis, R.W., Johnson, J.A., and Smith, W.R., Pineridge Press, Swansea, U.K., (1983), pp. 227-234.

55. Hsiao, J.S.: "An Efficient Algorithm for Finite-Difference Analysis of Heat Transfer with Melting and Solidification," Numerical Heat Transfer, Vol. 8. (1985), pp. 653-666.

56. Imber, M. and Huang, P.N.S.: "Phase Change in a Semi-Infinite Solid with Temperature Dependent Thermal Properties," Int. J. Heat Mass Transfer, Vol 16, No. 10, (1973), pp. $1951-1954$.

57. Incropera, F.P. and DeWitt, D.P.: Fundamentals of Heat Transfer, John W/iley \& Sons, New York, (1981).

58. Kamath, V.A. and Godbole, S.P.: "Evaluation of Hot Brine Stimulation Technique for Gas Production From Natural Gas Hydrates," J. Pet. Tech., (Nov.. 1987), pp. 1379-1388.

59. Kamath, V.A., Godbole, S.P. and Baena, C.J.: "Effect of Dissociation of Hydrates During Thermal Recovery of Heavy Oils on the North Slope, Alaska," SPE Paper 14224 presented at the 60th Annual Technical Conference and Exhibition of the Society of Petroleum Engineers held in Las Vegas, NV, (Sept. $22-25,1985)$. 
60. Kamath, V.A., Godbole, S.P. and Collett, T.S.: "Evaluation of Stability of Gas Hydrates on North Slope, Alaska," Cold Regions Science and Technology. (1987).

61. Keller, H.H., Couch, E.J. and Berry, P.M.: "Temperature Distribution in Circulating Mud Columns," Soc. Pet. Eng. Jour., (Feb., 1973), pp. 22-30.

62. Keung, C.S.: The Use of Sources and Sinks in Solving Two-dimensional Heat Conduction Problems with Change of Phase in Arbritrary Domains, Ph.D. Dissertation, Columbia University, New York, (1980).

63. Koh, J.C.Y., Price, J.F. and Colony, R.: "On Heat and Mass Transfer with Two Moving Boundaries," in Progress in Heat and Mass Transfer , Vol. 2, eds. Irvine, T.F. Jr., Hartnett, J.P., !bele, W.E. and Goldstein, R.J., Pergamon Press, Oxford, (1969).

64. Koiesnikov, P.M., Grishanova, L.V., Abrashin, V.N., Degtereva, L.N., Kolesnikova, N.S. and Tsurko, V.A.: "Analysis of Certain Problems of Heat and Mass Transfer with Phase Transition in Moving-Boundary Domains," Heat Transfer - Soviet Research, Vol. 10, No. 2, (March-April, 1978), pp. 33-37.

65. Kolodner, 1.I.: "Free Boundary Problem for the Heat Equation with Applications to Problems of Change of Phase," Comm. Pure Appl. Math., Vol. 9, (1956), pp. 1-31.

66. Kumar 1.J. and Gupta, L.N.: "An Approximate Solution of the Generalized Stefan Problem in a Porous Medium With Variable Thermal Properties," in Heat and Mass Saurcebook: Fifth All-Union Conference, Minsk, 1976; ids. Styrikovich, M.A., Zukauskas, A.A., Hartnett, J.P., and Irvin, T.F. Jr., John Wile. \& Sons, New York, (1977), pp. 215-221.

67. Landau, H.G.: "Heat Conduction in a Melting Solid," Quarterly of Applied Mathematics, Vol. 8, (1950), pp. 81-94. 
68. Lemmon, E.C.: "Multidimensional Integral Phase Change Approximations for Finite Element Conduction Codes," Numerical Methods in Heat Transfer, Edited by Lewis, R.W., Morgan, K., and Zienkiewicz, O.C., John Wiley \& Sons Ltd., (1981), pp. 201-213.

69. Lewis, R.W. and Morgan, K., (Eds.): Numerical Methods in Thermal Problems, Section 2, Pineridge Press, Swansea, (1979).

70. Lightfoot, N.H.M.: "The Solidification of Molten Steel," Proc. London Math. Soc., 31/2, (1930), pp. 97-116.

71. Lin, C.J. and Wheeler, J.D.: "Simulation of Permafrost Thaw Behavior at Prudhoe Bay," Jour. Pet. Tech., (March, 1978), pp. 461-467.

72. Lotkin, M.: "The Calculation of Heat Flow in Meiting Solids," Quart. Appl. Math., Vol. 18, No. 1, (1960), pp. 79-85.

73. Marshall, D.W. and Eentsen, R.G.: "A Computer Model to Determine the Temperature Distributions in a Wellbore," Jour. Can. Pet. Tech., (Jan.-Feb., 1982), pp. 63-75.

74. McGuire, P.L.: "Methane Hydrate Gas Production by Thermal Stimulation," paper presented at the fourth Canadian Permafrost Conference sponsored by the Natl. Research Council of Canada and the Canadian Geotechnic:l Soc., Calgary, (March 2-6, 1981).

75. Merriam, R., Wechsler, A., Boorman, R., and Davies, B.: "Insulated Hot OilProducing Wells in Permafrost," J. Pet. Tech., pp. 357-365, March, (1975).

76. Meyer, G.H.: "On a Free Interface Problem for Linear Ordinary Differential Equations and the One-Phase Stefan Problem," Num. Math., Vol. 16, (1970), pp. 248-267.

77. Meyer, G.H. "A Numerical Method for Two-Phase Stefan Problems," SIAM J. Numer. Anal., Vol. 8, No. 3, (Sept., 1971), pp. 555-569. 
78. Morgan, K., Lewis, R. and Zienkiewicz, O.: "An Improved Algorithm for Heat Conduction Problems with Phase Change," Int. J. Numer. Methods Eng., Vol. 12, (1978), pp. 1191-1195.

79. Morgan, K.: "A Numerical Analysis of Freezing and Melting with Convection," Computer Methods in Applied Mechanics and Engineering, North-Ho!land Publishing Company, 28, (1981), pp. 275-284.

80. Morgan, K., Smith, T.J., Pietlicki, R., Pugh, E.D.L., and Lewis, R.W.: "The Simulation of Thermal Fronts in Petroleum Reservoirs During Enhariced Oil Recovery Operations," in Numerical Methods in Thermal Problems Proceedings of the Third International Conference held in Seattle, WA, August 2-5, 1983, eds. Lewis, R.W., Johnson, J.A., and Smith, W.R., Pineridge Press, Swansea, U.K., pp. 1155-1171, (1983).

81. Murray, W.D. and Landis, F.: "Numerical and Machine Solutions of Transient Heat-Conduction Problems Involving Melting or Freezing," $\underline{\text { j. Heat Transfer, }}$ Vol. 81C, (May, 1959), pp. 106-112.

82 Neumann, F.: "Konigsberger Vorlesungen," Die partiellen DifferentialGLeichungen der mathematischen Physik, H. Weber, Vol. 2, 6th Ed., Braunschweig, (1919), p. 121.

83. Nickens, H.V.: "A Dynamic Computer Model of a Kicking Well: Part I - The Theoretical Model," SPE Paper 14183, presented at the 60th Annual Technical Conference and Exhibition of the Society of Petroleum Engineers, held in Las Vegas, Nevada, (Sept. 22-25, 1985).

84. Nickens, H.V.: "A Dynamic Computer Model of a Kicking Well: Part II - Model Predictions and Conclusions," SPE Paper 14184, presented at the 60th Annuai Technical Conference and Exhibition of the Society of Petroleum Engineers, Held in Las Vegas, Nevada, (Sept. 22-25, 1985). 
85. Niezgódka, M. and Pawlow, I.: "A Generalized Stefan Problem in Several Space Variables," Appl. Math Optim., 9, (1983), pp. 193-224.

86. Ockendon, J.R. and Hodgkins, W.R. (eds.): Moving Boundary Problems in Heat Flow and Diffusion, Clarendon Press, Oxford, (1975).

87. O'Neill, K. and Lynch, D.R.: "A Finite Element Solution for Freezing Problems, Using a Continuously Deforming Coordinate System," in Numerical Methous in Heat Transfer, Edited by Lewis, R.W., Morgan, K., and Zienkiewicz, O.C., John Wiley \& Sons Ltd., (1981), pp. 215-231.

88. O'Neal, P.V.: Advanced Engineering Mathematics, Wadsworth Publishing Company, Belmont, CA, (1983).

89. Patel, P.D.: "Interface Conditions in Heat Conduction Problems with Change of Phase," AlAA J., Vol. 6, (1968), p. 2454.

90. Paterson: Proc. Glasgow Math. Ass., Vol. 1, (1952-1953), pp. 42-47.

91. Pekeris, C.L. and Slichter, L.B.: "Problerns of Ice Formation," J. Appl. Phys., 10, (1939), pp. 135-137.

92. Perkins, T.K., Rochon, J.A. and Knowles, C.R.: "Studies of Pressures Generated Upon Refreezing of Thawed Permafrost Around a Wellbore," J. Pet. Tech., (Oct., 1974), pp. 1159-1166.

93. Poots, G.: "An Approximate Treatment of a Heat Conduction Problem Involving a Two-Dimensional Solidification Front," Int. J. Heat Mass Transfer, Vol. 5, (1962), pp. 339-348.

94. Poots, G.: "On the Application of Integral Methods to the Solution of Problems Involving the Solidification of Liquids Initially at the Fusion Temperature," Int. J. Heat Mass Transfer, Vol. 5. (1962), pp. 525-531.

95. Poulikakos, D. and Kimura, S.: "Numerical Methods in Convection," in Convection Heat Transfer, ed. Bejan, A., John Wiley \& Sons, New York, (1984). 
96. Pui, N.K. and Kljucec, N.M.: "Permafrost Melting Predictions Match Logs," The Oil and Gas Journal, (Aug. 15, 1977), pp. 66-70.

97. Rathjen, K.A. and Jiji, L.M.: "Heat Conduction With Melting or Freezing in a Corner," J. Heat Trans, Trans. ASME (C), Vol. 93, (1971), pp. 101-109.

98. Raymond, L.R.: "Temperature Distribution in a Circulating Drilling Fluid," Journal of Petroleum Technology, (March, 1969), pp. 333-341.

99. Raw, M.J. and G.E. Schneider: "A New Implicit Solution Procedure for Multidimensional Finite-Difference Modeling of the Stefan Problem," Numerical Heat Transfer, Vol. 8, (1985), pp. 559-571.

100. Reffstrup, J. and Houbak, N.: "Finite Element Modelling of Heat and Mass Transfer in Porous Media," in Numerical Methods in Thermal Problems Proceedings of the Third International Conference held in Seattle, WA, August 2-5, 1983, eds. Lewis, R.W., Johnson, J.A., and Smith, W.R., Pineridge Press, Swansea, U.K., (1983), pp. 173-183.

101. Rivlin, T.J.: An Introduction to the Approximation of Functions, Dover Publications, Inc., New York, (1969).

102. Roadifer, R.D., Godbole, S.P., and Kamath, V.A.: "Thermal Model for Establishing Guidelines for Drilling in the Arctic in the Presence of Hydrates," SPE Paper 16361, presented at the SPE California Regional Meeting held in Ventura, CA, (April 8-10, 1987).

103. Roadifer, R.D., Godbole, S.P., and Kamath, V.A.: "Estimation of Parameters for Drilling in Arctic and Offshore Environments in Presence of Hydrates," SPE Paper 16671, presented at the 62nd Annual Technical Conference \& Exhibition of SPE held in Dallas, TX, (Sept. 27-30, 1987).

104. Ruoff, A.L.: "An Alternate Solution to Stefan's Problem," Quart. Appl. Math., 16. (July, 1958), pp. 197-201. 
105. Selim, M.S. and Sloan, E.D.: "Modeling of the Dissociation of an In-SituHydrate," SPE Paper 13597, presented at the SPE 1985 California Regional Meeting, held in Bakersfield, CA, (March 27-29, 1985).

106. Sengul, M.: Numerical Solution of Heat Conduction with Phase Change in Cylindrical Systems, Ph.D. Dissertation, Dept. of Petroleum Engineering, Stanford University, Stanford, CA, (1977).

107. Shamsundar, N. and E.M. Sparrow: "Analysis of Multidimensional Conduction Phase Change via the enthalpy Model," ASME J. Heat Transfer, Vol. 97, No. 4, (1975), pp. 333-340.

108. Shamsundar, N.: "Comparison of Numerical Methods for Diffusion Problems with Moving Boundaries," in Moving Boundary Problems, edited by D.G. Wilson, A.D. Soloman, and P.T. Boggs, Academic Press, (1978), p $165+$.

109. Sorelle, R.R., Jardiolin, R.A., Buckley, P., and Barrios, J.R.: "Mathematical Field Model Predicts Downhole Density Changes in Static Drilling Fluids," SPE Paper 11118, presented at the 57th Annual Fall Technical Conference and Exhibition of the Society of Petroleum Engineers of AIME held in New Orleans, LA, (Sept. 26-29, 1982).

110. Sparrow, E.M. and Ohkubo, Y.: "Numerical Analysis of Two-Dimensional Transient Freezing Including Solid-Phase and Tube-Wall Conduction and Liquid-Phase Natural Convection," Numerical Heat Transfer, Vol. 9, (1986), pp. 59-77.

111. Sparrow, E.M., Patankar, S.V. and Ramadhyani, S.: "Analysis of Melting in the Presence of Natural Convection in the Melt Region," Numerical Heat Transfer, Trans. ASME, Vol. 99, (Nov., 1977), pp. 520-526. 
112. Stefan, J.: "On the Theory of Ice Formation, Especially on Ice Formation in Polar Seas," (Über die Theorie der Eisbildung, insebesondere über dire Eisbildung im Polarmeere). Sitz. Akad. Wiss. Wien. Mat. Natur. (1890) 98 (2a), pp. 965-983.

113. Stewart, J.M. and J.S. Weaver: "Permafrost and Hydrates Under the Beaufort Sea," SPWLA Twenty-Fourth Annual Logging Symposium, held June 27-30, (1983).

114. Stiff, H.A.: "Interpolating or Extrapolating Drilling Fluid Viscosities to Reference Temperatures," Soc. Pet. Eng. J., (Oct., 1970).

115. Tao, L.N.: "A Method for Solving Moving Boundary Problems," SIAM J. Appl. Math., Vol. 46, No. 2, (April, 1986), pp. 254-264.

116. Thompson, M. and Burgess, T.M.: "The Prediction of Interpretation of Downhole Mud Temperature While Drilling," SPE Paper 14180, presented at the SPE 60th Annual Technical Conference and Exhibition, Las Vegas, NV, (Sept. 22-25, 1985).

117. Tokuda, N.: "An Asymptotic, Large Time Solution of the Convection Stefan Problem with Surface Radiation," Int. J. Heat Mass Transfer, Vol. 29, No. 1. (1986), pp. 135-143.

118. Tragesser, A.F., Crawford, P.B. and Crawford, H.R.: "A Method for Calculating Circulating Temperatures," Jour. Pet. Tech., (Nov., 1967), pp. 1507-1512.

119. Trupp, A.C.: "The Numerical Finite-Difference Approach to Heat and Mass Difiusion Problems," paper presented at the First Western Canadian Heat Transfer Conference, Saskatoon, Saskatchewan, (Sept. 6, 1966).

120. Udell, K.S.: "Heat Transfer in Porous Media Considering Phase Change and Capillarity - the Heat Pipe Effect," Int. J. Heat Mass Transfer, Pergamon Press, Vol. 28, No. 2, (1985), pp. 485-495. 
121. Varga, R.S.: Matrix Iterative Analysis, Prentice Hall, Inc., Englewood Cliffs, NJ, (1962).

121. Voller, V.R. and M. Cross: "Use of the Enthalpy Method in the Solution of Stefan Problems," in Numerical Methods in Thermal Problems - Proceedings of the Third International Conference held in Seattle, WA, August 2-5, 1983, eds. Lewis, R.W., Johnson, J. A. and Smith, W.R., Pineridge Press, Swansea, U.K. (1983).

122. von Rosenberg, D.U.: Methods for the Numerical Solution of Partial Differential Equations, Publishing Division Gerald L. Farrar \& Associates, Inc., Tulsa, OK, (1977).

123. White, R.E.: "A Nonlinear Parallel Algorithm with Application to the Stefan Problem," Siam. J. Numer. Anal., Vol. 23, No. 3, (June, 1986), pp. 639-652.

124. Wilson, G.D., Solomon, A.D. and Boggs, P.T., eds.: Moving Boundzry Problems, Academic Press, (1978).

125. Wooley, G.R.: "Computing Downhole Temperatures in Circulation, Injection, and Production Wells," J.Pet. Tech., (Sept., 1980), pp. 1509-1522.

126. Yeh, L.T. and Chung, B.T.F.: " Solidification and Melting of Material Subjected to Convection and Radiation," J. Spacecr. Rockets, Vol. 12, (1975), pp. 329-334.

127. Yortsos, Y.C. and Gavalas, G.R.: "Heat Transfer Ahead of Moving Condensation Fronts in Thermal Oil Recovery Processes," Int. 1. Heat Mass Transfer, Vol. 25, No. 3, (1982), pp. 305-316. 


\section{CHAPTER NINE}

\section{DEVELOPMENT OF A FINITE ELEMENT MODEL TO SIMULATE THE DISSOCIATION OF NATURAL GAS HYDRATES IN POROUS MEDIA BY HOT FLUID INJECTION}

\subsection{Introduction}

A finite element scheme has been formulated to model the dissociation of gas hydrates in porous media by hot water injection. The finite element formulation is capable of conducting transient analysis of both conductive and convective heat transfer for two phase fluid flow in porous media and includes the latent heat effects from the hydrate phase change.

The finite element model was validated against analytical solutions for conductive and convective heat transfer, single and two-phase flow in porous media, and approximate analytical solutions for melting problems. Analytical solutions, experimental and field data for the hydrate recovery scheme are not available, thus restricting the ability to fully validate the formulation.

Any production scenario for the recovery of natural gas from hydrates with the exception of mining the hydrate sediments requires that the hydrates be dissociated in-situ. Hydrate phase behavior indicates that the hydrates can either be dissociated by reduction of pressure, increase in temperature, or injection of a hydrate inhibitor. Among the proposed gas recovery schemes from hydrates is the cyclic injection of a hot fluid such as brine, steam or hot water.

The thermal efficiency of gas recovery from hydrates for a cyclic steam injection scheme and a cyclic hot brine injection scheme was investigated by Kamath and Godbole (1987). They conducted simulation studies for the two recovery schemes with heat losses in the wellbore and to the overburden determined by analytical equations, and considered an energy balance approach for the sensible and latent heat requirements to dissociate the hydrates in the porous media. No treatment to that of convective heat transport within the dissociated portion of the nydrate 
reservoir was considered in the simulations. Results from the simulation runs indicated that the hot brine injection scheme was more energy efficient than the steam injection scheme.

Finite difference and finite element models have been developed to solve hydrate thawing in radial reservoir geometry (Roadifer, 1988 and Srivastava, 1988). These models treat the dissociation process as a moving boundary or Stefan type of problem where only conductive heat transfer is considered without treatment of the convective aspects of the thermal process.

During hot water injection into a reservoir the predominant heat transfer mechanism is convective heat transport, or heat transported by bulk fluid movement within the reservoir. Numerical models are available to solve hydrate dissociation problems considering only conductive heat transfer with a moving phase change boundary. The goal of this work was to advance the available conductive numerical models to include convective heat transfer for a two-phase (gas/water) system to more accurately simulate thermal recovery of gas from natural gas hydrates. To achieve this objective two specific features were added to the numerical model, namely, the ability to simulate convective heat transfer in porous media, and the ability to simulate two-phase immiscible fluid flow in porous media.

The improved numerical model of this study was developed by the finite element method, with the element equations formulated from the governing differential equations through either Galerkin method of weighted residuals or upwind element approach. Validation was conducted for the finite element scheme by comparing simulation runs to available analytical solutions for simple radial conduction and convection, radial thawing, and radial single-phase flow problems. Additional validation runs were conducted to the Buckley-Leverett, two-phase immiscible displacement solution for a radial geometry. Lack of field data for the 
hydrate thermal recovery scheme made it impossible to validate the complete simulation scheme of the thermal recovery process.

A limited amount of work has been conducted in the application of finite element analysis to modeling the hydrate dissociation process; however, a great deal of research has been conducted in areas that share many similarities with this problem. Applicable finite element work has been conducted in solving immiscible displacement problems (Dalen 1976 and 1979), and convective dispersion problems (Zyvoloski 1983, and Huyakorn 1976).

Finite element schemes for solutions of two-phase immiscible flow through porous media and for convective heat transport are plagued by many numerical difficulties. The numerical difficulties commonly encountered are severe oscillations in the neighborhood of sharp fronts, instability or inability to get converged solutions, and excessive computational effort to generate and solve large unsymmetric coefficient matrices. The numerical difficulties stem from the highly nonlinear nature of the equations describing this class of problems as well as the hyperbolic characteristics of the two-phase flow and energy transport equations when capillary forces are negligible and when convective heat transport is dominant.

Researcheis have addressed these problems in work on many subsurface immiscible flow problems. In particular, these numerical difficulties are encountered in 2-phase immiscible displacement phenomena typical of petroleum reservoir enhanced oil recovery processes, and in 2-phase geothermal problems. The usual approach to deal with the oscillations and stability difficulties is to apply an upstream mobility weighting scheme and to diagonalize or lump the mass matrix. As the traditional linear shape function of Galerkin method failed to make the scheme converge, a new upwind shape function has been used. This new scheme togehter with proper lumping scheme and damping factors significantly improved 
the convergence. However in many cases, the convergence was still a problem. To reduce computational time, a solution scheme can be formulated that results in symmetric coefficient matrices as well as puts the final matrix equation in a more desirable form where more efficient matrix solvers can be utilized.

\subsection{Development of Model}

\subsubsection{Reservoir Geometry}

Figure 9.1 represents the simplified geometry of a typical hydrate reservoir. As shown in Figure 9.1 the hydrate reservoir is divided into four zones. Hydrates are considered to be made up of gas and water in equilibrium proportion and the formation rock or sediments are assumed to be permeable in the dissociated zone. The dissociated zone is assur.ied to be saturated with a combination of two mobile fluids, namely gas and water. The hydrate zone, or frozen region, is where water and natural gas are in the solid hydrate form. The rock matrix in the hydrate zone is the same as in the dissociated zone, however the hydrates are assumed to fill the entire pore space and therefore this zone has effectively very low permeability to fluid movement. The remaining two zones, the overburden and underburden, are assumed to be impermeable.

The interface between the dissociated zone and the hydrate zone is the thaw front. Given the injection of hot fluid into the reservoir or just a temperature increase at the wellbore, the thaw front propagates outward, increasing the volume of the dissociated zone at the expense of the hydrate zorie.

The inner boundary of dissociated zone is the well face of the injection well where the fluid flux and most of the heat flux is introduced or removed from the system. Along this face there are a wide range of boundary 


\section{upper boundery}

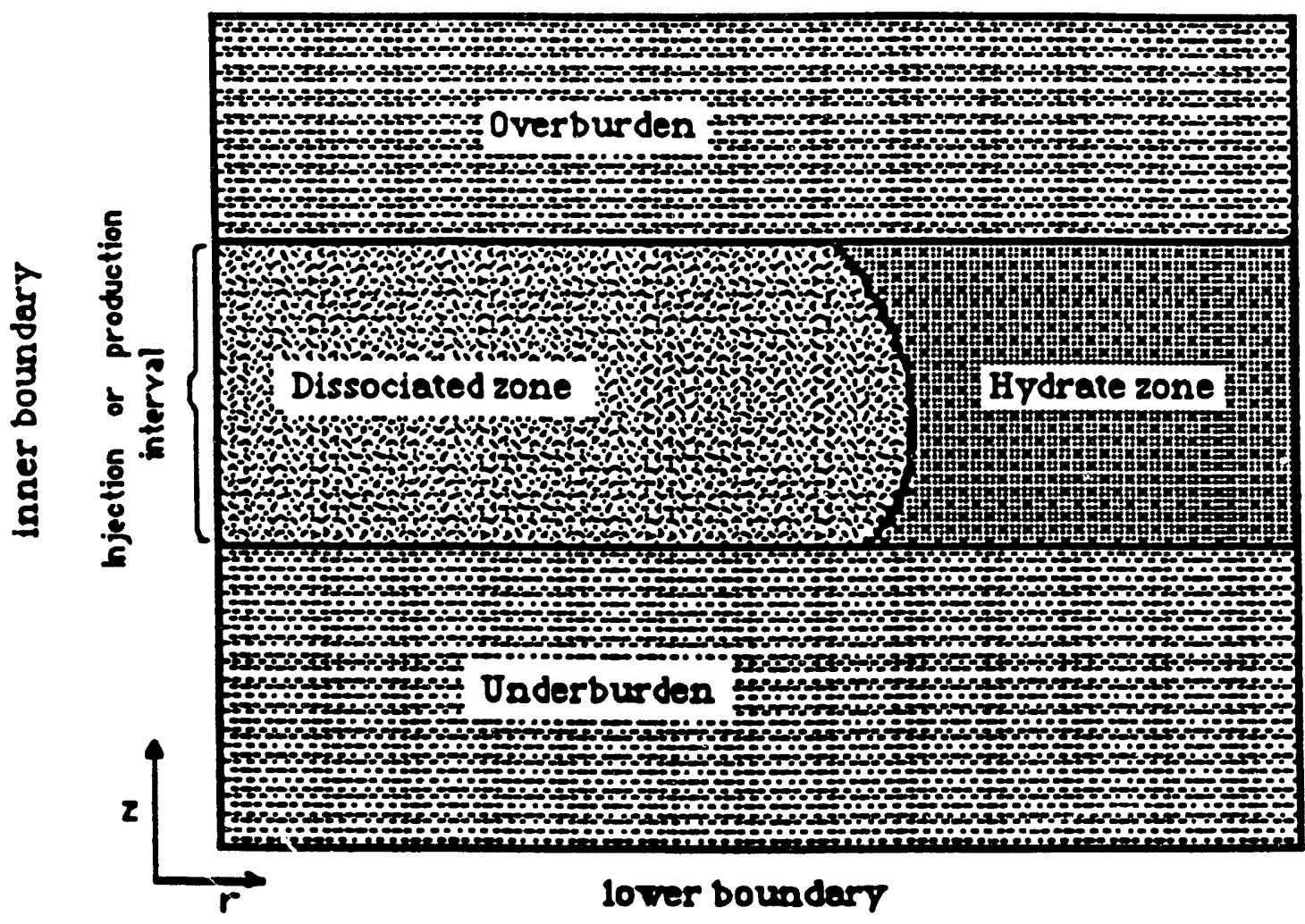

Figure 9.1: Model Hydrate Reservoir Geometry 
conditions that may be imposed depending on whether it is desired to specify flux (heat or fluid), or primary variables such as pressure or temperature. The inner boundary of the overburden and underburden zones are considered to be a zero fluid flux boundary, with temperatures specified.

The outer boundary is located at the limit of the reservoir or at a distance that is great enough to represent an infinite system. Generally this boundary is described by the primary variables of pressure and temperature specified.

The upper and lower boundary is considered to be at an infinite distance from the hydrate reservoir and can be assumed to be an insulated boundary. These are considered to be natural boundary conditions where heat and fluid flux are zero.

The initial conditions are considered to be original reservoir pressures, temperatures and saturations. It is possible to consider situations such as hydrate zone overlying a free gas zone, or only hydrate zone or partially dissociated hydrate zone at the beginning.

\subsubsection{Recovery Process}

The recovery process considered in this study is a cyclic thermal recovery scheme that consists of an injection, a soak and a production phase. The injection phase includes the injection of hot water into the dissociated zone of the reservoir. The soak phase entails shutting in the well to allow for the injected fluid to thaw a portion of the hydrate. The third and final phase is the production phase where the well is opened up to produce the fluids from the reservoir. All three phases can be classified as transient heat transfer problems with transient two-phase immiscible fluid flow in the dissociated zone.

The finite element model is designed to model all three phases of the cyclic recovery process. The full cycle simulation is accomplished by changing 
the boundary conditions at the well face. For the injection phase the injection temperature and injection pressure is specified at the well face. For the soak phase the well face is treated as a zero fluid flow, heat insulated boundary. For the production phase the bottom hole pressure is specified and then the water flux is calculated and added as nonlinear natural boundary condition to the model.

\subsubsection{Mathematical Formulation}

In the development of the mathematical model, certain assumptions were made to simplify the governing differential equations to a more manageable form. These assumptions are stated throughout the following mathematical derivation of the proposed finite element scheme.

\subsubsection{Governing Differential Equations}

For a confined reservoir containing water and gas, immiscible fluid flow in porous media is described by the following set of differential equations (Eqs 9.1 and 9.2). These two equations are the continuity of mass equations for water and gas respectively (Huyakorn and Pinder 1983).

$$
\begin{aligned}
& \frac{\partial\left(\phi S_{w \rho_{w^{\prime}}}\right.}{\alpha}+\frac{\partial}{\partial x_{i}}\left|\rho_{w_{i}}{ }^{\omega}\right|=Q_{w} \\
& \frac{\partial\left(\phi S_{g} \rho_{g}\right)}{\partial t}+\frac{\partial}{\partial x_{i}}\left|\rho_{g} u_{i}^{g}\right|=Q_{g}
\end{aligned}
$$


where:

$$
\begin{aligned}
& S=\text { saturation } \rho=\text { density } \\
& v=\text { velocity } t=t^{2}= \\
& Q=\text { source or sink } \Phi=\text { porosity }
\end{aligned}
$$

where the subscripts $w, g$ refer to water and gas respectivelly.

The fluid momentum equation for flow in porous media is given by Darcy's Law (from Huyakorn and Pinder 1983):

$$
v_{i}^{a}=-\frac{k_{r}^{a} k_{i j}}{\mu_{a}}\left(\frac{\partial P_{a}}{\partial x_{j}}+\rho_{a} g_{j}\right) \quad a=w, b
$$

where:

$$
\begin{array}{ll}
k=\text { absolute permeability } & k_{r}=\text { relative permeability } \\
\mu=\text { viscosity } & P=\text { pressure }
\end{array}
$$

$$
g_{j}=g \frac{d z}{2 x}
$$

$z=$ height above given datum

g $=$ gravitational constant

It should be pointed out that Darcy's La'N is only valid for laminar flow, which is usually a reasonable assumption for flow in porous media except in certain instances of very high velocities often encountered near the wellbore.

Substituting Darcy's Law into continuity equations (Eqs 9.1 and 9.2). neglecting the source terms and assuming that capillary forces are negligible gives: 


$$
\begin{aligned}
& \frac{\partial\left(\phi S_{w} \rho_{w}\right)}{\partial t}-\frac{\partial}{\partial x_{i}}\left|\tau_{i j}^{w}\left\{\frac{\partial P}{\partial x_{j}}+\rho_{w} g_{j}\right\}\right|=Q_{w} \\
& \left.\frac{\partial\left(\phi S_{g} \rho_{g}\right)}{\partial t}-\frac{\partial}{\partial x_{i}}\left|r_{i j}^{g}\right| \frac{\partial P}{\partial x_{j}}+\rho_{g} g_{j}\right\} \mid=Q_{g}
\end{aligned}
$$

where:

$$
\tau_{i j}^{a}=\frac{\rho_{a} k_{r}^{a} k_{i j}}{\mu_{a}} \quad a=w, g
$$

Assume that water is incompressible, and Eq (9.4) becomes:

$$
\phi P_{w} \frac{\partial S w}{\partial t}-\frac{\partial}{\partial x_{i}}\left(t_{i j}^{w} \frac{\partial P}{\partial x_{j}}\right)-\frac{\partial}{\partial x_{i}}\left(G W_{i}\right)=Q_{w}
$$

where:

$$
G W_{i}=g_{j} \rho_{w} \tau_{i j}^{w}
$$

Using the relation $S g=1-S w$ the gas continuity equation becomes:

$$
\Phi(1-S w) \frac{\partial p_{g}}{\partial t}-\phi p_{g} \frac{\partial S w}{\partial t}-\frac{\partial}{\partial x_{i}}\left(t_{i j}^{g} \frac{\partial P}{\partial x_{j}}\right)-\frac{\partial}{\partial x_{i}}\left(G G_{i}\right)=Q_{g}
$$

where:

$$
G G_{i}=g_{j} p_{B} r_{i j}^{g}
$$

Expanding $\partial \rho_{g} / \partial t$ assuming that $\rho_{g}=\rho_{g}(T, P)$, Eq (9.7) becomes:

$\phi(1-S w)\left|\frac{\partial p_{g}}{\partial T} \frac{\partial T}{\partial t}+\frac{\partial \rho_{g}}{\partial P} \frac{\partial P}{\partial t}\right|-\phi \rho_{g} \frac{\partial S_{w}}{\partial t}-\frac{\partial}{\partial x_{i}}\left(x_{i j} \frac{\partial P}{\partial x_{j}}\right)-\frac{\partial}{\partial x_{i}}\left(G G_{i}\right)=Q_{g}$

Define: 


$$
\beta \equiv \phi(1-S w) \frac{\partial \rho_{g}}{\partial T}, \quad Y \equiv \phi(1-S w) \frac{\partial \rho_{g}}{\partial T}, \quad \text { and } \varepsilon \equiv \phi \rho_{g}
$$

to simplify Eq (9.8) to:

$$
\beta \frac{\partial T}{\partial t}+y \frac{\partial P}{\partial t}-\varepsilon \frac{\partial S w}{\partial l}-\frac{\partial}{\partial x_{i}}\left(r_{i j}^{g} \frac{\partial P}{\partial x_{j}}\right)-\frac{\partial}{\partial x_{i}}\left(G G_{i}\right)=Q_{g}
$$

The differential equation describing energy transport in porous media is given by (from Prats 1986):

$$
\begin{gathered}
\Phi\left|\frac{\partial\left(S_{w} \rho_{w} C_{p w} \Delta T\right)}{\partial t}+\frac{\partial\left(S_{g} \rho_{g} C_{p g} \Delta T\right)}{\partial t}+\frac{\partial\left(S_{H} \rho_{H} C_{p H} \Delta T\right)}{\partial t}\right| \\
+(1-\phi) \rho C_{p r} \frac{\partial T}{\partial t}+\frac{\partial}{\partial x_{i}}\left[\rho_{w} C_{p w} \Delta T V_{i}^{\omega}\right] \\
\left.+\frac{\partial}{\partial x_{i}} \mid \rho_{w} C_{p g} \Delta T V_{i}^{g}\right]-\frac{\partial}{\partial x_{i}}\left|K_{i j} \frac{\partial T}{\partial x_{j}}\right|=0
\end{gathered}
$$

where:

$$
\begin{aligned}
& C_{p}=\text { isobaric specific heat } \\
& \Delta T=\left(T-T_{p}\right) \text { where } T_{r} \text { is the reference temperature } \\
& V=\text { Darcy velocity } \\
& K_{i j}=\text { thermal dispersion tensor which is equal to thermal } \\
& \text { conductivity if mechanical dispersion and molecular } \\
& \text { diffusion are neglected }
\end{aligned}
$$

and the $H$ subscript indicates hydrate.

Because derivatives of $\Delta T$ are equivalent to derivatives of $T, \Delta T$ will be replaced with $T$ in all following differential equations. 
To put the energy equation in a simpler form the following variables are defined:

$$
H=(1-\phi) \rho_{r} C_{p r} T+\phi\left(S_{w} \rho_{w} C_{p w} T+S_{B} \rho_{g} C_{p g} T\right)+\phi\left(S_{H} \rho_{H} C_{p l l} T\right)
$$

$$
I_{i}=\rho_{w} C_{p w} T V_{i}^{\omega}+\rho_{g} C_{p g} T V_{i}^{g}
$$

Substitution using the above relations simplifies the energy equation to:

$$
\frac{\partial H}{\partial t}+\frac{\partial I_{i}}{\partial x_{i}}-K_{i j} \frac{\partial^{2} T}{\partial x_{i}^{2}}=0
$$

\subsubsection{Finite Element Formulation}

The finite element method has been formulated from the three governing differential equations (9.6), (9.9) and (9.13). The finite element equations were formulated by the method of weighted residuals. A discussion of the weighted residuals method is given by Huyakorn (1979, 1983).

For finite element analysis, Huyakorn (1983) gave a detailed discussion. Consider the operator equation:

$$
A(u)=f \quad \text { in } \Omega
$$

where $A$ is the differential operator and $f$ is a known function of independent variables.

The solution of Eq. (9.14) is approximated by a trial function of the form: 


$$
u=\hat{U}=\sum_{j=1}^{n} N_{j} C_{j}
$$

where $N_{j}$ are piecewise basis functions and $C_{j}$ are the unknown nodal parameters and $n$ indicates the number of nodes on the element. Because $\hat{U}$ is an approximation of $u$, it will probably not satisfy the differential equation exactly so that substitution into Eq. (9.14) will result an error:

$$
\varepsilon=A(\hat{U})-f
$$

The method of weighted residuals is applied to minimize the error or residual $\varepsilon$ over the domain by weighting $\varepsilon$, integrating it over the solution domain, and setting the integral equation equal to zero.

$$
\int_{R} W_{l} \varepsilon d R=\int_{R} W_{l}(A(\hat{U})-f) d R=0 \quad l=1,2, \ldots, n
$$

where $W_{l}$ is the linear independent weighting function. Here the weighting functions proposed by Huyakorn (1979) are adopted:

$$
\begin{gathered}
w_{i}=L_{i}+3\left(a_{j} L_{k} L_{i}-a_{k} L_{j} L_{i}\right) \\
i=1,2,3, \quad j=2,3,1, \quad k=3,1,2 \text { respectively }
\end{gathered}
$$

where:

W: weighting functions.

$L: \quad(N)$ linear aera coordinates or shape functions of an element.

a: damping factors. 
more information about the damping factors can be found in Appendix 1. Obviously, when $a_{i}=0, w_{l}=N_{l}$, the following method becomes the Galerkin method.

Substitution of the trial function into the above equation results in a set of simultaneous equations where the unknown parameters, $C_{j}$, can then be determined. So the weighted residual method determines the parameters $C_{j}$ that will minimize the residual $\varepsilon$ over the solution domain considered.

For the particular problem investigated in this work, the dependnet variables are temperature, pressure, and water saturation. The dependent variables are approximated by the trial functions:

$$
\begin{aligned}
& T\left(X_{i}, l\right) \approx \hat{T}\left(X_{i}, \imath\right)=T_{j}(l) N_{j}\left(X_{i}\right) \quad j=1,2, \ldots, n e \\
& P\left(X_{i}, t\right) \approx \hat{P}\left(X_{i}, t\right)=P_{j}(t) N_{j}\left(X_{i}\right) \quad j=1,2, \ldots, n e \\
& S_{\omega}\left(X_{i}, t\right) \approx \hat{S}_{\omega}\left(X_{i}, t\right)=S_{\omega j}(t) N_{j}\left(X_{i}\right) \quad j=1,2, \ldots, n e
\end{aligned}
$$

where $N_{j}\left(X_{i}\right)$ is the appropriate shape function and ne is nodes per element. Other variables interpolated elementwise over the domain with the same shape functions are:

$$
G W\left(X_{i}, \imath\right) \approx \hat{G W}\left(X_{i}, \imath\right)=G W,(\ell) N_{j}\left(X_{i}\right) \quad j=1, \ldots, n e
$$




$$
G G\left(X_{i}, l\right)=\widehat{G G}\left(X_{i}, t\right)=G G_{j}(t) N_{j}\left(X_{i}\right) \quad j=1, \ldots, n e
$$

The water continuity equation (Eq. 9.6) in $r-z$ coordinates is (neglecting the source term, it will be treated separately)

$$
\Phi \rho_{w} \frac{\partial S_{w}}{\partial t}-\frac{1}{r} \frac{\partial}{\partial r}\left|r r_{r}^{w} \frac{\partial P}{\partial r}\right|-\frac{\partial}{\partial z}\left(\tau_{z}^{w} \frac{\partial P}{\partial Z}\right)-\frac{\partial}{\partial Z}\left(G W_{Z}\right)=0
$$

Note that $G W_{r}=0$ if the coordinate axis is asssumed to be aligned so that $g_{r}=0$ and $g_{z}=g$.

Manipulating Eq. (9.24) and applying the weighted residual scheme:

$$
\sum_{e} \int_{R e} W_{l}\left\{\frac{1}{r} \frac{\partial}{\partial r}\left|r \tau_{r}^{w} \frac{\partial P}{\partial r}\right|+\frac{\partial}{\partial Z}\left|{ }^{w} \frac{\partial P}{\partial Z}\right|+\frac{\partial G W_{Z}}{\partial Z}-\phi \rho_{w} \frac{\partial S_{w}}{\partial t}\right\} d R=0 \quad I=1,2, \ldots, n
$$

Applying the Green theorem to second-derivative terms, and to $G W$ term the equation becomes:

$$
\begin{aligned}
& \sum_{e}\left|-\int_{R=}\right| \tau_{r}^{\omega} \frac{\partial W_{l}}{\partial r} \frac{\partial P_{j}}{\partial r}+\iota_{z}^{w} \frac{\partial W_{I}}{\partial Z} \frac{\partial P_{j}}{\partial Z} \mid r d r d z-\int_{R e} \frac{\partial W_{I}}{\partial Z} \hat{G W}_{Z} r d r d z-\int_{R e} W_{I} \phi \rho_{w} \frac{\hat{\partial S}_{\omega}}{\partial t} \\
& r d r d z+\int_{B e}{ }_{t}^{w} W_{1} \frac{\partial P}{\partial r} n_{r} r d l+\int_{B e} W_{I}\left\{\frac{w_{z}^{\omega}}{\partial P} \frac{\hat{P}}{\partial Z}+G W_{z}\right\} n_{z} r d l \mid=0
\end{aligned}
$$

Substituting variables into Eq.(9.26) and applying finite difference in time gives: 


$$
\begin{aligned}
& \sum_{e} \mid-\int_{R e} P_{j}^{\left(k+\theta_{1}\right)}\left(\tau_{r}^{w} \frac{\partial W_{l}}{\partial r} \frac{\partial N_{j}}{\partial r}+\tau_{z}^{w} \frac{\partial W_{l}}{\partial Z} \frac{\partial N_{j}}{\partial Z}\right) r d r d z-\int_{R e} G W_{j}^{k+\theta} \frac{\partial W_{l}}{\partial Z} N_{j} r d r d z \\
& -\phi \rho_{w} \int_{R e} W_{l} N_{j} \frac{S_{w j}^{(k+1)}-S_{w j}^{(k)}}{\Delta t} r d r d z+\int_{B e}{ }^{{ }^{t}{ }_{r} W_{I}} \frac{\hat{\partial P}}{\partial r} n_{r} r d l+ \\
& \int_{B e} W_{I}\left|\mathrm{c}_{z}{ }^{\omega} \frac{\partial P}{\partial Z}+G W_{z}\right| n_{z} r d l \mid=0 \quad I=1,2, \ldots, n
\end{aligned}
$$

In Eq. (9.27), the superscripts $(k+1)$ and $(k)$ indicate new and old time levels respectively and $\theta$ is the time weighting factor, $0 \leqq \theta \cong 1$, with the superscript $(k+\theta)$ indicating the time marching scheme. For example: $P_{j}(k+\theta)=(1-\theta) P_{j}(k)+\theta P_{j}(k+1)$. A fully implicit finite difference scheme in time is given by $\theta=1$. For Crank-Nicolson marching scheme, $\theta=0.5$. In the same way, the gas continuity equation (Eq. 9.9) in $r-z$ coordinates is:

$$
-\frac{1}{r} \frac{\partial}{\partial r}\left|r r_{r}^{g} \frac{\partial P}{\partial r}\right|-\frac{\partial}{\partial Z}\left(r_{z}^{g} \frac{\partial P}{\partial Z}\right)-\frac{\partial}{\partial Z}\left(G G_{z}\right)+\beta \frac{\partial T}{\partial t}+y \frac{\partial P}{\partial t}-\varepsilon \frac{\partial S_{w}}{\partial t}=0
$$

Multiply Eq. (9.28) by $(-1)$ and apply the weighted residual scheme:

$$
\begin{gathered}
\sum\left|\int_{R e} W_{l}\right| \frac{1}{r} \frac{\partial}{\partial r}\left|r r_{r}^{g} \frac{\hat{\partial P}}{\partial r}\right| r d r d z+\frac{\partial}{\partial Z}\left(r_{z}^{g} \frac{\partial P}{\partial Z}\right)+\frac{\partial}{\partial Z}\left(\hat{G G}_{Z}\right) \mid r d r d z- \\
\int W_{l}\left|\beta \frac{\partial \hat{T}_{j}}{\partial t}+y \frac{\hat{P}_{j}}{\partial t}-\varepsilon \frac{\hat{S}_{w j}}{\partial t}\right| r d r d z=0 \quad I=1,2, \ldots, n e
\end{gathered}
$$

Applying divergence theorem to second-derivative and to $G G$ term: 


$$
\begin{aligned}
& \sum_{e}\left|-\int_{R e}\right| \mathfrak{r}_{r}^{g} \frac{\partial W_{1}}{\partial r} \frac{\hat{\partial P}_{j}}{\partial r}+\mathfrak{r}_{2}^{g} \frac{\partial W_{l}}{\partial Z} \frac{\hat{P P}_{j}}{\partial Z} \mid r d r d z-\int_{R e} \frac{\partial W_{l}}{\partial Z} \hat{G G}_{z} r d r d z \\
& -\int_{R e} W_{l}\left\{\beta \frac{\partial \hat{T}_{j}}{\partial t}+\chi \frac{\partial \hat{P}_{j}}{\partial t}-\varepsilon \frac{\partial \hat{S}_{w j}}{\partial t}\right\} r d r d z+\int_{B e} r r_{r}^{g} W_{l} \frac{\partial P}{\partial Z} n_{r} r d l \\
& +\int_{B e} N_{I}\left\{t_{z}^{g} \frac{\hat{\partial P}}{\partial Z}+\widehat{G G_{z}}\right\} n_{Z} r d l \mid=0 \quad I=1,2, \ldots, n
\end{aligned}
$$

Substitution of variables into Eq. (9.30) and finite difference in time gives:

$$
\begin{aligned}
& \left.\sum_{e}\left|-\int_{R e} P_{j}^{(k+\theta)}\right|\right|_{r} ^{g} \frac{\partial W_{I}}{\partial r} \frac{\partial N_{j}}{\partial r}+\tau_{Z}^{g} \frac{\partial W_{I}}{\partial Z} \frac{\partial N_{j}}{\partial Z} \mid r d r d z-\int_{R e} W_{l} N_{J} \\
& \left\{\beta \frac{T_{j}^{(k+1)}-T_{j}^{(k)}}{\Delta t}+\chi \frac{P_{j}^{(k+1)}-P_{j}^{(k)}}{\Delta t}-\varepsilon \frac{S_{w j}^{(k+1)}-S_{w j}^{(k)}}{\Delta t}\right\} r d r d z \\
& -\int_{R e} G G_{j}^{(k+\theta)} \frac{\partial W_{l}}{\partial Z} N_{j} r d r d z+\int_{B e}{ }_{r}^{\tau_{r}^{w}} W_{l} \frac{\partial}{\partial P} n_{r} r d l+ \\
& \int_{B e} W_{1}\left\{r_{B}^{g} \frac{\hat{\partial P}}{\partial Z}+\widehat{G G}{ }_{2}\right\} n_{2} r d l \mid=0 \quad I=1, \ldots, n \quad j=1, \ldots, n e
\end{aligned}
$$

In applying the finite element method to the energy equation, $H$ and $I$ are interpolated elementwise over the domain:

$$
\begin{gathered}
H\left(x_{i}, t\right) \approx \hat{H}\left(x_{i}, t\right)=H_{j}(t) N_{j}\left(X_{i}\right) \\
I\left(X_{i}, t\right) \approx \hat{I}\left(x_{i}, t\right)=I_{j}(t) N_{j}\left(X_{i}\right)
\end{gathered}
$$

The energy equation (Eq. 9.13) in $r-z$ coordinates is given by: 


$$
\frac{\partial H}{\partial t}+\frac{\partial I_{r}}{\partial r}+\frac{\partial I_{2}}{\partial Z}-k_{r} \frac{1}{r} \frac{\partial}{\partial r}\left|r \frac{\partial T}{\partial r}\right|-k_{z} \frac{\partial^{2} T}{\partial Z^{2}}=0
$$

The weighted residual scheme for the energy equation gives:

$$
\begin{gathered}
\sum_{e}\left|-\int_{R e} W_{1} k_{r} \frac{1}{r} \frac{\partial}{\partial r}\right| r \frac{\partial \hat{T}}{\partial r} \mid r d r d z-\int_{R e} W_{I} k_{2} \frac{\partial^{2} \hat{T}}{\partial Z^{2}} r d r d z+\int_{R e} W_{1} \frac{\partial \hat{I}}{\partial r} r d r d z \\
+\int_{R e} W_{1} \frac{\partial \hat{I}_{2}}{\partial Z} r d r d z \mid=0 \quad I=1,2, \ldots, n
\end{gathered}
$$

Applying the divergence theorem to second derivative term:

$$
\begin{gathered}
\sum_{e} \mid \int_{R e}\left(k_{r} \frac{\partial W_{l}}{\partial r} \frac{\partial \hat{T}_{j}}{\partial r}+k_{2} \frac{\partial W_{l}}{\partial Z} \frac{\hat{\partial T}}{\partial Z}\right) r d r d z+\int_{R e} W_{I} \frac{\hat{\partial I}_{r}}{\partial r} r d r d z+\int_{R e} W_{l} \frac{\partial \hat{I}_{z}}{\partial Z} r d r d z \\
+\int_{R e} W_{I} \frac{\hat{\partial H_{J}}}{\partial t} r d r d z-\int_{R e} W_{l} k_{r} \frac{\partial \hat{T}}{\partial Z} r d l \mid=0 \quad I=1,2, \ldots, n
\end{gathered}
$$

Substitution of variables into Eq. (9.36) and finite differencing in time gives:

$$
\begin{aligned}
& \sum_{e} \mid T_{j}^{(k+\theta)} \int_{R e}\left(k_{r}^{(k+\theta)} \frac{\partial W_{l}}{\partial r} \frac{\partial N_{j}}{\partial r}+\frac{\partial W_{l}}{\partial Z} \frac{\partial N_{j}}{\partial Z} k_{z}^{(k+\theta)}\right) r d r d z+ \\
&+I_{r}^{(k+\theta)} \int_{R e} W_{l} \frac{\partial N_{l}}{\partial r} r d r d z+I_{z}^{(k+\theta)} \int_{R e} W_{I} \frac{\partial N_{j}}{\partial Z} r d r d z+\int_{R e} W_{I} N_{j} \frac{H_{j}^{(k+1)}-H_{j}^{(k)}}{\Delta t} r d r d z \\
&\left.-\int_{B e} W_{l}{ }_{r} \frac{\partial T}{\partial r} N_{r} r d l-\int_{B e} W_{I} k_{B} \frac{\partial T}{\partial z} N_{z} r d l\right]=0 \quad I=1,2, \ldots, n
\end{aligned}
$$


The three nonlinear algebraic equations given by Eqs. (9.27), (9.31), and (9.37) are used to define three residuals:

\section{Water Continuity Residual Equation:}

$$
\begin{aligned}
& A_{l}=\sum_{e} \mid-P_{j}^{(k+1)} \int_{R e}\left(\tau_{r}^{\omega} \frac{\partial W_{l}}{\partial r} \frac{\partial N_{j}}{\partial r}+\iota_{L}^{\omega} \frac{\partial W_{l}}{\partial Z} \frac{\partial N_{j}}{\partial Z}\right) r d r d z-\int_{R e} G W_{J}^{(k+\theta)} \frac{\partial W_{l}}{\partial Z} N_{J} r d r d z \\
& -\phi \rho_{w} \int_{R e} W_{l} N_{j} \frac{S_{\omega j}^{(k+1)}-S_{\omega j}^{(k)}}{\Delta l} r d r d z+\int_{B e}{ }^{t_{r}^{w} W_{l}} \frac{\hat{\partial P}}{\partial r} n_{r} r d l \\
& +\int_{B e} W_{l}\left|{ }_{L}{ }_{2} \frac{\partial P}{\partial Z}+\hat{G W}_{Z}\right| N, r d l \mid=0 \quad I=1,2, \ldots, n
\end{aligned}
$$

\section{Gas Continuity Residual Equation:}

$$
\begin{aligned}
B_{l}= & \sum_{e}\left|-\int_{R e} P_{j}^{(k+\theta)}\right| r_{r}^{g} \frac{\partial W_{l}}{\partial r} \frac{\partial N_{J}}{\partial r}+\left.t_{z}^{g} \frac{\partial W_{I}}{\partial Z} \frac{\partial N_{j}}{\partial Z}\right|_{r d r d z}-\int_{R e} W_{l} N_{J} \mid \beta \frac{T_{j}^{(k+1)}-T_{j}^{(k)}}{\Delta l} \\
& \left.+y \frac{P_{j}^{(k+1)}-P_{j}^{(k)}}{\Delta t}-\varepsilon \frac{S_{w j}^{(k+1)}-S_{w j}^{(k)}}{\Delta t}\right\} r d r d z-\int_{R e} G G_{j}^{(k+\theta)} \frac{\partial W_{l}}{\partial Z} N_{j} r d r d z \\
& +\int_{B e} t_{r}^{w} W_{l} \frac{\partial P}{\partial r} n_{r} r d l+\int_{B e} W_{I}\left\{t_{z}^{g} \frac{\partial P}{\partial Z}+\hat{G G_{Z}}\right\} n_{Z} r d l=0 \quad I=1,2, \ldots, n
\end{aligned}
$$




\section{Energy Continuity Equation:}

$$
\begin{gathered}
C_{l}=\sum_{e}\left|-T_{j}^{(k+\theta)} \int_{R e}\right| k_{r}^{(k+\theta)} \frac{\partial W_{l}}{\partial r} \frac{\partial N_{J}}{\partial r}+\frac{\partial W_{l}}{\partial Z} \frac{\partial N_{j}}{\partial Z} k_{z}^{(k+\theta)} \mid r d r d z- \\
I_{r}^{(k+\theta)} \int_{R e} W_{1} \frac{\partial N_{j}}{\partial r} r d r d z-I_{z}^{(k+\theta)} \int_{R e} W_{l} \frac{\partial N_{j}}{\partial z} r d r d z-\int_{R e} W_{l} N_{j} \frac{H_{j}^{(k+1)}-H_{j}^{(k)}}{\Delta l} r d r d z \\
+\int_{B e} W_{l} k_{r} \frac{\partial{ }^{\prime} T}{\partial r} n_{r} r d l+\int_{B e} W_{l} k_{z} \frac{\partial T}{\partial Z} n_{z} r d l
\end{gathered}
$$

\subsubsection{Newton-Raphson Iterative jolution Scheme}

The Newton-Raphson iteration method was used to solve the above nonlinear equations for the three dependent variables: $P, S_{\omega}$ and $T$. The Newton-Raphson scheme seeks to reduce the three residuals ( $A, B$ and $C$ ) to zero through the Taylor series expansion about a starting value of $A_{l}{ }^{r}$. $B_{I}{ }^{r}$ and $C_{l}{ }^{r}$, where $r$ is the iteration index. The Taylor series expansion about $A_{l}^{r}, B_{l}^{r}$ and $C_{l}{ }^{r}$ is given by:

$$
\begin{gathered}
A_{I}^{r+1}=A_{l}^{r}+\left.\frac{\partial A_{l}}{\partial S_{w j}}\right|_{r}\left(S_{\omega l}^{(r+1)}-S_{w l}^{(r)}\right)^{(k+1)}+\left.\frac{\partial A_{l}}{\partial P_{j}}\right|_{r}\left(P_{I}^{(r+1)}-P_{I}^{(r)}\right)^{(k+1)} \\
+\left.\frac{\partial A_{l}}{\partial T_{j}}\right|_{r}\left(T_{I}^{(r+1)}-T_{I}^{(r)}\right)^{(k+1)}=0
\end{gathered}
$$




$$
\begin{aligned}
& B_{I}^{(r+1)}=B_{l}^{(r)}+\left.\frac{\partial B_{l}}{\partial S_{\omega j}}\right|_{r}\left(S_{w l}^{(r+1)}-S_{\omega l}^{(r)}\right)^{(k+1)}+\left.\frac{\partial B_{I}}{\partial P_{j}}\right|_{r}\left(P_{I}^{(r+1)}-P_{I}^{(r)}\right)^{(k+1)} \\
& +\left.\frac{\partial B_{I}}{\partial T_{j}}\right|_{r}\left(T_{I}^{(r+1)}-T_{I}^{(r)}\right)^{(k+1)}=0 \\
& C_{I}^{(r+1)}=C_{I}^{(r)}+\left.\frac{\partial C_{I}}{\partial S_{\omega J}}\right|_{r}\left(S_{w I}^{(r+1)}-S_{w I}^{(r)}\right)^{(k+1)}+\left.\frac{\partial C_{I}}{\partial P_{j}}\right|_{r}\left(P_{I}^{(r+1)}-P_{I}^{(r)}\right)^{(k+1)} \\
& +\left.\frac{\partial C_{I}}{\partial r}\right|_{j}\left(T_{I}^{(r+1)}-T_{I}^{(r)}\right)^{(k+1)}=0
\end{aligned}
$$

The above Taylor series expansion in matrix form is given as:

$$
\left[\begin{array}{lll}
\frac{\partial A_{l}}{\partial S_{\omega j}} & \frac{\partial A_{l}}{\partial P_{j}} & \frac{\partial A_{l}}{\partial T_{j}} \\
\frac{\partial B_{l}}{\partial S_{\omega j}} & \frac{\partial B_{l}}{\partial P_{j}} & \frac{\partial B_{l}}{\partial T_{j}} \\
\frac{\partial C_{l}}{\partial S_{\omega j}} & \frac{\partial C_{l}}{\partial P_{j}} & \frac{\partial C_{l}}{\partial T}
\end{array}\right]\left[\begin{array}{l}
\Delta S_{\omega j}^{(k+1)} \\
\Delta P_{j}^{(k+1)} \\
\Delta T_{j}^{(k+1)}
\end{array}\right]=-\left[\begin{array}{l}
A_{l}^{r} \\
B_{l}^{r} \\
C_{l}^{r}
\end{array}\right]
$$

where:

$$
\begin{aligned}
& \Delta S_{w j}^{(k+1)}=\left(S_{w l}^{(r+1)}-S_{W I}^{(r)}\right)^{(k+1)} \\
& \Delta P_{j}^{(k+1)}=\left(P_{I}^{(r+1)}-P_{I}^{(r)}\right)^{(k+1)}
\end{aligned}
$$




$$
\Delta T^{(k+1)}=\left(T_{l}^{(r+1)}-T_{l}^{(r)}\right)^{(k+1)}
$$

If the boundary conditions are treateil later, the nine terms of the Jacobian matrix above are given by:

$$
\begin{aligned}
\frac{\partial A_{l}}{\partial S_{u, j}} & =\sum_{e} \mid-\int_{R e}\left(\frac{\partial \tau_{r}^{w}}{\partial S_{w j}} \frac{\partial W_{l}}{\partial r} \frac{\partial N_{j}}{\partial r}+\frac{\partial W_{l}}{\partial Z} \frac{\partial N_{j}}{\partial Z} \frac{\partial \omega_{Z}^{w}}{\partial S_{w j}}\right) P_{j}^{(k+0)} r d r d z \\
& -\int_{R e} \frac{\partial W_{l}}{\partial Z} N_{j} \frac{\partial G W^{(k+())}}{\partial S_{w}} r d r d z-\phi \rho_{\omega} \int_{R e} \frac{W_{l} N_{J}}{\Delta t} r d r d z \mid
\end{aligned}
$$

$$
\frac{\partial A_{I}}{\partial P_{j}}=\sum_{e} \mid-\int_{R e}\left(\tau_{r}^{w} \frac{\partial W_{I}}{\partial r} \frac{\partial N_{j}}{\partial r}+\tau_{z}^{\omega} \frac{\partial W_{I}}{\partial Z} \frac{\partial N_{j}}{\partial Z}\right) P_{j}^{(k+\theta)} r d r d z
$$

$$
\frac{\partial A_{1}}{\partial T_{j}}=0
$$

$$
\begin{aligned}
\frac{\partial B_{I}}{\partial S_{\omega j}}= & \sum_{e}-\int_{R e}\left(\frac{\partial r_{r}^{g}}{\partial S_{\omega j}} \frac{\partial W_{I}}{\partial r} \frac{\partial N_{j}}{\partial r}+\frac{\partial x_{Z}^{g}}{\partial S_{\omega j}} \frac{\partial W_{I}}{\partial Z} \frac{\partial N_{j}}{\partial Z}\right) P_{j}^{(k+\theta)} r d r d z-\int_{R e} \frac{\partial W_{I}}{\partial Z} N, \frac{\partial G G^{(k+\theta)}}{\partial S_{\omega j}} \\
& r d r d z-\int_{R e} \frac{W_{I} N_{j}}{\Delta t}\left\{\frac{\partial \beta}{\partial S_{\omega j}}\left(T_{j}^{(k+1)}-T_{j}^{(k)}\right)+\frac{\partial \gamma}{\partial S_{\omega j}}\left(P_{j}^{(k+1)}-P_{j}^{(k)}\right)-\varepsilon\right\} r d r d z
\end{aligned}
$$




$$
\begin{aligned}
& \frac{\partial B_{l}}{\partial P_{j}}=\sum_{e}-\int_{R e}\left(\frac{\partial c_{r}^{g}}{\partial P} \frac{\partial W_{l}}{\partial r} \frac{\partial N_{j}}{\partial r}+\frac{\partial \varepsilon_{z}^{g}}{\partial P_{j}} \frac{\partial W_{I}}{\partial Z} \frac{\partial N_{j}}{\partial Z}\right) r d r d z-\int_{R e} \frac{\partial W_{r}^{g}}{\partial r} \frac{\partial N_{j}}{\partial r} \\
& \left.+r_{z}^{g} \frac{\partial W_{l}}{\partial r} \frac{\partial N_{j}}{\partial r}\right) r d r d z-\int_{R e} \frac{\partial W_{l}}{\partial Z} N_{j} \frac{\partial G G^{(k+\theta)}}{\partial P_{J}} r d r d z-\int_{R e} \frac{N_{l} N_{J}}{\Delta l} \mid \frac{\partial \beta}{\partial P} \\
& \left.\left(T_{j}^{(k+1)}-T_{j}^{(k)}\right)+\frac{\partial y}{\partial P_{j}}\left(P_{j}^{(k+1)}-P_{j}^{(k)}\right)+Y-\frac{\partial z}{\partial P_{j}}\left(S_{w j}^{(k+1)}-S_{w j}^{(k)}\right)\right\} r d r d z \\
& \frac{\partial B_{2}}{\partial T_{j}}=\sum_{e} \mid-\int_{R e} P_{j}^{(k+\theta)}\left(\frac{\partial r_{r}^{g}}{\partial T_{j}} \frac{\partial W_{l}}{\partial r} \frac{\partial N_{j}}{\partial r}+\frac{\partial r_{z}^{g}}{\partial T} \frac{\partial W_{l}}{\partial Z} \frac{\partial N_{j}}{\partial Z}\right) r d r d z \\
& -\int_{R e} \frac{\partial W_{I}}{\partial Z} N_{j} \frac{\partial G G^{(k+\theta)}}{\partial P_{J}} r d r d z-\int_{R e} \frac{W_{I} N_{j}}{\Delta t}\left\{\frac{\partial \beta}{\partial T_{j}}\left(T_{j}^{(k+1)}-T_{j}^{(k)}\right)+\beta^{(k+\theta)}\right. \\
& \left.+\frac{\partial \gamma}{\partial T_{j}}\left(P_{j}^{(k+1)}-P_{j}^{(k)}\right)-\frac{\partial z}{\partial T_{j}}\left(S_{\omega j}^{(k+11}-S_{\omega j}^{(k)}\right)\right\} r d r d z \mid
\end{aligned}
$$

$$
\begin{aligned}
& \frac{\partial C_{I}}{\partial S_{w}}=\sum_{e} \mid-\int_{R e}\left(\frac{\partial k_{r}}{\partial S_{w j}} T_{j}^{(k+\theta)} \frac{\partial W_{I}}{\partial} \frac{\partial N_{j}}{\partial}+\frac{\partial W_{I}}{\partial Z} \frac{\partial N_{j}}{\partial Z} \frac{\partial k_{Z}}{\partial S_{w j}} T_{J}^{(k+\theta)}\right) r d r d z \\
& \left.-\frac{\partial I_{r}}{\partial S_{w j}} \int_{R e} W_{I} \frac{\partial N_{J}}{\partial r} r d r d z-\frac{\partial I_{z}}{\partial S_{w j}} \int_{R e} W_{I} \frac{\partial N_{J}}{\partial Z} r d r d z-\int_{R e} \frac{N_{I} N_{j}}{\Delta l} \frac{\partial H_{J}}{\partial S_{w j}} r d r d z\right]
\end{aligned}
$$

$$
\frac{\partial C_{I}}{\partial P_{J}}=\sum_{e}\left|-\frac{\partial I_{r}}{\partial P_{j}} \int_{R e} W_{l} \frac{\partial N_{J}}{\partial r} r d r d z-\frac{\partial I_{2}}{\partial P_{j}} \int_{R e} W_{l} \frac{\partial N_{J}}{\partial Z} r d r d z-\int_{R e} \frac{W_{l} N_{j}}{\Delta l} \frac{\partial H}{\partial P_{j}} r d r d z\right|
$$




$$
\begin{aligned}
\frac{\partial C_{I}}{\partial T_{J}}=\sum_{e} \mid & -\int_{R e}\left(k_{r} \frac{\partial W_{l}}{\partial r} \frac{\partial N_{J}}{\partial r}+k_{z} \frac{\partial W_{l}}{\partial Z} \frac{\partial N_{J}}{\partial Z}\right) r d r d z-\int_{R e} \frac{\partial I_{r}}{\partial T} \frac{\partial N_{J}}{\partial r} r d r d z \\
& -\frac{\partial I_{z}}{\partial T_{j}} \int_{R e} N_{l} \frac{\partial N_{J}}{\partial Z} r d r d z-\int_{R e} \frac{N_{I} N_{J}}{\Delta l} \frac{\partial H}{\partial T_{j}} r d r d z \mid
\end{aligned}
$$

The integrals are determined in Appendix 2.

\subsubsection{Phase Change Treatment}

There are two methods to deal with the phase change problems: the enthalpy method and apparent heat capacity method. This work follows the apparent heat capacity approach that uses a Dirac delta function (step function) to approximate the temperature dependent heat capacity which was applied with success by O'Neill (1983). $\partial H / \partial T$ assumes an infinite value as the enthalpy undergoes a step change at the phasechange temperature. To handle this step change in the heat capacity, it is approximated in the following manner:

$$
\frac{\partial H}{\partial T}=C_{e f f}=C_{1}+L \delta\left(T-T_{0}\right)
$$

where $C_{1}$ is the sensible volumetric heat capacity, $L$ is the latent heat of fusion per unit volume of the substance, $\delta$ is the Dirac delta function, $T_{a}$ is the phase change temperature, $C_{\text {eff }}=\partial H / \partial T$. The Delta function has the following property:

$$
\int f \delta\left(T-T_{0}\right) d T=f\left(T_{0}\right)
$$


where the integration in $T$ crosses the phase change isotherm. It is evident that the only term affected by inclusion of latent heat term is

$$
\int_{R e} \frac{\partial H}{\partial T} N_{i} N_{j} r d r d z=\int_{R e} C_{e f f} N_{i} N_{j} r d r d z .
$$

For those elements without phase change, the heat capacity $C_{e f f}=C_{1}$, is a constant. But for those that contain the phase isotherm, the heat capacity should be corrected so as to obtain a jump of proper magnitude to correctly account for the latent heat,

$$
\begin{gathered}
M_{i j}^{(e)}=\int_{R e} C_{e f f} N_{i} N_{j} r d r d z \\
=\int_{R e}\left[C_{1}+L \delta\left(T-T_{0}\right)\right] r N_{i} N_{j} d r d z \\
=\int_{R e} C_{1} r N_{i} N_{j} d r d z+L \int_{R e} r \delta\left(T-T_{0}\right) N_{i} N_{j} d r d z
\end{gathered}
$$

Eq. (9.56) is a general equation. For the elements that do not contain the phase change isotherm, the latent heat integral in Eq. (9.56) reduces to zero and the constant heat capacity term is evaluated in exactly the same fashion as there is no phase change.

For the second part of heat capacity integral:

$$
L H I=L \int_{R e} \delta\left(T-T_{o}\right) r N_{i} N_{j} d r d z
$$

where, again, $N_{i}, N_{j}$ are the linear shape functions for a triangular element, and $r$ is the radial distance of any point on the phase change 
isotherm within the domain of the element under consideration. For a triangular element the coordinate $r$ can be written in terms of the shape function and the radial coordinates of each node:

$$
r=r_{1} N_{1}+r_{2} N_{2}+r_{3} N_{3}
$$

where $N_{1}, N_{2}$ and $N_{3}$ are shape functions evaluated at the nodal points (Reddy, 1984).

To use the property of delta function shown in Eq. (9.55), the integral in Eq. (9.57) needs to be reduced from one with respect to two space dimensions to another one with respect to temperature and another space dimension. This was done using a local coordinate system $(s, \tau)$ where one axis $(s)$ is perpendicular and the other parallel to the isotherm. Let the isotherm (which is linear in $r$ and $z$, since a linear variation of temperature is assumed within the element) intersect the element on points $a$ and $b$. In terms of local coordinates $(s, \tau)$, integral in Eq. (9.57) becomes:

$$
L H I=L \int_{R e} \delta\left(T-T_{0}\right) r N_{i}^{1} N_{j}^{1} d s d \tau
$$

where $N_{i}^{1}$ and $N_{j}^{1}$ are the new shape functions in terms of local coordinates and are written as:

$$
N_{i}^{1}=\frac{N_{i} b-N_{i} a}{l} \downarrow+N_{i} a
$$




$$
N_{j}^{1}=\frac{N_{j} b-N_{j} a}{l} \tau+N_{j} a
$$

where

$$
\begin{aligned}
& N_{i} a, N_{j} a=\text { value of shape function evaluated at } a . \\
& N_{i} b, N_{j} b=\text { value of shape function evaluated at } b . \\
& l \quad \text { length of isotherm within the element. }
\end{aligned}
$$

Rewriting integral in Eq. (9.59) with respect to temperature, it can be expressed as:

$$
L H I=L \iint_{R e} r \delta\left(T-T_{o}\right) d T N_{i}^{1} N_{j}^{1} \frac{d s}{d t} d \tau
$$

Because the above integral exists only for those elements that are undergoing phase change, the integral of delta function in Eq. (9.57) assumes a unit value and subsequently the integral in Eq. (9.59) can be written as:

$$
L \iint_{R e} r N_{i}^{1} N_{j}^{1} \frac{d s}{d t} d \tau \quad r=f(\tau)
$$

As the temperature gradient is perpendicular to the phase change isotherm, it is also parallel to the s-axis. Also, the temperature gradients are constant within each element for a linear triangular element. Hence $d T / d s$ represents the magnitude of temperature gradient such that

$$
\frac{d s}{d T}=\frac{1}{|\Delta T|}
$$


where $|\Delta T|$ represents the magnitude of temperature gradient.

The simplified expression for the gradient is given as follows:

$$
|\Delta T|=\frac{1}{2 A_{e}}\left(\sqrt{\left(T_{1} \beta_{1}+T_{2} \beta_{2}+T_{3} \beta_{3}\right)^{2}+\left(T_{1} Y_{1}+T_{2} Y_{2}+T_{3} Y_{3}\right)^{2}}\right)
$$

where $T_{1}, T_{2}, T_{3}$ are the temperature at three nodes. $\beta_{1}, Y_{1}, \beta_{2}, Y_{2}, \beta_{3}, Y_{3}$ are the coefficient used in the shape function (Reddy, 1984) and $A_{e}$ is the area of the element.

Substituting the inverse of temperature gradient (Eq. 9.65) into Eq. (9.63), one obtains:

$$
L H I=L \frac{1}{|\Delta T|} \int r N_{i}^{1} N_{j}^{1} d \tau
$$

Following Eq. (9.55), the radial coordinate ( $r$ ) is now expressed in terms of the shape functions which are based on the new local coordinate $(s, \tau)$ system,

$$
r=r_{1} N_{i}^{1}+r_{2} N_{2}^{1}+r_{3} N_{3}^{1}
$$

where the symbols have their usual meanings.

When the expressions for the radial coordinate and modified shape functions are introduced into Eq. (9.66), the following integral results:

$$
\begin{gathered}
L H I=L \frac{1}{|\Delta T|} \int_{0}^{l}\left(r_{1} N_{1}^{\prime}+r_{2} N_{2}^{\prime}+r_{3} N_{3}^{\prime}\right)\left(\left(\frac{N_{i} b-N_{i} a}{l} \imath+N_{i} a\right)\right. \\
\left(\frac{N_{j} b-N_{j} a}{l} \tau+N_{j} a\right) d \tau
\end{gathered}
$$


The above integral is evaluated within limits 0 to $l$ and results in a lengthy but simple integral that needs to be evaluated with proper care. After the necessary algebra of integrating and applying the limits, a general expression for the integral is obtained, and is:

$$
L H I_{l j}=L \frac{1}{|\Delta T|}\left(\frac{C_{1} l^{4}}{4}+\frac{C_{2} l^{3}}{3}+\frac{C_{3} l^{2}}{2}+C_{4} l\right)
$$

where $C_{1}, C_{2}, C_{3}$ and $C_{4}$ are expressed as:

$$
C_{1}=\frac{\left(N_{i} b-N_{i} a\right)}{l} \frac{\left(N_{j} b-N_{j} a\right)}{l}\left(r_{1} \frac{\left(N_{1} b-N_{1} a\right)}{l}+r_{2} \frac{\left(N_{2} b-N_{2} a\right)}{l}+r_{3} \frac{\left(N_{3} b-N_{3} a\right)}{l}\right)
$$

$$
\begin{gathered}
C_{2}=\frac{1}{l^{2}} \mid\left(N_{i} b-N_{i} a\right)\left(N_{j} b-N_{j} a\right)\left(r_{1} N_{1} a+r_{2} N_{2} a+r_{3} N_{3} a\right)+ \\
\left(N_{i} a\left(N_{j} b-N_{j} a\right)+N_{j} a\left(N_{i} b-N_{i} a\right)\right)\left(r_{1}\left(N_{1} b-N_{1} a\right)+\right. \\
\left.r_{2}\left(N_{2} b-N_{2} a\right)+r_{3}\left(N_{3} b-N_{3} a\right)\right) \mid
\end{gathered}
$$

$$
\begin{aligned}
C_{3}= & \frac{1}{l} \mid\left(N_{j} a\left(N_{i} b-N_{i} a\right)+N_{i} a\left(N_{j} b-N_{j} a\right)\left(r_{1} N_{1} a+r_{2} N_{2} a+r_{3} N_{3} a\right)+\right. \\
& N_{i} a N_{j} a\left(r_{1}\left(N_{1} b-N_{1} a\right)+r_{2}\left(N_{2} b-N_{2} a\right)+r_{3}\left(N_{3} b-N_{3} a\right)\right) \mid
\end{aligned}
$$




$$
C_{4}=N_{i} a N_{j} a\left(r_{1} N_{1} a+r_{2} N_{2} a+r_{3} N_{3} a\right)
$$

The above integration is done based on the line shape function or a special case of the weighting function $\left(W_{1}=N_{i}\right.$ for $a_{1}=a_{2}=a_{3}=0.0$ ). If the upstream weighting function $W_{l}$ is used, the following similar equations can be used as an approximation.

$$
L H I_{i j}=\frac{1}{\mid \Delta T}\left(\frac{C_{1} l^{4}}{4}+\frac{C_{2} l^{3}}{3}+\frac{C_{3} l^{2}}{2}+C_{4} l\right)
$$

where: $C_{1}, C_{2}, C_{3}$ and $C_{4}$ are expressed as:

$$
C_{1}=\frac{\left(W_{i} b-W_{i} a\right)}{l} \frac{\left(N_{j} b-N_{j} a\right)}{l}\left(r_{1} \frac{\left(N_{1} b-N_{1} a\right)}{l}+r_{2} \frac{\left(N_{2} b-N_{2} a\right)}{l}+r_{3} \frac{\left(N_{3} b-N_{3} a\right)}{l}\right)
$$

$$
C_{2}=\frac{1}{l^{2}} \mid\left(W_{i} b-W_{i} a\right)\left(N_{j} b-N_{j} a\right)\left(r_{1} N_{1} a+r_{2} N_{2} a+r_{3} N_{3} a\right)+
$$

$\left(W_{i} a\left(N_{j} b-N_{j} a\right)+N_{j} a\left(W_{i} b-W_{i} a\right)\right)\left(r_{1}\left(N_{1} b-N_{1} a\right)+\right.$

$$
\left.r_{2}\left(N_{2} b-N_{2} a\right)+r_{3}\left(N_{3} b-N_{3} a\right)\right)
$$

$$
\begin{aligned}
C_{3}= & \frac{1}{l} \mid\left(N_{j} a\left(W_{i} b-W_{i} a\right)+W_{i} a\left(N_{j} b-N_{j} a\right)\left(r_{1} N_{1} a+r_{2} N_{2} a+r_{3} N_{3} a\right)+\right. \\
& W_{i} a N_{j} a\left(r_{1}\left(N_{1} b-N_{1} a\right)+r_{2}\left(N_{2} b-N_{2} a\right)+r_{3}\left(N_{3} b-N_{3} a\right)\right) \mid
\end{aligned}
$$




$$
C_{4}=W_{i} a N_{j} a\left(r_{1} N_{1} a+r_{2} N_{2} a+r_{3} N_{3} a\right)
$$

Eqs. (9.74) to (9.78) are used in the implementation of the programs.

\subsubsection{Fluid Property Correlations}

To evaluate Eqs. (9.38) to (9.40), and Eqs. (9.45) to (9.53), it is required that gas properties such as density and viscosity, relative permeabilities, and formation conductivity, phase change temperature and latent heat be expressed in terms of the dependent variables: saturation, pressure and temperature.

\section{(1) Gas Density}

Gas density is calculated by the Benedict-Webb-Rubin equation of state with Newton-Raphson iteration method.

$$
P=\frac{R T}{V}+\frac{B_{0} R T-A_{0}-C_{0} / T^{2}}{V^{2}}+\frac{b R T-a}{V^{3}}+\frac{a a}{V^{6}}+\frac{C}{V^{3} T^{2}}\left(1+\frac{Y}{V^{2}}\right) \exp \left(-Y / V^{2}\right)
$$

where

$$
\begin{aligned}
& P=\text { pressure (psia) } \\
& V=\text { specific volume }\left(\mathrm{ft}^{3} / \mathrm{lbmole}\right) \\
& T=\text { Temperature }\left({ }^{\circ} \mathrm{R}\right) \\
& R=\text { gas constant }=10.73
\end{aligned}
$$

\section{(2) Gas Viscosity}

Gas viscosity is calculated by the Lee, Gonzolez and Eakin correlation:

$$
\mu_{g}=A \exp \left(B \rho_{g}^{c}\right)
$$


where $\mu_{g}$ is in $(c p), \rho_{g}$ is in $\left(g / \mathrm{cm}^{3}\right)$ and $T$ is in ${ }^{\circ} R$

$$
A=\frac{9.7208 T^{1.5}}{(513.76+T) \times 10^{4}}
$$

$$
B=3.5+(158.15 / T)
$$

$$
C=2.4-0.2 B
$$

\section{(3) Relative Permeabilities}

Relative permeabilities are represented by the power law correlations (Willhite, 1986)

$$
K_{r}^{g}=a_{1}\left(1-S_{\omega D}\right)^{m}
$$

$$
K_{r}^{w}=a_{2} S_{w D}^{n}
$$

where

$$
\begin{aligned}
& \qquad S_{w D}=\frac{S_{w}-S_{w i r}}{1-S_{g r}-S_{w i r}} \\
& S_{w i r}= \text { irreducible water saturation } \\
& S_{g r}= \text { residual gas saturation } \\
& S_{w}= \text { water saturation }
\end{aligned}
$$




\section{(4) Phase Change Temperature and Latent Heat}

The phase change temperature $\left(T_{f}\right)$ and the latent heat of dissociation ( $L$ ) are a function of the hydrostatic pressure at the hydrate zone and one expressed in the following form:

$$
T_{f}=\frac{15360.8}{37.05-\ln P_{r}}-459.7-a_{f}
$$

$$
L_{f}=\Phi S_{H}\left(10743.1-1.9204 T_{f}\right)
$$

where

$$
\begin{aligned}
& P_{r}=\text { hydrostatic pressure (psi) } \\
& T_{f}=\text { dissociation temperature }\left({ }^{\circ} \mathrm{F}\right) \\
& a_{f}=\text { freezing point depression of hydrates due to dissolved } \\
& \Phi=\text { solids such as salt }\left({ }^{\circ} \mathrm{F}\right) \\
& S_{H}=\text { porosity }
\end{aligned}
$$

\section{(5) Gas and Water Flux at Thawing Interface}

A scheme has been developed to include the gas and water introduced into the system when a portion of the hydrate is dissociated. As far as the gas and water continuity equations are concerned, the hydrate reservoir can be treated as a reservoir of mobile water and gas in the dissociated zone and immobile water and gas in the hydrate zone. An appropriate way to deal with the water and gas flux introduced when a portion of hydrate thaws would be to initialize the hydrate zone with a given amount of water and gas equivalent to the respective amounts of 
each fluid locked up as solid hydrate. To effectively make the fluids immobile, the permeability should be set equal to zero in the hydrate zone. As an element in the model becomes partially thawed, a permeability that reflects the proportionate elemental volume that is thawed should be specified.

$$
k_{e f f}=\frac{(T A) k}{A e}
$$

where

$k_{\text {eff }}=$ effective permeability of partially thawed element

$k=$ permeability of thawed zone

$(T A)=$ thawed area

$A e=$ element area

Difficulties were encountered when applying this method. Gas hydrates contain a very large amount of gas, as much as $180 \mathrm{scf}$ per $\mathrm{ft}^{3}$ of hydrate. To initialize the hydrate region with this amount of gas would require extremely high pressures (above 10,000 psi) which greatly exceeds the validity of the equations of state used in the model.

An alternate scheme would be to initialize the hydrate zone with the appropriate water saturation, and with a pressure that is within the range of the equation of state. The remaining gas flux could be intraduced through source terms within the element.

The following example illustrates how the source terms are determined. Figure 9.2 shows how the thawing isotherm is represented at time $t_{1}$ and $t_{2}$. 


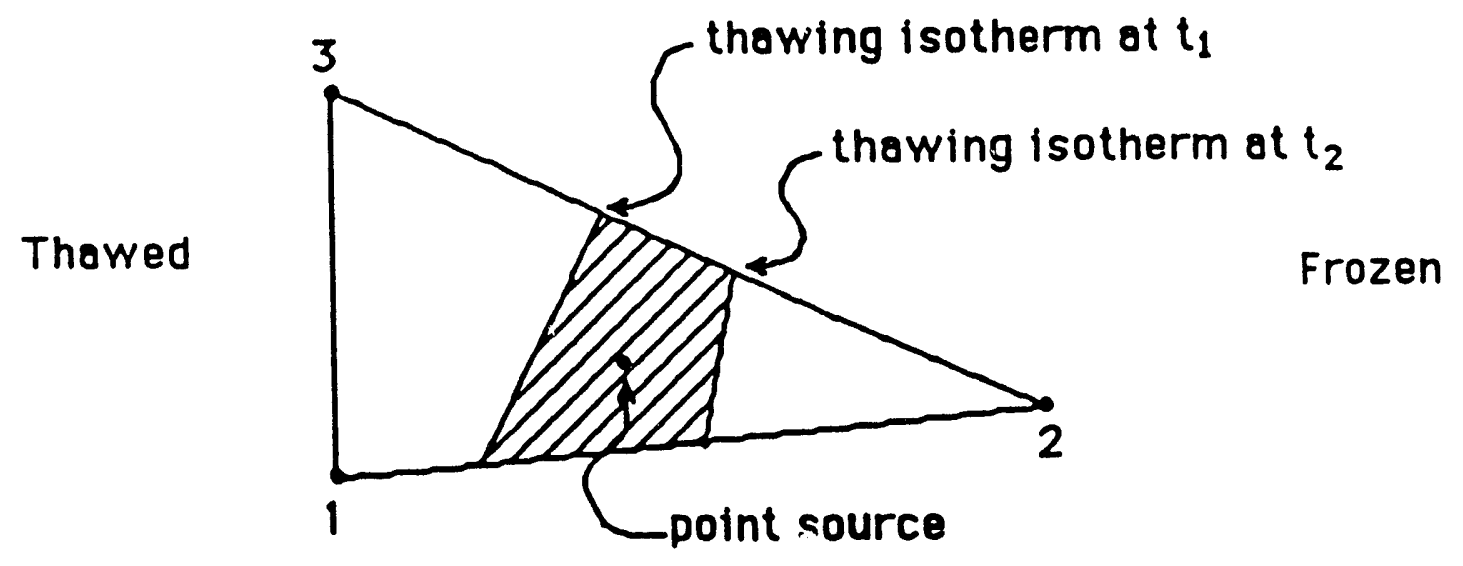

Figure 9.2: Calculation of Gas Source Terms 
The area of the element that was thawed between time $t_{1}$ and $t_{2}$ is found from:

$$
\Delta T A=(T A)_{t=2}-(T A)_{t=1}
$$

where

$\Delta(T A)=$ incremental area thawed from time $t_{1}$ to $t_{2}$.

$T A=$ thawed area of element

The incremental volume thawed over $\Delta t$ is given by:

$$
\Delta T V=\Delta(T A) \bar{r}_{\text {thaw }}
$$

where $\bar{r}_{\text {thaw }}$ is the radial coordinate of the centroid of the thawed area.

The amount of gas liberated by the thawing of the incremental volume is:

$$
\Delta m_{g}=g_{r \alpha t} \rho_{H} \phi \Delta T V
$$

where

$$
\begin{aligned}
& g_{\text {rat }}=\text { mass of gas per unit mass of hydrate } \\
& \rho_{H}=\text { density of hydrate } \\
& \Phi=\text { porosity }
\end{aligned}
$$

The amount of gas to be introduced into the system by the source term is equal to the amount of gas liberated from the incremental volume thawed, minus the amount of gas initialized into the hydrate zone by initially specifying the pressure.

$$
\Delta m g_{g}=\Delta m g-P_{g} \phi \Delta(T V)\left(1-S_{\omega}\right)
$$

The source term is then calculated by: 


$$
W_{\text {gas }}=\Delta m g_{s} /\left(t_{2}-t_{1}\right)
$$

The source term is then treated as a point source located at the centroid of $\Delta(11)$ (shown as the shaded area in Figure 9.2 and is distributed to the notes of the element by reverse interpolation using the linear shape functions

\section{(6) Physical Properties}

Hydrate zone:

$$
\begin{gathered}
\left(\rho C_{p H Z}\right)=(1-\Phi) \rho_{R} C_{\rho R}+\Phi \rho_{H} C_{\mu H} \\
k_{H Z}=k_{R}\left|\frac{\phi^{23}\left(\delta_{H}-1\right)+1}{\left(\delta_{H}-1\right)\left(\Phi^{23}-\Phi\right)+1}\right| \\
\delta_{H}=\frac{k_{H}}{k_{R}}
\end{gathered}
$$

where

$$
\begin{aligned}
& k_{H^{\prime}} k_{R}=\text { heat conductivities of hydrates and rocks respectively } \\
& C_{p H^{\prime}} C_{p K}=\text { heat capacities of hydrates and rocks respectively } \\
& \rho_{H^{\prime}} \rho_{R}=\text { densities of hydrates and rocks respectively } \\
& \Phi \quad=\text { porosity } \\
& H Z \quad=\text { subscript, means hydrate zone }
\end{aligned}
$$

Dissociated zone:

$$
\left(\rho C_{p}\right)_{\nu}=(1-\phi) \rho_{R} C_{p K}+\phi\left(\rho_{\omega} C_{p \omega} S_{\omega}+\rho_{g} C_{p g} S_{g}\right)
$$




$$
k_{D}=k_{R}\left\{\frac{S_{\omega}\left(\phi^{2 / 3}\left(\delta_{\omega}-1\right)+1\right.}{\left.\left(\delta_{\omega}-1\right) \Phi^{2 / 3}-\phi\right)}+\frac{S_{g}\left[\Phi^{2 / 3}\left(\delta_{g}-1\right)+1\right.}{\left(\delta_{g}-1\right)\left(\Phi^{2 / 3}-\phi\right)+1}\right\}
$$

$$
\delta_{w}=\frac{k_{w}}{k_{R}}
$$

$$
\delta_{g}=\frac{k_{g}}{K_{R}}
$$

where

$$
\begin{aligned}
& k_{w^{0}} k_{g}=\text { heat conductivities of water and gas respectively } \\
& S_{w^{\circ}} S_{B}=\text { water and gas saturations respectively } \\
& k_{D}=\text { heat conductivity of dissociated zone }
\end{aligned}
$$

partially thawed element:

$$
\left(\rho C_{p}\right)_{p}=\frac{a H_{2}}{A e}\left(\rho C_{p D}\right)+\frac{A e-A t_{2}}{A e}\left(\rho C_{p}\right)_{H Z}
$$

\subsubsection{Computer Implementation:}

The finite element formulation described in this chapter was coded in FORTRAN. The general flow chart for the program is given in Appendix 3. The program is written for liner triangular ring elements with integration accomplished. 


\subsection{Model Validation}

Since experimental data and analytical solutions are unavailable for the gas hydrate thermal recovery process, simplified runs where analytical solutions are available were conducted to validate the finite element formulation. The ivailable analytical solutions describe basic fluid flow and heat transfer mechanisms found in the hydrate recovery scheme for simplified geometries. Validation to the analytical solutions imply reliable modeling performance for specific components of the finite element scheme, and increases the overall confidence level of the schemes ability to simulate the proposed thermal recovery process. The finite element computer code was validated to six simplified cases where analytical solutions were available. The six cases were:
A. Single-phase fluid flow through porous media.
B. Radial conduction from a line source.
C. Radial conduction with moving phase-change boundary.
D. Convective heat transfer in an aquifer.
E. Convective and conductive heat transfer in an aquifer.
F. Two-phase immiscible flow in porous media.

All these runs used $a=0.0$ in $W_{l}$.

\subsubsection{Single Phase Fluid Flow Through Porous Media}

The analytical solution for flow of a single phase slightly compressible fluid in an infinite cylindrical reservoir with a line source well is given by Matthews and Russel (1967):

$$
P=P_{1}+70.6 \frac{q B \mu}{k h} E i\left(\frac{-948 \phi \mu C_{t} r^{2}}{k t}\right)
$$


where:

$$
\begin{aligned}
P_{i} & =\text { Initial reservoir pressure, psi } \\
q & =\text { Injection or production rate, STB/D } \\
B & =\text { Formation volume factor, RB/STB } \\
k & =\text { Permeability, millidarcies } \\
h & =\text { Reservoir thickness, ft } \\
\Phi & =\text { Porosity } \\
\mu & =\text { viscosity, cp } \\
t & =\text { time, hours } \\
C_{t} & =\text { Total compressibility } \\
E i & =\text { Exponential integral function. }
\end{aligned}
$$

$$
C_{t}=S_{w} C_{w}+S_{g} C_{g}+C_{f} \quad C_{\mathrm{a}}=\frac{1 \partial \rho}{\rho \partial P} \quad a=w, g, f
$$

Where the subscripts $w, g$, and $f$ indicate water, gas and formation rock respectively.

The following parameters were used for the validation run:

$$
\begin{array}{lll}
q=100 \mathrm{bbl} / \mathrm{day}\left(1.84 \times 10^{-4} \mathrm{~m}^{3} / \mathrm{s}\right) & S_{g}=10 \% \\
h=13 \mathrm{ft}(9.84 \mathrm{~m}) & \mu=1 \mathrm{cp}(1 \mathrm{~Pa} \cdot \mathrm{s}) \\
P_{i}=1500 \mathrm{psi}(10.342 \mathrm{MPa}) & \Phi=25 \% \\
C_{\boldsymbol{g}}=7.718 \times 10^{-4} \mathrm{psi}^{-1}\left(1.12 \times 10^{-7} \mathrm{~Pa}^{-1}\right) &
\end{array}
$$

Note that a $10 \%$ gas saturation was initialized into the finite element model to put an effective compressibility into the system to follow the assumption of a system with small compressibility. The gas phase was otherwise treated as an immobile fluid in the finite element model. 
Figures 9.3, 9.4, 9.5, and 9.6 show the results from the validation run at 1 , 2, .5 and 1.0 hours of injection time. The finite element model matched the analytical model very well, with better matching at later times.

\subsubsection{Radial Conduction From a Line Source}

The analytical solution for radial conduction in an infinite medium with a line source is given by Carslaw and Jaeger (1959) as:

$$
T=T_{i}+\frac{q}{4 \pi K} E i\left(\frac{-r^{2}}{4 a t}\right)
$$

where

$$
\begin{aligned}
& T_{i}=\text { Initial temperature of medium }\left({ }^{\circ} \mathrm{F}\right) \\
& q=\text { heat flux }(\mathrm{Btu} / \mathrm{ft} \mathrm{hr}) \\
& K=\text { thermal conductivity }\left(\mathrm{Btu} / \mathrm{ft} \mathrm{hr}{ }^{\circ} \mathrm{F}\right) \\
& a=\text { thermal diffusivity }\left(\mathrm{ft}^{2} / \mathrm{hr}\right) \\
& t \quad=\quad \text { time }(\mathrm{hr}) \\
& r \quad=\quad \text { radial distance from line source }(\mathrm{ft})
\end{aligned}
$$

The validation run was conducted with the following data:

$$
\begin{aligned}
& T_{i}=50^{\circ} \mathrm{F}\left(10^{\circ} \mathrm{C}\right) \\
& K=1.36 \mathrm{Btu} / \mathrm{ft} \mathrm{hr}{ }^{\circ} \mathrm{F}\left(2.35 \mathrm{w} / \mathrm{m}^{\circ} \mathrm{C}\right) \\
& q=500 \mathrm{Btu} / \mathrm{ft} \mathrm{hr}(480.65 \mathrm{w} / \mathrm{m}) \\
& \mathrm{a}=0.040719 \mathrm{ft}^{2} / \mathrm{hr}\left(.00378 \mathrm{~m}^{2} / \mathrm{s}\right)
\end{aligned}
$$

Figures 9.7, 9.8, and 9.9 show the finite element results vs the analytical solution for times of $.1, .5$ and 1.0 hours. The finite element results match the analytical solution fairly well with better results at later times. 


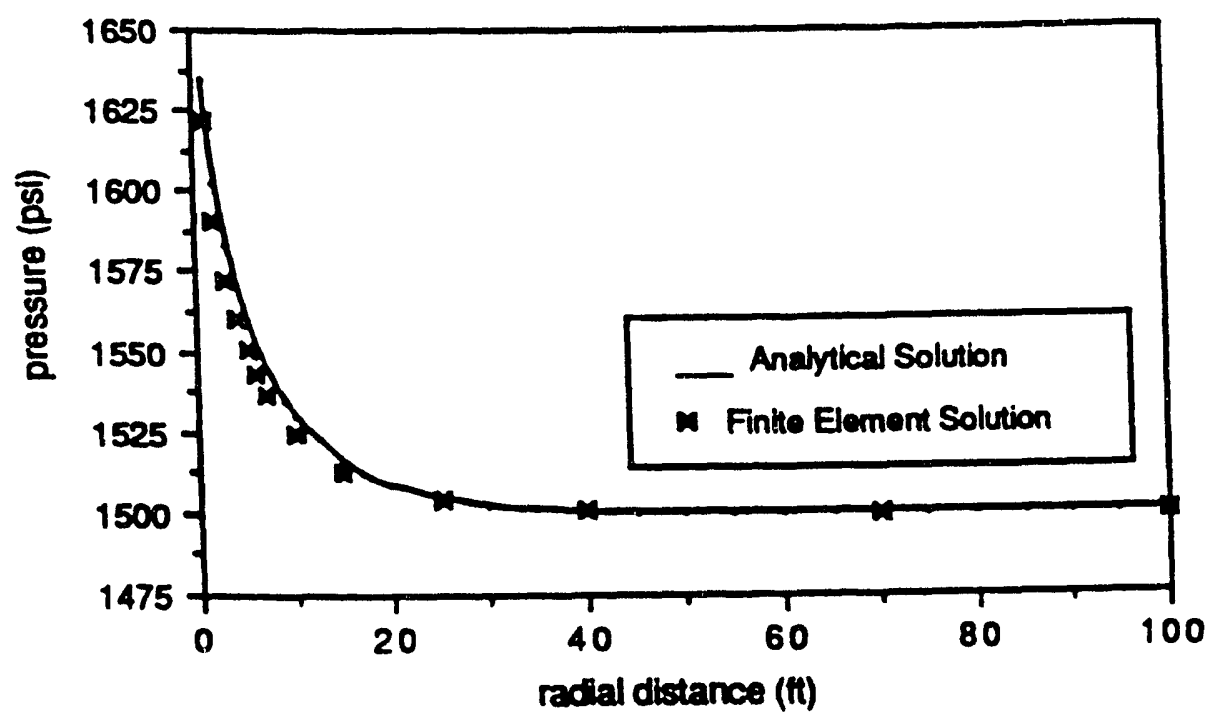

Figure 9.3: Radial Pressure Profile at Time $=0.1$ hours

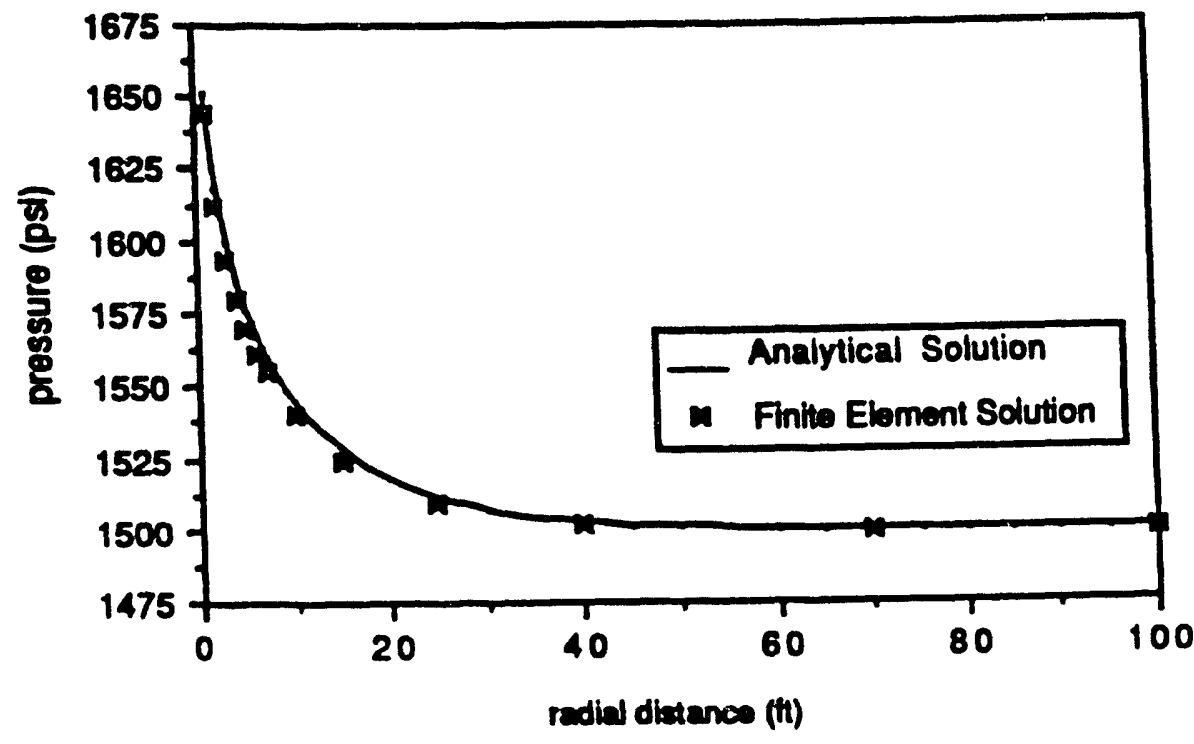

Figure 9.4: Radial Pressure Profile at Time $=0.2$ hours 


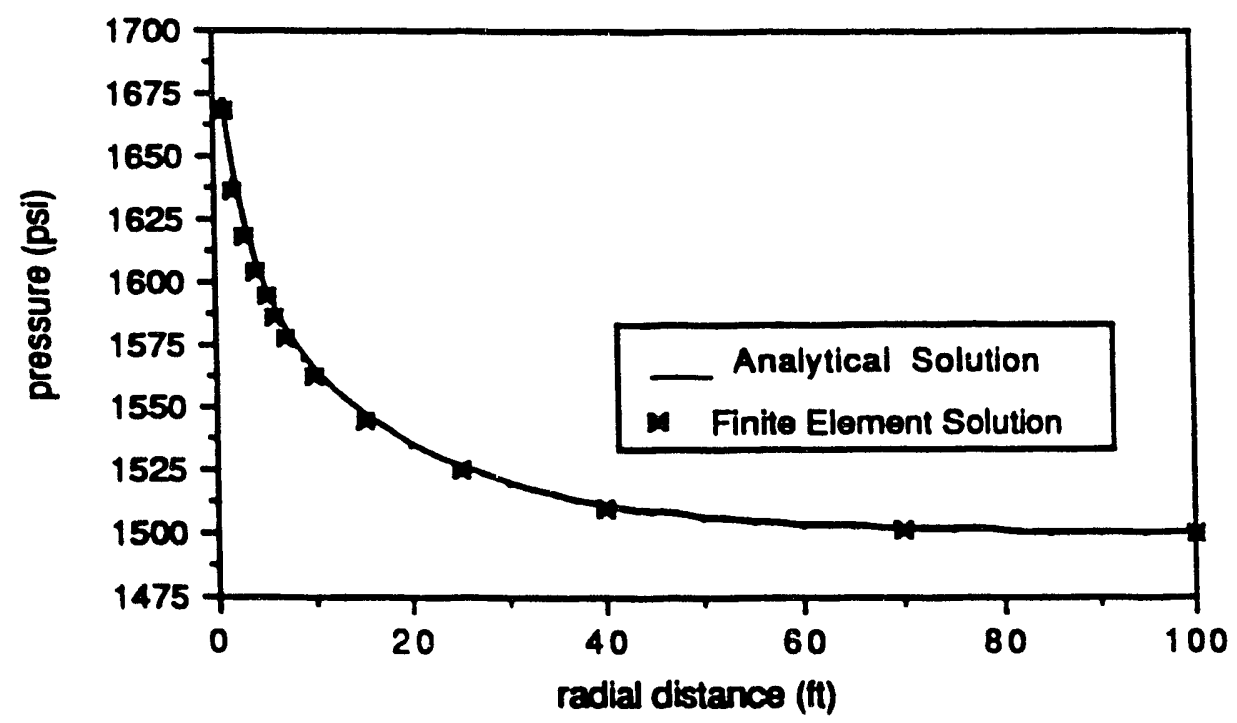

Figure 9.5: Radial Pressure Profile at Time $=0.5$ hours

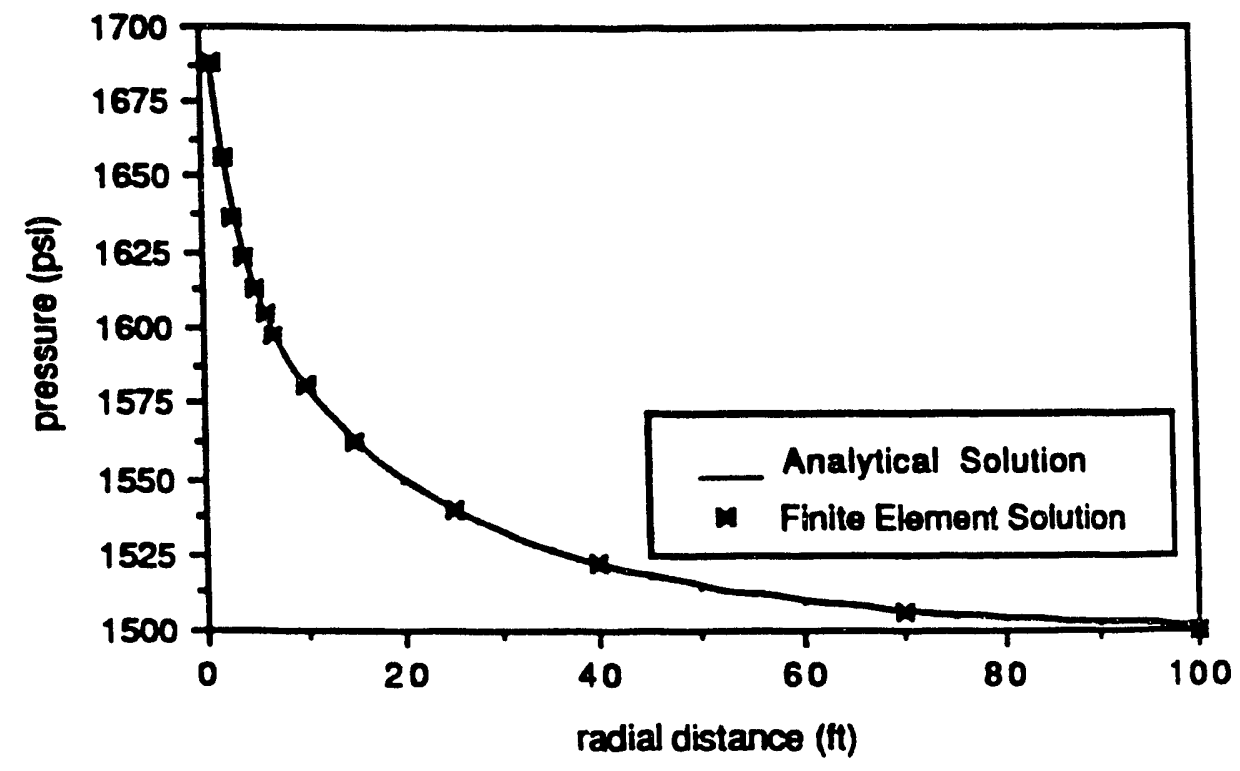

Figure 9.6: $\quad$ Radial Pressure Profile at Time $=1$ hours 


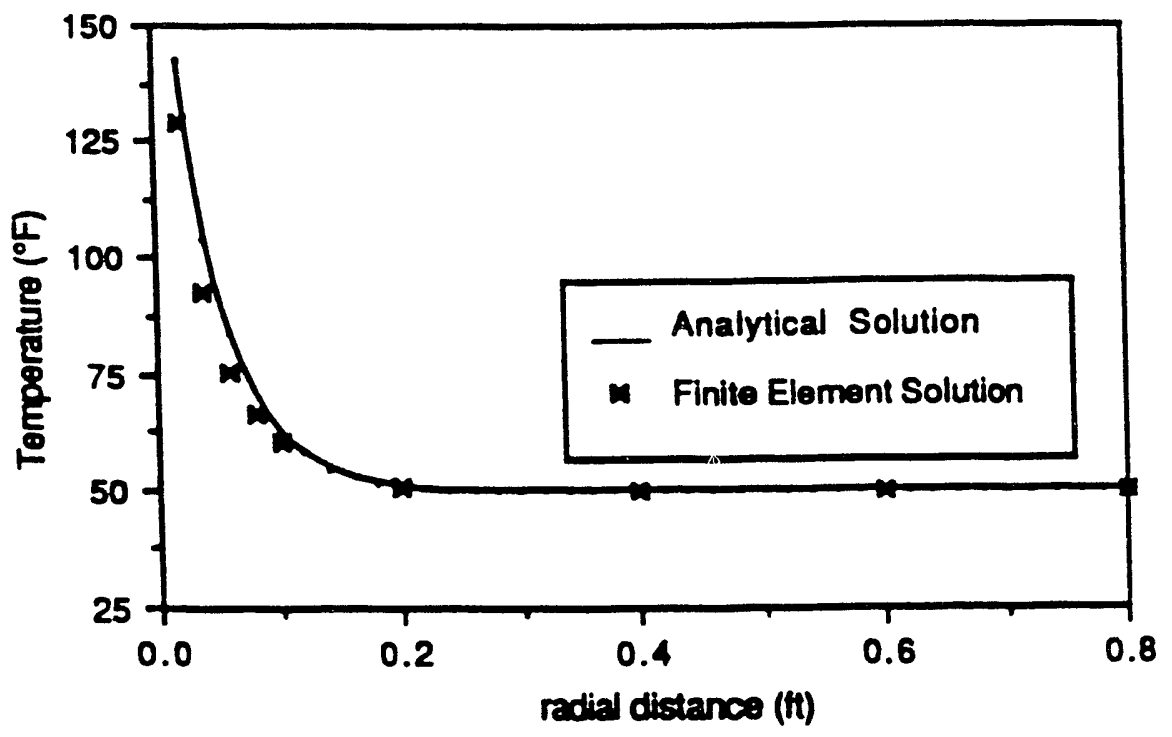

Figure 9.7: $\quad$ Radial Temperature Profile at Time $=0.1$ hours

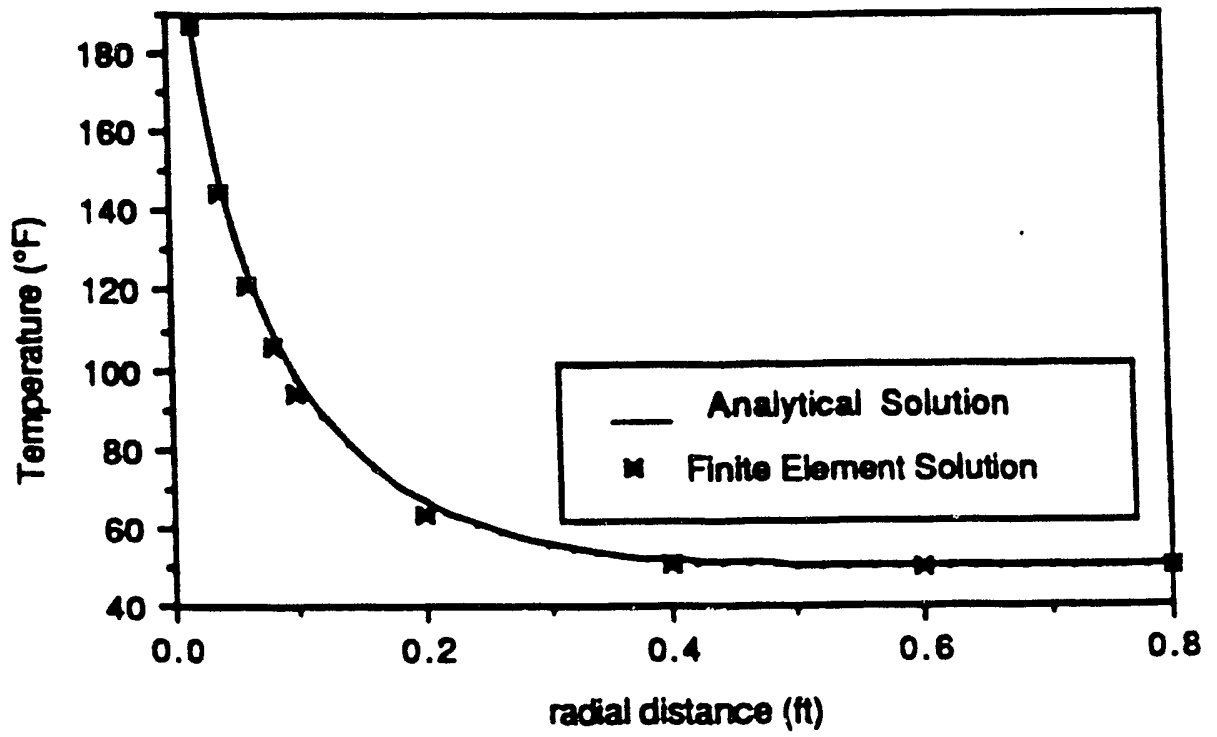

Figure 9.8: Radial Temperature Profile at Time $=0.5$ hours 


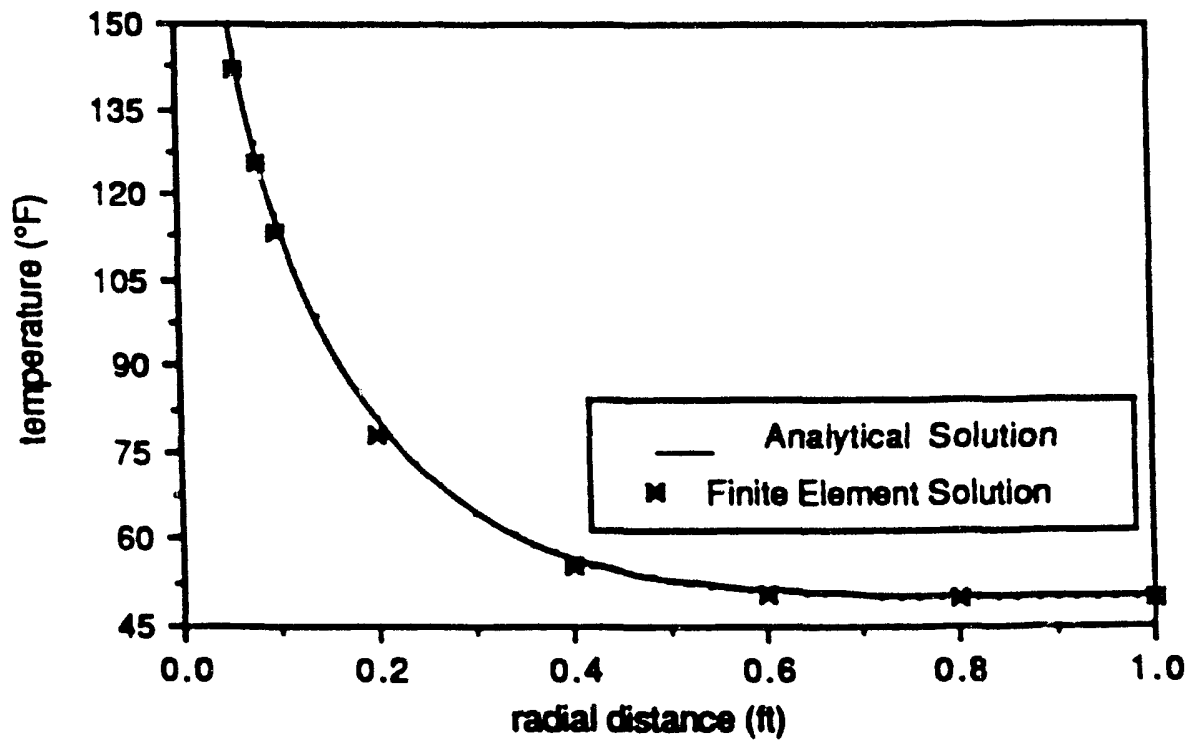

Figure 9.9: $\quad$ Radial Temperature Profile at Time $=1$ hours 


\subsubsection{Radial Conduction With Moving Phase-Change Boundary}

Two examples of phase change problems were investigated. The first problem was a radial freezing problem presented by O'Neill (1983). In this problem a time varying boundary temperature was specified on the inner and outer boundaries, (see figures $9.10 \mathrm{a}$ and $\mathrm{b}$ ), with an initial temperature of $4^{\circ} \mathrm{C}$.

The parameter used in this validation run were:

$$
\begin{aligned}
& \text { inner radius }=1 \mathrm{~cm} \\
& \text { outer radius }=10 \mathrm{~cm} \\
& \text { for frozen zone: } \\
& \qquad C_{1}=0.508 \mathrm{cal} / \mathrm{cm}^{3 \circ} \mathrm{C} \\
& K=0.0072 \mathrm{cal} / \mathrm{cm} \cdot \mathrm{s}^{\circ} \mathrm{C}
\end{aligned}
$$

with:

$$
L=36.0 \mathrm{cal} / \mathrm{cm}^{3} \text { and } T_{f r}=0^{\circ} \mathrm{C}
$$

Figure 9.11 shows the position of the thaw front with respect to time for both the finite element model and the data from the analytical solution used by $O^{\prime} N e i l l$. The finite element model came within very close agreement to the analytical solution.

A second validation for thawing was conducted with Lunardini's (1981) approximate solution for thawing around a circular pipe. The Lunardini problem is illustrated in Figure 9.12 . The medium is initially at temperature $T_{o^{\prime}}$ the phase change temperature is given as $T_{p}$ the inner surface is maintained at $T_{y^{\prime}}$ and the outer boundary at infinity is specified at $T_{v}$. The parameters for the problem investigated are:

$$
\begin{gathered}
\frac{K_{\text {thaw }}}{K_{\text {frazen }}}=1 \quad \frac{a_{\text {thaw }}}{a_{\text {frozen }}}=1 \\
S t=\text { Stefan number }=C\left(T_{s}-T_{f}\right) / L=1
\end{gathered}
$$




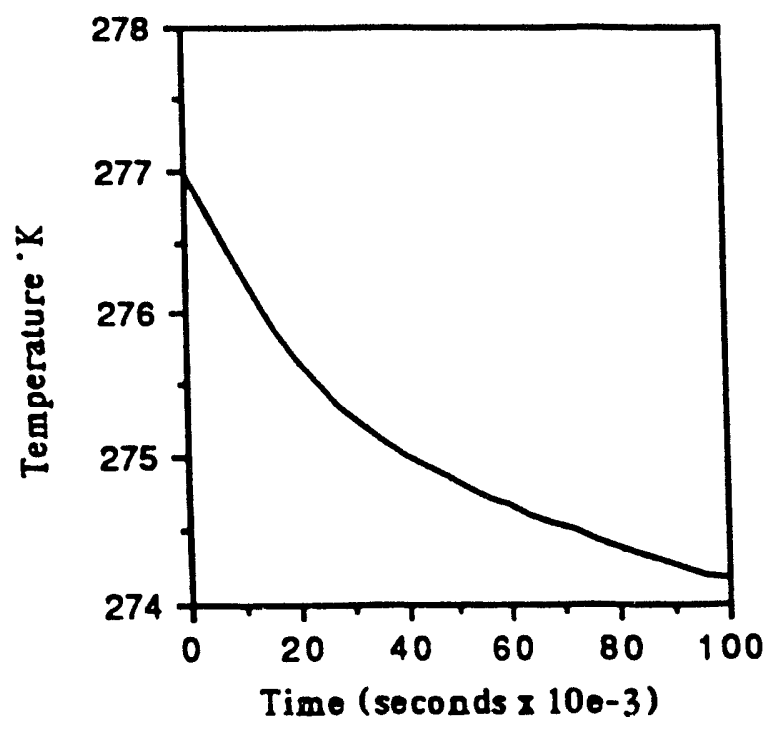

Figure 9.10a: Worm Temperature Boundary (O'Neill, 1983)

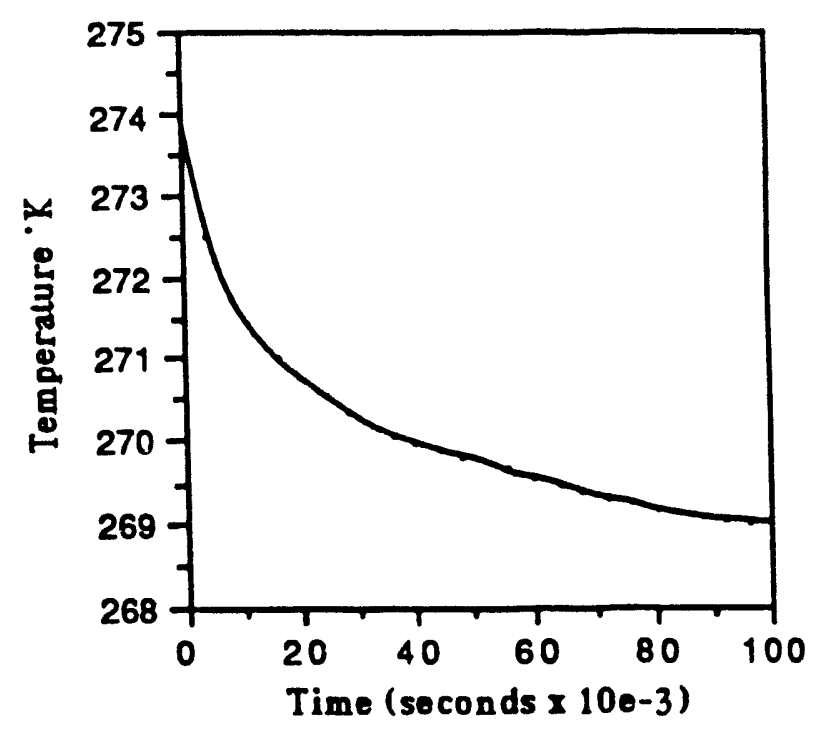

Figure 9.10b: Cold Temperature Boundary (O'Neill, 1983)

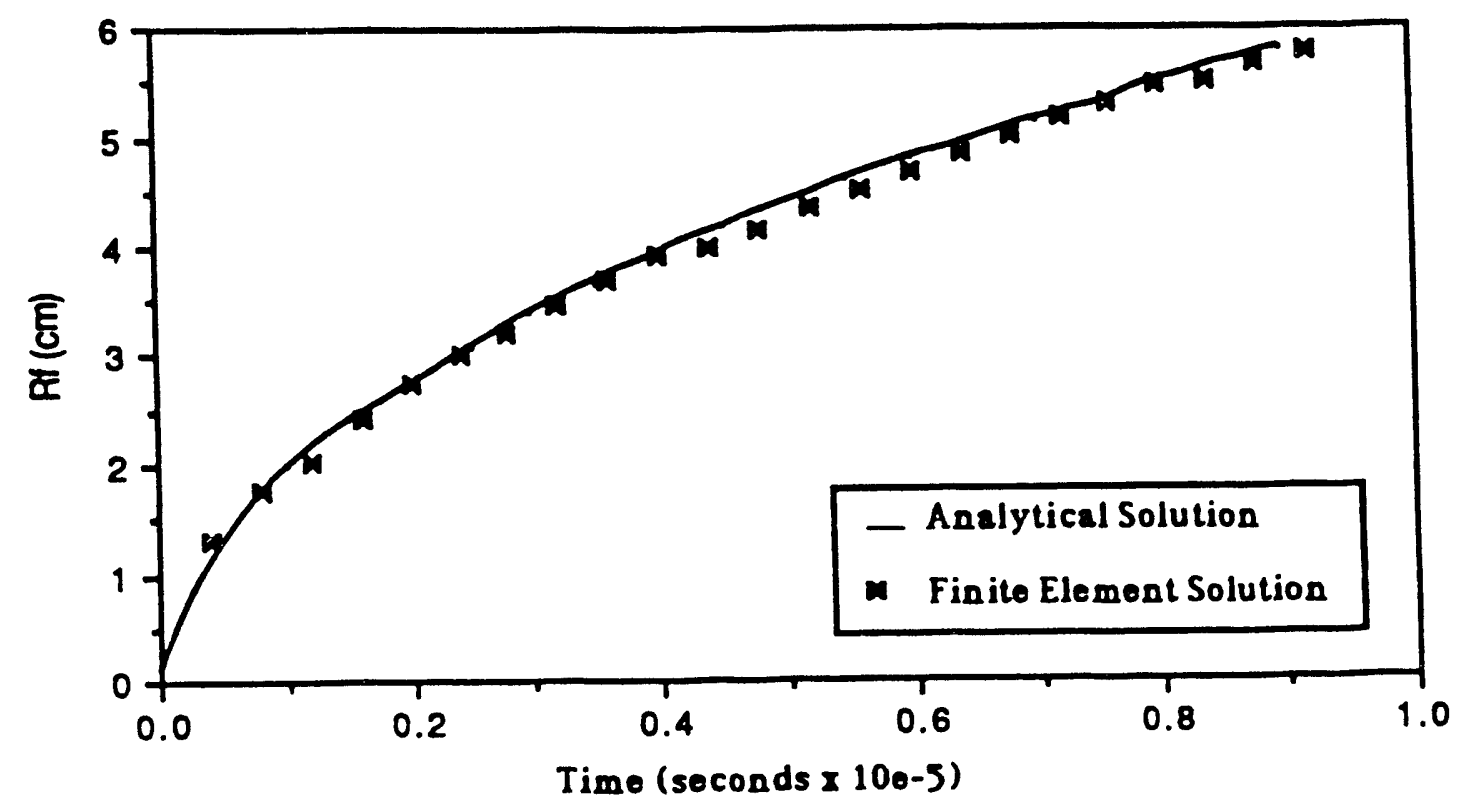

Figure 9.11: Phase Front Versus Time 


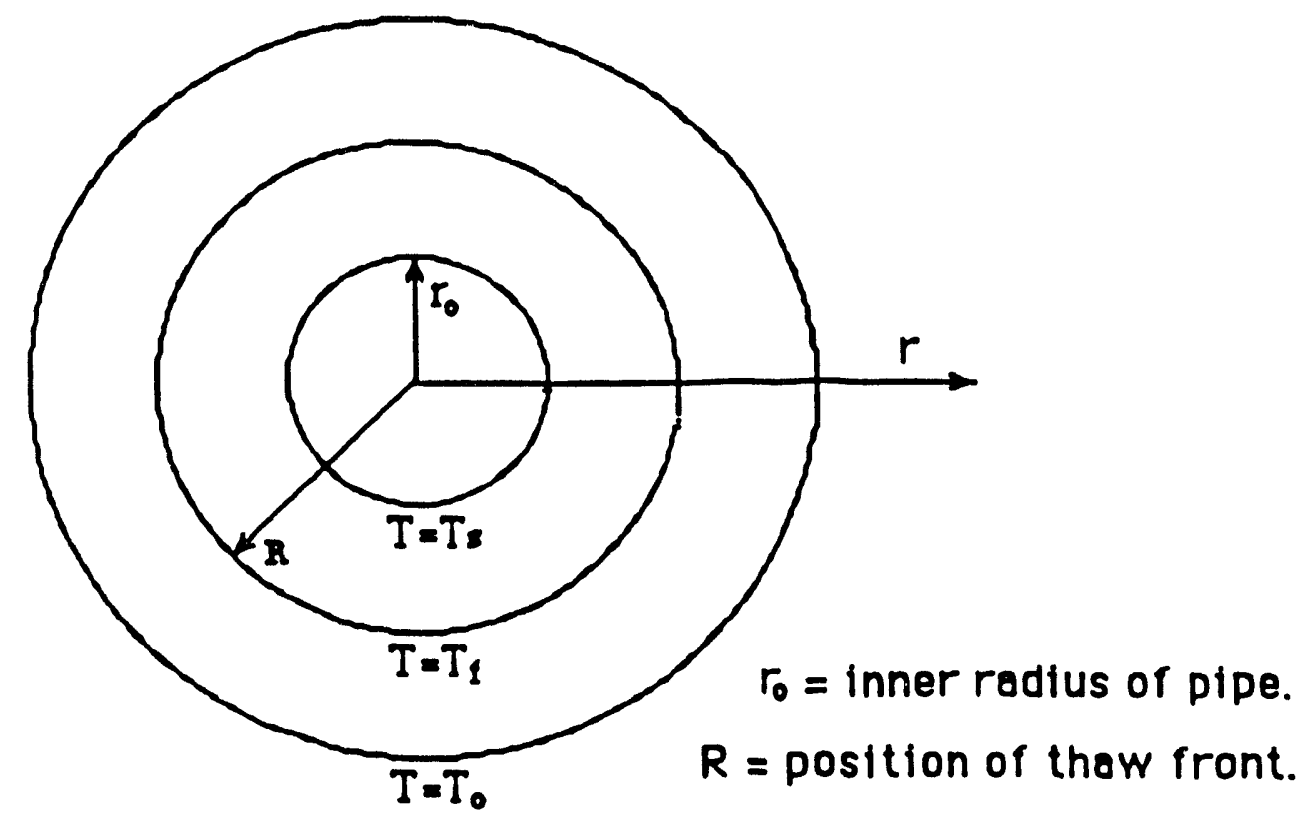

Figure 9.12: Lunardini Problem, Thawing Around a Circular Pipe

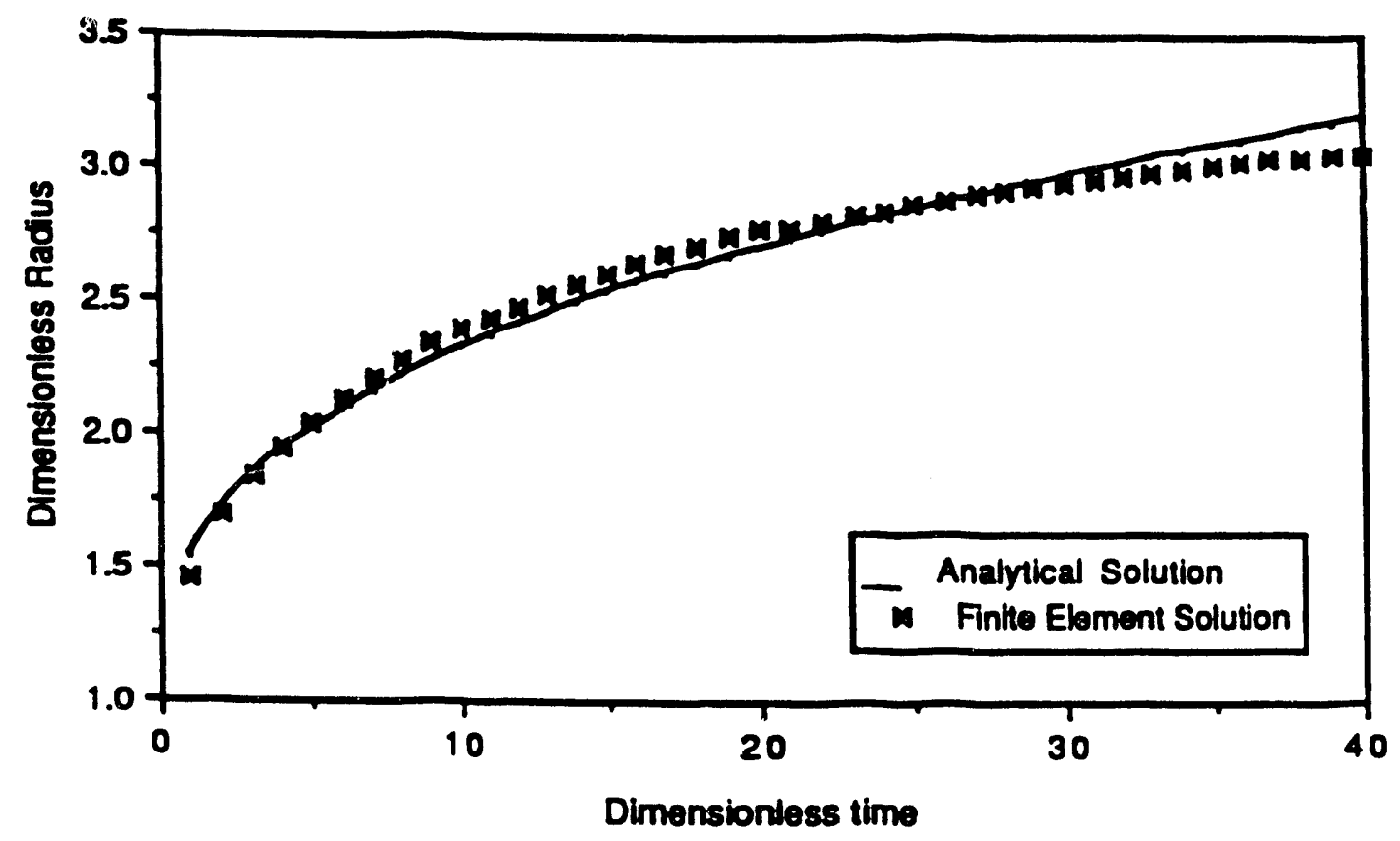

Figure 9.13: Comparison of Lunardini Solution With Finite Element Solution For Thawing Around Circular Pipe 
where

$$
\begin{aligned}
& C=\text { volumetric specific heat } \\
& L=\text { volumetric latent heat }
\end{aligned}
$$

The solution is defined in terms of the two dimensionless parameters $\tau$ and $\beta$ which are defined as:

$$
\tau=\frac{a_{\text {frozen }} S_{t} t}{r_{0}^{2}} \text { and } \beta=\frac{R}{r_{0}}
$$

Figure 9.13 shows the results of tha finite element model compared to the Lunardini solution. As shown in Figure 9.13, the finite element model compares fairly well to the approximate Lunardini solution.

\subsubsection{Convective Heat Transfer in an Aquifer}

An available analytical solution for convective heat transport in porous media is given by Lauwerier (1955). The assumptions of Lauwerier's solution are illustrated in Figure 9.14.

Lauwerier's solution assumes that heat transfer to adjacent formations is by vertical conduction only, the temperature distribution within the reservoir is independent of vertical position, and heat flow within the reservoir is by horizontal convection only.

Lauwerier's solution is given as:

$$
T_{D}=U\left(\iota_{D}-X_{D}\right) \operatorname{erfc} \frac{X_{D}+\Delta Z_{D}}{2 \sqrt{t_{D}-X_{D}}}
$$

where

$U(x)$ is the unit function which is defined as:

$$
U(x)=0 \text { for } x \leq 0
$$




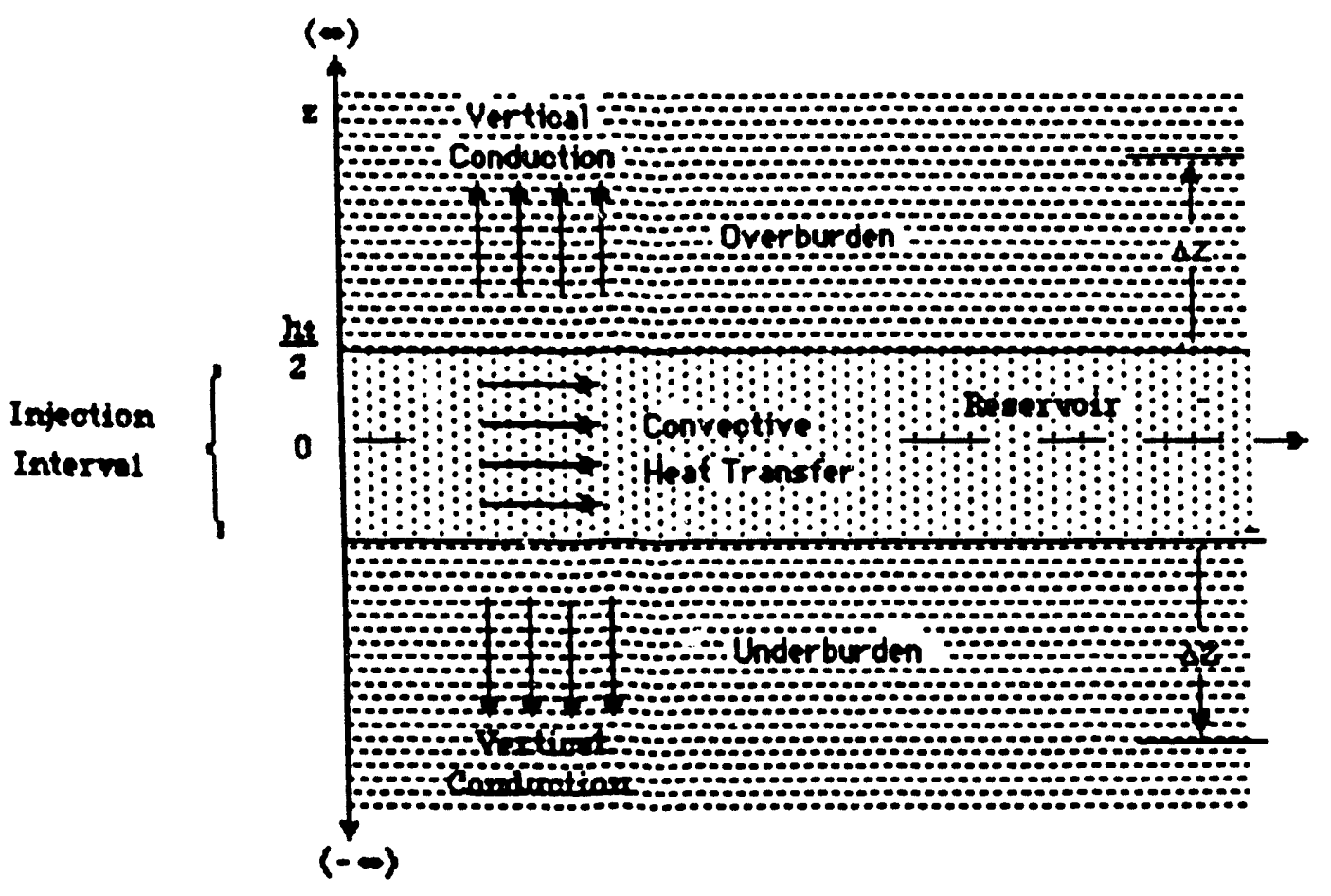

Figure 9.14: Lauwerier's Model For Heat Transfer In an Aquifer 


$$
U(x)=1 \text { for } x>0
$$

and

$$
T_{D}=\frac{T-T_{R}}{T_{i}-T_{R}}
$$

where

$$
\begin{aligned}
& T_{i}=\text { Temperature of injected fluid } \\
& T_{R}=\text { Temperature of reservoir initially }
\end{aligned}
$$

$t_{D}$ and $\Delta Z_{D}$ are defined by:

$$
t_{D}=4\left(\frac{M_{S}}{M_{R}}\right)^{2} \frac{a_{s}}{h^{2}} t
$$

$$
\Delta Z_{D}=\frac{2 M_{S}}{h_{t} M_{R}} \Delta Z
$$

Malofeev (1960) has extended Lauwerier's work to a radial system to give:

$$
X_{D}=\frac{4 \pi r^{2}}{M_{f} h_{t} q} \frac{a_{s} M_{s}^{2}}{M_{R}}
$$

The variables used in the above three equations are $d c$ fined as:

$$
\begin{aligned}
& M_{S}=\text { Volumetric heat capacity of adjacent formation } \\
& M_{R}=\text { Volumetric heat capacity of reservoir } \\
& M_{f}=\text { Volumetric heat capacity of fluid } \\
& a_{s}=\text { Thermal diffusivity of adjacent formation } \\
& q=\text { Injection rate } \\
& h_{t}=\text { Thickness of reservoir }
\end{aligned}
$$


To follow the assumption of vertical heat conduction in the adjacent formations, the finite element model was run with the radial component of thermal conductivity set to zero.

The following parameters were used for the Lauwerier validation run:

$$
\begin{array}{lll}
a_{s}=1 & M_{S}=1 & M_{R}=1 \\
M_{f}=1 & h_{t}=2 & q=2 n
\end{array}
$$

Using the above parameter simplifies Eq. (9.104) as follows:

$$
t_{D}=4\left(\frac{1}{1}\right)^{2} \frac{1}{2^{2}} t=t
$$

and simplifies Eq. (9.106) as follows:

$$
X_{D}=\frac{4 n \cdot r^{2}}{1 \cdot 2 \cdot 2 n} \frac{1 \cdot 1^{2}}{1}=r^{2}
$$

A second finite element scheme was investigated in the validation comparison to the Lauwerier convective solution. The second scheme was formulated with the convective term written explicitly in terms of pressure through substitution of Darcy's Law. Consider the convective term of the energy equation:

$$
\frac{\partial}{\partial x i}\left[p_{\omega} C p \omega \Delta T v_{i}^{\omega}\right]=\frac{\partial}{\partial x i}\left[p_{g} C p g \Delta T v_{i}^{g}\right]
$$

The enthalpy of the water and gas per unit mass is given by:

$$
h_{\omega}=\rho_{w} C p \omega \Delta T \quad h_{g}=\rho_{g} \operatorname{Cpg} \Delta T
$$

Substitute in $h_{w}$ and $h_{g}$ and substitute in Darcy's Law for velocity: 


$$
-\frac{\partial}{\partial x_{i}}\left|h_{w}{ }^{\imath}{ }^{\omega} \frac{\partial P}{\partial x_{j}}\right|-\frac{\partial}{\partial x i}\left|h_{g} g_{i j}^{g} \frac{\partial P}{\partial x_{j}}\right|
$$

Define:

$$
\lambda_{i j}=h_{w i j} \tau_{i j}^{u_{u}}+h_{g} \underline{r}_{i j}^{g}
$$

and the convective term simplifies to:

$$
-\frac{\partial}{\partial x_{i}}\left|\Lambda_{i j} \frac{\partial P}{\partial x_{j}}\right|
$$

The convective term above in $r-z$ coordinates:

$$
-\frac{1}{r} \frac{\partial}{\partial r}\left|r \lambda_{r} \frac{\partial P}{\partial r}\right|-\frac{\partial}{\partial z}\left|\Lambda_{2} \frac{\partial P}{\partial z}\right|
$$

When the weighted residual scheme is applied the convective term becomes:

$$
\int_{R e} W_{I} \frac{1}{r} \frac{\partial}{\partial r}\left\{r \lambda_{r} \frac{\hat{\partial P}}{\partial r}\right\} r d r d z+\int_{R e} W_{l} \frac{\partial}{\partial z}\left\{\lambda_{z} \frac{\partial P}{\partial z}\right\} r d r d z
$$

To be able to use linear shape functions the divergence theorem must be applied to decrease the order of this term resulting in:

$$
\begin{gathered}
\int_{R e} \Lambda_{r} \frac{\partial W_{l}}{\partial r} \frac{\hat{\partial P}}{\partial r} r d r d z+\int_{R e} \lambda_{z} \frac{\partial W_{l}}{\partial z} \frac{\hat{P}}{\partial z} r d r d z \\
-\int_{B e} \Lambda_{r} W_{l} \frac{\partial \hat{P}}{\partial r} n_{r} r d l-\int_{B e} W_{l} \lambda_{z} \frac{\partial \hat{P}}{\partial z} r d l
\end{gathered}
$$


Researchers have cautioned that making this divergence theorem transformation to the convective term may lead to numerical difficulties and should be done with caution (Huyakorn and Pinder, 1983).

Carrying out the appropriate substitutions gives:

$$
\begin{gathered}
P_{J}^{k+\theta} \lambda r \int_{R e} \frac{\partial W_{l}}{\partial r} \frac{\partial N_{J}}{\partial r} r d r d z+P_{J}^{k+\theta} \lambda z \int_{R e} \frac{\partial W_{l}}{\partial r} \frac{\partial N_{J}}{\partial z} r d r d z \\
-\int_{B e} \lambda r W_{l} \frac{\partial \hat{P}}{\partial r} n_{r} r d l-\int_{B e} W_{l} \lambda z \frac{\partial \hat{P}}{\partial z} n_{z} r d l
\end{gathered}
$$

where

$$
\lambda r=h{ }_{w}{ }_{r}^{w}+h g r_{r}^{g} \text { and } \Delta z=h w \tau_{z}^{w}+h g r_{z}^{g}
$$

Compared to the convective term for the energy residual equation:

$$
\int_{R e} W_{I} I_{r} \frac{\partial N_{J}}{\partial r} r d r d z+\int_{R e} W_{I} I_{z} \frac{\partial N_{J}}{d z} r d r d z
$$

where

$$
\begin{aligned}
& I_{r}=\rho_{\omega} C p w \Delta T v_{r}{ }^{\omega}+\rho_{\omega} C p g \Delta T v_{r}^{g} \\
& I_{z}=\rho_{\omega} C p w \Delta T v_{r}{ }^{\omega}+\rho_{\omega} C p g \Delta T v_{r}{ }^{g}
\end{aligned}
$$

Which was not transformed by the divergence theorem.

Figure 9.15 shows the comparison of the two finite element schemes to the Lauwerier solution at a dimensionless time of 20 . Finite element scheme $B$ is the scheme that includes the convective term in the form of Eq. (9.115) and finite element scheme $A$ is the scheme where the convective term is in the form of Eq. (9.116). Clearly finite element scheme B gives unsatisfactory results while scheme A gives excellent results. All further discussions will assume the convective term to be iormulated as outilined earlier (scheme A). Figures 9.16 , 


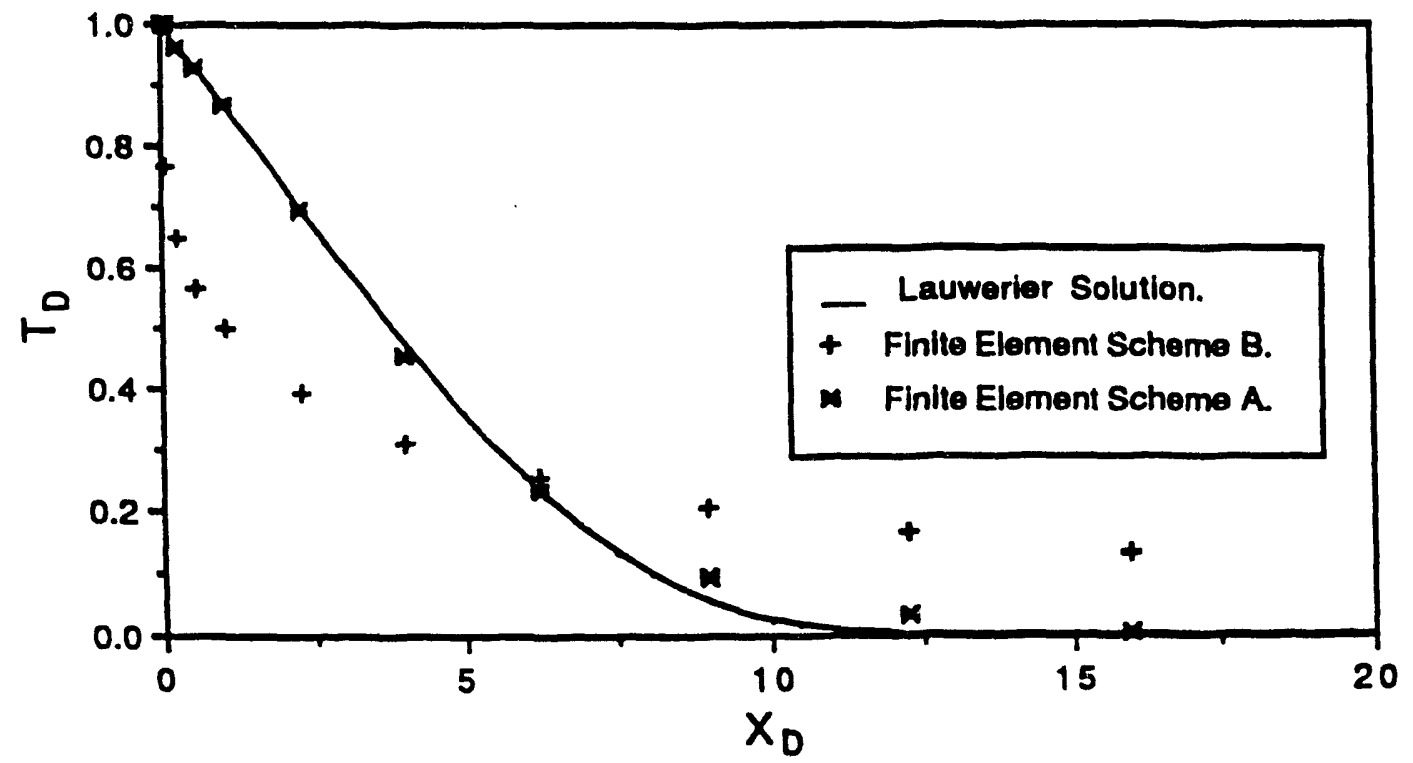

Figure 9.15: Comparison of Formulation $A$ with Formulation $B$ for at Convection at $t_{D}=20$

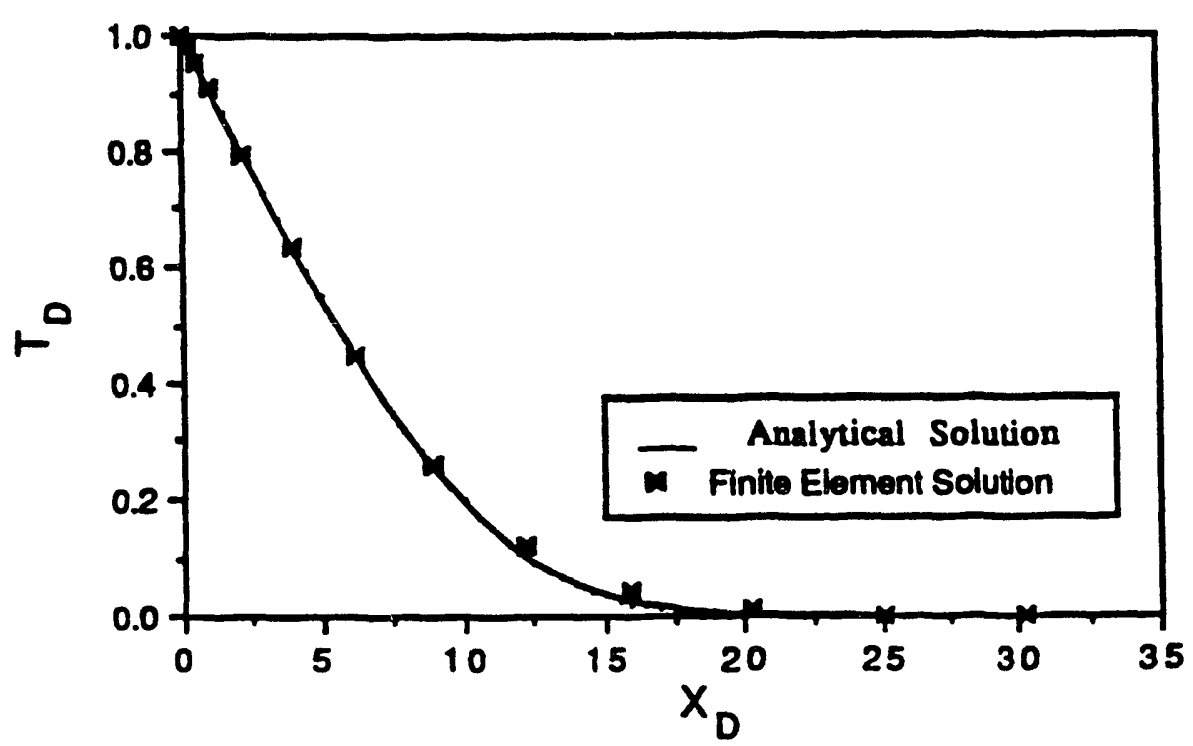

Figure 9.16: $T_{D}$ versus $X_{D}$ at $t_{D}=40$ 
9.17, and 9.18 show comparisons of the finite element formulation with Lauwerier's solution for dimensionless times of 40,60 and 80 . The finite element solution compares very favorably with the Lauwerier solution.

\subsubsection{Convective and Conductive Heat Transfer in an Aquifer}

A validation run was conducted for comparison with Avdonin's analytical solution for heat transfer in a confined aquifer. Lauwerier's solution is actually a special case of Avdonin's solution where radial heat conduction within the reservoir has been neglected.

An excellent discussion of Avdonin's solution is given by R. Schulz (1987). Schulz uses Avdonin's solution for an aquifer of radial geometry to analyze heat transfer phenomena in a confined aquifer in southern Germany. A validation run was conducted with the parameters used in Schulz's study and the radial temperature profiles were compared. The input parameters are shown in Table 9.1.

The validation run was conducted for a two year time span and after one year, the injection temperature was increased from $25^{\circ} \mathrm{C}$ to $30^{\circ} \mathrm{C}$.

The finite element results are compared to the analytical results in figure 9.19. The dimensionless temperature presented in Figure 9.19 is given by:

$$
T_{D}=\frac{T(r)-T_{i}}{T_{R}-T_{i}}
$$

where

$T_{i}=$ Initial injection temperature

$T_{R}=$ Undisturbed reservoir temperature

The finite element model did not match the analytical solution as well as expected. The discrepancy may be due in part to the assumption in the 


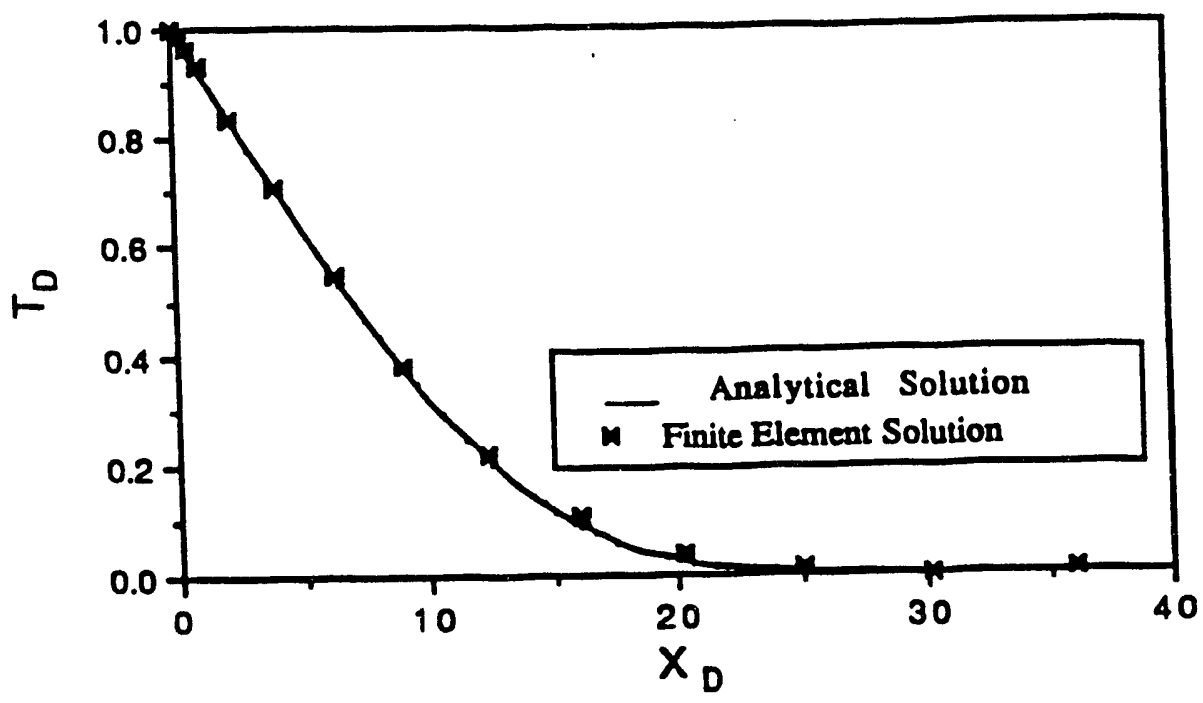

Figure 9.17: $T_{D}$ versus $X_{D}$ at $t_{D}=60$

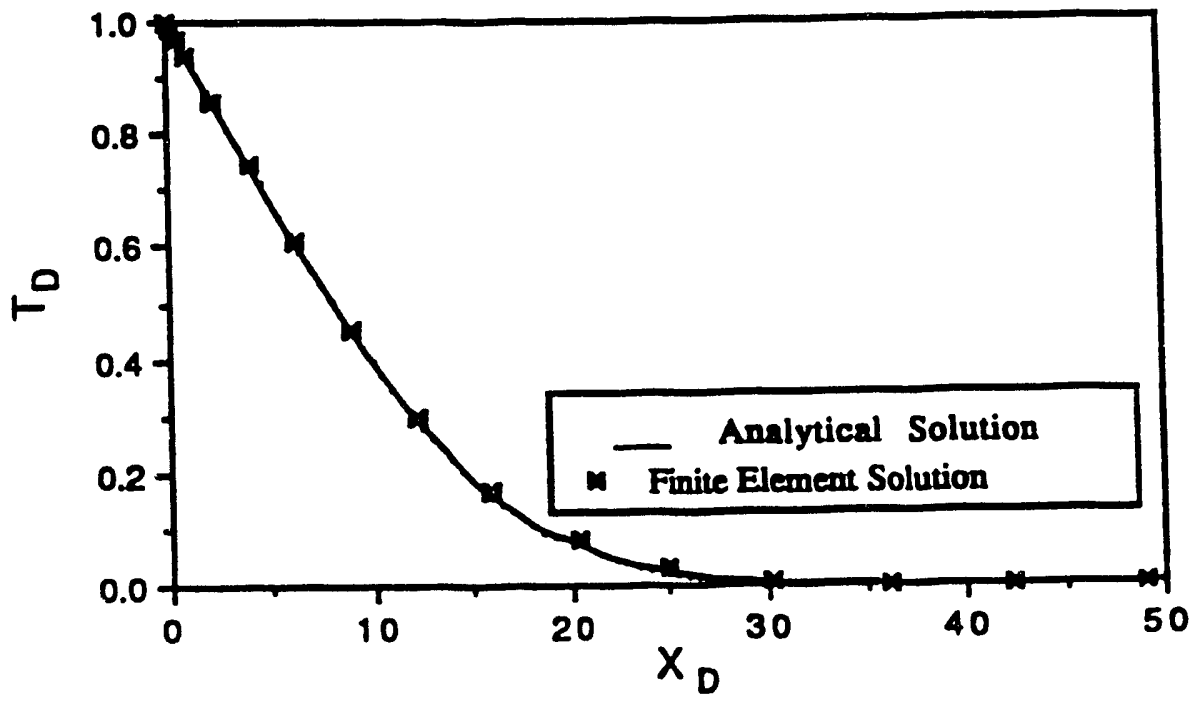

Figure 9.18: $\quad T_{D}$ versus $X_{D}$ at $t_{D}=80$ 
TABLE 9.1

PARAMETERS USED FOR AVDONIN VALIDATION CASE

\begin{tabular}{rrr}
\hline Parameters & Dimension \\
\hline $\begin{array}{r}\text { Specific Heat } \\
\text { Capacity of rock }\end{array}$ & 850.00 & $\mathrm{Jkg}^{-1} \mathrm{~K} \cdot 1$ \\
Density of rock & 2670.00 & \\
Thermal conductivity & 2.90 & $\mathrm{kgm}^{-1}$ \\
of rock & $\mathrm{Wm}^{-1} \mathrm{~K}^{-1}$ \\
Thickness of aquifer & 35.00 & \\
Porosity & 2.70 & $\mathrm{~m}$ \\
Undisturbed & 40.00 & ${ }^{\%}$ \\
Temperature & & ${ }^{\circ} \mathrm{C}$ \\
Injection Rate & 25.00 & ${ }^{\circ} \mathrm{C}$ \\
Injection Temperature & 0.03 & $\mathrm{~m}^{3} \mathrm{~s}^{-1}$ \\
\hline
\end{tabular}




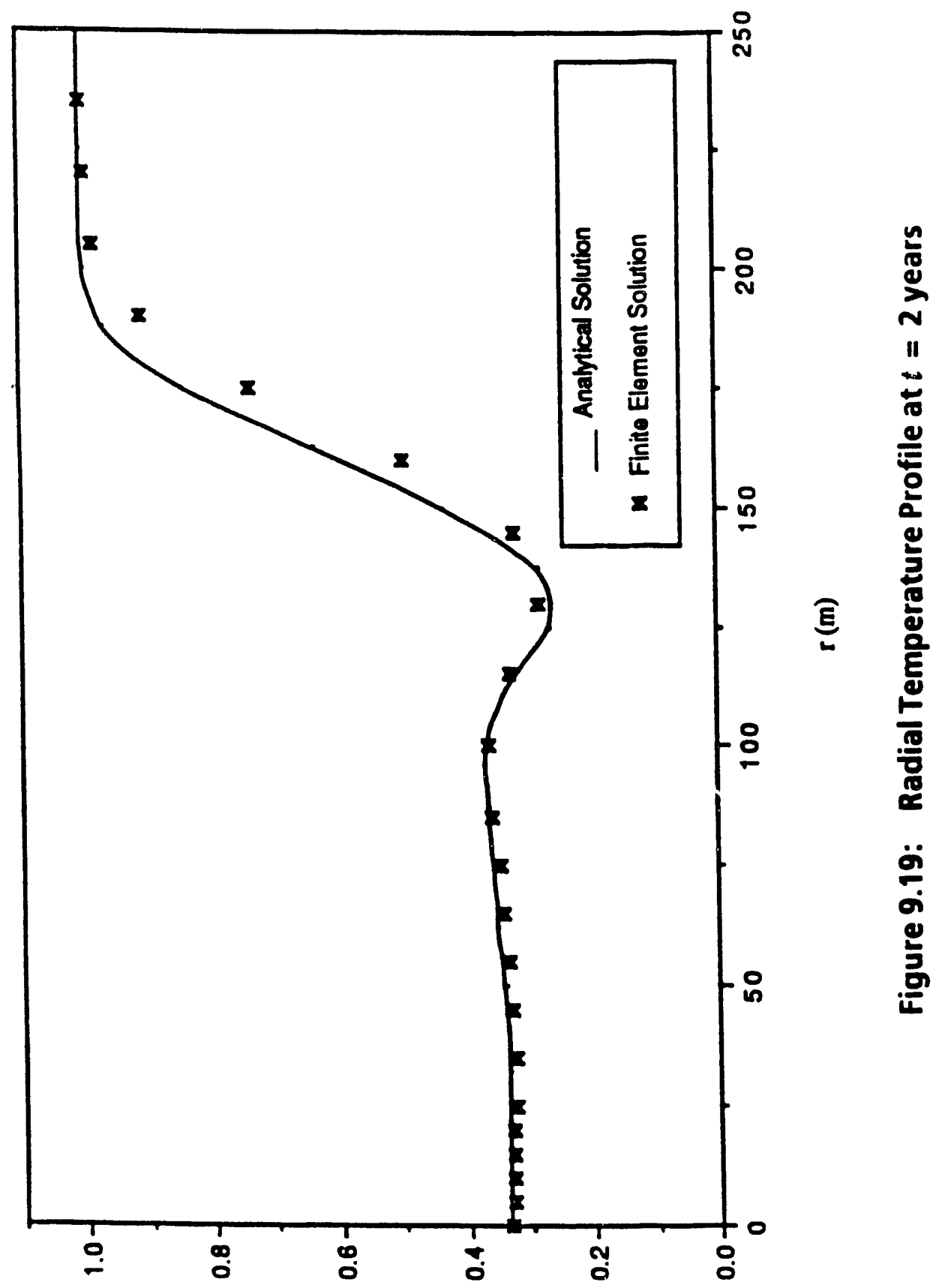

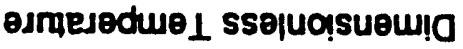


Avdonin model that the temperature in the aquifer is independent of vertical position, giving rise to an overestimation of heat transfer rate from adjacent formations to the aquifer.

\subsubsection{Two-Phase Immiscible Flow in Porous Media}

\subsubsection{Buckley Leverett Solution for Two-Phase Flow}

The radial Buckley Leverett solution is given by:

$$
R^{2}=V p_{i}\left(\frac{d f_{w}}{d S_{w}}\right)_{s w}
$$

where

$$
\begin{gathered}
V p_{i}=\text { Injected Pore Volume } \\
\left(\frac{d f_{w}}{d S_{w}}\right)_{s w}=\text { derivative of fractional flow curve at } S_{\omega} \\
R^{2}=\frac{r^{2}}{r_{e}^{2}}-\frac{r^{2}}{r_{e}^{2}} \quad r_{e}=\text { reservoir limit } \\
r_{e}=\text { well radius }
\end{gathered}
$$

Assumptions made in the derivation of the Buckley Leverett model are that both fluids in the system are incompressible, the fractional flow of the displacing fluid is only a function of it's own saturation, and that there is no mass transfer between fluid phases.

In order to investigate the two phase flow behavior of the finite element model, simplifications were made to the simulator to follow the assumptions of the Buckley Leverett model. Both fluids were treated as incompressible and their viscosities were equivalent, $\mu_{\omega} / \mu_{\circ}=1$. Relative 
permeability correlations for a hypothetical oil/water system from Willhite (1986) were used:

$$
\begin{array}{lll}
K_{r o}=a_{1}(1-S w d)^{m}, & a_{1}=1.0 \quad \text { and } m=2.56 \\
K_{r \omega}=a_{2}(S w d)^{n}, & a_{2}=0.78 \text { and } n=3.72
\end{array}
$$

All comparisons were made at a $V p i=.2$.

Literature has reported considerable difficulties in the numerical solutions for immiscible displacement problems. Often convergence is not achieved or convergence to wrong solutions that are characterized by sever oscillations at the location of the shock front are observed. These difficulties have been overcome by upstream weighting of mobilities and lumped formulations for the mass matrix. Several upstream weighting schemes have been proposed. The most straight forward and most commonly used scheme is evaluating the mobility between two adjacent nodes by using an average of the mobilities of the two nodes with greater weight given to the upstream node. A second scheme described by Huyakorn and Pinder is the upstream weighted residual technique. The spatial derivative terms of the continuity equations are weighted with an asymmetric weighting function that gives greater weighting to the upstream nodes.

Both of the upstream weighting methods were investigated in this study with no success. Convergence could only be achieved for a very narrow range of cases where initial water saturation was high enough so that no shock front or a very small shock front was given by the Buckley Leverett solution. 
Because of the unsuccessful attempts to match the Buckley Leverett solution with the above schemes, a simpler and more approximating scheme was developed. An upstream elemental average mobility was implemented into the finite element model. The scheme calculates the fluid relative permeabilities at a point upstream from the centroid of the element and treats the relative permeabilities as constant values over the element rather than interpolating them across the element. The scheme is described as follows.

Figure 9.20 illustrates the method. First the direction of the fluid flux is determined. Then a line segment is determined by passing the flux directional vector through the centroid of the element. The line segment is described in length by the intersection of the flux vector with the sides of the element. Then the portion of the line segment that is upstream of the centroid is scaled. The upstream mobility is then calculated by interpolating the saturations from the three nodes to a point on the scale reflecting the amount of upstream weighting desired and then using this saturation to calculate the fluid mobilities. The saturation value calculated at the intersection point of the line segment and the upstream element side is the result of weighting with a weighting factor equal to one, $w=1$, and the saturation calculated at the centroid is the result of $w$ $=0$.

A range of upstream weighting from 0 to 1.0 were investigated. Figures 9.21 through 9.26 show the effect of upstream weighting of mobilities. A weighting factor of 1.0 was found to give the best performance.

Note the spikes in the saturation profiles on Figures 21 through 26, which are found to be most severe around the location of the shock front. 


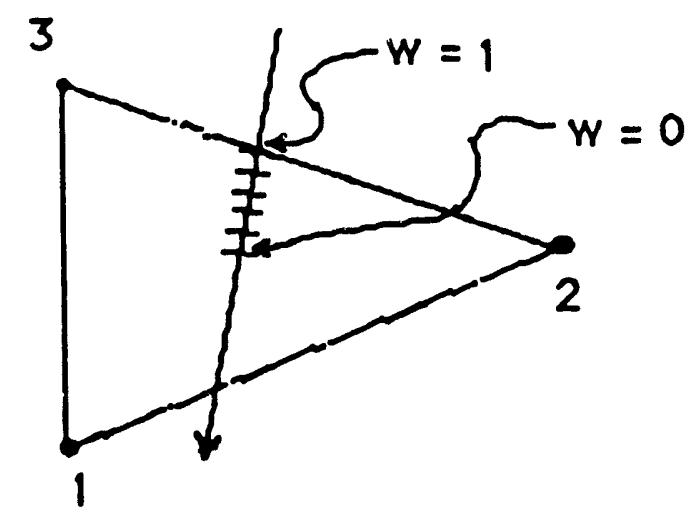

Figure 9.20: Upstream Weighting Scheme 


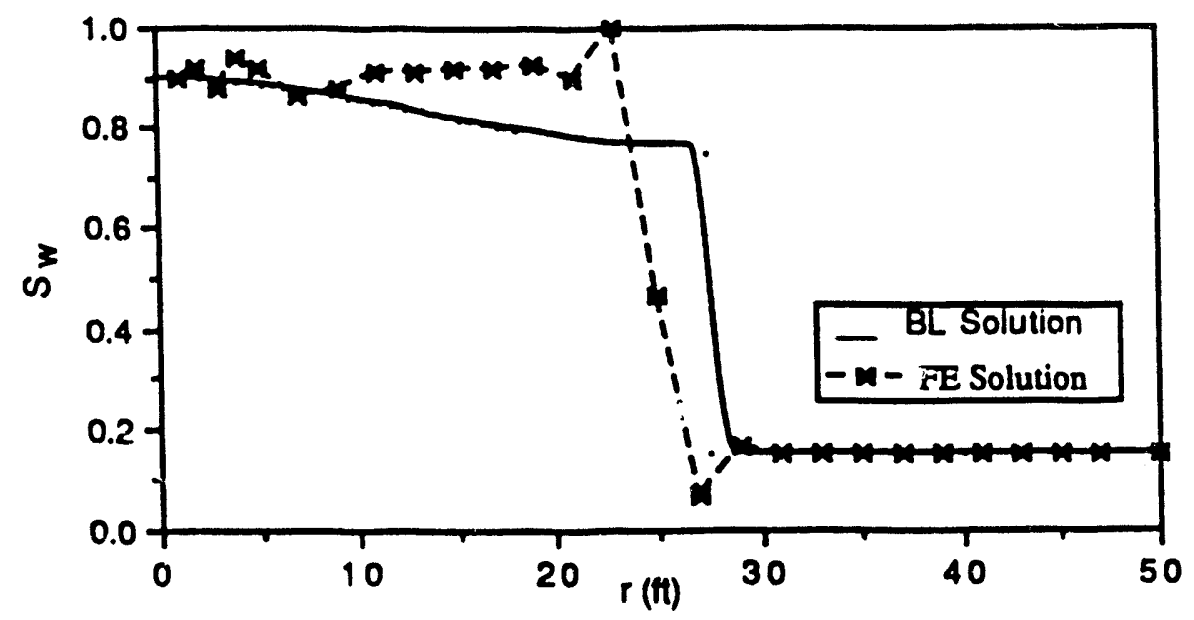

Figure 9.21: Saturation Profile For Viscosity Ratio $=1, w=0$, Consistent Formulation

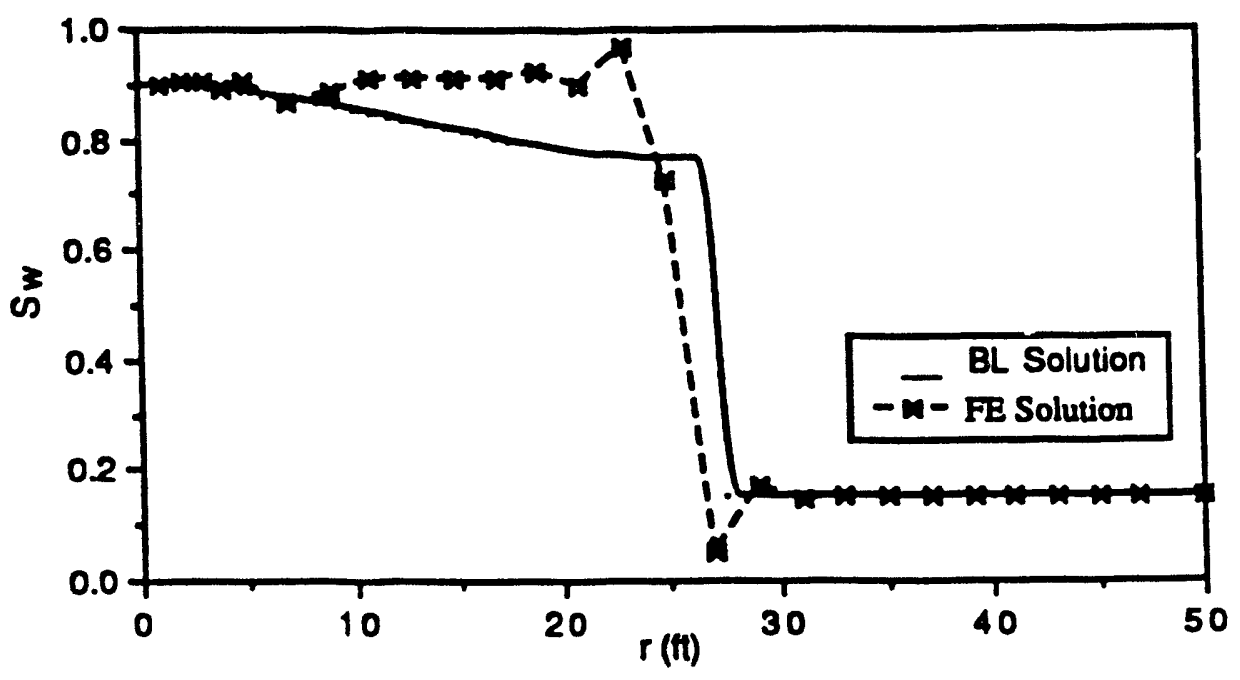

Figure 9.22: Saturation Profile For Viscosity Ratio $=1, w=0.2$. Consistent Formulation 


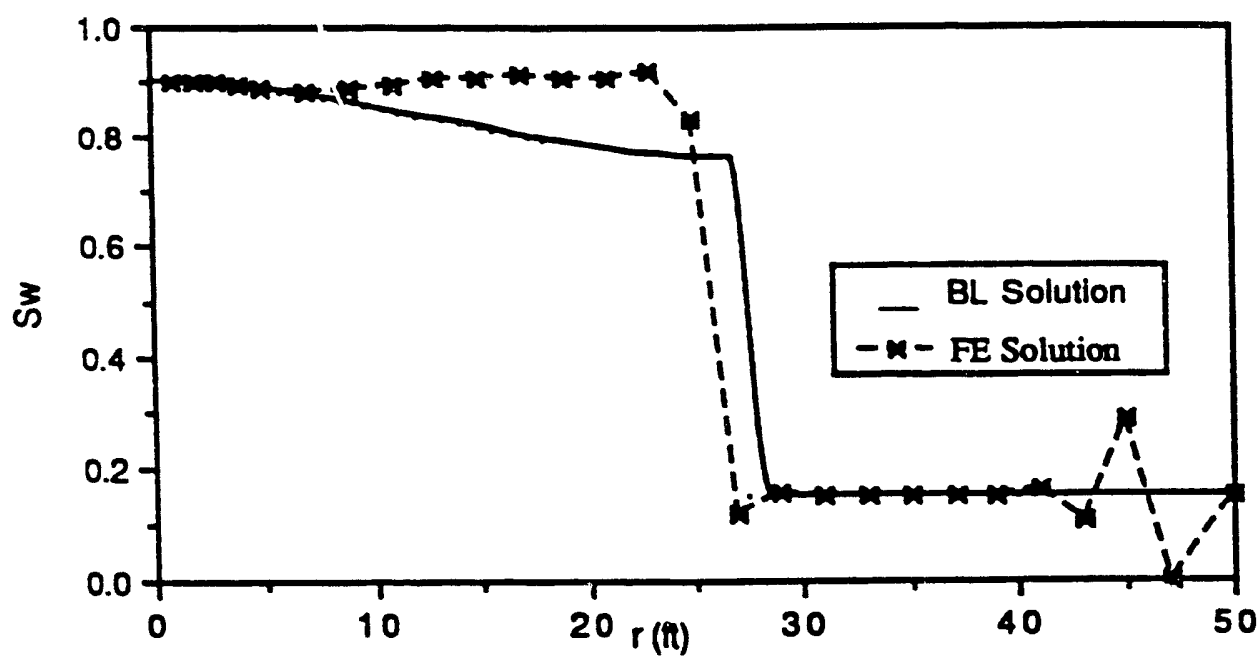

Figure 9.23: Saturation Profile For Viscosity Ratio $=1, w=0.4$, Consistent Formulation

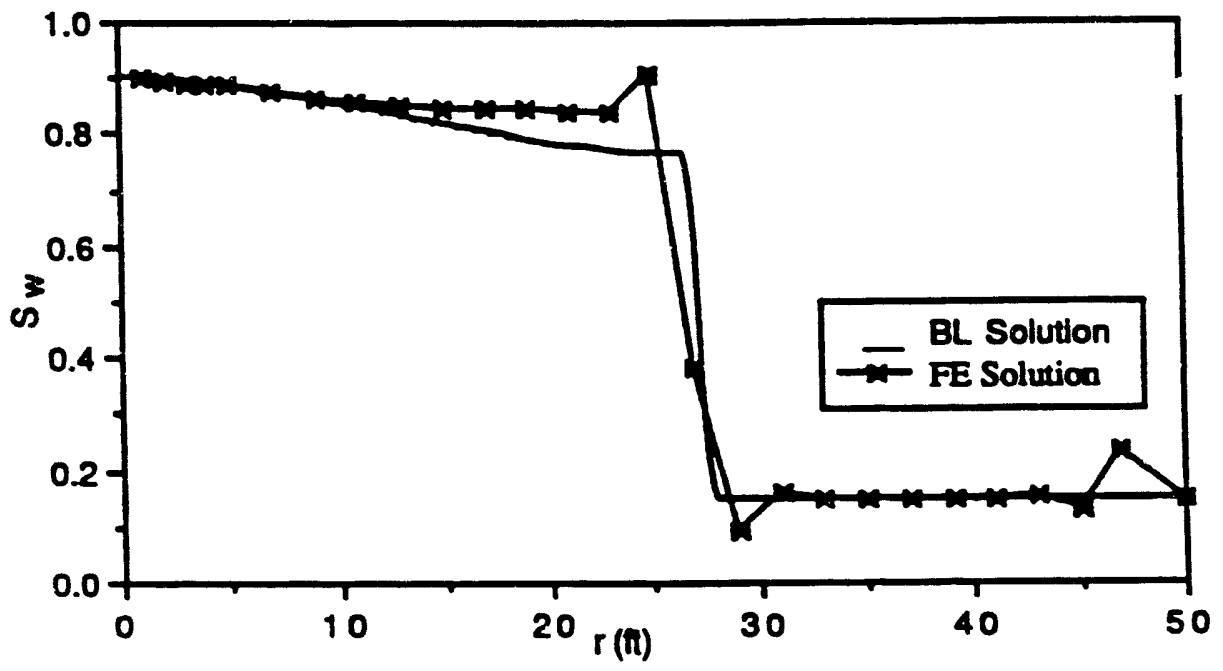

Figure 9.24: Saturation Profile For Viscosity Ratio $=1, w=0.6$, Consistent Formulation 


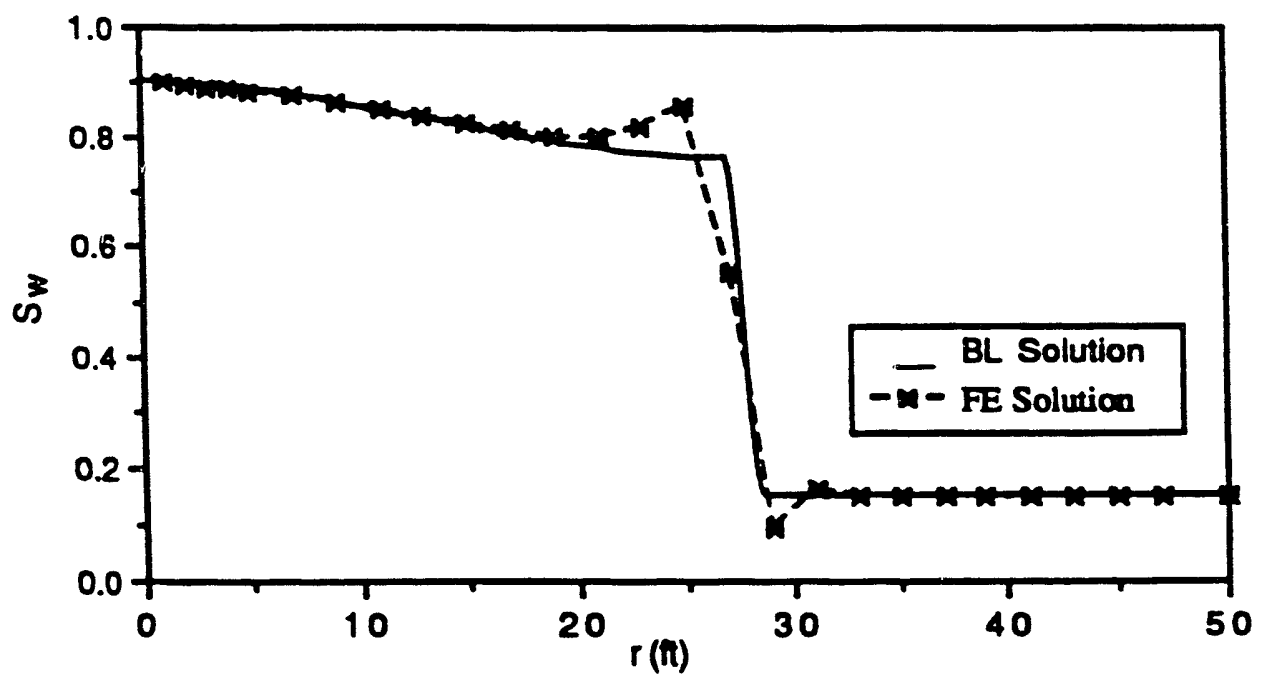

Figure 9.25: Saturation Profile For Viscosity Ratio $=1, w=0.8$, Consistent Formulation

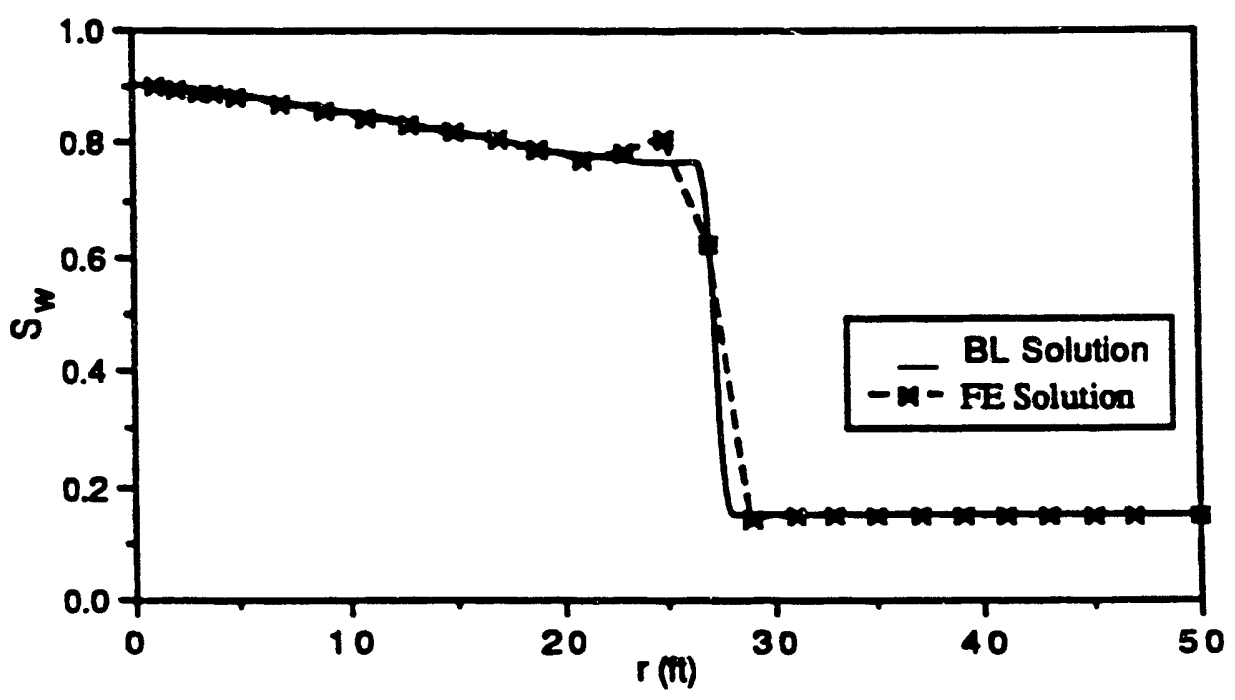

Figure 9.26: Saturation Profile For Viscosity Ratio $=1, w=1.0$, Consistent Formulation 
It has been found that lumping of the mass matrix will alleviate oscillations in the saturation profile and smooth these spikes.

Consider the mass term of Eq (9.38)

$$
\phi \mathrm{\rho}_{w} \int_{R e} N_{l} N_{J} \frac{S w_{J}^{k+1}-S w_{J}^{k}}{\Delta l} r d r d z
$$

Bringing the saturation time derivative out of the integral:

$$
\phi \rho_{w} \frac{S w_{J}^{k+1}-S w_{J}^{k}}{\Delta t} M_{I J}^{e}
$$

where:

$$
M_{l J}^{e}=\int_{R e} N_{l} N_{J} r d r d z
$$

The lumping scheme is applied to the triangular ring elements by:

$$
M_{n}^{e}=\frac{A_{e} \bar{r}}{n^{e}}
$$

$$
M_{l J}^{e}=0 \text { for } I \neq J
$$

Where $A e$ is the area of the element, $n^{e}$ is number of nodes per element, $n^{e}=3$, and $\bar{r}=\left(r_{1}+r_{2}+r_{3}\right) / 3$ for triangular elements.

Figures 9.27 through 9.34 show the results from a lumped formulation. While the lumped formulation appears to be a bit more inaccurate than the consistently formulated mass matrix, a much smoother saturation profile is obtained and convergence was observed to 


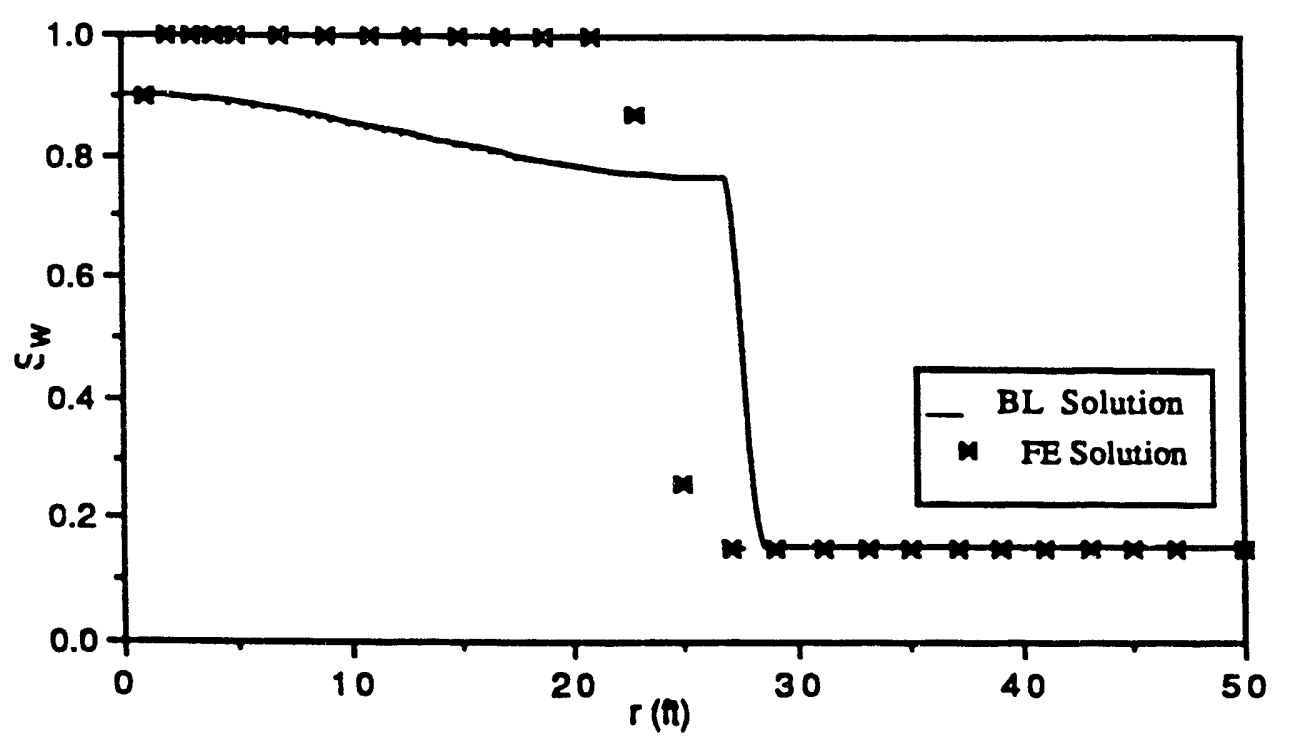

Figure 9.27: Saturation Profile For Viscosity Ratio $=1, w=0$, Lumped Formulation

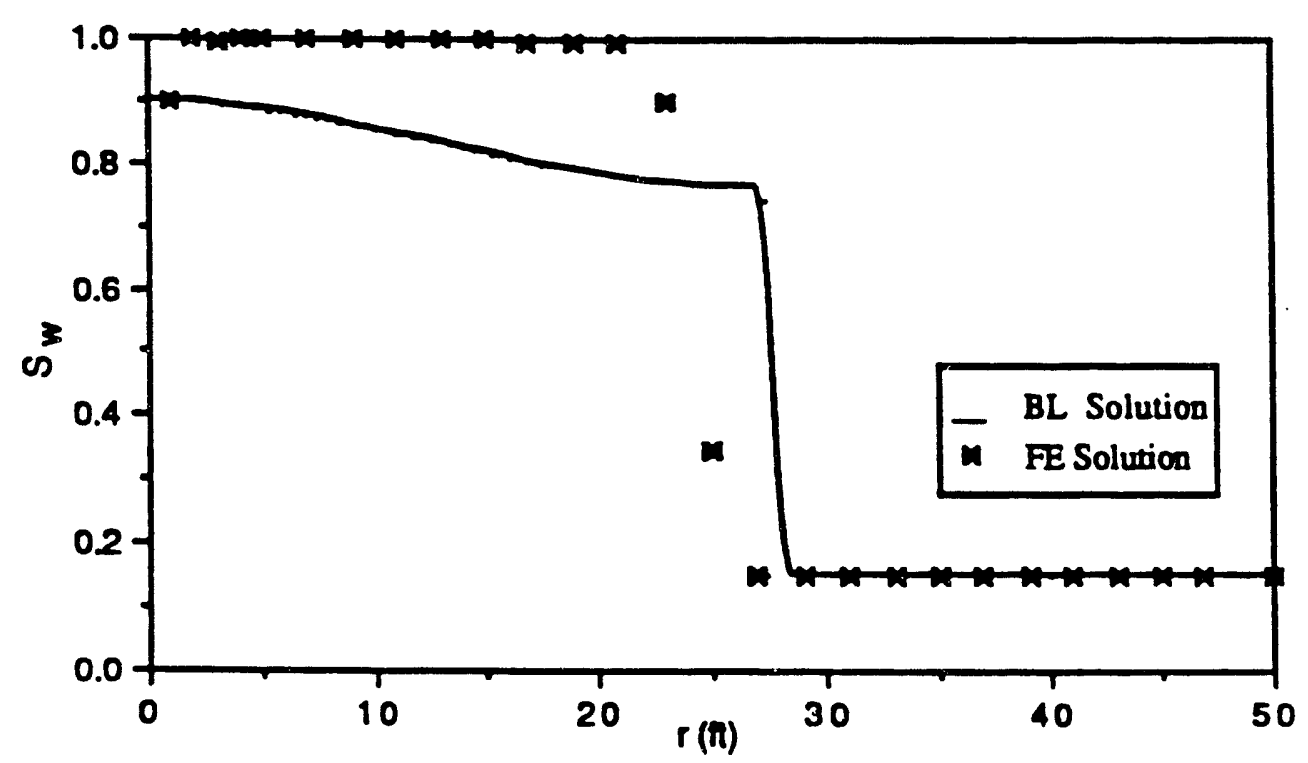

Figure 9.28: Saturation Profile For Viscosity Ratio $=1, w=0.2$, Lumped Formulation 


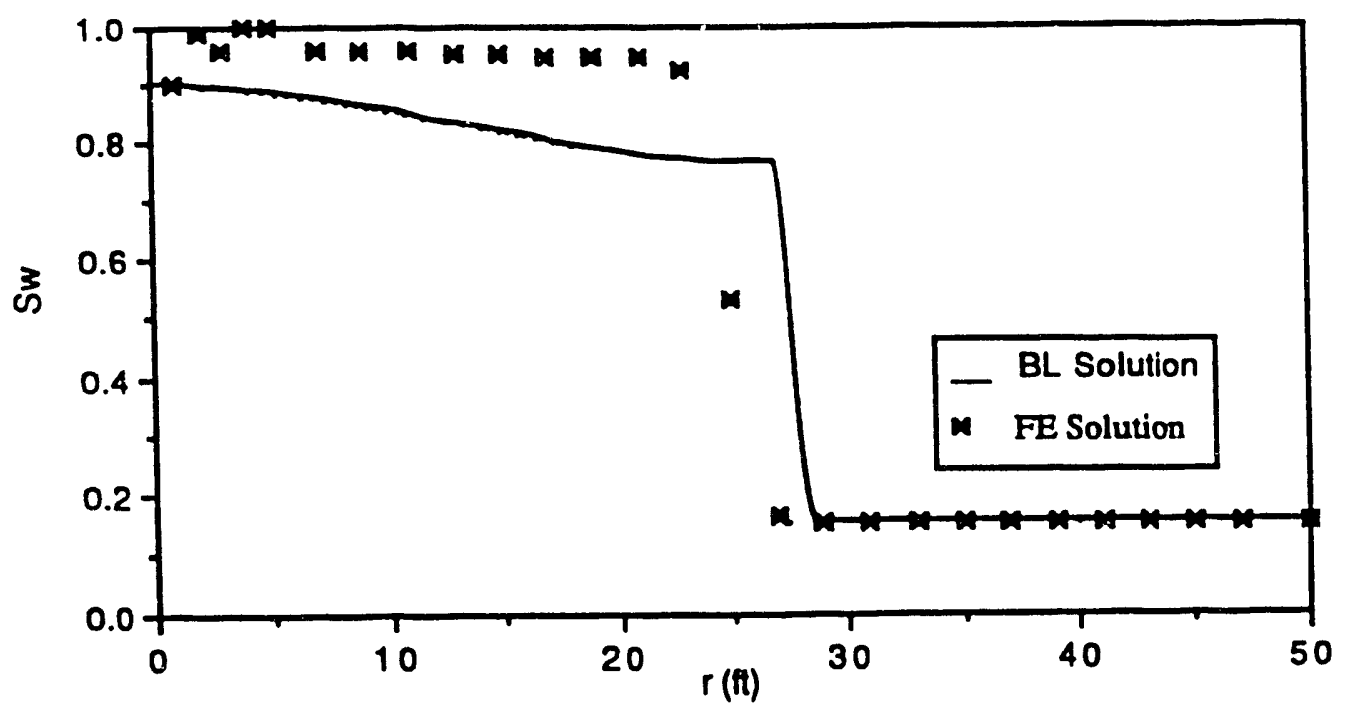

Figure 9.29: Saturation Profile For Viscosity Ratio $=1, w=0.4$, Lumped Formulation

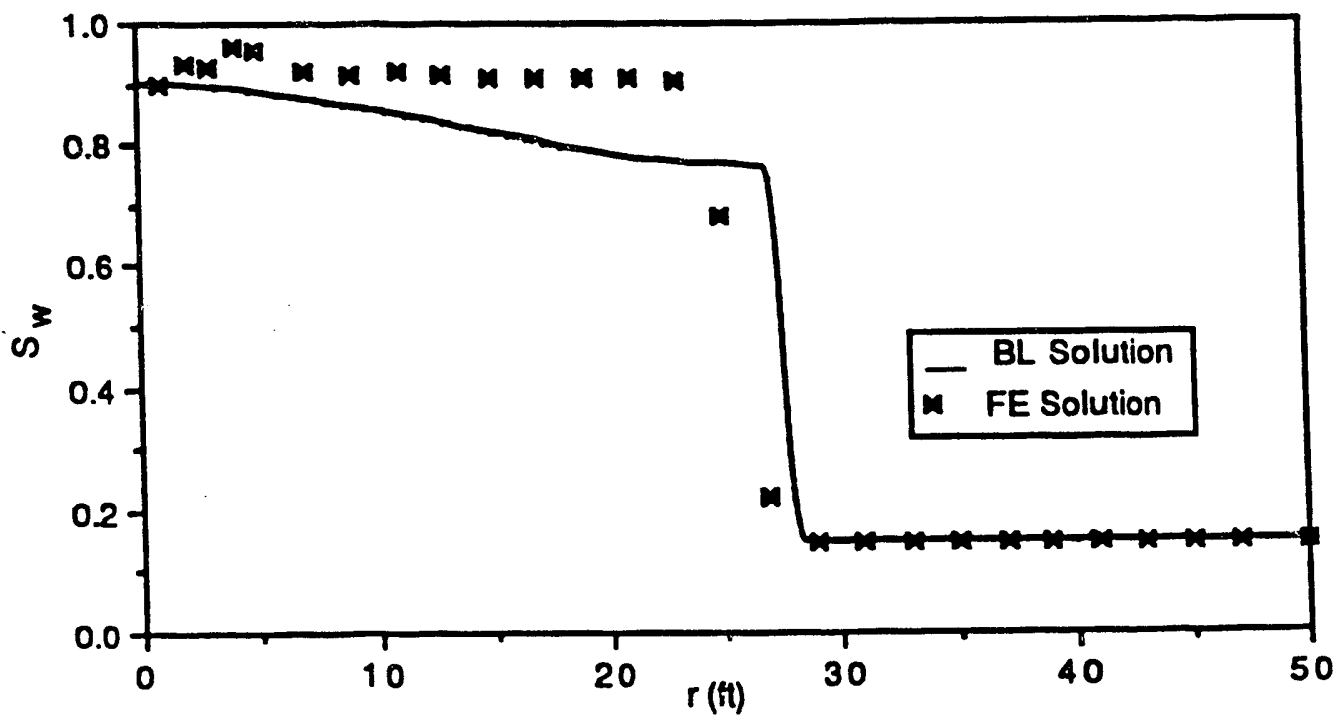

Figure 9.30: Saturation Profile For Viscosity Ratio $=\mathbf{1}, \mathbf{w}=\mathbf{0 . 6}$, Lumped Formulation 


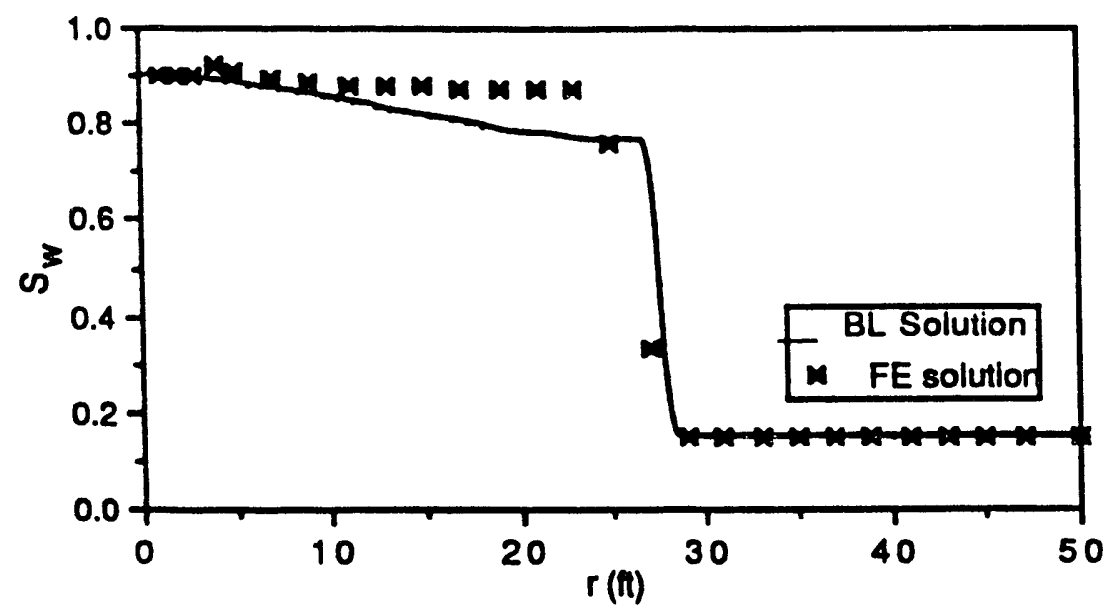

Figure 9.31: Saturation Profile For Viscosity Ratio $=1, w=0.8$, Lumped Formulation

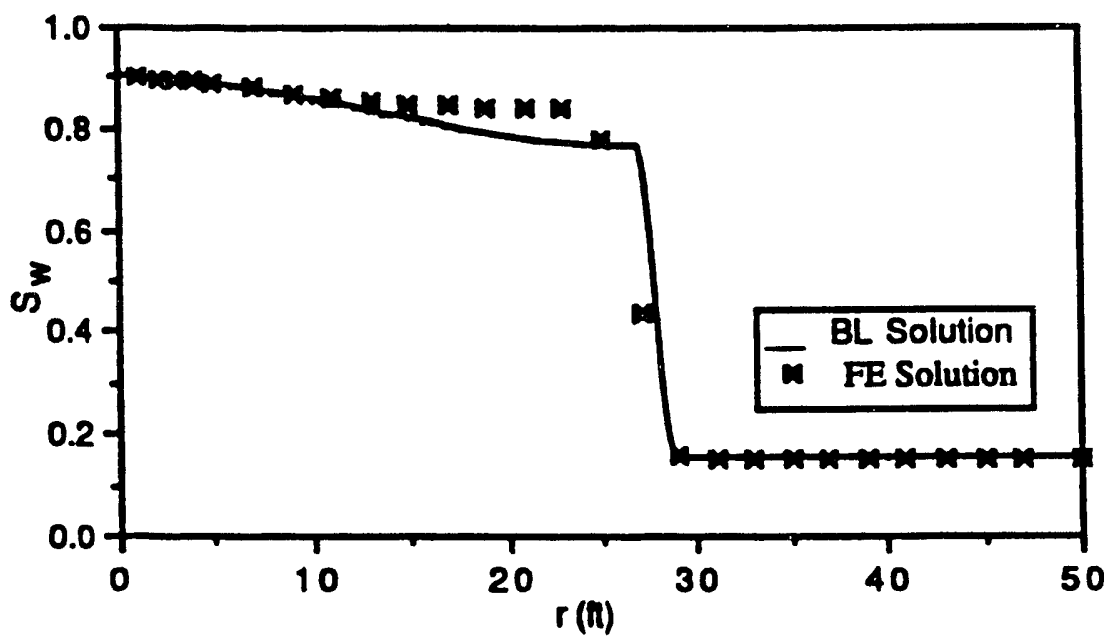

Figure 9.32: $\quad$ Saturation Profile For Viscosity Ratio $=1, w=1.0$, Lumped Formulation 


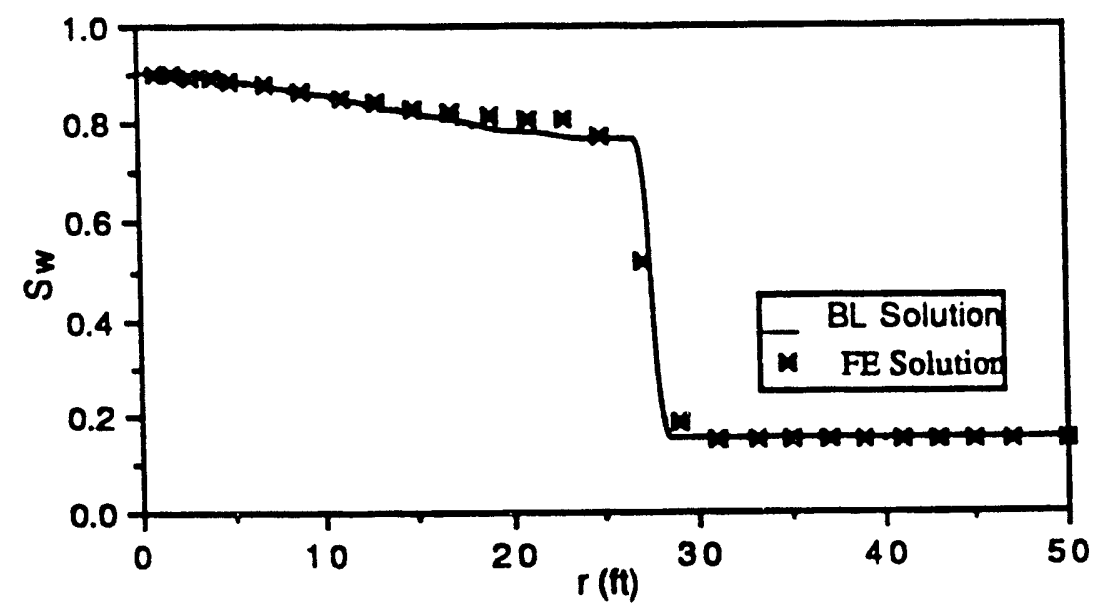

Figure 9.33: Saturation Profile For Viscosity Ratio $=1, w=1.2$, Lumped Formulation

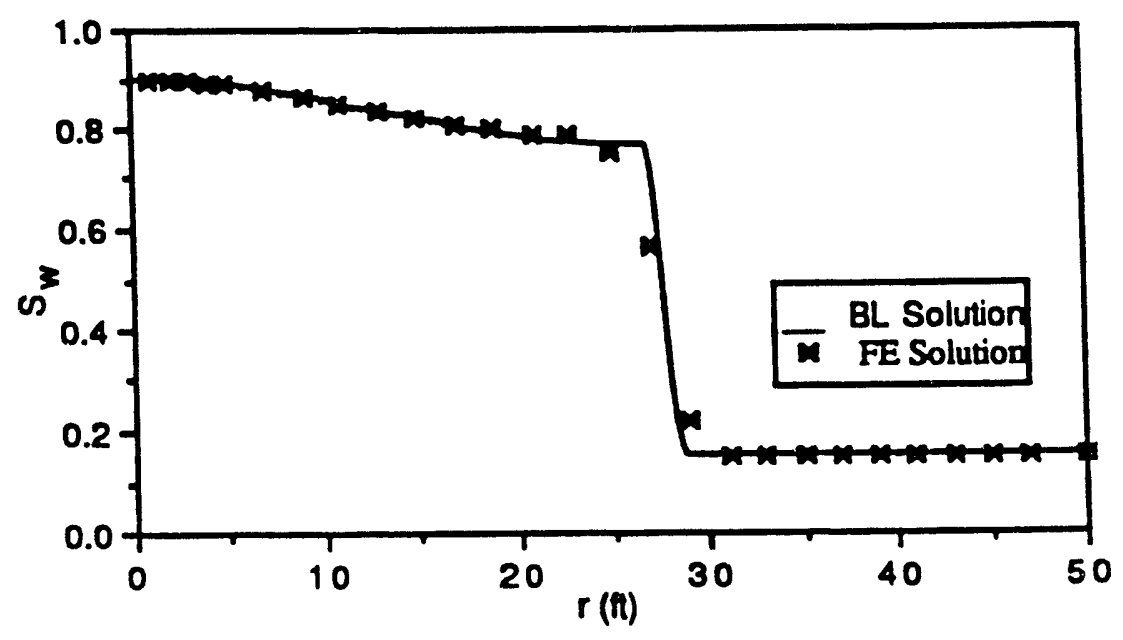

Figure 9.34: Saturation Profile For Viscosity Ratio $=1, w=1.4$, Lumped Formulation 
be achieved with fewer iterations with the lumped formulation over the consistent formulation.

\subsubsection{Piston-Like Displacement}

Investigating the displacement behavior of an oil/water system gave insight into the effect of upstream weighting and lumping, however it did not investigate the exact conditions that will be encountered in a hydrate reservoir. For the case of a gas/water system, the displacing fluid to displaced fluid viscosity ratio is in the order of 100 , much higher than the viscosity ratio of unity that was used in the above investigation. The fractional flow curve for water displacing oil is shown in Figure 9.35, while the fractional flow curve for water displacing gas is shown in Figure 9.36. Figure 9.35 clearly indicates that a typical Buckley Leverett type saturation profile will be generated. Figure 9.36 however, indicates that piston-like displacement will take place causing a sharp saturation change from $1-S_{g r}$ to $S_{\omega r}$ at the front.

A simulation run was conducted for the case of water injected into a gas saturation reservoir. The residual water saturation was specified at $15 \%$ and the residual gas saturation was specified at $10 \%$. Figure 9.37 compares the finite element solution for the saturation profile to the piston like displacement curve at a .2 pore volume of injected water. To obtain adequate performance for this case, an upstream weighting parameter of 3.0 was used with limits on the upstream mobility calculations not to exceed the mobility at a water saturation of $1-S_{g r}$. 


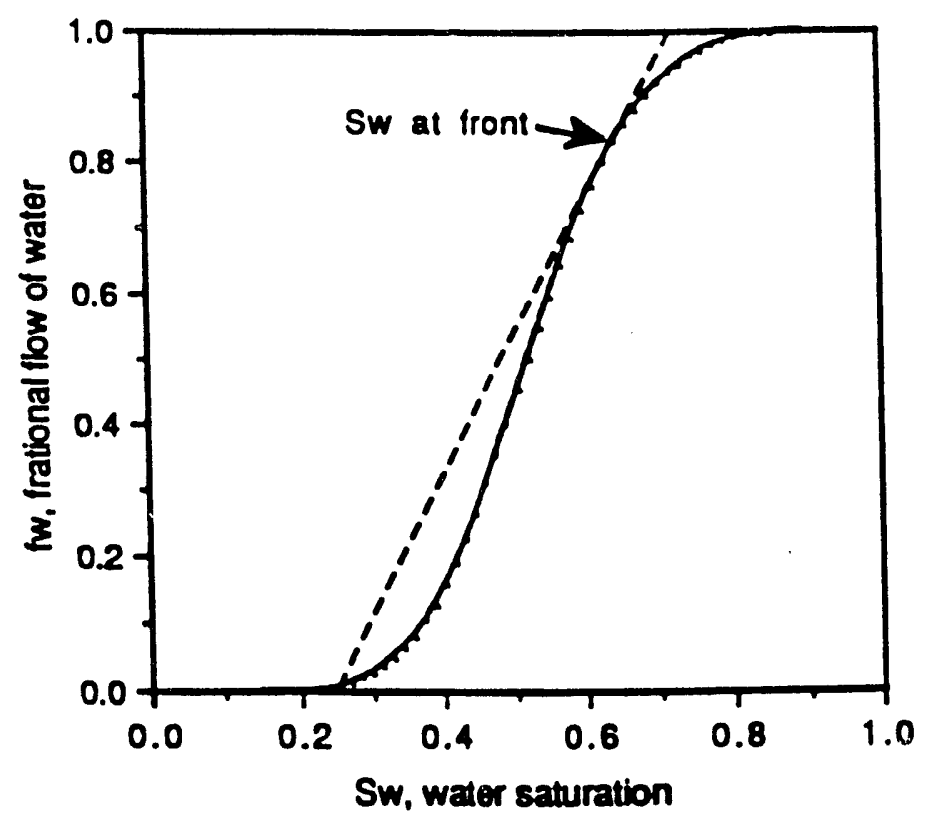

Figure 9.35: Fractional Flow Curve For Viscosity Ratio $=1$

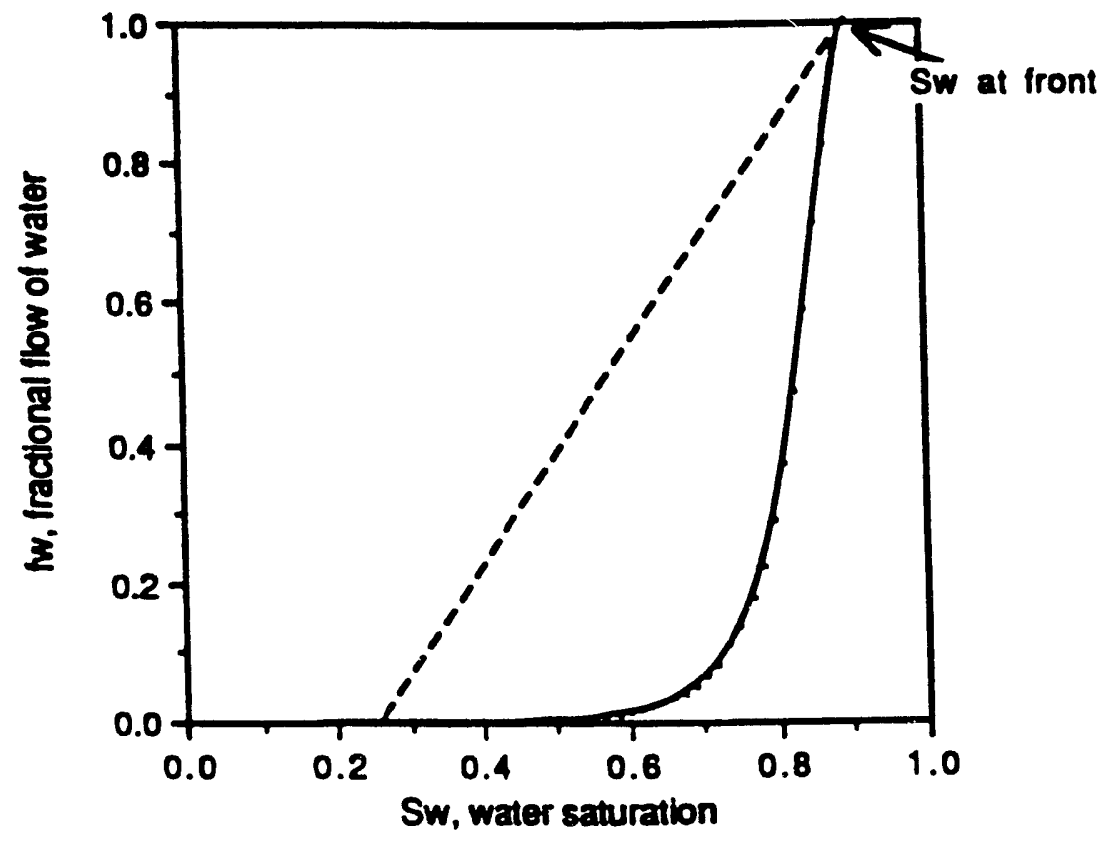

Figure 9.36: Fractional Flow Curve For Viscosity Ratio $=100$ 


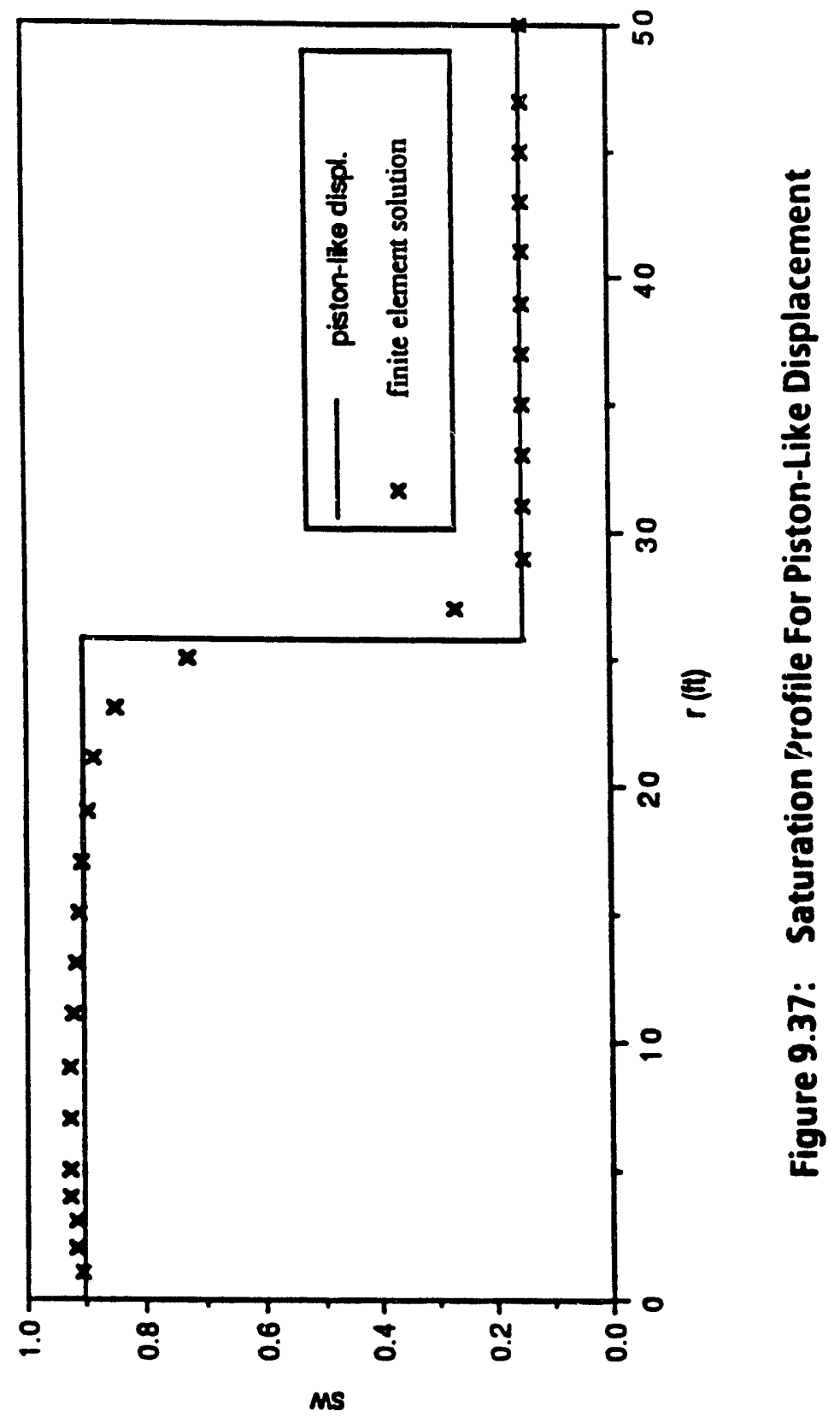




\subsection{Application of Model to Hydrate Reservoir}

Two remaining steps were considered to gain insight into the proposed finite element scheme to model thermal recovery of gas hydrates. The first step entails investigating the performance of the simulator for two-phase convective heat transfer cases. The second step being the implementation and testing of a scheme to deal with the addition of water and gas into the system along the thawing interface as the hydrates dissociate.

\subsubsection{Two-Phase (gas/water) Convective Heat Transfer}

An example was run for the injection of hot water into a reservoir that is saturated with a combination of water and gas. This run was made to investigate the convective heat transport behavior for the two-phase gas/water system. An analytical solution is not available to validate this problem, however, intuitive investigation of the simulator's results is beneficial in understanding the capabilities and performance of the proposed finite element scheme. The reservoir is described by the properties presented in Table 9.2. The water saturation, pressure, and temperature were specified along the wellface at $.9,2000 \mathrm{psi}$, and $100^{\circ} \mathrm{F}$ respectively to simulate the injection of hot water at a constant bottom hole pressure.

Two anomalies appeared in the temperature profile for this simulation run (see Figure 9.38). The dashed lines of Figure 9.38 indicate the upper and lower limits of the possible temperature range for this problem. The first anomaly is clearly seen as a excessive temperature rise near the wellbore. From Figure 9.39 the second anomaly is seen as a dip in the temperature profile immediateiy before the saturation front. 
TABLE 9.2

PARAMETERS FOR TWO-PHASE CONVECTIVE HEAT TRANSFER CASE

\begin{tabular}{ll} 
Reservoir thickness & $5.0 \mathrm{ft}$ \\
Reservoir pressure & $1000 \mathrm{psi}$ \\
Reservoir temperature & $40{ }^{\circ} \mathrm{F}$ \\
Initial water saturation & 0.40 \\
Residual water saturation & 0.15 \\
Residual gas saturation & 0.05 \\
Reservoir porosity & 0.25 \\
Reservoir permeability & $0.01 \mathrm{Darcys}$ \\
Conductivity of rock matrix & $1.36 \mathrm{Btu} / \mathrm{hr} \mathrm{ft}^{\circ} \mathrm{F}$ \\
Heat capacity formation & $0.2 \mathrm{Btu} / \mathrm{lb}^{\circ} \mathrm{F}$ \\
Density of rock matrix & $167 \mathrm{lb} / \mathrm{ft}^{3}$ \\
upstream weighting parameter & 3.0 \\
Wellbore diameter & $1 \mathrm{ft}$ \\
\hline
\end{tabular}




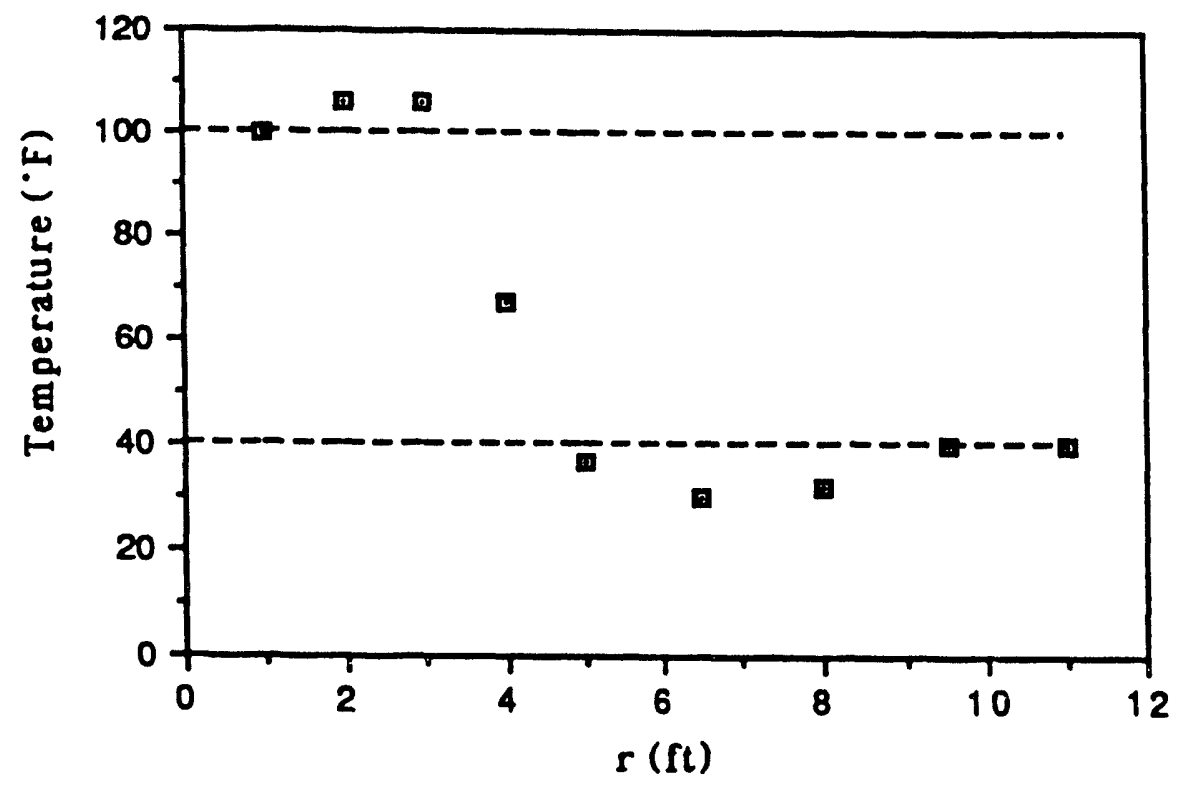

Figure 9.38: Radial Temperature Profile For Hot Water Injection Into Gas/Water System

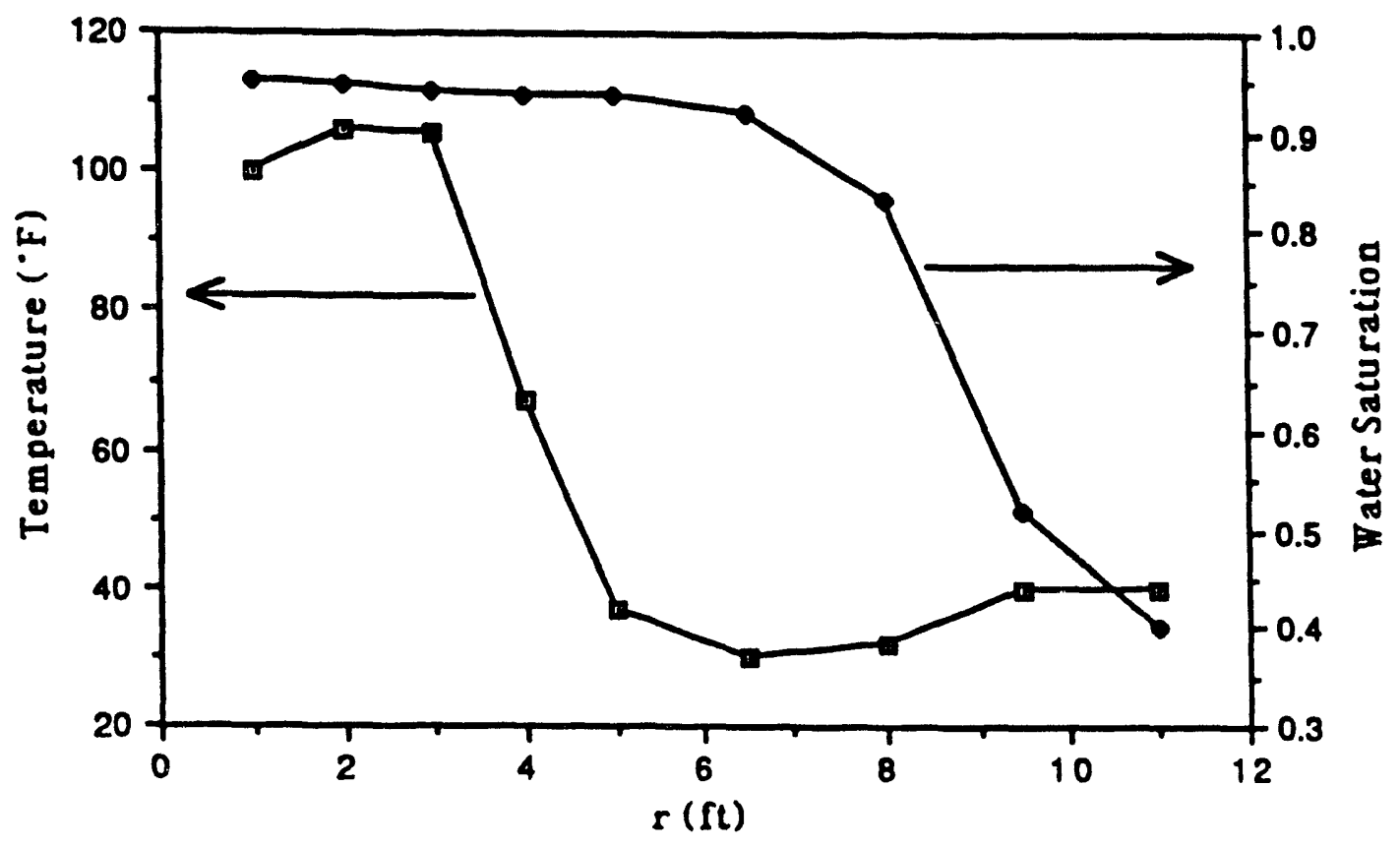

Figure 9.39: Radial Temperature and Saturation Profiles For Hot Water Injection Into Gas Water System 
The anomalies are suspected to be caused from the finite element formulation of the convective term. Consider the convective terms of the finite element formulation outlined in earlier section (from Eq 9.30):

$$
\int_{R e} N_{I} I_{r} \frac{\partial N_{J}}{\partial r} r d r d z+\int_{R e} N_{1} I_{2} \frac{\partial N_{J}}{d z} r d r d z, \quad J=1,2, \ldots, n_{e}
$$

where,

$$
I_{r}=\rho_{\omega} C_{p w} T V_{r}^{\omega}+\rho_{g} C_{p g} T V_{r}^{g} \quad I_{z}=\rho_{\omega} C_{p w} T V_{z}^{\omega}+\rho_{g} C_{p g} T V_{z}^{g}
$$

The velocity in the $I$ terms are calculated by Darcy's Law:

$$
v_{i}^{0}=\frac{k_{r}^{a} k_{i j}}{\mu_{a}}\left(\frac{\partial P}{\partial x_{j}}\right) \quad a=w, g \text {, (neglecting the gravity term.) }
$$

Where the relative permeability of each respective fluid is a strong function of the fluid's saturation in the porous media $\left(k_{r}^{a}=k_{r}^{a}\left(S_{a}\right), a=w, g\right)$. The relative permeabilities are calculated by an upstream weighting scheme that is described in earlier sections. The upstream weighting scheme treats the relative permeabilities as elemental properties. In other words, they are represented as constant properties in each element rather than inteipolated properties over the elemental domain. Treating the relative permeability as a constant value over the element is not entirely correct, especially across elements with large saturation changes. So the fluid velocities are essentially treated as averaged elemental properties in the finite element model because of the way the relative permeabilities are calculated.

Rewriting the $I_{r}$ and $I_{2}$ terms as: 


$$
\begin{aligned}
& I_{r_{J}}=\left(V_{r}^{\omega} \rho_{w} C_{p w}+V_{r}^{g} \rho_{g} C_{p g}\right)_{e} T_{J} \\
& I_{z_{J}}=\left(V_{z}^{w} \rho_{w} C_{p w}+V_{z}^{g} \rho_{g} C_{p g}\right)^{T} T_{J}
\end{aligned}
$$

Looking at Eqs. (9.124) and (9.125) it is apparent that $I_{r}$ and $I_{z}$ are not really fully interpolated across the elemental domain because the terms $\left(V_{r}{ }^{\omega} \rho_{w}\right.$ $\left.C_{p w}+V_{r}^{g} p_{g} C_{p g}\right)_{e}$ and $\left(V_{z}{ }^{\omega} p_{w} C_{p \omega}+V_{z}^{g} p_{g} C_{p g}\right)_{e}$ are treated as constants over the element. The only variable being interpolated across the elemental domain in Eq. (9.122) is temperature. Further work is required to determine the cause of the anomalies in the temperature profile and to devise a scheme that is capable of fully interpolating the variable " $I$ " across the element.

A second formulation of the energy equation was investigated that appeared to give better performance for simulation of the gas/water twophase convective heat transfer problem. Consider the accumulation term of the energy balance equation, from Eq. (9.10):

$$
(1-\phi) \rho C_{p} \frac{\partial T}{\partial t}+\Phi\left|\frac{\partial\left(S_{w} \rho_{w} C_{p w} T\right)}{\partial t}+\frac{\partial\left(S_{g} \rho_{g} C_{p g} T\right)}{\partial t}\right|
$$

. with hydrate neglected in this case.

If all variables in the time derivatives except for temperature are treated as constants with time then this term can be written as:

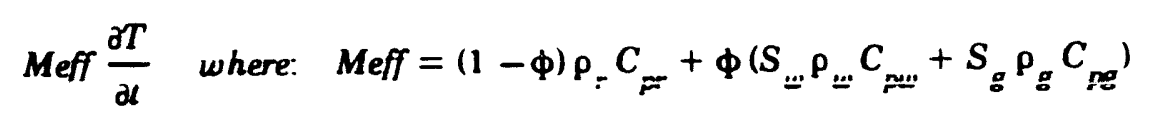


Meff is commonly referred as the volumetric specific heat.

Following the same formulation steps outlined earlier, the finite element energy equation is given by:

$$
\begin{aligned}
& C_{I}=\sum_{e}\left|I_{r}^{k+\theta} \int_{R e} N_{I} \frac{\partial N_{J}}{\partial r} r d r d z+I_{z}^{k+\theta}\right|_{R e} N_{l} \frac{\partial N_{J}}{\partial z} r d r d z \\
& +K^{k+\theta} T_{J}^{k+\theta} \int_{R e}\left(\frac{\partial N_{I}}{\partial r} \frac{\partial N_{J}}{\partial r}+\frac{\partial N_{I}}{\partial z} \frac{\partial N_{J}}{\partial z}\right) r d r d z \\
& +\int_{R e} N_{I} N_{J} M e f f_{J} \frac{T_{J}^{k+1}-T_{J}^{k}}{\Delta t} r d r d z \\
& -\int_{B e} N_{I} K_{r} \frac{\partial T}{\partial r} n_{r} r d 1-\int_{B e} N_{1} K_{z} \frac{\partial T}{d z} n_{z} r d 1 \mid, I=1,2, \ldots, n
\end{aligned}
$$

A simulation run was conducted with the parameters of Table 9.2 using the above formulation and compared to the formulation outlined in earlier sections. Figure 9.40 shows the comparison of the two formulations where scheme $A$ is the formulation outlined in eariter, and scheme $C$ is the formulation given by Eq. (9.128). Formulation $C$ appears to give better performance for solving this problem than formulation $A$.

\subsubsection{Hydrate Thawing Problem}

Two schemes for handling gas and water flux along thawing hydrate interface were described earlier.

To implement this scheme into the finite element model three runs were investingated. The first run is a simple case with a row of constant source terms. The first case is investigated to make sure the addition of source terms does not 


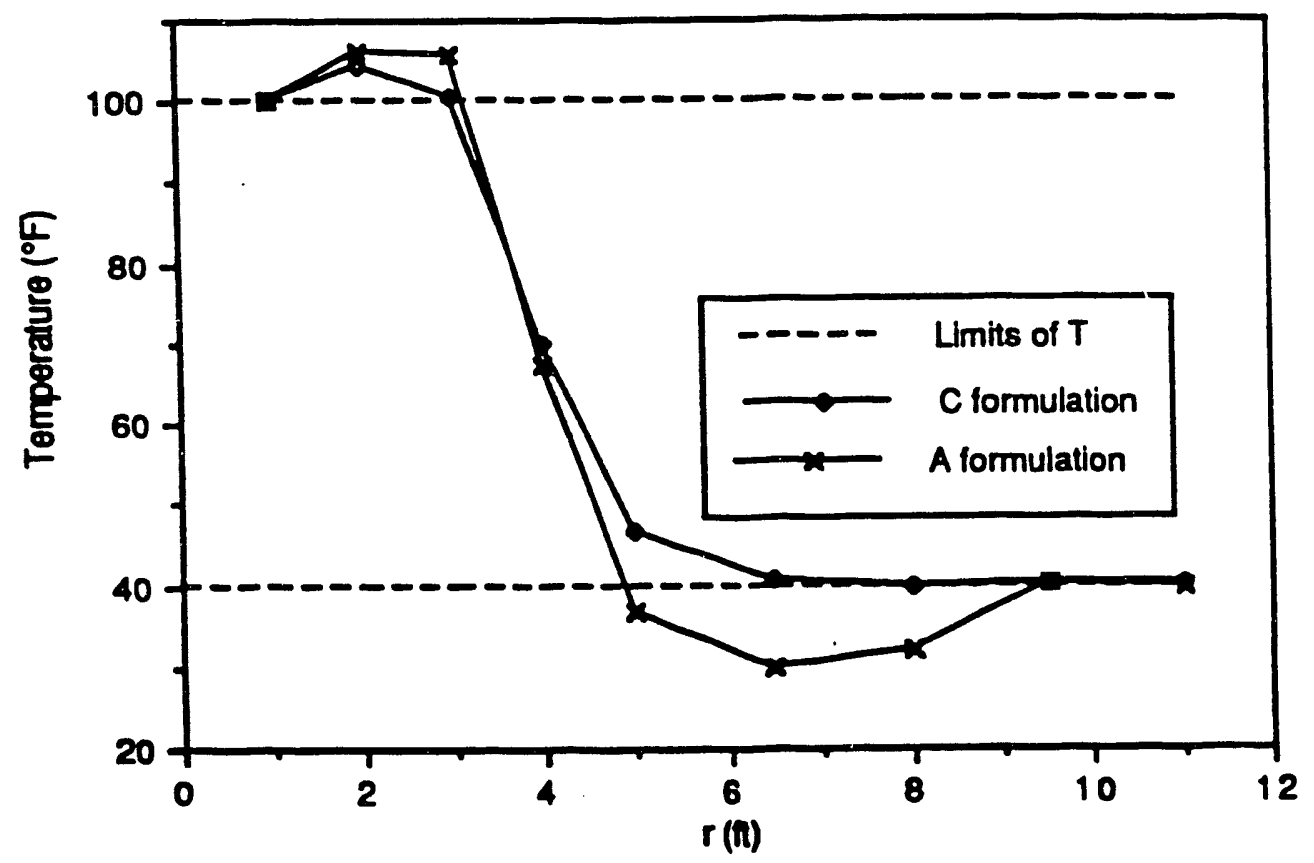

Figure 9.40: Comparison of A Formulation With C Formulation 
upset the stability of the simulator and to validate that the source terms are implemented into the computer code properly. Note that the source terms are fixed at a constant rate in this run and are not dependent on the rate of thawing as is the scheme described above.

The second case is a run with a frozen zone that is initialized with immobile gas and water. As elements begin to thaw in the frozen zone, the permeability is adjusted by Eq. (9.89). Source terms are not in place for the second case, so the large amount of gas that is released as a hydrates thaws is not represented.

The third case attempted is the complete hydrate dissociation model where all the aspects of case 2 are investigated with the addition of the source terms calculated by Eq. ( 9.90$)$.

\subsubsection{Case \#1 Run with Constant Source Terms}

The grid shown in Figure 9.41 was used for case 1 with six source terms located at a distance of 2.5 to $3.0 \mathrm{ft}$ from wellbore and impermeable rock after $3.0 \mathrm{ft}$ from the wellbore.

The source terms had a rate of $80 \mathrm{lbm} /$ day and the inner boundary had a specified pressure of 2000 psi, temperature of $80^{\circ} \mathrm{F}$, and a saturation of .95. The reservoir had a initial pressure of 1000 psi, initial temperature of $60^{\circ} \mathrm{F}$, and an initial water saturation of .60 . When the pressure gradient at the wellface became greater than 0 , the specification of the water saturation at the wellface boundary was relaxed and the boundary term of the water continuity equation was calculated and added into the residual equation. This was done to impose a condition on the boundary that wi!! !et on!y water flow into the reservoir through the wellface but will allow both fluids to flow out of the reservoir when a positive radial 


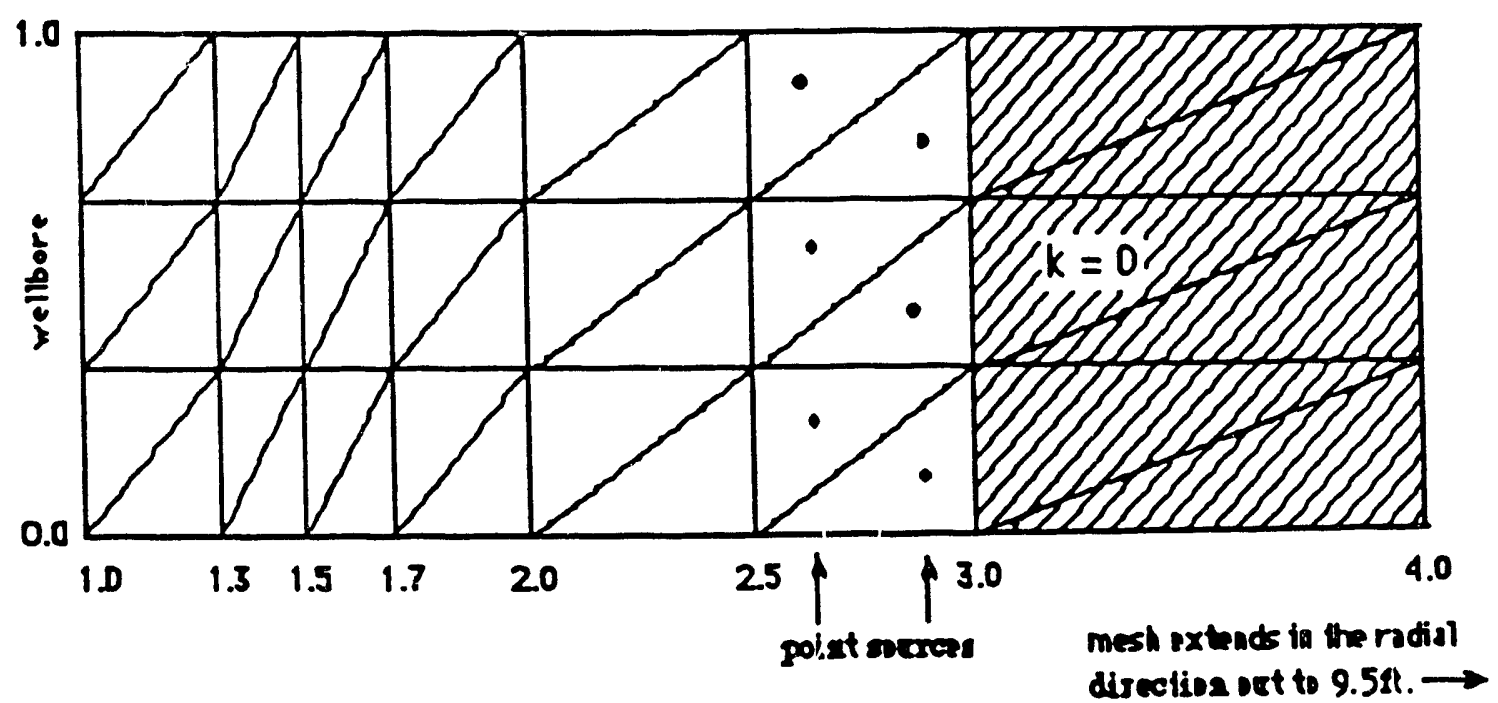

Figure 9.41: Mesh For Case \#1 Simulation Run 
pressure gradient is established. The pressure and saturation profile for the simulation are shown in Figures 9.42 and 9.43 respectively.

Figure 9.42 shows the pressure increasing with time until a positive pressure gradient is established, indicating flow radially in towards the well. The saturation profile of Figure 9.43 shows a slight increase in saturation near the wellbore where water is injected until a positive pressure gradient is established, causing flow of water back towards the wellbore. The saturation profile then decreases, indicating the gas injected by the source terms is effectively blowing the water back into the wellbore. The results from the simulation run of case \#1 were reasonable, indicating that the source terms are functioning properly.

\subsubsection{Case \#2 Thawing Run with Frozen Region Initialized with Gas and Water}

For case \#2, the reservoir geometry was given by Figure 9.44 . The shaded region of Figure 9.44 represents the hydrate region that is treated as impermeable rock but is initialized with a water saturation of $80 \%$ and a pressure of 2000 psi. As an element in the hydrate region begins to thaw, the effective permeability in the element is adjusted by Eq. (9.89).

The phase change temperature and latent heat are calculated by correlations given by Eqs. (9.129) and (9.130).

$$
\begin{aligned}
& T f r=\frac{15360.8}{37.05-\ln \left(P_{\text {avg }}\right)}-459.6-a_{f x}\left({ }^{\circ} F\right) \\
& \text { Lhe }=10743.1-1.9204 \mathrm{Tfr} \quad(\text { Btullbm })
\end{aligned}
$$




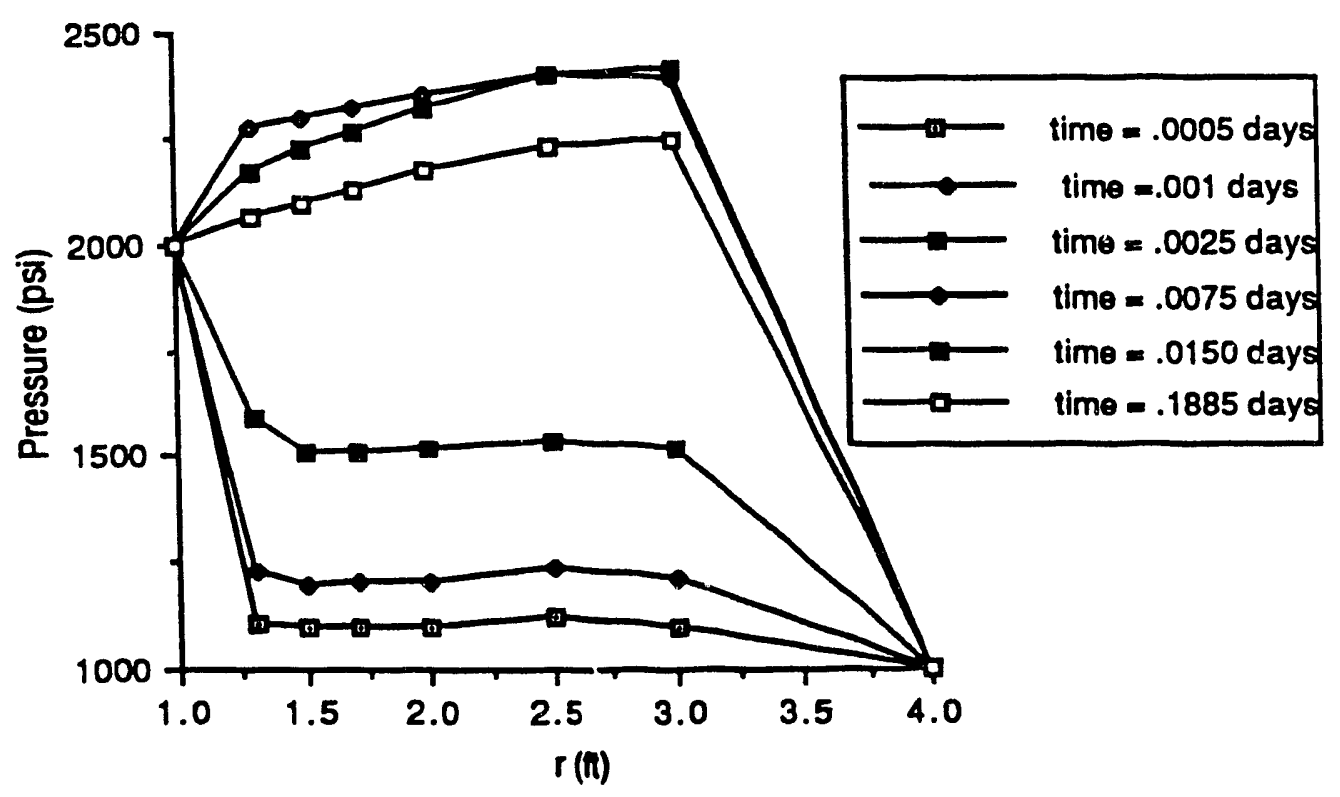

Figure 9.42: Pressure Profile For Case \#1

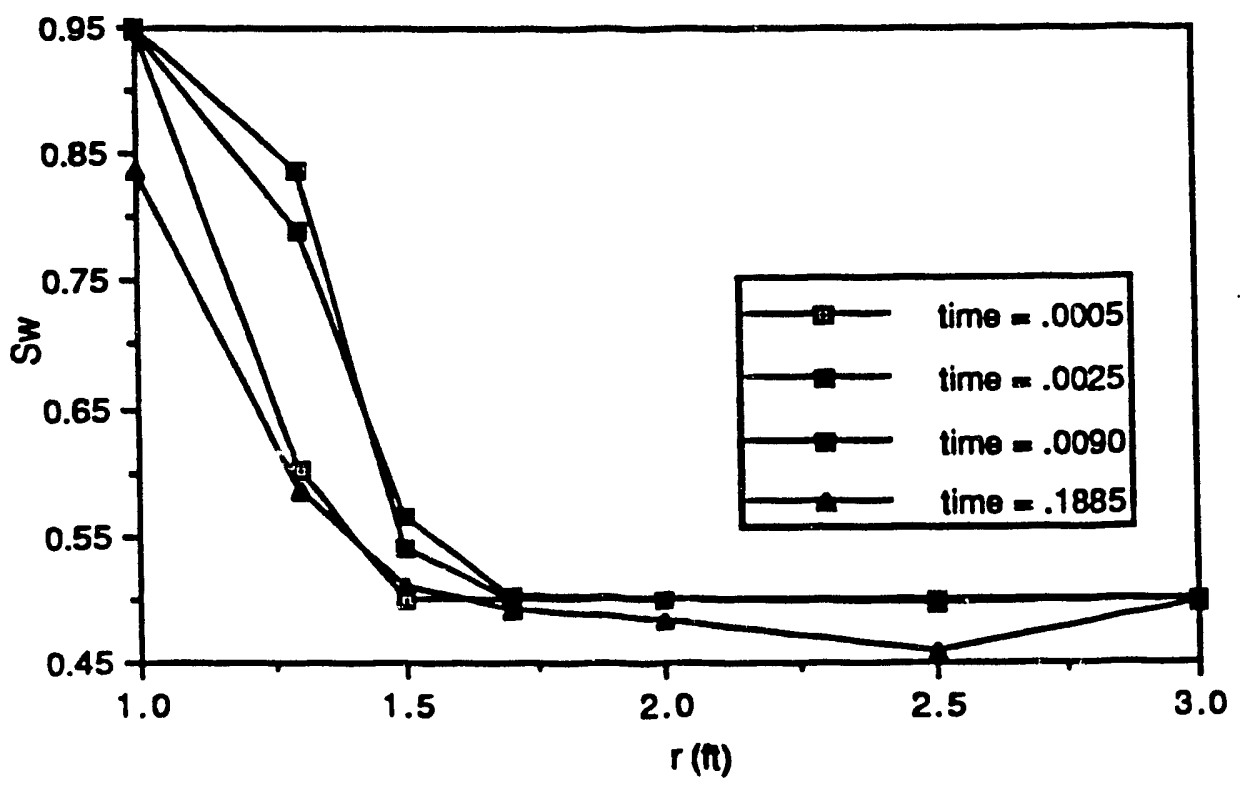

Figure 9.43: Saturation Profile For Case \#1 


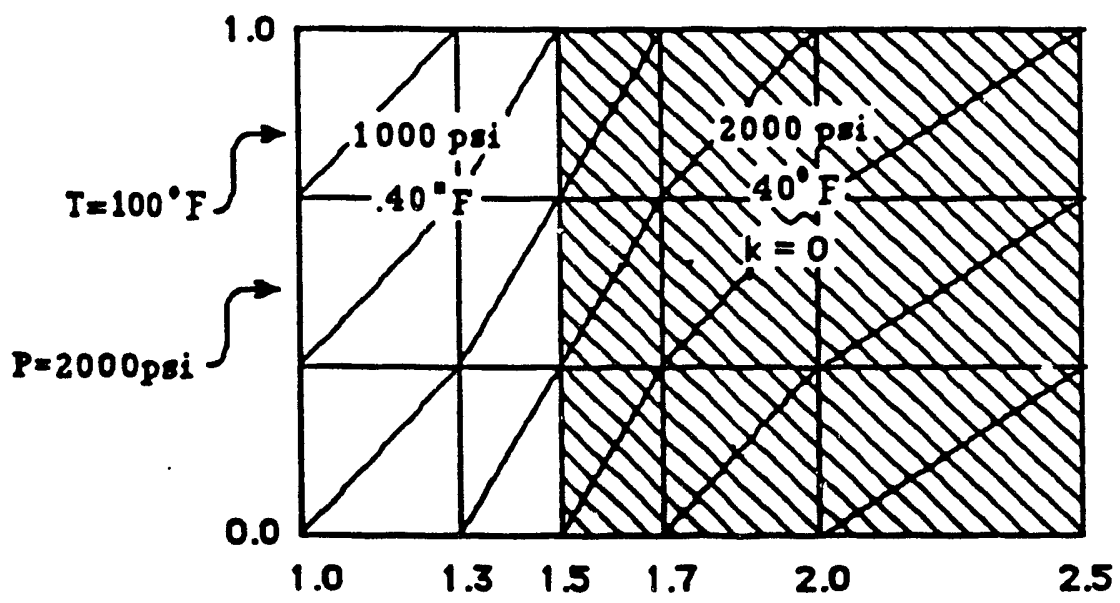

Figure 9.44: Mesh For Case \#2 Simulation Run 
where $a_{f_{x}}$ is the freezing point depression due to salinity and $P_{\text {avg }}$ is the average pressure in the element, determined from the thawed nodes of the element only.

Figures $9.45,9.46$ and 9.47 show the radial temperature, pressure and saturation profiles for the simulation run of case \#2 up until the start of thawing at time $=0.834$ days. Reasonable pressure, temperature, and saturation profiles are observed in this time span.

Figures $9.48,9.49$ and 9.50 show the radial temperature, pressure and saturation profiles after thawing in the hydrate region is observed. For the first two time steps of thawing, $t=.0834$ and $t=.0898$ days, the pressure solution did not converge after 16 iterations. Figure 9.51 shows the thawing isotherms position from $t=.0834$ to $t=.200$ days. Notice that the position of the isotherm actually moves backwards from $t=$ 0.0898 to $t=.0930$ days. This behavior is a result of the phase change temperature's dependence on pressure. The phase change temperature at $t_{1}$ is calculated using the pressure solution at $t_{2}$, thus $T$ fr calculated at $t$ $=.0930$ from the abnormally high pressure solution at $t=.0898$, gives an abnormally high $T f r$ and causes the thawing isotherm to move backwards. Additionally, one would expect the pressure profiles to eventually level off, or seek equilibrium at 2000 psi. The pressure profiles shown in Figure 9.49 do not show any trend towards seeking a level pressure profile of 2000 psi. Case \#2 has demonstrated the inadequacy of the proposed method to deal with the release of water and gas into the system as hydrates thaw.

\subsubsection{Case \#3, Run with Complete Hydrate Thawirg Model}

Case \#3 is the run with the complete hydrate thawing model with the same geometry as case \#2 and with the source terms include into the 


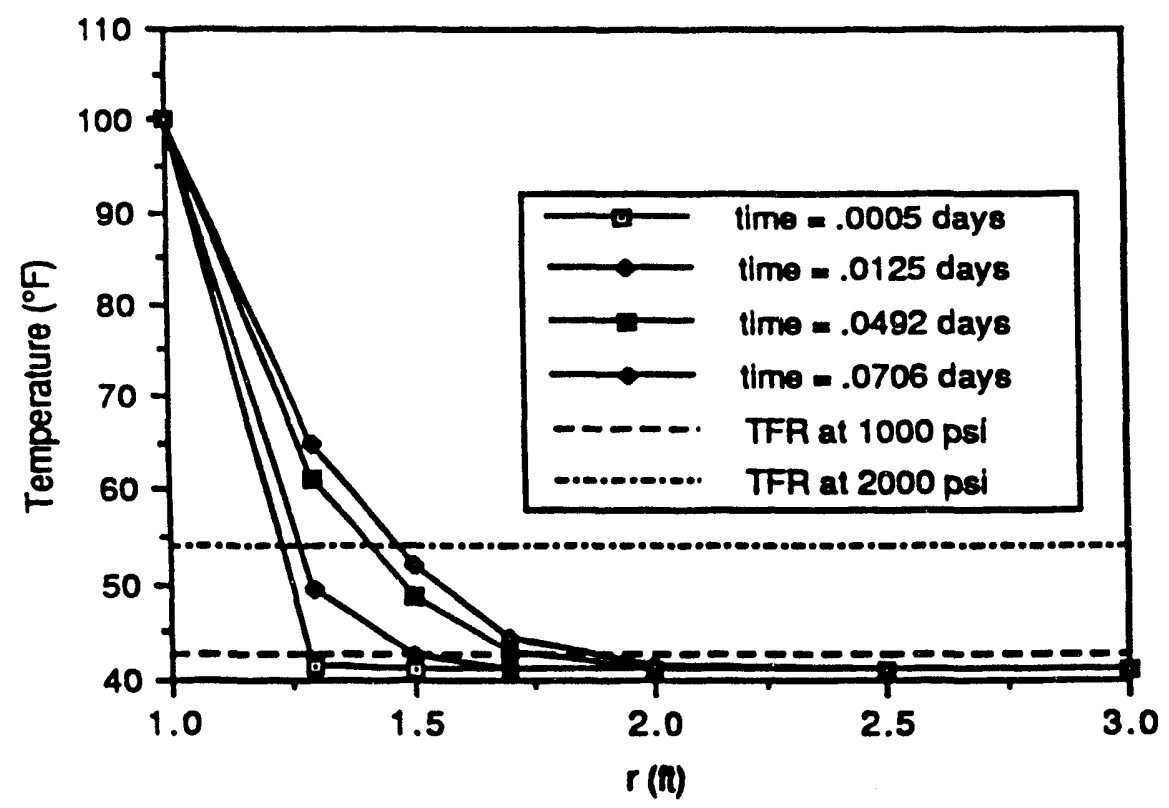

Figure 9.45: Temperature Profile For Case \#2, Before Thawing

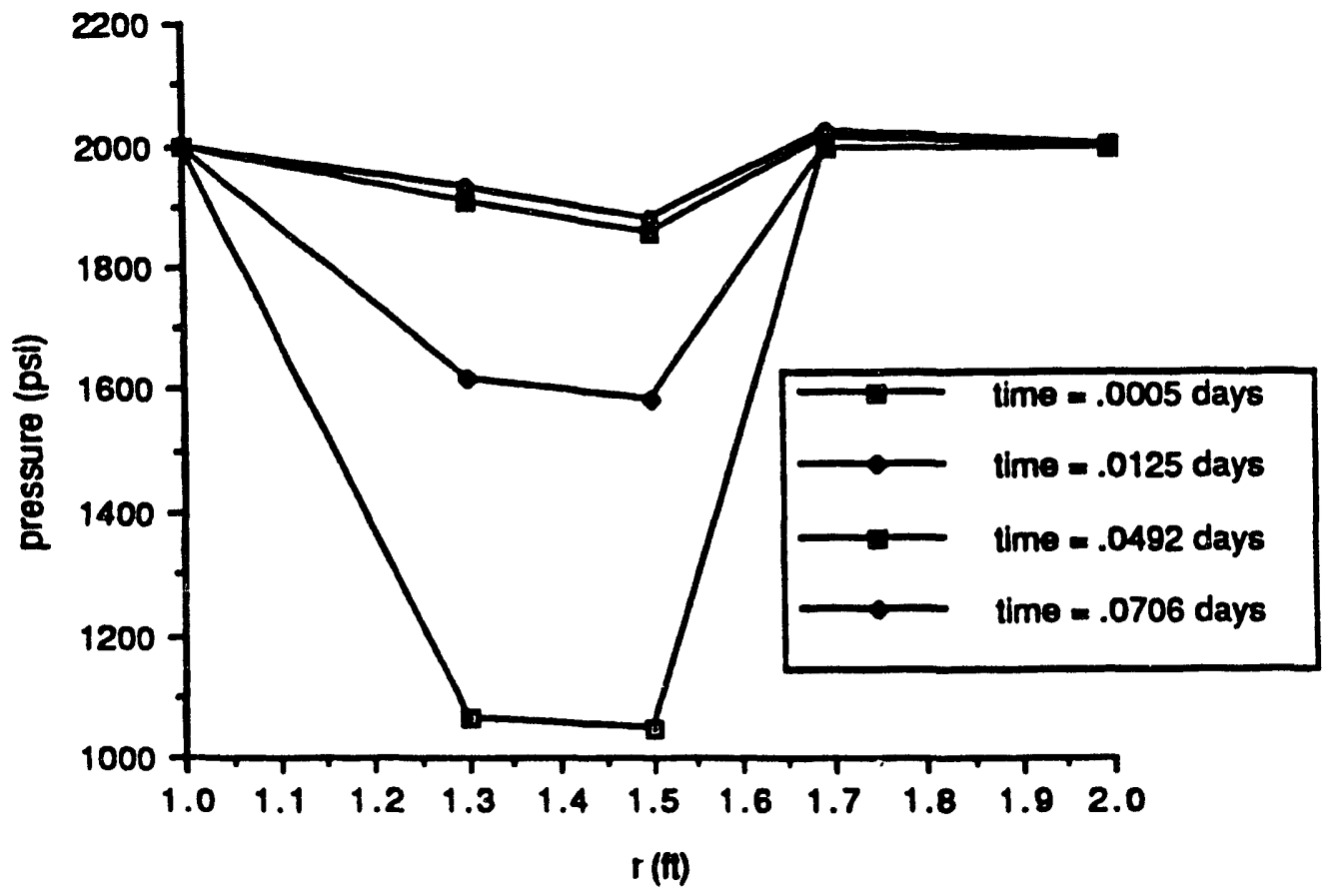

Figure 9.46: Pressure Profile For Case \#2, Before Thawing 


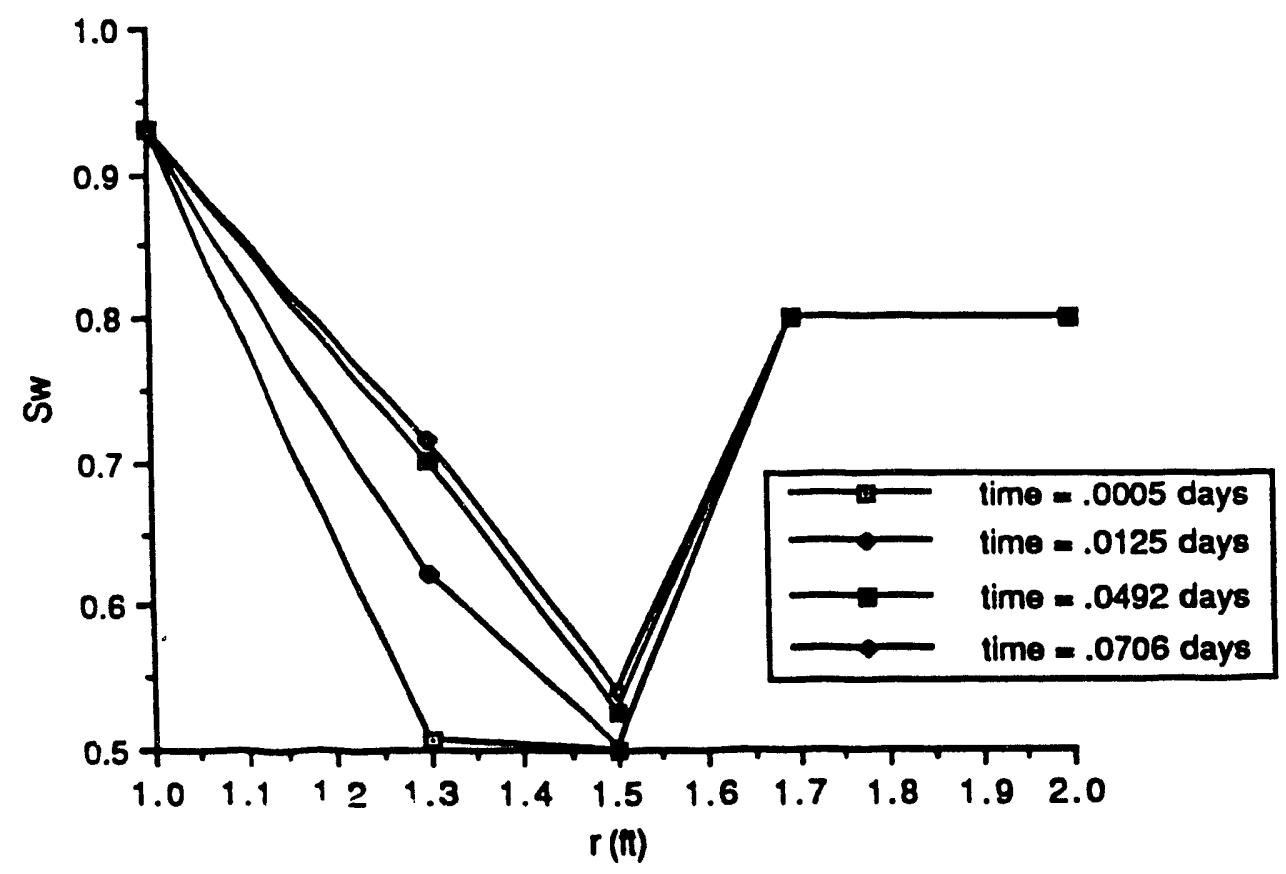

Figure 9.47: Saturation Profile For Case \#2, Before Thawing

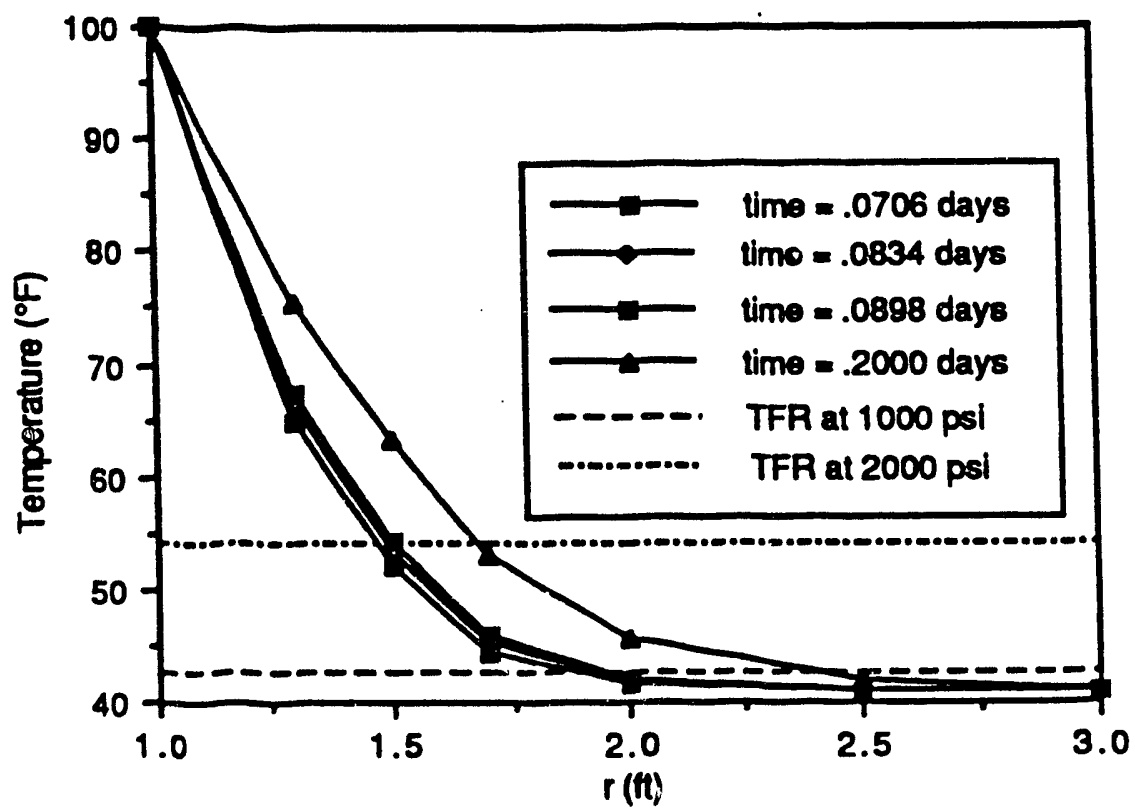

Figure 9.48: Temperature Profile For Case \#2 After Thawing 


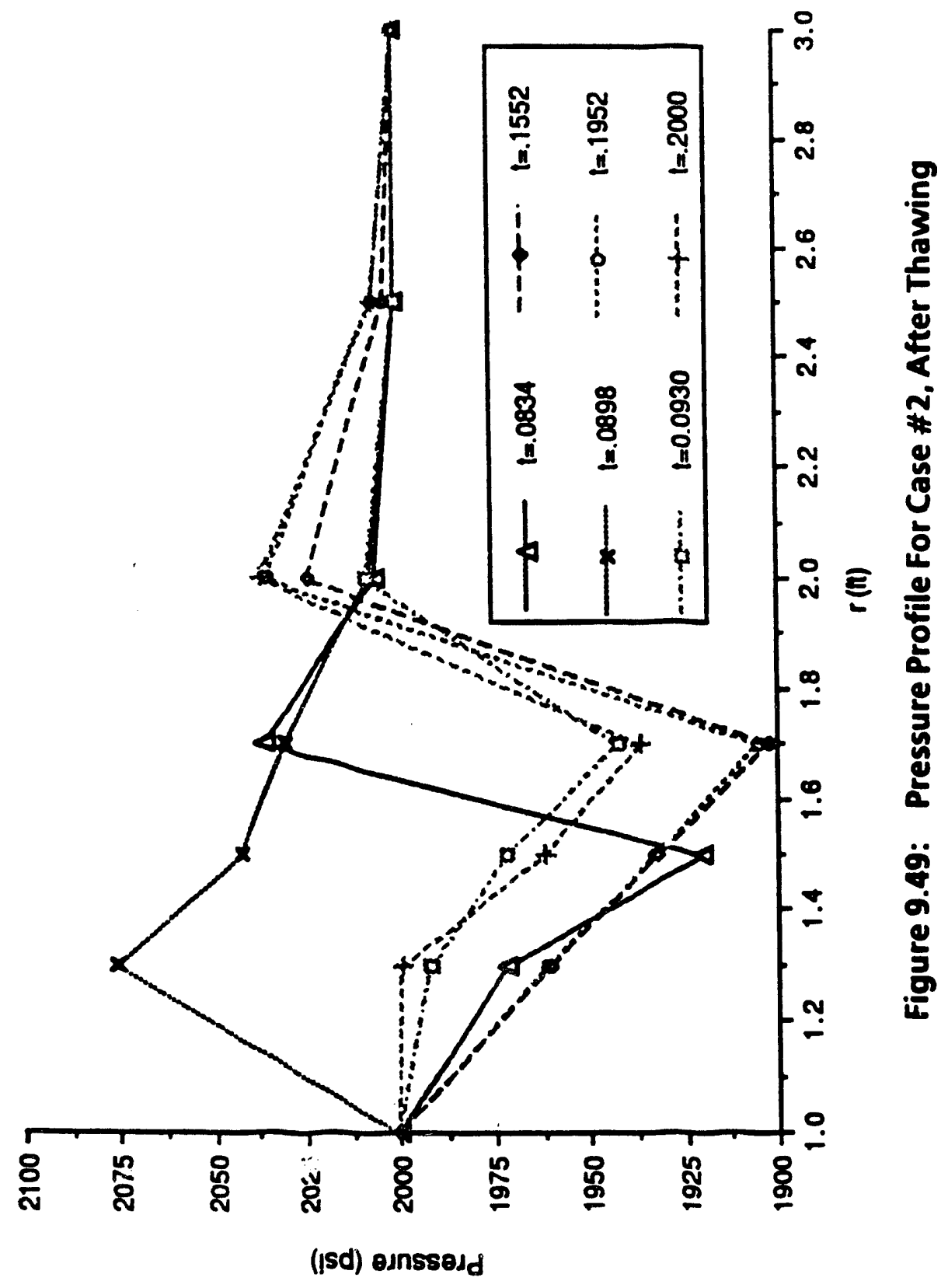




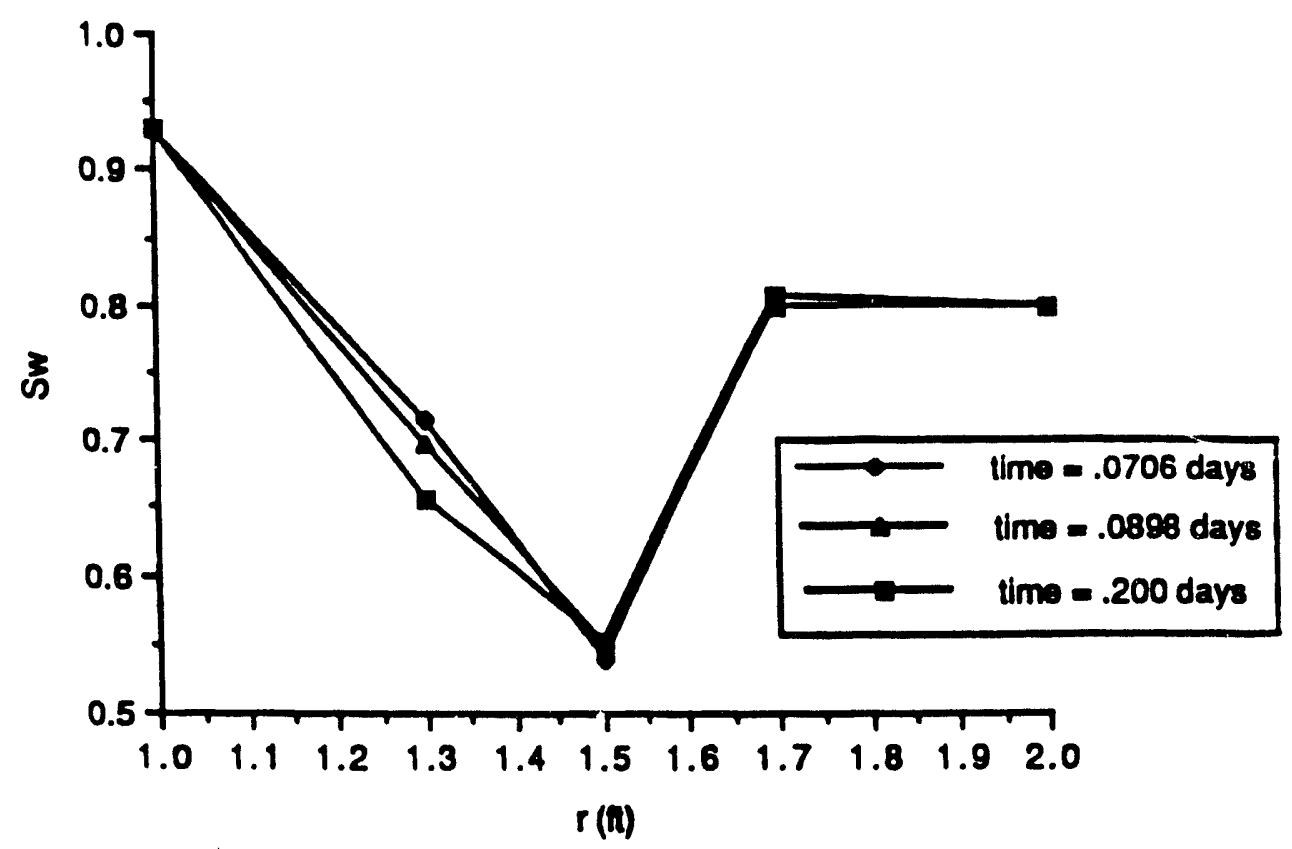

Figure 9.50: Saturation Profile For Case \#2, After Thawing

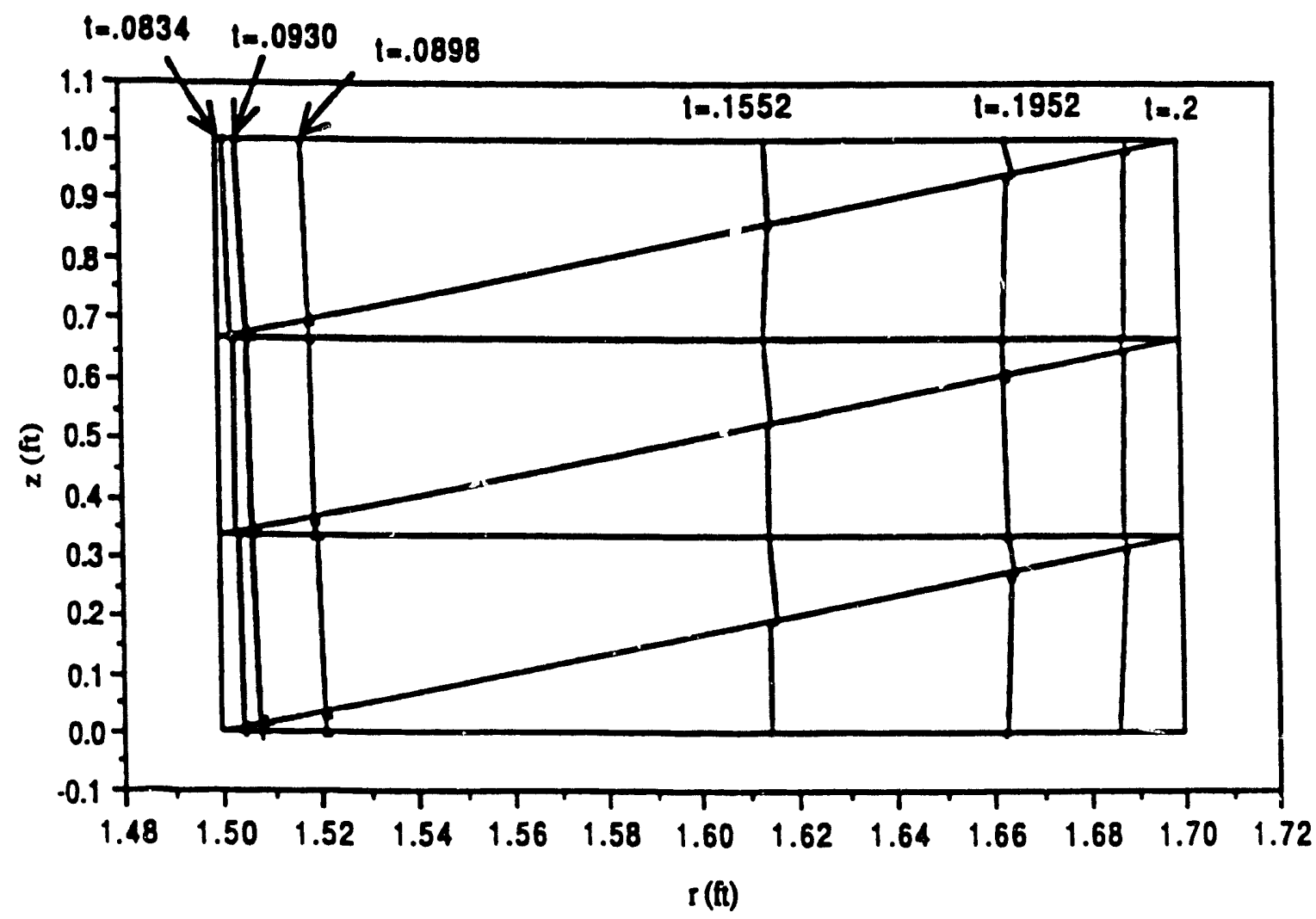

Figure 9.51: Thawing Isotherms For Case \#2 
model. The source terms were calculated from Eq. (9.90). The simulation was identical to case \#2 up until the start of thawing. At the start of thawing, when the source terms were calculated, the pressure, temperature, and saturation solutions all failed to converge and eventually the pressures and temperatures diverged outside of the range of the equation of state and the program could no longer run. The divergent behavior is thought to be caused from the magnitude of the source terms, and the fact that they are calculated from conditions at the new time level, causing a high degree of nonlinearity to the problem.

\subsection{Model Performance With Other Corivergence Schemes}

As mentioned earlier, literature has reported considerable difficulties for simulations of various transport phenomena governed by the general convection diffusion equation Several studies have shown that the numerical solution of this kind of equation presents serious difficulties when convection terms are important. These difficulties concern the problem of oscillation in the computed solution, and stem from the combination of the first and second order differential operators and the parabolic nature of this combination as the second derivative terms becomes relatively small.

Although numerical instability of this type has been recognized for some time, it is not treated very widely. Huyakorn $(1977,1979,1983)$ recommended to use weighting functions of asymmetric forms. Unfortunately, in his papers, he dealt with linear differential equations.

For the problem dealt with here, it involves convection diffusion equation, non-linear and with phase change. All these hard-to-converge factors combine together and make the problem especially difficult to be solved. Acsording to our search, no paper has dealt with the same kind of problems with finite element 
method. From the experience gained from the effort to make the simulation of this problem successful, we recommend future work of similar problems should be done with finite difference uritil the finite element method has been developed further in solving non-linear diffusion-convection equations.

The following upstream weight, lumped schemes and different dampening factors have been tried:

\subsubsection{Asymmetric Weighting Function}

The only assymetric weighting function method reported in literature on similar but simpler problems, gave the following asymmetric weighting function that gives greater weighting to the upstream nodes:

$$
W_{l}=3\left(a_{j} N_{k} N_{i}-a_{k} N_{j} N_{i}\right)+N_{i}
$$

For $a_{1}=a_{2}=a_{3}=1.0, W_{1}$ and $W_{3}$ are sketched in Figure 9.52, since all weighting functions are expressed in terms of area coordinates, the element matrices can be generated in a simple manner by performing exact integration using the following formula:

$$
\int_{A} N_{1}^{m} N_{2}^{n} N_{3}^{p} d A=\frac{2 A m ! n ! p !}{(m+n+p+2) !}
$$

where $A$ is the triangular element area.

It should be noted, in our axisymetric geometry,

$$
r d r d z=\left(r_{1} N_{1}+r_{2} N_{2}+r_{3} N_{3}\right) d A
$$



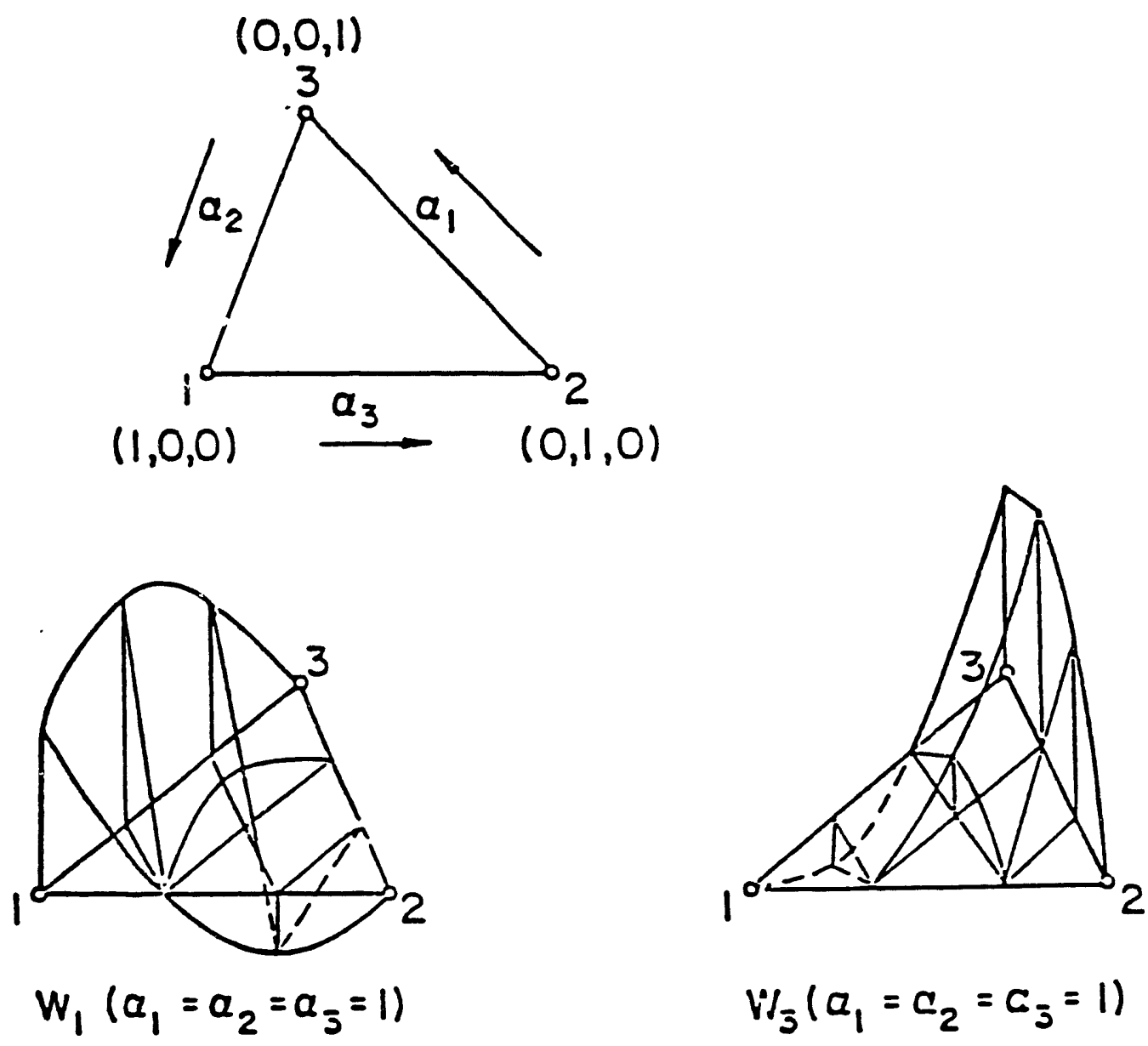

Figure 9.52: Asymmetric Weighting Functions 
$a$ is called 'damping factor' by Huyakorn (1976, 1977, 1979) which, according to the author, can damp out the oscillation, but decrease the accuracy of the simulation results. Absolute value of a can be $0-1$. The bigger the absolute value of $a$, the stronger the effect of damping, but the less the accuracy. Optimum values of a can be calculated from the following formula:

$$
a_{o p k}=\operatorname{coth}\left|\frac{V h}{2 k}\right|-\frac{2 k}{V h}
$$

where

$$
\begin{aligned}
& V \quad=\text { the average velocity of one of triangular side } \\
& h \quad=\text { the length of side } I J \\
& k \quad=\text { thermal conductivity }
\end{aligned}
$$

$$
v=\frac{1}{2}\left(\bar{v}_{1}+\bar{v}_{J}\right) \cdot \bar{l}
$$

where

$$
\begin{aligned}
V_{l}, V_{J} & =\text { velocity vectors at node } I \text { and } J \text { respectively } \\
l & =\text { direction vector of a particular side } I J
\end{aligned}
$$

The sign of a should be determined in accordance with:

$$
\begin{aligned}
& a>0 \text { if } V>0 \\
& a<0 \text { if } V<0
\end{aligned}
$$

so that the weighting functions has an upstream weighting ct:aracteristics.

The following formula was used in this implementation to two phase flow problem: 


$$
\begin{gathered}
\bar{V}_{I}=\bar{V}_{g l}+\bar{v}_{w I} \\
\ldots \ldots \ldots \\
k=\left|\left(S_{\omega} k_{w}+S_{g} k_{g}\right) \Phi+(1-\Phi) k_{r}\right| \frac{A t_{2}}{A e}+\frac{A e-A l_{2}}{A e}\left(\Phi k_{h}+(1-\phi) k_{r}\right)
\end{gathered}
$$

where

$$
\begin{aligned}
& V_{g d^{\prime}} V_{w, l}=\text { gas and water velocity vectors respectively } \\
& k_{w^{\prime}} k_{g^{\prime}} k_{r^{\prime}} k_{h}=\text { water, gas, rock matrix and hydrate heat conductivity } \\
& \text { coefficients respectively } \\
& \mathrm{Att}_{2} \quad=\quad \text { thawed area at time level } 2 \\
& \text { Ae } \quad \text { element area } \\
& \Phi \quad \text { = porosity } \\
& S_{\omega^{\circ}} S_{g} \quad=\quad \text { water and gas saturations respectively }
\end{aligned}
$$

After implemented, several runs were conducted without satisfactory results: with optimum $a_{8}$ convergence can be reached for hot water injection to a gaswater system but the converged results showed improper pressure, saturation and temperature trends.

Runs were also carried out for $a=0.1,0.2,0.3,0.4,0.5,0.6,0.7,0.8,0.9$, $0.95,1.3,1.5$. All these runs converged, but without success. Also, $a= \pm 0.1$, $0.2,0.3, \ldots . \pm 0.95$ (choose + when $V>0$, negative when $V<0$ ) had been tried without success. All these calculations show.

From convergence point of view, a equal to a positive value $(\mathbf{e . g} .+\mathbf{0 . 5})$ for all element sides is better than $a_{o p t}$ and $a= \pm$ constant with $a_{o p t}$ is the worst.

\subsubsection{Upstream Weighting of Mobility}

In the validation of Buckley Leverett solution, convergence problem had been encountered. It was solved by upstream weighting of mobilities as 
described earlier. An upstream elemental average mobility was implemented into the finite element model. The scheme calculates the fluid relative permeabilities at a point upstream from the centroid of the element and treats the relative permeabilities as constant values over the element rather than interpolating them across the element. The scheme is described as follows.

As shown in Figure 9.30, first the direction of fluid flux is determined. Then a line segment is determined by passing the flux directional vector through the centroid of the element. The line segment is described in length by the intersection of the flux vector with the side of the element. Then the portion of the line segment that is upstream of the centroid is sealed The upstream mobility is then calculated by interpolating the saturations from the three nodes to a point on the scale reflecting the amount of upstream weighting desired and then using this saturation to calculate the fluid mobilities. The saturation value calculated at the intersection point of the line segment and the upstream element side is the result of weighting with a weight factor equal to one, $w=1.0$ and the saturation calculated at the centroid is the resuit of $w=0.0$.

A range of upstream weighting from 0 to 1.0 were investigated. A weighting factor of 1.0 was found to give the best performance.

\subsubsection{Lumped Schemes}

Lumped scheme is another way to make diffusion - convection equation convergible (Huyakorn, 1977, 1979, 1983). But no report has been found to be successfully used in the same complex problems.

According to Huyakorn (1979), lumped scheme is helpful in finding converged results. The following schemes were tried:

(1) Scheme 1 (consistent scheme with $W_{l}$ ). Let the integral of 


$$
\int_{R e} W_{I} N_{J} r d R=M_{l J}^{e}
$$

For this scheme, nothing was done to $M_{l J}$.

(2) Scheme 2 (Huyakorn Lumping Scheme)

in this scheme, the $M_{I J}{ }^{e}$ is obtained from:

$$
M_{I I}^{e}=A \int_{R e} W_{I} N_{I} r d R / \sum_{I=1}^{n e} \int_{R e} W_{I} N_{l} r d R
$$

$$
M_{L J}^{e}=0 \quad \text { for } \quad I \neq J
$$

where $n^{e}$ is the number nodes on the element

(3) Scheme 3 (Galerkin Consistent Scheme):

This third scheme is given by:

$$
M_{I J}^{e}=\int_{R e} N_{I} N_{J} r d R
$$

(4) Scheme 4 (Galerkin Consistent Scheme)

This is the scheme used to lump Eq. (9.142).

$$
\begin{gathered}
M_{I J}=A \int_{R e} N_{l} N_{J} \operatorname{rdR} /\left(\sum_{i=1}^{n_{e}} N_{l} N_{J} r d R\right) \\
M_{I J}=0 \quad \text { for } \quad l \neq J
\end{gathered}
$$


All these schemes were implemented and their performances were tested. The following conclusions were drawn:

(1) All of them helped to improve the rate of convergence but the converged results were considered physically improper.

(2) Scheme 2 and 4 can make the program converge in a wider range than Scheme 1 and 3.

(3) Only from convergence point of view, Scheme 3 is the best with (a $=0.5)$.

\subsection{Conclusions and Recommendations}

A finite element model has been developed with the final objective of studying the recovery of natural gas by a cyclic thermal recovery scheme. The finite element scheme has been successfully validated to analytical solutions for conductive and convective heat transfer, for radial thawing, and for single and two-phase flow in porous media. The validation process has demonstrated the versatility of the finite element scheme, and its potential for applications in other areas.

A converged solution was not achievable with the present model when including the scheme to account for the influx of gas and water at the thawing interface. Non-convergence of the solution was most likely a result of the strong nonlinearity introduced into the model with the addition of source terms used to input the gas into the system at the thawing interface. The influx behavior at the thaw interface is an indirect function of the dependent variables temperature, pressure, and saturation. However, it is difficult to explicitly express the flux in terms of the dependent variables, resulting in the inability to express derivatives of the influx terms with respect to the dependent variables which are required to accurately express the terms of the Jacobian matrix. 
Abnormal results were observed when solving two-phase convective heat transport problems. It is suspected that the abnormalities stem from treatment of the convective term in the energy equation. Treating the capacitance term in the energy equation as a constant property within each time step appears to give more reasonable results for two-phase convective heat transport problems, however, this may not be a valid assumption for elements undergoing large saturatinn changes within a timestep. Further work is currently in progress to address these abnormalities.

The goal of this study was to develop a finite element simulator that is capable of modeling the recovery of natural gas from in-situ hydrates by hot water injection. Use of this simulator is not limited to studies in this area however. The validation process demonstrated the basic heat transfer and fluid flow mechanisms that the simulator is capable of handling. The simulator has the potential to handle any process that consists of some or all of these mechanisms in a $r-z$ geometry.

Validation to the Avdonin and Lauwerier solutions has demonstrated the ability of the model to simulate single-phase convective heat transport problems. This class of problems has applications in geothermal, environmental, arid petroleum engineering. Validation to the Buckley Leverett solution demonstrated the simulators ability to handle two-phase immiscible displacement problems often encountered in enhanced oil recovery schemes such as waterflooding.

A particular useful application of the model is for simulation of a hot water injection scheme for the recovery of viscous oil. The models formulation in radial coordinates makes it well suited to handle cyclic recovery schemes where flow is predominantly radial. The model could also be useful in hot waterflooding studies for the evaluation of heat losses to adjacent formations in the neighborhood of the injection well where heat losses would be most severe. 
Finally, only limited success was achieved in applying this model to simulate hydrate thawing problems. Currently further work is in progress to devise a better scheme to handle hydrate thawing problem.

\subsection{Nomenclature}

A operator

Ae element area

$A_{i} \quad$ water continuity residuals

$B$ formation volume factor

$B_{i} \quad$ gas continuity residuals

C compressibility

$C_{i} \quad$ energy continuity residuals

$C_{j} \quad$ general unknown nodal parameters

$C_{p} \quad$ isobaric specific heat

$f$ a known function of independent variables

g gravitational constant

GG parameter

$g \quad$ mass of gas per unit mass of hydrate

$G W$ parameter

$h \quad$ reservoir thickness

H parameter

I parameter

$P \quad$ permeability

$K$ thermal conductivity

$l$ boundary length

$L \quad$ linear area coordinate of an element

$L_{f} \quad$ latent heat of dissociation of hydrate 


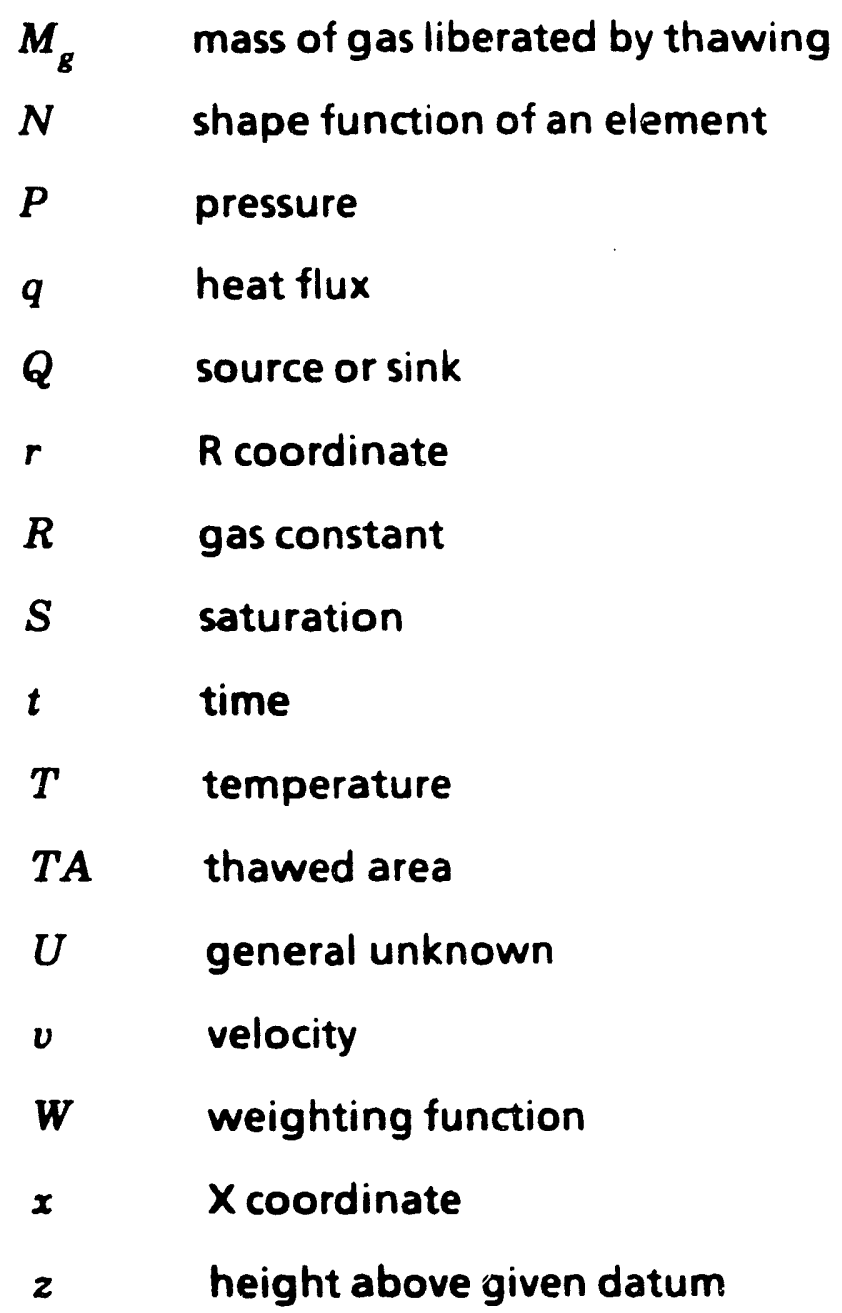

\section{Greek:}

$\begin{array}{ll}\text { a } & \text { damping factor } \\ \boldsymbol{\tau} & \text { parameter } \\ \boldsymbol{\beta} & \text { parameter } \\ \boldsymbol{Y} & \text { parameter } \\ \boldsymbol{\varepsilon} & \text { parameter; error } \\ \boldsymbol{\Phi} & \text { porosity } \\ \boldsymbol{P} & \text { density } \\ \boldsymbol{\mu} & \text { viscosity } \\ \boldsymbol{A} & \text { parameter }\end{array}$




\section{Subscripts:}

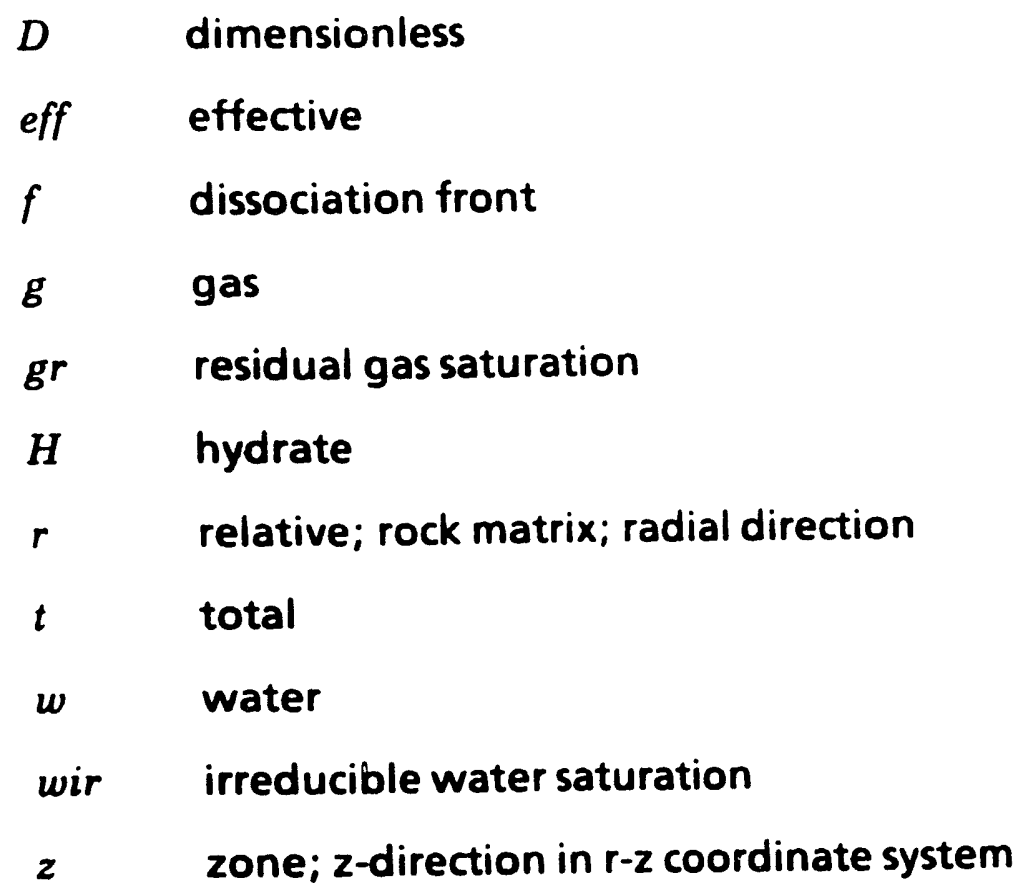

\section{Superscripts:}

$\begin{array}{ll}g & \text { gas } \\ k & \text { old time level } \\ k+1 & \text { new time level } \\ k+\theta & \text { time matching scheme } \\ r, r+1 & \text { iteration index } \\ w & \text { water }\end{array}$

\subsection{References}

1. Bayles, G.A., Sawyer, W.K.., Anada, H.R., Feddy, S. and Malone, R.D.: "A Steam Cycling Model for Gas Production From a Hydrate Reservoir," paper presented 
at the American Institute of Chemical Engineers Winter National Meeting, Atlanta, Georgia, (March 11-14, 1984).

2. Bily, C. and Dick, J.W.L.: "Naturally Occurring Gas Hydrates in the Mackenzie Delta, N.W.T.," Bulletin of the Canadian Petroleum Geology, Vol 22, No. 3. (1974), pp. 340-352.

3. Boberg, T.C. and Lantz, R.B: "Calculation of the Production Rate of Thermally Stimulated Well," JPT, (Dec., 1966), pp. 1613-1623.

4. Carey, G.F. and Jiang, B.N.: "Least-Squares Finite Elements for Convective Transport Problems," SPE Paper 16016, presented at the Ninth Symposium on Reservoir Simulation, San Antonio, TX, (Feb. 1-4, 1987).

5. Carslow, H.S. and Jeager, J.C.: Conduction of Heat in Solids, Second edition, Published by Oxford University Press, New York, (1959).

6. Cheriski, N.V. and Makogon, Y.: "Solid Gas World Reserves are Enormous," Oil Gas Invest. Vol. 10, No. 8, (1970), p. 82.

7. Chung, T.J.: Finite Element Analysis in Fluid Dynamics, McGraw-Hill, Inc., (1978).

8. Cramer, D.L. and Cook, W.R.: "Gas Dehydration: Fine-Tuning Existing Field Installations," World Oil, (Jan., 1981).

9. Dalen, V.: "Immiscible Flow By Finite Elements," Paper presented at the International Conference on Finite Elements in Water Resources, Princeton U., Finceton, NJ, (July, 1976).

10. Dalen, V.: "Simplified Finite Element Niodels for Reservoir Flow Problems," Society of Petroleum Engineers Journal, Vol. 19, No. 5, (1979), pp. 333-343.

11. Godbole, S.P. and Ehlig-Economides, E.: "Natural Gas Hydrates in Alaska: Quantification and Economic Evaluation," SPE Paper 13593, presented at the SPE 1985 California Regional Meeting, held in Bakersfield, California, (March 27-29, 1985). 
12. Goo'bole, S.P., Kamath, V.A. and Ehlig-Economides, C.: "Natural Gas Hydrate in Alaska Arctic," JPE Formation Evaluation, (March, 1988).

13. Holder, G.D., Corbin, G. and Papadopoulos, K.D.: "Thermodynamic and Molecular Properties of Gas Hydrates from Mixtures Containing Methane, Argon and Krypion," Ind. Eng. Chem. Fundam., Vol. 19, (1980), pp. 282-286.

14. Holder, G.D. and Godbole, S.P.: "Measurement and Prediction of Dissociation Pressure of Isobutane and Propane Hydrates Below the Ice Point," AlChE Journal, Vol. 28, No. 6, (1982), pp. 930-934.

15. Holder, G.D., Kamath, V.A. and Godbole, S.P.: "The Potential of Natural Gas Hydrates as an Energy Resource," Ann. Rev. Energy, No. 9. (1984), pp. 427-445.

16. Huyakorn, P.S.: "An Upwind Finite Element Scheme for Improved Solution of the Convection-Diffusion Equation," Water Resource Program, Research Report No. 76-WR-2, (1976).

17. Huyakorn, P.S.: "Solution of Steady-State Convective Transport Equation Using an Upwind Finite Element Scheme," Appl. Math. Modelling, Vol. 1, (1977), pp. 187-195.

18. Huyakorn, P.S. and Nilkuha, K.: "Solution of Transient Transport Equation Using an Upstream Finite Element Scheme," Appl. Math. Modelling, Vol. 3, (1979), pp. 7-17.

19. Huyakorn, P.S. and Pinder, G.F.: Computational Methods in Subsurface Flow, Academic Press, (1983).

20. Ikoku, C.: Natural Gas Enqineering, Published by John Wiley \& Sons, Inc., (1984), pp. 50-51.

21. Kamath, V.A. and Godbole, S.P.: "Evaluation of Hot Brine Stimulation Technique for Gas Production From Natural Gas Hydrates," SPE Paper 13596. presented at the California Regional Meeting held in Bakersfield, California, (March 27-29, 1985). 
22. Kamath, V.A., Goldbole, S.P., and Ostermann, R.D.: "Evaluation of the Stability of Gas Hydrates in the Northern Alaska," Cold Regions Science and Technology, Vol. 14, (1987), pp. 107-119.

23. Kamath, V.A., Mutalik, P.N., Sira, J.H. and Patil, S.L.: "Experimental Study of Brine Injection and Depressurization Methods for Dissociation of Gas Hydrates," SPE Paper 19810, presented at the 64th Annual Technical Conference and Exhibition of the Society of Petroleum Engineers held in San Antonio, TX, (October 8-11, 1989).

24. Lauwerier, H.A.: "The Transport of Heat in an Oil Layer Caused By Injection of a Hot Fluid," Applied Scientific Research, A5، (1955), pp. 145-150.

25. Lee, A.L., Gonzalez, M.H. and Eakin, B.E.: "The Viscosity of Natural Gases," JPT, pp. 997-1000, (Áugust, 1966).

26. Lunardini and Vergii, J.: Heat Transfer in Cold Climates, Published by Van Nostrand Reinhold Co., New York, (1981).

27. Malofeev, G.E.: "Calculation of the Temperature Distribution in a Formation When Pumping Hot Fluid Into a Well," Neft i Gaz, Vol. 13, No. 7. (1960), pp. 5964.

28. Marx, J.W. and Lanenheim, R.H.: "Reservoir Heating By Hot Fluid Injection," Trans. AIME, Vol 216, (1959), pp. 312-314.

29. Mathews, C.S. and Russell, D.G.: "Pressure Buildup and Flow Tests in Wells," Society of Petroleum Engineers, Monograph Vol 1, Published by the Society of Petroleum Engineers, Richardson, TX, (1967).

30. Mercer, J.W. and Faust, C.R.: "The Application of Finite Element Techniques to Immiscible Flow in Porous Media," in Proceedings of the First International Conference on Finite Elements in Water Resources, Pentech Press, Plymouth, England, (1976), pp. 121-158. 
31. O'Neill, K.: "Fixed Mesh Finite Element Solution for Cartesian TwoDimensional Phase Change," Transactions of the ASME, Vol. 105, December, (1983), pp. 436-441.

32. Paranjpe, S.G., Patil, S.L., Kamath, V.A. and Goldbole, S.P.: "Ternary Mixture of Methane, Propane, Isobutane, and n-Butane: Effect of Salinity," SPE Reservoir Engineering, (November, 1989).

33. Perry, R.H. and Chilton, C.H.: Chemical Engineers' Handbook, Published by McGraw-Hill, (1973).

34. Prats, M.: "Thermal Recovery." Society of Petroleum Engineers, Monograph, Vol. 7, (1982).

35. Reddy, J.N.: An Introduction to the Finite Element Method, McGraw-Hill Book Company, (1984).

36. Roadifer, R.D., Godbole, S.P. and Kamath, V.A.: "Thermal Model for Establishing Guidelines for Drilling in the Arctic in the Presence of Hydrates," SPE Paper 16361, presented at the California Regional Meeting held in Ventura, (April 8-10, 1987).

37. Roadifer, R.D., Godbole, S.P. and Kamath, V.A.: "Estimation of Parameters for Drilling in Arctic and Offshore Environment in the Presence of Hydrates," SPE Paper 16671, presented at the 62th Annual Technical Conference and Exhibition of the Society of Petroleum Engineers held in Dallas, TX, (September 27-30, 1987).

38. Roadifer, R.D.: "Numerical Solution 2-D (R-Z) Cylindrical Coordinate Dissociation of Natural Gas Hydrate With Variable Thermal Properties," M.Sc. Thesis, University of Alaska Fairbanks, Fairbanks, Alaska, (1988).

39. Schulz, R.: "Analytical Model Calculations for Heat Exchange in a Confined Aquifer," Journal of Geophysics, Vol. 61, (1987), pp. 12-20. 
40. Scott, M.D.: "The Development of a Finite Element Model for the Dissociation of Natural Gas Hydrates in Porous Media By Hot Water Injection," M. Sc. Thesis, University of Alaska Fairbanks, Fairbanks, Alaska, (1989).

41. Selim, M.S. and Sloan, E.D.: "Heat and Mass Transfer During the Dissociation of Hydrates in Porous Media," paper submitted to the AlChE for publication, (1989).

42. Sharma, G.D., Kamath, V.A. and Patil, S.L.: "The Potential of Natural Gas in the Alaskan Arctic," SPE Paper 17456, presented at the SPE California Regional Meeting held in Long Beach, California, (March 23-25, 1988).

43. Sira, J.H., Patil, S.L. and Kamath, V.A.: "Study of Hydrate Dissociation By Methano: and Glycol Injection," SPE Paper 20770, presented at the 65th Annual Technical Conference and Exhibition of the Society of Petroleum Engineers held in New Orleans, LA, (Sept. 23-26, 1990).

44. Smith, J.M. and Van Ness, H.C.: Introduction to Chemical Engineering Thermodymamics, published by McGraw-Hill, inc., (1975).

45. Srivastava, V.: "Finite Element Solution of a Cylindrical Phase Change Problem and Its Application to Dissociation of Gas Hydrates," Master Thesis, University of Alaska Fairbanks, Fairbanks, Alaska, (1988).

46. Stasa, L.F.: Applied Finite Element Analysis for Engineering, CBS College Publishing, (1985).

47. Willhite, P.G.: Waterflooding, Soriety of Petroleum Engineers Textbook Series, Vol. 3, published by the Society of Petroleum Engineers, Richardson, TX, (1986).

48. Yuan, Y. and Wang, W.: "On the Finite Elements of Two-Phase (Oil and Water) Immiscible Flow Displacement Problem," ACTA PETROLEI SENCA (chinese), Vol. 1, No. 4, (1980), pp. 65-76. 
49. Zhang, Z. and Qu, D.: "Finite Element Method For Rectangular Subdivision of the Numerical Simulation for 2-D \& 2-P Flow Through Porous Medium," P.G.O.D.D., Vol. 6, No. 3, (1987), pp. 43-66.

50. Zienkiewicz, O.C. FRC and Taylor, R.L.: The Finite Element Method, McGrawHill Book Company, (1977, 1989).

51. Zyvoloski, G.: "Finite Element Methods for Geothermal Reservoir Simulation," International Journal for Numerical Analytical Methods in Geomechanics, Vol. 7. (1983), pp. 75-86.

\section{Appendix 1: Damping Factors}

For triangular elements, the upwind weighting functions are given:

$$
\begin{aligned}
& w_{1}=N_{1}-3 a_{3} N_{2} N_{1}+3 a_{2} N_{3} N_{1} \\
& w_{2}=N_{2}-3 a_{1} N_{3} N_{2}+3 a_{3} N_{1} N_{2} \\
& w_{3}=N_{3}+3 a_{1} N_{2} N_{3}-3 a_{2} N_{1} N_{3}
\end{aligned}
$$

or put them in a general form:

$$
w_{i}=N_{i}-3 a_{k} N_{j} N_{i}+3 a_{j} N_{k} N_{i}
$$

where

$$
\begin{aligned}
& a_{1}, a_{2}, a_{3}=\text { damping factors of the element sides } \\
& N_{1}, N_{2}, N_{3}=\text { aera coordinates of the triangular } \\
& W_{1}, W_{2}, W_{3}=\text { upwind weighting functions }
\end{aligned}
$$


The general procedures for determining the sign and optimal value of a daniping factor a may be described as follows.

To determine the sign of $a_{\text {, let }} \bar{l}_{l J}$ denote the direction vector of a particular side $I J$ and let $\bar{V}_{l}$ and $\bar{V}_{J}$ denote velocity vectors at node $I$ and $J$ respectively (the positive sense of direction of $\bar{l}_{l d}$ is depicted in Figure 9.53. The component of an average velocity along side $I J$ is obtained by taking the scalar product:

$$
v=\frac{1}{2}\left(\bar{v}_{l}+\bar{v}_{J}\right) \cdot \bar{l}_{l J}
$$

The sign of $a$ is determined in accordance with

$$
\begin{aligned}
& a>0 \text { if } V>0 \\
& a<0 \text { if } V<0
\end{aligned}
$$

The optimal absolute value of $a$ is calculated from:

$$
a_{o p x}=\operatorname{Coth}\left|\frac{V h}{2 D}\right|-\frac{2 D}{V h}
$$

where $h$ is the length of side $I J$ and $D$ is the dispersion coeffient.

\section{Appendix 2: Integrals}

Since all weighting functions are expressed in terms of area coordinates, the integration can be performed exactly by using the following formula:

$$
\int_{A} N_{1}^{m} N_{2}^{n} N_{3}^{p} d A=\frac{2 A m ! n ! p !}{(m+n+p+2) !}
$$

And also, $r=r_{1}, N_{1}+r_{2} N_{2}+N_{3} r_{3}$. 


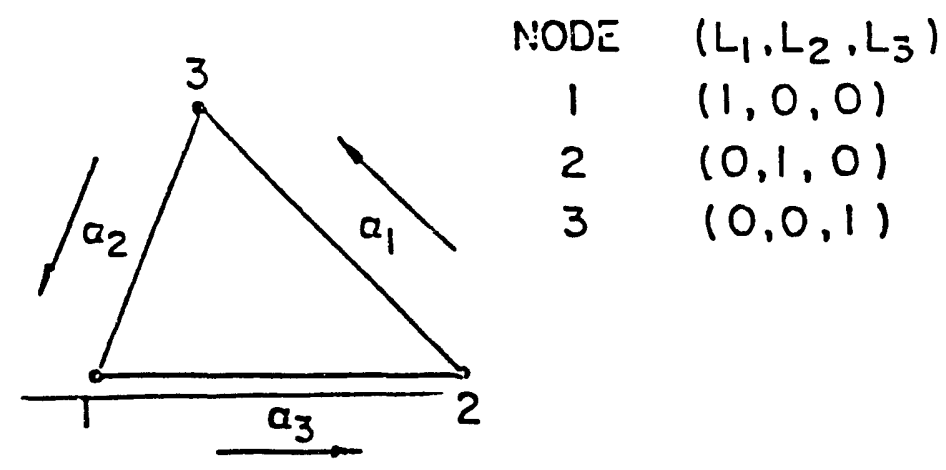

Figure 9.53: Damping Factors For Triangular Elements 
All the required integrals are listed as follows: (for all the following integrations, $i=1,2,3$ and $n=1,2,3, j$ and $k$ depend on $i, j=2,3,1, k=3,1,2$ correspondingly)

$$
\begin{aligned}
& \int_{R e} W_{i} \frac{\partial N_{n}}{d z} r d r d z=C_{n}\left|\frac{3 \bar{r}+r_{i}}{24}+a_{j} \frac{3 \bar{r}+r_{i}+r_{k}}{40}-a_{k} \frac{3 \bar{r}+r_{i}+r_{j}}{40}\right| \\
& \ldots \ldots \\
& \int_{R e} W_{i} \frac{\partial N_{n}}{\partial r} r d r d z=\beta_{n}\left|\frac{3 \bar{r}+r_{i}}{24}+a_{j} \frac{3 \bar{r}+r_{i}+r_{k}}{40}-a_{k} \frac{3 \bar{r}+r_{i}+r_{j}}{40}\right|
\end{aligned}
$$

$$
\begin{gathered}
\int_{R e} \frac{\partial W_{i}}{\partial z} N_{n} r d r d z=C_{i}\left(\frac{3 \bar{r}+r_{i}}{24}\right)+3\left(a_{j} C_{k}-a_{k} C_{j}\right)\left(\frac{3 \bar{r}+2 r_{i}}{60}\right) \\
+3 a_{j} C_{i}\left(\frac{3 \bar{r}}{60}-\frac{r_{j}}{120}\right)-3 a_{k} C_{i}\left(\frac{3 \bar{r}}{60}-\frac{r_{k}}{120}\right) \quad \text { for } n=i
\end{gathered}
$$

$$
\begin{gathered}
=C_{i} \frac{3 \bar{r}+r_{n}}{24}+\left(a_{n} C_{k}-a_{k} C_{n}\right) \frac{6 \bar{r}-r_{k}}{40}+a_{n} C_{i} \frac{6 \bar{r}-r_{i}}{40} \\
-a_{k} C_{i} \frac{3 \bar{r}+2 r_{n}}{20} \text { for } n=j
\end{gathered}
$$

$$
\begin{aligned}
& =C_{i} \frac{3 \bar{r}+r_{j}}{24}+3\left(a_{j} C_{k}-a_{k} C_{j}\right)\left(\frac{3 \bar{r}}{60}-\frac{r_{k}}{120}\right) \\
& +3 a_{j} C_{i}\left(\frac{3 \bar{r}}{60}-\frac{r_{i}}{120}\right)-3 a_{k} C_{i} \frac{3 \bar{r}+2 r_{j}}{60} \text { for } n=k
\end{aligned}
$$




$$
\begin{aligned}
& \int_{R e} W_{I} N_{I} r d r d z=A\left|\frac{2 r_{i}+3 \bar{r}}{30}+\frac{a_{j}\left(3 \bar{r}+2 r_{i}+r_{k}\right)}{60}-a_{k} \frac{3 \bar{r}+2 r_{i}+r_{j}}{60}\right| \\
& \ldots \ldots \\
& \int_{R e}\left(\frac{\partial W_{i}}{\partial r} \frac{\partial N_{n}}{\partial r}+\frac{\partial W_{i}}{\partial z} \frac{\partial N_{n}}{\partial z}\right) r d r d z=\frac{b_{n}}{2 A} \mid b_{i} \frac{\bar{r}}{2} \\
& +\left(a_{j} b_{k}-a_{k} b_{j}\right) \frac{3 \bar{r}+r_{i}}{8}+a_{j} b_{i} \frac{3 \bar{r}+r_{k}}{8}-a_{k} b_{i} \frac{3 \bar{r}+r_{j}}{8} \mid \\
& +\frac{C_{n}}{2 A}\left|C_{i} \frac{\bar{r}}{2}+\left(a_{j} C_{k}-a_{k} C_{j}\right) \frac{3 \bar{r}+r_{i}}{8}+a_{j} C_{i} \frac{3 \bar{r}+r_{k}}{8}-a_{k} C_{i} \frac{3 \bar{r}+r_{j}}{8}\right|
\end{aligned}
$$

where

$a_{1}, a_{2}, a_{3}=$ calculated by the method detailed in Appendix 1.

$$
\begin{aligned}
& \beta_{i}=z_{j}-z_{k} \\
& C_{i}=r_{k}-r_{j}
\end{aligned}
$$

$r, z_{i}$ nodal coordinates in $r-z$ coordinate system.

$i, n=1,2,3$ respectively.

$j=2,3,1$ correspondingly.

$k=3,1,2$ correspondingly. 

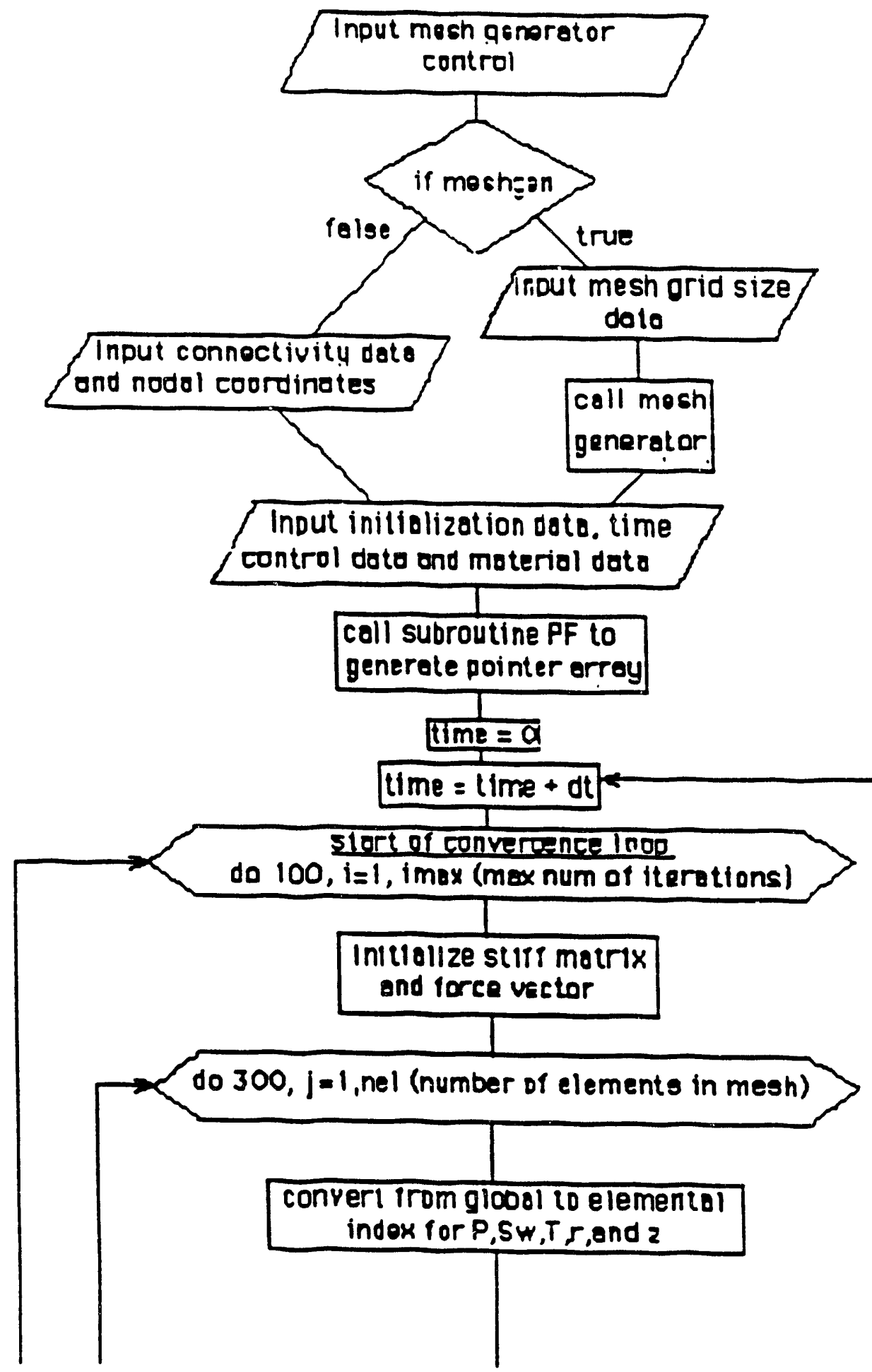


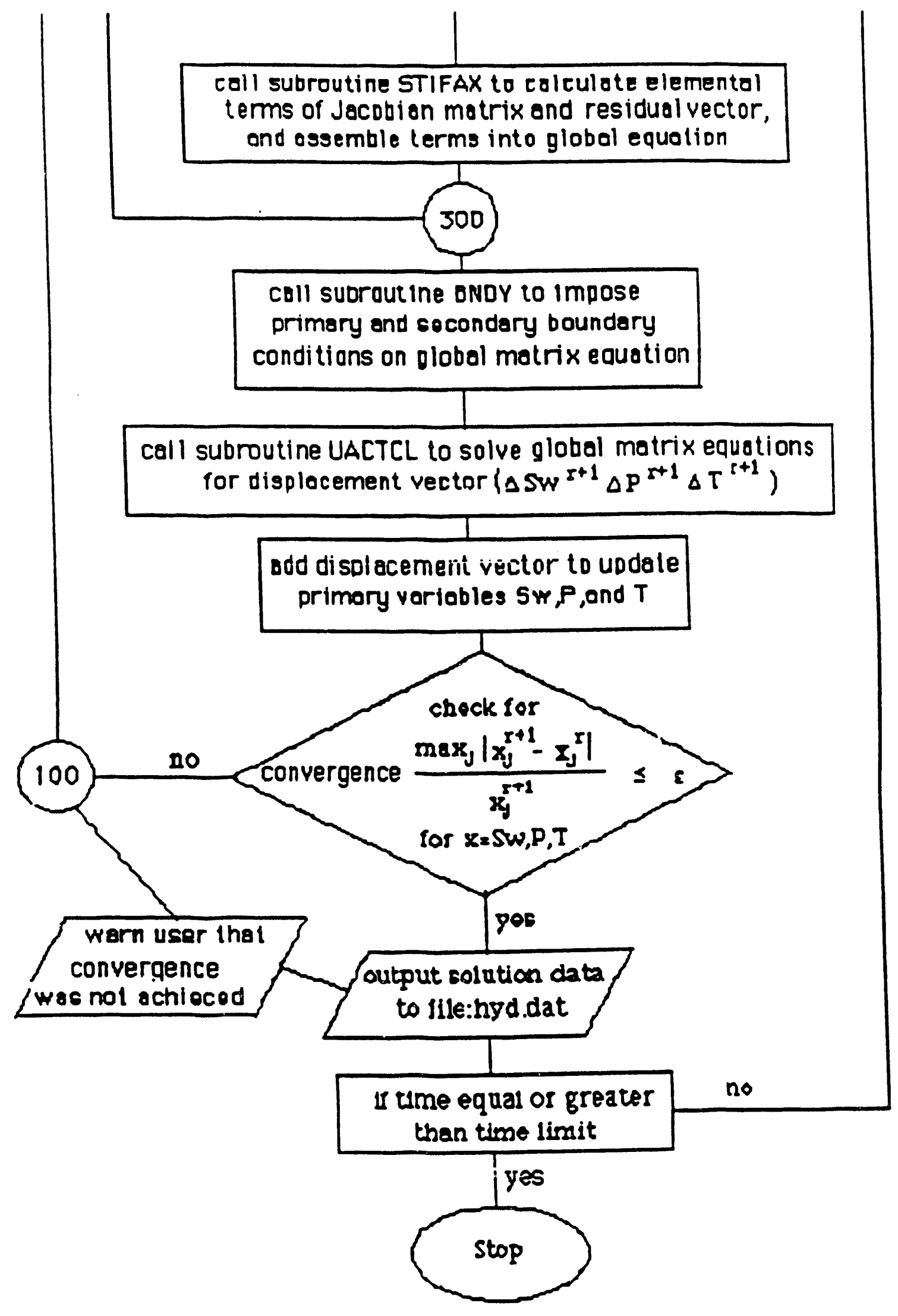




\title{
DEVELOPMENT OF ALASKAN GAS HYDRATE RESOURCES:
}

Experimental Study of Hydrate Decomposition During Steam Injection

\author{
Addendum To Final Report \\ December 1991
}

\author{
BY \\ V.A. Kamath \\ G.D. Sharma \\ S.L. Patil \\ Petroleum Development Laborato y \\ University of Alaska Fairbanks \\ Fairbanks, AK 99775-1260
}

Work Performed Under the Grant \#DE-FG21-86FE61114

For the Period: October 1, 1986 - June 30, 1991

\author{
Prepared For \\ U.S. Department of Energy \\ Morgantown Energy Technology Center \\ Rodney D. Malone, Project Manager \\ Morgantown Energy Technology Center \\ P.O. Box 880 \\ Morgantown, WV 26507
}




\section{TABLE OF CONTENTS}

PAGE

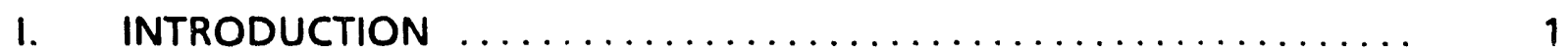

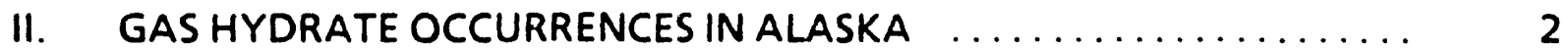

III. DESCRIPTION OF GAS HYDRATE RESERVOIR IN PRUDHOE BAYKUPARUK RIVER UNITS $\ldots \ldots \ldots \ldots \ldots \ldots \ldots \ldots \ldots \ldots \ldots \ldots, 4$

IV. RECOVERY OF GAS FROM HYDRATE RESERVOIRS $\ldots \ldots \ldots \ldots \ldots \ldots \quad 7$

V. STEAM INJECTION EXPERIMENTS FOR HYDRATE DECOMPOSITION . 9

A. Objectives $\ldots \ldots \ldots \ldots \ldots \ldots \ldots \ldots \ldots \ldots \ldots \ldots \ldots \ldots \ldots \ldots, g$

B. Description of Experimental Set Up and Modifications ...... 9

C. Experimental Procedure $\ldots \ldots \ldots \ldots \ldots \ldots \ldots \ldots \ldots \ldots . \ldots \ldots$

D. Data Analysis and Results $\ldots \ldots \ldots \ldots \ldots \ldots \ldots \ldots \ldots \ldots \ldots$

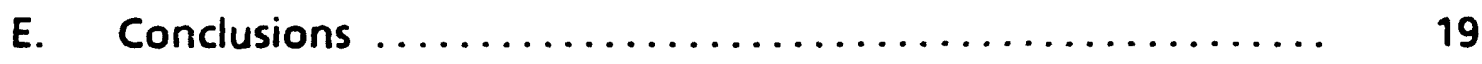

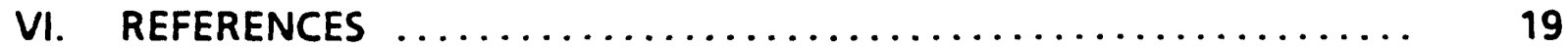




\section{INTRODUCTION}

Extensive deposits of naturally occurring gas hydrates have been found in many regions of the world in principally three different environments, where thermodynamically favorable conditions for formation of hydrates existed for millions of years and still exist. These include: 1) shallow, arctic onshure sediments overlain by a continuous thick permafrost, e.g., Prudhoe Bay and Kuparuk River regions of the Alaskan North Slope, huge Messoyakha field in Western Siberia (Makogon, 1965), Timan-Pechora and Kamchatka regions of U.S.S.R. (Cherskiy et al., 1985), MackenzieDelta regions of Canada and arctic islands (Bily and Dick, 1974; Judge, 1988); 2) d $\operatorname{ap}$ oceanic sediments of tropical regions, e.g., Gulf of Mexico, Blake Bahama Outer Ridge, offshore regions of California, Guatemala, Pariama, Nicaragua, Costa Rica, New Zealand, Australia, Columbia, Peru, Japan, West Norway, Gulf of Oman, Black Sea, Caspian Sea (Sloan, 1990); and 3) sediments underneath arctic and subarctic offshore waters, e.g., Beaufort Sea shelf and slope, Bering Sea slope (Navarin basin, Aleutian basin), North Pacific Ocean and Gulf of Alaska (Malone, 1987). Even though, in many of these regions, the delineation of hydrate resource is not complete, the most reliable worldwide estimates of natural gas in onshore nydrates are $1014 \mathrm{~m}^{3}$ and in offshore hydrates are $1 \times 1016-1.8 \times 1016 \mathrm{~m}^{3}$ (Makogon, 1988; Kvenvolden, 1988). In the Western Hemisphere, the natural gas resources in the onshore and offshore hydrate deposits are estimated to be 20 to 80 trillion $\mathrm{m}^{3}$ (Malone, 1987).

The naturally occurring hydrates typically contain 160-180 standard $\mathrm{m}^{3}$ of natural gas per $\mathrm{m}^{3}$ of hydrates and have a composition of $80-85$ mol\% water and $15-$ $20 \mathrm{~mol} \%$ natural gas. Gas compositional data suggests that hydrates on the Alaskan North Slope contain predominantly methane (92-95 mol\%) with small quantities of $\mathrm{N}_{2}, \mathrm{C}_{2}-\mathrm{C}_{4}$ hydrocarbons, $\mathrm{CO}_{2}$ and $\mathrm{H}_{2} \mathrm{~S}$. Hydrate samples from other regions around the world show similar gas compositions. In terms of energy content, gas hydrates 
are more similar to heavy oil and ar sand resources $\left(1.7 \times 109-2.2 \times 109 \mathrm{Joules} / \mathrm{m}^{3}\right.$ reservoir) than other unconventional gas resources. In one $\mathrm{m}^{3}$ of reservoir volume, hydrates contain 40-50 standard $\mathrm{m}^{3}$ gas, conventional gas reservoir contains 10-20 standard $m^{3}$ gas, coal bed methane contains 8-12 $\mathrm{m}^{3}$ of gas, tight sands contain 5-10 $m^{3}$ of gas and Devonian shales or geopressured aquifers contain 1-2 $m^{3}$ of gas. Thermodynamically, decomposition of hydrates to gas requires only $8-12 \%$ of its energy content. Therefore, in comparison with other natural gas deposits, hydrate deposits have by far the most accumulation of gas per unit volume.

Extensive analysis of hydrate samples (Nalone, 1987) indicate that the naturally occurring hydrates exist: in four forms: 1) disseminated or dispersed, 2) nodular, 3) layered, and 4) massive. Disseminated hydrates form in-situ with very little gas migration and contain hydrate erystals dispersed throughout the formation. Such h;drates have been recovered from unconsolidated sediments of the Gulf of Mexico and are also believed to occur in consolidated formations of onshore areas. Nodular hydrates are similar to dispersed form except hydrate nodules are larger $(2-5 \mathrm{~cm}$ diameter). Such hydrates have been found in the Green Canyon area of the Gulf of Mexico. Layered hydrates contain hydrates inierbedded by thin layers of sediments. Core samples containing layered hydrates have been recovered from Blake Bahama, offshore South Carolina to Florida. It is believed that the layered hydrates are formed in sediments deposited both in offshore and onshore. Hydrates on the Alaskan North Slope belong to this type of hydrate formation. Massive hydrates are more common in offshore regions and are composed primarily of hydrates (80-95\%) with minor sediment inclusions (5-20\%).

\section{GAS HYDRATE OCCURRENCES IN ALASKA}

It is estimated that 14 to 20 trillion standard $\mathrm{m}^{3}$ of natural gas is trapped in the form of hydrates in offshore and onshcre areas oi Âlaska (iviaione, i987). iñ cõm- 
parison, the estimated proven reserves of conventional natural gas in contiguous United States are only 2-4 trillion standard $\mathrm{m}^{3}$.

In the offshore regions of Alaska, the seismic surveys (Bottom Simulating Reflectors) indicate the presence of subsurface gas hydrates in the Beaufort Sea shelf and slope, Bering Sea slope (Navarin and Aleutian basins), North Pacific Ocean and Gulf of Alaska. Seismic surveys indicate that along the Beaufort Sea shelf and slope, extensive hydrates occur between 90 to $274 \mathrm{~m}$ below sea floor at water depths between 365 to $2250 \mathrm{~m}$. The areal extent of hydrates exceeds $16,850 \mathrm{~km}^{2}$. Free gas may exist below the impermeable cap of hydrates in this region. The hydrate deposits in other offshore regions of Alaska have not been mapped.

Subsurface onshore hydrate occurrence under permafrost was first observed in the Northwest Eileen Well \#2 of the Prudhoe Bay field in March 1972. In 1982, Galate and Goodman noticed subsurface hydrates in National Petroleum Reserves of Alaska (NPRA). In 1983, Collett examined 125 wells in the North Slope of Alaska for potential hydrate occurrence. Kamath et al. (1987) studied the thermodynamic and geologic parameters which control the distribution and stability of gas hydrates in the permafrost regions of northern Alaska. The study included influence of mean annual surface temperature, geothermal gradients above and below the base of the permafrost, subsurface pressures, gas composition and pore-fluid salinity on hydrate formation. Hydrate stability diagrams were constructed for 46 wells to determine the zones of potential hydrate occurrence or the zones of hydrate stability. The effect of various parameters on the zones of hydrate stability was studied since these parameters were found to vary considerably on the Alaskan North Slope. A nomogram was developed for delineating hydrates in subsurface (Godbole et al., 1988). Collett et al. (1984) developed Pickett crossplot technique along with corrected neutron and sonic porosities to determine the depths, thicknesses, porosities and saturations of in-situ gas hydrates in the Kuparuk River Unit of North Slope, Alaska. 
Recently, Collett et al. (1990) completed the analyses of well logs, core data, drill cuttings, drilling reports and seismic surveys for $\mathbf{4 4 5}$ wells on the Alaskan North Slope and concluded that Prudhoe Bay-Kuparuk River area alone contain up to 1.25 trillion $\mathrm{m}^{3}$ of natural gas trapped as hydrates. Large free gas accumulations were also found to occur downdip below hydrates. In addition, it is also believed that gas hydrates occur in the North up-dip extension of the Walakpa gas field located near Barrow, Alaska. The areal extent of hydrates is considered to be $310 \mathrm{~km}^{2}$.

\section{DESCRIPTION OF GAS HYDRATE RESERVOIR IN PRUOHOE BAY-KUPARUK RIVER UNITS}

Gas hydrates were first discovered in this region on March 15, 1972, when hydrate cores were recovered at several depths between 577 and $776 \mathrm{~m}$ from the Northwest Eileen Well \#2. The hydrate reservoir in this region has been described mostly from well log analysis (Collett et al., 1984; Collett et al., 1990). Gas hydrates lie below the base of Eocene transgressive siltstone unit and are found in 450 to $600 \mathrm{~m}$ thick non-marine to marine sequence of deltaic sandstone reservoirs of the Sagavanirktok Formation (Brookian sequence). The gas hydrates occur in six laterally continuous sandstone and conglomerate formations and are geographically restricted to the east end of the Kuparuk River Unit and the west end of the Prudhoe Bay Unit. The distributions of gas hydrate and free gas accumulations in the Prudhoe Bay-Kuparuk River area are shown in Figure 1. The total area occupied by these six gas hydrate horizons is about $1,643 \mathrm{~km}^{2}$, with the areal extent of the individual units ( $A$ through $F$ ) ranging from 3 to $404 \mathrm{~km}^{2}$. The gas-in-place is estimated to be 1 to 1.25 trillion standard $m^{3}$ in hydrates and this is probably the largest known onshore gas hydrate reservoir in the world.

The hydrates occur within relatively porous, discrete rock units. Multiple gashydrate bearing units with thicknesses ranging from 3 to $31 \mathrm{~m}$ have been observed 


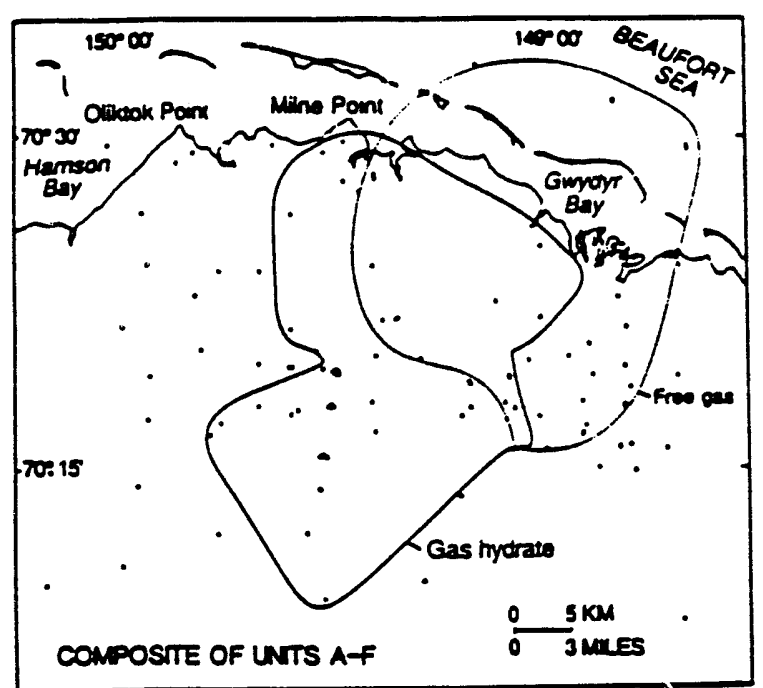

Figure 1: Map of Pruchoe Bay-Kuparuk diver Areas Dopicting Areal Extent of Gas Hydrate and Fres Eas Accumulations (Collent et al, 1990).

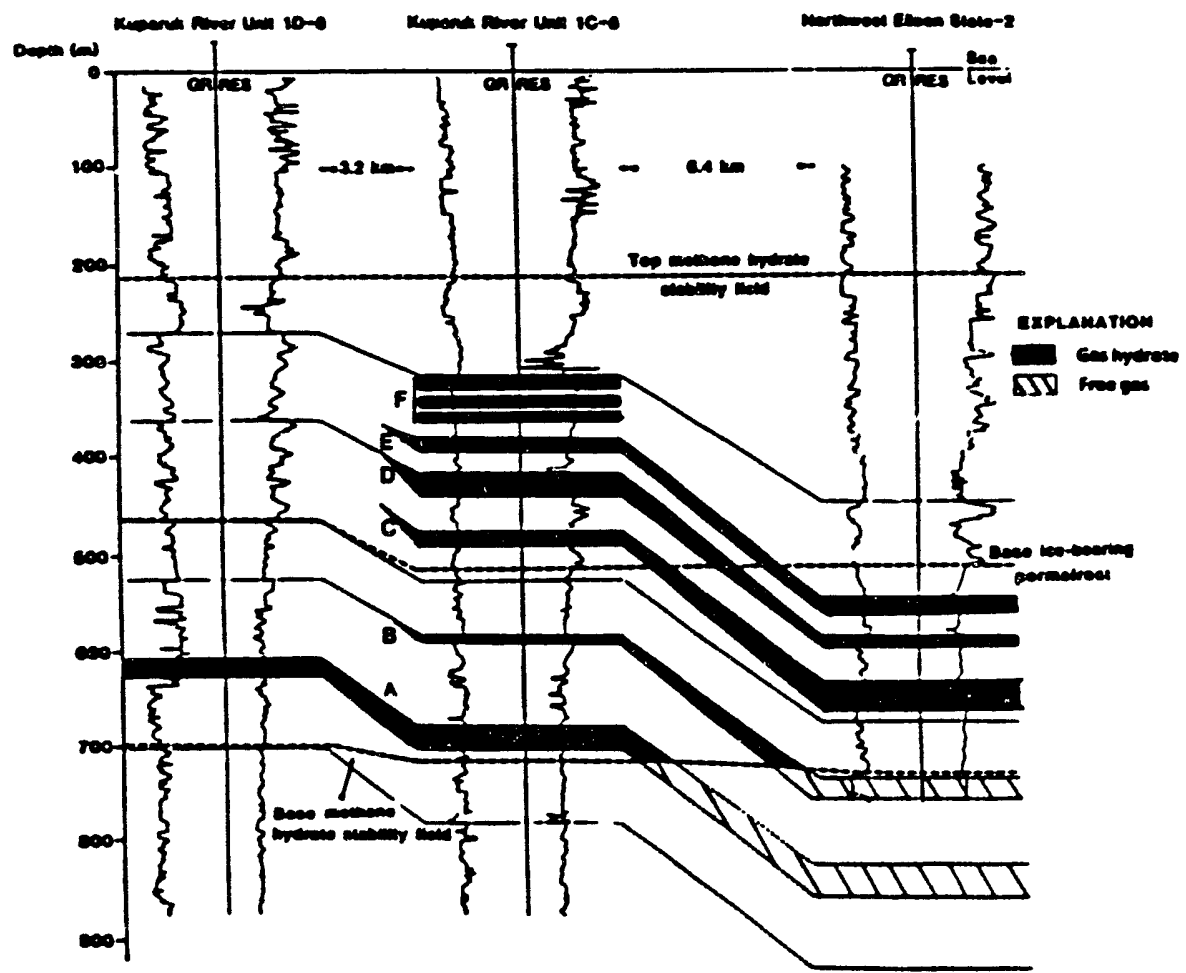

Fipure 2: East-West Codopic Cross Section of fruchoe Coy-xuparts Nhwer Area Showing Vertical and Wearal Extons of Six Hydrate Easing Unies (Cothett et at, 1950). 
in many wells. The lateral and vertical extent of six gas-hydrate bearing units with underlying free gas accumulation in the east is shown in figure 2 . The reservoir has a gentle dip of 1 to 50 to the northeast. The shallowest, Unit F, is least continuous and occurs at depths between 310 and $360 \mathrm{~m}$. The deepest, Unit $A$, is the most laterally continuous and occurs at depths between 605 and $720 \mathrm{~m}$ from west to east. Unit $A$ is thickest of all units with an average thickness of $17 \mathrm{~m}$. The thinnest unit is $E$ with an average thickness of $11 \mathrm{~m}$. The porosity in these units ranges from 37 to $42 \%$ with an average of $39 \%$. The hydrate saturation varies between 88 and $95 \%$ with an average of $93 \%$.

Carman and Hardwick (1983), based on the geochemical investigation, postulated that the upward and westward migrating oils from deeper Sadlerochit formation of the Prudhoe Bay field were trapped in the shallower sands of the Kuparuk River Unit to form Kuparuk, West Sak and Ugnu oil reservoirs. Collett et al. (1990) further extended this process to explain the origin of hydrates in this region. Upward migration of gas and oils occurred either along Eileen or other faults into the uverlying shallow sedimentary rocks. The impermeable siltstone may have blocked the upward movement of gas. The trapped free gas was subsequently converted to hydrates as thermal regimes changed. Alternatively, hydrates may have formed during the up-dip gas migration process as gas moved into hydrate stability zone and formed trap for the free gas beneath it.

Units $A$ and $B$ have the greatest potential for natural gas production since in both of these units there are large accumulations of free gas downdip below hydrates. This entrapment of gas is similar to Messoyakha Field where hydrates overlie free gas and gas has been produced for past 19 years by depressurization technique. 


\section{RECOVERY OF GAS FROM HYDRATE RESERVOIRS}

Gas hydrates are relatively impermeable and immobile within reservoirs, the production of gas from hydrates requires in-situ decomposition of hydrates into gas and water. This three phase decomposition process requires the latent heat of approximately $0.35-0.5 \mathrm{KJ} / \mathrm{cm}^{3}$ hydrate.

Several techniques for in-situ decomposition of gas hydrates have been proposed and are reviewed by Kamath et al. (1991) and Sloan (1990). The proposed techniques are based on one or more of the three principles: 1) reduction in reservoir pressure below the hydrate dissociation pressure known as depressurization; 2) thermal stimulation by external heat and raising temperature of reservoir above hydrate decomposition temperature by in-situ combustion, electrical or microwave heating or cyclic injection of hot fluids such as hot water, steam or brine; and 3) alteration of hydrate decomposition equilibria by injection of hydrate inhibiting chemicals such as methanol and glycols.

During depressurization, since no heat is injected into the reservoir, hydrates dissociate by means of conduction of heat from the surrounding formations due to Joule-Thompson effect. The rate of decomposition, therefore, is controlled by the thermal conductivity of surrounding formations. Depressurization only will not be feasible for reservoirs that contain only hydrates. However, this technique is most advantageous and practical for reservoirs that contain hydrates overlying a free gas zone. In such cases, the gas can be produced from free gas zone in a conventional manner, and hydrate dissociation can provide additional gas as a bonus. This method has been used successfully to produce gas from Messoyakha field in western Siberia (Makogon, 1988).

For thermal recovery, thermodynamic calculations indicate that for a $100 \%$ thermally efficient process (i.e., all the injected heat is used by hydrate dissociation only), the maximum energy efficiency ratio (the heating value of produced gas times 
cumulative gas produced divided by the cumulative heat injected) is about 15 to 17 . For obvious reasons, in-situ combustion and continuous injection of hot fluids are not practical in hydrate reservoirs. Thermal stimulation of hydrates by cyclic injection of hot fluids followed by soaking and production of dissociated gas and water through depressurization would be more suitable, provided high energy efficiency ratios and injectivity of fluids can be maintained. Fracturing will be needed to maintain high injection rates and high fluid-hydrate contact area. Energy efficiency ratio will be controlled by heat losses to well bore, surrounding formations and thief zones. Kamath and Godbole (1987) have evaluated energy efficiency ratios for cyclic injection of hot brine, hot water, and steam for wide range of reservoir parameters and have reported that brine is more thermally efficient than steam and hot water. Brine also acts as hydrate inhibitor and lowers dissociation temperature, thus resulting in lower reservoir heating, latent heat of decomposition, heat losses and higher energy efficiency ratio and gas production rate. A horizontal well may be used to increase gas deliverability, which would be comparable to several vertical wells and fracturing. Electrical heating downhole offers advantage of elimination of well bore heat losses in fluid injection methods but suffers from the sharp decline in gas production rate with the hydrate decomposition front moving farther away from the heat source. It is generally perceived that use of hydrate inhibitors such as glycols and methanols alone will not be economical, since large quantities of these expensive chemicals are required for commercial production. This method can be combined with depressurization where depressurization will provide long-term production and inhibitors will provide short-term increases in production by stimulating wells. Such chemicals have been used in 8 wells in the Messoyakha field to increase well production rate by factor of 5 to 10 (Makogon, 1988).

Bayles et al. (1986) developed a model for cyclic steam injection in a single well located in the hydrate zone of the permafrost region, to generate upper bounds and 
lower bounds on the energy efficiency ratio. The proposed process had three steps: a) steam injection, b) a soak period, c) a production period. The model incorporated heat losses during steam injection phase, with remainder of the heat consumed in hydrate decomposition and heating the overburden and underburden. For various model and reservoir parameters, energy efficiency ratios were determined and ranged between 4 and 9.6. The results showed that the energy efficiency ratios increased with increase in porosity, thickness of hydrate zone and depth of the hydrate zone.

\section{STEAM INJECTION EXPERIMENTS FOR HYDRATE DECOMPOSITION}

No experimental studies have been reported prior to this study which focussed on steam injection for hydrate decomposition. In our previous report (Kamath et al., 1991), we have described experimental results and data for hydrate decomposition by depressurization, and injection of hot water, brine, methanol and ethylene glycol solutions.

\section{A. Objectives}

The objectives of our experimental work were as follows:

1) To develop an experimental set up and techniques to study decomposition of hydrates in cores containing methane hydrates during continuous saturated steam injection.

2) To measure hydrate decomposition rates achievable at different steam injection rates and at different steam temperatures.

\section{B. Description of Experimental Set Up and Modifications}

The detailed description of the experimental set up used for hydrate decomposition experiments have been reported earlier (Kamath et al., 1991). Only the modi- 
fications to the experimental set up for conducting steam injection experiments are described here. The modifications were as follows:

1) Replacement of previous fluid injection pump by two Constametric IIIG constant rate water injection pumps manufactured by LDC Milton Roy Inc. and each designed for constant rate of water injection up to $10(\mathrm{cc} / \mathrm{min})$ with an accuracy of $\pm 0.01(\mathrm{cc} / \mathrm{min})$.

2) Installation of a steam generator unit manufactured by Temco, Inc. The steam generator unit consisted of a steam tube with heating elements, steam pressure indicator and a steam temperature indicator and controller. The unit was tested to determine if saturated steam at a controlled temperature and pressure can be generated at a constant rate.

3) Installation of back pressure regulator between steam generator and core hoider to control the pressure of the steam being injected.

4) Modifications to the piping of the system and the insulation of all the lines that had steam flow.

\section{Experimental Procedure}

The experimental procedure for formation of methane hydrates in the cores was same as used previously for other decomposition experiments (Kamath et al., 1991).

Once hydrates were formed, hydrate decomposition was accomplished by continuous injection of saturated steam of desired constant temperature and pressure at a constant preset rate from the steam generator into the top portion of the hydrate core holder. The port of steam injection was about $10 \mathrm{~cm}$ above the top of the hydrate core initially. As steam entered into the core holder, it condensed and provided heat to hydrates to decompose them. In each dissociation experiment, the pressure in the core holder was maintained constant by means of a back pressure 
regulator and the gas from hydrates was produced through a wet test gas flow meter. During entire dissociation experiment, the temperature of steam, the temperature of water phase in the core holder, the temperature of hydrates in the core holder, the pressure in the core holder, the cumulative gas produced from hydrate dissociation and the temperature of produced gas were monitored continuously with time.

\section{Data Analysis and Results}

A total of six experiments were conducted and the experimental data for each experiment were analyzed by a computer program.

The computer program used the following data:

1) Hydrate Formation Data

- core length

- core porosity

- hydrate formation period

- initial amount of frost used to form core

- pressure and temperature of the core prior to hydrate formation

- pressure and temperature of the core as a function of time during entire hydrate formation period

2) Hydrate Decomposition Data

- steam injection rate

- initial pressure and temperature of hydrate core prior to decomposition

- temperature of steam, temperature of condensed water in core, temperature of hydrates, pressure in the core holder, cumulative gas produced as a function of time during entire hydrate decomposition period 
Based on the hydrate formation data, the rate of hydrate formation and the amount of hydrates formed $(v o l \%)$ in the core during hydrate formation period were computed for each run. The properties of methane hydrate cores used in these experiments are summarized in Table 1.

Based on the decomposition data, the average rate of gas production from hydrates, the average core holder pressure, the average rate of hydrate dissociation rate in terms of molar gas flux and average steam temperature were determined. Table 2 gives the summary of experimental conditions for all hydrate decomposition runs.

In runs 1-3, the rate of steam injection was kept constant at $10(\mathrm{gm} / \mathrm{min})$ and steam temperature was varied from 488 to $553(K)$, whereas in runs 4-6, the steam injection rate was $20(\mathrm{gm} / \mathrm{min})$ and steam temperature was varied from 502 to $535(K)$. Due to experimental limitations, the higher steam injection rates could not be studied.

Figure 3 shows the rate of gas production from hydrate dissociation as a function of time for a typical dissociation run. Figures 4 and 5 show the effect of steam temperature on the cumulative gas production versus time. The results show that hydrate dissociation rate increased from $450(\mathrm{scc} / \mathrm{min})$ at $215^{\circ} \mathrm{C}$ steam to 1428 (sc/ $/ \mathrm{min})$ at $280^{\circ} \mathrm{C}$ steam at injection rate of $10(\mathrm{gm} / \mathrm{min})$, whereas the dissociation rate increased from $2118(\mathrm{scc} / \mathrm{min})$ at $228.9^{\circ} \mathrm{C}$ steam to $3558(\mathrm{scc} / \mathrm{min})$ at $261.7^{\circ} \mathrm{C}$ steam at injection rate of $20(\mathrm{gm} / \mathrm{min})$. Figure 6 shows the effect of steam injection rate on the average rate of hydrate dissociation at various steam temperatures.

For steam injection runs, the gas production per gm of steam injected varied from 45 to 178 (scc gas/gm steam injected) depending upon steam injection rate and steam temperature. In comparison, for hot water injection runs reported previously (Kamath et al., 1991), the gas production per gm of hot water injected varied from 0.5 to 7.4 (scc gas/gm water injected) depending upon temperature and injection 


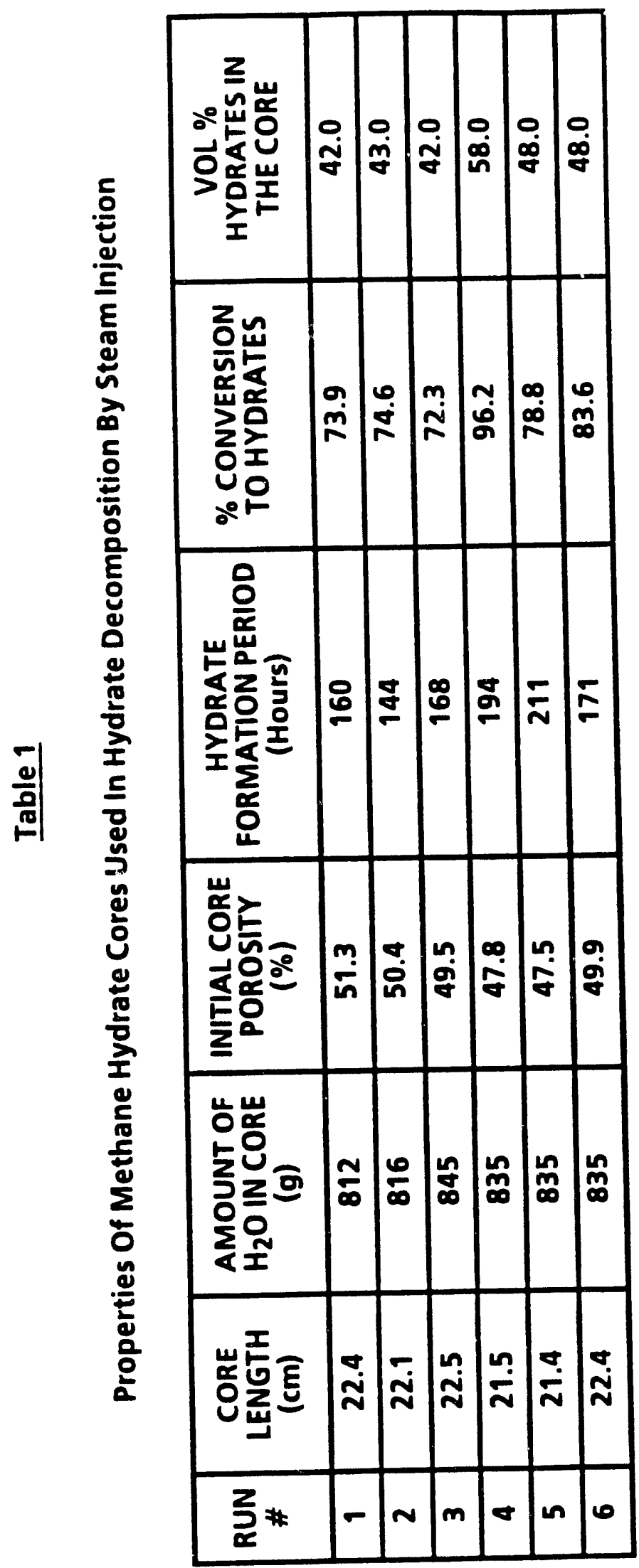




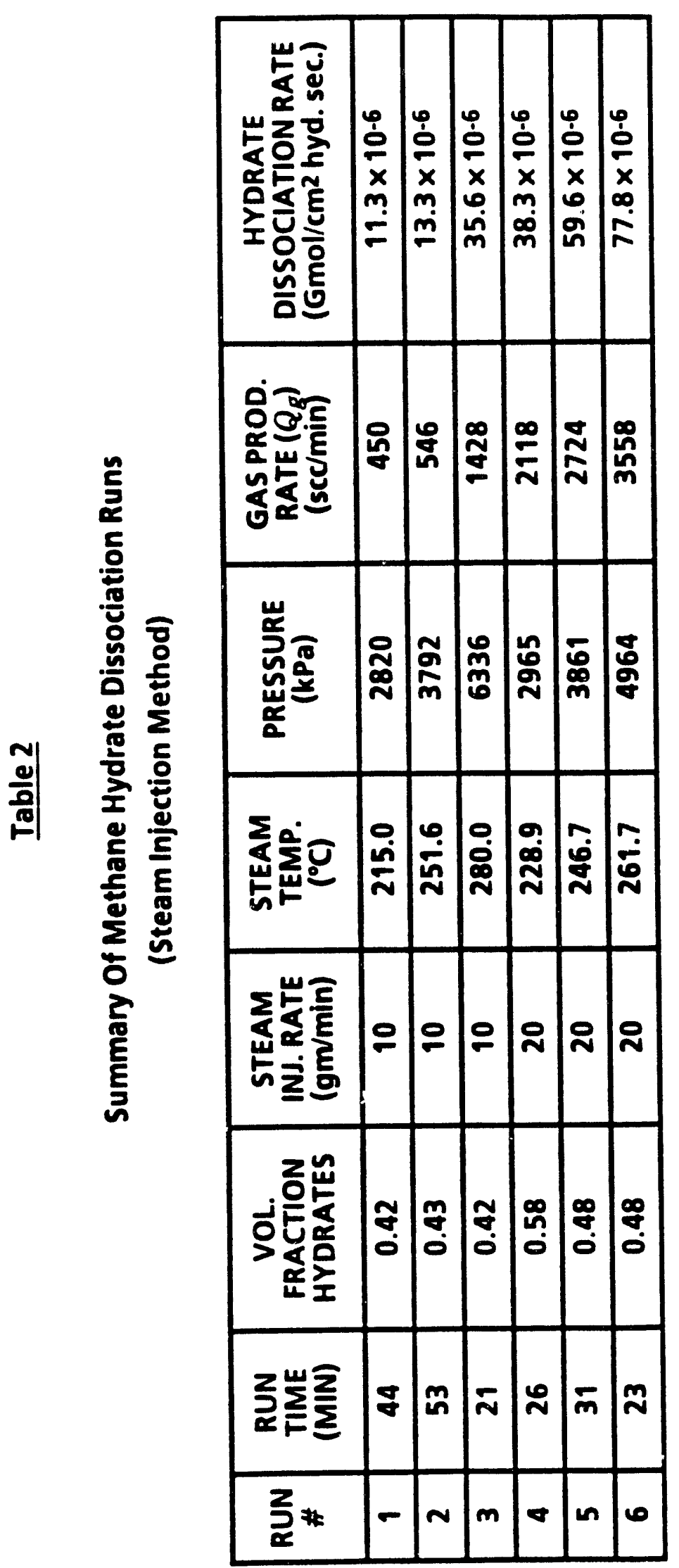




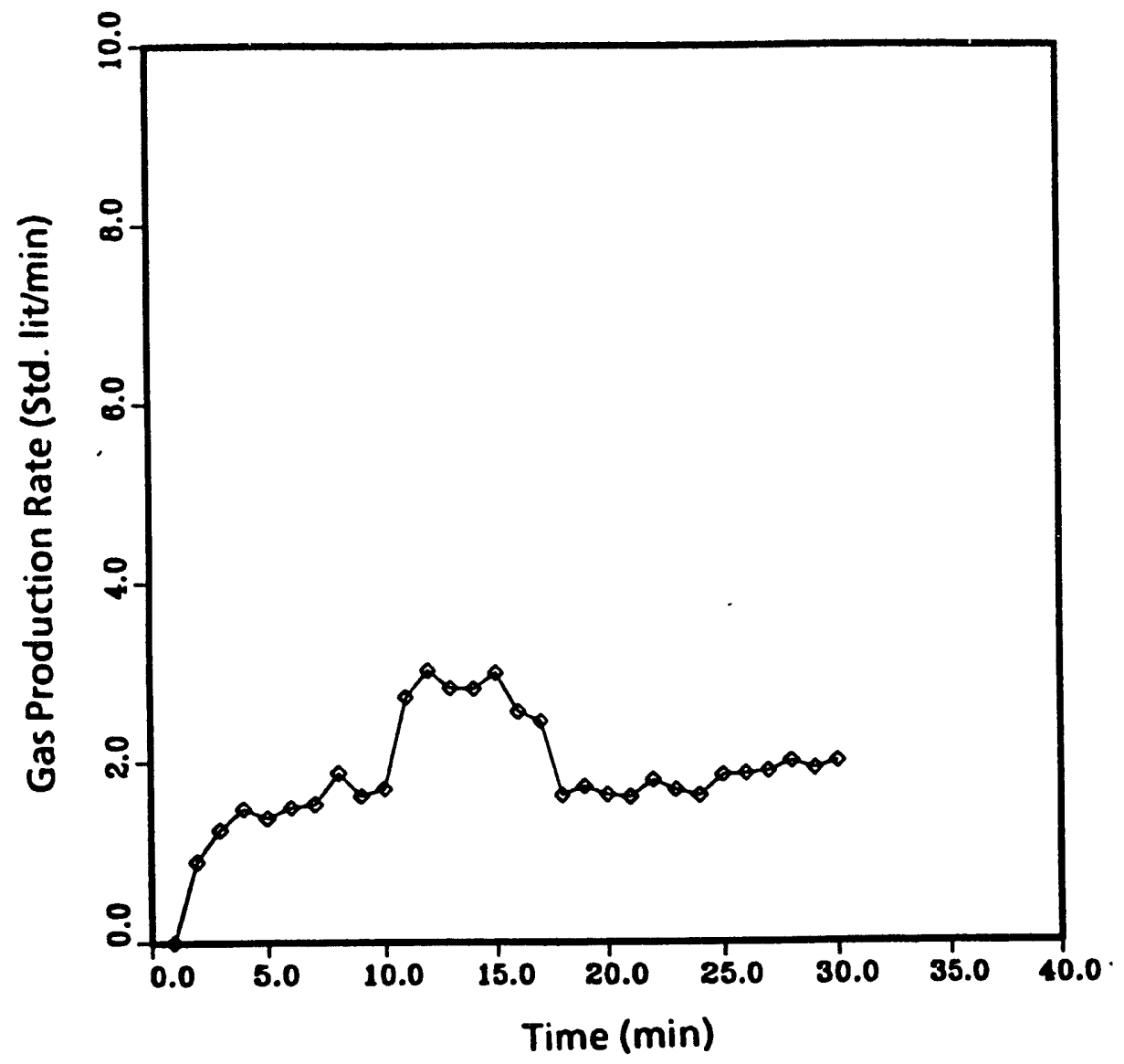

Figure 3: Hydrate Decomposition Behavior For a Typical Steam Injection Run 


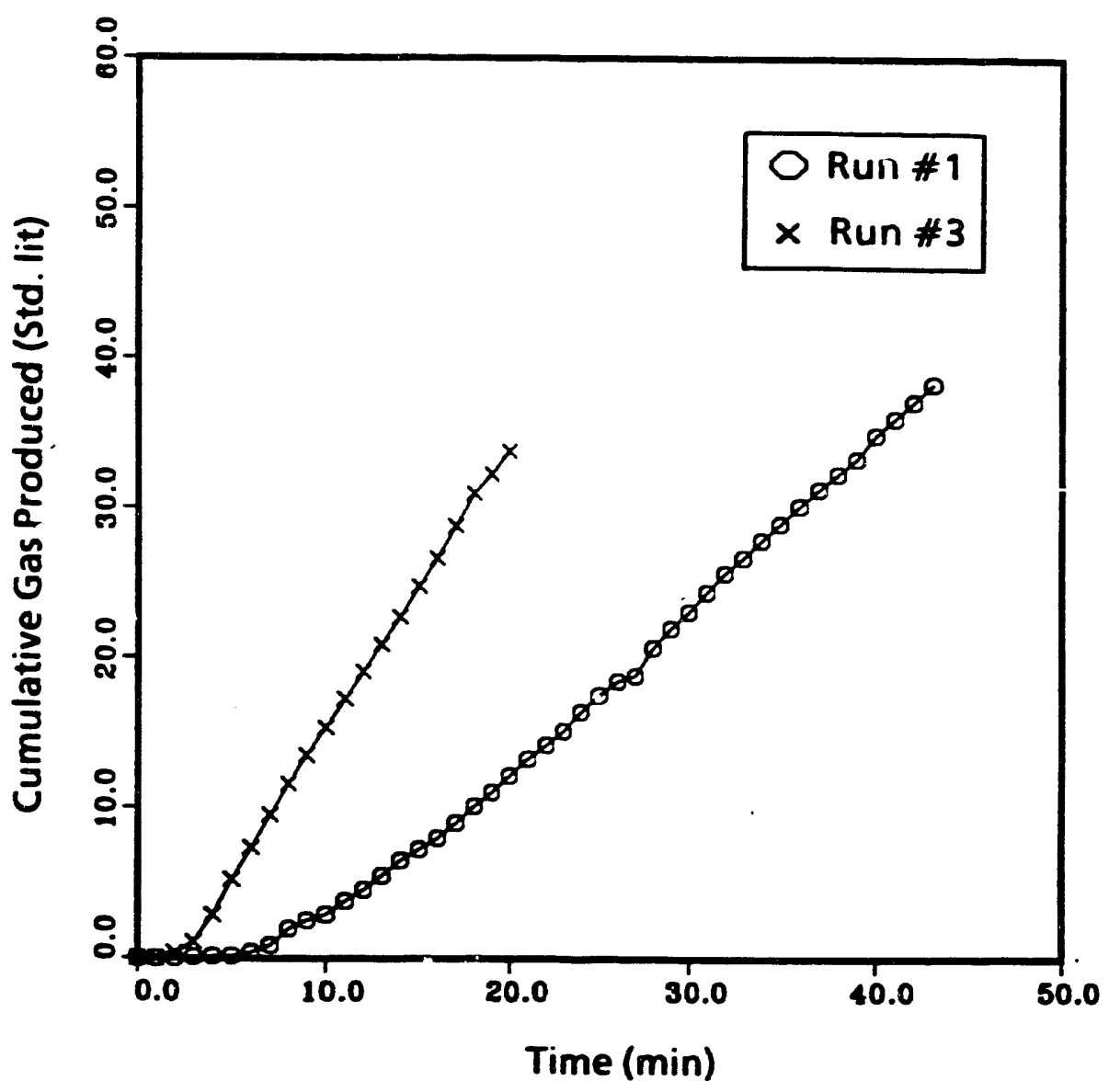

Figure 4: Cumulative Gas Production Versus Time (Steam Injection Rate $=10 \mathrm{gm} / \mathrm{min}$ ) 


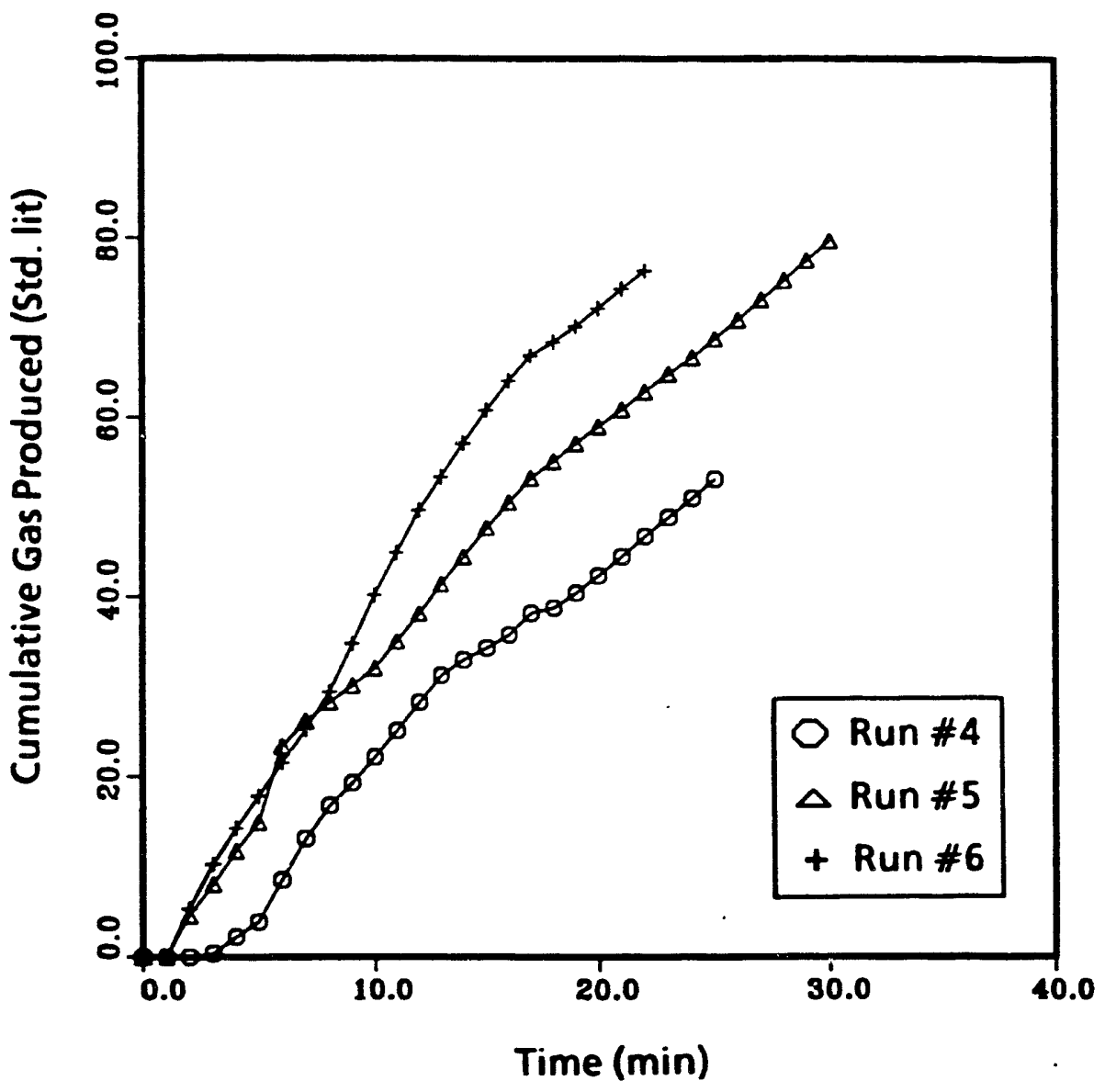

Figure 5: Cumulative Gas Production Versus Time (Steam Injection Rate $=20 \mathrm{gm} / \mathrm{min}$ ) 


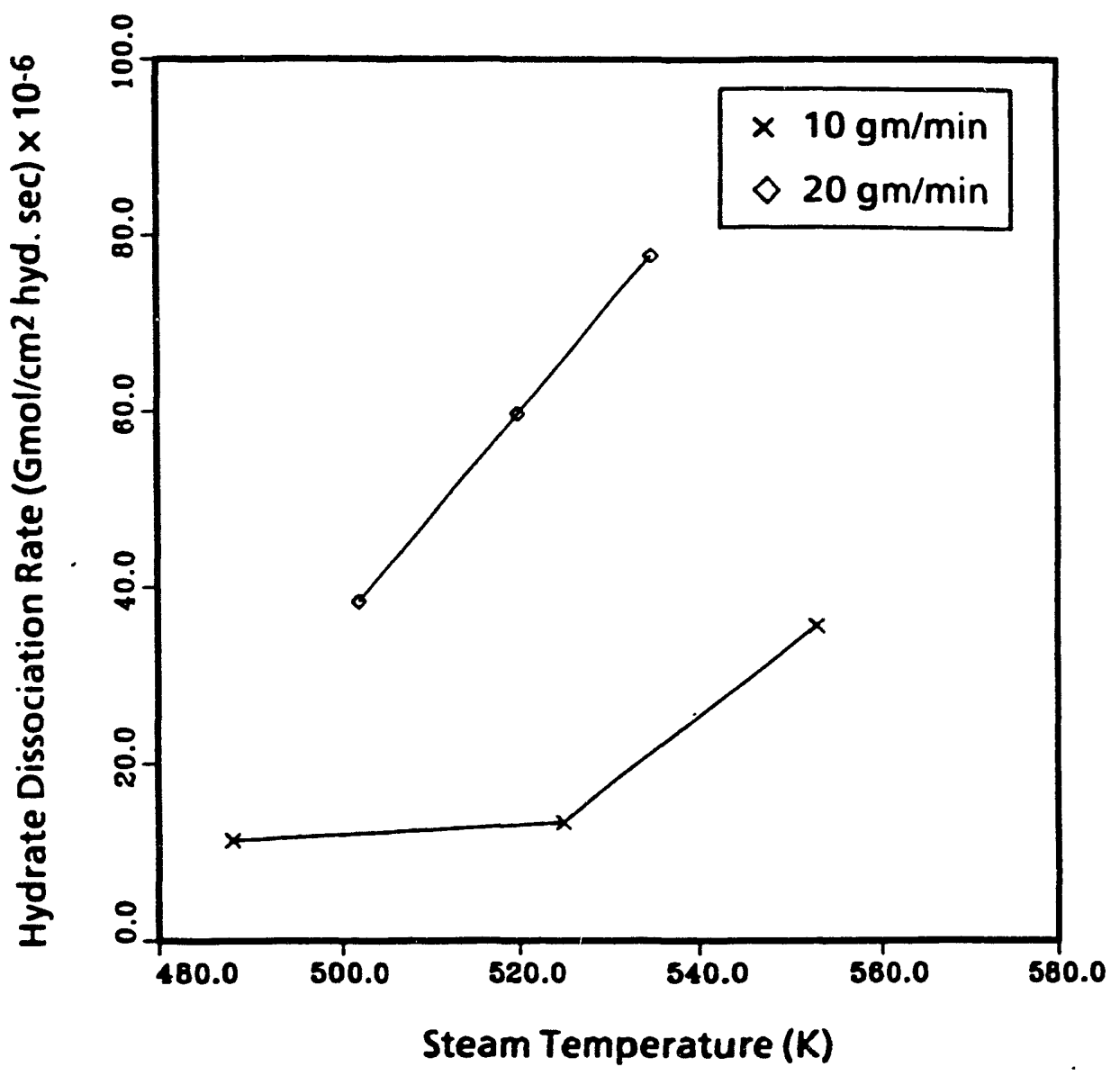

Figure 6: Effect of Steam Injection Rate and Steam Temperature On the Rate of Hydrate Dissociation 
rate of hot water. This shows that hydrate decomposition process is heat transfer limited process. Due to limited amount of data collected, no efforts were made to develop a correlation for hydrate dissociation rate for steam injection experiments.

\section{E. Conclusions}

In this study the experimental data on methane hydrate decomposition by steam injection are reported. The experimental results show that:

1) The hydrate decomposition is a heat transfer limited process.

2) The hydrate decomposition rates increased with increase in steam temperature and increase in steam injection rate.

3) In case of steam injection, the gas production varied from 45 to 178 (scc gas/gm steam injected) depending upon steam temperature and steam injection rate, whereas in case of hot water injection, the gas production varied from 0.5 to 7.4 (scc gas/gm hot water injected) depending upon hot water temperature and hot water injection rate.

\section{REFERENCES}

1. Bayles, G.A., Sawyer, W.K., Anada, H.R., Reddy, S. and Malone, R.D. (1986). "A Steam Cycling Model For Gas Production From A Hydrate Reservoir," Chem. Eng. Communications, Vol. 47, pp. 225.

2. Bily, C. and Dick, J.W.L. (1974). "Naturally Occurring Gas Hydrates in the Mackenzie Delta, N.W.T.," Bull. Can. Pet. Geol., Vol. 22, No. 3, pp. 340-352.

3. Carman, G.J. and Hardwick, P. (1983). "Geology and Regional Setting of the Kuparuk River Oil Field, Alaska," Am. Asso. Pet. Geoi. Bull., Vol. 67, No. 6, pp. 1014-1031. 
4. Cherskiy, N.V., Tsarev, V.P. and Nikitin, S.P. (1985). "Investigation and Prediction of Conditions of Accumulation of Gas Resources in Gas Hydrate Pools," Pet. Geol., Vol. 21, pp. 65-89.

5. Collett, T.S. (1983). “Detection and Evaluation of Natural Gas Hydrates From Well Logs, Prudhoe Bay, Alaska،" M.S. Thesis, U. Alaska Fairbanks, pp. 1-77.

6. Collett, T.S., Godbole, S.P. and Economides, C.E. (1984). "Quantification of Gas Hydrates on North Slope of Alaska," Proc. 35th Ann. Meeting of Can. Inst. Min., Calgary, Canada.

7. Collett, T.S., Bird, K.J., Kvenvolden, K.A. and Lee, M.W. (1990). "Terrestrial Gas Hydrate Occurrences," Proc. Nat. Gas. R.D. Contr. Rev. Meeting, DOE/METC91/6117, pp. 205-214.

8. Galate, J.W. and Goodman, M.A. (1982). "Review and Evaluation of Evidence of In-Situ Gas Hydrates in the NPRA," USGS Report, Contract No. 14-08000119148, pp. 1-102.

9. Godbole, S.P., Kamath, V.A. and Economides, C.E. (1988). "Natural Gas Hydrates in the Alaskan Arctic," SPE Formation Evaluation, Vol. 3, No. 1, p. 263266.

10. Judge, A.S. (1988). "Mapping the Distribution and Properties of Natural Gas Hydrates in Canada," Proc. ACS Third Chem. Congress of North Am. Cont., June 6-7, Toronto, Ontario, Paper No. 29.

11. Kamath, V.A., Holder, G.D. and Angert, P.F. (1984). "Three Phase Interfacial Heat Transfer During Dissociation of Propane Hydrates," Chem. Eng. Sci., Vol. 39, No. 10, pp. 1435-1442.

12. Kamath. V.A. and Godbole, S.P. (1987). "Evaluation of Hot Brine Stimulation Technique for Gas Production From Natural Gas Hydrates," J. Pet. Tech., Vol. 39, No. 11. pp. $1379-88$. 
13. Kamath, V.A. and Holder, G.D. (1987). "Dissociation Heat Transfer Characteristics of Methane Hydrates," Am. Inst. Chem. Eng. J., Vol. 33, No. 2, pp. 347349.

14. Kamath. V.A., Godbole, S.P., Ostermann, R.D. and Collett, T.S. (1987). "Evaluation of the Stability of Gas Hydrates in Northern Alaska," Cold Reg. Sci. and Tech., Vol. 14, pp. 107-19.

15. Kamath, V.A., Mutalik, P.N., Sira, J.H. and Patil, S.L. (1989). "Experimental Study of Brine Injection and Depressurization Methods for Dissociation of Gas Hydrates," Proc. 64th Ann. Tech. Conf. and Exh. of SPE, Paper \# 19810, Oct. 811, San Antonio, TX.

16. Kamath, V.A., Sharma, G.D. and Patil, S.L. (1991). "Development of Alaskan Gas Hydrate Resources," Final Report Submitted to U.S.D.O.E., Grant \#DEFG21-86FE61114, pp. 1-473.

17. Kvenvolden, K.A. (1988). "Methane Hydrate - A Major Reservoir of Carbon in the Shallow Geosphere," Chem. Geol., Vol. 71, pp. 41.

18. Makogon, Y.F. (1965). "Hydrate Formation in Gas Bering Strata Under Permafrost," Gozoy Promst., Vol. 5, pp. 14.

19. Makogon, Y.F. (1988). "Natural Gas Hydrates: The State of Study in the USSR and Perspective For Its Use," Proc. Am. Chem. Soc. Third Chem. Cong. of North Am. Cont., June 5-10, Toronto, Ontario.

20. Malone, R.D. (1987). "Gas Hydrates - Technology Status Report," DOE/METC87/0246, U.S. Dept. of Energy, pp. 1-25.

21. Sira, J.H., Patil, S.L. and Kamath, V.A. (1990). "Study of Hydrate Dissociation by Methanol and Glycol Injection," Proc. 65th Ann. Tech. Conf. and Exh. of SPE. Paper \#20770, Sept. 23-26, New Orleans, LA, Vol-Prod. Operations and Eng., pp. 977-984. 
22. Sloan, E.D., Jr. (1990). "Clathrate Hydrates of Natural Gases," Marcel Dekker Inc., pp. 391-476. 

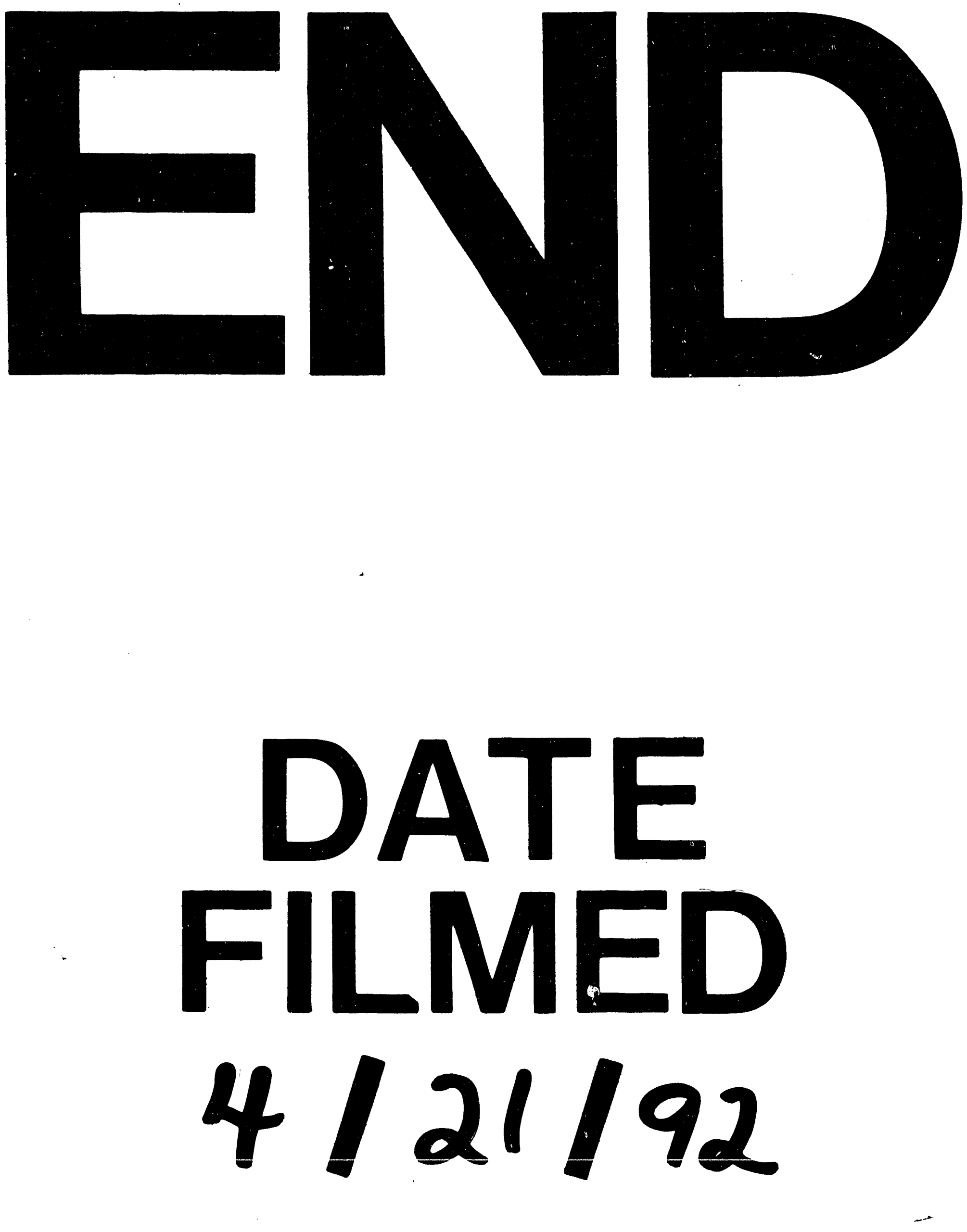
